U.S. Department of the Interior

U.S. Geological Survey

\title{
Digital Mapping Techniques '01- Workshop Proceedings
}

\author{
Edited by David R. Soller
}

May 20-23, 2001

Tuscaloosa, Alabama

Convened by the

Association of American State Geologists

and the

United States Geological Survey

Hosted by the

Geological Survey of Alabama 
This report is preliminary and has not been reviewed for conformity with U.S. Geological Survey editorial standards. Any use of trade, product, or firm names in this publication is for descriptive purposes only and does not imply endorsement by the U.S. Government or State governments. 


\section{FOREWORD}

The Annual Digital Mapping Techniques Workshops sponsored by the U.S. Geological Survey (USGS) and the Association of American State Geologists (AASG) have become very popular and productive forums for the exchange of information and sharing of experiences in the world of digital geologic mapping. The Geological Survey of Alabama hosted DMT'01, and the Alabama staff did an excellent job of organizing the workshop and providing a pleasant and relaxing milieu characterized by southern ambience. The AASG/USGS Data Capture Working Group organized an interesting and up-to-the-moment program of topics for the workshop.

There were significant presentations covering 3-D digital geologic mapping, database design, use of the proposed North American Data Model, science-language standards, field data-capture technologies, GIS certification, and geologic-map authorship. The comfortable and informal setting, which is standard for the DMT workshops, allowed open exchange and plenty of questions.

DMT'01, like the previous four workshops, did much to advance the National Geologic Map Database (NGMDB), which is a requirement of the National GeologicMapping Act of 1992 and its subsequent reauthorizations. The development of the NGMDB is greatly heightened in importance by the terrorist attacks of September 11, 2001. Pressing forward to build an on-line, digital geologic-map database is crucial to protecting our natural resources (particularly ground water) from terrorist acts. In the present world situation, it is important to quickly access digital geologic maps and their attendant databases for the entire nation. Building the NGMDB will require the full support of all citizens and high government officials. We commend all of the participants in DMT'01 for their contributions to the workshop and this Open-File Report. You have done much to make geoscience serve the public good. We look forward to DMT'02.

Thomas M. Berg Ohio State Geologist Chair, AASG Digital Geologic Mapping Committee 


\section{CONTENTS}

\section{Foreword}

By Thomas M. Berg (Ohio Geological Survey) .............. III

\section{Introduction}

By David R. Soller (U.S. Geological Survey) . . . . . . . . . . . 1

\section{Oral Presentations}

Data Capture Techniques for the Digital Database of the Monterey

Quadrangle, California

By Dave Wagner (California Division of Mines and Geology) ...... 3

From Conventional Airphotos, to 2.5D Maps and Digital Mosaic

Terrain Reconstructions: A Simple but Complete Digital Technique

Used at GSC-Québec, Canada

By Serge J. Paradis (Geological Survey of Canada),

Marco Boutin (INRS-Géoressources), Ruth Boivin (Natural

Resources of Canada), and Hugo Larocque

(INRS-Géoressources) . . . . . . . . . . . . . . . . . . . .

3D Geologic Maps and Visualization: A New Approach to the Geology of the Santa Clara 'Silicon' Valley, California

By Robert Jachens, Carl Wentworth, Donald Gautier (U.S. Geological

Survey) and Skip Pack (Dynamic Graphics, Inc.) . . . . . . . . 13

The Three-Dimensional Geologic Model as an Access Portal

By Skip Pack (Dynamic Graphics, Inc.) .............. 25

Developing the North American Geologic Map Data Model

By the North American Data Model Steering Committee ........ 29

A Case Study in Database Design: The Alaska Geologic Database

By Lawrence K. Freeman (Alaska Division of Geological and

Geophysical Surveys) $\ldots \ldots \ldots \ldots \ldots \ldots \ldots \ldots \ldots$

Using the Proposed North American Data Model in a Distributed

Database Environment

By Eric Boisvert, Annie Morin, Kathleen Lauziére, and Daniel Lebel

(Geological Survey of Canada - Québec Geoscience Center)........

Improving Access to Metadata Using Keywords from Controlled Vocabularies

By Peter N. Schweitzer (U.S. Geological Survey) .............

The National Geologic Map Database: A Progress Report

By David R. Soller (U.S. Geological Survey) and Thomas M. Berg

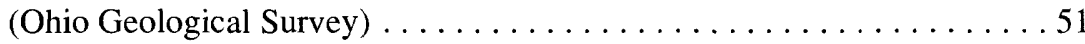


The U.S. Geological Survey National Paleontological Database

By Bruce R. Wardlaw, Nancy R. Stamm, and David R. Soller

(U.S. Geological Survey) ....................

Progress Report on the National Geologic Map Database, Phase 3an Online Database of Map Information

By David R. Soller and Ron Wahl (U.S. Geological Survey), Jerry Weisenfluh (Kentucky Geological Survey), Boyan Brodaric (Pennsylvania State University and Geological Survey of Canada) Jordan Hastings (University of California, Santa Barbara), Robert Laudati (GE-Smallworld Systems, Inc.), and Roger Fredericks (Techni Graphic Systems, Inc.) . . . . . . . . . .

Map Unit Descriptions and the North American Data Model

By Gerald A. Weisenfluh (Kentucky Geological Survey). . . . . . . .

The National Park Service Digital Geologic Map Model: Transformation from Paper to Digital, Featuring Legends, Cross Sections, Map Notes and Keyword Searchability

By Steve Fryer, Joe Gregson, Tim Connors, Anne Poole and

Bruce Heise (National Park Service) . . . . . . . . . . . . .

Special Session: Field Data Capture of Geologic Map Information ....

101

Removing Science Workflow Barrieres to Adoption of Digital

Geologic Mapping by Using the GeoMapper Universal Program and Visual User Interface

By George H. Brimhall and Abel Vanegas (University of

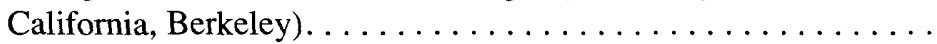

Using Handheld Personal Computers as Field Data Collection Tools:

Some Lessons Learned in the School of Hard Knocks in the Wingate Wash Project and Related Projects Using FieldLog/Fieldworker Software Exported into ArcInfo

By Terry L. Pavlis (University of New Orleans) and Jason Little

(California Division of Mines and Geology) . . . . . . . . . . . .

Quebec Geomining Information System (SIGÉOM): Field Data

Capture Model

By Charles Roy (Ministére des Ressources Naturelles, Quebec) ....

Conclusions From Four Years of Collecting Digital Map Data

Using a PDA

By Van S. Williams (U.S Geological Survey) .............

Development and Use of a Laptop-Based Geological Mapping

System: Experiences at the University of Kansas

By Ross Black and J. Douglas Walker (University of Kansas) .....

Rock Classification for Geologic Map Database Applications

By Stephen M. Richard (Arizona Geological Survey) .......... 
Interactive Geologic Maps Using ArcIMS, with Links to Related

Data and Images

By David R. Collins and Jorgina A. Ross (Kansas Geological Survey), and Detlev Doherr (University of Applied Sciences, Offenburg, Germany) . . . . . . . . . . . . . . . .

The Growing Issue of GIS Certification and Its Possible

Ramifications to Geological Mapping Science

By David J. McCraw (New Mexico Bureau of Geology and Mineral Resources $) \ldots \ldots \ldots \ldots \ldots \ldots \ldots \ldots \ldots$

Map Authorship and Citation Guidelines: Summary of a

Discussion Session

By C.R. Berquist, Jr. (Virginia Division of Mineral Resources) and David R. Soller (U.S. Geological Survey) . . . . . . . . . .

Vendor Presentations and Contact Information $\ldots \ldots \ldots \ldots \ldots \ldots$

\section{Poster Sessions}

Data Structure for the Arizona Geological Survey Geologic Information System: Basic Geologic Map Data

By Stephen M. Richard and Tim R. Orr (Arizona Geological Survey) . . . . . . . . . . . . . . . . . . . . . .

Geology of the Cretaceous West Gulf Coastal Plain in Southwestern

Arkansas

By William D. Hanson and Daniel K. Smith

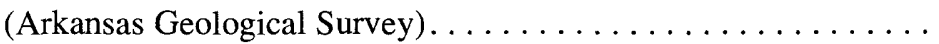

GIS May Make Maps Fast: But Cartography is Still and Art!

By William S. Schenck (Delaware Geological Survey) and

Nicole M. Minni (Delaware Water Resources Agency). . . . . . . . . .

Illinois 1998/1999 Digital Orthophoto Quadrangles: Recent Additions to the Illinois Natural Resources Geospatial Data Clearinghouse

By Sheena K. Beaverson and Christopher S. McGarry

(Illinois State Geological Survey) . . . . . . . . . . . . .

Making Improved Geotechnical Maps with Spatial Analysis

By Steven L. Martin (Kentucky Geological Survey). . . . . . . . . .

GIS Data Compilation Techniques for Mapping the Geology of the

Fort Polk Region of Louisiana

By R. Hampton Peele and Richard P. McCulloh

(Louisiana Geological Survey)...................

Geographic Information Systems (GIS) Applications to Karst

Studies - Frederick Valley, Maryland

By David K. Brezinski and Liana E. Dunne

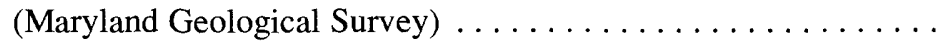


Three Dimensional Representations of Aeromagnetic and Isostatic Residual Gravity Surfaces with Geology in Montana By Patrick J. Kennelly (Montana Bureau of Mines and Geology). . . .

Development of a Digial Geologic Map for Mesa Verde National Park

By Anne R. Poole, Steve Fryer, Tim Connors, Bruce Heise Joe Gregson, and Allan Loy (National Park Service) . . . . . . . .

Brief Summaries from the New Jersey Geological Survey

By Gregory C. Herman, Scott D. Stanford, Mark A. French Zehdreh Allen-Lafayette, and Jeffrey L. Hoffman (New Jersey Geological Survey)

Integrated Digital Geospatial Data for the Cape Girardeau, Missouri Area in the New Madrid Seismic Zone: A Central United States Atlas Concept By Rick H. Bradford (U.S. Geological Survey) . . . . . . . . .

Will a Standard Data Model Work for Washington, DC Area Geologic Geospatial Data?

By Adam M. Davis (U.S. Geological Survey and Indiana University) . . 225

Selling Science to the American Public

By The Central Publications Group (U.S. Geological Survey) . . . . . . . 231

Cartographic Choices for the Surficial Geologic Map of Central and Southern New Jersey By Will R. Stettner and Elizabeth D. Koozmin

(U.S. Geological Survey) 233

Appendix A. List of Workshop Attendees . . . . . . . . . . . . 241

Appendix B. Workshop Web Site. . . . . . . . . . . . . . . . . 245

Appendix C. List of Addresses, Telephone Numbers, and URLs for Software and Hardware Suppliers . . . . . . . . . . . . . . . . . 247 


\title{
Introduction
}

\author{
By David R. Soller
}

\author{
U.S. Geological Survey \\ 908 National Center \\ Reston, VA 20192 \\ Telephone: (703) 648-6907 \\ Fax: (703) 648-6937 \\ e-mail: drsoller@usgs.gov
}

The Digital Mapping Techniques '01 (DMT’01) workshop was attended by 108 technical experts from 48 agencies, universities, and private companies, including representatives from 31 state geological surveys (see Appendix A). This workshop was similar in nature to the first four meetings, held in Lawrence, Kansas (Soller, 1997), in Champaign, Illinois (Soller, 1998a), in Madison, Wisconsin (Soller, 1999), and in Lexington, Kentucky (Soller, 2000). This year's meeting was hosted by the Geological Survey of Alabama, from May 20 to 23, 2001, on the University of Alabama campus in Tuscaloosa. As in the previous meetings, the objective was to foster informal discussion and exchange of technical information. When, based on discussions at the workshop, an attendee adopts or modifies a newly learned technique, the workshop clearly has met that objective. Evidence of learning and cooperation among participating agencies continued to be a highlight of the DMT workshops (see example in Soller, 1998b, and various papers in this volume).

The meeting's general goal was to help move the state geological surveys and the USGS toward development of more cost-effective, flexible, and useful systems for digital mapping and geographic information systems (GIS) analysis. Through oral and poster presentations and special discussion sessions, emphasis was given to: 1) methods for creating and publishing map products (here, "publishing" includes Web-based release); 2) continued development of the National Geologic Map Database; 3) progress toward building a standard geologic map data model; 4) field data-collection systems; and 5) map citation and authorship guidelines.

The five annual DMT workshops were coordinated by the AASG/USGS Data Capture Working Group, which was formed in August, 1996, to support the Association of American State Geologists and the USGS in their effort to build a National Geologic Map Database (see Soller and Berg, this volume, and <http://ncgmp.usgs.gov/ ngmdbproject/standards/datacapt/>). The Working Group was formed because increased production efficiencies, standardization, and quality of digital map products were needed to help the Database, and the State and Federal geological surveys, provide more high-quality digital maps to the public.

\section{ACKNOWLEDGMENTS}

I thank the Geological Survey of Alabama (GSA), and their Chief and State Geologist, Donald F. Oltz, for hosting this very productive and enjoyable meeting. I especially thank Nick Tew and April Lafferty (GSA), who coordinated the meeting, provided excellent support for the attendees, offered suberb social and technical activities (e.g., the catfish fry!), and managed the meeting's web site (see Appendix B). Thanks also to Ruth Collier, Kit Richter, and Sharon Alexander (GSA) and Marty Gates (University of Alabama, Department of Geology) for helping with the meeting logistics. I also note with gratitude the contributions of the following individuals: Tom Berg (Chair, AASG Digital Geologic Mapping Committee) for his help in conducting the meeting and for his continued support of AASG/USGS efforts to collaborate on the National Geologic Map Database; the members of the Data Capture Working Group (Warren Anderson, Kentucky Geological Survey; Rick Berquist and Elizabeth Campbell, Virginia Division of Mines and Geology; Rob Krumm and Barb Stiff, Illinois State Geological Survey; Scott McColloch, West Virginia Geological and Economic Survey; Gina Ross, Kansas Geological Survey; Dave Wagner, California Division of Mines and Geology; and Tom Whitfield, Pennsylvania Geological Survey) for advice in planning the workshop's content and the suggestions to authors; and Nancy L. Polend for typesetting these and the previous three Proceedings. Finally, I thank all attendees for their participation; their enthusiasm and expertise were the primary reasons for the meeting's success. 


\section{PRESENTATIONS}

The workshop included 25 oral presentations. Nearly all are supported by a short paper contained in these Proceedings. Some presentations were coordinated with Discussion Sessions, described below. The papers represent approaches that currently meet some or all needs for digital mapping at the respective agency. There is not, of course, a single "solution" or approach to digital mapping that will work for each agency or for each program or group within an agency - personnel and funding levels, and the schedule, data format, and manner in which we must deliver our information to the public require that each agency design their own approach. However, the value of this workshop, and other forums like it, is through their role in helping to design or refine these agency-specific approaches to digital mapping and to find approaches used by other agencies that are applicable. In other words, communication helps us to avoid "reinventing the wheel."

The papers are generally organized by topic, including field data systems; database design, standards, and data models; and creation, management, and delivery of map publications and data. Information about the software and hardware referred to in these Proceedings is provided in Appendix C.

\section{POSTERS}

More than 20 posters were exhibited throughout the workshop. These posters provided an excellent focus for technical discussions and support for oral presentations. Many are documented with a paper in these Proceedings, following the oral presentations; the other posters generally provided material in support of oral presentations, and so are not documented herein.

\section{DISCUSSION SESSIONS}

To provide the opportunity to consider a topic in some detail, special discussion sessions are held at the DMT workshops. This year there were two: 1) field data capture systems, and 2) geologic map authorship and citation guidelines. Discussion session \#1 included an oral presentation session, a 2-hour informal session focusing on field demonstration of hardware and software that was described in the oral presentations, and a question and answer session. Discussion session \#2 began by revisiting the presentation of ideas and suggestions proposed at DMT'99 and DMT'00 (see <http://pubs.usgs.gov/ openfile/of99-386/> and $<\mathrm{http} / / /$ pubs.usgs.gov/openfile/ of $00-325 />$. The paper by Berquist and Soller (this volume) describes this session and its outcome. These two sessions highlight an important aspect of the DMT workshop series - it provides for these disciplines a rather unique venue for sharing technical information and experience.

\section{THE NEXT DMT WORKSHOP}

The sixth annual DMT meeting will be held in late Spring, 2002, hosted by the Utah Geological Survey. While planning for that event, the Data Capture Working Group will carefully consider the recommendations offered by DMT'01 attendees.

\section{REFERENCES}

Soller, D.R., editor, 1997, Proceedings of a workshop on digital mapping techniques: Methods for geologic map data capture, management, and publication: U.S. Geological Survey Open-File Report 97-269, 120 p., <http://ncgmp.usgs.gov/pubs/of97-269/>.

Soller, D.R., editor, 1998a, Digital Mapping Techniques '98 Workshop Proceedings: U.S. Geological Survey Open-File Report 98-487, 134 p., <http://pubs.usgs.gov/openfile/ of $98-487 />$.

Soller, D.R., 1998b, Introduction, in: D.R. Soller, ed., Digital Mapping Techniques ' 98 - Workshop Proceedings: U.S. Geological Survey Open-File Report 98-487, p. 1-3, <http://pubs.usgs.gov/openfile/of98-487/intro.html>.

Soller, D.R., editor, 1999, Digital Mapping Techniques ‘99 Workshop Proceedings: U.S. Geological Survey Open-File Report 99-386, 216 p., <http://pubs.usgs.gov/openfile/ of 99-386/>.

Soller, D.R., editor, 2000, Digital Mapping Techniques '00 Workshop Proceedings: U.S. Geological Survey Open-File Report 00-325, 209 p., <http://pubs.usgs.gov/openfile/ of $00-325 />$. 


\title{
Data Capture Techniques for the Digital Database of the Monterey Quadrangle, California
}

\author{
By David L. Wagner \\ California Division of Mines and Geology \\ 80-1 K St. MS 12-31 \\ Sacramento, CA 95814 \\ Telephone: (916) 324-7380 \\ Fax: (916) 322-4765 \\ e-mail: dwagner@consrv.ca.gov
}

\section{INTRODUCTION}

At DMT 97 I presented a paper (Wagner, 1997) describing the data capture techniques employed by the California Division of Mines and Geology (CDMG). At that time we were just beginning to work on a digital compilation of a geologic map and database of the Monterey 1:100,000-scale quadrangle and the adjacent seafloor of Monterey Bay. A main point of the paper was that we digitize geologic data for a 1:100,000-scale quadrangle at the largest scale possible, preferably 1:24,000. Now, the compilation has been completed and is undergoing review for release approval. This paper will discuss some of the points put forth at DMT 97.

This map and database are a step forward in the understanding of geology of coastal California. Monterey Bay is a marine sanctuary that has been intensively studied by the Moss Landing Marine Laboratories (MLML), the Monterey Bay Aquarium Research Institute (MBARI) and the U.S. Geological Survey (USGS). As a consequence, the geology and the physiography of Monterey Bay is sufficiently well known to prepare a seamless geologic map of the onshore and offshore. Digital geologic and physiographic data were compiled independently by CDMG, MLML, MBARI, and USGS and integrated into a single database. The Monterey Quadrangle is an example of the benefits of cooperation between research-oriented institutions that emphasize data-gathering activities and a state survey that emphasizes data distribution.

\section{COMPILATION}

This project was initiated in 1988 when D. L. Wagner and C. L. Pridmore compiled an analog geologic map of the quadrangle. Compilation of a digital database began in 1998 by digitizing geologic maps at $1: 24,000$ scale and tiling the maps together to make a seamless 1:100,000 geologic map. Sarah Watkins and Jason Little of the CDMG Regional Geologic and Hazards Mapping Project digitized $287.5^{\prime}$ ' quadrangles, mostly at a scale of 1:24,000. Two quadrangles, Monterey and Seaside, already published in digital form by the USGS, were used directly, although the stratigraphic nomenclature was modified slightly for consistency with the rest of the map. $\mathrm{H}$. Gary Greene compiled the offshore geology of the continental slope and Monterey Canyon system, which was digitized by Joseph Bizzarro at the Moss Landing Marine Laboratory. Steve Eittreim interpreted the geology of the continental shelf (water depths less than 150 meters) on screen at a scale of 1:6,000 from acoustic imagery of 2.4 meter resolution. The digital database is in ArcInfo format and employs the ALACARTE data model (Fitzgibbon and Wentworth, 1991).

The base for the Monterey quadrangle consists of a shaded-relief and a topographic map. The topographic base covers only the onshore part of the quadrangle. It is a digital line graph (DLG) of the Monterey and part of the Palo Alto 1:100,000 scale quadrangles provided by C. M. Wentworth (USGS). David Ramsey (USGS) assembled the altitude grid from 30 meter DEMs of the 7.5' quadrangles that make up the Monterey 1:100,000 quadrangle that he downloaded from the USGS database in Sioux Falls. George Saucedo (CDMG) generated the onshore part of the shaded-relief map from a 30-meter digital elevation model (DEM) using the technique described by Haugerud and Greenberg (1998). Norman Maher of the Monterey Bay Aquarium Research Institute (MBARI) prepared the shaded-relief image of the Monterey Bay submarine canyon and surrounding area from Simrad EM300 $(30 \mathrm{kHz})$ multibeam bathymetric data collected by MBARI and the USGS. He also provided the bathymetric contours. Steve Eittreim (USGS) provided imagery for the 
Monterey Bay shelf (water less than 150 deep). That imagery is available online at

$<$ http://terraweb.wr.usgs.gov/TRS/projects/MontereySonar>. Versions of the map with and without the shaded-relief base are included because the gray tones of the shadedrelief darken the lighter-colored tones of the map units. The shaded-relief base map particularly affects the yellow surficial units.

\section{DATA CAPTURE TECHNIQUES}

Usually $1: 24,000$ scale maps are not available for an entire $100 \mathrm{~K}$ quadrangle so a decision has to be made whether to conduct new geologic mapping or to use existing data at smaller scales. Although approximately one and a half $7.5^{\prime}$ quadrangles were mapped as part of the Monterey project, most of the area, both onshore and offshore were covered by good geologic maps, mostly at 1:24,000 scale. Most of the other 1:100,000-scale maps now being prepared by CDMG required substantial new geologic mapping before a compilation could begin. In southern California, a multiyear mapping project, partially supported by the USGS National Cooperative Geologic Mapping Program's STATEMAP component, was conducted to map all of the onshore part of the Oceanside $1: 100,000$-scale quadrangle. CDMG is now exploring partnership possibilities to upgrade the geologic data on the continental borderland to produce a seamless map covering the offshore as well.

Table 1 shows a comparison of estimates of the time required for tasks in the preparation of a 1:100,000-scale quadrangle made by Wagner (1997) to the time each step actually required in preparation of the Monterey Quadrangle. The time required for digitizing individual 7.5 ' quadrangles was overestimated by a factor of 3 to 4 . Thus the earlier estimate for a single 7.5' quadrangle of about $\$ 2280$ was clearly too high and is now considered to be about $\$ 500$ to $\$ 700$. Part of the overestimation is due to the growing proficiency of the digitizers as they gain experience. Table 1 also demonstrates that while digitizing 7.5 ' quadrangles is a relatively inexpensive, straightforward process, tiling them together to make a seamless map is not. The main problem here is complexities of matching the geology across map borders (edgematching).

Several factors affect edgematching, including: 1 ) inconsistencies between mappers; 2) inconsistencies in geologic nomenclature; 3) complex geology where there are rapid facies changes and time transgressive units; and 4) scale differences. Inconsistencies between mappers are the most vexing problems facing any compiler of geologic maps. These inconsistencies may arise from scientific perspectives of the mapper, evolution of the understanding of the geology of an area, or the reason why the mapping was done. A map by an academic researcher may have a completely different emphasis than a map prepared by an engineering geologist concerned with the siting of a critical facility. Geologic nomenclature evolves over time and unless a compiler is familiar with how the nomenclature has evolved it may be very difficult to produce a coherent map. As the understanding of geologic relationships evolve, maps portraying the same rock units may be quite different. In California for example, most of the northern and central coastal ranges are underlain by the Franciscan Complex, a tectonically deformed, lithologically diverse collection of rocks now considered to be the type example of a subduction complex. Originally named the Franciscan Formation, mappers labored unsuccessfully for decades to describe it in terms of classical stratigraphic nomenclature. Eventually the Code of Stratigraphic Nomenclature was revised to account for such situations. As a result, newer maps depict the geology much differently than the older ones. Economic interests drove most of the early mapping done in California. Thus until fairly recently, most mapping was done in Tertiary marine terranes in search of hydrocarbons, or in igneous/metamorphic terranes where most mineralized rock occurs. These maps tend to lump most Quaternary units into alluvium and mostly ignore landslides or other features considered superficial. In contrast, mapping today tends to be driven by geologic hazards considerations, engineering applications, land-use, and environmental issues so the superficial features and materials have prominence. Time and effort expended in investigating and resolving inconsistencies before the digital compilation begins can lessen the seemingly endless revisions after the initial compilation is completed.

Prior to beginning the digital compilation, we compiled an analog version of the Monterey Quadrangle that proved invaluable. My experience as a compiler of regional geologic maps (scales of 1:100,000 and smaller) has convinced me that establishing the stratigraphic framework and the preparation of the map explanation requires more time and effort than the preparation of the map itself. Preparation of an analog map is expensive and time consuming but it more than pays off in the long run. It is analogous to a set of plans to guide the construction of a building. The compiler needs to visualize how the pieces are to fit together before the project starts and not have to make midcourse corrections. This however adds at least a year to the project and requires one to two person years of geologist time.

\section{BENEFIT OF DIGITIZING AT THE LARGEST SCALE POSSIBLE}

An unfortunate consequence of digitizing geologic maps is that once in digital form, they appear free of scale 
Table 1. Comparison of estimates by Wagner (1997) of time required for tasks in compilation of a 1:100,000-scale quadrangle to the time actually spent on the same tasks during compilation of the Monterey quadrangle. The first three steps are the digitization of the individual 1:24.000-scale quadrangles and last two are assembling the quadrangles to produce a seamless map. The edgematch and review steps are iterative, time-consuming tasks that are difficult to quantify. Close collaboration between the geologistlcompiler and the digitizer is required for this part of the project.

\begin{tabular}{|l|l|l|}
\hline $\begin{array}{l}\text { Tasks for compilation of } \\
\text { 100k geologic map }\end{array}$ & $\begin{array}{l}\text { Estimated time } \\
\text { (Wagner, 1997) }\end{array}$ & $\begin{array}{l}\text { Actual time during } \\
\text { compilation of Monterey } \\
\text { quad }\end{array}$ \\
\hline $\begin{array}{l}\text { 1. Digitize linework for a } \\
\text { 1:24,000-scale } \\
\text { quadrangle }\end{array}$ & 16 to 32 hours & 3.5 to 8 hours \\
\hline $\begin{array}{l}\text { 2. Attribute polygons on } \\
\text { a 1:24,000-scale } \\
\text { quadrangle }\end{array}$ & 8 to 16 hours & 1 to 4 hours \\
\hline $\begin{array}{l}\text { 3. Prepare structure } \\
\text { layer; attribute faults } \\
\text { and point data. }\end{array}$ & 16 to 32 hours & 4 to 10 hours \\
\hline $\begin{array}{c}\text { 4. Edgematch } \\
\text { quadrangles }\end{array}$ & Variable & Uncertain $>1,000$ hours \\
\hline $\begin{array}{l}\text { 5. Review and edit } \\
\text { Ru } 24 \text { hours }\end{array}$ & $\begin{array}{l}\text { Uncertain- driven by } \\
\text { edgematching }\end{array}$ \\
\hline
\end{tabular}

limitations. In my experience, many users, even professional geologists who should know better, violate the resolution of the data. Regional geologic maps are especially subject to abuse because they cover large areas, even entire states seamlessly. Despite admonitions in readme files and metadata, enlarging from regional scales to sitespecific scales is a common practice. A benefit of digitizing and doing all of the edits at 1:24,000 scale is that the $1: 100,000$-scale map is a mosaic of thirty-two $1: 24,000$ scale geologic maps. Thus the resolution of the 1:100,000scale digital compilation will be $1: 24,000$. It is possible then to enlarge the data to $1: 24,000$ scale without violating their resolution. It is far more efficient to release a compilation that can be enlarged to $1: 24,000$ than it is to release 32 individual 7.5' quadrangles.

An example of the utility of this approach was recently demonstrated when CDMG received a request from a sister agency, the Division of Oil, Gas and Geothermal Resources (DOGGR). DOGGR has a program to mitigate the effects of improperly abandoned oil wells that are leaking. They were evaluating old wells in the Sargent Oil field central California Coast Ranges. The Sargent Oil field is on the Monterey 1:100,000 quadrangle and was compiled from several sources at 1:24,000. DOGGR asked CDMG to provide the most up to date geologic map of the area. In a matter of hours we were able to clip out a part of the map at 1:24,000 scale, add explanatory and border text using Adobe Illustrator and deliver a PDF image of a finished-looking, colored geologic map (Figure 1).

\section{CONCLUSIONS}

The Geologic Map of the Monterey Quadrangle and Adjacent Areas is one of the first geologic maps to show geology across the terrestrial/marine transition seamlessly and therefore is a major step forward in portraying California coastal geology. This map is the result of a cooperative effort by several government agencies, as well as academic and private research institutions. Wagner (1997) described data capture for 1:100,000 scale geologic maps involving digitization at the largest scale possible (preferably 1:24,000) and tiling the maps together.

Estimates of the time necessary to digitize individual 7.5' quadrangles proved to be high. However, as expected, edge matching the quadrangles turned out to be a major part of the effort. This method is much more time consuming than digitizing at 1:100,000-scale, but the database is much more versatile. If the digitization and subsequent edits are all done at 1:24,000-scale, then the 1:100,000 scale map is a seamless mosaic of thirty-two $7.5^{\prime}$ ' quadrangles. 


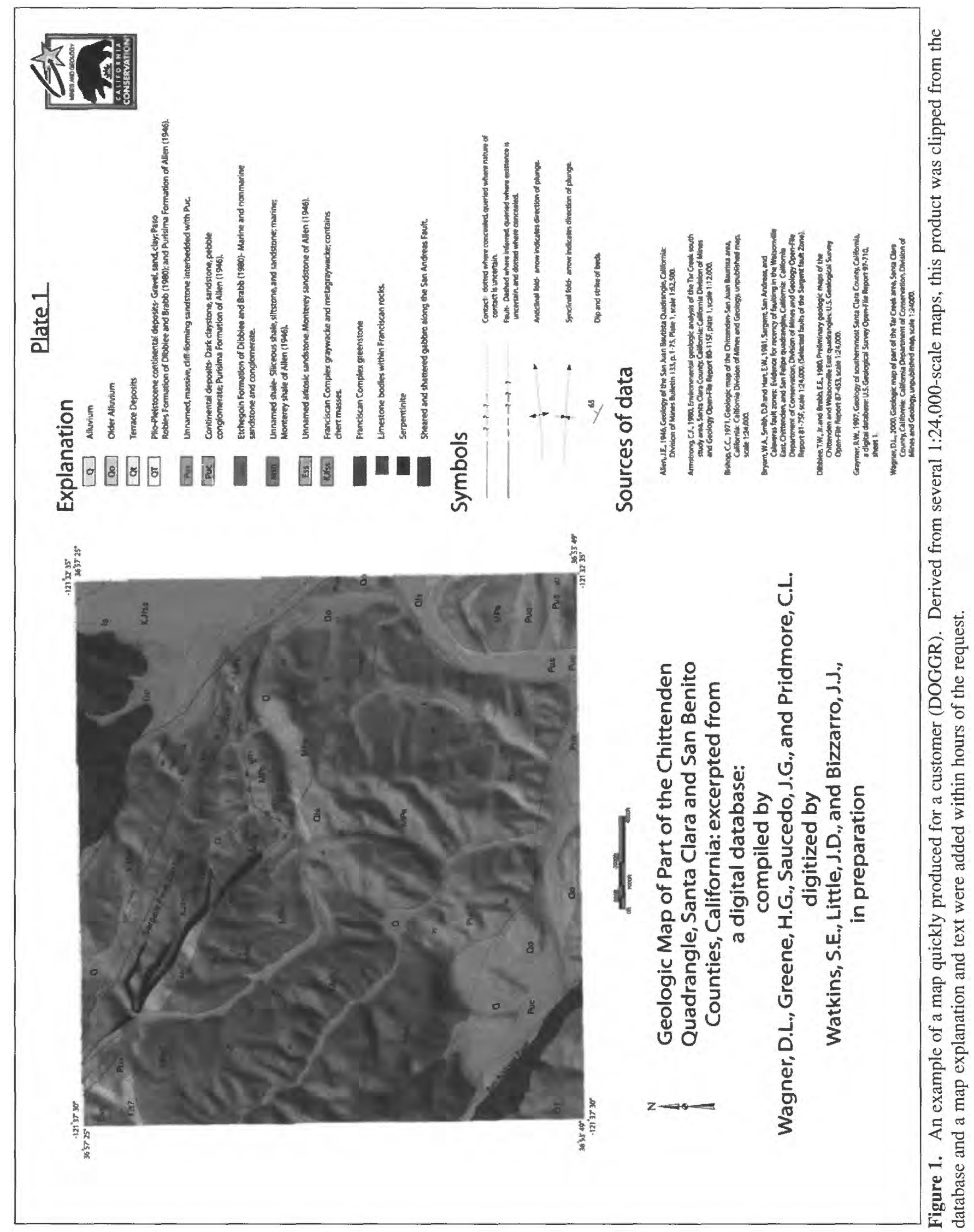




\section{REFERENCES}

Fitizgibbon, T.T., and Wentworth, C.M., 1991, ALACARTE User Interface-AML code and demonstration maps: U.S. Geological Survey Open-File Report 91-587, 10 p.

Haugerud, Ralph, and Greenberg, H.M., 1998, Recipes for Digital Cartography: Cooking with DEMs, in David R.

Soller, editor, Digital Mapping Techniques '98 - Workshop Proceedings: U.S. Geological Survey Open-File Report 98-
487, p. 119-126, <http://pubs.usgs.gov/openfile/ of $98-487 /$ haug2.html $>$.

Wagner, D.L., 1997, Digital mapping techniques employed by the California Division of Mines and Geology, in David R. Soller, editor, Proceedings of a workshop on digital mapping techniques: Methods for geologic map data capture, management, and publication: U.S. Geological Survey Open-File Report 97-269, p. 35-38, <http://pubs.usgs.gov/openfile/of97-269/wagner.html>. 


\title{
From Conventional Airphotos, to 2.5D Maps and Digital Mosaic Terrain Reconstructions: A Simple but Complete Digital Technique Used at GSC-Québec, Canada
}

\author{
By Serge J. Paradis ${ }^{1}$, Marco Boutin ${ }^{2}$, Ruth Boivin ${ }^{3}$, and Hugo Larocque ${ }^{2,4}$ \\ ${ }^{1}$ Geological Survey of Canada \\ Québec Geoscience Centre \\ 880 Ch. Ste-Foy, CP 7500 \\ Ste-Foy, Québec, Canada, G1V 4C7 \\ Telephone: (418) 6542556 \\ Fax: (418) 654-2615 \\ e-mail: sparadis@nrcan.gc.ca, \\ 2INRS-Géoressources \\ Québec Geoscience Centre \\ 880 Ch. Ste-Foy, CP 7500 \\ Ste-Foy, Québec, Canada, G1V 4C7 \\ e-mail: ess-inrs-mboutin@x1.nrcan.gc.ca \\ ${ }^{3}$ Natural Resources of Canada \\ ESS-Info \\ 880 Ch. Ste-Foy, CP 7500 \\ Ste-Foy, Québec, Canada, G1V 4C7 \\ e-mail: ruboivin@rncan.gc.ca \\ ${ }^{4}$ Hugo Larocque \\ Present address : 1157 rue De Liesse, \\ Masson-Angers, Québec, Canada,J8M 1H7 \\ e-mail: hugo.larocque@statcan.ca
}

\section{INTRODUCTION}

Photogrammetry is a technique that allows representation of objects, volume and form, and particularly relief when stereophotography is coupled with topographic data. This well known technique enables us to create modern topographic $2.5 \mathrm{D}$ maps as well as digital terrain reconstructions using data derived directly from conventional airphotos. The expression 2.5D is used in contrast with $2 \mathrm{D}$ because the thematic map or the digital terrain reconstruction are respectively combined with a digital elevation model (DEM) or a triangular irregular network (TIN) which gives an impression of 3D.
In 1997, the Québec Geoscience Centre acquired a Digital Video Plotter (DVP), which is a photogrammetric software package. It allowed upgrading the methodology for transferring data with an accurate and relatively fast method, from multi-scale conventional airphotos to multiscale topographic bases. With time, we developed multidisciplinary applications for this software.

\section{THE OLD DAYS}

In the old days, five years ago, data from the airphotos were transferred manually by the photo-interpreter using a 
Mapograph reflector projector (fig.1). This method was arduous and needed repeated verifications until the final compilation was completed. It was usually difficult to achieve the absolute orientation of the airphotos on the reproduced transparent topographic base.

Furthermore, the only way to minimize radial distortion was by manually displacing the airphotos on the support located under the glass compartment of the projector. Also, with the mapograph used at GSC-Québec, if the scale of the airphotos was more than 2.5 times that of the topographic base, the transfer step had to be repeated. This double manipulation was time consuming and added the possibility of introducing errors to the final product.

\section{NEW TECHNIQUE}

Digital videorestitution using the DVP (fig.2) enables us to achieve absolute orientation easily and with an even higher degree of precision compared to the reflector projector method. Absolute orientation consists of estimating transformation parameters for the earth coordinates and fixing the exact spatial references of the stereoscopic model to the digital topographic base (Paradis and Boutin, 2000a,b).

Thus, it is possible to transfer information from airphotos that have a significant scaling difference compared to the topographic base (eg: airphotos at 1:40 000 scale on a topographic base at 1:250 000 scale) in a single operation (Paradis and Parent, in press a,b; Paradis et al. 2000). Since the airphotos are scanned at $400 \mathrm{dpi}$ resolution (image size $8.5 \mathrm{MB}$ ); it is possible to use them while conserving their original scale ( $23 \mathrm{~cm} \times 23 \mathrm{~cm}$ format) or any other scale following a reduction or a zoom on the cathodic screen. Therefore, the airphotos can be reported on the topographic base, whatever its scale, without adding errrors in the transfer procedure.

Digital videorestitution is a videogrammetric technique that allows $2 \mathrm{D}$ or $3 \mathrm{D}$ visualisation of digital images or graphics on a cathodic screen. To optimize the use of the 2D technique, which is favored at GSC-Québec, two very important steps are needed to recreate the geometric situation that prevailed when the original photos were taken. This topic has been previously discussed in detail by Paradis and Boutin (2000a) so we will only succinctly mention them for the benefit of the present reader.

(1) Internal orientation: consists of defining the focal distance of the camera when the photo was taken and the registration of the exact distance between the fiducial marks (located in the four corners of the photo, represented by a circle or a cross depending on the type of camera).

(2) Absolute orientation: as mentioned above, consist of estimating transformation parameters for the coordinates between the stereoscopic model and the numerical topographic base.

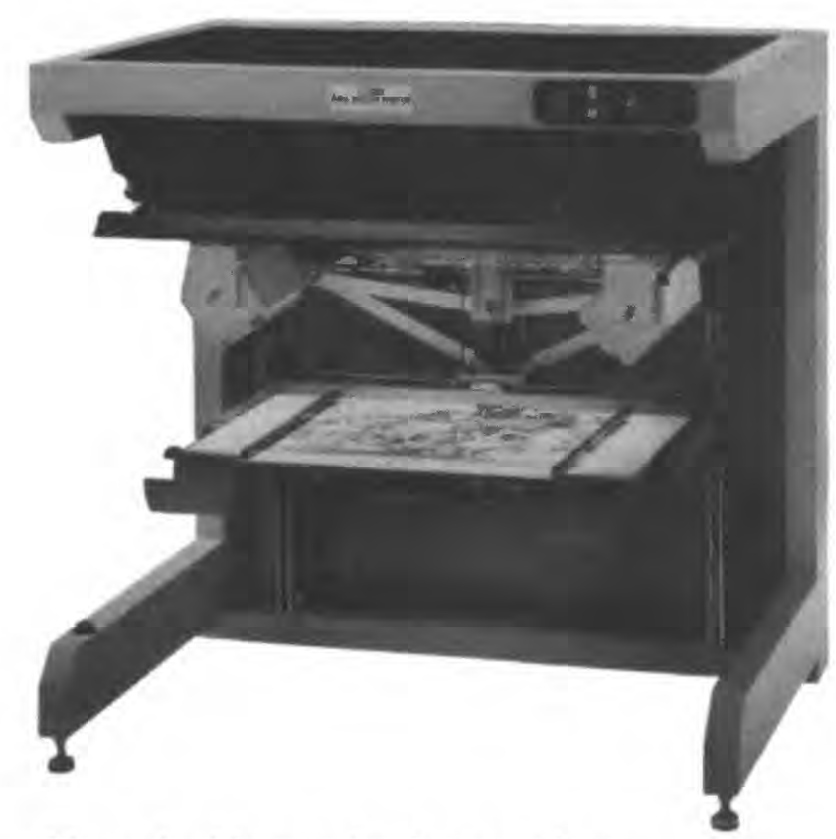

Figure 1. Mapograph reflector projector.

These steps require special attention, because they control the precision of displacement, following $\mathrm{x}$ and $\mathrm{y}$ axes, of captured elements from the airphotos to the compilation on the digital topographic base. For a map at 1:20 000 scale and air photos at 1:15000 scale (Paradis et al. 1999), the degree of precision in the transfer of information is on the order of 1 meter or less. Alternate positioning techniques such as global positioning systems or electronic total stations allow us to increase this precision. For comparison, the width of a line traced with a rapidograph pen (point 00 ) on an airphoto at 1:15 000 scale corresponds in the field to a band of 7.75 meters wide.

\section{THE PROCEDURE AT GSC-QUÉBEC}

The actual procedure used at GSC-Québec has evolved considerably since 1997 . The DVP orientation, rectification and mosaic modules are still the main softwares used in the compilation of information derived from airphoto interpretation. It has been coupled recently with a Descartes module from Microstation. We were working first on single airphotos, we are now building airphoto mosaics of 16 to 20 photos. These alternatives have been developed to increase effectiveness of digitizing geologic map information. For a map at 1:250 000 scale and air photos at 1:40 000, we have gained an impressive $40 \%$ in digitizing speed/time performance. In real time, this means a gain of 3 months on an 8 months digitizing job.

The procedure, step by step, is as follows:

1) the geologist finishes his field work and starts his photo-interpretation, mapping all geologic or geomor- 


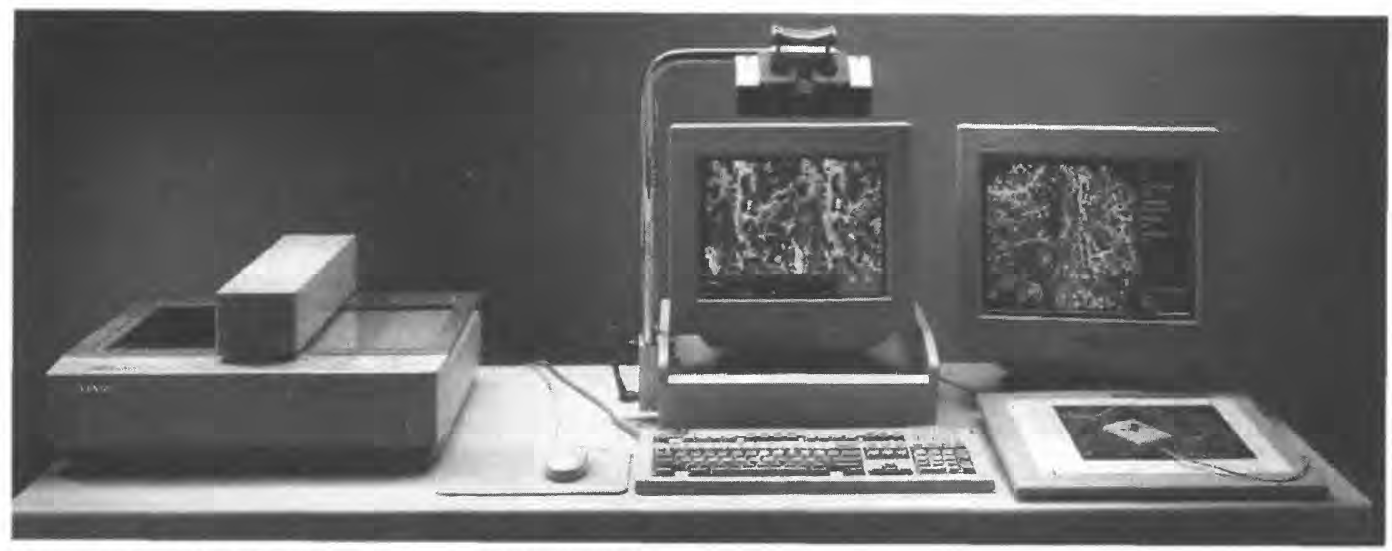

Figure 2. Digital Video Plotter with digitizing table.

phologic features that have to be integrated to the final map compilation; these informations are directly inscribed with a special pen ( 00 rapidograph with black ink) on the original airphotos;

2) the airphotos are scanned at $400 \mathrm{dpi}$., creating derived tiff files of 8.5-10 MB (we are presently using a scanning digitizer Sharp JX-610 with a resolution of 600 $\mathrm{dpi}$; almost any modern regular scanning digitizer could do the job);

3) each individual photo has to be oriented individually using the DVP orientation module (internal and absolute orientation);

4) each individual photo is orthorectified, so that they can be perfectly superposed on to the numerical topographic base; this is done using the DVP rectification module;

5) individually rectified airphotos are merged together (groups of 16-20) into a large mosaic creating one image / derived file of 50-60 MB using the DVP mosaic module;

6) a decision has to be made at this point: will the end product be a digital terrain reconstruction or a $2.5 \mathrm{D}$ map compilation;

7) to obtain the digital terrain reconstruction the mosaic must be draped on a TIN (Triangular Irregular Network) that is created using the Geoterrain Microstation module;

8) to produce the final 2.5D map compilation, the mosaic is imported into the Descartes Microstation module where all the linework, polygons, linear structures or any geological or geomorphological element that are not points, are digitized;

9) the same mosaic is then transferred in the DVP digitizing module where all the other elements are digitized; the merging of the two mosaic files (Descartes, DVP) is done within the DVP using DXF files; importing in Descartes is also possible;

10) when the digitization is complete, a DXF file is created and imported into ArcInfo where the data are sep- arated in three files: a) the geological contact file used to build polygons; $b$ ) the geological linear feature file (ex: moraines, eskers) and c) the geological point feature file (ex: outcrop, striae); the three files are then corrected, standardized and edited;

11) following this editing, the different map covers are prepared (ex: boundary, hydrology, topography, roads etc.);

12) the legend is compiled and edited;

13) using ArcInfo and GRID (ArcInfo module) a hydrology file is created and a Digital Terrain Model (DTM) is built using a 2 step AML semi-automated procedure;

14) using GRIDCOMPOSITE (ArcInfo command) we can superpose the geological color map (completed at step 15) on the DTM;

15) map composition AMLs are then prepared including logos, scale, location map, and the 2.5D map then is ready for printing.

\section{CONCLUSION}

Digital videorestitution is a very powerful method to speed up transfer and recompilation of different data visible on conventional airphotos. It also keeps a high degree of precision and quality in the manipulation and transformation of these same data (eg. Paradis, 2000a,b,c). Videorestitution also gives us the opportunity to do all kinds of measurements (distance between two points, altitude of one particular point or structure, elevation of different types of geomorphological phenomenon, length, width, etc) without having to retransform the original data.

For 35 K (2001, Canadian dollars), without ArcInfo and ArcInfo modules, you can get the setup we are using at GSC-Québec, Canada, including a Pentium, Windows NT 4.0., Sharp JX-610 scanner, one 17 inch and one 21 inch Viewsonic screens, the Digital Video Plotter (DVP) software and the Microstation software. 


\section{ACKNOWLEDGEMENT}

Special thanks to the GSC for funding. Gratitude is expressed to Éric Boisvert, Andrée Bolduc (GSC-Québec) and David Soller (USGS) for their review of the manuscript.

\section{REFERENCES}

Paradis, S.J., 2000a, Géologie des formations superficielles, Lac Opawica, Québec (32 G/12): Commission géologique du Canada, Dossier public 3846, 1 color map, scale 1:50,000.

Paradis, S.J., 2000b, Géologie des formations superficielles, Lac Inconnu, Québec (32 G/13): Commission géologique du Canada, Dossier public 3847, 1 color map, scale 1:50,000.

Paradis, S.J., 2000c, Géologie des formations superficielles, Lac des Orignaux, Québec (32 G/14): Commission géologique du Canada, Dossier public 3898, 1 color map, scale $1: 50,000$.

Paradis, S.J., and Boutin, M., 2000a, L'utilisation d'un vidéorestituteur numérique comme outil de cartographie détaillée (Saguenay, Québec): Recherche en cours 2000-D13, 8 p., <http://www.nrcan.gc.ca/gsc/bookstore>.
Paradis, S.J. and Boutin, M., 2000b, La vidéorestitution numérique, technologie multi-scalaire adaptée aux besoins de la cartographie géoscientifique: IXe congrès de l'Association québécoise pour l'étude du Quaternaire conjointement avec la réunion annuelle du groupe canadien de recherche en géomorphologie, Programme et résumé de l'AQQUA - CGRG Montréal, août 2000, p. 9 (Conférence).

Paradis, S.J. and Parent, M., in press a, Géologie des formations superficielles, Lac Bermen Est, Québec: Commmission géologique du Canada, Carte 1976A, scale 1:125,000.

Paradis, S.J. and Parent, M., in press b, Géologie des formations superficielles, Lac Bermen Ouest, Québec: Commmission géologique du Canada, Carte 1977A, scale 1:125,000.

Paradis, S.J., Parent, M., Boutin, M., Boivin, R. and Larocque, H., 2000, Cartographie détaillée $2.5 \mathrm{D}(1: 250,000)$ des formations superficielles de la région de la rivière Koroc (24 I) dans le Grand-Nord québécois dans Séminaire d'information sur la recherche géologique, 2000: Résumés, Ministère des Ressources naturelles du Québec, DV-2000-03, p. 50.

Paradis, S.J., Parent, M., Perret, D. and Bégin, C., 1999, Géologie des formations superficielles, Saint-Fulgence et La Baie, Québec: Commission géologique du Canada, Dossier public 3710,2 color maps, scale 1:20,000, 22D 07-2000201 and 22D 07-200-0101. 


\title{
3D Geologic Maps and Visualization: A New Approach to the Geology of the Santa Clara (Silicon) Valley, California
}

\author{
By R.C. Jachens ${ }^{1}$, C.M. Wentworth ${ }^{1}$, D.L. Gautier ${ }^{1}$, and S. Pack ${ }^{2}$ \\ ${ }^{1}$ U.S. Geological Survey \\ 345 Middlefield Road, MS 989 \\ Menlo Park, CA 94025 \\ Telephone: (650) 329-5300 \\ Fax: (650) 329-5133 \\ e-mail: jachens@usgs.gov \\ ${ }^{2}$ Dynamic Graphics, Inc. \\ 1015 Atlantic Avenue \\ Alameda, CA 94501-1154 \\ Telephone: (510) 522-0700 \\ Fax: (510) 522-5670 \\ e-mail: skip@dgi.com
}

\begin{abstract}
The USGS recently began a long-range project to construct a 3D geologic map of the Santa Clara ('Silicon') Valley, southern San Francisco Bay area, California. This is part of a larger project that also involves developing techniques for constructing 3D models, defining uncertainties associated with geologic elements and properties, and designing procedures for visualizing, accessing, and releasing 3D geologic information. This multipurpose map is intended to provide a quantitative basis for modeling processes including groundwater flow, contaminant dispersion from naturally occurring mercury and asbestos, ground shaking, seismic wave propagation, and tectonic strain accumulation. The fundamental map architecture is defined by critical surfaces (faults, intrusive contacts, unconformities, other depositional contacts) interacting to form volumes, which ultimately are assigned measurement-based properties according to geologic identity, geometric position, or both. Quantitative definition of critical surfaces is based mainly on surface geology, drillhole data, cone penetrometer testing, gravity and magnetic modeling, seismic reflection and refraction profiling, and earthquakes. Critical surfaces are assembled into a 3D map using earthVision (Dynamic Graphics, Inc.) modeling software.
\end{abstract}

The map volume is $45 \mathrm{X} 45 \mathrm{~km}$ by $14 \mathrm{~km}$ deep, and spans the valley floor and surrounding hillsides between the San Andreas and Calaveras faults. It is divided by 11 major faults into blocks, within which the Cenozoic section is represented by up to three layers, and the Mesozoic section by more than six units. The 3D map exists in the computer as 1) a set of numerical grids (large cell raster datasets) that quantitatively define the positions and shapes of the critical surfaces, 2) a set of instructions that specify how these surfaces interact when they encounter each other, and 3) the software to assemble the surfaces according to the specified instructions and to assign properties to the map volume. The present 3D map includes the fundamental geometry, architecture, and interaction instructions, though many of the surfaces are as yet only approximately defined. This framework allows us to progressively refine the individual surfaces in an iterative fashion without altering the fundamental model architecture.

\section{INTRODUCTION}

Computer-based representations of areal geology extended into the subsurface as 3-dimensional geologic maps can now be developed to provide continuous quantitative 3-D geologic information for a variety of practical needs. Such 3-D databases and appropriate computer software will allow even the inexperienced user to figuratively 'walk around' in the earth to examine the data and extract needed information. One important application unique to 
3-D geologic maps is predictive process modeling of geologic, tectonic, and hydrologic processes needed for landuse planning, hazard mitigation, and resource management. Examples of immediate applications of 3-D maps include ground shaking estimation, refined earthquake relocation, fault segmentation analysis for probabilistic earthquake forecasting, resource exploration, contaminant source and dispersion pathway definition, and ground water flow modeling for resource management.

Traditional geologic maps, which show the distribution and orientation of geologic materials and structures at the ground surface, have served for many decades as effective tools for storing and transmitting geologic information. The introduction of Geographic Information Systems (GIS) enhanced traditional geologic maps in terms of ease of use and communication of surface geologic information. However, these maps, even enhanced with GIS capabilities, are insufficient for storing and transmitting subsurface information, information that is critical in the role of the map as a window into the subsurface. Fortunately, advances in computer hardware and geologic modeling and visualization software now provide us with the potential to construct 3-D geologic maps that retain all the information in a traditional geologic map while quantitatively extending this information into the subsurface. This year the U.S. Geological Survey launched a project titled 3Dimensional Geologic Maps and Visualization that is designed to take the strong Survey background in the production of traditional geologic maps to the next level by explicitly adding the third dimension.

The goal of the project is to produce, display, and release quantitative 3-dimensional geologic maps, initially in the San Francisco Bay region. The 3-D maps will include, in a continuous quantitative volumetric format, the information contained in traditional 2-D geologic maps and thus can form the bases for predictive process modeling as well as address, in 3-dimensions, traditional geologic map-based questions. A critical component of these 3-D maps will be the inclusion of a continuous representation of uncertainties, a feature only partly realized in traditional geologic maps. Fundamental techniques peculiar to 3-D map generation will be developed to accomplish this goal.

\section{D GEOLOGIC MAP ARCHITECTURE}

The 3D maps, which are being designed and constructed under this project are framed around the earthVision geologic modeling and visualization software, retain the fundamental architecture of traditional geologic maps while extending it into the third dimension. Lines on a 2D geologic map (e.g. faults, intrusive contacts, depositional contacts, etc.) become surfaces, and areas transform into volumes in 3 dimensions.

We follow a rigorous sequence of procedures in constructing our 3D geologic maps. First, point data repre- senting discrete 3D locations on a given geologic surface (e.g. a fault) are assembled from surface geologic mapping, well data, geophysical inversions, seismicity, geologic reasoning, and any other sources available. A numerically defined surface is then passed through these data points in order to predict the position of the geologic surface throughout the 3D map volume. Uncertainty as a function of position is assigned to each surface. Once all important surfaces have been defined in this way, they are assembled into a 3D structure according to 'rules' that specify how the surfaces interact (i.e., which surfaces truncate which). The surfaces, together with the interaction rules, define volumes that correspond to fault blocks and geologic units. Properties are then assigned throughout the 3D geologic map according to xyz location, geologic identity, proximity to surfaces, geologic process model considerations, or some combination of these parameters. Thus the $3 \mathrm{D}$ geologic map exists in the computer as a collection of numerically defined surfaces with associated uncertainties, a set of rules that specify spatial interactions where surfaces encounter each other, and a volume distribution of properties with associated uncertainties. Note that because the map is numerical, it is capable of an enormous dynamic range when defining features. Theoretically, strata a few $\mathrm{cm}$ thick could be faithfully included in a geologic map that extends through the entire earth's crust.

Once the 3D map has been assembled within the computer, graphical representations (e.g. figs. 1, 2) permit the user to examine the map from various directions, slice it to examine its interior, disassemble it to examine individual geologic units, compare it graphically with other geographically defined data, and perform a number of other tasks. While graphical representations are valuable tools with which to make use of the 3D geologic map they are simply graphical extracts from the real 3D geologic map that exists digitally within the computer.

\section{DATA SOURCES}

One of the constraints we have imposed on this project is that the tools, techniques, and 3D geologic maps developed here must be based on the types of data that typically would be available. In our map areas, we cannot necessarily expect to have 3D seismic surveys, detailed high-density drill-hole arrays, or similar data sets on which the exploration industries generally base their site-specific 3D geologic models. Furthermore, in most cases we will need to work with data that were collected for other purposes. The types of data that might generally be available are:

\section{Geologic Maps}

In most areas, geologic maps of the ground surface provide the scientific and conceptual framework for the 


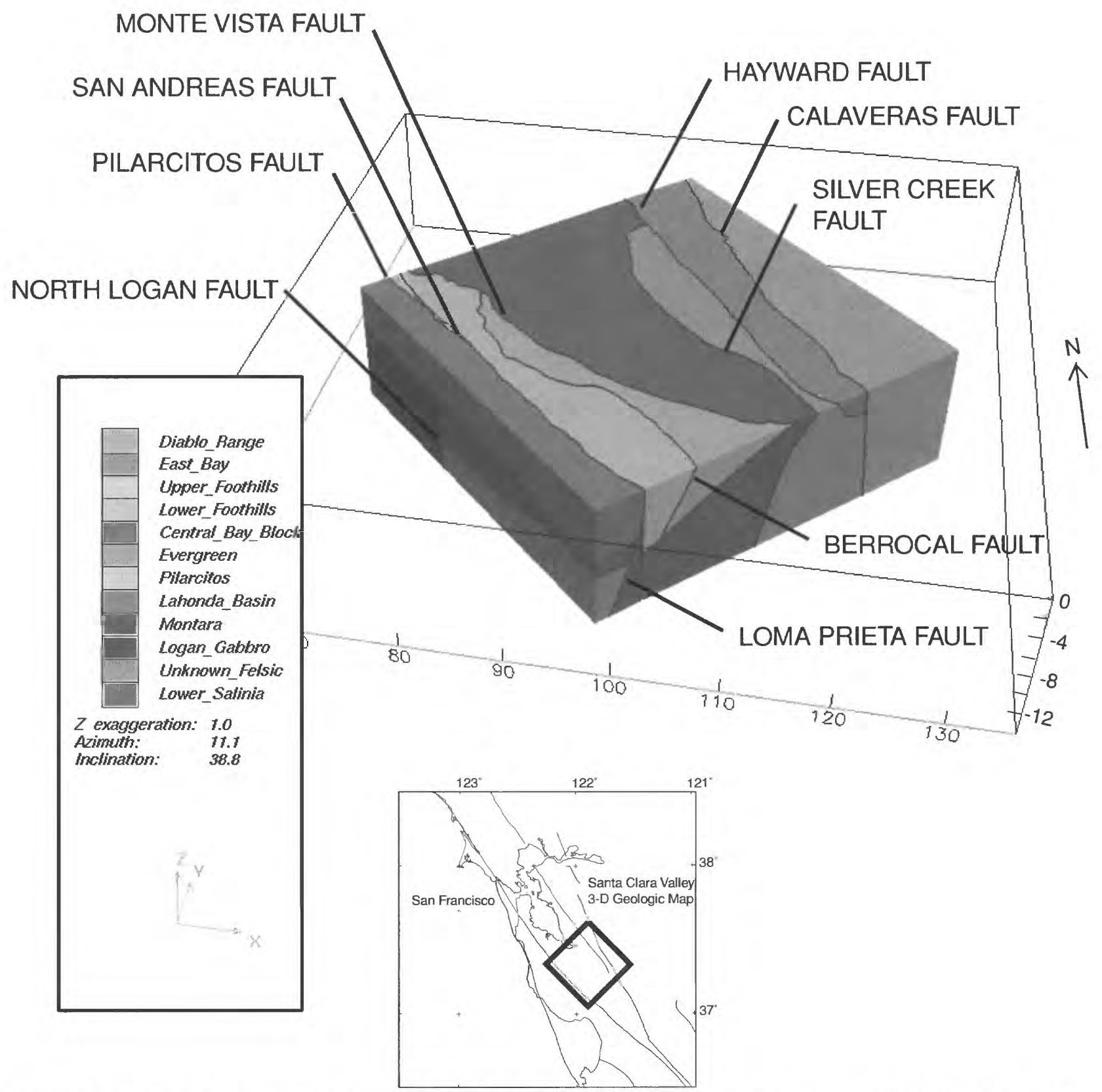

Figure 1. Fault block diagram of the Santa Clara Valley 3D geologic map. Map volume is divided by 11 major faults. Fault surfaces shown are only approximate representations of the actual fault surfaces, and have been assembled to show the fault block architecture of the 3D map. No vertical exaggeration.

3D geologic map, and constitute one of the most complete data sets in terms of areal coverage. The surface maps identify the geologic units and the major structures that must be included in the 3D map, and the relationships among these units and structures. The geologic and tectonic history inferred from the map will guide many of the decisions that will be needed to specify the geologic units and structures everywhere in the subsurface. Finally, the maps include quantitative point data for constraining the location and shape of critical surfaces, and background information for characterizing properties associated with geologic materials.

\section{Well Data}

Data from drill-holes are generally the most important source of point data for defining the locations of critical surfaces in the subsurface. It is possible that a number of different well data sets may be available. These might include:

1. water wells, with associated driller's logs and, occasionally, geophysical logs

2. geotechnical wells from large construction projects or groundwater contamination investigations, which 
tend to be shallow but often have detailed lithologic and geophysical logs

3. miscellaneous wells such as those drilled during exploration for natural resources (hydrocarbon, geothermal, or mineral resources).

\section{Seismic Profiles}

Seismic reflection and refraction profiles and their interpretations provide important $2 \mathrm{D}$ subsurface information along profiles and provide critical links between subsurface physical property boundaries and geologic structures and contacts mapped at the surface. If properly placed, they can be used to integrate well data with surface geology and to define the subsurface locations of critical surfaces between points determined from well data.

Typical sources of seismic profile data include university and U.S. Geological Survey scientific investigations of the Earth's crust, seismic reflection surveys for oil and gas exploration, and shallow seismic studies in support of large construction projects and groundwater basin evalua- tions. Areas that include large water masses such as bays, large lakes, and open oceans along the coasts, often contain marine seismic reflection profiles collected for exploration or hazard mitigation purposes.

\section{Electrical Sounding and Profiles}

Vertical electrical soundings based on direct current resistivity measurements or controlled source electromagnetic measurements provide point or $2 \mathrm{D}$ information on the subsurface distribution of electrical properties. These data, combined with electrical and geologic data from wells, can be used in a manner similar to seismic profiles, i.e., to define $2 \mathrm{D}$ positions of geologic interfaces in the subsurface. However, caution should be exercised in the use of these data because unambiguous correlation of electrical properties with geologic features is challenging.

Electrical sounding and profile data typically are collected in support of ground water investigations and engineering studies. Some data may be found in areas with geothermal resource potential.

\section{SANTA CLARA VALLEY (SILICON VALLEY)}

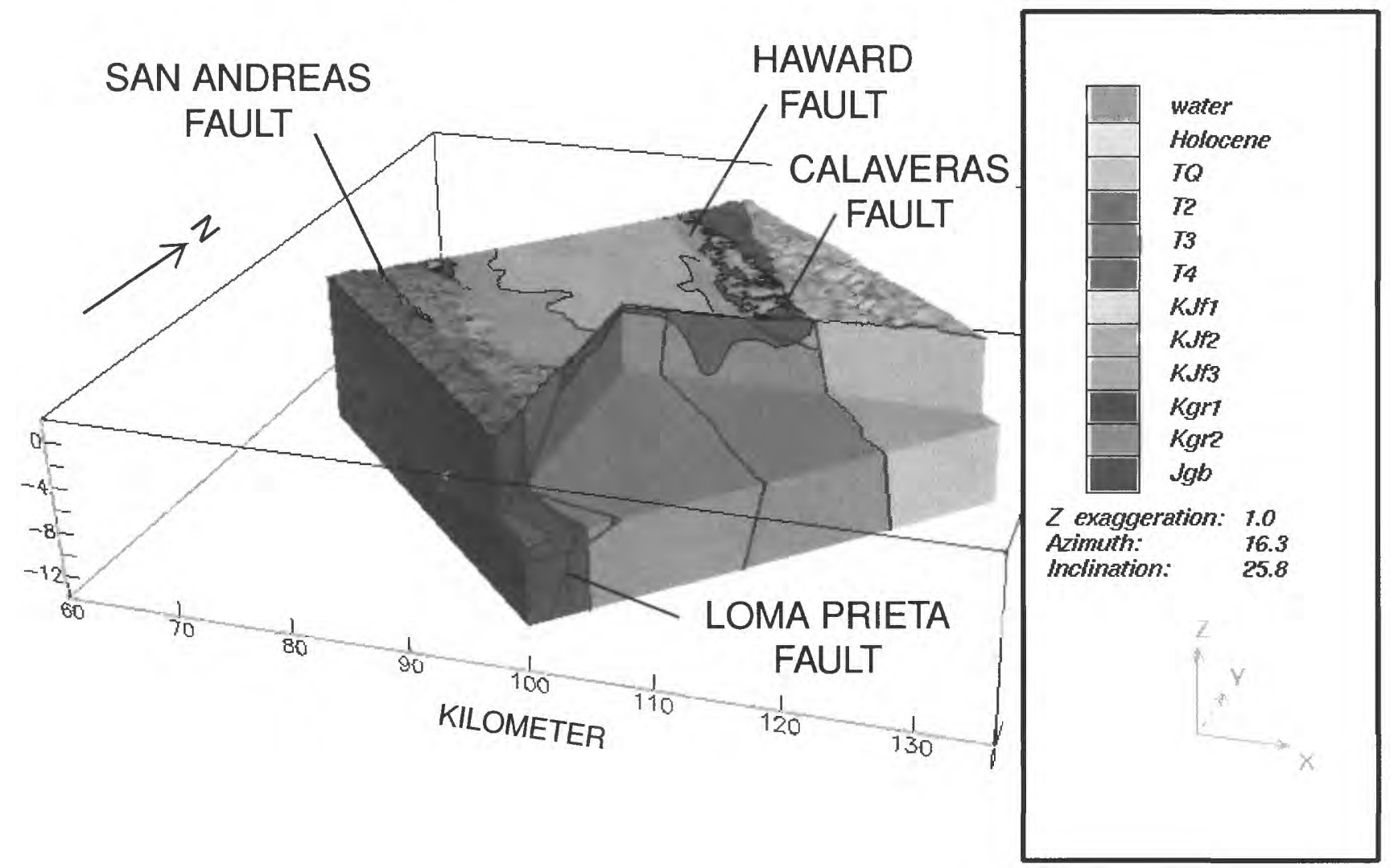

Figure 2. Simple 3D geologic map of the Santa Clara Valley and surrounding hillsides. Only gross geologic units and approximate geologic surfaces are shown. Block has been 'chair' cut to reveal some internal geologic information. Topographic surface derived from the $30 \mathrm{~m}$ digital elevation model (DEM) of the San Francisco Bay region. No vertical exaggeration. 


\section{Seismicity}

In seismically active regions, the 3D locations of earthquakes (hypocenters) can provide unique information on the subsurface shape and location of active faults. Such faults tend to be major structures in 3D geologic maps. Modern methods used to locate earthquakes (Ellsworth and others, 2000) produce distributions of hypocenters that, in some cases, define curviplaner features with surface areas measured in hundreds of $\mathrm{km}^{2}$, yet fault-normal thicknesses of a few hundred meters or less (fig. 3). Few techniques, other than drilling and seismic reflection profiling, provide such accurate subsurface information.

\section{Gravity and Magnetic Map Data}

Maps of gravity and magnetic anomalies (figs. 4,5 ) are available for most of North America and much of the rest of the world. These maps reflect the subsurface variations of rock density (gravity anomaly) or rock magnetization (magnetic anomaly), properties that often can be related to rock type. Any gravity or magnetic anomaly produced by a subsurface geologic body contains quantitative information about the size, shape, and subsurface location of the source body. The information is ambiguous, however, because a gravity and/or magnetic anomaly does not uniquely define its source. Quantitative interpretation of

\section{EARTHQUAKES BENEATH SANTA CLARA VALLEY}

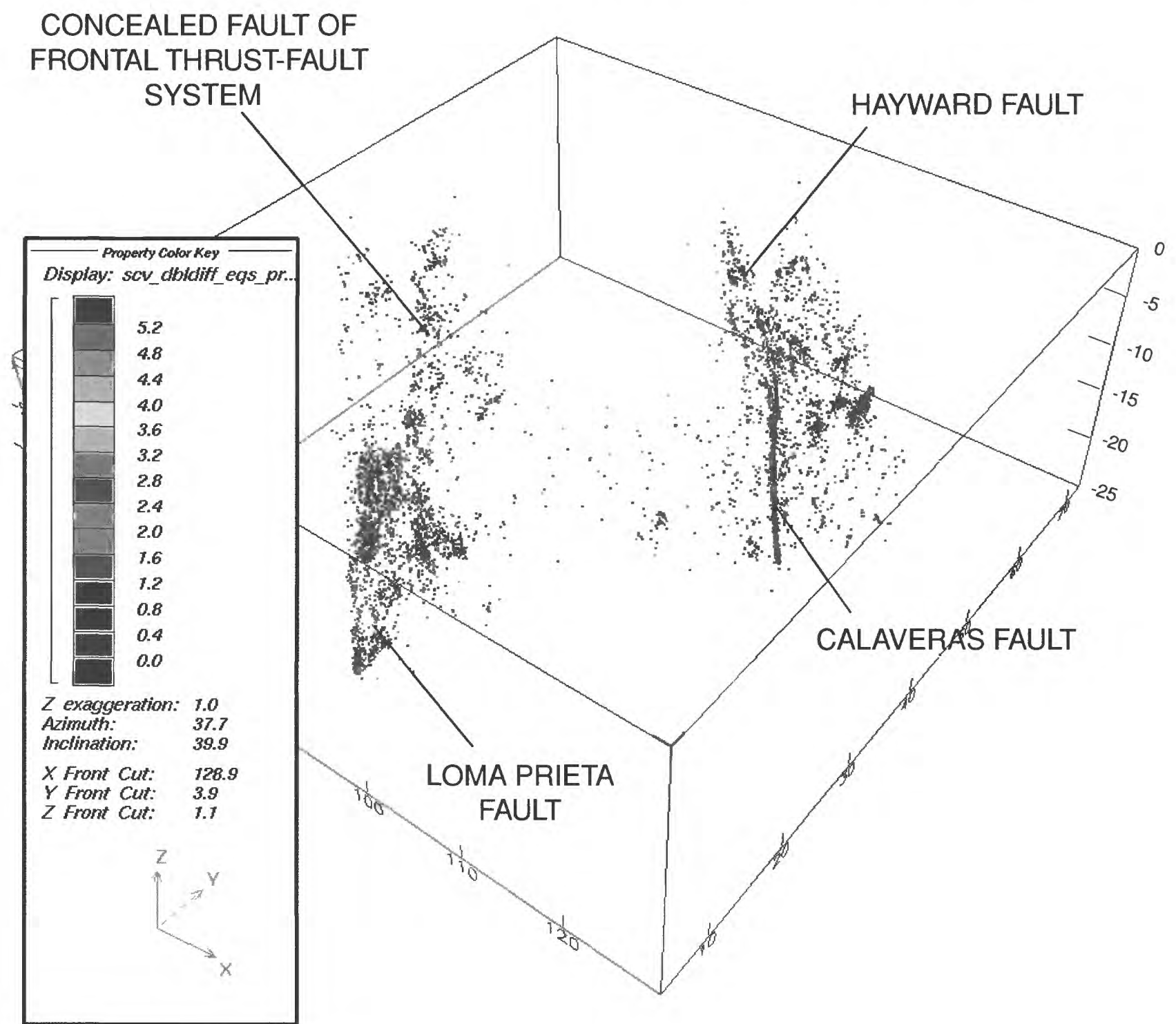

Figure 3. Earthquakes (1984-2000) within the Santa Clara Valley 3D geologic map. Volume is aligned to permit sighting northwest along the seismicity occurring on the Calaveras fault. Other clusters of seismicity associated with faults are identified, including an elongate distribution that we speculate occurs on a concealed, outboard member of the frontal thrust-fault system that bounds the southwest edge of the Santa Clara Valley. No vertical exaggeration. 


\section{GRAVITY FIELD}

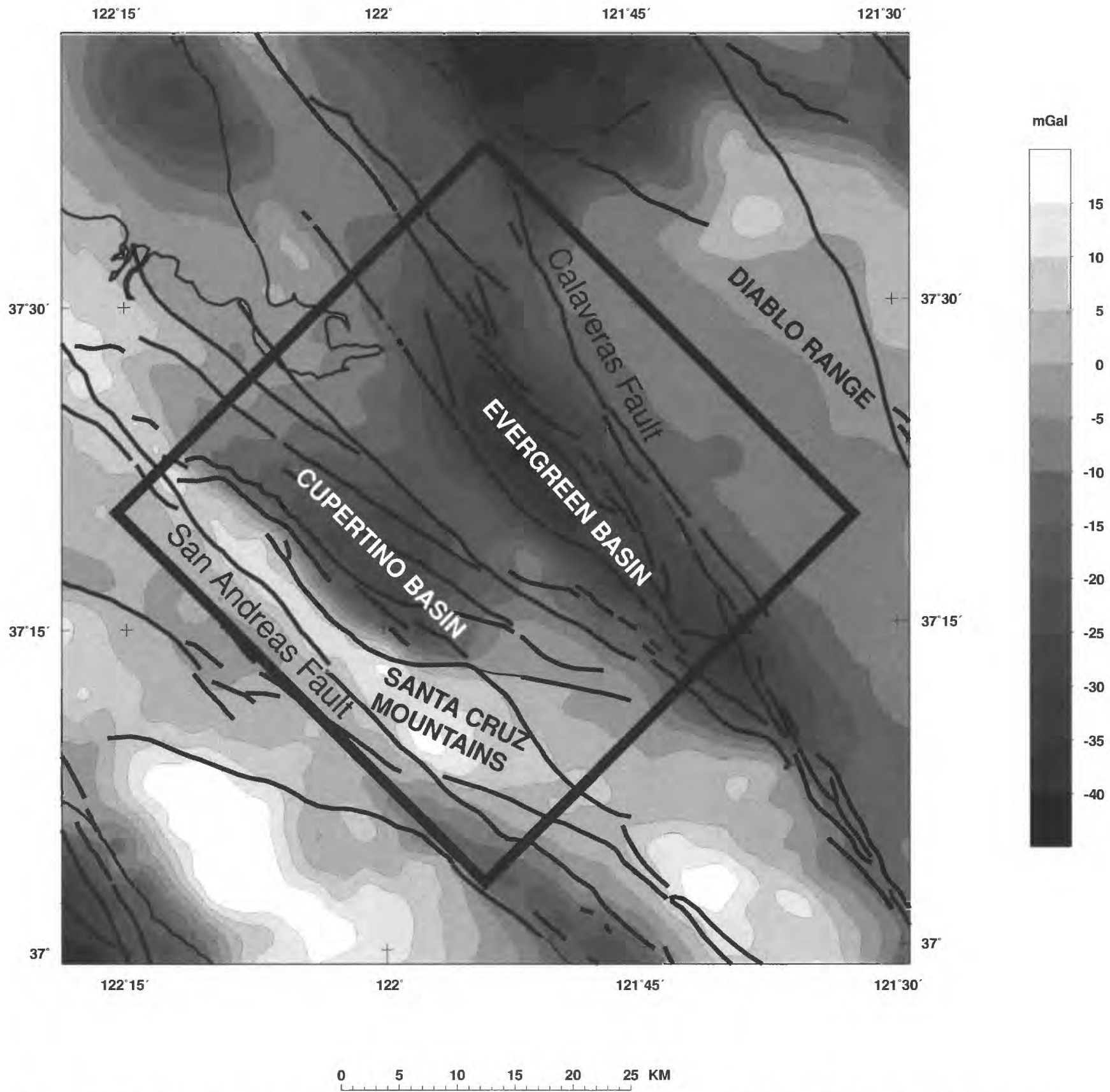

Figure 4. Map showing the residual gravity field of the Santa Clara Valley and vicinity. The gravity field, in conjunction with mapped geology, drill hole data, seismic profiling, and other geophysical interpretations, is used to infer the location and shape of the contact between the Cenozoic deposits and the underlying Mesozoic bedrock. This interface, which tends to be a strong density contrast in the Santa Clara Valley, shows considerable relief, especially in the Cupertino and Evergreen basins. Heavy rectangle is map view outline of the 3D geologic map of the Santa Clara Valley. Faults after Jennings (1994). Contour interval, 5 mGal.

gravity and magnetic anomalies within constraints provided by geology, well data, other geophysical interpretations, and physical reasoning can be effective in reducing the ambiguity.
Because gravity and magnetic anomaly data typically will cover the entire area of interest (2D map format), yet reflect the geology of the subsurface, one of their most useful roles is as an interpolator between other scattered 


\section{MAGNETIC FIELD}

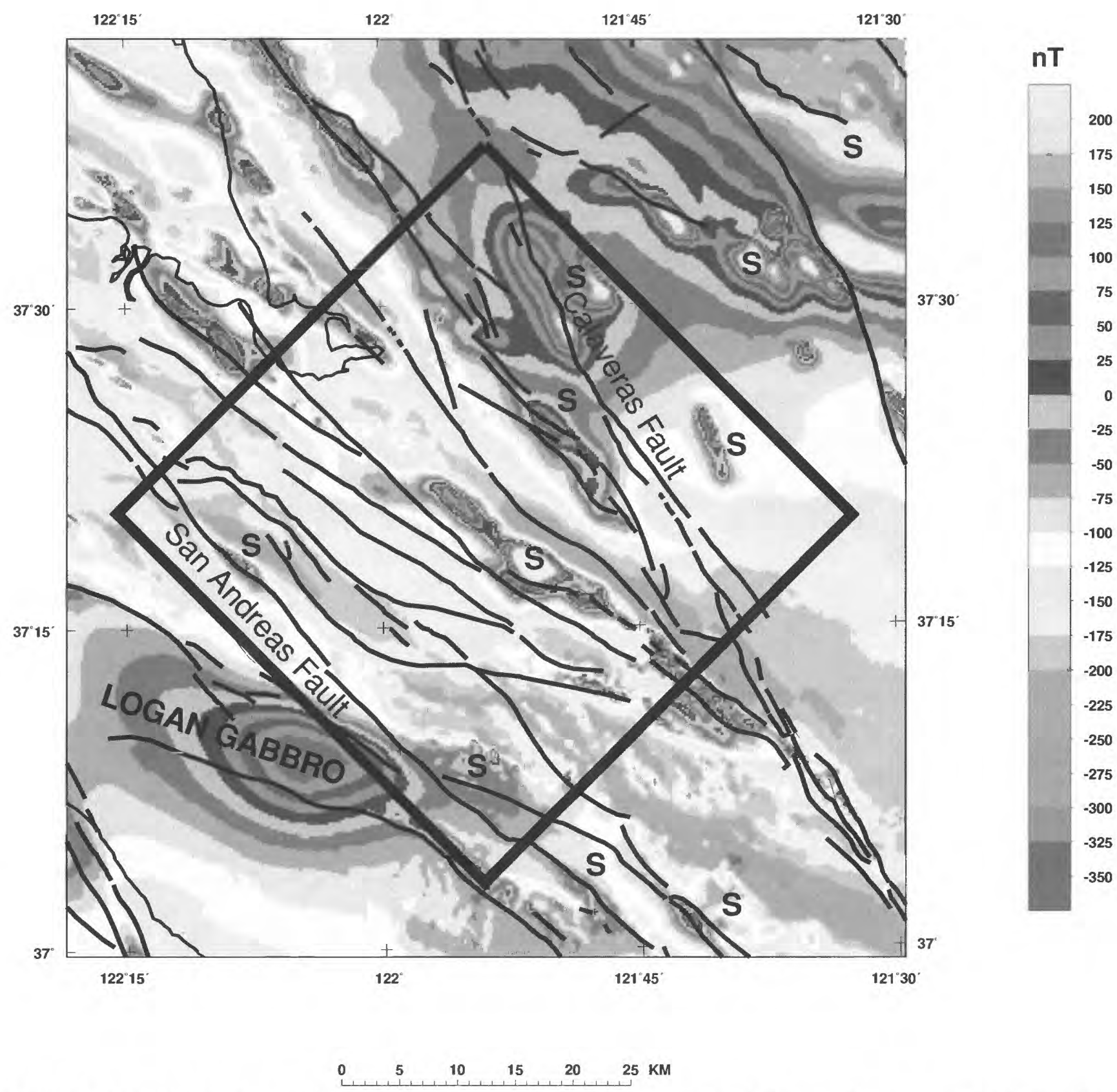

Figure 5. Map showing the residual magnetic field of the Santa Clara Valley and vicinity. The magnetic field is used to define the shape and location of the buried Logan Gabbro southwest of the San Andreas fault, and various serpentinite (designated by ' $S$ ') and metavolcanic bodies northeast of the fault. Heavy rectangle is map view outline of the 3D geologic map of the Santa Clara Valley. Faults after Jennings (1994). Contour interval, 25 nanoTesla.

data. For example, a subsurface density boundary (e.g. the contact between crystalline basement rocks and overlying Cenozoic sedimentary deposits) might be known in a few locations where penetrated by wells, be known from surface mapping as an exposed contact, and be imaged along an isolated seismic reflection profile. Gravity anomaly data provide a basis for connecting the isolated point data with a spatially continuous 3D surface representing this contact. Magnetic anomaly data can be used in a similar fashion to define 3D surfaces separating geologic bodies with different magnetic properties. In still other cases, the gravity and magnetic data may be interpreted nearly inde- 
pendently to produce 3D representations of the geology and structure of the subsurface.

\section{Other Data}

The foregoing data types are typically the most readily available, although on occasion other types of data such as seismic tomography, magnetotelluric soundings, geochemical sampling, or hydrologic modeling, might be used to help construct a 3D geologic map. When viewed in the context of trying to define the geologic map everywhere in the subsurface, the distribution and number of these data seem extremely limited. They are almost never dense enough to support direct geospatial modeling of the type used in mining exploration or ground water contamination remediation investigations. Therefore, in order to construct a fully 3D geologic map from these types of data, it is necessary to develop tools with which to make better use of the data.

\section{TOOLS FOR CONSTRUCTING QUANTITATIVE 3D GEOLOGIC MAPS}

\section{Projecting Geology Quantitatively into the Subsurface}

Geologic maps portraying the geology at the ground surface typically constitute one of the most detailed and extensive data sets available for constructing quantitative 3D geologic maps. New techniques are needed, however, for projecting this geology into the subsurface and defining the uncertainties associated with the projection of various geologic entities. As an initial effort, we are developing an interactive computer-based system that will facilitate the generation of geologic cross sections which then can be linked by 'tie-lines' to produce a 3D map (Fitzgibbon and others, 2001).

\section{D Inversion of Gravity and Magnetic Data}

Gravity and magnetic anomaly maps contain quantitative information about the distribution of density and magnetization contrasts contained within the crust, and often these physical property distributions can be related directly to geology (Blakely, 1995). For example, in the Santa Clara Valley much of the character expressed in the gravity anomaly field is attributable to variations in the thickness of Cenozoic deposits overlying Cretaceous and older bedrock. Similarly, more than $90 \%$ of the magnetic anomalies reflect exposed and concealed tabular bodies of serpentinite or metavolcanic rock. Defining these geologic elements in 3 dimensions will go a long way toward building a good 3D geologic map of the Santa Clara Valley. In particular, the serpentinite bodies not only make up a sig- nificant part of the pre-Cenozoic rock beneath the Santa Clara Valley, but they often lie within, and thus define, fault zones cutting the pre-Cenozoic bedrock.

For this project, we have begun by evaluating existing techniques for the 3D inversion of gravity and magnetic anomalies, and developing an inversion technique specifically designed to determine quantitatively the 3D location and shape of tabular magnetic bodies in the subsurface. We are also experimenting with the application of gravity inversion techniques to magnetic inversions through the use of the pseudogravity transform (Baranov, 1957).

\section{Smart Interpolation Techniques}

To be successful in constructing a useful 3D geologic map from incomplete or sparse data, techniques are needed for defining the positions of the surfaces between control points that are 'smarter' than simply connecting the control points with lines or planes. Two general categories are 1) those that use remotely sensed data containing somewhat ambiguous information about the surface to constrain the shape of a given concealed surface between control points, and 2) techniques that use geologic principles and models to interpolate between control points.

In the first category, we are refining a procedure that uses surface gravity observations to infer the $3 \mathrm{D}$ position of a concealed density interface (e.g. the contact between the Cenozoic and pre-Cenozoic rocks beneath the Santa Clara Valley) subject to constraints from surface geology, well penetrations, and other geophysical interpretations (Jachens and Moring, 1990). We also are examining uncertainties associated with this inversion, especially in terms of the observed gravity and assumed subsurface density distributions. In the second category, we are looking toward utilizing the extensive developments that have taken place within the petroleum-related sciences related to the application of sedimentological models, diagenetic concepts, sequence stratigraphy principles, balanced cross section analyses, etc., and their possible applications to the construction of $3 \mathrm{D}$ geologic maps. In particular, we are looking to the petroleum-related sciences for techniques that can be used with water well log data to generate 3D geologic maps of the upper few hundred meters of the crust.

\section{Statistical vs. Deterministic Representations of Geology and Rock Properties}

For some processes and at some scales, statistical representations of geology or rock properties may be more appropriate than deterministic representations. For example. estimating the total storage capacity of an aquifer or the total amount of water that might be extracted before subsidence and fissuring become a problem could be cases where statistical representations of hydrogeologic properties are adequate. We have not yet strayed from our intent 
to construct a deterministic 3D geologic map of the Santa Clara Valley, but the availability of a small number of volumetrically restricted but intensely studied contamination sites could provide the data for such a statistical representation of a part of the subsurface.

\section{3-DIMENSIONAL GEOLOGIC MAP OF THE SANTA CLARA VALLEY: PRESENT STATUS}

The 3D geologic map of the Santa Clara Valley is still in its infancy, due to the fact that the project is only about 8 months old, large data compilation efforts are required before the map can be generated, and many of the tools needed to construct the map are not available and are not simple to develop. Nevertheless, progress has been made, and the preliminary 3D map, while crude, already is providing fascinating insights into some important geologic problems.

\section{Current Map}

Our major map-related accomplishment has been the definition of the fundamental 3D architecture of the Santa Clara Valley 3D map, and the construction of a 'strawman' map populated with rough approximations or surrogates of the surfaces that will be needed in the final map (figs 1,2). Details of the 'strawman' are based mostly on new geologic compilations (Graymer and others, 1996; Brabb and others, 1998; Wentworth and others, 1998), inferences from gravity and magnetic anomalies (figs. 4,5 ), seismicity (fig. 3 ), and limited well information. The map exists in the computer as a set of digital grids that define the critical geologic surfaces in 3 dimensions, and a set of instructions in earthVision that specify how the surfaces interact when they encounter each other (i.e. which surfaces truncate which). This digital map is represented in the flow diagram shown in figure 6 , and the block diagrams of the map shown in figures 1 and 2 can be thought of as cartographic representations of the digital map. The map volume is divided into fault blocks by 11 major faults, some of which are active today (fig. 1). At present, each fault block includes no more than five major geologic units (fig. 2 ), although future versions will include more complexity.

The present 3D map is in a flexible format that permits refinement without disrupting its fundamental architecture, and, further, allows existing scientific questions to be addressed before the map is completed. Progressive refinement can and will take place surface by surface. Whenever a specific geologic surface (e.g. the San Andreas fault) is better defined, we simply replace the surrogate digital grid in the computer with our new grid, activate the geologic-structure-building software, and produce a refined version of the $3 \mathrm{D}$ geologic map. Individual fault blocks or geologic units can be subdivided by additional faults and/or contacts without disrupting other fault blocks or geologic units simply by adding new surfaces and interaction instructions, and again activating the geologic-structure-building software. We currently are focussing efforts on refining those fault surfaces that are reflected in the seismicity (San Andreas, Calaveras, and Hayward faults, and elements of the Monte Vista fault zone) and on the contacts that mark the bases of the Holocene and Tertiary deposits.

\section{Current Science}

The present 3D geologic map of the Santa Clara Valley, even in its crude, approximate state, already is providing insights into some scientific questions by facilitating the comparison of different data sets within a coherent 3D framework. This is particularly true of comparisons between seismicity and 3D geology.

Seismicity triggered by the 1989 Loma Prieta earthquake occurred in the region northwest of the primary aftershock region (labeled 'concealed fault of frontal thrust-fault system' in figure 3). In our model, this corresponds to the northwest half of the map (fig. 2) along the San Andreas fault, in the region immediately northeast of the fault. Examining this triggered seismicity within the 3D geologic map suggests that it occurred along a lowangle, southwest-dipping fault that roots in the San Andreas fault at depths of $7-8 \mathrm{~km}$. Toward the northeast the fault terminates beneath the Santa Clara Valley where it intersects the top of buried Mesozoic bedrock (the base of the Tertiary deposits $\mathrm{T} 2$ in figure 2). The seismicity could be occurring on a concealed, basinward member of the southwest-dipping frontal thrust-fault system (McLaughlin and others, 2000) represented by the Berrocal and Monte Vista faults (fig. 1). This fault could pose a direct hazard to the Santa Clara Valley.

The shape of the Mesozoic bedrock surface beneath the Santa Clara Valley indicates a deep Cenozoic basin along its southwest edge that could contain as much as 4-5 $\mathrm{km}$ of Cenozoic deposits. This inference is based on inversion of the gravity data but has not been confirmed by deep drilling, seismic profiling, or any other direct methods. However, recent studies of oil extracted from wells and seeps along the southwest edge of the Santa Clara Valley indicates that the oil originated in the Miocene deposits and matured at minimum depths of 2-3 $\mathrm{km}$ (Stanley and others, 1996). Thus, the preliminary 3D geologic map provides a possible explanation for the origin of oil seeps in the Santa Clara Valley, whereas the studies of the oil itself provide indirect confirmation of the existence of a deep basin beneath the valley.

The mainshock of the 1989 Loma Prieta earthquake and many of its aftershocks have occurred along a southwest-dipping plane that lies close to, but southwest of, the mapped trace of the San Andreas fault. Some researchers 


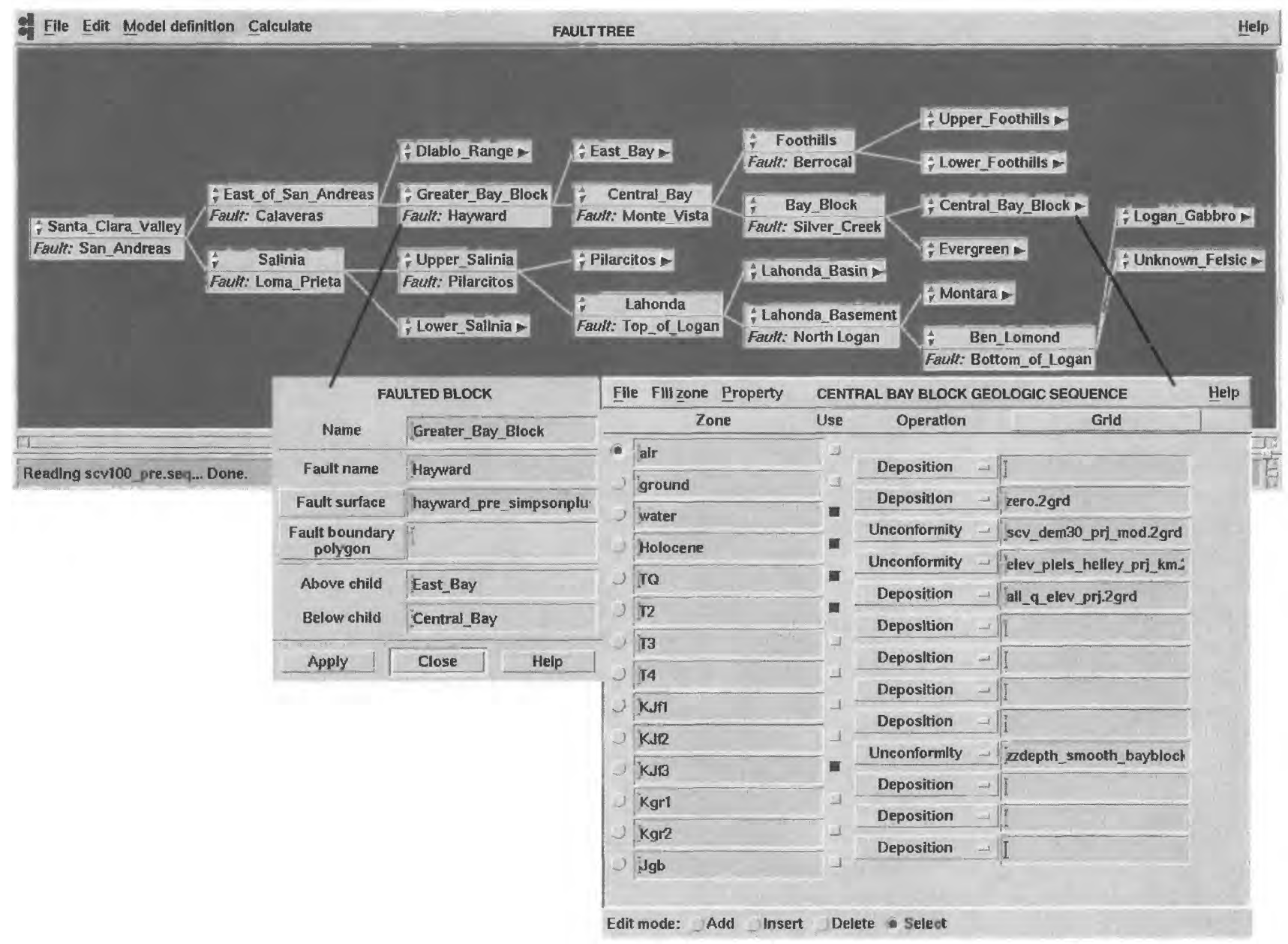

Figure 6. Schematic representation of the Santa Clara Valley 3D geologic map. This schematic defines the fault-block structure and the geologic units that make up the 3D geologic map. The map is composed of:

1. surfaces (faults, contacts, etc.) defined by numerical grids (e.g. scv_dem30_prj_mod.2grd)

2. rules governing how the surfaces interact where they meet

3. volumes bounded by multiple surfaces

4. properties assigned to volumes

FAULT TREE-gives the arrangement of faults that divide the map into fault-blocks. Placement of a fault in the tree structure determines its relation to other faults. A given fault truncates against all faults to its left.

GEOLOGIC SEQUENCE - gives the arrangement of geologic units within a fault-block. Placement of a unit in the vertical stack determines its relative location in the vertical dimension of the map, and the geologic relations (deposition, unconformity, channel erosion) control how the bounding surfaces interact where they meet.

have argued that the earthquake was not on the San Andreas fault proper (e.g. Segal and Lisowski, 1990), but no consensus has been reached. In the present 3D geologic map (figs. 1,2), the lower half of the fault block southwest of the San Andreas fault is divided by the North Logan Fault (fig. 1), a fault inferred from the aeromagnetic data (fig. 5) to lie along the straight northern boundary of the concealed magnetic Logan Gabbro. The magnetic anomaly implies that the fault is about $40 \mathrm{~km}$ long, cuts across the entire block between the San Andreas fault and the San Gregorio fault to the west, but does not offset the San Andreas fault (Jachens and others, 1998). Thus, these data suggest that the North Logan fault is confined entirely to the block southwest of the San Andreas fault.

Interestingly, the southwest-dipping Loma Prieta aftershock distribution lies only south of the inferred North Logan fault and terminates (farthest northwest extent) at the inferred location of the North Logan Fault. We argue that the spatial coincidence of the dipping Loma Prieta aftershock distribution with geologic units and structures confined to the fault block southwest of the San Andreas fault supports the interpretation that the Loma Prieta earthquake occurred on a fault within the southwestern block and not on the San Andreas fault itself. 


\section{FUTURE PLANS}

This project is still in its infancy, but initial results are extremely encouraging. We plan to continue building the 3D geologic map by addressing a wide range of tasks. These include surface geologic mapping to address specific problems, analysis of well information, constrained inversion of geophysical data, analysis and application of sedimentological models, development of new tools for improved use of the available data, and development and evaluation of effective methods for visualization and distribution of 3D geologic maps. These tasks are difficult and complex, and we realize that we may not fully succeed in completing them. Our experience to date, however, gives us confidence that we will be able to construct a 3D geologic map of the Santa Clara Valley that will significantly improve upon such information as is currently available. In the meantime, we will capitalize on the evolving 3D map to support our scientific investigations.

\section{REFERENCES CITED}

Baranov, V., 1957, A new method for interpretation of aeromagnetic maps: Pseudo-gravimetric anomalies: Geophysics, v. 22, p. 359-383.

Blakely, R.J., 1995, Potential theory in gravity and magnetic applications: Cambridge University Press, $441 \mathrm{p}$.

Brabb, E.E., Graymer, R.W., and Jones, D.L., 1998, Geology of the Palo Alto $30 \times 60$ minute quadrangle, California: a digital database: U.S. Geological Survey Open File Report 98348.

Ellsworth, W.L., Beroza, G.C., Julian, B.R., Klein, F., Michael, A.J., Oppenheimer, D.H., Prejean, S.G., Richards-Dinger, K., Ross, S.L., Schaff, D.P., and Waldhauser, F., 2000, Seismicity of the San Andreas fault system in central California: Application of the double-difference location algorithm on a regional scale: Eos, Transactions, American Geophysical Union, v. 81, p. F919.

Fitzgibbon, T.T., Phelps, G.A., and Jachens, R.C., 2001, GIS tools for the construction of $3 \mathrm{D}$ geologic models:
Geological society of America Abstracts with Programs v. 33 , p. A-40.

Graymer, R.W., Jones, D.L., and Brabb, E.E., 1996, Preliminary geologic map emphasizing bedrock formations in Alameda County, California: a digital database: U.S. Geological Survey Open File Report 96-252.

Jachens, R.C., and Moring, B.C., 1990, Maps of the thickness of Cenozoic deposits and the isostatic residual gravity over basement for Nevada: U.S. Geological Survey Open-File Report 90-404, 15 p., 2 sheets, scale 1:1,000,000.

Jachens, R.C., Wentworth, C.M., and McLaughlin, R.J., 1998, Pre-San Andreas location of the Gualala block inferred from magnetic and gravity anomalies, in Elder, W.P., (ed.), Geology and tectonics of the Gualala block, northern California: The Pacific Section, SEPM, Society of Sedimentary Geology, Book 84, p. 27-64.

Jennings, C.W., 1994, Fault activity map of California and adjacent areas, with locations and ages of recent volcanic eruptions: California Division of Mines and Geology California Geologic Data Map Series 6, scale 1:750,000.

McLaughlin, R.J., Langenheim, V.E., Schmidt, K.M., Jachens, R.C., Stanley, R.G., Jayko, A.S., McDougal, K.A., Tinsley, J.C., and Valin, Z.C., 2000, Neogene contraction between the San Andreas fault and the Santa Clara Valley, San Francisco Bay Region, California, in Ernst, W.G., and Coleman, R.G., (eds.), Tectonic studies of Asia and the Pacific rim: Geological society of America, International Book Series, v. 3, p. 265-294.

Segall, P. and Lisowski, M, 1990, Surface displacements in the 1906 San Francisco and 1989 Loma Prieta earthquakes: Science, v. 250, p. 1241-1244.

Stanley, R.G., Jachens, R.C., Kvenvolden, K.A., Hostettler, F.D., Magoon, L.B., and Lillis, P.G., 1996, Evidence for an oilbearing sedimentary basin of probable Miocene age beneath "Silicon Valley", California: annual Meeting AbstractsAmerican Association of Petroleum Geologists and society of Economic Paleontologists and Mineralogists, v. 5, p.133134.

Wentworth, C.M., Blake, M.C., Jr., McLaughlin, R.J., and Graymer, R.W., 1998, Preliminary geologic map of the San Jose 30 X 60-minute quadrangle, California: a digital database: U.S. Geological Survey Open-File Report 98-795. 
24 


\title{
The Three-dimensional Geologic Model as an Access Portal
}

\author{
By Skip Pack
}

\author{
Dynamic Graphics, Inc. \\ 1015 Atlantic Avenue \\ Alameda, CA 94501 \\ Telephone: $510522-0700$ \\ Fax: 510 522-5670 \\ e-mail: skip@dgi.com
}

As data collection efforts and technology advance, the amount of data potentially available to government, academic and commercial users of that data is rapidly expanding. Beyond the formidable tasks of cataloguing and storing the topographic, image, geologic, geophysical, and other types of data, models, and knowledge, it is very desirable that survey organizations provide an intuitive means for customers to quickly understand what forms of data and information are available for their particular geographical areas of interest. Catalogues and map indices can work for a research-oriented person, but for others, 3D geologic models with entities such as symbols, lines, surfaces, and volumes which can then be queried to reveal indices and display various types of the data may be a useful approach. I approach this discussion from a geological software developer/vendor's point of view, and propose a casual discussion group for investigation into implementation of methods for using $3 \mathrm{D}$ geologic modes as visual indices. A CD with several models and a demonstration viewer is available to discussion group participants to help them understand and contribute to the investigation.

As of the date of this conference, May, 2001, participating geologic survey organizations are making progress in cataloguing existing geologic maps and related data, and designing and implementing data models and database structures for the subsequent inclusion of the catalogued maps and data in compatible databases. These efforts significantly improve the chances that a geologist beginning a new investigation will be able to find and review all or most previous work related to the area of interest. This is a necessary, formidable first step in a process of increasing the utility of the geologic mapping process and its outputs to society.

As this effort progresses, survey organizations face additional challenges, born of technological advance, that will need to be addressed. Enormous volumes of data related to geology are being gathered by governments and by commercial organizations. By law, and under varying time scales, most of this data becomes public property without legal access restriction. Remotely sensed geophysical data is the most rapidly proliferating form, but boring/well logs, cores, well tests, and geochemical analyses, form part of a long list. This data explosion has some important characteristics. First, much of the data concerns the subsurface, yielding the greatest value when it is used in a full, three-dimensional context. Secondly, it is numeric, in most cases, and often cannot be summarized effectively in a planimetric representation. Certainly some of the data requires animated three-dimensional representations to capture a fourth dimension. Finally, some of the older data and almost all of the recently gathered and produced data are in digital form, either numeric, or in formats that can often be used by clients, the data consumers, in subsequent computer processes before those data are distilled in a report, map, graphic, or other representation. The polygons and lines that reflect the stratigraphy and structure in a traditional geological map are the true product, not the map itself.

The customer interface for provision of geologic data is oriented to traditional paper systems or to digital analogues of those paper systems. Catalogs and tables, with indexical maps and graphics provide orderly access to bins of maps and directories of digital files. This system works well, but it lacks one desirable feature - a general ability to relate each of the available data sets in a given region to the others spatially. GIS systems do this planimetrically, and are becoming the natural digital analog to the paper systems.

Some GIS systems are extending into three-dimensions, allowing effective representation of subsurface data in a spatial context, but ultimately, a combination of GIS techniques and concepts applied to three and four dimensional geologic volume models can provide the most effective interface to the existing data for a given region. Such models are potentially very intuitive; provide a spatial context in three or four dimensions for volume, areal, lin- 
ear, and point data; and integrate subsurface data and knowledge into a more accessible form. Such models brutally highlight inconsistencies between data or geologic components derived from different collection or interpretation efforts. Survey organizations would either work to resolve the inconsistencies, or allow the models to highlight their existence, more effectively informing the client.

Because the three and four-dimensional models can provide a rich spatial context for most types of data, care must be taken in accurately conveying the character of each data set represented. Raw data, 'cleaned' data, models, and more generalized knowledge are all appropriate components of a regional geological index model. The degree of interpretation and integration are the variables in the progression from raw data to a regional geologic model. Descriptions of the interpretation and integration processes become part of the model metadata.

In the realm of more or less pure data, we deal with topographic and surficial descriptions of geology, boring and well data directly or geophysically sampled, image data, and a bewildering variety of geophysical data with varying spatial contexts. The list includes many more geo... and paleo... data types. Almost every type of data here actually requires a measure of processing by a geoscientist to become what most of us would call a useful data set for general consumption. As we move from the types of information we tend to call data to the class we call models, we are dealing with the degree of interpretive input, not the sudden introduction of interpretation to the process.

Models ultimately need to use as many dimensions as necessary to integrate their data inputs. If all you have are data relating to surface locations, with some shape for the surface, a three-dimensional surface model is sufficient. When you begin to integrate, or just represent, many data sources into a regional model, the use of volume models, possibly with the addition of a fourth dimension for time becomes almost unavoidable. Perhaps not as numerous as data types, volume model types run the gamut from structure and stratigraphic models which then allow introduction of properties related to the surfaces and volumes, to dynamic models concerned with structural, thermal, fluid, and geochemical variation over time. A feature of models with more dimensions is the potential for using different representations for specific purposes. Sections, contour maps, and thematic maps can all be derived from the 3D models with significant improvements in spatial consistency, containing additional information that can only be derived from a three of four-dimensional model.

The knowledge component that should accompany the collection of the data and model representations would include the interpretive descriptions and discussions related to the current representations as well as the those of the past, contextual information, and relational information. All of these could be available in text, audio, multimedia, and video form. The three or four-dimensional model could key these elements as easily, though not so directly as the data and models.

Is it currently possible to use a three-dimensional geologic model as a visual key for all the data types mentioned? Yes, with development that would only involve adaptations of processes that have already been put in place for similar purposes. An ideal combination of development partners would involve GIS and geologic model building software developers, with survey and academic participation to guide implementation in the right direction. The latest PC hardware (including modestly priced graphics accelerators) is sufficiently powerful at reasonable cost. The highest cost will be the time and effort required to pull all the various relevant data into consistent three-dimensional geological models. This will always be a steep price, but there will be specific regions of interest where the effort will be demanded and funded. It seems very appropriate to begin to address the flood of new data and data types and to enable a broader survey client base with customer interfaces that exploit the powerful, intuitive utility of true 3D models.

\section{AN AVAILABLE CD}

A CD was handed out at the DMT 2001 Conference to help familiarize people interested in the use of a 3D model as an access portal. It contains three models of two locations in EarthVision's ffaces file format, with 3D viewers for Windows NT4, Linux, Sun Ultrasparc, and SGI platforms. EarthVision is a 3D visualization, modeling, and analysis software package developed by Dynamic Graphics, Inc. The first model is a large scale model of the Mahomet Valley Bedrock Aquifers developed by David Soller and Susan Price (U.S. Geological Survey) and Richard Berg and John Kempton (Illinois State Geological Survey). The project was published in a three sheet map set and can be viewed on the worldwide web at $<$ http://pubs.usgs.gov/I-maps/i2669>.

The second project, the Villa Grove Quadrangle, was developed by the Illinois State Geological Survey as a prototype for three-dimensional geologic mapping of traditional quadrangle-sized areas. Additional quads are now being studied and mapped as an initial production effort built on lessons learned on this prototype. Principal investigors were Zakaria Lasemi and Donald G. Mikulic with a mapping team comprised of Curtis C. Abert, Richard C. Berg, et. al. Two models are included. The first is a 3D volume model of 18 horizons from the most recent alluvium down to an Ordovician bedrock unit. The second model, of the same area shows grain size as a geologic property in shallower units. This volume model that is equivalent, in three dimensions, to a classification map from a GIS system. A data file of sample locations and grain sizes can be posted and queried in the $3 \mathrm{D}$ viewer. 
The projects on the distributed CD do not contain a lot of secondary information as delivered, but can be a starting point for developing approaches to do just that. I am eager to interact with those who have an interest in discussing data elements and the access methods involved with the 3D models, including adding data and methods to the models provided as proof of concept and for demonstration of concept.

To receive a copy of the CD discussed above, or to discuss the topic above with thoughts of adding indexed data types to a model, please contact me.

\section{REFERENCES}

Soller, D.R., Price, S.D., Kempton, J.P., and Berg, R.C., 1999, Three-Dimensional Geologic Maps of Quaternary Sediments in East-Central Illinois: U.S. Geological Survey Geologic Investigations Series Map I-2669, $<$ http://pubs.usgs.gov/I-maps/i2669>.

Shilts, W.W., Lasemi, Zakari, Mikulic, D.G., and Abert, C.C., 1999, Geologic Mapping of the Villa Grove Quadrangle, Illinois: Illinois State Geological Survey. 


\title{
Developing the North American Geologic Map Data Model
}

\author{
By the North American Data Model Steering Committee
}

\author{
Members: \\ Dave Soller (Committee Coordinator and U.S. Geological Survey, drsoller@usgs.gov) \\ Tom Berg (Ohio Geological Survey, thomas.berg@dnr.state.oh.us) \\ Boyan Brodaric (Geological Survey of Canada, brodaric@gsc.nrcan.gc.ca) \\ Bruce Johnson (U.S. Geological Survey, bjohnson@usgs.gov) \\ Murray Journeay (Geological Survey of Canada, MJournea@nrcan.gc.ca) \\ Rob Krumm (Illinois State Geological Survey, krumm@zydeco.isgs.uiuc.edu) \\ Jon Matti (U.S. Geological Survey, jmatti@usgs.gov) \\ Scott McColloch (West Virginia Geological and Economic Survey, mccolloch@geosrv.wvnet.edu) \\ Peter Schweitzer (U.S. Geological Survey, pschweitzer@usgs.gov) \\ Loudon Stanford (Idaho Geological Survey, stanford@uidaho.edu) \\ Jerry Weisenfluh (Kentucky Geological Survey, jerryw@kgs.mm.uky.edu)
}

The development of a standard data model for geologic map information will benefit the geoscience community by providing the common structure for describing geologic phenomenon and for managing the spatial and attribute information in publicly-accessible computer systems. In North America, representatives of geological surveys in Canada and the United States have agreed to work together to address the challenges of building a standard data model and the software tools that permit it to be effectively used. They are working together through the mechanism of the North American Data Model Steering Committee (NADMSC).

Evolution of this cooperatively-developed data model is documented in various informal papers from 1996 to present (for example, Geologic Map Data Model Steering Committee,1999). The data model described in those papers is conceptual in nature, because this work was necessary before the concepts could be evaluated and implemented in various computer systems. Attention has now turned toward testing and implementation; several papers in this and in previous Proceedings volumes describe efforts to begin to implement the concepts, and more certainly will follow in the years ahead. Because the conceptual model could not stipulate the nature of the GIS and database software in which an agency might choose to develop a geologic map database, there have been modifications to the conceptual model as it was test-implemented in various systems across the U.S. and Canada. This is to be expected, as the data model evolves from a conceptual to a physical state.
The geoscience community is composed of diverse agencies and individuals, with a wide range of technical expertise, budgets, and user-support requirements. Therefore, the NADMSC expects that when the various Canadian and U.S. geological surveys evaluate and implement the data model in the coming years, they will modify it as needed to suit their system and user requirements. The role of the NADMSC will be to support these implementations with: 1) technical assistance and data model documentation; 2) modifications to the conceptual model as needed; 3) coordination of software tool development; and 4) the proposal of standard scientific terminology with which to attribute digital geologic maps. To fulfill these roles, the NADMSC formed six Technical Teams, as follows:

- Requirements Analysis (to refine our understanding of the data analysis requirements of various users);

- Data Model Design (to continue refining the conceptual model based on the Requirements Analysis, deliberations of the other technical teams, and user comments);

- Scientific Language (to develop standard terminologies for the various elements that comprise geologic maps, e.g., rock classification);

- Software Tool Development (to design tools that meet user needs as specified in the Requirements Analysis);

- Data Interchange (to develop translators among various implementations of the conceptual model);

- Documentation (to improve public understanding of data model design and software tools). 
Each Technical Team is now staffed and is conducting its assignments; progress will be reported at the NADMSC Web site, <http://geology.usgs.gov/dm/>, and in public venues such as these Proceedings. Interested persons are invited to register at the site and, through comments, guidance, and test-implementations, contribute to the data model's continued evolution.

\section{REFERENCE}

Geologic Map Data Model Steering Committee, 1999, Progress toward development of a standard geologic map data model, in D.R. Soller, ed., Digital Mapping Techniques '99 Workshop Proceedings: U.S. Geological Survey Open-file Report 99-386, p. 57-58, <http://pubs.usgs.gov/openfile/ of $99-386 /$ steercom.html>. 


\title{
A Case Study in Database Design: The Alaska Geologic Database
}

\author{
By Lawrence K. Freeman \\ Alaska Division of Geological \& Geophysical Surveys \\ 794 University Ave, Suite 200 \\ Fairbanks, AK 99709-3645 \\ Telephone: (907) 451-5027 \\ Fax: (907) 451-5050 \\ e-mail: Larry_Freeman@dnr.state.ak.us
}

\section{THE CHALLENGE}

In designing a spatially referenced geologic database for Alaska, the Division of Geological \& Geophysical Surveys (DGGS) encountered several unique problems not experienced by geological surveys in the rest of the United States:
- Alaska's size and its northern latitude combine to complicate unified digital mapping.
- Alaska has more surface area than the next three largest states combined
(see <http://www.dced.state.ak.us/tourism/student/ student7.htm $>$ ).
- Alaska comprises one hundred fifty-three 1:250,000- scale quadrangle maps, 11 UTM grid zones, five prin- cipal meridians, and GIS data in multiple projections.

The complex and sometimes active Alaskan geologic environment supports numerous agencies that collect, store, and distribute geologic data. The database under construction must coordinate with data stored by at least 11 other agencies and institutions. During 2000, these agencies tracked, among other things, 154 earthquakes over magnitude $4.0<$ http://giseis.alaska.edu/Seis/ html_docs/db2catalog.html>, 21 potentially active volcanoes <http://www.avo.alaska.edu/avo4/atlas/intro.htm>, \$1 billion worth of minerals extraction (Szumigala and Swainbank, 2001), and nearly 400 million barrels of oil production <http://www.dog.dnr.state.ak.us/oil/programs/ royalty/production.htm $>$. Geologic resources information in Alaska changes daily, and is in high demand from the public.

Among other tasks, DGGS is charged with producing 1:63,360-scale geologic maps. To date, only 15 percent of the state has been mapped at that scale. Even with the small percentage of mapping completed, Alaska accounts for 4 percent of the entries in the National Geologic Names Database (GEOLEX)

$<$ http://ngmdb.usgs.gov/Geolex/geolex_home.html>. Each geologic map produced by DGGS defines or redefines many map units. All of DGGS's new geologic maps are produced using ArcInfo, a geographic information system (GIS).

The most critical factor in preparing the database design now is personnel turnover in DGGS. Since 1990, the survey has changed dramatically. Certain tasks such as hydrology have been moved to other agencies. In 1990 DGGS had a staff of 36 (not including the Hydrology Section); at present there are 27 on staff, but only 12 of the staff members from 1990 remain. Digital data files stored on individual hard drives, CD-ROMS, Zip disks, and outdated media is at risk for corruption, loss, and obsolescence due to DGGS staff turnover. A unified, centralized data storage, entry, and retrieval system will plug this data drain.

\section{ACKNOWLEDGMENT}

This project encompasses the data and database configuration work required of the Alaska Division of Geological \& Geophysical Surveys (DGGS) as part of the interagency Minerals Data and Information Rescue in Alaska (MDIRA) project. Funding for the DGGS database creation is through a contract from the U.S. Geological Survey (USGS), as part of the MDIRA.

\section{MEETING THE CHALLENGE}

"The DGGS geologic database system will maintain a consistent data and information archival input, organization, and storage architecture and will provide data identi- 
fication and retrieval functions that guide and encourage users to access appropriate data on-line." Milt Wiltse, Alaska State Geologist (written communication, 2000).

\section{Methods}

The initial step in DGGS's database design process was an internal needs assessment. This consisted of interviews with individuals and working groups mostly within the survey. Everyone in DGGS, and some key players outside of DGGS such as in the USGS in Alaska, University of Alaska, and the Alaska Department of Natural Resources (DNR), were interviewed. These interviews resulted in a long list of function statements such as "DGGS geologists record coordinates, an accuracy estimate, date, place name, project, and comments for each field station." Part of this process included gathering samples of forms, reports, tables, maps, and legacy databases. Lists of data processes, entities and attributes, relationships, and rules were distilled out of this process; this was the initial data model.

The second step of this process was verification of the initial model. The entire DGGS staff participated in multiple focus group discussions, multi-part surveys, and a request for geologic questions. The group discussions were used to rewrite the original model, the surveys were used to prioritize the modeI, and the questions will be used to check that all the entities, attributes, and relationships are present. The data model (fig. 1), a robust, entity-relationship diagram, was constructed in Microsoft Visio.

\section{Conceptual Data Model}

The data model resulting from this process is subdivided into seven major data groups subdivided by function and type. The groups are field data, sample data, geologic map objects, spatial dataset inventory, reference/legend information, publications database, and thematic databases. A diagram showing the data model is available in PDF format, at <http://wwwdggs.dnr.state.ak.us/download/ rfp_2002_1000_2669_app7.pdf>.

Field data includes location, descriptive, and instrumental data recorded in the field. Data recording is largely manual, using state-of-the-art, analog methods-field note books, in plain English. Field locations include three types: outcrop observations, measured sections, and well logs. Entities include location information, lithology description, map unit, structural measurement, sample description, photograph information, magnetic susceptibility measurements, water level, permafrost level, penetration test, seismic velocity, alteration description, mineralization description, morphology description, and paleoenvironment description. If the database system is capable and robust, field sketches and detail maps could be included as graphic files.

Sample data comprises descriptive, instrumental, and chemical analyses that are completed after the end of the field season. Samples are identified by a sample number and are always associated with a field station. These data include whole-rock major and minor element analyses, trace-metal analyses, isotope geochemistry, organic geochemistry, coal analyses, petrography, paleontology reports, geochronology, and materials engineering tests. Laboratory information and cited references are related to each sample analysis. Each analysis is related through the sample description and sample number to a field location in the field database.

Geologic map objects include polygons and lines. They are generally located through analog means on hardcopy maps and then digitized in ArcInfo or MapInfo. Attributes of map objects in the DGGS system are similar to those of the North American Geologic Map Data Model (Johnson and others, 1999). The goal is to be compatible with both the Geologic Map Data Model and with the data model being used to digitize 1:250,000-scale maps in Alaska (for example see Wilson and others, 1998) as well as to serve DGGS needs. In the DGGS data model, geologic polygons have attributes including spatial definition, lithology, maximum and minimum geologic age, characteristic fossils, thickness, spatial object and dataset identification, and map unit name. Geologic line objects tracked in the database will only consist of significant features including faults and unconformities. Line attributes include spatial definition, spatial object and dataset identification, type of feature, minimum and maximum age of feature, location accuracy estimate, orientation, and feature name. Storing a spatial definition of geologic map objects in a relational database system will allow statewide queries based on geologic mapping.

The spatial dataset inventory will hold or link to metadata elements for GIS datasets created or housed in the DGGS system. The attributes of the inventory will be compatible with the Federal Geographic Data Committee (FGDC) metadata standard <http://www.fgdc.gov/ standards/documents/standards/metadata/v2_0698.pdf> and the National Geologic Map Database (NGMDB) $<$ http://ncgmp.usgs.gov/ngmdbproject/cathelp/manual.html>. Each record will include a file path name so that a user on the DGGS system can open a selected dataset. Having this inventory will help DGGS geologists to eliminate duplication and to share work more readily. It will also help keep track of all the projections and grid systems so DGGS can ensure that projections and grid systems are used consistently.

Reference/legend information includes all the nomenclature, terminology, bibliographic information, and spatial definitions of attributes and objects used throughout the database. Entities include lithology, map units, named structures, and cited references. Each entity will be 
defined and many will have internal hierarchical relationships. These tables will be used to validate data entry elsewhere in the database. This information can also be used in making map legends, compiling metadata, and assisting with data searches. In essence, this will be our digital reference library and the foundation of a functional database.

The Publications Database is, in part, a subset of the cited reference information but contains more information specific to DGGS publications. The publications database will help manage data access, sales, distribution, and production of our publications.

Thematic databases include information specific to minerals resources and geologic hazards. Most of the databases refer to point-type spatial objects, but some will be line- and polygon-type objects as well. Some databases will only contain minimal information, but will contain links to databases held by other agencies. Database entities will include mines and prospects, coal resources, minerals industry activity, Holocene faults, seismic events, active volcanoes, and geotechnical boreholes. Some of these databases are legacy databases that will be resurrected, others are under construction now, and still others are awaiting development of the DGGS database system. Specific links for minerals resources will include the Alaska Resource Data Files (ARDF) <http://ardf.wr.usgs.gov/> and the Minerals Availability System/Minerals Industry Location System (MAS/MILS) <http://imcg.wr.usgs.gov/dem.html>, $<$ http://imcg.wr.usgs.gov/cgi-bin//qalaska3.cgi $>$. The database will link to an earthquake database, Alaska Earthquake Information Center (AEIS)

$<$ http://giseis.alaska.edu/Seis/html_docs/db2catalog.html>, for seismic events and the Alaska Volcano Observatory volcano atlas

$<$ http://www.avo.alaska.edu/avo4/atlas/atlas.htm>. The thematic databases will be related to the geologic sample, cited reference, and field data databases; they will be related to geologic objects through the spatial definitions.

\section{Data System}

DGGS already has significant computer resources including at least 45 desktop computers (running Windows NT and Windows 2000), 12 portable computers (running Windows 98 and 2000), six Sun workstations served by a Sun Ultrasparc Enterprise 450, and the numerous switches, printers, plotters, and scanners that make up our local area network (LAN). Our GIS consists of ArcInfo8, operating on the Sun system, and served to the Windows machines over the LAN. It is essential that the database system operate within these physical constraints.

Point data such as field stations and sample sites may be located by GPS or by digitizing from maps. We will continue to create maps and the geologic objects on them by working on hard-copy maps in the field, then digitizing semi-final maps into our GIS system. Interpretation will be facilitated by having field, sample, and imagery available in the GIS. When the maps have reached the final technical review then geologic objects will be transferred into the database and will have attributes assigned. Other entities with spatial attributes will be treated like geologic map objects, digitized and checked in the GIS, then attributed in the database. Data will be queried in the database and then viewed in the GIS or output as tables, in custom forms, or for use with other software.

The database system will consist of a data server, a relational database management software package, and connections and utilities to interface with the DGGS LAN and GIS. It is essential that the database system be capable of holding spatial data and able to complete spatial searches, as almost all of DGGS data has spatial attributes. The storage capacity of the system needs to be large; our geologic, geochemical, and geophysical map inventory contains over 4,000 maps. The database system must also function with DGGS's GIS system. The database must also be available to multiple users on SUN workstations and on Windows machines via our LAN. DGGS geologists also need to be able to replicate spatially constrained sets of the data for seasonal fieldwork on portable computers. At this point, we envision using Oracle $8 \mathrm{i}$ with Oracle Spatial served on a Sun or Windows NT data server. We would need to add ArcSDE to the GIS to facilitate transfer of spatial data from project files to the database. DGGS intends to continue to use ArcInfo GIS as its main geologic mapping, analysis, and cartographic tool and to supplement it with a centralized relational database to manage all the data.

\section{Implementation Schedule}

DGGS has issued a Request For Proposal for a contract to install the database system hardware and software, to design and program the database and supporting functions, and to train staff and support the system for the first two years. We expect to have the system installed and operational by the end of 2001. By April 2002, we will have digital data loaded, and will start digitizing and loading our prioritized legacy hard-copy data.

During the next six months, we will be working with other agencies in the Interagency Minerals Coordinating Group, Alaska Department of Natural Resources, and the NGMDB to coordinate data transfer, and determine Internet data needs; we will also look to the Alaska public to determine the scope and style of Internet access to the data. By the end of 2002, we intend to have the database accessible to the public.

\section{OUTCOME}

The digital geologic database of Alaska will assist with the preservation and distribution of Alaska's mineral 


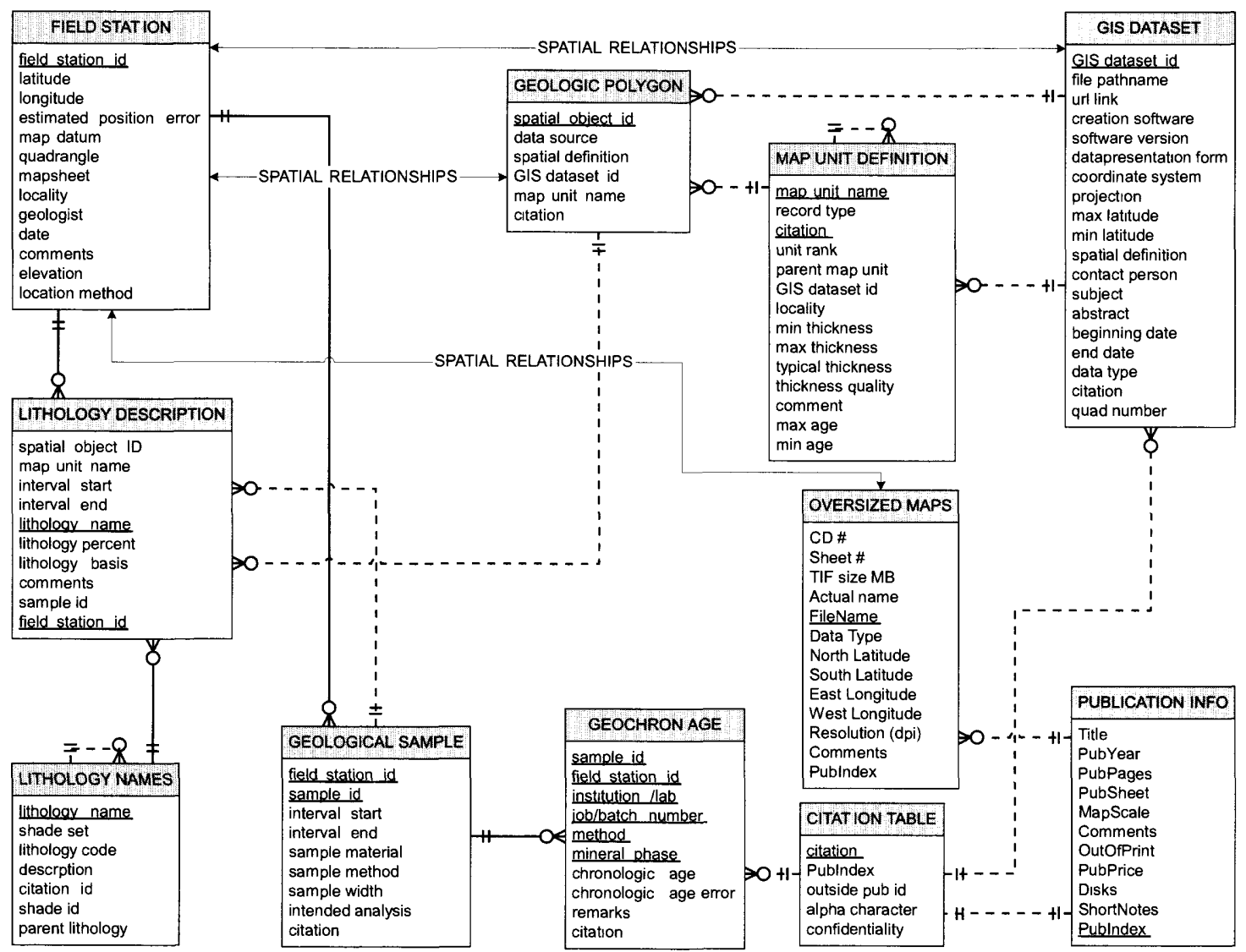

Figure 1. Entity-relationship diagram with selected entities from each of the seven functional groups of the DGGS Alaskan geologic database.

and geologic data. DGGS has already made all our publications available on the Internet $<$ http://wwwdggs.dnr.state.ak.us/ pubs.html $>$ and published a guide to Alaska minerals and geologic information (Daley, 1998) <http://wwwdggs.dnr. state.ak.us/Libguide/intropage.htm $>$ ). The database will help us keep these publications and information current and will facilitate access by providing search tools. It will also broaden the scope of the information by showing where and what data is available, and how it can be accessed. The amount of information will grow by the addition in the database of appropriate links to other agencies and institutions.

With this database, a casual user will be able to conduct searches of information and data, view the data, and download publications and datasets, all from an office or home. In a state like Alaska, with vast distances and travel limitations, this kind of access is vital.

\section{REFERENCES}

Daley, E.E., 1998, Guide to Alaska Geologic and Mineral Information: Alaska Division of Geological \& Geophysical Surveys Information Circular 44, 90 p.

Johnson, B.R., Brodaric, B., Gary L. Raines, Hastings, J.T., and Wahl, R., 1999, Digital geologic map model; Version 4.3: Unpublished Association of American State Geologists/U.S. Geological Survey draft document, 69 p., <http://geology.usgs.gov/dm/model/Model43a.pdf>

Szumigala, D.J., and Swainbank, R.C., 2001, Alaska's mineral industry 2000: A summary: Alaska Division of Geological \& Geophysical Surveys Information Circular 47, 14 p., <http://wwwdggs.dnr.state.ak.us/download/ic47.pdf>

Wilson, F.H., Dover, J.H., Bradley, D.C., Weber, F.R., Bundtzen, T.K., and Haeussler, P.J., 1998, Geologic map of central (interior) Alaska: U.S. Geological Survey Open-File Report OF 98-133, 1:250,000 scale, <http://wrgis.wr.usgs.gov/ open-file/of98-133-a/> 


\title{
Using the Proposed North American Data Model in a Distributed Database Environment
}

\author{
By Eric Boisvert, Annie Morin, Kathleen Lauzière, and Daniel Lebel \\ Geological Survey of Canada - Québec Geoscience Center \\ 880 Chemin Ste-Foy \\ Quebec City, Québec \\ P.O. Box 7500 \\ G1V $4 \mathrm{C} 7$ \\ Telephone: (418) 654-3705 \\ Fax: (418) 654-2615 \\ e-mail: \{eboisver,amorin,klauzier,dlebel\}@nrcan.gc.ca
}

\section{INTRODUCTION}

Web digital libraries are fast becoming a medium of choice for gathering and accessing multiple geoscience datasets and knowledge bases. To a large extent however, data models and reliable tools to extract relevant information over the Web from digital geoscience information and exploration are still rare. Geoscientists want to access information intuitively and be provided with contextual knowledge bases that are at least as rich as what they are accustomed to in a physical library or document environment. Web-enabled systems have the potential to make the experience of visiting a digital library much richer, if based on scientifically sound semantic data models. The North American Data Model (NADM) is such a model and is gaining momentum at the GSC within several virtual library projects that address various aspects of NADM implementation. The NADM used in most Canadian projects is a variant of the official 4.3 version available from the Steering Committee web site (http://geology.usgs.gov/dm/). This variant of the model is variously referred to as "NADM 5.2, NADM 5.X and NADM Cordlink (Brodaric et al, 1999b). In this paper, we will only use "NADM" to implicitly refer to "Variant NADM 5.2".

Important work has been done along regional or thematic contexts, such as the Cordlink (Canadian Cordillera, $<$ http://rgsc.nrcan.gc.ca/cordlink>), GASL (Geological Atlas of the St.Lawrence, <http://www.cgq-qgc.ca/gasl/>), Hydrolink (Canadian Hydrogeology <http://www.cgq-qgc.ca/ hydrolink $>$ ), Moose Mountain (very detailed 3D database of a small portion of the Canadian Cordillera foothills) and Northern Ontario (Berdusco \& Boisvert, 2001). New projects led by the GSC in partnership with provincial and
Territorial geological surveys are aimed at implementing a nation-wide contextual data model framework and distributed database for bedrock and surficial geology.

Within the Quebec division of the GSC, we are focusing our present efforts at offering interoperability between independently constructed projects, which have led to three distinct implementations of NADM, supporting a web based Virtual Library. These three small databases are a microcosm of what is emerging as an important problem through the building of an increasing number of virtual libraries based on NADM. It is likely that more projects will consider NADM to support their data management and we will end up facing a problem of anarchic proliferation of NADM database instances and web sites. The implications of having multiple distinct databases are well known:

1) for an end-user (either our clients or our own staff), a global search is generally not possible unless all databases share a common data model or dictionary, and

2) for the organisation managing the data, more work is needed to maintain the data holdings and to maintain standardisation.

The obvious solution is to merge the content of all the small databases into a single database, but there are compelling reasons that preclude this approach. An interoperability approach has been used therefore, and this paper is a presentation of the challenges and possible solutions.

The prototype we wished to create had two general requirements:

1) The system must permit agencies maximum flexibility. Imposing a database structure on each agency 
was simply not an option. Several agencies are using a proprietary database structure to support their business, and switching to another one would be too costly.

2) The system must go beyond "documents" and support "feature level metadata". This means that features composing the map (which is a document) can also be documented and manipulated as valid entities. The database not only keeps information about the published document but also about the geological features displayed on the map and how these geological features are related to other features within the same document or other documents.

\section{CENTRAL OR DISTRIBUTED?}

\section{Constraints and Options}

At GSC-Québec, three NADM databases have been implemented for diverse purposes. The HYDROLINK project built a hydrogeology oriented database, a more bedrock/tectonic map repository has been initiated for GASL, while the Moose Mountain project has just begun to use NADM to store specific information about structural geology and oil and gas resources. The hydrogeology and bedrock geology communities have several common needs for content but differ in more than one aspect. If this kind of divergence is significant within a single organisation, we can imagine that it will only increase in a project undertaken by multiple organisations in different agencies. Organisations might not only differ in their practices, but also in their terminology, their jurisdictions and mandates, mapping techniques, historical backgrounds, etc. The most acute problem is "data custody". Most agencies are reluctant to relinquish management of "their" data to some centralised system as they feel they lose control over the content of their database. They are also generally reluctant to have their corporate knowledge managed and directed by another organisation, while they recognise that sharing information with the national geoscience community is very important. In the wider context of Canadian Geoscience Knowledge management (<http://www.cgkn.net $>$ ), different governments, mandates, jurisdictions and objectives rule out a completely centralised system.

The physical and technological pros and cons of a centralised database are inherent issues of system architectures and have been discussed in several advanced computing papers, but these issues are somewhat external to the problem we are facing. The problem is not one of a classic client/server/hardware/software system architecture but rather a more organic problem that can be characterised as a need for a semantic framework for knowledge management. The basic problem is not "how do we con- solidate distributed databases", but "how do we consolidate distributed geological knowledge and practices". The small multiple databases activity (Hydrolink, GASL and Moose Mountain) that we presented above is an excellent opportunity to examine how many repositories of geological knowledge can act in a distributed environment. The progress made so far is still exploratory and more work will be done this year to solve real life problems.

\section{Why Not Replication?}

Replication implies that each agency must maintain an exact copy of the "global" database, and changes made to one of the copies must be "replicated" in all other copies to maintain data integrity. Most RDBMS vendors allow changes to any database to be replicated to all mirrored (copies of) databases. A set of replicated databases is in fact a physically distributed database, but it acts as a centralised system, since the content of all those databases gives the user the feeling that there is only one big virtual database. This is clearly not the mechanism we want to see as we explained earlier. Although in fact some parts of the database can be exact replicas (formal time scales, mineral names, etc.), most of the content of the database is specific in either the type of content (hydrogeology versus bedrock geology) or other aspects related to jurisdiction, mandates or tradition. It is clear that all NADM databases share a certain level of commonality but we are not speaking of "exact copies" and therefore total replication is not considered further.

The alternative to full replication is "partition" where portions of the database are distributed on different servers. For example, a given database can hold time scales and another one can manage rock types. Another option is to have one database holding a subset of time scale records while the remainder are scattered among other databases (i.e. Holocene is in database A, Palaeozoic in database $\mathrm{B}$ and so on). This system still requires close co-ordination to avoid duplicates and inconsistency, but the overall logic is more appealing for our situation.

\section{Semantic Interoperability}

Semantic interoperability (SI) is probably the most interesting approach to distributed databases. Crudely explained, SI is a system that can translate (or restructure) on the fly information from databases having different structures and content, and can merge different result sets into a single coherent set. Although databases used in a given application domain (such as geology) may have different structures, they often have compatible content, they address the same theme and it is often possible to map the structure of one database to another, at least partially. Although this seems to be the perfect system, making two databases communicate using SI is non-trivial. The technique involves "mediators", which are software modules 
that solve the structural and semantic differences between databases. Although more work is required to use this approach, the benefits can greatly exceed that of other technologies.

These approaches have been weighed against the problem we wanted to solve and we built a prototype named GEOMDB (Geoscience Multiple DataBases) to test different aspects. The semantic interoperability approach seemed to be the most promising avenue and we built a prototype (the result is mostly the work of the second author) that implements certain SI ideas.

\section{GEOMDB AND < X>LINK - DISTRIBUTED DATABASE PROTOTYPE}

\section{Background}

The NADM variant used in this project is a generalised version of the formal 4.3 version (Johnson et al., 1998) supported by the NADM Steering Committee (<http://geology.usgs.gov/dm/>). The model itself can almost be seen as a metamodel because several parts of the model can be customised for different purposes. Changes to the model can then be registered in special metadata tables that can be accessed by tools such as Geomatter (Brodaric et al, 1999a, Boisvert et al., 2000) to allow on the fly customisation. The type of data that can be manipulated varies from one database to another. For our experiment, we chose two databases because of their relative maturity: HYDROLINK stores hydrogeology related maps, images and documents while GASL addresses the bedrock geology of the Saint Lawrence River region. They are both NADM variant databases customised for their specific domains. Some attributes are shared between databases, such as rock type and geochronology, but each database requires particular attributes that have limited usage for the other. For instance, Hydrolink has a specialised table that contains conductivity values for different aquifers. Even for similar attributes, such as rock type, slight variations exist between both implementations. Both teams used the same basic dataset but customised it to fit their particular needs. Map unit types also significantly differ and the tree structure of Compound Object Archive (COA) that lives at the heart of the NADM structure is built according to different mapping traditions and logical organisations, even though the more general concepts are shared. This example illustrates two databases that address two different issues but partially overlap on certain themes. The database structure is not the only impediment to the construction of a "single global database".

GEOMDB developed at GSC-Québec as a prototype is a distributed model search engine and data extraction system that relies on the NADM COA tree to synchronise information between databases. The system requires a "global database" and a series of local databases. The communication between the global database and local ones is done by an HTTP based mediator (by exchange of HTML files), so a database can be located virtually anywhere (we are of course toying with the idea of using XML as an exchange mechanism). The client accessing the global database is in fact unaware of the interaction with distributed databases from which he will extract information (figure 1).

The mediator module has been developed in Allaire ColdFusion. Our set up consists of MS Access databases on different servers, and all servers are equipped with a ColdFusion Server and an appropriate web server software (IIS on one server and Apache on the other).

\section{Global Database Set Up}

The global database is a stripped down NADM database (figure 2) that contains only COA and Subject tables and associated tables (tree, lookups, and attributes). The database also contains a list of local databases that are "registered" to provide services. Metadata about each local database are maintained on the global database. The COA and subject database together are uniquely identified with Global Unique IDs (GUID). (A subject table was added in the $v 5.2$ of NADM to link to the Georef classification scheme). A GUID is a long binary sequence ( 16 bytes) that is generated by an algorithm that guarantees that this value cannot ever be generated twice. Unique values generated by this procedure are of the form \{7DD18D503F04-11D5-BF80-0001022439EA\}. If you ever peeked into your Windows registry base, this should look familiar. The value is a mixture of network card ID, Universal Time, and other arbitrary parameters that ensure its uniqueness at the global system level. All COA records in the global database have this kind of ID.

\section{Local Database Set up}

Local databases are regular NADM databases. On the local server is a series of Cold Fusion templates (mediation modules) that can be requested by the global server. The pages are specially formatted to be parsed by the server upon reception. At this point, it is possible for the local database administrator to alter the templates to adjust to small variations in database implementation (for example, one local database could use version 4.3 of NADM, or any other database structures). The global database only expects to receive the answer in the correct format (whatever the content) and assumes the local database understands the NADM ontology. Within the local database, a special table holds the correlation between the local COA values and the global equivalence. The content of the local COA tree is not a copy of the global tree; the local 


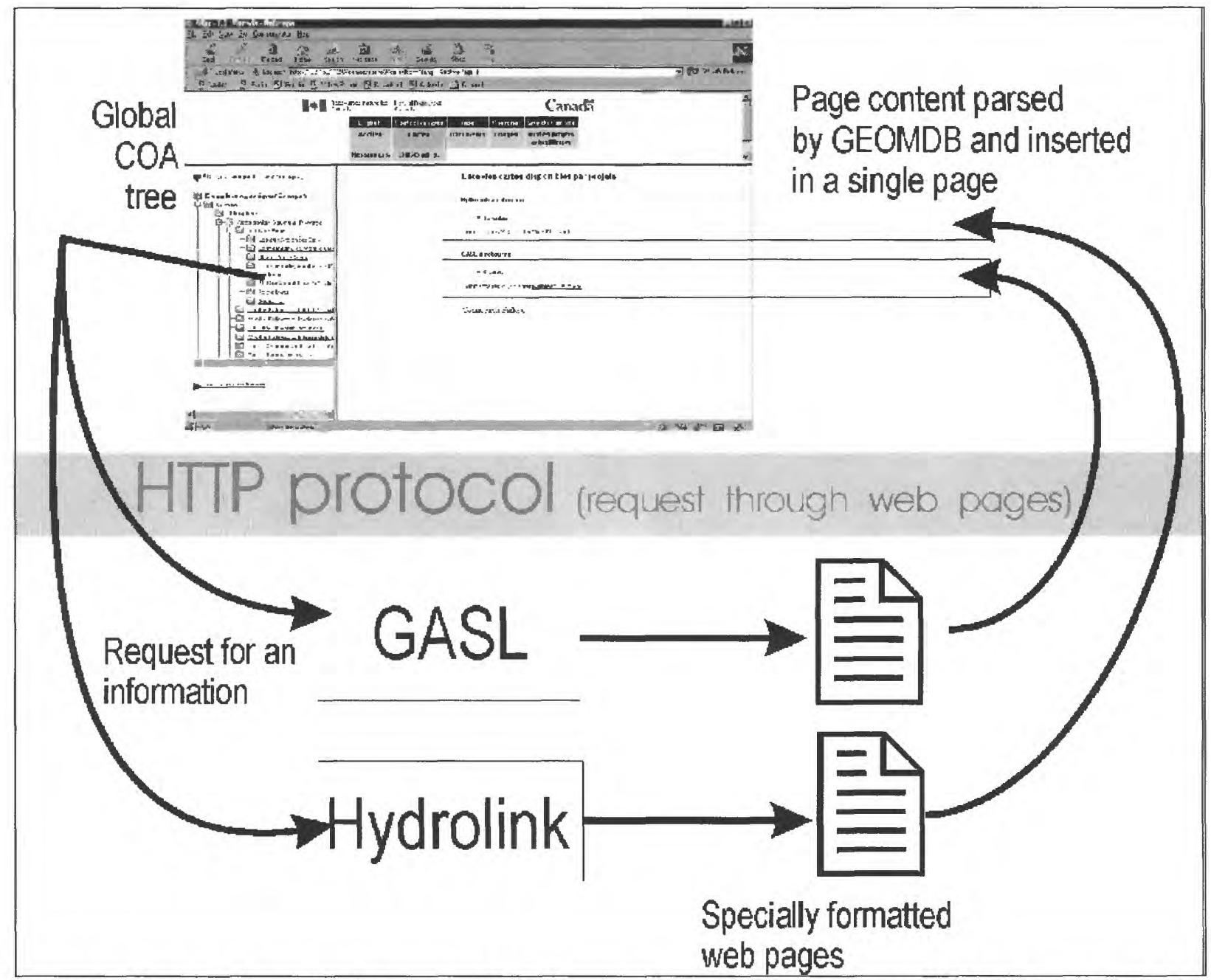

Figure 1. Merging information from several NADM sources. The HTML text sent to GEOMDB is merged back into a single web page.

database administrator simply defines his local COA record to be equivalent to a particular global COA record.

Table 1 shows an example of such a correlation table. This table makes a parallel between "globally" known concepts (global COA) and local representation in the database. Of course, the local database can have more data items to fulfil its organisation's needs than the global database. The only requirement for the local database is to maintain compatible trees. A compatible tree is a tree where all parent-child relations at the local level are the same as the ones defined at the global level (see figure 3). More items can be inserted in the tree, or a global item can also be "missing" (an intermediate item is found in the local tree but does not have any linkage to a global concept), but no item can be inverted. For example, an organisation can simply forget about the Supergroup level because it is not recognised as a formal unit in this organisation. Other units can be used in local classifications while they are not recognised at the global level (the term assemblage is an example in the Quebec local database on figure 4).

Another tree based on geoscience themes (extracted from GeoRef) is organised the same way and the technique can also be used with themes instead of COA. The theme tree has been introduced into NADM by the Cordlink project team. Themes are used to classify sources, images and texts using the logic of a library and facilitate the navigation of the Cordlink web site (and its clones, such as Hydrolink and GASL). So far, all our NADM implementations use exactly the same tree, making replication a more suitable technology for themes.

\section{How the System Works}

The user accessing the site can select from either a COA tree or a Subject tree. The COA tree structure lists all geological concepts while the subject tree lists themes (a theme can group several geological concepts while con- 


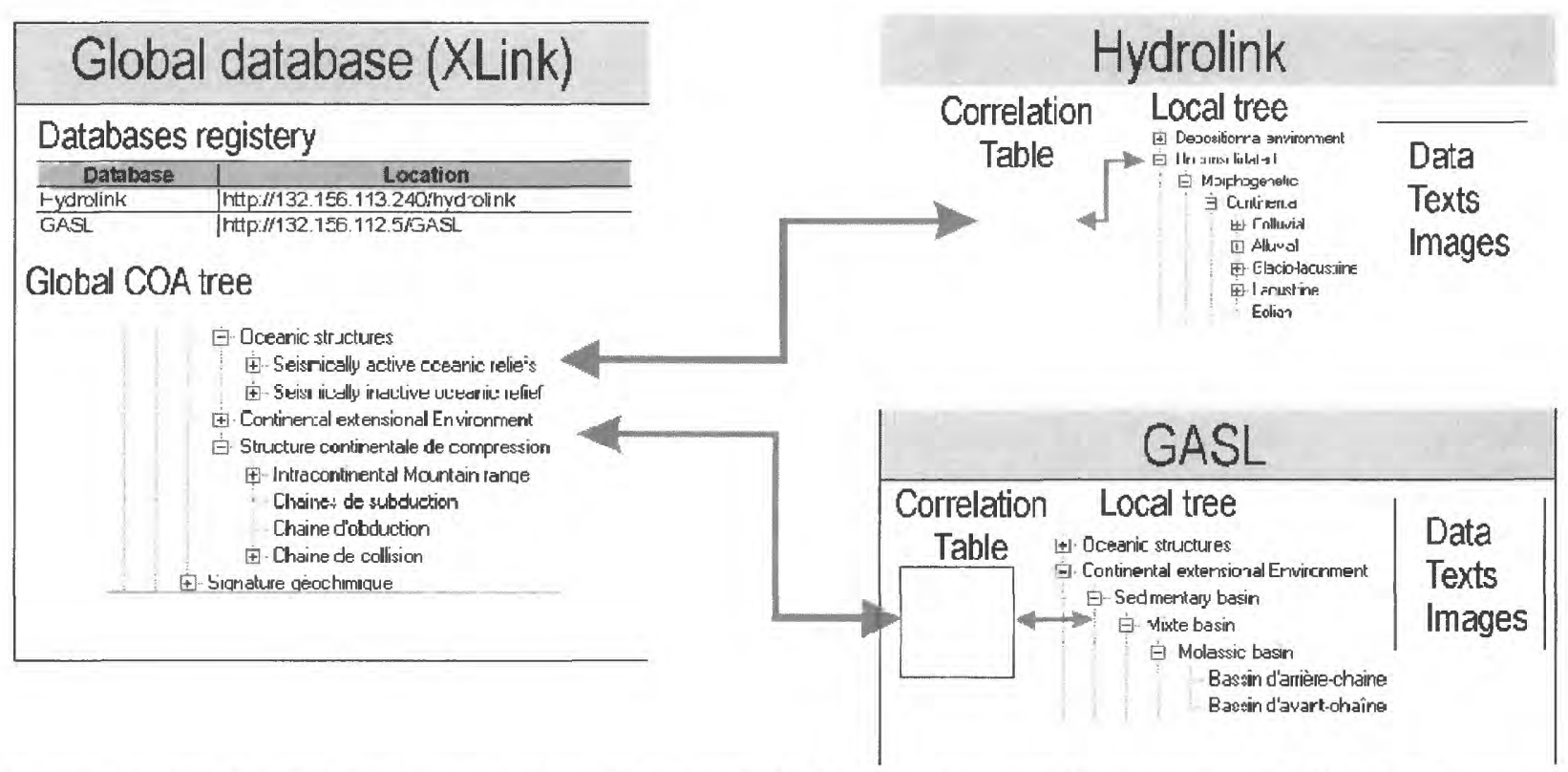

Figure 2. Small distributed system set up. The global database is a trimmed down version of NADM 5.2 containing only a global COA tree and themes with related information. Local databases have their own trees that are both a subset of the global tree (limited by the geoscience domain) but can also contain more precise definitions as extensions of the global tree. A correlation table maintains a correspondence between local and global entries.

Table 1. Example of correlation (mapping) between locally identified COA and their global equivalent.

\begin{tabular}{|c|c|c|}
\hline Local COA_id & Local COA Name & Global COA \\
\hline 45 & Supergroup SG1 & $\{383887 \mathrm{~B} 0-3 F 1 E-11 \mathrm{D} 5-\mathrm{BF} 80-0001022439 \mathrm{EA}\}$ \\
\hline 46 & Group G1 & $\{383887 B 1-3 F 1 E-11 D 5-B F 80-0001022439 E A\}$ \\
\hline 67 & Formation F1 & $\{383887 \mathrm{~B} 2-3 F 1 E-11 D 5-B F 80-0001022439 E A\}$ \\
\hline 68 & Member M1 & $\{383887 B 3-3 F 1 E-11 D 5-B F 80-0001022439 E A\}$ \\
\hline 71 & Group G2 & $\{383887 B 4-3 F 1 E-11 D 5-B F 80-0001022439 E A\}$ \\
\hline 77 & Formation F2 & $\{383887 B 5-3 F 1 E-11 D 5-B F 80-0001022439 E A\}$ \\
\hline 80 & Group G3 & $\{383887 B 6-3 F 1 E-11 D 5-B F 80-0001022439 E A\}$ \\
\hline 82 & Formation F3 & $\{383887 B 7-3 F 1 E-11 D 5-B F 80-0001022439 E A\}$ \\
\hline 101 & Group G4 & $\{383887 \mathrm{~B} 8-3 F 1 E-11 \mathrm{D} 5-\mathrm{BF} 80-0001022439 \mathrm{EA}\}$ \\
\hline
\end{tabular}

cepts can be part of several themes). The trees displayed to the user are coded with GUID. When an item is chosen, GEOMDB checks its database to identify all distributed databases it can forward the request to (Database registry of figure 2). The GEOMDB web site requests all local web sites for the required pages using the GUID selected by the user. The local mediator (Cold Fusion page) uses the correlation table to map this GUID to some local id and when a match is made, which is not always the case, requested information is extracted from the database in a specific format. The report is then parsed and merged to a single page by the global system. Different sets of reports are created for different purposes. So far we have pages that request documents, maps, and images from different servers and plan to add more data related features (age, rock unit description, etc.).

An example of a system dialog (over the future Canadian Geoscience Knowledge Network?) might translate in everyday language as follows:

\section{Global:}

Guys.. do you have anything related to \{7DD18D50-3F04-11D5-BF80-0001022439EA\}?

Local Ottawa:

Yes, I've got 45 entries and 89 children items. (an entry can be a document, an image or a map) 
Local Halifax:

No.

Local Québec:

Yes, I've got 34 entries and 15 children items.

Global: (the global system now tests this part of the tree structure)

Is the tree structure (parent to child) equivalant to?

$>$ 77DD18D54-3F04-11D5-BF80-0001022439EA $\}$

$>\{7 \mathrm{DD} 18 \mathrm{D} 53-3 \mathrm{~F} 04-11 \mathrm{D} 5-\mathrm{BF} 80-0001022439 \mathrm{EA}\}$

$D\{7 D D 18 D 52-3 F 04-11 D 5-B F 80-0001022439 E A\}$

$>\{7 D D 18 D 51-3 F 04-11 D 5-B F 80-0001022439 E A\}$

$>\{7 D D 18 D 50-3 F 04-11 D 5-B F 80-0001022439 E A\}$

At this point, the global system sends a complete branch (from the root up to the terminal leaf) to check if all parent-child relationships are "compatible".

\section{Local Ottawa:}

Oops, No, I have a problem... will send a message to our DBA.
Local Québec:

Yes, and have intermediate entries, but the tree is equivalent.

Global:

Guys, please send report about source (get_source.cfm)

Global to client

Found 134 references (45 are exactly what you are looking for) in Ottawa but there might be inconsistencies

Found 49 references (34 are exactly what you are looking for) in Québec.

Here's the list [...] (display the list on browser):

GEOMDB then sends the information to the client browser. At this point, GEOMDB merges back the information from various servers into a single page (figure 1). GEOMDB parses the result and creates links to further explore the database. The exact content returned by the local databases is not restricted and can of course contain links back to specific information maintained in the local

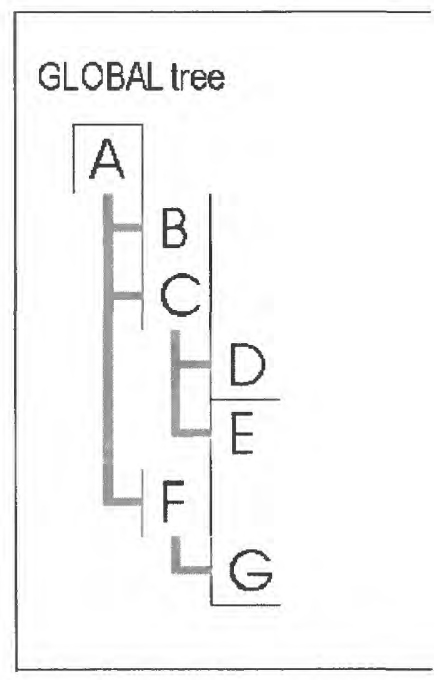

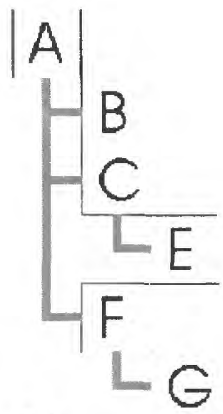

OK

Missing item
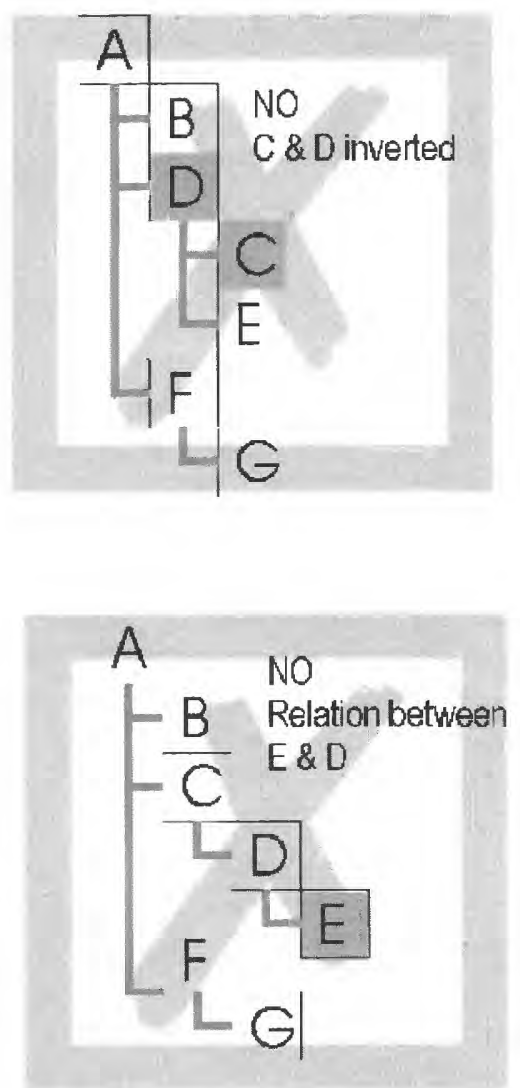

Figure 3. Example of "compatible trees". The global tree is the tree everyone agreed to. Other trees are various legal and non-legal variations of the same tree. 


\section{Global Server}

- (383a87BO FF1E 11 DF BF80-00MU22439EA) SUPERGROUP SG1

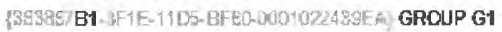

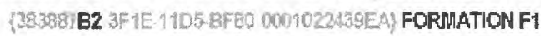

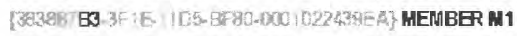

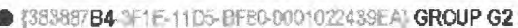

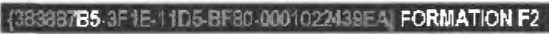

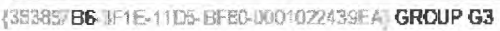

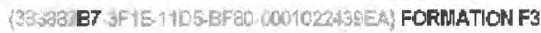

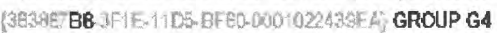

\section{Local Ottawa}

-

- (383897B1 FF1E-11LS-BF80-000102243GEA) GROUPG1 (3969) B2-3F1E-1105-EFED-0001022439-A\} FORMATION F1

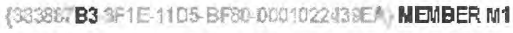
I3E3981B4 PFIE 11D5 EF80 0001022439EAY EORMATION G2

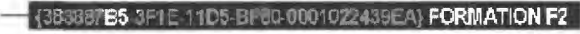

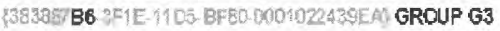
[383837B7 SF TE. 1 ID5-BF80.0001022459EA) FORMATION F3

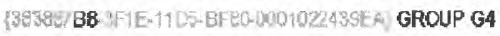

\section{Local Quebec}

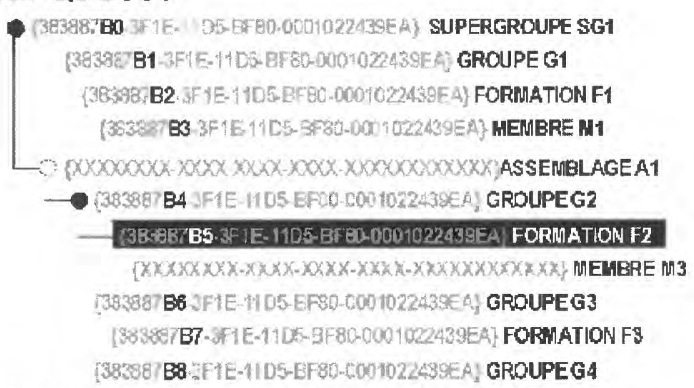

Figure 4. Tree structure used in the information exchange dialogue. The Ottawa tree shows a non compatible branch where the parent of Formation 2 is not the one expected (should be Group2). The Quebec tree also shows uses "anonymous" items inserted in the tree (Assemblage 1 and Member 3), not recognised at the global level.

database. GEOMDB does not expect the remote database to be NADM compliant, but only establishes "contracts" with the remote database using mediation code.

GEOMDB only requires from the local database an answer for a specific request using a specific format with agreed parameters. The local database must have some mechanism to map GUID to local concepts.

This system offers interesting possibilities: NADM, being able to offer a mechanism to relate pieces of information together, is the start of a potential knowledge base. For example, we can encode in NADM that "Dike D" cuts "Granite G" and establish a relative age between concepts. This kind of relationship might only be encoded in a single database, but since both Dike D and Granite $G$ are correlated to some global COA, this information can then be used at the global level as "shared knowledge".

\section{LET'S DREAM}

Figure 5 is a dream scenario: Imagine a typical geological map in shape format. The shape file has a special field (called CGKN_GUID) that represents a COA. A special tool can be customised to query the global server, to search for information about specific geological features. In this example on figure 5, the user was wondering if any relationship has been observed between this specific dike and a granite, but other information can be extracted as well. Maybe the Ottawa database has a list of geochronological ages for this granite and a student in Quebec dated the dike and this information can be extracted back to confirm (or deny) the explicit relation made in the Halifax database.

\section{LOOKS LIKE A METADATA SERVER TO ME!}

This is a metadata driven system. A good part of NADM is in fact a feature level metadata system. Unlike FGDC, it does not work with a list of keywords to find the information but relies on strictly defined features (identified with GUID) that lie within the document to be searched. This system would not be impossible to create using other metadata manager systems but an NADM based system has the benefit of also being the database we would use to store our maps and related information (instead of maintaining separate databases) and provides the ontology for the system. A reasonable portion of NADM can be mapped directly to the FGDC metadata profile, and attempts to map a subset of the FGDC profile are underway.

\section{CONCLUSION}

The work done for the GEOMDB is very preliminary but it already shows great potential for a larger implementation. We can see at least three benefits of using this architecture:

- An improved way to map complex (hierarchical) information into a coherent global infrastructure while maintaining a customised local nomenclature.

- A way to link several pieces of information, such as rock unit descriptions, ages, documents, or images to one or more classification schemes (COA or Thematic). The COA (or Theme) can be seen as a "bucket" containing different pieces of information (Nelson et al., 1999; Maly et al. 1999).

- A way to create a knowledge based classification scheme. NADM offers a powerful structure to manage rela- 

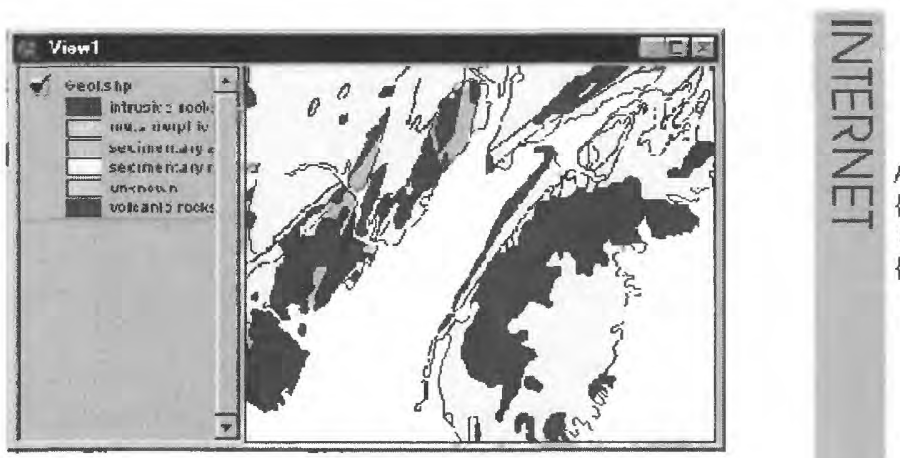

Any known relation between

$\{00625850-492 F-11$ C5-BF83-0001022439EA\} and

$\{00625852-492 \mathrm{~F}-11 \mathrm{D} 5-\mathrm{BF} 83-0001022433 \mathrm{EA}\}$
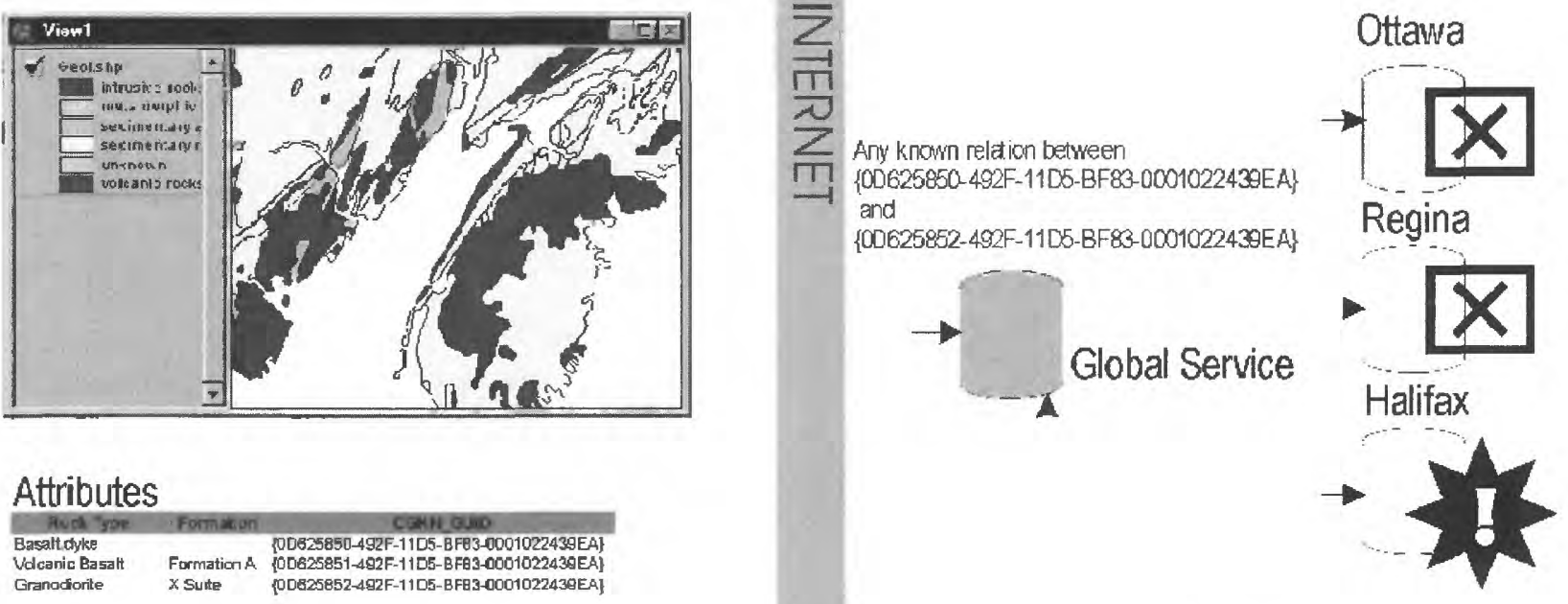

\title{
What kind of relation these dykes and this granite has?
}

\author{
$\{00625850-492 F-11 D 5-B F 83-0001022430 E A\}$ \\ cuts \\ \{00625852-492F-11D5-BF83-0001022439EA\}
}

\section{According to Halifax DB, This dyke cuts that granit}

Figure 5. Dream application. The global (GEOMDB) can act as a "service" that can deliver geoscience information to various datasets. Each feature on the map has a GUID that can be used to fetch information from distributed sources. In this example, the global system has been asked to find information about the relationship between two features and in turn forwards the query to all registered databases. One of the databases could send back information to the global system which returns it to the client application.

tions between COA items and create an "information space" (Feng et al.2001 - see figure 2)

In future work, we will explore how to implement the "dream system", but results so far are encouraging. The technology required is relatively simple since it uses a regular web server and inexpensive dynamic web generation tools (Cold Fusion, ASP, PHP (Apache), etc).

\section{ACKNOWLEDGEMENTS}

Gratitude is expressed to Dave Soller (USGS) and Peter Davenport for improving this paper. Special thanks to John Broome for finding necessary funds to attend DMT 2001.

\section{REFERENCES}

Berdusco, B., and Boisvert, E. , 2001, Building a digital map with Geomatter II at the Ontario Geological Survey (Poster): Geological Association of Canada - Mineralogical Associtation of Canada joint meeting, May 2001. St-John's Newfoundland, Canada,
<http://gis.geosurv.gov.nf.ca/GAC_2001/seven/ sub_program.asp?sess $=98 \&$ form $=10 \&$ abs_no $=618>$.

Boisvert, E., Desjardins, V., Brodaric, B., Berdusco, B., Johnson, B., and Lauzière, K., 2000, Geomatter II: A Progress Report, in D.R. Soller, editor, Digital Mapping Techniques '00 — Workshop Proceedings: U.S. Geological Survey Open-File Report 00-325, p. 87-95,

$<$ http://pubs.usgs.gov/openfile/of00-325/boisvert.html>.

Brodaric, B., Boisvert, E., and Lauzière, K., 1999a, Geomatter: A Map-Oriented Software Tool for Attributing Geologic Map Information According to the Proposed U.S. National Digital Geologic Map Data Model, in D.R. Soller, editor, Digital Mapping Techniques ' 99 - Workshop Proceedings; U.S. Geological Survey Open-File Report 99-386, p. 101-106, $<$ http://pubs.usgs.gov/openfile/of99-386/brodaric2.html>.

Brodaric, B., Journeay, M.. Talwar. S., and Boisvert, E.. 1999b, Cordlink Digital Library. Geological Map Data Model, Version 5.2, June 18, 1999 <http://132.156.108.208/Cordlink1/>.

Feng, L., Jeusfeld, M.A., and Hoppenbrouwers, J., 2001, Towards Knowledge-Based Digital Libraries: SIGMOD (Special Interest Group on Management of Data) Record, March 2001, <http://www.acm.org/sigs/sigmod/record/>, $<$ http://citeseer.nj.nec.com/408336.html>. 
Johnson, B.R., Brodaric, B., Raines, G.L., Hastings, J., and Wahl, R., 1998, Digital Geological Map Data Model 4.3: unpublished document of Association of American State Geologists / U.S. Geological Survey Data Model Working Group, <http://ncgmp.usgs.gov/ngmdbproject>.

Maly, K., Nelson, M.L., and Zubair, M., 1999, Smart Objects, Dumb Archives, A User centric, Layered Digital Library
Framework: D-Lib Magazine, March 1999, Vol. 5, Issue 3.

Nelson, M.L., Maly, K., Zubair, M., 1999, SODA: Smart Objects, Dumb Archives: Proceeding of the third European Conference on research and Advance Technology for Digital Library, Paris, France, September 22-24, 1999., p. 453-464. 
44 


\title{
Improving Access to Metadata Using Keywords from Controlled Vocabularies
}

\author{
By Peter N. Schweitzer \\ U.S. Geological Survey \\ Mail Stop 918 National Center \\ Reston VA 20192 \\ Telephone: (703) 648-6533 \\ Fax: (703) 648-6560 \\ e-mail: pschweitzer@usgs.gov
}

Since the introduction of the National Spatial Data Infrastructure in 1995, the development of well-structured metadata has held the promise that geospatial data could be better organized by the people who maintain them and better presented to the public by the people who provide access to them.

One aspect of the metadata standard that facilitates this is keywords. Where keywords are stored in FGDC metadata, the source of those keywords must be indicated as well. This does not require that terms be chosen from published lists of key words, but allows advantages of such controlled vocabularies to accrue for the user of the metadata. Controlled vocabularies refers to formallydefined lists of terms, usually hierarchical, that are preferred for use in specific ways. In a controlled vocabulary the scope of meaning of each term can be specified, along with relationships to other terms (broader, narrower, related, or preferential). Controlled vocabularies are maintained by an authority (a person or group) who ensures that the terms are all defined consistently and have welldefined relationships.

This paper describes the use of a controlled vocabulary, for place names, to categorize geoscientific spatial metadata. Its focus is on the technology used for choosing appropriate terms and storing the terms in each metadata record.

\section{A CONTROLLED VOCABULARY FOR PLACE NAMES}

For place names I have chosen to use two Federal Information Processing Standards (FIPS), 6-4 and 10-4. FIPS 6-4 specifies numerical codes for states and counties (or equivalent entities) in the US and its territories. Each state is identified using a two-digit number, and each county within the state is identified using a three-digit number.
Thus a county can be unambiguously identified using a five-digit code consisting of its state code and its county code. Unique codes are needed for these place names because many states have counties with the same name (for example Washington, Jefferson, Franklin, Lincoln, and Jackson counties all occur in 24 or more states).

FIPS 10-4 specifies alphanumeric codes for countries of the world and first-order subdivisions of them. Of the first-order subdivisions I have used only states in the United States and in Mexico and provinces in Canada. This decision reflects the distribution of data that I wish to categorize by place.

I have augmented these standard place names with names of major oceanic regions and names of continental regions. These groupings allow me to build a pick-list interface with a relatively narrow and deep hierarchy, so that users don't have too many choices at the highest level, where they begin to choose places.

\section{Internet resources}

Place keywords and unique id codes are found at <http://geo-nsdi.er.usgs.gov/metadata/placekey.txt>.

These place keywords are arranged hierarchically; the hierarchical relationships are shown by indentation. On each line the unique identification code of the place is given followed by a colon and then the place name. A short section of this file is listed below.

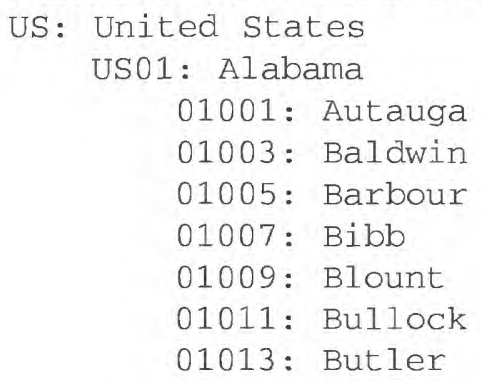


01015: Calhoun

01017: Chambers

A web interface utilizing these place keywords is found at <http://geo-nsdi.er.usgs.gov/cgi-bin/place $>$.

This utility operates as a Common Gateway Interface (CGI) process attached to a web server. It presents to the user a set of simple text links that traverse the hierarchy of the place keywords. At each point in the hierarchy, it lists as links any metadata records that have been assigned the chosen place name. An example screen is shown in figure 1 .

\section{PLACE KEYWORD ASSISTANT: A TOOL TO SELECT PLACE NAMES FOR METADATA}

Place names by themselves don't help much; the key is to associate each metadata record with the corresponding place names from the controlled vocabulary. You can do this manually, of course, using your favorite text editor or Tkme (http://geology.usgs.gov/tools/metadata/tools/ doc/tkme.html). Just add lines like this:

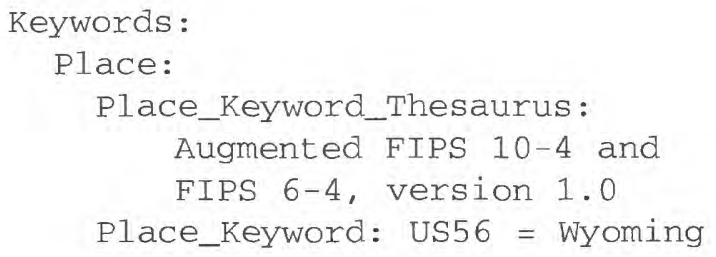

But when you're dealing with a large number of records, it helps to use a specialized tool for this purpose. The tool I've developed is called the Place Keyword Assistant. This tool is written in Tcl/Tk, so to use this tool, you'll need to install $\mathrm{Tcl} / \mathrm{Tk}$ on your system and also install the mq extension that enables Tcl/Tk scripts to read, modify, and write FGDC metadata.

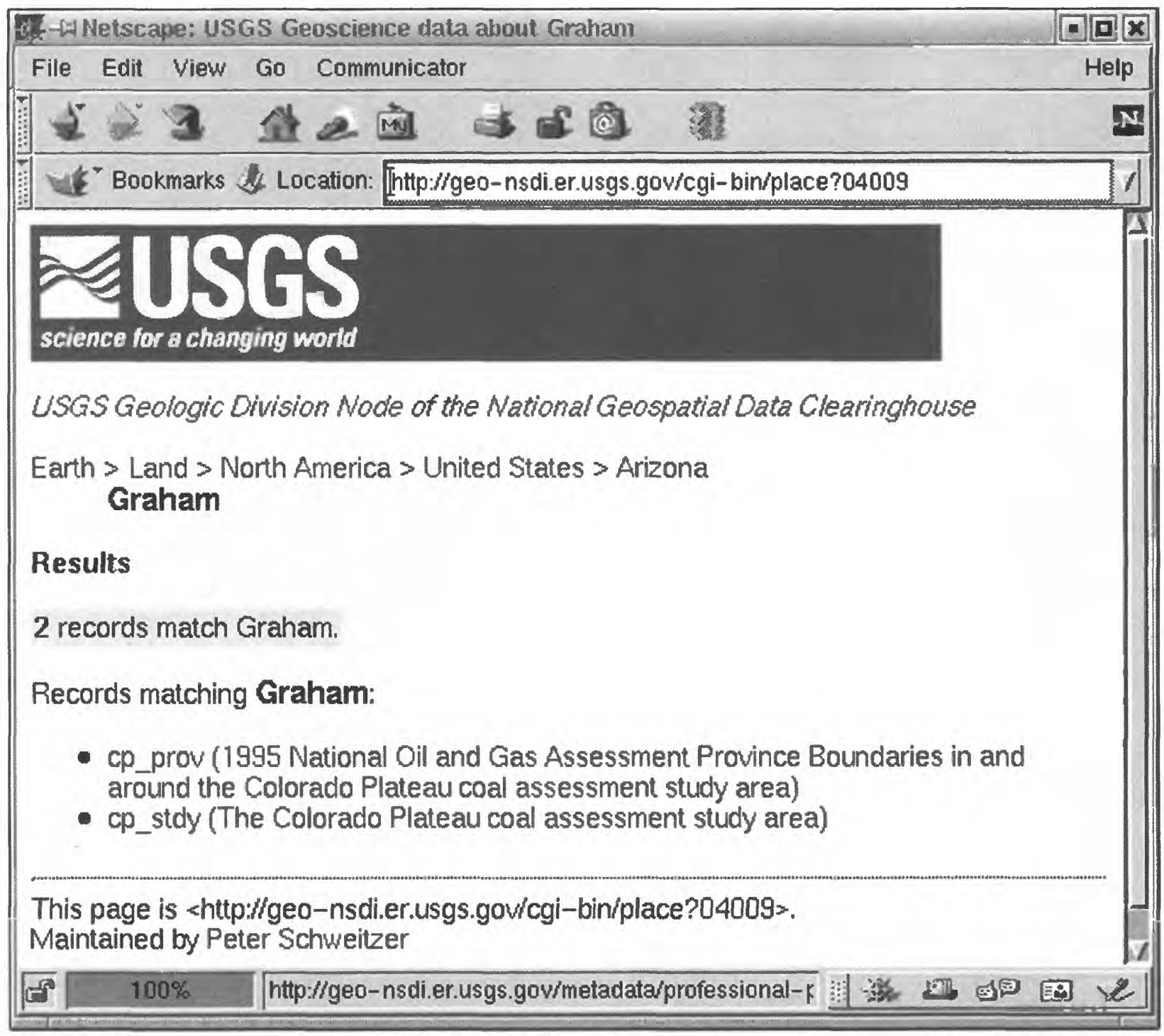

Figure 1. Place keyword search at USGS Geoscience Data node of the National Geospatial Data Clearinghouse. 
The Place Keyword Assistant has the following major functions:

1. Reads metadata records. Metadata records may be

a. named on the command line

b. listed in a file that is named on the command line, or

c. found recursively from current directory and its subdirectories.

2. Displays each record as it is selected. The text is shown in a simple scrollable window.

3. Presents hierarchical place keywords for the user to choose, and keeps track of keywords that have been chosen.

4. Saves the selected place keywords in the metadata record.

The Place Keyword Assistant creates three windows. One contains a list of metadata records (by file name) that you can select. It creates this list by traversing all of the directories below the one from which the program is run.
Choose a metadata record from this list. Entries shown in green have some place keywords assigned using this software; those shown in red might have place keywords but not keywords chosen from this list. The second window simply shows the text of each record as it is selected. This can be used to make decisions about which places to assign to the record. The third window shows you the place names that you can assign to the metadata record.

The keyword chooser window is shown in figure 2 and some functions are described in table 1. It consists of five list windows, each of whose contents are determined by the window to its left. In this example the user chose Land from among Oceans and Land, then North America from the list of continents, then United States from the list of countries in North America, then the state of Arizona, and from its counties the one named Graham. The list in the lower right corner contains those places whose names have been selected for inclusion in the metadata record. Its background is blue to distinguish it from the others

\section{Flace Keyword Assistant}

File Edit Keyword

\section{Oceans}

Land

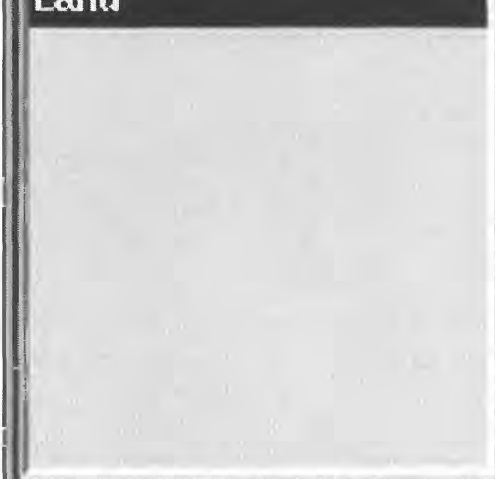

Alabama

Alaska

Arizona

Arkansas

Califomia

Colorado

Connecticut

Delaware

District of Columbia

Forida

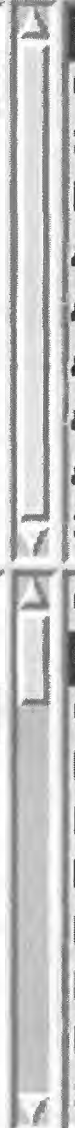

Rorth America

Central America

South America

Europe

Africa

Australia and New Zeala

Antarctica

Asia

Asia Minor and Middle E

Southeast Asia

Gila

Graham

Greenlee

La Paz

Maricopa

Mohave

Navajo

Pima

Pinal

Santa Cruz

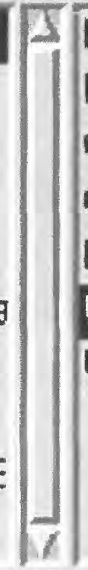

Bahamas, The
Bermuda
Canada
Greenland
Mexico
United States

U.S. possessions and a:

A 04017 = Navajo

04005 = Coconino

04015 = Mohave

04001 = Apache

04025 = Yavapai

04007 = Gila

04011 = Greenlee

04009 = Graham

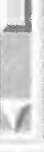

1

Save Prev

Skjp

Next

Figure 2. The keyword selection window. 
Table 1. Keyword selection buttons, keystroke equivalents, and what they do.

\begin{tabular}{|c|c|c|}
\hline Button & Keystroke & Descriptions \\
\hline Add & Enter & $\begin{array}{l}\text { Include the most specific place name currently } \\
\text { selected. }\end{array}$ \\
\hline Remove & Backspace & Remove the selected place name from the list. \\
\hline Clear & (none) & Remove all place names from the list. \\
\hline Save & Ctrl-S & Write the listed place names into the metadata record. \\
\hline Prev & Ctrl-P & $\begin{array}{l}\text { Write the listed place names into the metadata record } \\
\text { and load the previous metadata record from the file } \\
\text { list. }\end{array}$ \\
\hline Skip & PgDn & $\begin{array}{l}\text { Leave the current metadata record unchanged and } \\
\text { load the next record from the list. }\end{array}$ \\
\hline Next & Ctrl-N & $\begin{array}{l}\text { Write the listed place names into the metadata record } \\
\text { and load the next metadata record from the file list. }\end{array}$ \\
\hline \multicolumn{3}{|c|}{ Choices on the Edit menu } \\
\hline Copy & Ctrl-C & $\begin{array}{l}\text { Copy the current list of place keywords to the } \\
\text { clipboard. }\end{array}$ \\
\hline Paste & Ctrl-V & $\begin{array}{l}\text { Paste the clipboard's contents into the current } \\
\text { record's list of place keywords. }\end{array}$ \\
\hline
\end{tabular}

visually, and its entries include the unique FIPS code associated with each area.

\section{DETAILED INSTALLATION INSTRUCTIONS FOR USE ON MS-WINDOWS}

\section{Install Tcl/Tk}

a. Download tc1832 . exe from <http://dev.scriptics.com/ftp/tcl8_3/tcl832.exe>.

b. Run tcl832. exe. Choose default install in C: \Program Files $\backslash \mathrm{TCl}$.

c. Restart. This makes the system recognize file names ending with .tcl as Tcl scripts.

\section{Install MQ}

a. Download the complete package of metadata tools for MS-Windows from <http://geology.usgs.gov/ tools/metadata/all_win.exe>.

b. Run all_win.exe. Allow the installer to store the files in C: VUSGS.

c. Copy C: \USGS tools $\backslash$ bin $\backslash$ mq2 2 . dll into $\mathrm{C}: \backslash$ Program Files $\backslash \mathrm{TCl} \backslash \mathrm{lib}$.

d. Create directory $\mathrm{C}: \backslash$ Program Files $\backslash \mathrm{TC} I \backslash$ lib $\backslash \mathrm{mq}$. e. Copy C: \USGS\tools $\backslash$ bin $\backslash p k g I n d e x . t c l$ into $\mathrm{C}: \backslash$ Program Files $\backslash \mathrm{TCl} \backslash 1 \mathrm{ib} \backslash \mathrm{mq}$.

f. Test by running Wish

1. Choose Wish from the Start menu, following Programs $>\mathrm{Tcl}>$ Wish.

2. Two windows appear. One is labeled "Console" and contains a prompt (percent sign). Click this window.

3. At the \% prompt, type package require mq then press Enter.

4. The interpreter should respond with the version number of mq. At this writing this value is 2.5.11. If you get an error message instead, something wasn't installed correctly.

\section{Install Place Keyword Asssistant}

a. Find a directory above those where you have stored your metadata. There can be other files in its subdirectories, but this works out-of-the-box if your metadata files all have the extension . met. For this example, suppose this is $\mathrm{D}: \backslash$ data.

b. Download placekey . txt from http://geo-nsdi. er.usgs.gov/metadata/placekey.txt $>$ and save it in $D: \backslash$ data .

c. Download placer. tcl from <http://geo-nsdi.er. usgs.gov/metadata/placer.tcl $>$ and save it in D: \data. This file should have a "Tk" icon. 
d. Double-click placer.tcl. The windows should appear.

\section{USING ARCEXPLORER 3 WITH THE PLACE KEYWORD ASSISTANT}

ESRI's ArcExplorer 3 can be used to display US counties (here focusing on the Southwest) with scientific data overlying the county boundaries. Because the counties are shown as polygons, these can be selected when their layer is made active (figure 3 ). After selecting the counties that overlap the scientific data, the user clicks on the Attributes button in the ArcExplorer toolbar to bring up the table of attributes of the selected counties. This table is divided in two panes by a vertical bar. In the left pane the names of the selected counties are shown. The right pane contains the attributes of the county selected last.

Note that what ArcExplorer shows in the left side of the attribute window is the first item of the layer's DBF file that is not an intrinsic attribute of ArcInfo. The counties layer I have used here was downloaded from the National Atlas of the US. I modified the DBF file by deleting the Arclnfo intrinsic attributes and swapping the column positions of the state name and county name attributes, so that the county name comes first.

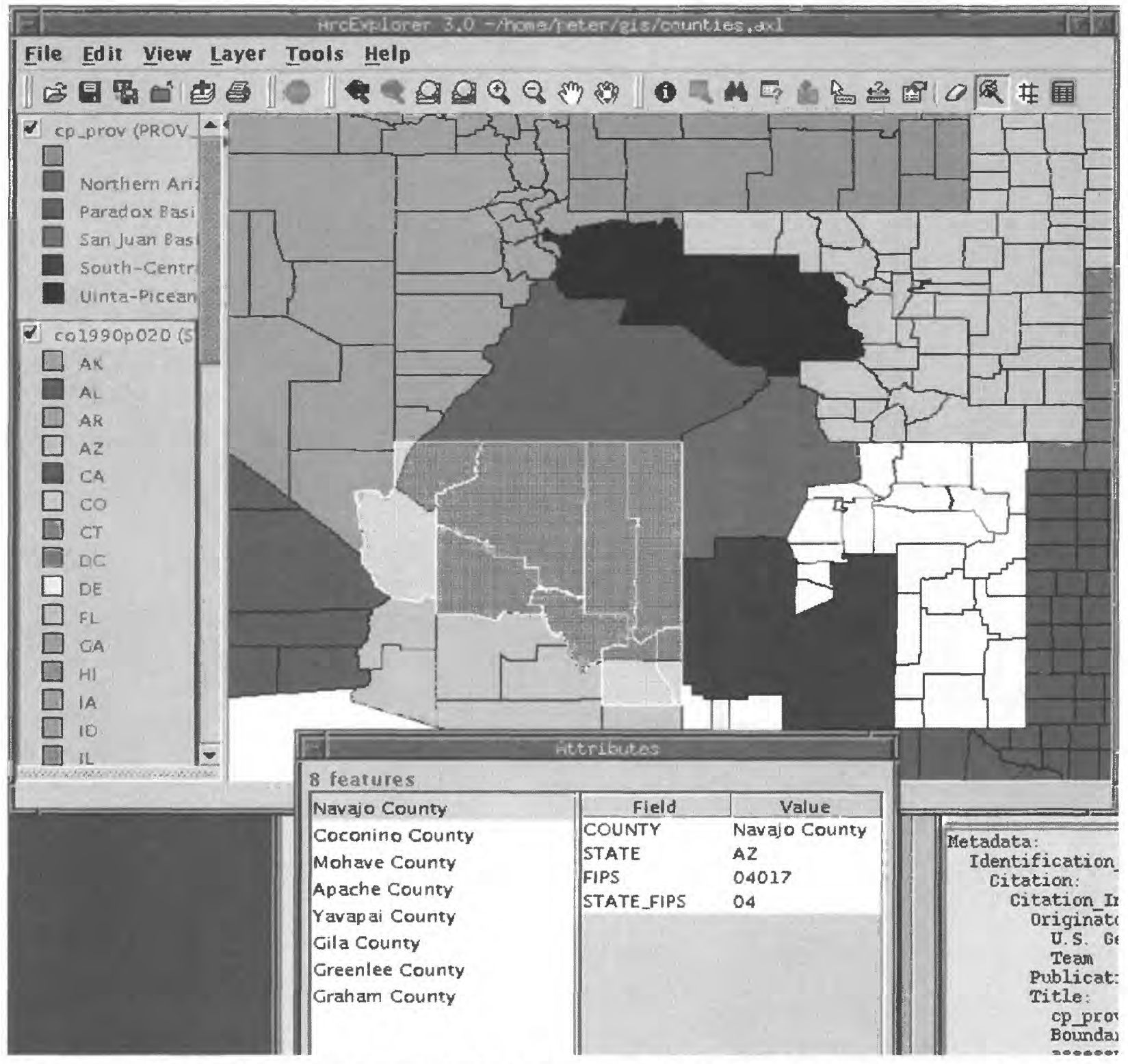

Figure 3. ArcExplorer 3 map showing counties in the southwest US with some data over them, 8 counties of New Mexico selected. 
50 


\title{
The National Geologic Map Database: A Progress Report
}

\author{
By David R. Soller ${ }^{1}$ and Thomas M. Berg 2 \\ ${ }^{1}$ U.S. Geological Survey \\ 908 National Center \\ Reston, VA 20192 \\ Telephone: (703) 648-6907 \\ Fax: (703) 648-6937 \\ e-mail: drsoller@usgs.gov \\ ${ }^{2}$ Ohio Geological Survey \\ 4383 Fountain Square Dr. \\ Columbus, $\mathrm{OH} 43224$ \\ Telephone: (614) 265-6988 \\ Fax: (614) 268-3669 \\ e-mail: thomas.berg@dnr.state.oh.us
}

The Geologic Mapping Act of 1992 and its reauthorizations in 1997 and 1999 (PL106-148) require that a National Geologic Map Database (NGMDB) be designed and built by the U.S. Geological Survey (USGS), in cooperation with the Association of American State Geologists (AASG) and other entities participating in the National Cooperative Geologic Mapping Program. The Act notes that the NGMDB is intended to serve as a "national archive" of geologic maps, to provide the information needed to address various societal issues. The Act requires the NGMDB to also include the following related map themes: geophysics, geochemistry, paleontology, and geochronology. In this progress report, the term "geoscience" is used to refer to these five map themes.

In mid-1995, the general stipulations in the Act were addressed in the proposed design and implementation plan developed within the USGS and the Association of American State Geologists (AASG). This plan was summarized in Soller and Berg (1995). Because many maps are not yet in digital form and because many organizations produce and distribute geologic maps, it was decided to develop the NGMDB in several phases.

The first and most fundamental phase includes a comprehensive, searchable catalog of all geoscience maps in the United States, whether in either paper or digital format. The Mapping Act stipulates that the NGMDB will be built to address societal needs, hence this map catalog is designed for use by a wide variety of people, from private citizens to professional geologists. Figure 1a shows how the map catalog can be used to find a particular map showing the geology beneath a user's home. Upon searching the NGMDB catalog and identifying the needed map(s), the user is linked to the map data, the metadata, or to the appropriate organization for information about how to purchase the map. (The organization could be a participating state or federal agency, association, university, or private company.) The map catalog presently is supported by two databases developed under the NGMDB project: 1) GEOLEX, a searchable geologic names lexicon; and 2) Geologic Mapping in Progress, which provides information on current mapping projects, prior to inclusion of their products in the map catalog.

The second phase of the project focuses on public access to digital geoscience maps, and on the development of digital map standards and guidelines needed to improve the utility of those digital maps. The third phase proposes, in the long term, to develop an online, "living" database of geologic map information at various scales and resolution. The third phase is discussed in a separate paper in these proceedings (Soller and others). Some functions of the planned online database, and its links to databases developed under Phase 1, are shown in Figure 1b.

In late 1995, work began on phase one. The formation of several Standards Working Groups in mid-1996 initiated work on phase two. Progress was summarized in Soller and Berg (1997, 1998, 1999a, 1999b, and 2000). At the Digital Mapping Techniques ' 98 through ' 00 workshops, a series of presentations and discussion sessions 


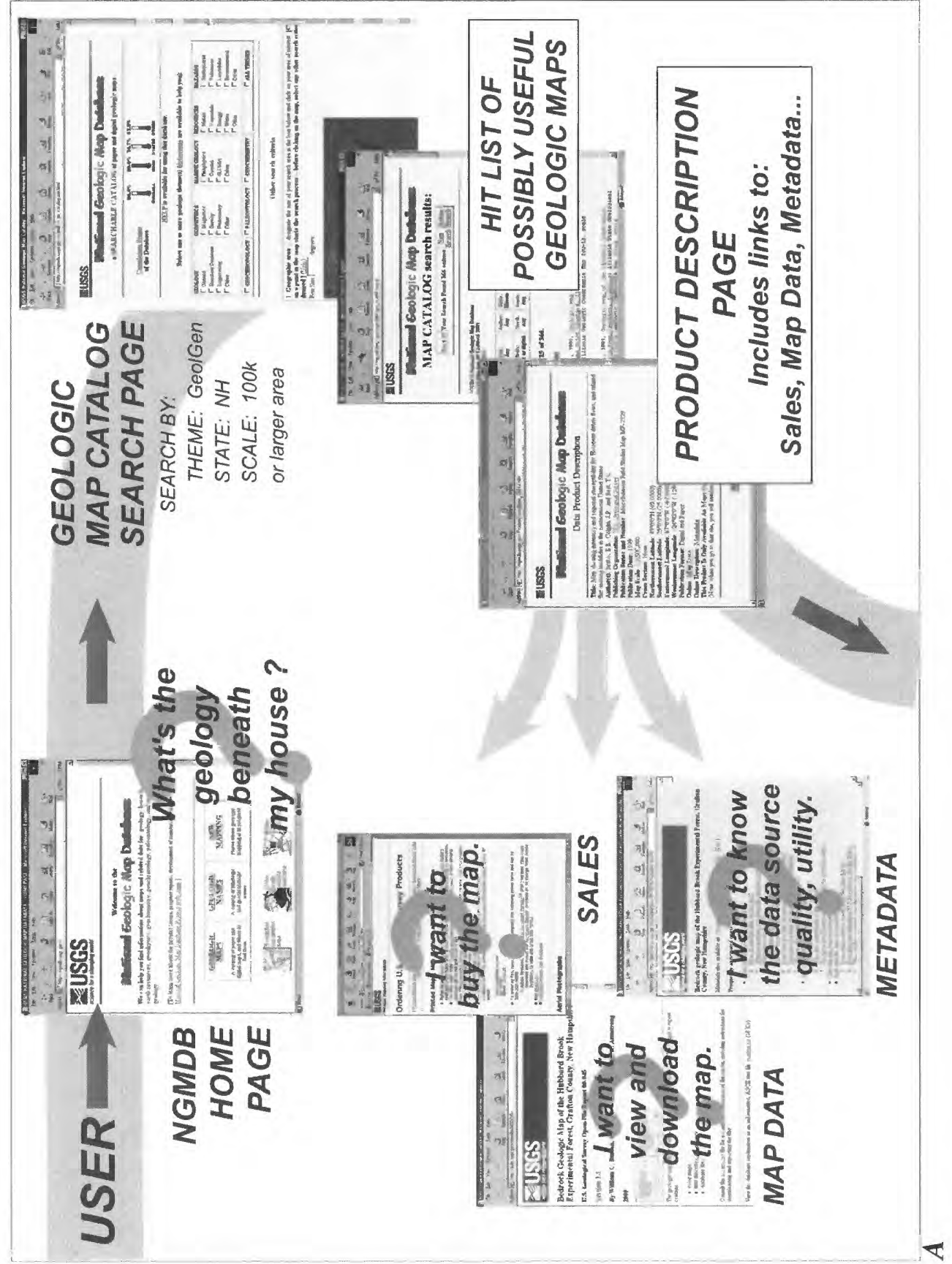




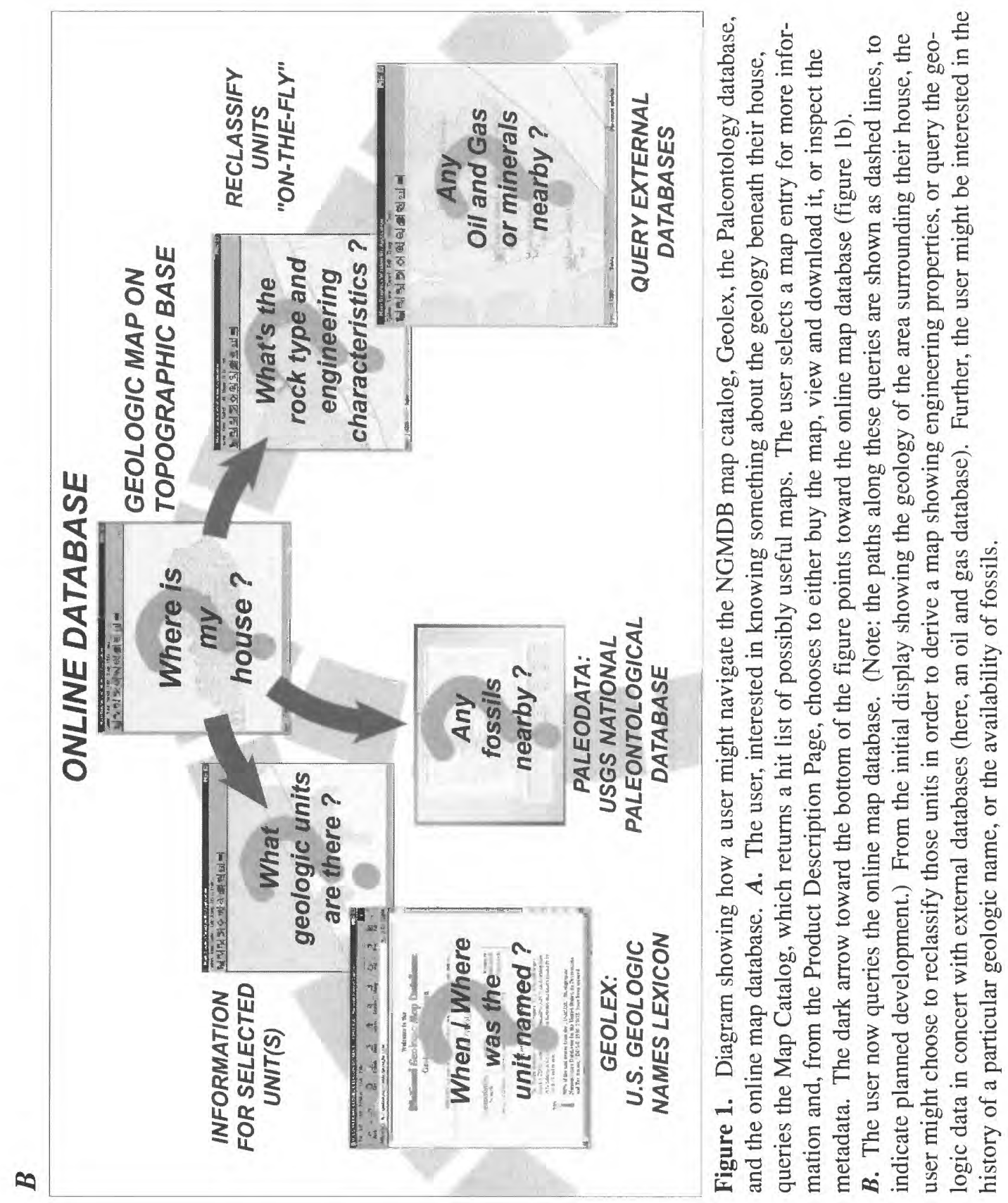


provided updates on the NGMDB and, specifically, on the activities of the Standards Working Groups. This report summarizes progress since mid-2000. Further and more current information may be found at the NGMDB projectinformation Web site, at <http://ncgmp.usgs.gov/ ngmdbproject $>$. The searchable database is available at $<$ http://ngmdb.usgs.gov>.

\section{PHASE ONE}

\section{The Map Catalog}

The map catalog is designed to be a comprehensive, searchable catalog of all geoscience maps of the United States, in paper or digital format. Entries to the catalog include maps published in geological survey formal series and open-file series, maps in book publications, maps in theses and dissertations, maps published by park associations and scientific societies, maps published by other agencies, and publications that do not contain a map but instead provide a geological description of an area (for example, a state park). At the time of this conference, the catalog contained a record for each of nearly 38,500 map products. Essentially all USGS maps have been recorded in the catalog, and emphasis has now shifted to assisting the state geological surveys to enter all their maps and related maps (e.g., University theses) into the catalog. By the date of the DMT'01 meeting, geological surveys in 27 states were entering map records, as well as one University (Stanford); participation is now significantly greater than in the past. Since the time when essentially all USGS maps were entered into the map catalog, Web usage statistics indicate a clear increase in multiple visits to the site per month. This suggests the site is becoming a more useful resource, and additional increases in use are expected as the state geological survey maps are entered into the catalog.

\section{Geologic Names Lexicon}

The searchable, on-line, geologic-names lexicon ("GEOLEX") now contains roughly $90 \%$ of the geologic names found in the most recent listing of USGSapproved geologic names (published in 1996 as USGS Digital Data Series DDS-6, revision 3) and is estimated to contain roughly $75 \%$ of all geologic names in the United States. Prior to loading into GEOLEX, the information on DDS- 6 was consolidated, revised, and errorcorrected. In the past year, work focused on resolving name conflicts and adding reference summary and other information for each entry. Work remaining includes incorporating geologic names not found on DDS-6 but recorded in the geologic names card catalog at USGS Headquarters, and incorporating names approved by the state geological surveys but not yet in the USGS records.
GEOLEX is intended to be the comprehensive, authoritative listing of approved geologic names, and is available as a resource for geologic mappers nationwide. Many state geological surveys have been registering new geologic names with the USGS for decades, and are encouraged to continue this practice under GEOLEX, through a Web-based application form.

\section{Geologic Mapping in Progress Database}

To provide users with information about current mapping activities at 1:24,000- and 1:100,000-scale $(1: 63,360$ and 1:250,000-scale in Alaska), a Geologic Mapping in Progress Database is maintained. This database is available at <http://ngmdb.usgs.gov/MapProgress/ MapProgress_home.html>.

\section{Paleontology}

The NGMDB project has now begun to design and develop a national paleontology database (see Wardlaw and others, in these Proceedings). Our general plan is to build prototypes of this database in areas where geologic mapping is underway, so that we can work with mapping projects to design a database useful to science as well as to the public.

\section{PHASE TWO}

Most efforts related to phase two have been directed toward the development of standards and guidelines needed to help the USGS and state geological surveys more efficiently produce digital geologic maps, and to produce those maps in a more standardized and common format among the various map-producing agencies. Significant progress has been made toward developing some of these standards and guidelines, and to providing map catalog users with access to online products.

\section{Standards Development}

The following summaries concern activities of the AASG/USGS Standards Working Groups and their successors. General information about the Working Groups, and details of their activities, are available at $<$ http://ncgmp.usgs.gov/ngmdbproject>.

\section{Geologic Map Symbolization}

A draft standard for geologic map line and point symbology and map patterns and colors, published in a USGS Open-File Report in 1995, was in 1996 reviewed by the AASG, USGS, and Federal Geographic Data Committee (FGDC). It was revised by the NGMDB project team and members of the USGS Western Region Publications Group and was circulated for internal review in late 1997. The 
revised draft then was prepared as a proposed Federal standard, for consideration by the FGDC. The draft was, in late 1999 through early 2000, considered and approved for public review by the FGDC and its Geologic Data Subcommittee. The document was released for public comment within the period May 19 through September 15, 2000 (see <http://ncgmp.usgs.gov/fgdc_gds/mapsymb/> for the document itself and for information about the review process). This draft standard is described in some detail in Soller and Lindquist (2000). With assistance from a newly-formed standing committee to oversee resolution of review comments and long-term maintenance of the standard, the document is being revised for 2002 submittal to FGDC, for discussion and adoption as a Federal standard.

\section{Digital Mapping}

The Data Capture Working Group has coordinated four annual "Digital Mapping Techniques" workshops for state, federal, and Canadian geologists, cartographers, managers, and industry partners. These meetings have been highly successful, and have resulted in adoption within agencies of new, more efficient techniques for digital map preparation, analysis, and production. The most recent workshop, held in Tuscaloosa, Alabama, and hosted by the Geological Survey of Alabama, was attended by approximately 110 representatives of 48 state, federal, and Canadian agencies and private companies. The workshop proceedings are published (Soller, 1997, 1998, 1999, 2000, and in this volume) and served on-line at (<http://ncgmp.usgs.gov/pubs/of97-269>; $<$ http://pubs.usgs.gov/openfile/of98-487>; $<$ http://pubs.usgs.gov/openfile/of99-386>, $<$ http://pubs.usgs.gov/openfile/of00-325>, and $<$ http://pubs.usgs.gov/openfile/of01-223>. Published copies of the Proceedings may be obtained from Soller or Berg.

\section{Map Publication Requirements}

Through the USGS Geologic Division Information Council, one of us (Soller) led development of the USGS policy "Publication Requirements for Digital Map Products" (enacted May 24, 1999). A less USGS-specific version of this document was developed by the AASG/USGS Data Information Exchange Working Group and presented for technical review at a special session of the Digital Mapping Techniques '99 workshop (Soller and others, 1999). The revised document (entitled "Proposed Guidelines for Inclusion of Digital Map Products in the National Geologic Map Database") is now under review by the AASG Digital Geologic Mapping Committee for consideration as a guideline for newly-produced digital maps compiled under support of the STATEMAP compo- nent of the National Cooperative Geologic Mapping Program and available through the NGMDB.

\section{Metadata}

The Metadata Working Group developed its final report in 1998. The report provides guidance on the creation and management of well-structured formal metadata for digital maps (see <http:// ncgmp.usgs.gov/ngmdbproject/ standards/metadata/metaWG.html $>$ ). The report contains links to metadata-creation tools and general discussions of metadata concepts (see, for example, the metadata-creation tools, "Metadata in Plain Language," and other helpful information at <http://geology.usgs.gov/tools/metadata/ > .

\section{Geologic Map Data Model}

State and USGS collaborators on the NGMDB continue to serve as representatives to the North American Data Model Steering Committee (NADMSC), assisting in the process of developing, refining, and testing the North American Geologic Map Data Model. The NADMSC has now formed various technical teams to conduct specific tasks within a one-year period, and longer time-frames. If interested, please visit the NADMSC web site, $<$ http://geology.usgs.gov/dm/s. More information is provided in a separate paper by the NADMSC in these Proceedings.

\section{Access to Online Products}

As standards are developed under Phase Two and via other mechanisms, the products released by geological surveys increasingly are standardized in format and content. A principal goal of Phase Two is to provide links from the Map Catalog to the more standardized of these products. Through searches of the NGMDB Map Catalog, users are directed to web sites for perusal of selected online products. This feature of the Map Catalog is now available for USGS products served on USGS Regional Publications Servers, and for metadata served on the USGS Clearinghouse node. At the time of this meeting, more than 500 links exist to online map products and their metadata.

\section{PHASE THREE, AND INTEGRATION WITH OTHER ASPECTS OF THE PROJECT}

Over the past few decades, significant advances in computer technology now permit complex spatial information to be stored, managed, and analyzed to the satisfaction of a growing number of geoscientists. At the beginning of the NGMDB project, we judged that computer-based map- 


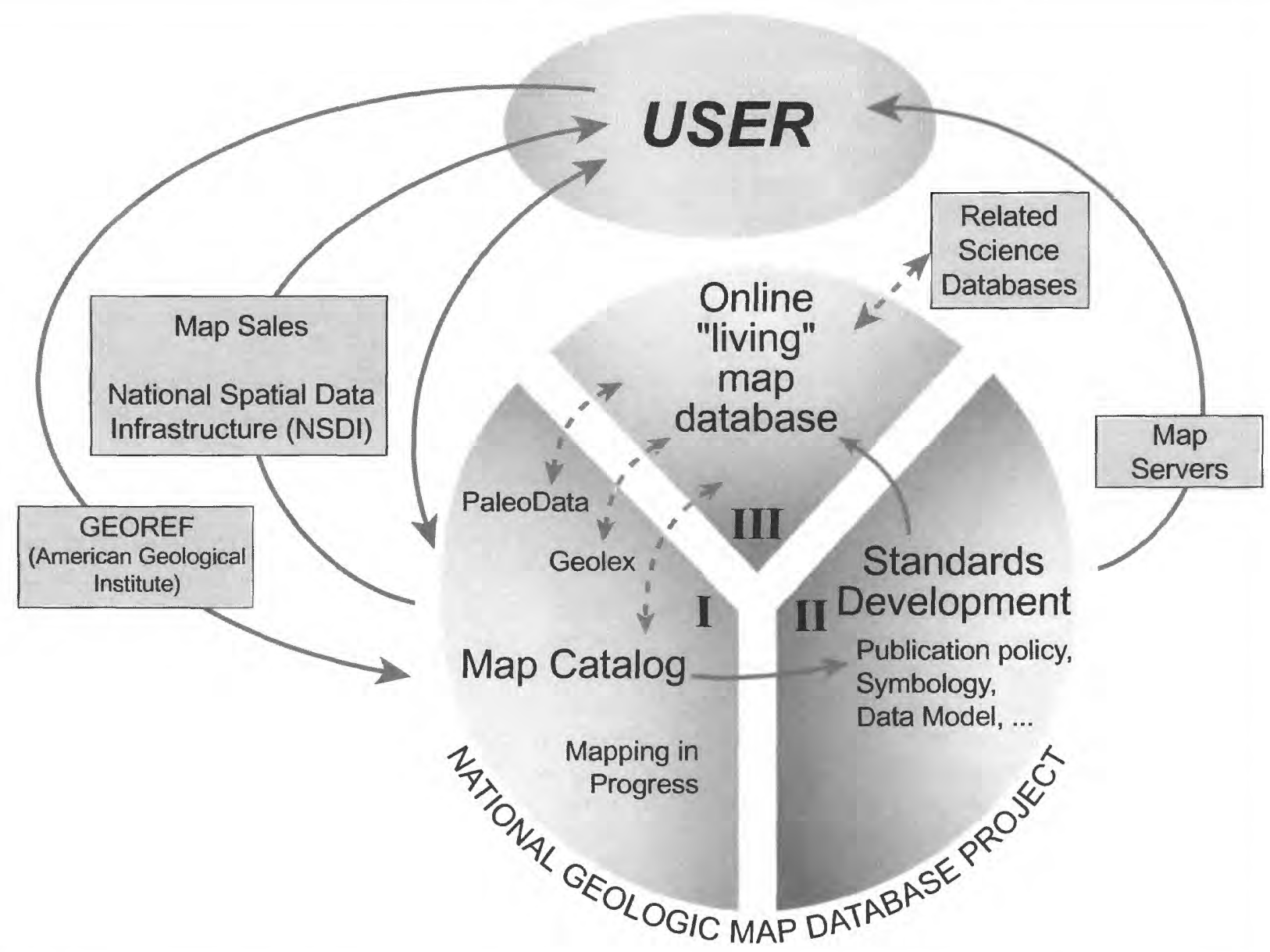

Figure 2. Diagram showing user access to the various components of the National Geologic Map Database (NGMDB) project, and to related external databases and services. The three project phases are shown, and the relations among them. Dashed arrows indicate planned relations.

ping was not a sufficiently mature discipline to permit us to develop an online database. Further, technology for display and query of complex spatial information on the Web was in its infancy, and hence was not seriously considered by the NGMDB project as a viable means of delivering useful information to the general public. Now, six years after the project's inception, there exists sufficient digital geologic map data, sufficient convergence on standard data formats, data models, digital mapping practices, and field data capture techniques, and sufficient technological advances in Internet delivery of spatial information to warrant a research effort aimed at building a prototype, online National Geologic Map Database.

To design an online database, project personnel have held numerous discussions with geoscientists and the general public, to gauge interest in an online database, and to define its scope. Based on these discussions, it is clear that this database should be:
1. built from edge-matched geologic maps at various scales,

2. managed and accessed as a coherent body of map information, not just as a set of discrete map products,

3. updated by mappers and/or a committee, "on the fly" when new information becomes available (i.e., a "living" database),

4. standardized, adhering to a standard data model and with standard scientific terminology, and

5. available to users via Internet browsers and common GIS tools (e.g., ArcExplorer).

The NGMDB project has begun a series of prototypes designed to build this online, "living" database; an introduction to the design approach is given in Soller and others (2000). In 1999, we designed some basic requirements for a prototype geologic map database, and tested our concepts using some newly-developed digital data for the 
Greater Yellowstone Area of Wyoming and Montana (Wahl and others, 2000). That first prototype was presented for discussion at the Geological Society of America Annual Meeting, in October, 1999. The prototype was wellreceived, and plans were begun for a second prototype, with a more complex set of tasks. That prototype, conducted in cooperation with the Kentucky Geological Survey, is summarized in Soller and others (this volume). We anticipate further prototypes that will advance our understanding of the technical and management challenges to be addressed in development of the operational system.

The online map database is being designed to integrate with other databases developed under this project. For example, a user accessing the online map database might identify a map unit of interest, and then want to purchase or download the original, published map product, or inquire about fossils found within that unit or the history of the unit's geologic name. These user questions exploit the power and flexibility of databases, and we anticipate building into the system the functionality diagrammed in figure 2. As another example of the interaction of the various NGMDB phases, this diagram shows that a user might access the Map Catalog and identify a map of interest; the user might then purchase the map or link to a map server where the product can be downloaded. In the latter case, the arrow passing through "Standards Development" indicates that the NGMDB project's standards development activities affect the content and format of products served.

\section{ACKNOWLEDGEMENTS}

The authors thank the members of the NGMDB project staff and collaborators for their enthusiastic and expert support, without which the project would not be successful. In particular, we thank: Ed Pfeifer, Alex Acosta, Dennis McMacken, Jana Ruhlman, and Michael Gishey (USGS, Flagstaff, AZ; Website and database management), Nancy Blair and Chuck Mayfield (USGS Library; map catalog content), Nancy Stamm and Bruce Wardlaw (USGS; Geolex database), and John Sutter (USGS; Geologic Mapping in Progress database).

\section{REFERENCES}

Soller, D.R., editor, 2000, Digital Mapping Techniques '00 Workshop proceedings: U.S. Geological Survey Open-file Report 00-325, 209 p., <http://pubs.usgs.gov/openfile/ of $00-325 />$.

Soller, D.R., editor, 1999, Digital Mapping Techniques '99 _ Workshop proceedings: U.S. Geological Survey Open-file Report 99-386, 216 p., <http://pubs.usgs.gov/openfile/of99-386/>.

Soller, D.R., editor, 1998, Digital Mapping Techniques ‘98 Workshop Proceedings: U.S. Geological Survey Open-File
Report 98-487, 134 p., <http://pubs.usgs.gov/openfile/ of $98-487 />$.

Soller, D.R., editor, 1997, Proceedings of a workshop on digital mapping techniques: Methods for geologic map data capture, management, and publication: U.S. Geological Survey Open-File Report 97-269, 120 p., <http://ncgmp.usgs.gov/ pubs/of97-269/>.

Soller, D.R., and Berg, T.M., 2000, The National Geologic Map Database-A progress report, in Soller, D.R., editor, Digital Mapping Techniques ' 00 - Workshop proceedings: U.S. Geological Survey Open-file Report 00-325, p. 27-30, $<$ http://pubs.usgs.gov/openfile/of00-325/soller2.html>.

Soller, D.R., and Berg, T.M., 1999a, Building the National Geologic Map Database: Progress and challenges, in Derksen, C.R.M, and Manson, C.J., editors, Accreting the continent's collections: Geoscience Information Society Proceedings, v. 29, p. 47-55, <http://ncgmp.usgs.gov/ngmdbproject/ reports/gisproc98.html>.

Soller, D.R., and Berg, T.M., 1999b, The National Geologic Map Database - A progress report, in Soller, D.R., editor, Digital Mapping Techniques ' 99 - Workshop proceedings: U.S. Geological Survey Open-file Report 99-386, p. 31-34, <http://pubs.usgs.gov/openfile/of99-386/soller1.html>.

Soller, D.R., and Berg, T.M., 1998, Progress Toward Development of the National Geologic Map Database, in Soller, D.R., editor, Digital Mapping Techniques '98 Workshop proceedings: U.S. Geological Survey Open-file Report 98-487, p. 37-39, <http://pubs.usgs.gov/openfile/ of $98-487 /$ soller $2 . h t m l>$.

Soller, D.R., and Berg. T.M., 1997, The National Geologic Map Database-A progress report: Geotimes, v. 42, no. 12, p. 29-31.

Soller, D.R., and Berg, T.M., 1995, Developing the National Geologic Map Database: Geotimes, v. 40, no. 6, p. 16-18.

Soller, D.R., Berg, T.M., and Wahl, Ron, 2000, Developing the National Geologic Map Database, Phase 3 - An Online, "Living" Database of Map Information: Digital Mapping Techniques '00 - Workshop Proceedings: U.S. Geological Survey Open-File Report 00-325, p. 49-52, $<$ http://pubs.usgs.gov/openfile/ofo0-325/soller4.html>.

Soller, D.R., Duncan, Ian, Ellis, Gene, Giglierano, Jim, and Hess, Ron, 1999. Proposed Guidelines for Inclusion of Digital Map Products in the National Geologic Map Database, in D.R. Soller, ed., Digital Mapping Techniques '99 Workshop Proceedings: U.S. Geological Survey Open-File Report 99-386, p. 35-38, <http://pubs.usgs.gov/openfile/ of $99-386 /$ soller2.html>.

Soller, D.R., and Lindquist, Taryn, 2000, Development and Public Review of the Draft "Digital Cartographic Standard for Geologic Map Symbolization”, in D.R. Soller, ed., Digital Mapping Techniques ' 00 - Workshop Proceedings: U.S. Geological Survey Open-File Report 00-325, p. 43-47, $<$ http://pubs.usgs.gov/openfile/of00-325/soller3.html>.

Wahl, R.R., Soller, D.R., and Yeldell, Steven, 2000, Prototype Implementation of the NADMSC Draft Standard Data Model, Greater Yellowstone Area, in D.R. Soller, ed., Digital Mapping Techniques ' 00 - Workshop Proceedings: U.S. Geological Survey Open-File Report 00-325, p. 57-63, $<$ http://pubs.usgs.gov/openfile/ofo0-325/wahl.html>. 


\title{
The U.S. Geological Survey National Paleontological Database
}

\author{
By Bruce R. Wardlaw, Nancy R. Stamm, and David R. Soller \\ U.S. Geological Survey \\ 926A National Center \\ Reston, VA 20192 \\ Telephone: (703) 648-5288 \\ Fax: (703) 648-6953 \\ e-mail: bwardlaw@usgs.gov
}

\section{INTRODUCTION}

As an integral part of the Geologic Mapping Act, and under the umbrella of the National Geologic Map Database (NGMDB) project, the USGS is developing a national paleontologic database. It is a research and a mapping-support tool, and is designed to be used in concert with other NGMDB databases (see related papers in these Proceedings)

The USGS has a long and storied history of paleontologic collections cited in classic monographs, professional papers, but also a less known dataset amassed over 110 years of informal reports on fossil collections. These collections were submitted by government, industry, and private individuals and field teams and reported on by paleontologists employed by the Survey. It was a natural conclusion in developing a prototype for a paleontologic database to incorporate the data from both the classic formal reports and the abundant informal reports. The informal reports, dating back to 1889 , have been the subject of various attempts at digitization since 1970. All previous attempts failed. Only one complete paper set of the reports now exists. So, in addition to the congressional mandate to develop a paleontologic database, there was the added incentive to save this large informal dataset before it was lost. These informal reports, called "E\&R's", for

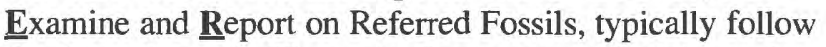
the form shown in Figure 1. To preserve this data, each report is being scanned and the digital copy will become part of the database. Pertinent information needed to fill out the standard locality and specimens tables is then taken from the report. The quality of the locality data in these reports varies from detailed descriptions that can be fully integrated into a digital map database (as in the example in Figure 1) to those that we will be lucky to place in the proper 1:100,000 quadrangle.

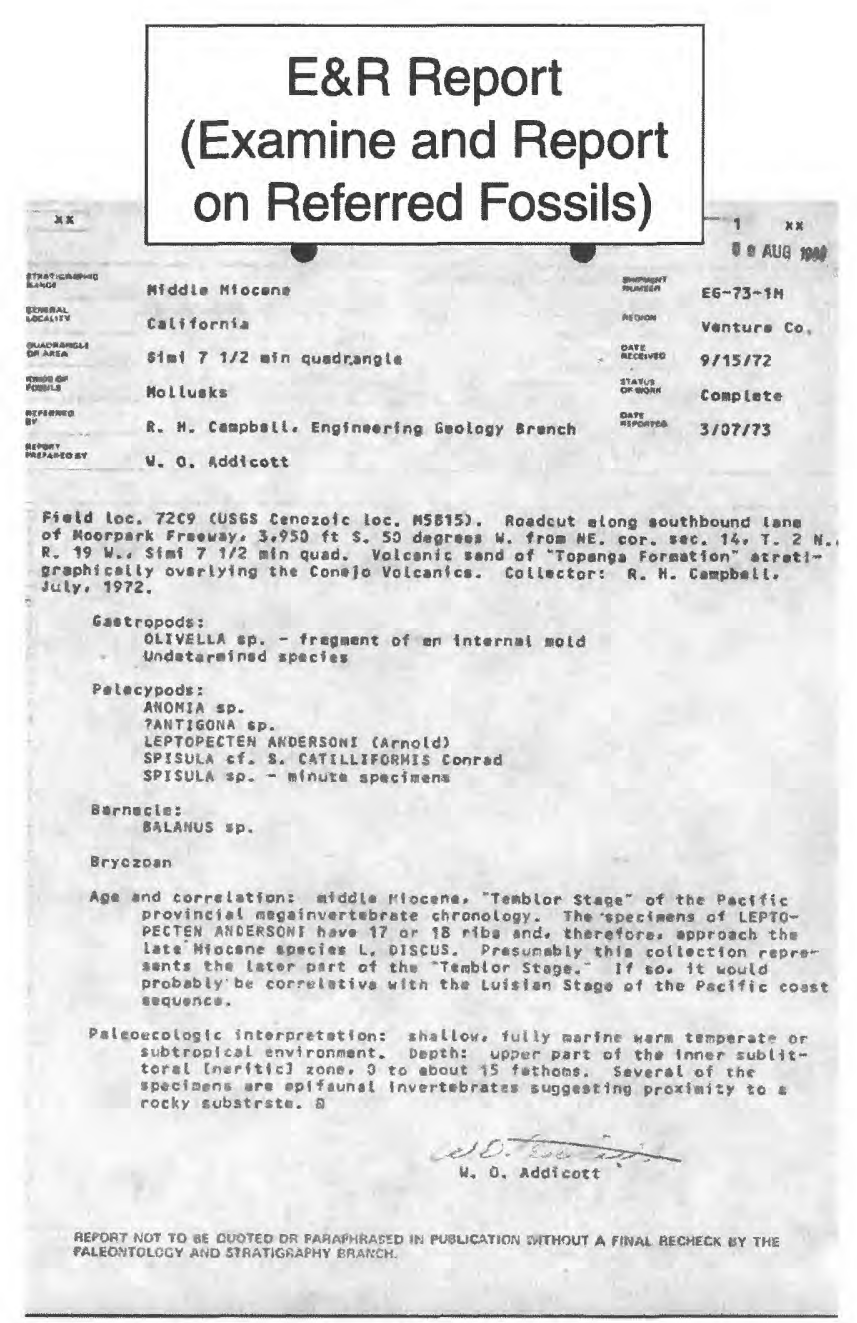

Figure 1. Example of an E\&R Report. 
Additionally, the USGS has traditionally emphasized the practical application of paleontology to solve earth science problems, so the stratigraphic context of each fossil collection is highlighted. To this end, measured sections, range charts, and biostratigraphic interpretations are included in the dataset.

Representatives of figured specimens from each quadrangle are also maintained in the database and tied to the museum repository numbers so that the user can find the specimen indexed.

These various factors drove the formation of the data model and the particular structure of USGS national paleontologic database, Paleodata.

The data model (fig. 2) incorporates the seemingly disparate relational tables discussed above of the E\&R reports, measured sections, biostratigraphic information, and figured specimens along with locality and specimen identification.

We are constrained by the data we have at hand and the nature of our business. We do not believe that the design of our paleontologic database is more correct or superior to any other. On the contrary, we feel it is important to show the status of its development, to encourage discussion that might lead us toward an improved database.

\section{PALEODATA SEARCH PAGE}

Paleodata searches are based on geologic age, fossil group, geographic area or E\&R (fig.3).

The geologic time scale accepted by the USGS and used for Paleodata is that currently accepted by the International Commission on Stratigraphy (Remane, 2000), and is subject to change as the Commission ratifies international boundaries that are currently being proposed.

The fossil groups we use are those developed through compromise with federal land managers. Federal land managers are interested in protecting all vertebrate fossils and tracks and trails and have a much lesser concern for invertebrate or plant fossils. So, these are convenient groups to make first-cut fossil assessments on maps. The fossil subgroups we use are simply generated by those for which we have a lot of data, and not from grand, apriori schemes of fossil classification. It should be noted that Palynomorphs (Plants) are all organic-walled plant microfossils including dinocysts, acritarchs, pollen, and spores. We do not have enormous collections or reports of crinoids, blastoids, cystoids, or echinoids, so these are listed in one category, echinoderms. We use the common names for most groups and include related groups within the search topic (For instance, fossil hydrozoans would be

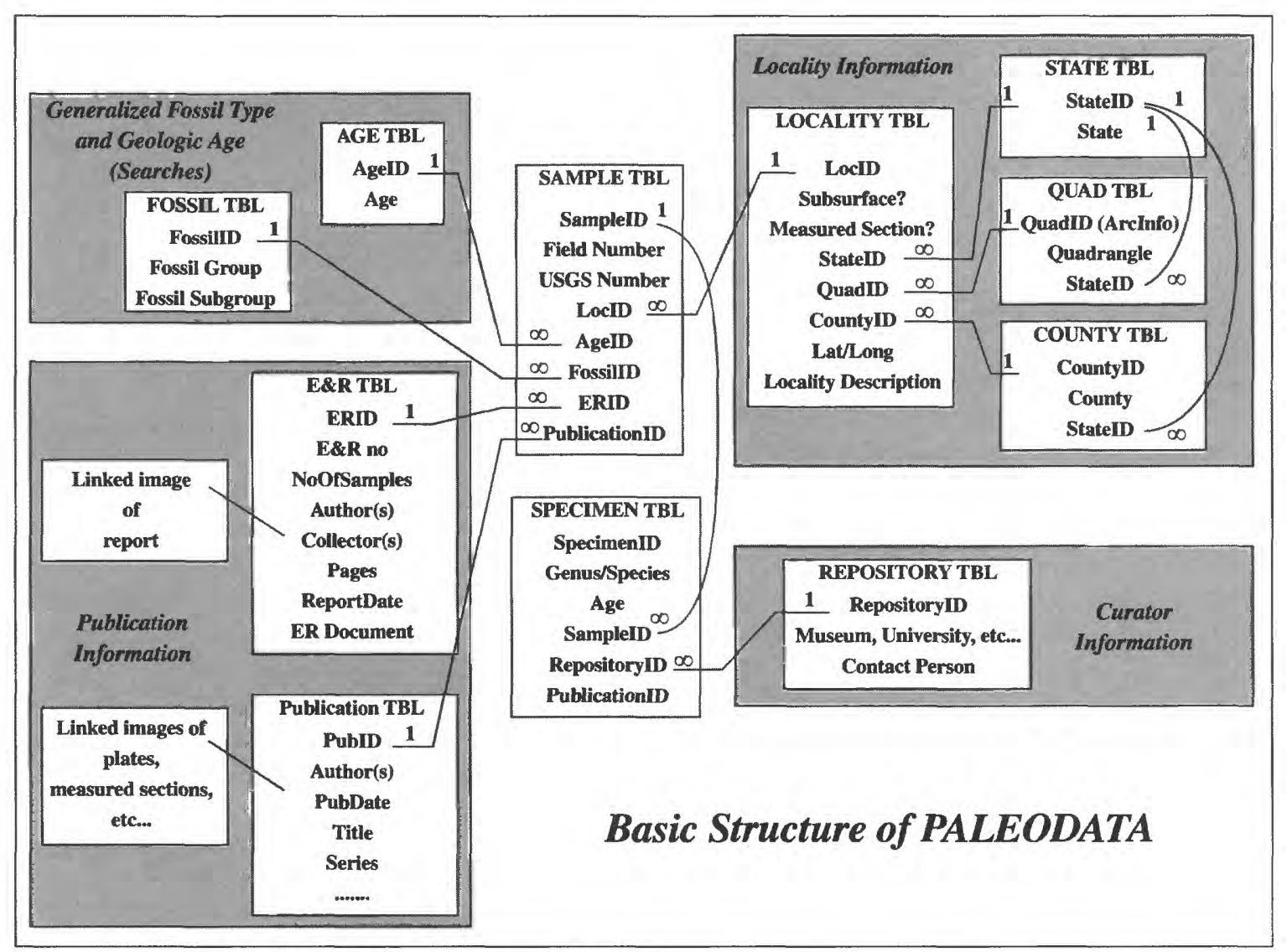

Figure 2. The Data Model: Basic structure of Paleodata. 
found with "Corals"). Conodonts, for which we have a wealth of data, were separated from fish (where they belong), because of the amount of data and because many of our users prefer to search for conodonts and not other fish fossils. We will most likely increase our subcatagories as the database becomes more robust.

The geographic search is by state, counties or $100 \mathrm{k}$ quadrangle.

The E\&R search requires some knowledge of the E\&R or the former Paleontology and Stratigraphy Branch of the USGS, in order to search by report number, author, sample (field) number, or USGS collection number.

\section{A KANSAS MAP SEARCH}

Figures 4-9 show the various information that will be available from a map search. Selecting the Manhattan 1:100k quadrangle (fig. 4) will produce a map with fossil localities marked and a pop-up box showing the locality identification number and (or) sample numbers (fig. 5). In the case of locality 13510 there are two samples from the same location. In the case of BMW-08, it is a measured section with numerous samples, as shown in the locality information tables retrieved by double-clicking on the locality. Clicking on the sample will bring up the fossil specimen list for the locality (figs. 6, 8). Clicking on any of the highlighted specimens will bring up an image of the fossil which are variously catalogued to each map (e.g., fig. 7). In the case of brachiopods, all the brachiopods illustrated from the Manhattan quadrangle from Mudge and Yochelson (1962) are on one plate. Bracketed names following a specimen name are modern generic designations. All specimens in the database maintain their original name from the publication cited. In case of the measured section, BMW-08, the specimen list for a specific

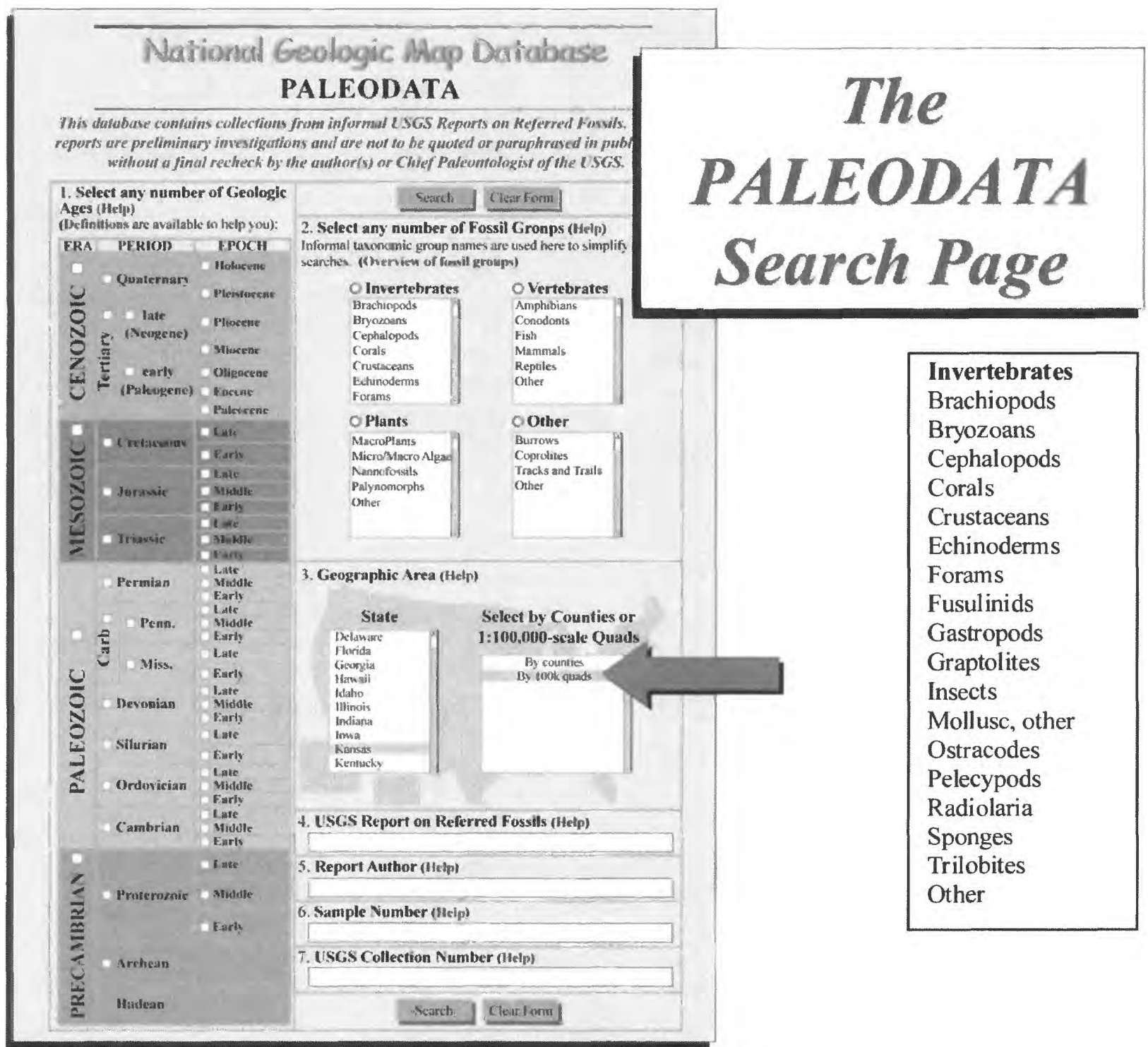

Figure 3. The Paleodata Search Page with Invertebrate category enlarged. 
sample can lead to either the measured section (by clicking on the section id) or the specimens (by clicking on a highlighted specimen, fig. 9). The samples listed on the measured section lead back to the specimen list and to the figured specimens. The conodonts are organized into illustrated specimens from a given sample.

\section{LINKS TO RELATED USGS DATABASES}

\section{Both the NGMDB's Geolex (the online Geologic} Names Lexicon) and the geologic Map Catalog will be accessible from Paleodata. Geolex can be accessed from the National Geologic Map Homepage or the user will be able to go directly to the Geolex search page from any stratigraphic name or columnar section in Paleodata (figs. 10-12). In the example used here, the Red Eagle Limestone, which contains the Pennsylvanian-Permian boundary is selected. The Map Catalog is accessed by clicking back to the National Geologic Map Homepage and then searching for the available geologic maps (here by county in Kansas, figs. 13-15).

\section{A TEXAS MAP}

The Guadalupe Peak 1:100k quadrangle was also examined in development of Paleodata because it contains a wealth of fossil data from a variety of publications and informal reports. Also, it was instrumental in developing sequence stratigraphy and contains a National Park. National Parks pose a delicate problem in education and preservation, because fossil collecting is tightly controlled. As alluded to earlier, most federal land managers want to control vertebrate fossil site information. To accommodate this concern, we separate out large vertebrate fossil sites and only identify them to the $1: 100 \mathrm{k}$ quadrangle and refer the user to the local land manager for further information. Fortunately, in the Guadalupe Peak quadrangle, the only common vertebrate fossils are conodonts and other fish debris (scales and teeth), which are still treated much like invertebrate fossils. Figures 16 and 17 show the quadrangle and representative information tables. Figures 18-20 show a glimpse of some of the graphic fossil data available. Brachiopods (fig. 21) are particularly diverse in the Permian (the time period represented by most of the rocks in the Guadalupe Peak Quadrangle) and show numerous morphologies including coral-like and oyster-like forms. Guadalupe Mountains National Park is the first US park to have established international boundary stratotypes, and we took it as a challenge to serve this information along with other fossil data (fig. 22).

\section{REFERENCES}

Boardman, D.R., II, Nestell, M.K., and Wardlaw, B.R., 1998, Uppermost Carboniferous and lowermost Permian deposition and conodont biostratigraphy of Kansas, USA, in Jin, Yugan, Wardlaw, B.R., and Wang, Yue, eds., Permian Stratigraphy, Environments and Resources, Volume 2: Stratigraphy and Environments: Palaeoworld 9, p. 19-32.

Cooper, G.A., and Grant, R.E., 1972, Permian brachiopods of West Texas, I: Smithsonian Contributions to Paleobiology, no. 14 , p. 1-232.

Cooper, G.A., and Grant, R.E., 1974, Permian brachiopods of West Texas, II: Smithsonian Contributions to Paleobiology, no. 15 , p. 233-794.

Cooper, G.A., and Grant, R.E., 1975, Permian brachiopods of West Texas, III: Smithsonian Contributions to Paleobiology, no. 19, p. 795-1922.

Cooper, G.A., and Grant, R.E., 1976, Permian brachiopods of West Texas, IV: Smithsonian Contributions to Paleobiology, no. 21, p. 1923-2608.

Cooper, G.A., and Grant, R.E., 1976, Permian brachiopods of West Texas, V: Smithsonian Contributions to Paleobiology, no. 24 , p. $2609-3160$.

Cooper, G.A., and Grant, R.E., 1977, Permian brachiopods of West Texas, VI: Smithsonian Contributions to Paleobiology, no. 32, p. 3161-3370.

Miller, A.K., and Furnish, W.M., 1940, Permian ammonoids of the Guadalupe Mountain region and adjacent areas: Geological Society of America Special Papers, no. 26, 242p.

Mudge, M.R., and Yochelson, E.L., 1962, Stratigraphy and paleontology of the uppermost Pennsylvanian and lowermost Pemian rocks in Kansas: U.S. Geological Survey Professional Paper 323, 213 p.

Ormiston, A., and Babcock, L., 1979, Follicucullus, new radiolarian genus from the Guadalupian (Permian) Lamar Limestone of the Delaware basin: Journal of Paleontology, v. 53 , no. 2 , p. $328-334$.

Remane, J., 2000, International Stratigraphic Chart: Geneva, Switzerland, Division of Earth Sciences, UNESCO and International Union of Geological Sciences.

Wilde, G.L., 1986, An important occurrence of early Guadalupian (Roadian) fusulinids from the Cutoff Formation, western Guadalupe Mountains, Texas, in Moore, G.E., and Wilde, G.L., eds., Lower and Middle Guadalupian Facies, Stratigraphy, and Reservoir Geometries, San Andres/Grayburg Formations, Guadalupe Mountains, New Mexico and Texas: Permian Basin Section SEPM Publication no. 86-25, p. 65-68. 


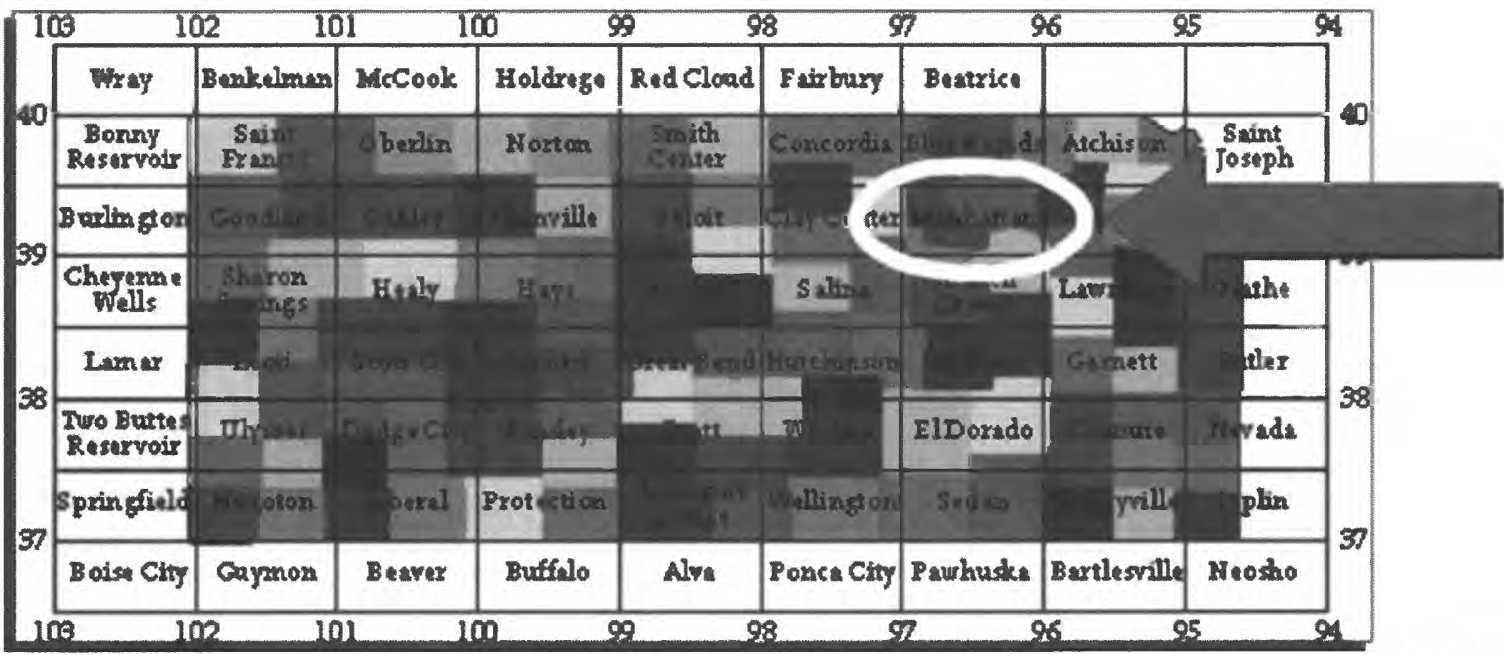

Figure 4. Search of 1:100,000 scale maps of Kansas, in this case highlighting the Manhattan quadrangle.

\section{Manhattan, KS 1:100,000 Quadrangle}

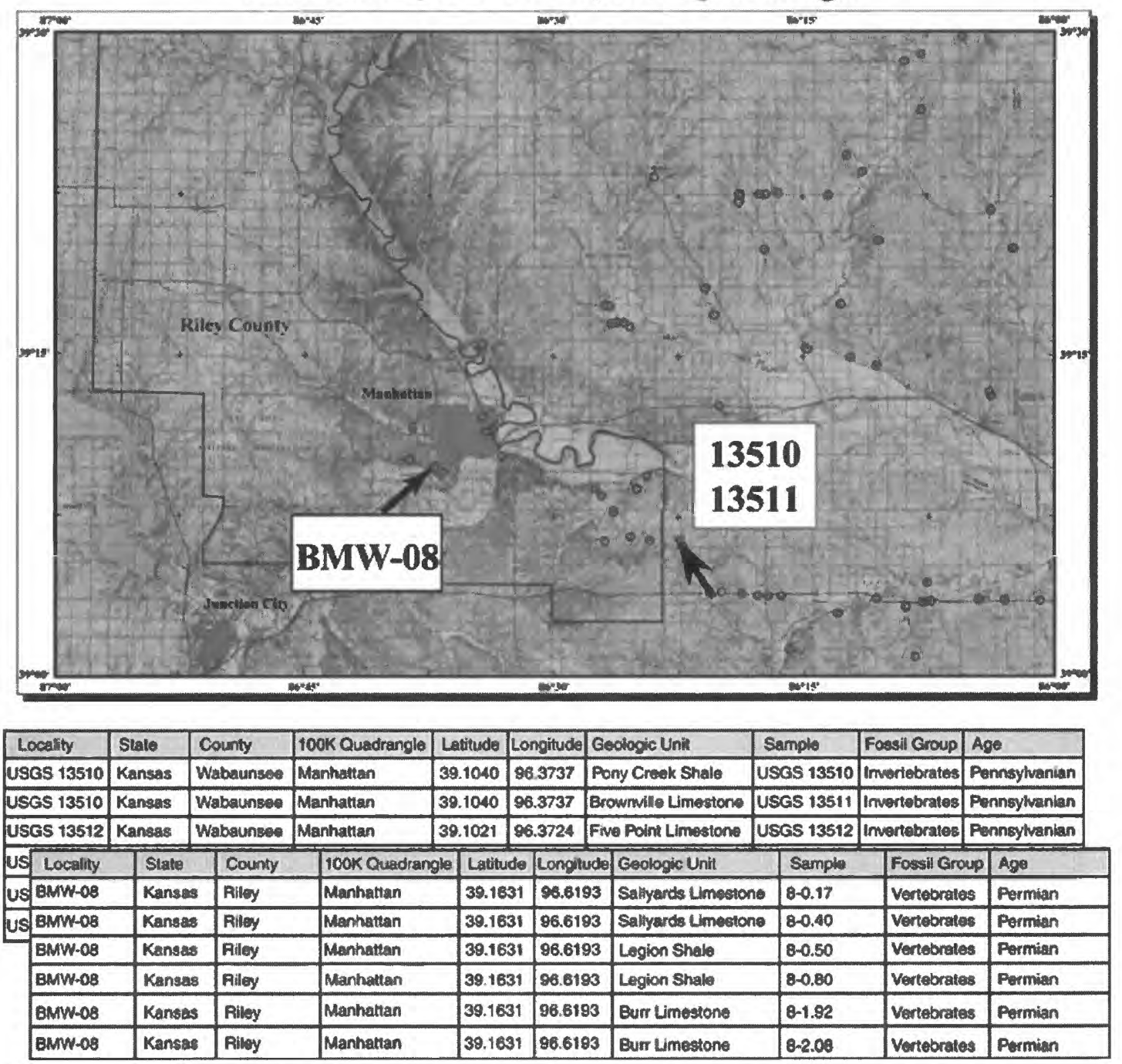

Figure 5. Manhattan, KS 1:100,000 Quadrangle Fossil Localities and examples of Locality Information Tables for two sites. 


\begin{tabular}{|l|}
\hline 13511 \\
Brownille Limestone \\
Mudge and Yochelson (1962) \\
Bryozoa \\
Ramose forms \\
Brachiopoda \\
Crurithyris expansa \\
Composita subtilita \\
Meekella sp. \\
Lissochonetes sp. \\
Dictyoclostus huecoensis \\
Juresania sp. \\
Marginifera wabashensis \\
Linoproductus sp. \\
Enteletes cf. E. hemiplicatus \\
Dielasma bovidens \\
Punctospirifer kentuckensis \\
Gastropoda \\
Amphiscapha muricata \\
Arthropoda \\
Trilobite remains \\
\hline
\end{tabular}

Figure 6. Fossil Specimen List for USGS Locality 13511.

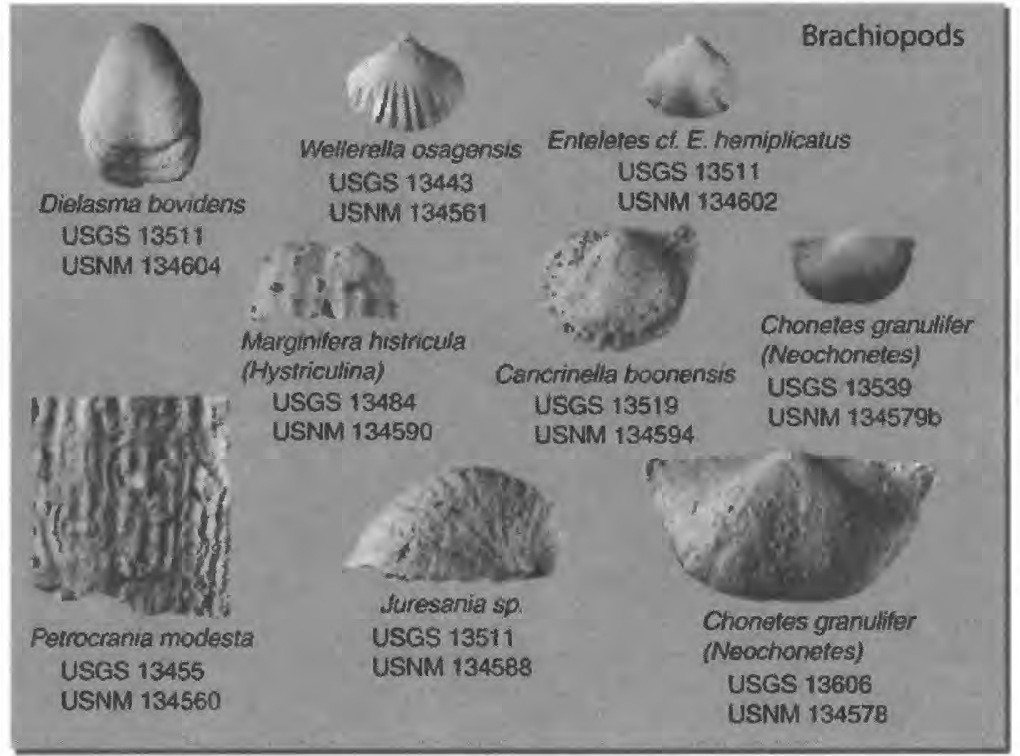

Figure 7. Figured Specimens of Brachiopods from the Manhattan 1:100,000 Quadarangle with USGS Locality Number and USNM (United States National Museum) Repository Number (from Mudge and Yochelson, 1962).

\begin{tabular}{|l|}
\hline BMW-08 \\
$7.58 \mathrm{~m}$ (unit 27) \\
Neva Limestone \\
Conodonta \\
Streptognathodus fuchengensls \\
Streptognathodus lineatus \\
Streptognathodus nevaensis \\
Streptognathodus postelongatus \\
Streptognathodus translinearis \\
\hline
\end{tabular}

Figure 8. Fossil Specimen List for Sample 8-7.58, bed 27, $7.58 \mathrm{~m}$ above base of measured section BMW- 08 of Boardman and others (1998). Conodonts are a fossil subgroup of Vertebrates.

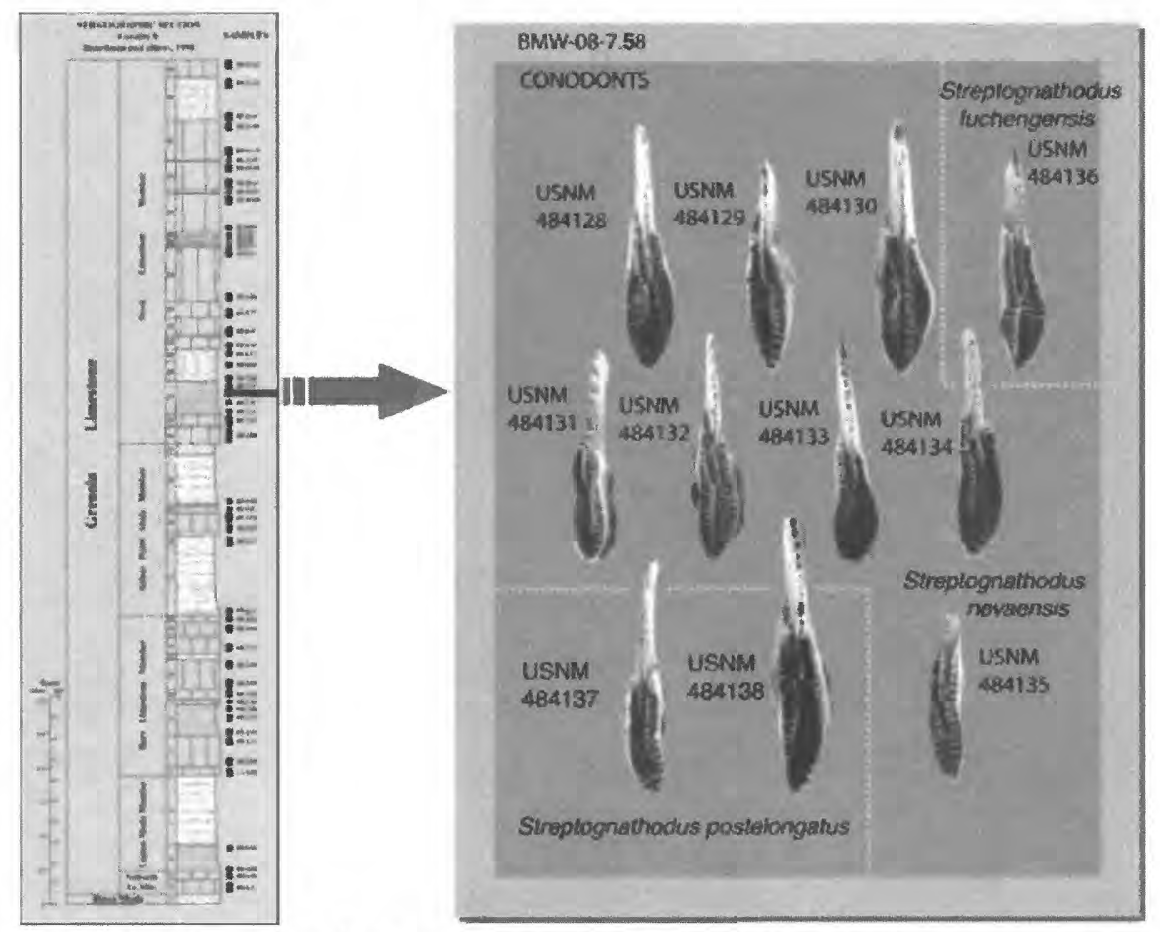

Figure 9. Columnar Section of measured section BMW-08 showing samples and figured specimens of conodonts from sample BMW-08-7.58 with USNM Repository Numbers. 


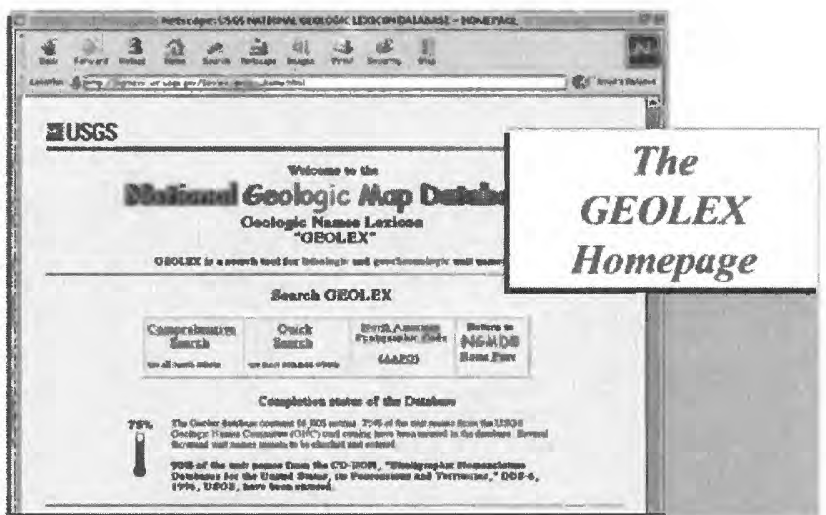

Figure 10. The Geolex Homepage.

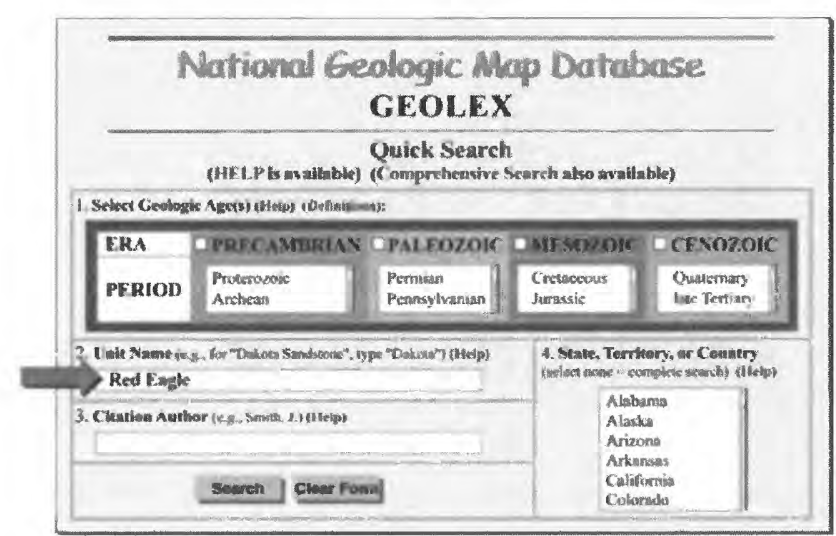

Figure 11. Geolex Quick Search page. A Comprehensive Search page also is available. The Geologic unit selected to search for is "Red Eagle'.

\section{National Geologic Map Database GEOLEX database \\ New Refine \\ Search Search \\ Geologic Unit Name: Red Eagle}

\section{Usage of Geologic Unit Name:}

Red Eagle Limestone of Council Grove Group (KS",NE*,OK*)

Red Eagle Limestone of Vanoss Group (OK)

Red Fagle Formation (NE)

Red Eagle Limestone Member of Konawa Formation (OK)

\begin{tabular}{|l|l|l|}
\hline \multicolumn{1}{|c|}{ Age: } & \multicolumn{1}{|c|}{ Geologic Province: } & Areal Extent: \\
\hline $\begin{array}{l}\text { Permian, Early* } \\
\text { Pennsylvanian, Late* }\end{array}$ & Chautauqua platform* & $\begin{array}{l}\text { KS* } \\
\text { NE* } \\
\text { OK** }\end{array}$ \\
\hline
\end{tabular}

\section{Type Iocality:}

Named for exposures near Red Eagle School, southwest of Foraker, Osage County, OK (Heald, 1916).

Subunits:

(Descending): Howe Limestone Member (KS*,NE*), Bennet Shale Member (KS*NE*), Gtenrock

Limestonc Member (KS*,NE*).

\section{History:}

Named (Heald, 1916). Not used by OK State Survey (Miver. 1926). Geographically extended into northwest MO and southeast NE (Condra, 1935). Age modified (Moorc, 1936). Overview in KS (Moore and others, 1944). Overview in OK (Greig. 1959: West, 1960). Mapped 1:500k in KS (Jewett and others, 1964).

Note: For more information, comtact Nancy Stamm (nstamm@ usggegav).

Asterisks (*) indicate usage by the U.S. Geological Survey.

"No currenl usage" implies that a name has been abandoned or that it has fallen into disuse. Former usage, and, if known, replacement name given in parentheses ().

Slashes ( / ) indicate unit name usage violates the 1983 North American Stratigraphic Code. This violation may be explained within brackets [ ].

$\begin{array}{cc}\text { New } & \text { Refine } \\ \text { Search } & \text { Search }\end{array}$

Figure 12. Geolex Search Results for Geologic Unit Name: Red Eagle. 


\section{Map Catalog}

Search Page

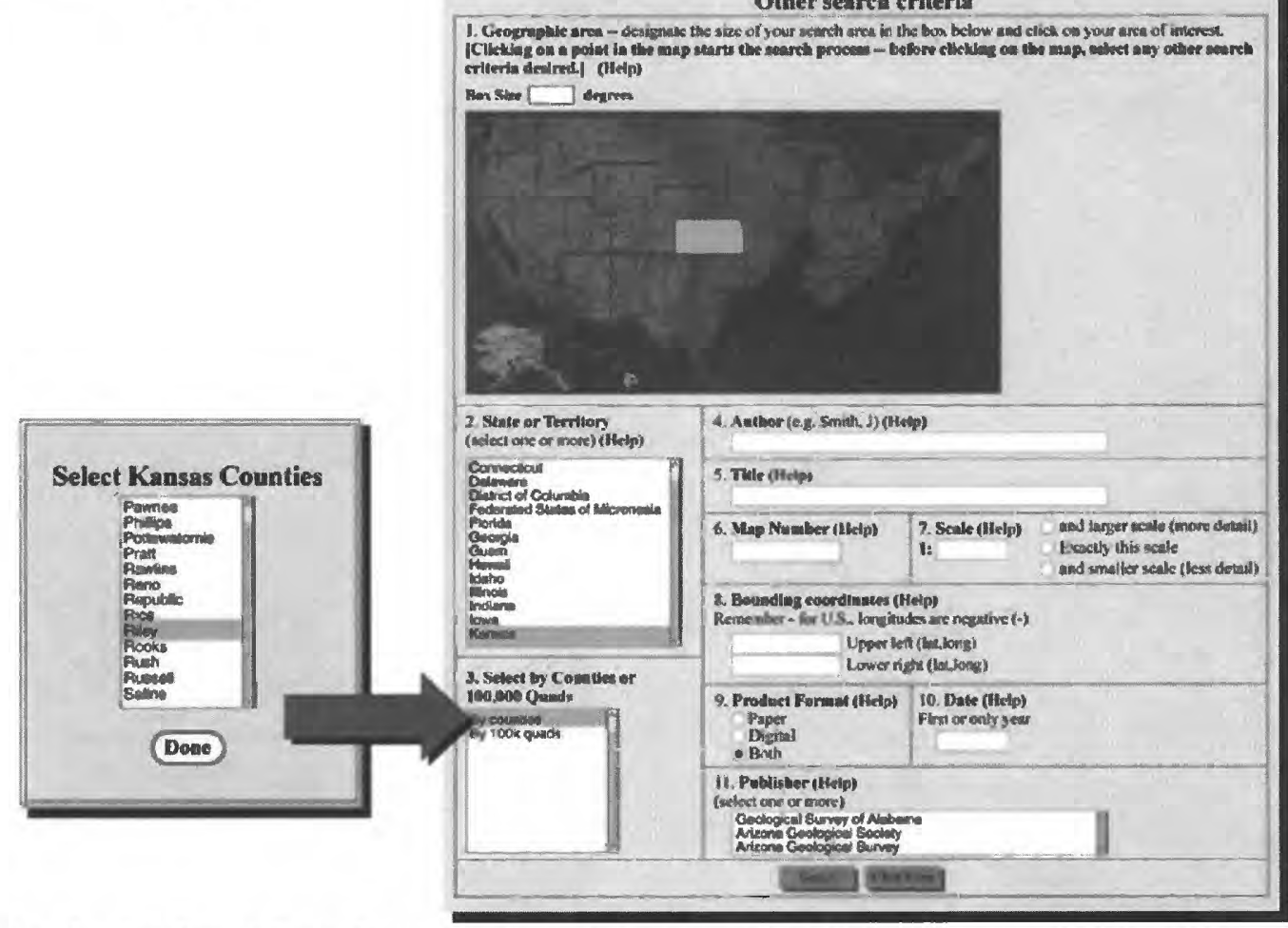

Figure 13. The Map Catalog Search Page. The state "Kansas" is selected (highlighted on map of US) and the county "Riley" is selected from drop down menu of Kansas Counties.

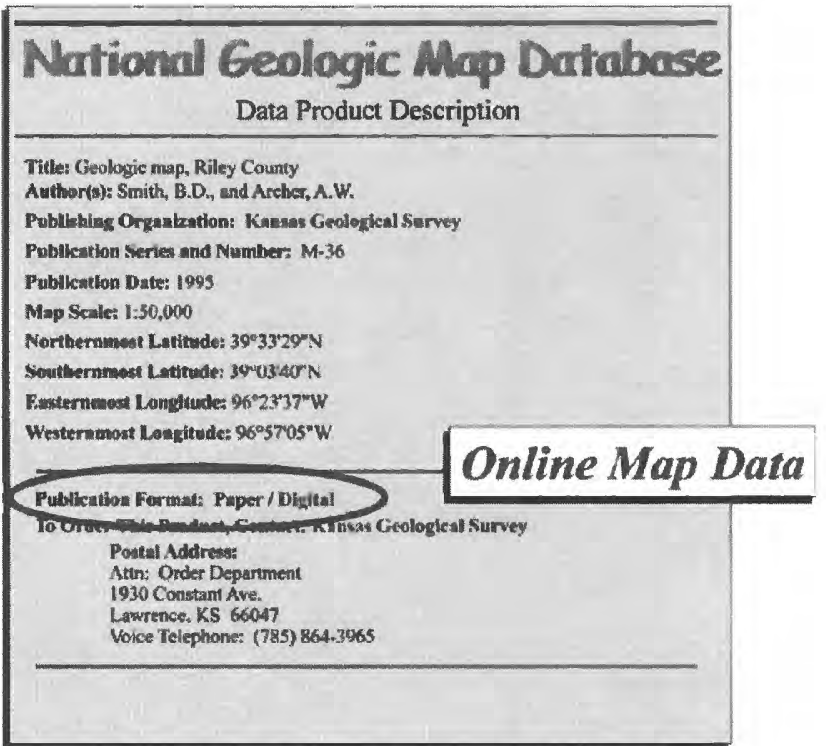

Figure 14. Available geologic map data including online digital geologic map of Riley County.

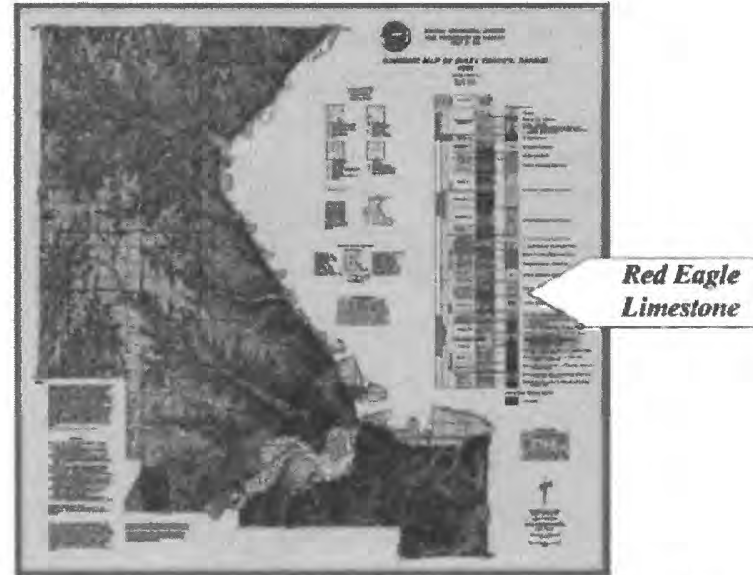

Figure 15. Geologic Map of Riley County available from the Kansas Geological Survey that includes columnar section with Red Eagle Limestone. Lithic representation and its map distribution may be determined from the map. 


\section{Guadalupe Peak, TX-NM 1:100,000 Quadrangle}

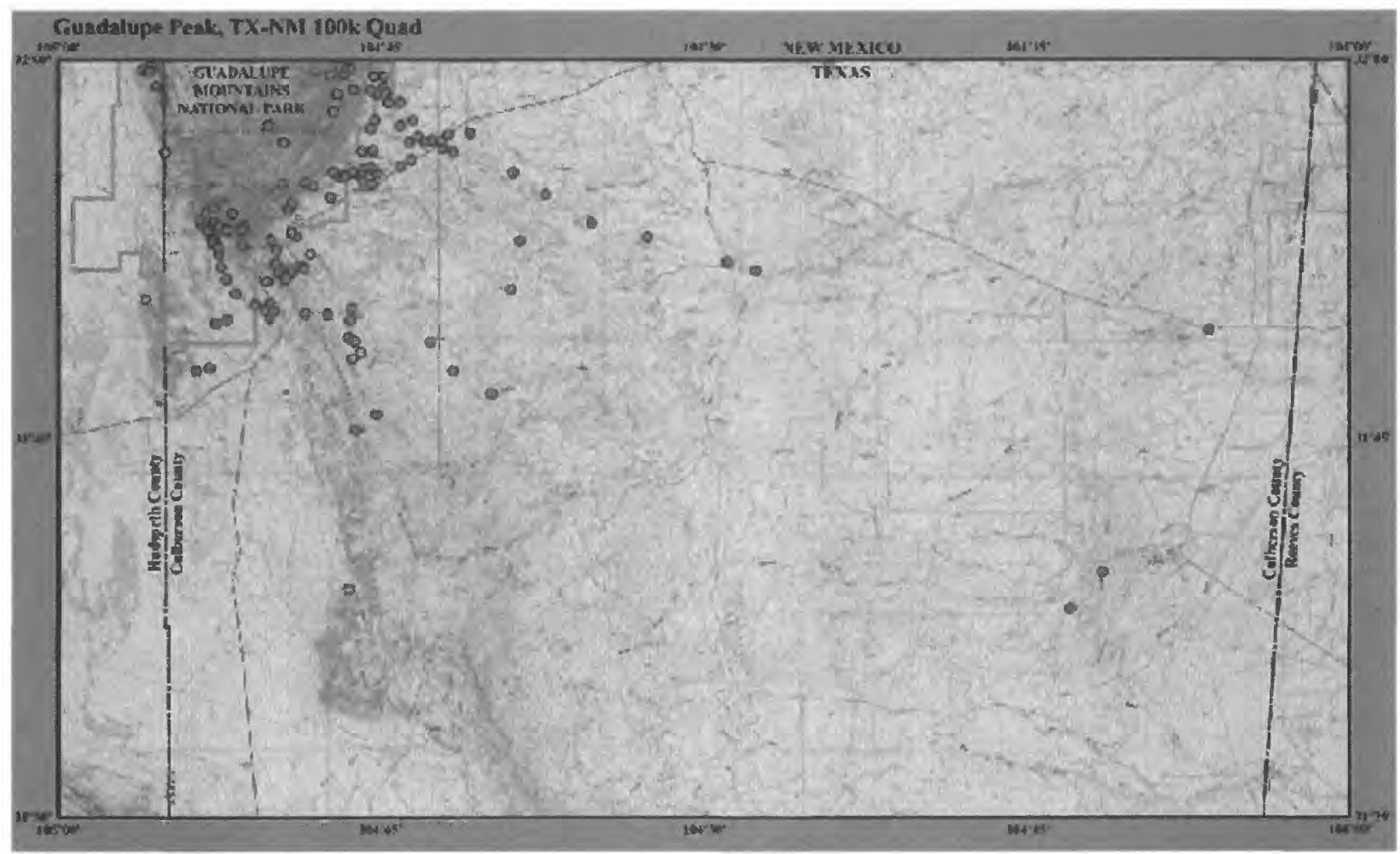

Figure 16. Guadalupe Peak 1:100.000 Quadrangle Fossil Localities.

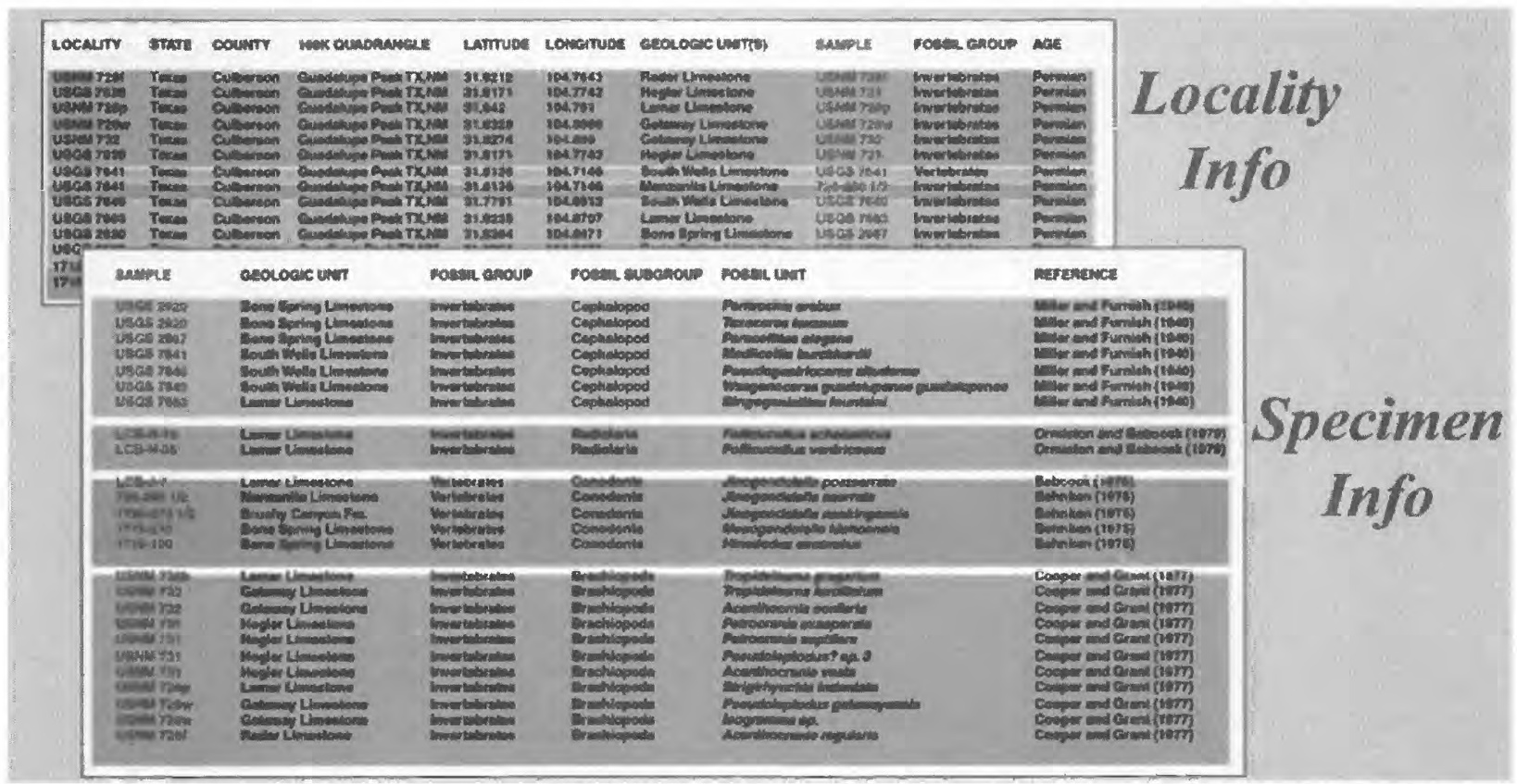

Figure 17. Examples of Fossil Locality Information Tables and Specimen Information Tables for the Guadalupe Peak Quadrangle. 


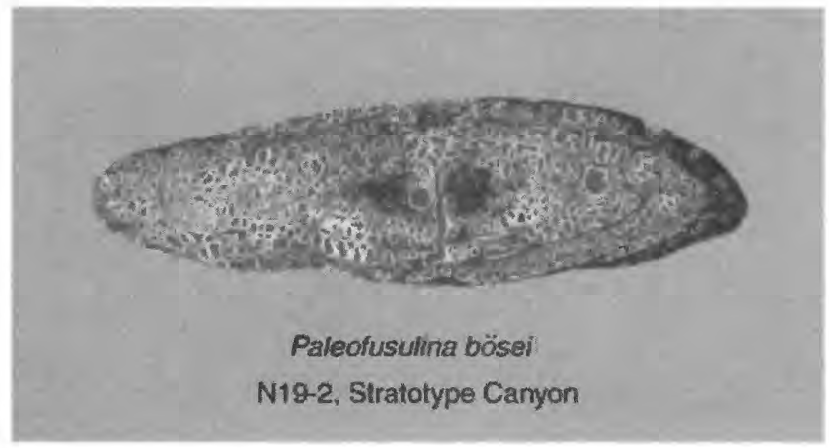

Figure 18. Microphotograph of Fusulinid species in the database (from Wilde, 1986).

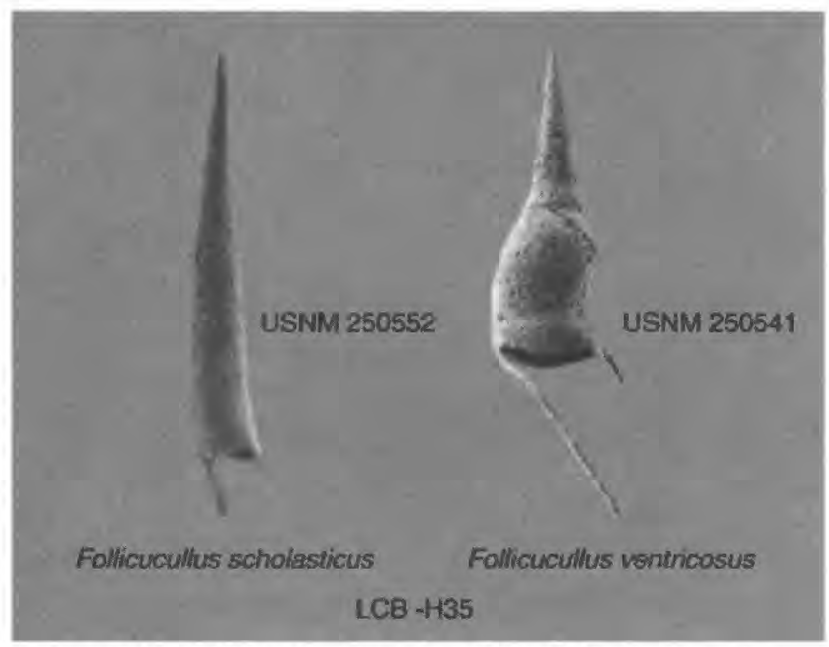

Figure 19. Microphotographs of Radiolarian species holotypes from Guadalupe Peak Quadrangle (from Ormiston and Babcock, 1979).

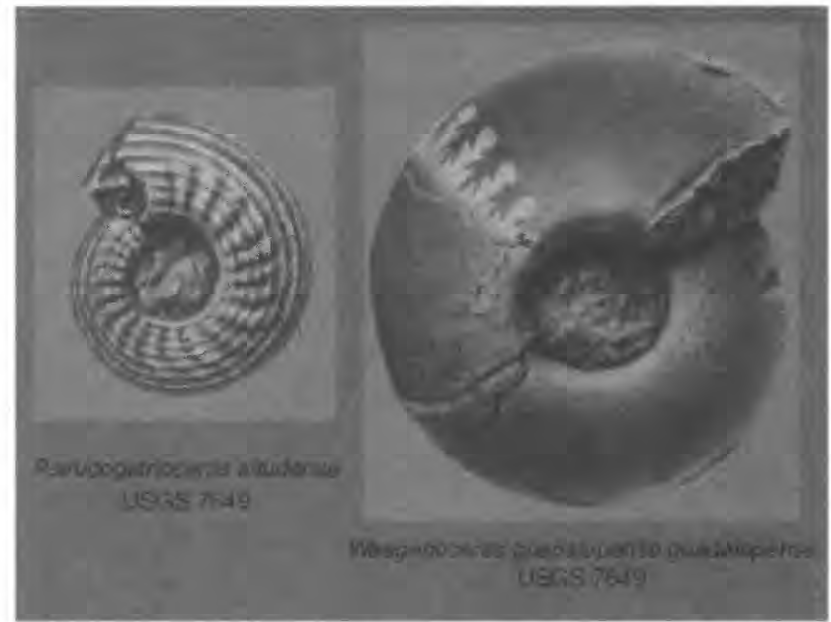

Figure 20. Specimens of ammonoids originally collected by Girty in the early 1900's and described by Miller and Furnish (1940). 


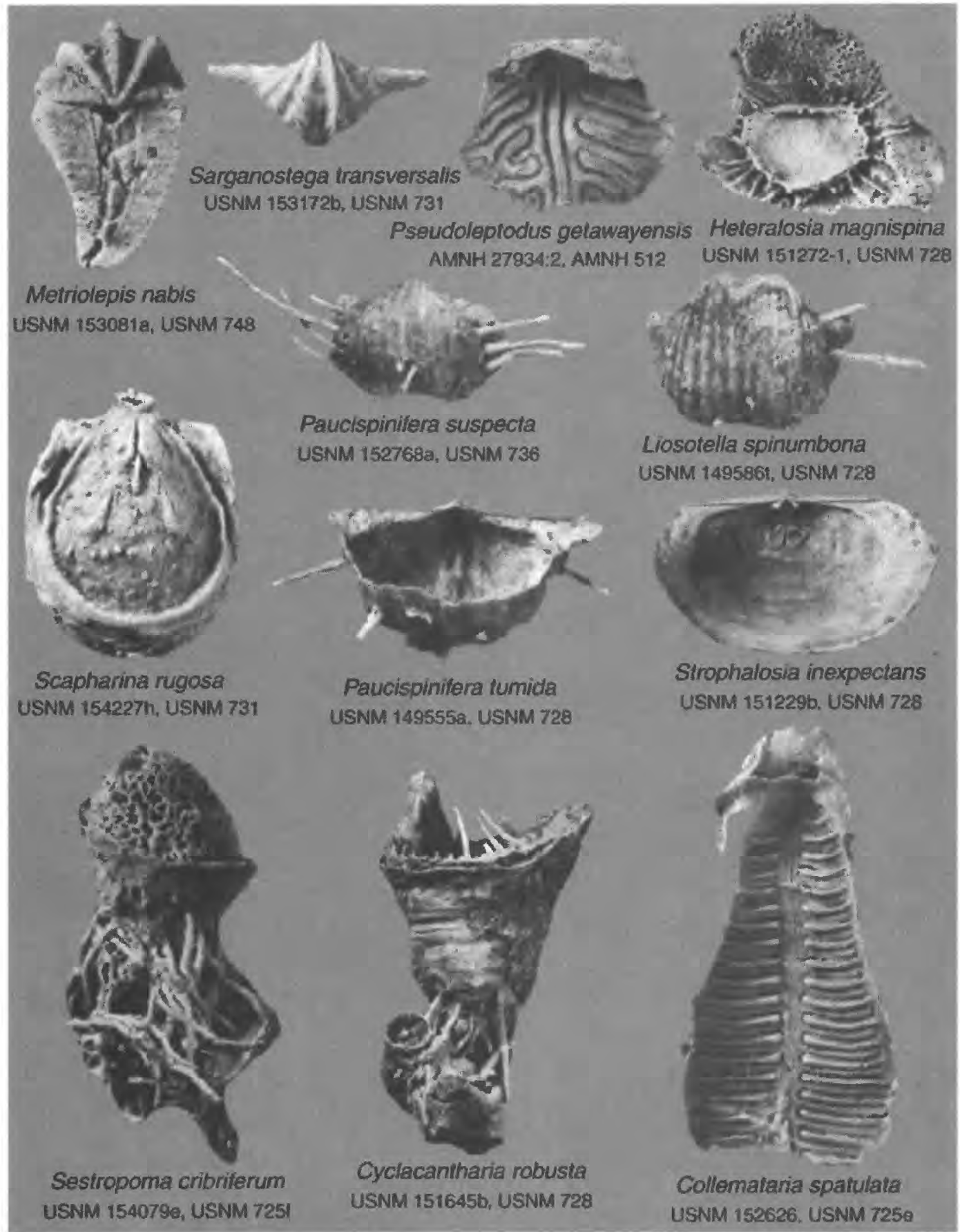

Figure 21. Photographs of holotypes and topotypes of Brachiopod species from the the wealth of material described by Cooper and Grant (1972-1977). Several hundred specimens from the Guadalupe Peak Quad. are illustrated in those publications. Only one representative specimen (usually the holotype) of each species named from material from the Guadalupe Peak Quadrangle will be digitally served in Paleodata. 


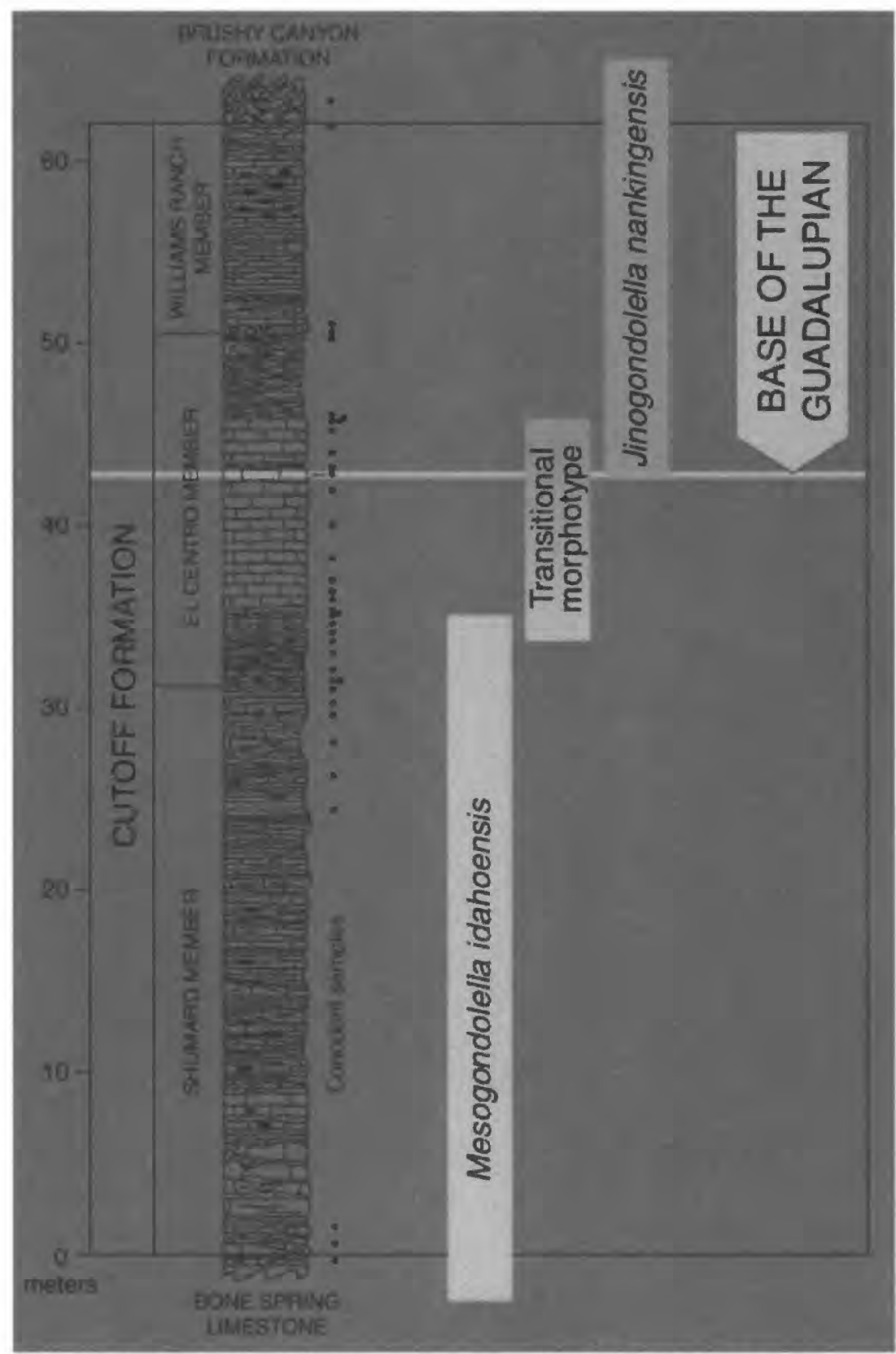

Figure 22. Guadalupe Mountains National Park (within the Guadalupe Peak 1:100k Quadrangle) contains the GSSP (Global Stratotype and Stratigraphic Point) for the internationally recognized Middle Permian (Guadalupian and its constituent stages, Roadian, Wordian, and Capitanian). This information along with the defining ranges of conodonts are also included in Paleodata. Here, the base of the Guadalupian is defined in a section in Stratotype Canyon by the first appearance of specimens which retain the characters of Jinogondolella nankingensis in adult forms. 


\title{
Progress Report on the National Geologic Map Database, Phase 3 - an Online Database of Map Information
}

\author{
By David R. Soller ${ }^{1}$, Ron Wahl2 ${ }^{2}$, Jerry Weisenfluh 3 , Boyan Brodaric ${ }^{4}$, \\ Jordan Hastings ${ }^{5}$, Robert Laudati ${ }^{6}$, and Roger Fredericks ${ }^{7}$
}

\author{
${ }^{1}$ U.S. Geological Survey \\ 908 National Center \\ Reston, VA 20192 \\ Telephone: (703) 648-6907 \\ Fax: (703) 648-6937 \\ e-mail: drsoller@usgs.gov \\ ${ }^{2}$ U.S. Geological Survey \\ e-mail: rwahl@usgs.gov \\ ${ }^{3}$ Kentucky Geological Survey \\ e-mail: jerryw@kgs.mm.uky.edu
}

\author{
${ }^{4}$ Pennsylvania State University and Geological Survey of Canada \\ e-mail: brodaric@nrcan.gc.ca \\ ${ }^{5}$ University of California, Santa Barbara \\ e-mail: jordan@geog.ucsb.edu \\ ${ }^{6}$ GE-Smallworld Systems, Inc. \\ e-mail: robert.laudati@smallworld-us.com \\ ${ }^{7}$ Techni Graphic Systems, Inc. \\ e-mail: rogerf@tgstech.com
}

The provisions of the Geologic Mapping Act of 1992 and its reauthorizations in 1997 and 1999 (PL106-148) require the U.S. Geological Survey (USGS) to design and build a National Geologic Map Database (NGMDB), with the assistance of the state geological surveys and other entities participating in the National Cooperative Geologic Mapping Program. After discussion among the principal architects of the NGMDB, a general plan for its initial design and evolution was proposed (Soller and Berg, 1995); minor updates to the plan, enhancements, and progress reports have been presented annually since 1997 (for example, Soller and Berg, 2000, and this volume).
The NGMDB design identifies three complementary phases to the project. Because many geologic maps are not yet in digital form and because many organizations produce and distribute them, it was decided to first identify and catalog all geoscience maps in the United States, in either paper or digital format. This first phase, a searchable map catalog, is the most fundamental aspect of the NGMDB; it enables users to identify whether a map has been produced for their area and/or theme of interest. The map catalog presently is supported by two additional databases developed under the NGMDB project: 1) GEOLEX, a searchable geologic names lexicon; and 2) Geologic 
Mapping in Progress, which provides information on current mapping projects. When each mapping project concludes, their map products will be entered in the map cata$\log$.

The second phase of the project focuses on public access to digital geoscience maps, which in turn requires the development of certain digital map standards and guidelines to improve the utility of those digital maps. This is an extremely important activity that requires a high level of interaction with all stakeholders to ensure that any proposed standards and guidelines are useful, necessary, and will be widely adopted.

Although these activities produce valuable information for the public and the geoscience community, the ultimate goal of the NGMDB project is to create an online database containing geologic map information that can be queried, customized for display, and downloaded. Further, the map information in the database would be a coherent whole composed of the best information compiled from various map sources. The database would be updated as new maps are published and so could be termed a "living", or dynamic database. The design and implementation of this database constitutes the project's third phase. Work on the third phase has begun, and is the subject of this paper.

\section{GENERAL CONCEPTS AND REQUIREMENTS}

The general concepts and requirements of the third phase are provided in Soller and others (2000). Numerous discussions with geoscientists and the general public have determined that this database should be:

- built from edge-matched geologic maps at various scales (mostly standard scales such as 1:100,000 and 1:24,000, but not excluding other scales),

- managed and accessed as a coherent body of map information, not just as a set of discrete map products,

- updated by mappers and/or a committee, "on the fly" when new information becomes available, with the "old" original data available as a version,

- standardized, adhering to a standard data model and with standard scientific terminology and symbols, and

- available to the public via Internet browsers and common GIS tools (e.g., ArcExplorer).

\section{FIRST STEPS IN BUILDING THE DATABASE}

Designs and implementations for this database are being evaluated through a series of prototypes. Each prototype is designed to prove key technical concepts, forge relations and agreements among the contributors to this database (i.e., principally, the nation's geological surveys), and amass a growing collection of geologic map information. In 1999, basic requirements for a prototype geologic map database were designed, and concepts were tested using some newly-developed digital data for the Greater Yellowstone Area of Wyoming and Montana (Wahl and others, 2000). That first prototype was presented for discussion at the Geological Society of America Annual Meeting, in October, 1999. The prototype was wellreceived, and plans were begun for a second prototype, with a more complex set of tasks.

In late 1999, a series of planning meetings occurred between the USGS, the Kentucky Geological Survey (KGS), and representatives of various state constituency groups, universities, and vendors. Following the meetings, the second prototype was designed. This effort involved a broad spectrum of expertise and cooperators, as indicated by the list of authors. The various parties agreed to this work because Kentucky has:

- a large amount of detailed (1:24,000-scale) map data available, which had been standardized and edgematched into 1:100,000-scale quadrangles,

- a strong interest in designing a prototype and implementing a standard data model, and

- proven statewide economic benefits from the geologic mapping.

In 2000, funds were secured, contracts were written, and the work began in mid-year. The results of this "Kentucky prototype" are discussed in detail below.

\section{Objectives of the "Kentucky" Prototype}

The specific objective of the Kentucky prototype was to test applicability of the Greater Yellowstone Area research results in a production geologic mapping environment at the state level. Also, we intended to develop a firm foundation upon which subsequent prototypes are based, so that a publicly-accessible, online "living" NGMDB would evolve. After some preliminary work, the objective was refined into four tasks:

1) Implement the North American draft standard conceptual geologic map data model, in an object-oriented software architecture (in this discussion, the term includes object-relational architecture). The current version of the data model endorsed by the North American Data Model Steering Committee (http://geology.usgs.gov/dm/), v.4.3, is relational. An object-oriented architecture was selected in order to explore its potentially greater facility for representing and managing complex spatial information. Because the map database may contain multiple source maps and multiple versions of maps generated as each map is compiled into the database, the selected O-O system must be capable of managing multiple versions of each object on a map (e.g., the outcrop belt of the " $X$ " Formation as 
shown on various maps of a region), and a large number of editorial changes to each object as submitted by various authors, compilers, and editors.

2) Manage information derived from multiple source maps. The KGS is conducting a program to convert to digital form the entire statewide coverage of published, 1:24,000-scale geologic maps (Anderson and others, 1999). For this prototype, a few quadrangles were used, to demonstrate the system's capability.

3) Develop and demonstrate in the database certain core capabilities for data management and user access. For example:

a) Demonstrate links between the prototype map database and related geoscience databases (i.e., the KGS oil and gas database, the USGS geologic names lexicon). Conceptually, the user could select a map unit and, upon request, view the summary of information about the unit's geologic name, which is stored in a separate database.

b) Develop the capability for users to extract selected areas of the prototype map database for downloading to a personal computer, in a selectable file format (e.g., georeferenced image or ArcView shapfiles).

4) Evaluate the interagency, collaborative nature of this effort, especially mechanisms by which agencies can retain ownership of their data when held in a jointly-built database.

The first task, implementing an object-oriented data model and demonstrating its compliance with the North American Data Model, was emphatically the principal and overriding concern of this prototype.

\section{Results}

A preliminary presentation of the Kentucky prototype was made during the annual NGMDB evening presentation at the Geological Society of America's Annual Meeting in November, 2000. In the months following, the prototype system was designed and made available for demonstration and public comment at the Digital Mapping Techniques 2001 meeting. Below, progress toward the prototype's objectives is described.

\section{1) Implementing the North American draft standard conceptual geologic map data model in an object-ori- ented architecture}

The first objective, implementation of an object-oriented data model and demonstrated compliance with the North American Data Model, was completed. A summary of this data model is provided in Hastings and Brodaric (2001), and briefly excerpted:

"The NADM v4.2 and v4.3 models were explicitly designed in an ERD-like notation, and have been implemented on traditional, relational DBMS platforms. The Canadian v5.x extensions had an objectoriented "flavour", although these, too, were realized in relational software. By contrast, our recent work for the NGMDB project is firmly object-oriented, and also seeks such an implementation. In this new conception, a geologic map database comprises four (near) top-level classes of objects:

- Symbols: The cartographic notations used to depict objects (explicit in the map legend and on the map figure)

- Concepts: The geologic formalisms selected for representation, e.g. formation and lithologic types (implicit in overall map construction)

- Occurrences: The geologic realities recognized in the field, and/or laboratory (summarized in the map legend, and/or exemplified on the map figure)

- Descriptors: the digital values chosen to characterize map Symbols, Concepts, and Occurrences (commonly apparent/derived from the map narrative).

These four meta-objects are related in the model's core "diamond diagram" (Figure 1). In summary, map Symbols cartographically depict both Concepts and Occurrences in manifold ways. Occurrences may be symbolized on the map figure, or, if (too) numerous, small, dense or sparse, etc., may be classified and symbolized as a group Concept through the legend. Descriptions, which may be either incidental or normative, can be applied to Concepts and Occurrences equally, and also to Symbols as needed. This entire meta-structure is infinitely mutable, but operates essentially in two major directions: elaboration of Concepts, which leads into geologic ontology (what we know); and elaboration of Occurrences, which leads into geologic epistemology (how we know)."

This data model was implemented in a mature objectoriented GIS/database, GE-Smallworld. [See details at <http://www.gesmallworld.com/english/products/spatial/ core.asp $>$ ]. This software, widely used for intricate $\mathrm{map} /$ database management in the electric utility industry, was tested for its applicability to geologic objects (i.e., features such as faults, contacts, and map units, and also regional names and sampling points). Preliminary results are encouraging, and the software will be further explored in the next prototype.

\section{2) Managing information derived from multiple source maps}

The second objective also was completed, by loading four adjacent 1:24,000-scale geologic quadrangle maps and managing them as both discrete entities and as a coherent whole. In the future, a substantial number of such maps in Kentucky will be loaded into the system, to 


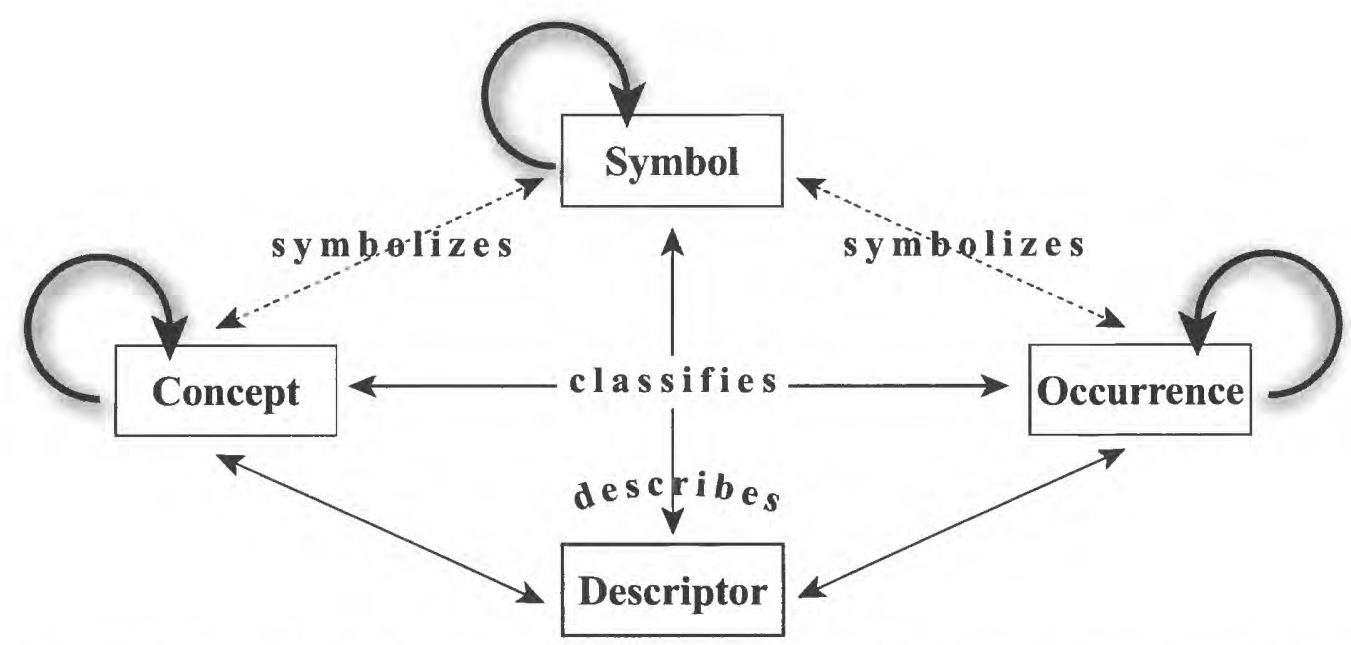

Figure 1. Core of the geologic map information meta-model. The rectilinear arrows indicate relationships between meta-objects, and the reflexive arrows indicate self-referential hierarchies within the meta-object classes.

evaluate the ability to manage, query, and display a large collection of map data.

\section{3) Developing and demonstrating in the database cer- tain core capabilities for data management and user access}

The third objective was addressed via a demonstration of typical queries and functions that are made feasible with this data model and software (including the examples noted in Objectives, above). The demonstration was patterned on a typical user session, as follows:

A. Display an orienting map showing available data

B. Select a map area, zoom and pan

C. Display and query external databases

D. Perform spatial analyses

E. Create derivative maps from analyses

F. Export selected map data

G. View exported map data in third-party GIS viewer.

The demonstration was conducted live, over the Internet, with a laptop "user" computer in Tuscaloosa, Alabama accessing the GE-Smallworld map server at the USGS offices in Denver, Colorado via a T-1 (1.544 Mbps) line. Several members of the audience remarked that performance was excellent.

A. Display an orienting map showing available data: Figure 2 shows an overview map of Kentucky with the available map data highlighted. This demonstrates a fundamental point - maps can be nested (i.e., a map of maps) and inter-related. Also, the system needs to store map footprints, as well as base maps, in the data model; these map objects can be related to metadata about the source documents to facilitate map-based queries.

B. Select a map area, zoom and pan: Figure 3 is a detailed view of the map area selected in step 1 . To facilitate readability during zoom operations, the level of geologic detail must be appropriate to the map view (i.e., at larger scales, more detail is revealed). This requires several levels of map detail that can be accessed as the user increases the magnification. Also, map symbology must be scale-sensitive, thereby allowing the cartographic display to change according to the zoom level. In this demonstration, geologic features were assigned scaledependent symbolization at the system level.

Alternatively, software methods could be designed to achieve this functionality.

C. Display and query external databases: To maximize the utility of a geologic map database, it must be useable in concert with the variety of other spatial and nonspatial databases (e.g., census/demographic and economic

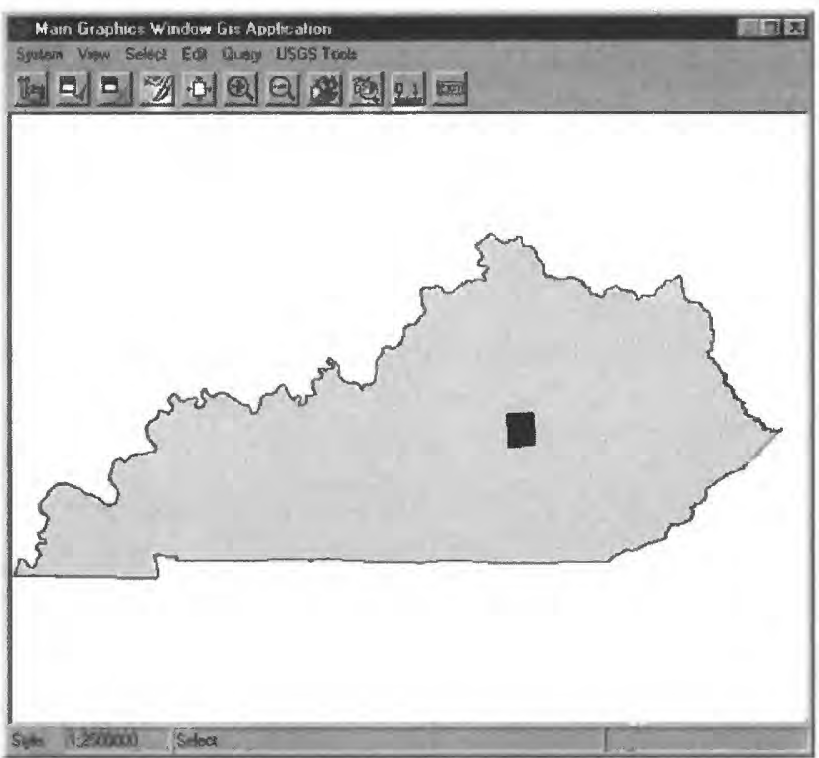

Figure 2. Overview map showing prototype map area. [Task - demonstrate capability to display area of interest.] 


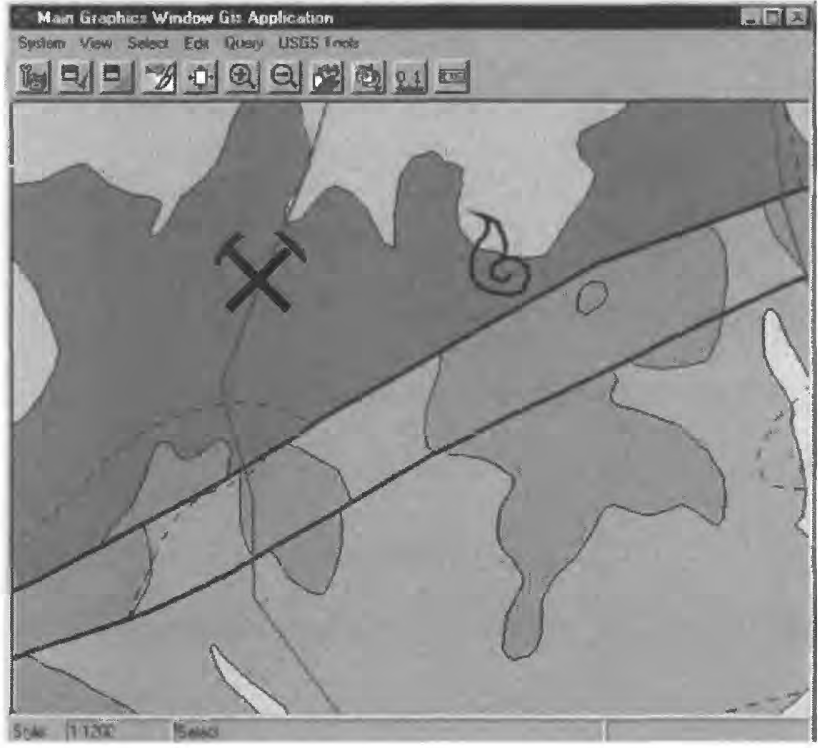

Figure 3. Detailed map area showing more features, including map units, geologic contacts, faults, structure contours, point features, and streams. [Task - demonstrate capability to zoom and pan.]

data; topographic and hydrologic data; and geoscience data including engineering, mineral occurrence, and seismic). Already, and increasingly in the future, access to these databases is via the World Wide Web. Accordingly: a) the geologic map display and database should be Webenabled; b) there must be stable links to external databases; and c) the system must display, read, and manipulate spatial data in foreign formats. In the demonstration, two external databases were remotely accessed, and queried, in concert with the geologic map data (Figures $4 a$ and $4 b$ ). The dynamic link to these databases was demonstrated by the instantaneous update of the display following modification of the external oil and gas database shown in figure 4a.

D. Perform spatial analyses: New thematic information and interpretations can be derived from geology and other databases, on-the-fly. This is perhaps the most critical function of an online, user-accessible map database; it must be an efficient and user-friendly process, otherwise the map database serves as little more than a digital storehouse for previously-published maps. Figure 5 displays the map database (with rock units reclassified by lithologic composition) and external databases (oil and gas wells, and stream traces). The spatial analysis accessed information from all databases and returned a result that identified karst-prone geologic units that were proximal to oil and gas wells.

E. Create derivative maps from analyses: In order to generate a derivative map from database queries and analyses, either the user must compose a suitable map legend and symbology, or else the system must be capable of dynamically generating this information. The latter

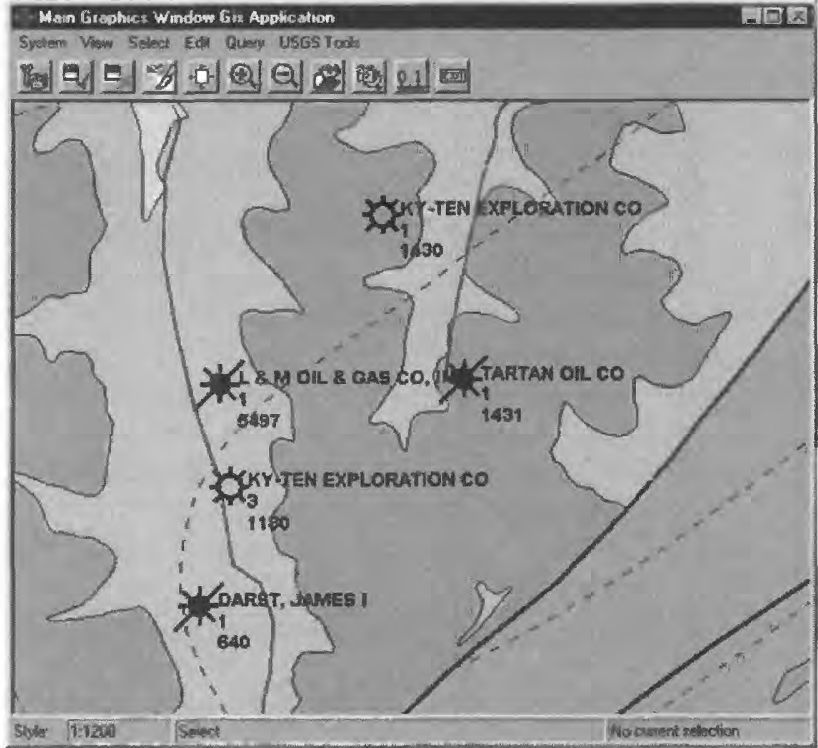

Figure 4a. Further detail of map area and a set of oil wells, whose information is maintained in an external relational database managed by the Kentucky Geological Survey. [Task - display and use various external data, without importing it into the data model.]

approach provides a powerful tool for the user, but it requires a system and data model capable of traversing and interpreting relations among the various data and data model tables. Figure 6 shows a map of primary lithology, where the symbology is automatically generated.

F. Export selected map data: A database is most useful if data can be exported from it and imported into software of the user's choice, there to be manipulated in ways perhaps not anticipated by the database managers. These exported data can be either "raw" contents from the map database, or derivative information created by queries and analyses (above). To enable this feature:

1. the system must be capable of reading and writing a wide variety of common standard file formats (i.e., investments in computer equipment and personnel training must be respected),

2. the database system administrators must identify the appropriate data fields to be exported with various types of spatial data (e.g., all fields, or those judged to be pertinent and/or permitted to the type of spatial data requested for export), and

3. strong coordination must exist among cooperating agencies and users, in order to ensure success of the above two items.

The prototype system uses a well-known import/export tool, FME (Feature Manipulation Engine, $<$ http://www.safe.com/>), with support for essentially all the common GIS file formats.

G. View exported map data in third-party GIS viewer: The selected set of map data represented by Figure 6 was exported to ESRI shape-file format, downloaded from the 


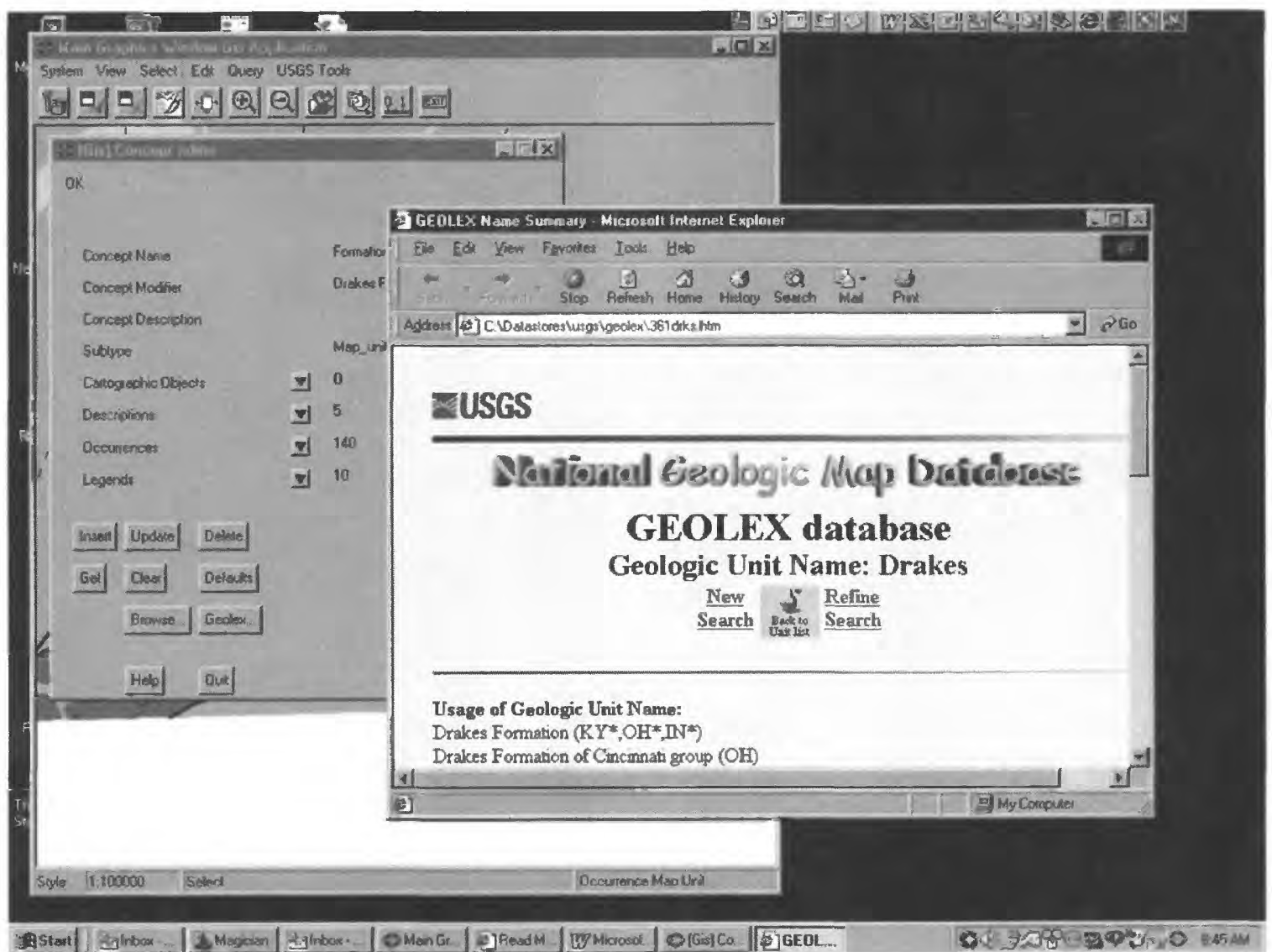

Figure 4b. Dynamic linkage from a selected geologic map unit to the corresponding entry in the NGMDB's Geologic Names Lexicon ("Geolex"), which is maintained by USGS on an Oracle server in Flagstaff, AZ. [Task - display and use various external data, without importing it into the data model.]

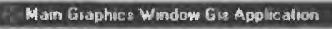

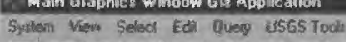

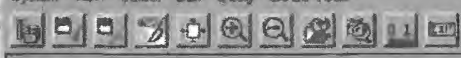

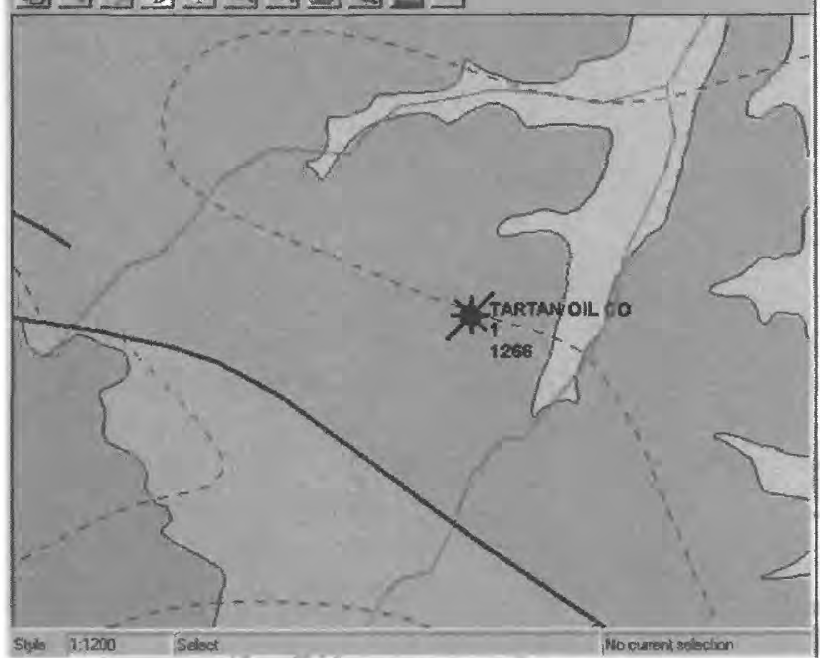

Figure 5. Analysis performed simultaneously on the map database and on external data. Pertinent questions might include: have active oil wells been spudded in a karst-prone unit, such as limestone? are streams near enough to transmit contaminants downstream to other karst-prone units? [Task - perform spatial analysis on map data and on various external data.]

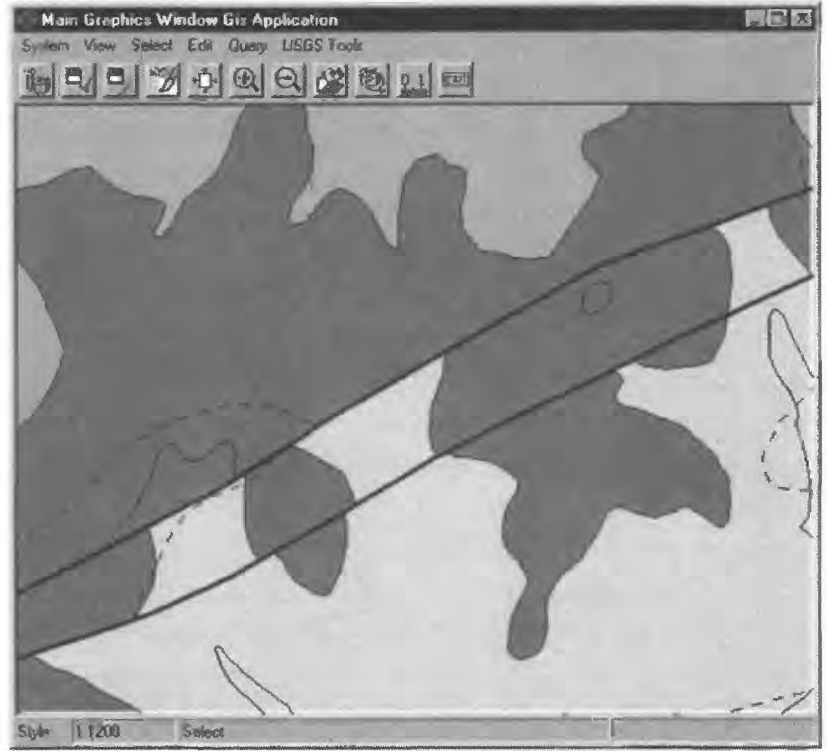

Figure 6. A map of primary lithology, automatically derived from the map database. The map extent can be defined to be the map boundary, the GIS view extent, or some arbitrary, user-designated boundary. [Task — create derivative maps from the spatial analysis.] 
Web server to a local desktop computer, and viewed in ArcView (Figure 7). The downloaded data were then completely available to the user for further local analysis and display. [These data also can be used in many other commercial and freely-distributed software products.]

\section{4) Evaluating the interagency, collaborative nature of this effort}

As stipulated in the Geologic Mapping Act, the NGMDB is intended to be a State-Federal collaboration. It is therefore essential that each prototype draw together the collaborators, to ensure that together they study the project goals and the available technology, and define the scope of their involvement in it. This is perhaps the most important and challenging, yet ultimately rewarding, aspect of the project. The Kentucky prototype fulfilled this objective by bringing together a diverse group of scientists and technical experts to address the needs of both the Kentucky Geological Survey and the NGMDB. Although it is premature to describe the eventual design and content of this online database, the working relations built during this prototype indicate that a national, jointlybuilt and maintained database is feasible.

\section{CONCLUSIONS}

The Kentucky prototype demonstrates that a multimap database supported by robust object-oriented concepts and technology can provide users with simple data access, complex queries, and derivative information and maps. This prototype begins to explore the nature of a mature system, where data can be exported, edited, and replaced into the database (i.e., a "closed loop"). Subsequent prototypes will further test the technology to develop a useraccessible database, and will explore among the NGMDB partners the extent to which this online database will serve the needs of both partners, their prospective customers, and the general public.

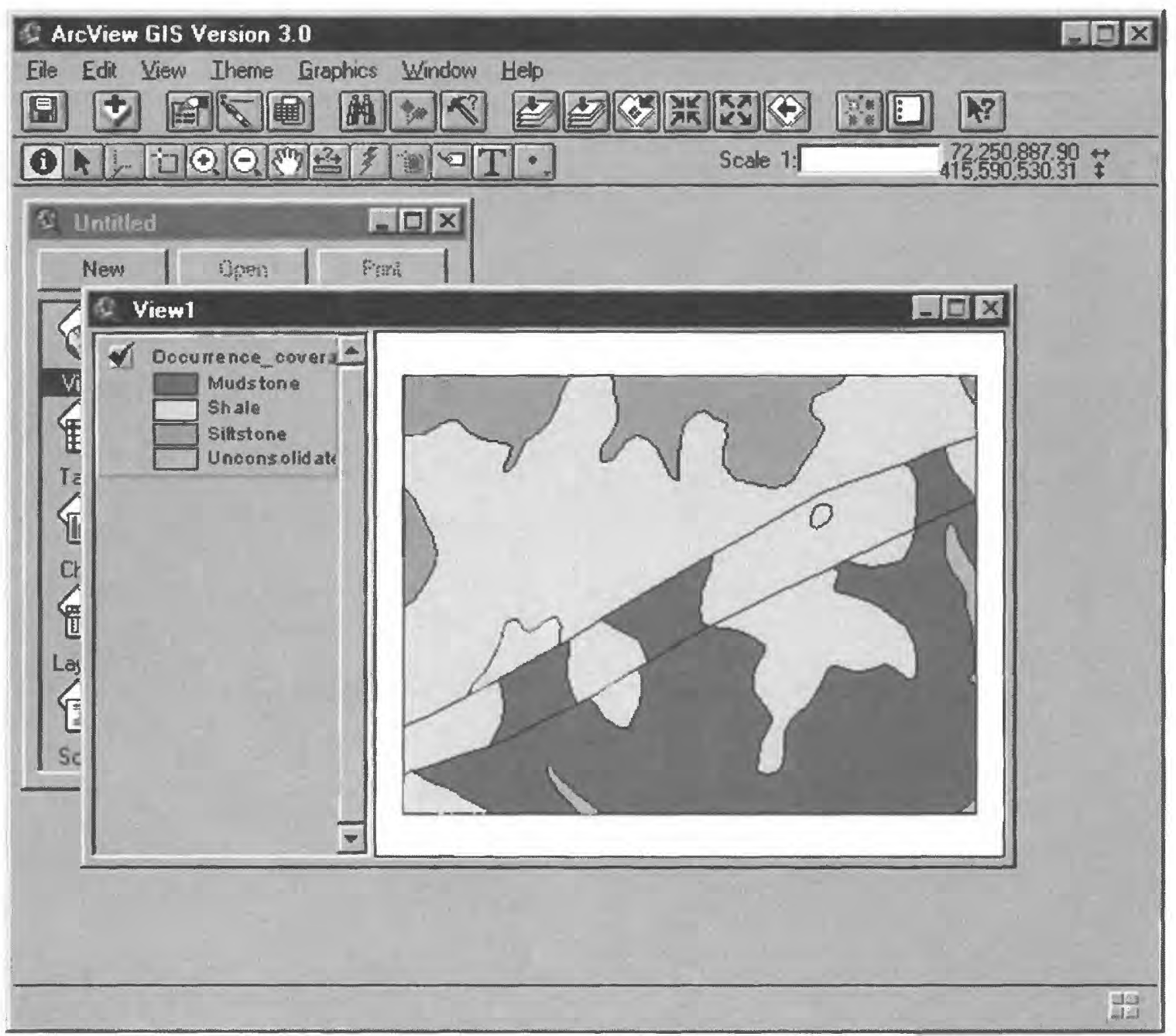

Figure 7. From the central map database to a local desktop, the derivative map may be exported to other GIS formats (for example, to ArcView, as shown here), to be available for further analysis by the enduser. [Task - export, view, and use the map data on the local desktop.] 


\section{REFERENCES}

Anderson, W.H., Sparks, T.N., Patton, J.A., Yang, Xin-Yue, and Sergeant, R.E.,1999, Integration of Relational Geologic Databases and a Spatial Map Database in Kentucky, in D.R. Soller, ed., Digital Mapping Techniques '99 — Workshop Proceedings: U.S. Geological Survey Open-File Report 99386, p.123-125, <http://pubs.usgs.gov/openfile/ of 99-386/anderson1.html>.

Hastings, Jordan, and Brodaric, Boyan, 2001, Evolution of an Object-Oriented, NADM-based Data Model Prototype for the USGS National Geologic Map Database Project: Proceedings of the 2001 Annual Conference of the International Association for Mathematical Geology, Sept. 612, Cancun, Mexico <http//www.kgs.ukans.edu/Conferences/ IAMG/Sessions/l/brodaric.html>.

Soller, D.R., and Berg, T.M., 2000, The National Geologic Map Database: A Progress Report, in D.R. Soller, ed., Digital
Mapping Techniques ' 00 - Workshop Proceedings: U.S. Geological Survey Open-File Report 00-325, p.27-30, <http://pubs.usgs.gov/openfile/ofo0-325/soller2.html>.

Soller, D.R., and Berg, T.M., 1995, Developing the National Geologic Map Database: Geotimes, v. 40, no. 6, p. 16-18.

Soller, D.R., Berg, T.M., and Wahl, Ron, 2000, Developing the National Geologic Map Database, Phase 3 - An Online, "Living" Database of Map Information, in D.R. Soller, ed., Digital Mapping Techniques ' 00 - Workshop Proceedings: U.S. Geological Survey Open-File Report 00-325, p.49-52, $<$ http://pubs.usgs.gov/openfile/of00-325/soller4.html>.

Wahl, R.R., Soller, D.R., and Yeldell, Steven, 2000, Prototype Implementation of the NADMSC Draft Standard Data Model, Greater Yellowstone Area, in D.R. Soller, ed., Digital Mapping Techniques ' 00 - Workshop Proceedings: U.S. Geological Survey Open-File Report 00-325, p.57-63, $<$ http://pubs.usgs.gov/openfile/of00-325/wahl.html>. 


\title{
Map Unit Descriptions and the North American Data Model
}

\author{
By Gerald A. Weisenfluh \\ Kentucky Geological Survey \\ 228 Mining and Mineral Resources Bldg. \\ University of Kentucky \\ Lexington, KY 40506-0107 \\ Telephone: (859) 257-5500 \\ Fax: (859) 257-1147 \\ e-mail: jerryw@kgs.mm.uky.edu
}

\section{INTRODUCTION}

Geologic maps contain a significant amount of descriptive information. Graphics explaining aspects of the map area and its geologic features are compiled in map collars. The North American Data Model (NADM) and its variants store information of this kind and relate it to map objects. The NADM has advantages over simple GIS files that contain spatial data and associated attributes because of its capabilities of storing relationships, hierarchies, and metadata. Whatever the data model, however, map descriptions are complex elements that pose a number of challenges for implementation.

The format of map descriptions as text and graphics is not conducive to easy compartmentalization in data structures. A central problem of converting descriptive prose to database formats is determining precisely what each descriptive element refers to. This requires an analysis of the map's components and how they can be represented in a database. Some descriptions refer to specific spatial objects or groups of objects in a map database (i.e., digitized features), while others apply only to abstract concepts (e.g., unmapped subdivisions of a formation). Characteristics of geologic map units found in other reports or databases also give rise to the possibility of multiple descriptions for the same geologic features. Although this is not a significant difficulty for database storage, multiple descriptions can be confusing for the end user.

The language of map description, especially lithologic terminology, presents interesting challenges for map database design. Current efforts at standardizing scientific language will be useful for future data collection; however, historical data are characterized by a diverse, nonstandardized language. Successful data model designs will have to provide mechanisms for treating such information.

This paper discusses elements of map description that relate to data model development. The ideas evolved from the ongoing task of converting Kentucky's existing geologic maps into database format. These maps contain over 10,000 individual text descriptions for geologic units that were prepared by a wide variety of authors. Converting these descriptions into database format and relating them to geologic map features is challenging due to the high variability of format and grammar of the text. The paragraphs contain a large element of lithologic description and this paper discusses methods of treating this information for both historical and newly collected data. These observations are based on past experience with creating core-logging manuals for sedimentary rocks in the coal fields of the United States.

\section{MAP-UNIT DESCRIPTIONS}

\section{Map Components}

Map unit descriptions on all of Kentucky's geologic map legends occur as discrete text paragraphs that refer to some part of the map (Fig. 1). These descriptions are almost exclusively for sediments and sedimentary rocks, are arranged vertically on the map according to stratigraphic age, and relate to the map by means of a map color and symbol (explained in the legend).

Inspection of paragraphs on almost any map reveals a number of issues that relate to database development. Not every cartographic map unit has a single description whereas some descriptions have no cartographic representation. Figure 2 shows examples of descriptions that have no spatial representation. Subdivisions of geologic units are often described but not mapped, and they may be formal or informal. In Figure 2, the Reba Member has two separate descriptions for its lithologically distinct upper and lower parts (informal units). Remaining formal mem- 
Clays Ferry Formation: Limestone, shale, and siltstone. Limestone (60 percent), dark- to light-gray, weathers yellowish brown; fine grained and medium to coarse grained, in part silty; in fairly even beds 1 to 12 inches thick; fragmented and whole fossils, chiefly brachiopods, but also bryozoans, trilobites and crinoid columnals, common in medium- and coarse-grained layers. Shale (20 to 30 percent), greenish-gray, in part silty and calcitic; laminated in sets 1 to 12 inches thick interstratified with limestone and siltstone; locally contains a few brachiopods and bryozoans. Siltstone (10 to 20 percent), calcitic, greenish-gray, weathers yellowish gray; mostly in even beds 1 to 5 inches thick; sparse brachiopods. Base not exposed. Crops out only in northwest corner of quadrangle.

Figure 1. Example map unit description from the Lancaster 7.5-minute quadrangle, Kentucky.

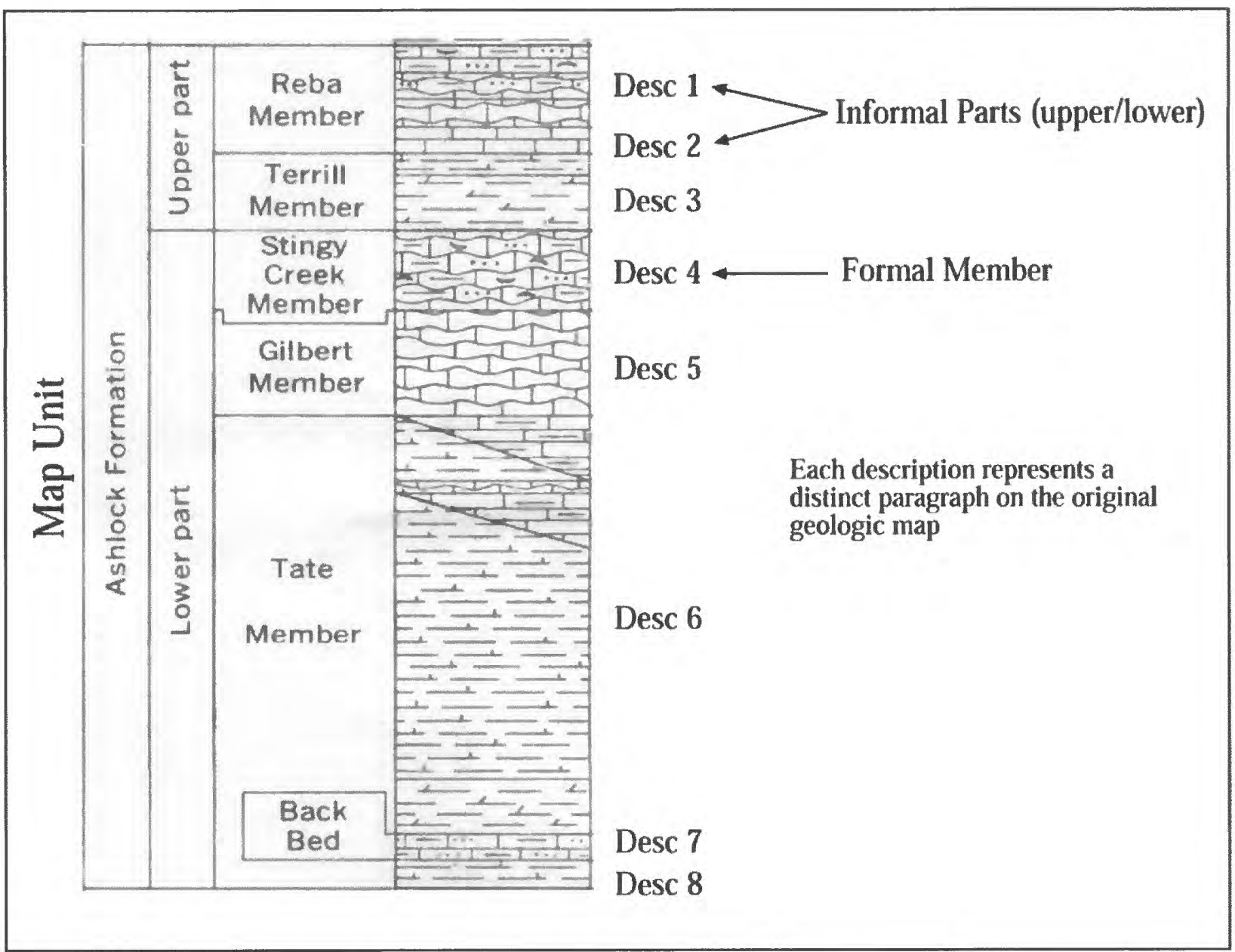

Figure 2. Formal and informal descriptive components of map units.

bers each have a single description, but were also not cartographically depicted on the map. In this example, the map unit (Ashlock Formation) has no unique description except for the composite descriptions of its formal and informal members. As map units may have components, each constituent lithology may also have descriptive components. Figure $3 \mathrm{~A}$ shows the heterolithic character of typical eastern Kentucky geologic units (map-unit compo- nents). Figure 3B indicates that some of the lithologies also have distinct components, which is an important design issue for encoding rock composition.

Another challenge in designing the database for Kentucky geologic maps relates to map compilations. When maps have been digitally combined from multiple sources to prepare new products, revised descriptions are also compiled for the aggregated map areas. This results 


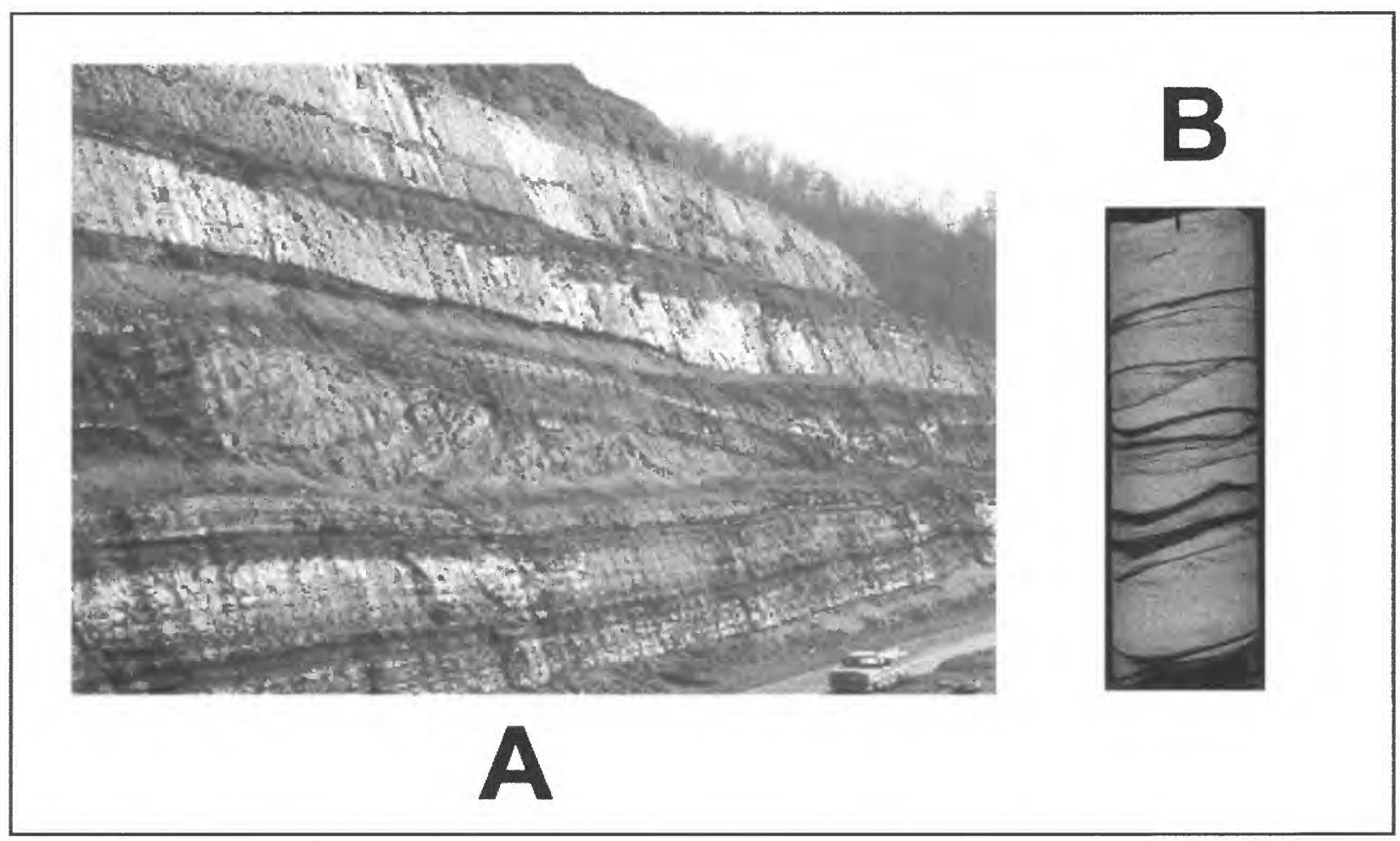

Figure 3. Map-unit and lithology components for heterolithic units. A. Lithologically heterogeneous map unit. B. Heterogeneous lithology.

in multiple descriptions for the same geologic features in the map database (i.e., one for the original published map and another for the compilation). In most cases descriptive "versions" relate to maps compiled at different scales, but could also result from different authorship at the same scale.

\section{Map-Unit Properties}

On Kentucky's maps, much of the descriptive information pertains to components of map units, but a number of properties typically relate to the map unit as a whole.

These include

- Thickness

- Age

- Quality of exposure

- Geomorphologic form

- Diagnostic features

- Bedding

- Contact relations with adjacent map units.

An important aspect of such map-unit properties is that many are expressed as ranges or multiple values rather than as discrete values.

\section{Implications for the Data Model}

The concept of hierarchical components has been integral to the NADM from its inception, and can be designed in terms of parent/child relationships. The design of relationship classes may differ according to implementation (e.g., relational vs. object-oriented technology). The efficiency with which data can be queried may vary significantly among such applications. This will only be known when methods are implemented using a specific software process. The challenge for successful design will be to make complex data relationships appear relatively simple (or at least understandable) to the user. Equally important will be creating intuitive data-entry mechanisms that will allow map unit properties to be cataloged in an efficient way. This requires a means for identifying map components and relating descriptive properties to them. Because of the complexity of map-unit descriptions, it will also be desirable to preserve the full text in the database in order to retain original context.

Geologic features that have more than one description (e.g. derived from two versions of a map, or two scales of compilation) present problems for user interfaces. For example, if a selected map unit has more than one lithologic description, the software system should have a rule set for determining which to return to a user's request. One means of establishing these rules is to assign a rank to descriptions that would indicate preferred data. Ranking could be based on scale, where attributes derived from larger scales would have a higher rank. Ranking descriptions could also permit the design of methods for returning information appropriate to a users' map extent or selection 
set. This issue will become increasingly important as seamless databases are constructed from multiple source maps.

Some of the concepts found in the Kentucky descriptions (and presumably other geologic maps) would require the addition of new data model tables. Examples are exposure conditions and engineering properties. Current implementations of the data model store much of the lithologic information in a single table. The prevalence of range data (e.g., minimum and maximum thickness) and the potentially large number of parameters suggests that individual tables for each property would be more suitable. Data model implementations should provide the flexibility for adding such features.

\section{LITHOLOGY DESCRIPTIONS}

Lithologic description will be vital to the functionality of any map database. Many of the proposed queries for testing the NADM involve some aspect of finding map objects by specifying lithologic properties. A number of efforts are under way to standardize lithologic terminology and classification of sediments and rocks, and this discussion is not intended to supplant them. Many of the problems currently being discussed were also found during the preparation of field core-logging manuals for the coal industry (Ferm and Weisenfluh, 1981; Ferm and others, in press). Solutions found during the development of the core manuals may also be applicable to the NADM.

\section{Rock Classification}

In the early and mid-1970's, energy shortages in the U.S. led to an increase demand for coal and resulted in intensified core-drilling programs in the Appalachian coal fields. The rock core from this exploration drilling was being described by a wide variety of personnel with varied experience and logging systems. Research programs designed to analyze the volumes of information that were being generated quickly identified the problem of inconsistent descriptions. This lack of consistency resulted in an inability to compare results from one drill hole to another and led to an effort to develop a new rock classification and field methods to reduce this problem. The outcome was a number of photographic core-logging manuals; subsequently, computer methods were developed for processing the data that resulted from using the manuals. Several tenets (explained below) became evident during this program that define a common-sense approach to rock classification in general.

Consistent results. Any successful rock classification should facilitate repeatable results, particularly among different users. It may seem obvious to state that every practitioner should be able to look at a rock and derive the same name for it. But this is difficult to achieve because of the complexity of some classifications and difficulty in judging category boundaries. During the development of the core books, repeatability was measured by conducting trials in which a group of people were given criteria for classification categories and asked to place a number of samples in the appropriate category. If agreement was not high, the categories were reevaluated and boundaries adjusted to improve consistency. Two problems relating to definition of rock categories became apparent. First was the universal tendency to define too many categories. This resulted in users having to make fine distinctions of properties, usually without a high degree of success. For a given range of a gradational property, more than three or four subdivisions generally led to low levels of agreement.

The second problem was the placement of a classification boundary within a gradational series at a naturally high frequency for a property. This could be judged because samples were taken to represent the frequency of different rock types. When arrays of samples were prepared to assess the variability of important properties (Fig. 4) distinct patterns in frequency distributions often became apparent. Placement of class boundaries at low frequency points reduced error because fewer samples would occur close to that boundary. For arrays in which there were no obvious natural boundaries, the only technique that resulted in high consistency was to keep the number of categories low. For these reasons, rock classifications that use arbitrary class boundaries inevitably result in some classes that are difficult for users to discriminate with consistent results.

Standard information. The core-book project was originally undertaken, in part, because previous core logs produced by drilling or coal company personnel lacked important lithologic details. Initial experiments to improve logging used experienced geologists to collect the descriptive information. These efforts were not entirely successful because there was no uniformity about what rock properties should be included in the primary rock and which should be treated as ancillary comments. This is an important distinction because of the operators' tendency to omit comments after long periods of observation (i.e., descriptions tended to become more simple toward the end of the day). Another tendency resulted from repetitive information; if a particular property was nearly invariant, operators would discontinue recording the information over time. For example, if all sandstones in a core were "lithic" in composition, only the first few occurrences would be described as such and subsequent samples would only be described as "sandstone". Although uniformity of the intervals was understood by the operator, future users of the data would be uncertain about sandstone composition.

The solution to this problem was to build as many of the important properties into the rock term as was possible and to make it simple for the operator to record this information in a field or laboratory setting. A hierarchical system of description was created that recorded the properties 


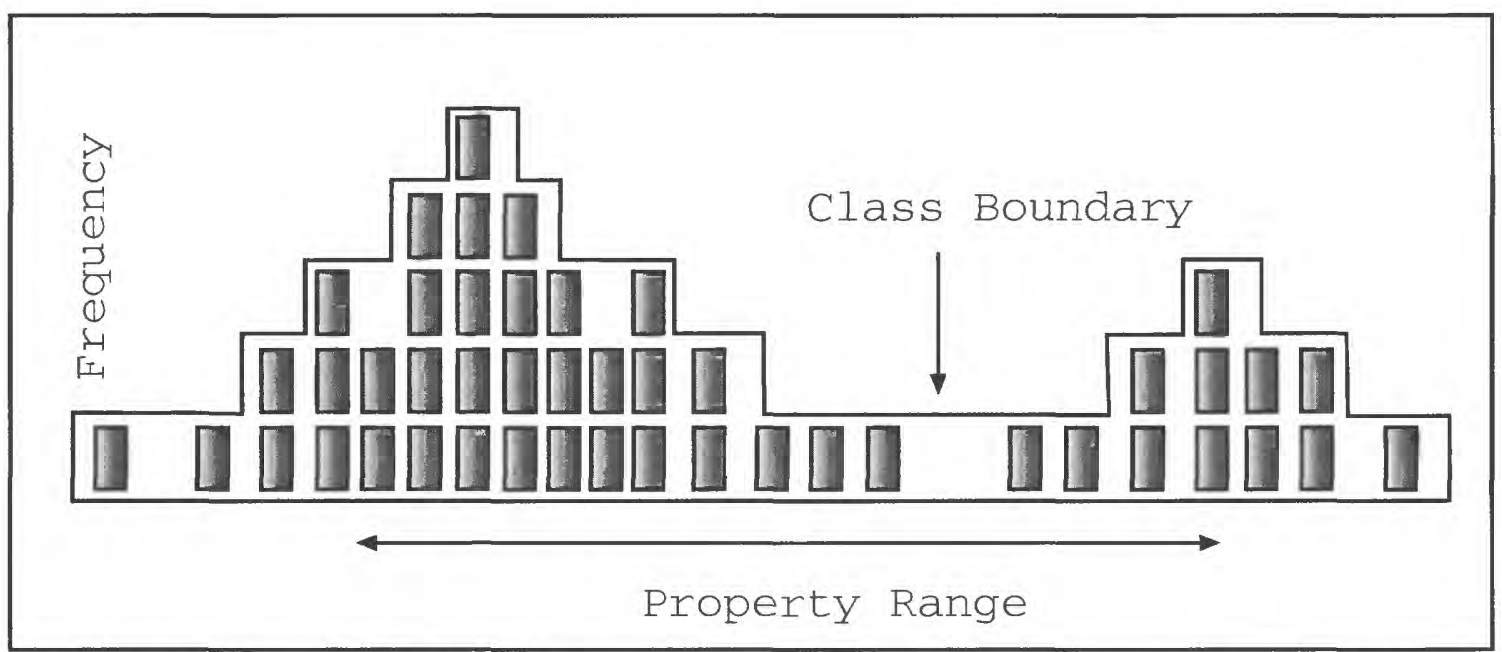

Figure 4. Frequency distribution of a hypothetical rock-property based on systematic sampling. Sample array shown for set of core samples.

in a three-digit (subsequently increased to four-digit) numeric code (Fig. 5). These codes were not arbitrarily assigned; rather, each digit had significance with respect to rock properties. For example, the first digit always recorded the primary rock group (sandstone, shale, etc), and the last records sedimentary structures. The use of the middle digit was dependant on the primary rock group. For example, the code 551 indicates a primary rock group of sandstone (first digit 5), mineral composition of quartzose (second digit 5) and crossbedded structure (third digit 1). The numeric classification was documented by full-scale color photographs that depicted the range of properties for each class. English text was assigned to the codes, based on terminology in common use in the region for which each manual was prepared. The resulting numeric logging system was easy to learn and encouraged the recording of detail, because recording 541 (crossbedded lithic arenite) took no more effort than writing 500 (sandstone). The system did not preclude the use of generalized terms (i.e., 500 was a valid code). Many users did prefer to use a text rock term rather than a number and therefore the problem of consistent terminology could not be completely avoided.

Flexible terminology. Regardless of how much effort is put into standardization of geologic terminology, many users in different locales and with varied training will continue to use variations of rock terms. Moreover, geologic databases must be capable of storing the large amount of historical data that has been collected using various descriptive systems. Nonstandard terminology between regions of the United States (and the world) proved to be a significant problem when the core manuals were prepared. Figure 6 shows an example of a root-penetrated rock that is known by different names in various parts of the country. In Pennsylvania, the term claystone is used for this rock, but that same term has very different usage in other regions. Rather than require users to adopt a single term with which they may be unfamiliar or uncomfortable, the core manuals retained regional terminology while maintaining a consistent numerical classification to unify descriptions. Therefore, the code " 137 " (or any other) always indicated the same lithology, irrespective of its geographic occurrence; photographs illustrating rock properties helped to reduce ambiguity in nomenclature.

\section{Data Model Implementation}

All the elements of a hierarchical rock classification are present in current implementations of the NADM; however, none take advantage of numerical coding systems for recording data. Dictionaries for lithologic descriptions will be necessary to address two of the issues discussed above: generalizations and synonyms. An example is shown in Figure 7. The fields of this sample dictionary record the type of term (class), its numeric representation (code), and the English equivalent (text). The second and third records shown in Figure 7 encode generalized versions of the first by use of the digit " 0 " in the rock code. Each of the three text names is considered the "standard" form of the rock term for this hypothetical dictionary. The last two records are variations of the standard term "quartzarenite" and therefore share the same numeric code. The "class" field is used to indicate a region, classification or dataset to which that name applies. If lithologies are entered in the database in code format, the corresponding text is assigned by selection of a standard or non-standard class. Alternatively, if data are collected and entered as text, the appropriate numeric code can be determined by the same means. While many geologists are adverse to using numerical descriptors, most who have 


\section{Classification Name}

Crossbedded Quartzarenite

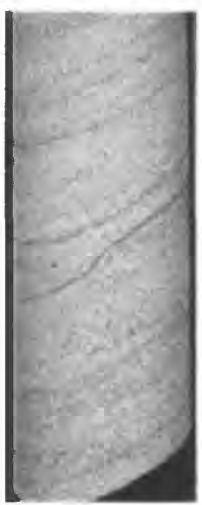

\section{Hierarchical Code}

551

\section{Standard Properties}

5

Grainsize

Sand
5 Composition

$>95 \%$ Quartz
1

Structure

Crossbedded

Figure 5. Elements of a numeric rock classification system and related properties.

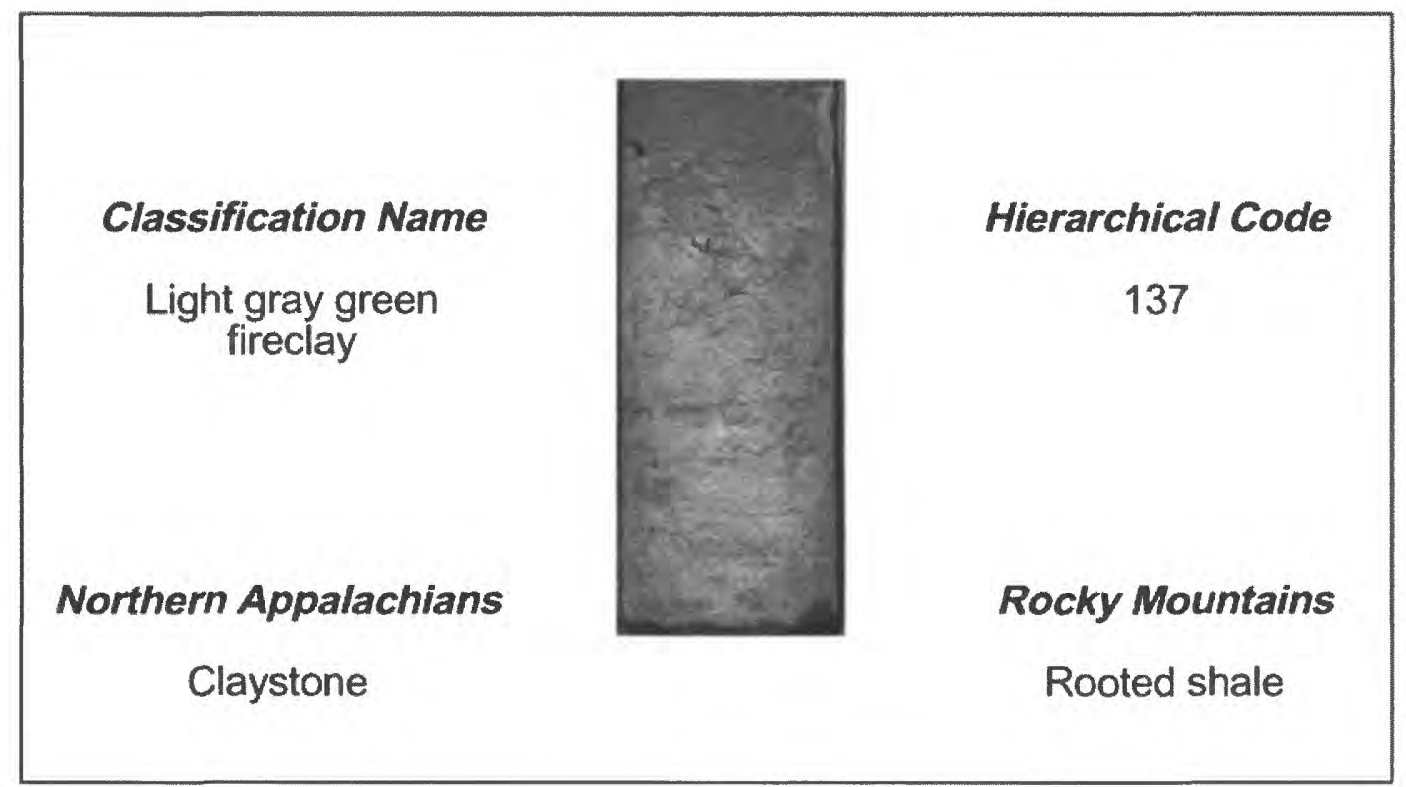

Figure 6. Relating regional terminology through photographs and the numeric code.

used the core books found the method easy to learn and an effective means of communicating with others about lithologic properties. At the same time, the logging system does not require recording of data in the numeric system.

Use of a numeric code system for lithologic descriptions increases the efficiency of data collection and is well suited for processing in computer systems. Because the digits are directly related to rock properties, they can easi- ly be linked to other tables of property names that have specified definitions and criteria. Code-based descriptions also facilitate searching of large databases for units that contain certain properties. Figure 8 illustrates a data model design that could be used for storing and retrieving lithologic descriptions. A rock description generally has a source document (published or unpublished), which can be stored in the database as a text block with appropriate 


\section{Lithologic Dictionary}

\begin{tabular}{|l|l|l|l|}
\hline Record & Class & Code & \multicolumn{1}{c|}{ Text } \\
\hline 1 & Standard & 551 & Crossbedded Quartzarenite \\
\hline 2 & Standard & 550 & Quartzarenite \\
\hline 3 & Standard & 500 & Arenite \\
\hline 4 & Region 1 & 550 & Crystallized Sandstone \\
\hline 5 & Region 2 & 550 & White Sandstone \\
\hline
\end{tabular}

Figure 7. Generalizations (records 2-3) and synonyms (records 4-5) in a lithologic dictionary.

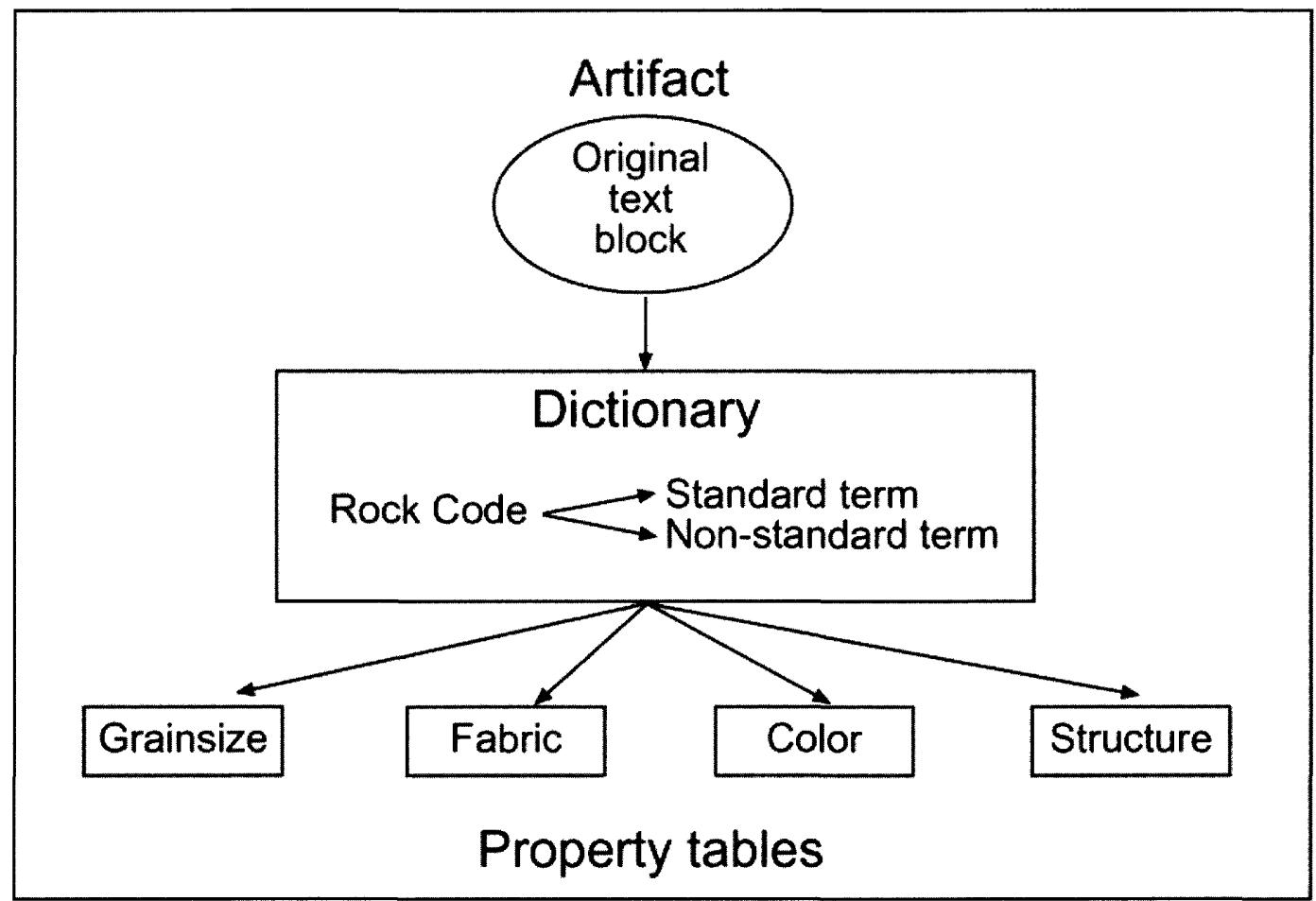

Figure 8. A sample data model design for lithologic descriptions.

metadata. Each lithology component in a description can be related to predefined classifications by associating them with an entry in a system dictionary. The dictionary consists of numeric codes with one standard and many nonstandard text names. Each lithology code will have preassigned standard rock properties that will be stored in separate description tables. Lithologies may also have nonstandard properties that could relate directly to a lithologic occurrence. For example, the rock ' 551 ' or crossbedded quartzarenite would have standard properties of grain size (sand), mineral composition (quartzose), and sedimentary structure (cross stratified). An occurrence of ' 551 ' could have a nonstandard property of carbonate cement or brittle fractures.

Data input for an occurrence would consist of picking the appropriate lithology code or term from the dictionary. Because each term would have pre-defined properties, users would not have to reenter that information. Queries to lithologic databases typically relate to individual properties rather than the rock terms assigned to the map unit. For example, users may desire all units with quartz-rich lithologies or those with a particular grain size.

Dictionaries and related property tables will allow for efficient query tools to access lithology information in this manner.

\section{CONCLUSIONS}

Important database design issues for storing map-unit descriptions in a data model include:

- provide an intuitive means of assigning descriptive elements to the map and lithology components to which they apply 
- where geologic objects have multiple descriptions, permit ranking to facilitate user access to the data

- implement rock classifications as hierarchical, numeric systems

- document rock classifications with photographs as well as definitions to reduce ambiguity

- use dictionaries to permit nonstandard lithology terms to be related to standard classifications

- assign standard properties to dictionary terms to make rock type queries more flexible.

\section{REFERENCES}

Ferm, J.C. and Weisenfluh, G.A., 1981, Cored rocks of the Southern Appalachian Coal Fields: Lexington, University of Kentucky, 93 p.

Ferm, J.C., Weisenfluh, G.A., and Smith, G.C., in press, A method for development of a system of identification for Appalachian coal-bearing rocks: International Journal of Coal Geology, Special Publication. 


\title{
The National Park Service Digital Geologic Map Model: Transformation from Paper to Digital, Featuring Legends, Cross Sections, Map Notes and Keyword Searchability
}

\author{
By Steve Fryer ${ }^{1}$, Joe Gregson ${ }^{1}$, Tim Connors ${ }^{2}$, Anne Poole ${ }^{3}$, and Bruce Heise ${ }^{2}$ \\ ${ }^{1}$ National Park Service \\ Natural Resources Information Division \\ 1201 Oak Ridge Drive, Suite 350 \\ Fort Collins, CO 80525 \\ Telephone: (970) 225-3584 \\ Fax: (970) 225-3585 \\ e-mail: Steve_Fryer@nps.gov,Joe_Gregson@nps.gov \\ 2National Park Service \\ Geologic Resources Division \\ 12795 West Alameda Parkway \\ P.O. Box 25287 \\ Denver, CO 80225 \\ Telephone: (303) 969-2093 \\ Fax: (303) 987-6792 \\ e-mail:Tim_Connors@nps.gov, Bruce_Heise@nps.gov \\ ${ }^{3}$ National Park Service \\ Intermountain GIS Support \\ Bandelier Hall West, Room 203 \\ Albuquerque NM 87131 \\ Telephone: (505) 346-2885 extension 260 \\ Fax: (505) 346-2889 \\ e-mail: Anne_Poole@nps.gov
}

\section{SUMMARY}

Beginning in 1998, the National Park Service (NPS) initiated a Geologic Resources Inventory (GRI) to document and evaluate the geologic resources of about 272 National Park System units (national parks, monuments, recreational areas, historic sites, seashores, lakeshores, etc.). GRI workshops have been held for 56 parks, geologic bibliographies developed for 235 parks, digital geologic maps produced for 11 parks (numerous more in progress and nearing completion), and geologic reports produced for 11 parks in Utah.
User-friendly (i.e. main users are NPS Natural Resource Managers) GIS tools have been developed in ESRI ArcView format for the digital geologic maps. Applications including the NPS-developed ArcView Theme Manager, graphical cross section viewer and legend text display tools are integrated with a standard geology-GIS model that is in development to reproduce the components of a "paper" geologic map into a digital geologic database. The evolving geology-GIS model is based on the Washington State ArcInfo GIS data model (Harris 1998) that is being adapted for ArcView GIS and extended to include components of the North American 
Geologic Map Data Model (NADM), $<$ http://geology.usgs.gov/dm/>.

\section{INTRODUCTION}

Bedrock and surficial geologic maps and supporting information provide the foundation for studies of groundwater, geomorphology, soils, and environmental hazards. Geologic maps describe the underlying physical conditions of many natural systems and are an integral component of the physical science inventories stipulated by the National Park Service (NPS) in its Natural Resources Inventory and Monitoring Guideline (NPS-75) and the 1997 NPS

Strategic Plan.

The NPS Geologic Resources Inventory (GRI) is a cooperative endeavor to implement a systematic, comprehensive inventory of the geologic resources in NPS units. Cooperators include the NPS Geologic Resources Division, NPS Inventory and Monitoring (I\&M) Program (Natural Resource Information Division), U.S. Geological Survey (USGS), and individual state geological surveys. The GRI for the 272 park units with significant natural resources consists of four main products:

1. "GRBib", compilation of a bibliography of geologic literature and maps;

2. "scoping sessions", an on-site evaluation of park geologic maps, resources, and issues;

3. digital geologic map products with accompanying supporting information; and

4. a summary report with basic geologic information on hazards, issues, and existing data and studies.

\section{STATUS OF GEOLOGIC RESOURCES INVENTORIES}

In the fall of 1997, the NPS Geologic Resources Division and Inventory and Monitoring Program sponsored a workshop on baseline geologic data in Denver, Colorado. Its purpose was to receive input from the NPS, USGS, state geological survey personnel, and cooperators on needed basic geologic data that the NPS Inventory and Monitoring Program could provide. At the meeting, Colorado, Utah, and North Carolina were chosen as pilot project states to maximize cooperation among the agencies and provide consistency in workshop planning. The group discussed and adopted the four main inventory phases that are reviewed briefly below.

\section{Geologic Bibliographies}

"GRBib", the bibliography of existing geologic maps and literature for 235 NPS units is available on the Internet (URL: <http://165.83.36.151/biblios/geobib.nsf>; LOGIN: "geobib read", PASSWORD: "anybody") and is also prepared as printable documents at <http://www2.nature.nps.gov/grd/geology/gri/products/ geobib/>. Also, geologic index maps showing the location of associated geologic maps and their scale have been prepared for these same parks. In general, after map coverage for each park is determined, map products can be evaluated, and if needed, additional mapping projects identified and initiated.

\section{Park Workshop Meetings}

GRI Park Workshops (scoping sessions) have been conducted for 56 parks in Colorado, Utah, Idaho, North Carolina, California, Texas, New Mexico, Arizona and the National Capital area to evaluate each park's geologic resources. As a result of these workshops, park teams have evaluated existing maps for digital products and identified needed geologic mapping. New geologic mapping may be initiated on a case-by-case basis after careful evaluation of needs, costs, potential cooperators, and funding sources.

GRI staff are developing geologic-GIS standards to ensure uniform data quantity and quality for digital geologic maps throughout the National Park System. The NPS is attempting to align these digital standards with those of the USGS and the National Geologic Map Data Model that is still in development. In addition to standardized data definitions and structure, NPS resource managers also need user-friendly GIS applications that allow the digital geologic map products to "look and feel" like the original published paper maps. Pilot digitization projects are providing additional information for the evolving NPS digital map standards.

Park workshops suggest several applications for park resource management that can come from an enhanced understanding of the parks' geology as gained from a digital geologic map. Examples include the use of geologic data:

- To construct fire histories,

- to identify habitat for rare and endangered plant species,

- to identify areas with cultural and paleontological resource potential, and

- to locate potential hazards for park roads, facilities, and visitors.

\section{Geologic Mapping and Digitizing Projects}

The NPS I\&M Program has cost-shared with the Utah Geological Survey new geologic field mapping for Zion National Park (NP) and Glen Canyon National Recreation Area (NRA). Additional field mapping projects have been initiated or completed for the geologic maps for Bent's Old Fort National Historic Site (NHS), Curecanti NRA, 
Florissant Fossil Beds National Monument (NM), Great Sand Dunes NP, Capitol Reef NP, Cedar Breaks NM, Golden Spike NHS, and Natural Bridges NM.

Digitization of geologic maps has been completed for Arches NP, Bent's Old Fort NHS, Black Canyon of the Gunnison NP, Colorado NM, Curecanti NRA, Florissant Fossil Beds NM, Great Sand Dunes NP, Hovenweep NM, Mesa Verde NP, Natural Bridges NM and Rocky Mountain NP. This data is available for download at $<\mathrm{ftp}$ ://gis01.nature.nps.gov/>.

The NPS Geologic Resources Inventory is being actively developed with the formal cooperation of USGS and state geological surveys. However, many opportunities for project collaboration may exist that have not yet been identified, and effective communication among cooperators is a key factor for success of the inventory.

Another challenge of inventory planning is the development of digital map standards that are adaptable to diverse geological conditions but still provide quality, uniform products and firm guidance for map developers. Indeed, the diversity of geologic resources found in the National Park System will provide a continuing challenge for effective project management. The National Park Service has identified GIS and digital cartographic products as fundamental resource management tools, and the I\&M Program and Geological Resources Division are developing an efficient inventory program to expedite the acquisition of digital geologic information for NPS units throughout the country. Again, the NPS is attempting to align these digital standards with those of the USGS and the National Geologic Map Data Model that is still in development.

\section{Summary Geologic Reports}

Upon completion of an inventory in a park, the available geological literature and data from the NPS, USGS, state, and academic institutions will be documented in a summary report. The content, format, and database structure of such reports are still being developed.

\section{GIS ISSUES AND IMPLEMENTATION - MAKING GEOLOGY “USER-FRIENDLY”}

One of the unresolved issues facing developers of digital geologic maps and geology-GIS models is how to include map unit descriptions, supplemental explanatory text (references and map notes), geologic cross sections, and the variety of other printed information that occur on published maps. This issue is particularly important to the National Park Service because there are few geologists employed at parks, and resource managers rarely have the GIS and geologic expertise needed to develop a useful product from digital layers of polygons, lines, points, and associated tabular data. The overarching development goal of the NPS I\&M Program is to produce digital products that are immediately useful to anyone familiar with their analog counterparts. For geologic maps, this means that the map unit legend must be sorted and shaded appropriately by geologic age and that all textual, graphical, and other information from the published maps must be available interactively to the user. In short, the digital product must "look and feel" like its published source.

Since NPS resource managers use GIS as a tool in a wide array of collateral duties, the I\&M Program is developing most digital products in ESRI (Environmental Systems Research Institute) ArcView GIS. ArcView interfaces effectively with other software running on the Microsoft Windows operating system. Also, integrating a variety of tools including the Windows Help software, a Microsoft Visual Basic graphics viewer program, the ArcView legend editor, and the Avenue script language has allowed query and automatic display of published map information in the GIS.

\section{Automating Map Unit Descriptions and Other Textual Information}

In most GIS applications, the spatial database structure does not facilitate the use of voluminous textual data. For example, in ArcView, the database text fields only accommodate 254 characters ( 320 for INFO tables) which limits the ability to include lengthy map descriptions with the spatial data. Several options are available in ArcView to overcome this limitation including concatenating database fields, independent text files, linking to other database system files, and linking to a Microsoft Windows Help file. After testing several options, NPS developers have been implementing the Windows Help system.

This process begins with an approach using the creation of the Help file table of contents (object table). The table includes a title, a listing of all source map units (sorted by geologic age), and a list of source map references and notes. Text descriptions of map units that are page sorted by geologic age are entered next. For compiled geologic maps, maps produced from more than one source map, a unit's description often consists of multiple map unit descriptions. Finally, the source map references and notes text, also one per page, were entered. Help context IDs (HELP_ID), topic names, keywords, page numbers, and linking codes were then added to the footnotes of each page. The data was then saved as a rich text format (.RTF) file, and compiled into a Windows Help file.

Once compiled, the Windows Help file can be opened and used with almost any Microsoft Windows software. The table of contents has each map unit symbol and unit name "hot-linked" to the descriptions, and each description is hot-linked to the references and notes. Using the builtin Windows Help tools, users can jump instantly to the 
table of contents, page through the age-sorted unit descriptions, search for keywords, or index the file and perform full-text searches of the entire file. The Black Canyon/Curecanti pilot project help file consists of more than 50 printed pages of information for more than 130 map units. Advantages of the Windows Help file are that most text formatting, such as font, size, color, etc., are preserved in the final product, many graphics and tables are also supported, and the help system can be developed somewhat independently of the digital geologic map.

In ArcView GIS, three Avenue scripts were written to function with a toolbar button to automate the Windows Help file and call unit descriptions interactively from the geologic map. The button tool is only active when the geology theme is turned on. The user selects the map unit help tool from the ArcView toolbar and clicks on the desired map unit to view the associated unit description. Using the map unit symbol (GLG_SYM, see data model in figure 1) and the corresponding help context ID (HELP_ID), the Avenue routine loads the Windows Help file and pages to the map unit description. Thus, the map unit descriptions and other text are interactively available to the user of the digital map.

\section{Automating the Geologic Cross Sections}

Geologic cross sections are integral components of many published geologic maps and provide important spatial visualization tools to assist users with understanding the mapped geology. The I\&M Program has developed a simple interactive system for displaying cross sections using ArcView and a Microsoft Visual Basic (VB) graphics viewer program. The cross sections are scanned digital graphics files (JPEG format) that ArcView can load and display via system calls to the VB graphics viewer program. This allows the user to interactively select the cross section(s) to view. With projects such as the Black Canyon/Curecanti pilot, the ability to quickly view some 28 cross sections throughout the area is a powerful asset toward understanding the area's geology.

To prepare the cross sections for viewing, the graphics are first scanned at 100 dots-per-inch (DPI) and saved as a digital JPEG (.jpg extension) graphics file. The JPEG format was chosen to allow the graphics to be served and viewed over the Internet in the future. Once again, the 8.3 file naming convention is used to facilitate sharing across all platforms, and file names are based on the map series designation and the designated cross section on the map (e.g., "gq1516a.jpg" is the A-A' cross section on the USGS Geologic Quadrangle Map GQ-1516).

Although ArcView and the Avenue language provide several ways to display graphics and images, ArcView's capabilities are inadequate for efficient viewing of cross sections that could be up to 6" $\mathrm{x} 48$ " in size. Therefore, a simple VB graphics viewer program was developed to provide this capability. The viewer displays the graphics at
$100 \%$ with the ability to scroll from one end of the section to the other.

In ArcView GIS, three Avenue scripts were written to function with a toolbar button to automate the cross sections and call graphics files interactively from the geologic map. The button tool is only active when the cross section theme (CODESEC, see data model section below) is turned on. The user selects the cross section viewer tool from the ArcView toolbar and clicks on the desired cross section line displayed on the map. Using the cross section line and the corresponding filename, the Avenue script loads the graphics viewer and displays the selected section. Thus, the cross sections are interactively available to the user of the digital map.

\section{GIS Map Unit Legend}

In ArcView, theme legends can be customized to reproduce map feature symbols and colors of published source maps. To represent map features of a particular theme, an attribute field is selected in that theme's legend editor that relates map feature type with legend symbol type and color. In the NPS geology-GIS data model (presented below), the attribute field that denotes map feature type is typically either COV_TYPE for point themes or COV_LT for line themes, where COV represents the theme/coverage abbreviation. For polygon themes (themes typically representing geologic map units of aerial extent), and also for point and line themes that represent point and line geologic map units, respectively, GLG_AGE_NO is the attribute field that relates feature type with symbol type (pattern) and color. As mentioned in the data dictionary section of the paper, the GLG_AGE_NO is a numeric attribute field also used to sort map units by geologic time.

For point symbols that indicate or represent directionality, ArcView also allows for those symbols to be aligned to their correct orientation using a second attribute or rotation field. For attitude observation points, (e.g. strike and dip of bedding, trend and plunge of inclusions ..), which is the only coverage presently in the data model that has oriented point symbols, the ATD_AV_ROT field designates the desired symbol rotation value.

When a theme legend is completed, it can be saved as an ArcView legend file (.avl extension). In the data model, a legend file is named as per the theme/coverage file name. By default in ArcView, if a legend file exists with the same file name as a theme, when that theme is added to a view the legend file is automatically loaded.

\section{REVISED DRAFT NPS GEOLOGY-GIS DATA MODEL}

As mentioned above, a standard geology-GIS data model has been developed for the National Park Service Geologic Resources Inventory (GRI). The model is based 


\section{Database Table Relationships for Tables \\ Outlined in Data Dictionary}

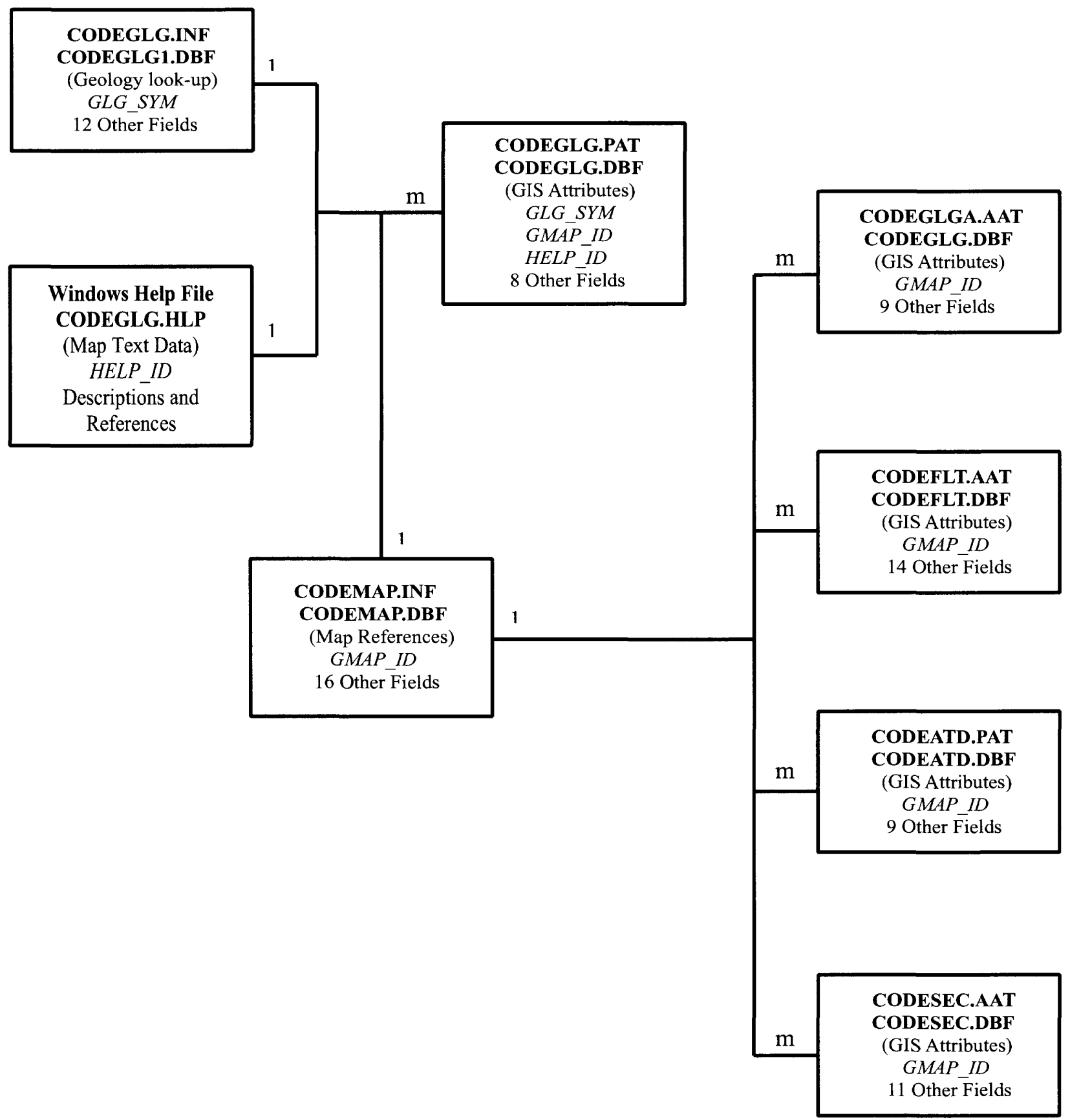

Figure 1. Simplified relationships among database tables presented in data dictionary. Bold type denotes database file names for ArcInfo (top) and ArcView (below). The tabular relationships are coded with " $m$ " for many, and " 1 " for one. Related field or key names are in italics. Table types are in parentheses. 
on ArcInfo and integrates with user-friendly ArcView GIS software. As per ArcView and dBase requirements, database field names have been limited to ten characters or less. In addition, although many modern operating systems allow for long file names, theme/coverage file names within the model adhere to the 8.3 file name convention. Typically, themes/coverages and associated table file names are seven characters in length. The use of only seven characters allows for an additional character to be appended to a coverage name for related look-up tables. For an NPS unit digital geologic map, the first four characters or prefix of a coverage name (CODE) are the NPS unit's alpha code. The next three characters (suffix) abbreviate the type of geologic coverage (COV). For INFO look-up tables associated with a coverage, an additional or eighth character, typically an integer, is appended to the theme/coverage name. An exception to the file naming convention presented above is arc/line map features of a polygon theme/coverage.

ArcInfo allows for both arc/line and polygon labels to exist within the same (polygon) coverage, however,

ArcView does not. Thus two themes are needed to present both the arc/line and polygon attribution of an Arclnfo polygon coverage in ArcView. For an ArcView arc/line theme associated with a polygon coverage, an ' $\mathrm{A}$ ' $(\operatorname{arc})$ is appended to the seven character polygon file name.

As with any digital map model, alterations and additional components, many derived from unique or uncommon map components, continue to advance and expand the model. See Fryer et. al., 2000, Gregson et. al., 1999 and Gregson, 1998 for previous published (abbreviated) versions of the geology-GIS data model. The NPS geologyGIS data model was initially based on the GIS-geology data model published by Carl Harris (1998), with contributions from the AASG/USGS Draft Digital Geologic Map DataModel, Version 4.2 (Johnson et. al., 1998).

\section{GEOLOGIC THEMES}

The NPS geology-GIS model's data themes or coverages are listed below.

\begin{tabular}{|c|c|c|}
\hline Theme & Theme Type & Theme Description \\
\hline$\overline{\text { CODEGLG }}$ & poly/line & $\begin{array}{l}\text { Map units or geologic spatial data containing both polygon data line } \\
\text { describing the map units and linear data describing the interface between } \\
\text { those units. }\end{array}$ \\
\hline CODEGLN & line & $\begin{array}{l}\text { Map units or geological spatial data represented as lines due to map scale } \\
\text { limitations. }\end{array}$ \\
\hline CODEGPT & point & $\begin{array}{l}\text { Map units or geological spatial data represented as points due to map scale } \\
\text { limitations. }\end{array}$ \\
\hline CODEFLT & line & Faults. \\
\hline CODEFLD & line & Linear fold axes/hingelines. \\
\hline CODEATD & point & Attitude observation points. \\
\hline CODEDAT & point & Age-date sample location points (fossil or radiometric age estimates). \\
\hline CODEVNT & point & Volcanic vents, eruptive centers, features mapped as points. \\
\hline CODEVLN & line & Linear volcanic crater, eruptive and flow features. \\
\hline CODEDKE & line & Individual lithologic dikes. \\
\hline CODEDKS & poly/line & $\begin{array}{l}\text { Areas of lithologic dikes too numerous to map as individua line segments } \\
\text { (e.g. dike swarms). }\end{array}$ \\
\hline CODEMIN & point & Mine and mining related features. \\
\hline CODESEC & line & Cross section lines. \\
\hline CODEASH & poly/line & $\begin{array}{l}\text { Volcanic ash map units containing both polygon data describing line the map } \\
\text { units and linear data describing the interface between those units. }\end{array}$ \\
\hline CODEMET & line & Metamorphic grade boundaries. \\
\hline CODEMOR & line & Linear glacial moraine features. \\
\hline CODEJLN & line & Linear joint features. \\
\hline CODELN\# & line & Contour and other lines. \\
\hline CODESPF & point & Geologic point data deemed sensitive by NPS Unit. \\
\hline CODEUPF & point & Unique 'non-sensitive' geologic point data. \\
\hline
\end{tabular}


CODESUR poly/line

CODEMUT point
Surficial geology consisting of both polygon data describing surficial map units and linear data describing the interface between those units.

\# denotes a number assigned to theme/coverage name.

\title{
Theme/Coverage Data Dictionary
}

At present, all of the 22 themes/coverages presented in the data model have been evaluated and adapted into a coverage data dictionary. Of note, each theme/coverage has several attribute fields that ArcInfo adds automatically to a coverage. For polygon and point coverages, AREA, PERIMETER, CODECOV\# and CODECOV-ID are added to the coverages polygon attribute table (.pat). For arc/line coverages and polygon coverage arc/line attribution, FNODE\#, TNODE\#, LPOLY\#, RPOLY\#, CODECOV\# and CODECOV-ID are added to the coverages arc attribute table (.aat). Two INFO look-up tables relating to map source information (CODEMAP) and additional lithology unit data (CODEGLG1) are also presented.

To limit the length of this paper, only four data model themes/coverages are presented. In addition to the themes presented, two INFO look-up tables relating to additional lithology unit data (CODEGLG1) and map source information (CODEMAP) are also presented. Figure 1 illustrates relationships among data model themes/coverages presented in this paper to INFO and dBase database tables and the Windows Help File System (CODEGLG.HLP).

SPATIAL THEME (FILENAME): Area Geologic Map Units (CODEGLG)

THEME DESCRIPTION: Polygon and Arc/line coverage(s)

TABLE COVERAGE/FILE NAME: CODEGLG.PAT (ArcInfo), CODEGLG.DBF (ArcView)

TABLE FORMAT: INFO table (ArcInfo), dBase IV (ArcView)

NUMBER OF FIELDS: 10

$\begin{array}{ll}\text { FIELD NAME } & \text { TYPE - WIDTH } \\ \text { AREA } & \mathrm{F}-4 \\ \text { PERIMETER } & \mathrm{F}-4 \\ \text { CODEGLG_ } & \mathrm{B}-4 \\ \text { CODEGLG_ID } & \mathrm{B}-4 \\ \text { GLG_IDX } & \mathrm{I}-6 \\ \text { GLG_SYM } & \mathrm{C}-12 \\ \text { USGS_SYM } & \mathrm{C}-12 \\ \text { GLG_AGE_NO } & \mathrm{N}-7.4 \\ \text { GMAP_ID } & \mathrm{I}-6 \\ & \\ \text { HELP_ID } & \mathrm{C}-12\end{array}$

\author{
FIELD DEFINITION \\ area of the polygon \\ perimeter of the polygon (in map units) \\ unique internal $(\mathrm{PAL})$ sequence number for each polygon, converted \\ from CODEGLG\# (ArcInfo field). \\ sequence ID-number for each polygon, converted from \\ CODEGLG-ID (ArcInfo field) \\ user-defined ID-number for each polygon, \\ age-lithology unit symbol, used to relate coverage with the \\ CODEGLG1.INF look-up table \\ geologic symbol from USGS geologic map(s) \\ number to age-sort units in legend \\ unique number assigned to each source map by the GRI that relates \\ map feature to series and citation information in CODEMAP.INF \\ look-up table \\ code (code typically GLG_SYM value) used to link to associated \\ geologic text in Help File System
}

\section{SPECIAL COVERAGE GUIDELINES}

1. Water Areas: Non-intermittent areas of water, area rivers, lakes, ponds and reservoir, are to be captured in the CODEGLG coverage/theme. If however, the 'underlying' geologic unit or units can be visually discerned on the source map, then these areas are not to be captured in the CODEGLG coverage/theme. Intermittent bodies are not to be captured unless the 'underlying' geologic unit or units can not be visually discerned on the source map. Captured water areas are denoted in the GLG_SYM and USGS_SYM fields (see field descriptions above) with the text 'WATER', and a GLG_AGE_NO (see field description above) value of 99. 
2. Fault Zones: Areas mapped as fault zones are to be captured in the CODEGLG coverage/theme. These areas are denoted in the GLG_SYM and USGS_SYM fields (see field descriptions above) with the text 'FAULTZONE', and a GLG_AGE_NO (see field description above) value of 98 .

\section{SPATIAL THEME (FILENAME): Geologic Map Unit Boundaries/Contacts (CODEGLG (ArcInfo)/ CODEGLGA (ArcView)) \\ TABLE COVERAGE/FILE NAME: CODEGLG.AAT (ArcInfo), CODEGLGA.DBF (ArcView) \\ TABLE FORMAT: INFO table (ArcInfo), dBase IV (ArcView) \\ NUMBER OF FIELDS: 11}

\begin{tabular}{|c|c|}
\hline FIELD NAME & TYPE \\
\hline FNODE_ & B - 4 \\
\hline TNODE_ & B -4 \\
\hline LPOLY_ & B -4 \\
\hline RPOLY & B -4 \\
\hline LENGTH & $F-4$ \\
\hline CODEGLG_ $_{-}$ & B -4 \\
\hline CODEGLG_ID & B -4 \\
\hline GLGCNT_IDX & I - 6 \\
\hline GLGCNT_TYP & I - 2 \\
\hline FLTCNT & $C-1$ \\
\hline GMAP_ID & I -6 \\
\hline HELP_ID & C -12 \\
\hline
\end{tabular}

FIELD DEFINITION

internal number of arc segment From Node, converted from FNODE\# (ArcInfo field)

internal number of arc segment To Node, converted from TNODE\# (ArcInfo field)

internal left polygon number of arc segment, converted from LPOLY\# (ArcInfo field)

internal right polygon number of arc segment, converted from RPOLY\# (ArcInfo field)

length of arc segment

unique internal sequence, converted from CODEGLG\# (ArcInfo field)

sequence ID-number for each polygon, converted from CODEGLG-ID (ArcInfo field)

user-defined ID-number for each arc segment

code value for type of polygon (contact) boundary*

flags lithologic contacts that are also faults*

unique number assigned to each source map by the GRI that relates map feature to series and citation information in CODEMAP.INF look-up table code used to link to associated geologic text in Help File System

* see Field/Attribute Code Value Lists below

\section{FIELD/ATTRIBUTE CODE VALUE LISTS:}

GLGCNT_TYP (polygon boundary/geologic contact type code)

1 known location

2 approximate location

3 concealed

4 queried

5 approximate location, queried

6 concealed, queried

7 inferred location

8 inferred, queried

9 gradational boundary

10 quadrangle boundary

11 extent/map boundary

12 shoreline

13 shoreline, approximate

14 ice boundary

15 ice boundary, approximate

FLTCNT (contact a fault?)

Y Yes, the lithologic contact is also a fault.

$\mathrm{N} \quad \mathrm{No}$, the lithologic contact is not also a fault. 


\section{SPECIAL COVERAGE GUIDELINES}

1. Contact Arcs in Multiple Themes: Contact arcs that are also geologic faults or are also linear geologic units (FLTCNT $=$ ' $Y$ ', see FLTCNT field description above) are present in both the geology (CODEGLG) and fault (CODEFLT) themes, or the geology (CODEGLG) and linear geologic (CODEGLN) themes, respectively.

2. Contact Arc Directionality: Contact arcs that are also faults are captured with the down-thrown fault block, if applicable, on the 'right side' of the arc. The 'right' and 'left' sides of an arc are determined from 'starting' at the arc's 'from node' (FNODE_) and moving to the arc's 'to node' (TNODE_. . Thus, the down-thrown fault-block should be the arc segment's RPOLY . For fault arcs where the down-thrown block is not or can not be determined, or is not applicable (i.e. a fault with only lateral displacement (heave) and no vertical displacement (throw)), directionality does not matter. Fault arc (capture) directionality is primarily used for graphical representation of a fault where one side of a fault has symbology that is different than the other side of the fault (e.g. a thrust fault with 'teeth' on the up-thrown side).

SPATIAL THEME (FILENAME): Geologic Faults (CODEFLT)

THEME DESCRIPTION: Arc/line coverage

TABLE COVERAGE/FILE NAME: CODEFLT.AAT (ArcInfo), CODEFLT.DBF (ArcView)

TABLE FORMAT: INFO table (ArcInfo), dBase IV (ArcView)

NUMBER OF FIELDS: 15

FIELD NAME

FNODE

TNODE_ $\quad$ B -4

LPOLY_ B -4

RPOLY_ B -4

LENGTH $\quad \mathrm{F}-4$

CODEFLT_ $\quad$ B -4

field)

CODEFLT_ID B - 4

FLT_IDX I - 6

FLT_SEG_N I - 3

FLT_SEG_T I - 2

FLT_TYPE I - 2

FLT_LT I - 3

FLTCNT C -1

FLT_NM C -60

GMAP_ID I - 6

HELP_ID $\quad$ C -12
FIELD DEFINITION

internal number of arc segment From Node, converted from

FNODE\# (ArcInfo field)

internal number of arc segment To Node, converted from TNODE\#

(ArcInfo field)

internal left polygon number of arc segment, converted from

LPOLY\# (ArcInfo field)

internal right polygon number of arc segment, converted from

RPOLY\# (ArcInfo field)

length of arc segment

unique internal sequence, converted from CODEFLT\# (ArcInfo

sequence ID-number for each polygon, converted from

CODEFLT-ID (ArcInfo field)

user-defined ID-number for each arc,

number for each fault segment

code value used to differentiate fault segment line types*

code value for type of fault offset/displacement*

fault and line segment type code value used for line representation*

flags faults that are also contacts*

fault name, if any, common to all arc segments with the same

FLT_IDX.

unique number assigned to each source map by the GRI that relates

map feature to series and citation information in CODEMAP.INF

look-up table

code used to link to associated geologic text in Help File System

* see Field/Attribute Code Value Lists below

\section{FIELD/ATTRIBUTE CODE VALUE LISTS:}

FLT_SEG_T (geologic fault segment line type code)

1 known location

2 approximate location 


$\begin{array}{cl}3 & \text { concealed } \\ 4 & \text { queried } \\ 5 & \text { approximate location, queried } \\ 6 & \text { concealed, queried } \\ 7 & \text { inferred location } \\ 8 & \text { inferred, queried } \\ \text { FLT_TYPE (fault offset/displacement type code) } \\ 1 & \text { thrust fault } \\ 2 & \text { reverse fault } \\ 3 & \text { low angle normal fault } \\ 4 & \text { normal fault } \\ 5 & \text { right lateral strike-slip fault } \\ 6 & \text { left lateral strike-slip fault } \\ 7 & \text { reverse right lateral strike-slip fault } \\ 8 & \text { reverse left lateral strike-slip fault } \\ 9 & \text { normal right lateral strike-slip fault } \\ 10 & \text { normal left lateral strike-slip fault } \\ 11 & \text { unknown offset/displacement } \\ 12 & \text { landslide scarp } \\ 13 & \text { detachment fault } \\ 14 & \text { high angle fault } \\ 15 & \text { right lateral fault, vertical displacement/offset unknown } \\ 16 & \text { left lateral fault, vertical displacement/offset unknown } \\ \text { FLTCNT (fault also a contact?) } \\ \text { Y } & \text { Yes, the fault is also a contact between different map units. } \\ \text { N } & \text { No, the fault is not a contact between different map units } \\ 18 & \text { thrust fault, inferred, queried } \\ 11 & \text { thrust fault } \\ 13 & \text { thrust fault, approximate location } \\ 14 & \text { thrust fault, concealed } \\ 15 & \text { thrust fault, queried } \\ 16 & \text { thrust fault, approximate location, queried } \\ \text { thrust fault, concealed, queried } \\ \text { FLT_LT (line type code) }\end{array}$

\section{SPECIAL COVERAGE GUIDELINES}

1. Fault Arcs in Multiple Themes: Fault arcs that are also geologic contacts between different geologic units or are also linear geologic units (FLTCNT = 'Y', see FLTCNT field description above) are present in both the fault (CODEFLT) and geology (CODEGLG) themes, or the fault (CODEFLT) and linear geologic (CODEGLN) themes, respectively.

2. Fault Arc Directionality: Fault arcs are captured with the down-thrown fault block, if applicable, on the 'right side' of the arc. The 'right' and 'left' sides of an arc are determined from 'starting' at the arc's 'from node' (FNODE_) and moving to the arc's 'to node' (TNODE_). The down-thrown fault-block should be the arc segment's RPOLY_. See Standard ArcInfo Arc Attribute Fields section for FNODE_, TNODE_ and RPOLY_definitions/descriptions. For fault arcs where the down-thrown block is not or can not be determined, or is not applicable (i.e. a fault with only lateral displacement (heave) and no vertical displacement (throw)), directionality does not matter. Fault arc (capture) directionality is primarily used for graphical representation of a fault where one side of a fault has symbology that is different than the other side of the fault (e.g. a thrust fault with 'teeth' on the up-thrown side). 
SPATIAL THEME (FILENAME): Attitude Observation Points (CODEATD)

THEME DESCRIPTION: Point Coverage

TABLE COVERAGE/FILE NAME: CODEATD.PAT (ArcInfo), CODEATD.DBF (ArcView)

TABLE FORMAT: INFO table (ArcInfo), dBase IV (ArcView)

NUMBER OF FIELDS: 10

FIELD NAME

AREA

PERIMETER

CODEATD_

CODEATD_ID

ATD_IDX

ATD_TYPE

ATD_ST

ATD_DP

ATD_AV_ROT

GMAP_ID

HELP_ID

TYPE - WIDTH
$\begin{aligned} & \text { F - } 4 \\ & \text { F - } 4 \\ & \text { B - } 4\end{aligned}$

B - 4

I - 6

I - 2

I - 3

I - 2

I - 3

I -6

* see Field/Attribute Code Value Lists below

\author{
FIELD DEFINITION \\ area of the point \\ perimeter of the point (in map units) \\ unique internal sequence number for each point, converted from \\ CODEATD\# (ArcInfo field). \\ sequence ID-number for each point, converted from CODEATD-ID \\ (ArcInfo field) \\ user-defined ID-number for each point \\ code value for type of attitude measurement* \\ azimuth of strike or trend, (0-359) degrees clockwise from the north \\ with dip direction clockwise from strike direction (right-rule \\ method). non-applicable strike values assigned a value of 999 . \\ dip or plunge degrees from horizontal \\ ArcView symbol rotation value field, used for symbol presentation \\ unique number assigned to each source map by the GRI that relates \\ map feature to series and citation information in CODEMAP.INF \\ look-up table \\ code used to link to associated geologic text in Help File System
}

\section{FIELD/ATTRIBUTE CODE VALUE LISTS:}

ATD_TYPE (observation code for structural attitude point)

1 strike and dip of beds

2 strike and dip of overturned beds

3 strike of vertical beds

4 horizontal beds

$5 \quad$ strike and dip of beds, tops known from sedimentary structures

6 strike and dip of overturned beds, tops known from sedimentary structures

7 strike and dip of beds, tops known from sedimentary structures, dot indicates top of beds

8 strike and dip of variable bedding

9 approximate strike and dip of beds

10 strike of beds, dip amount unspecified

11-87 additional attitude point features types

\section{SPECIAL COVERAGE GUIDELINES}

1. Point Placement: For most attitude point types, placement of a digitized point is at the center of the point's graphical symbol. However, for many attitude points that represent fault or fold type, directionality and/or attitude, point placement should be on the related fault or fold arc/line.

2. Feature Symbol Rotation and Strike/Trend Values: The rotation value used to correctly orient many attitude feature symbols in ArcView, as mentioned in the ATD_AV_ROT field description presented above, is dependent on the type of attitude feature, the symbology used to represent that feature in ArcView, and the default or non-rotated orientation of that symbol. For many of these features, a directional component or azimuth, either strike or trend, measured at the locality is conveyed in the graphical orientation of that feature, and is therefore directly related to a value that rotates the orientation of that feature's symbol. Thus, it is possible to determine the ATD_ST value from the ATD_AV_ROT field, and vice versa. Formulas to calculate the ATD_ST value from the ATD_AV_ROT value, and vice versa, are presented in an appendix file, ATDAVROT.DOC. 
SPATIAL THEME (FILENAME): Cross Section Lines (CODESEC)

THEME DESCRIPTION: Arc/line coverage

TABLE COVERAGE/FILE NAME: CODESEC.AAT (ArcInfo), CODESEC.DBF (ArcView)

TABLE FORMAT: INFO table (ArcInfo), dBase IV (ArcView)

NUMBER OF FIELDS: 12

\begin{tabular}{|c|c|c|}
\hline FIELD NAME & TYPE - WIDTH & FIELD DEFINITION \\
\hline FNODE_ & B -4 & $\begin{array}{l}\text { internal number of arc segment From Node, converted from FNODE\# } \\
\text { (ArcInfo field) }\end{array}$ \\
\hline TNODE_ & B -4 & $\begin{array}{l}\text { internal number of arc segment To Node, converted from TNODE\# } \\
\text { (ArcInfo field) }\end{array}$ \\
\hline LPOLY $_{-}$ & B -4 & $\begin{array}{l}\text { internal left polygon number of arc segment, converted from } \\
\text { LPOLY\# (ArcInfo field) }\end{array}$ \\
\hline RPOLY & B -4 & $\begin{array}{l}\text { internal right polygon number of arc segment, converted from } \\
\text { RPOLY\# (ArcInfo field) }\end{array}$ \\
\hline LENGTH & $F-4$ & length of arc segment \\
\hline CODESEC_ & B -4 & $\begin{array}{l}\text { unique internal sequence, converted from CODESEC\# (ArcInfo } \\
\text { field) }\end{array}$ \\
\hline CODESEC_ID & B -4 & $\begin{array}{l}\text { sequence ID-number for each polygon, converted from } \\
\text { CODESEC-ID (ArcInfo field) }\end{array}$ \\
\hline SEC_IDX & I -6 & unique ID-number for each cross section line \\
\hline SEC_ABV_O & $C-6$ & initial cross section abbreviation on geologic map \\
\hline SEC_ABV & C -6 & cross section abbreviation on digital map \\
\hline SEC_FILE & $C-60$ & $\begin{array}{l}\text { file directory path and graphics file name of cross section .jpg file, } \\
\text { path and filename is 'passed' to a graphics viewer program that } \\
\text { displays the cross section graphic (ex. d:Dblcaldatalnrdatalgeologyl } \\
\text { graphics } 5 \text { 584a.jpg), }\end{array}$ \\
\hline GMAP_ID & I - 6 & $\begin{array}{l}\text { unique number assigned to each source map by the GRI that relates } \\
\text { map feature to series and citation information in CODEMAP.INF } \\
\text { look-up table }\end{array}$ \\
\hline
\end{tabular}

\section{SPECIAL COVERAGE GUIDELINES}

None.

\section{ACCESSORY DATA FILES}

Additional data on unit lithology and source map information are included in two look-up tables that are related to map coverages through a primary or secondary key field.

TABLE COVERAGE/FILE NAME: CODEGLG1.INF (ArcInfo), CODEGLG1.DBF (ArcView)

TABLE FORMAT: INFO table (ArcInfo), dBase IV (ArcView)

NUMBER OF FIELDS: 11

$\begin{array}{ll}\text { FIELD NAME } & \text { TYPE - WIDTH } \\ \text { GLG_SYM } & \text { C }-12 \\ \text { GLG_NAME } & \text { C }-100 \\ \text { G_REL_AGE } & \text { C }-5 \\ \text { G_SSCR_TXT } & \text { C }-6 \\ \text { GLG_AGE_NO } & \text { N }-7.4 \\ \text { G_AGE_TXT } & \text { C }-50 \\ \text { G_MJ_LITH } & \text { C }-3 \\ \text { G_LITH_ID } & \text { I }-10 \\ \text { G_LITH_TXT } & \text { C }-100\end{array}$

\section{FIELD DEFINITION}

age-lithology unit symbol, used to relate the coverage with the CODEGLG.INF or CODEGLG1.DBF

formal name of map unit, if any

relative age of geologic units

subscript from the map symbol

number to age-sort map units in legend

geologic time period of map unit

code value for lithologic type*

code value used to describe lithology

brief text describing lithology 


$\begin{array}{ll}\text { G_NOTE_TXT } & \text { C }-254 \\ \text { GMAP_SRC } & \text { C }-100\end{array}$

* see Field/Attribute Code Value Lists below descriptive notes about the map unit source map(s) with organization and map series number (i.e. USGS GQ-1402, USGS GQ-1568)

FIELD/ATTRIBUTE CODE VALUE LISTS:

G_MJ_LITH (map unit major lithology code)

EXT extrusive igneous

IAM intrusive igneous and metamorphic

INT intrusive igneous

MET metamorphic

SED sedimentary

VAS volcanic and sedimentary

UNC unconsolidated

Example record from CODEGLG1.INF or CODEGLG1.DBF

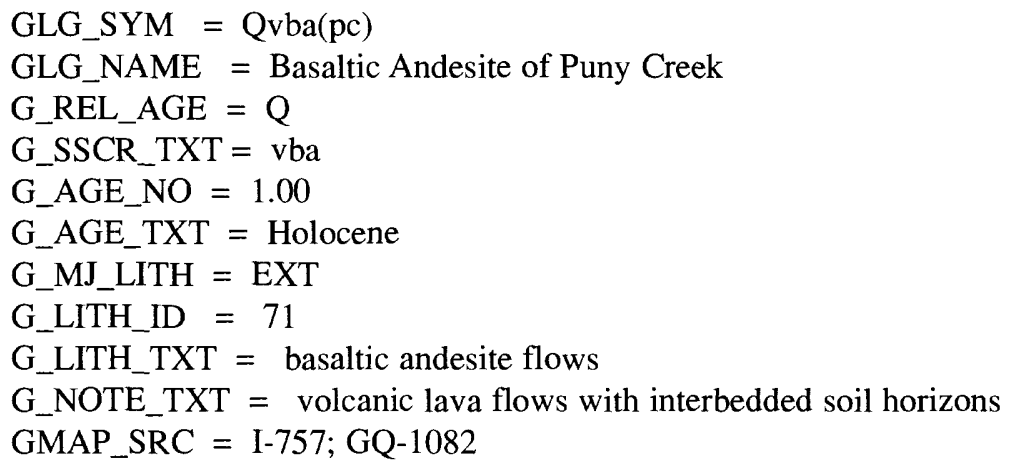

TABLE COVERAGE/FILE NAME: CODEMAP.INF (ArcInfo), CODEMAP.DBF (ArcView)

TABLE FORMAT: INFO table (ArcInfo), dBase IV (ArcView)

NUMBER OF FIELDS: 18

$\begin{array}{ll}\text { FIELD NAME } & \text { TYPE - WIDTH } \\ \text { GMAP_ID } & \mathrm{I}-6 \\ \text { GMAP_CODE } & \mathrm{C}-4 \\ \text { GMAP_ABBRV } & \mathrm{C}-150 \\ & \\ & \\ \text { GMAP_YEAR } & \mathrm{I}-4 \\ \text { GMAP_AUTH } & \mathrm{C}-254 \\ \text { GMAP_ORG } & \mathrm{C}-100 \\ \text { GMAP_TITLE } & \mathrm{C}-200 \\ \text { GMAP_SER } & \mathrm{C}-40 \\ \text { GMAP_SCALE } & \mathrm{I}-7 \\ \text { GMAP_PROJ } & \mathrm{C}-100 \\ \text { GMAP_REF } & \mathrm{C}-254 \\ \text { GMAP_DESC } & \mathrm{C}-254 \\ \text { GMAP_XMAX } & \mathrm{N}-9.6 \\ \text { GMAP_XMIN } & \mathrm{N}-9.6 \\ \text { GMAP_YMAX } & \mathrm{N}-9.6 \\ \text { GMAP_YMIN } & \mathrm{N}-9.6 \\ \text { GMAP_SRC } & \mathrm{C}-100\end{array}$

\section{FIELD DEFINITION}

unique number assigned to each source map by the GRI

unique 4-letter abbreviation code assigned to each source map by the GRI

abbreviation of map title, often includes map name and interpretation technique (e.g., Preliminary) and/or a term that indicates the type of material (e.g., Surficial, Bedrock)

compilation or publication year

map author(s)

organization that created or compiled the map

complete map title

map series or organizational identifier (e.g., USGS GQ-1516)

source map scale denominator

name or description of map projection with projection datum complete map citation in USGS style

brief description of the map

western limit of map in decimal degrees eastern limit of map in decimal degrees northern limit of map in decimal degrees southern limit of map in decimal degrees source map(s) with organization and map series number (i.e. USGS GQ-1402, USGS GQ-1568) 
Example record for the Geologic map of Rocky Mountain National Park and Vicinity, Colorado. The 4-letter NPS alpha code for Rocky Mountain NP is ROMO.

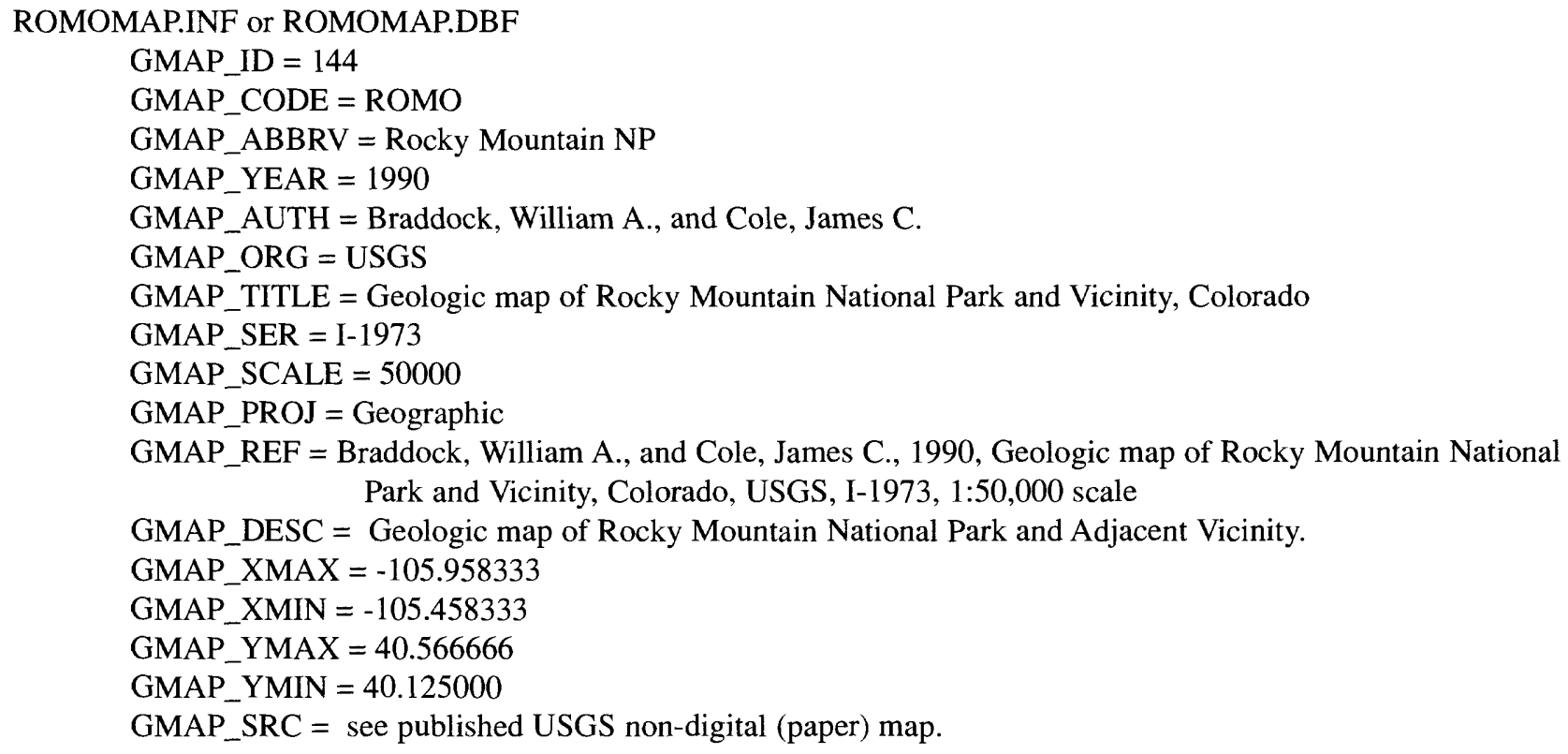

\section{REFERENCES}

Fryer, S.L., Gregson, Joe, Poole, Anne, Connors, Tim, and Heise, Bruce, 2000, The National Park Service Digital Geologic Map Model: Transformation from Paper to Digital, Featuring Legends, Cross Sections, Map Notes and Keyword Searchability, in D.R. Soller, ed. Digital Mapping Techniques ' 00 - Workshop Proceedings: U.S. Geological Survey Open-File Report 00-325, p.69-82,

$<$ http://pubs.usgs.gov/openfile/of00-325/fryer.html>.

Gregson, J.D., Fryer, S.L., Poole, Anne, Heise, Bruce, Connors, Tim, and Dudek, Kay, 1999, Geologic Resources Inventory for the National Park System: Status, Applications, and Geology-GIS Data Model: in D.R. Soller, Digital Mapping Techniques '99-Workshop Proceedings, U.S. Geological Survey Open-File Report 99-386, p. 151-162, <http://pubs.usgs.gov/openfile/of99-386/gregson.htm>.
Gregson, J.D., 1998, Geologic Resources Inventory-Geologic Resources Division, Inventory and Monitoring Program: in D.R. Soller, Digital Mapping Techniques '98-Workshop Proceedings, U.S. Geological Survey Open-File Report 98487 , p. 109-111, <http://pubs.usgs.gov/openfile/ of $98-487 /$ gregson.html $>$.

Harris, Carl F.T., 1998, Washington State's 1:100,000-Scale Geologic Map Database: An ArcInfo Data Model Example: in D.R. Soller, Digital Mapping Techniques '98-Workshop Proceedings, U.S. Geological Survey Open-File Report 98487 , p. $27-35$, <http://pubs.usgs.gov/openfile/of $98-487 /$ harris.html>.

Johnson, B.R., Brodaric, Boyan, and Raines, G.L., 1998, Draft Digital Geologic Map Data Model, Version 4.2: American Assoc. of State Geologists/U.S. Geological Survey Geologic Map Data Model Working Group, May 19, 1998, <http://geology.usgs.gov/model/model42.pdf/>. 


\section{Special Session: Field Data Capture of Geologic Map Information}

Digital techniques for preparing and analyzing geologic map information continue to evolve rapidly. This is especially true for preparation, in the office, of GIS-ready products and data sets. There, digital techniques recently have become the conventional means for creating and producing geologic maps. As a result, the data that are used to create these maps can become available to build map databases. In turn, the map databases can be used for sophisticated spatial analyses. We all recognize that, ideally, the principal product of geologic mapping should be a database, from which both analyses and traditional maps can be derived. To most fully address this ideal, digital information must be created not after the maps are produced, but in the field, as the geologic observations and interpretations are being recorded. Otherwise, only the subset of field information deemed suitable for display on the map will be available to the database.

However, field geologists do not yet commonly record their observations in digital form. Many variables contribute to this situation, for example:

- there exists a wide variety of hardware and software tools,

- the cost of these tools is in many cases prohibitive,

- the rate of technological change is high, which causes tools to quickly become obselete,

- systematic, formal evaluations of hardware and software, by field geologists, are few in number,

- the significant differences in geologic setting and topographic conditions in various field areas affect the choice of optimum field system, and perhaps most significantly,

- geologists, like any other group of people, tend to prefer to work with familiar techniques that enhance rather than constrain their activities.

To help provide more information on field data capture systems, previous DMT workshops have included the following presentations and papers on the subject:

Brodaric, Boyan, 2000, Digital Geological Knowledge:

From the Field to the Map to the Internet (DMT'00; USGS Open-file Report 00-325;

http://pubs.usgs.gov/openfile/of00-325/brodaric.html).

Kramer, J.H., 2000, Digital Mapping Systems for Field

Data Collection (DMT'00; USGS Open-file Report 00-325; http://pubs.usgs.gov/openfile/of00-325/ kramer.html).

Walsh, G.J., Reddy, J.E., and Armstrong, T.R., 1999, Geologic Mapping and Collection of Geologic
Structure Data with a GPS Receiver and a Personal Digital Assistance (PDA) Computer (DMT'99; USGS Open-file Report 99-386; http://pubs.usgs.gov/openfile/of99-386/walsh.html).

Brodaric, Boyan, 1997, Field Data Capture and Manipulation Using GSC Fieldlog v3.0 (DMT'97; USGS Open-file Report 97-269; http://pubs.usgs.gov/openfile/of97-269/ brodaric.html).

Williams, Van, 1997, Using the GSMCAD Program with GPS for Data Collection in the Field and as a Quick and Efficient Way of Creating Arc/Info Geologic Map Coverages (DMT'97; USGS Open-file Report 97-269; http://pubs.usgs.gov/openfile/of97-269/ williams.html).

At last year's DMT workshop, the attendees asked for a more lengthy focus on field data capture systems. This year's workshop therefore provided a set of oral presentations and hands-on field demonstrations, as an introduction to techniques, software, and hardware used for digital collection of geologic map information in the field. The following presentations were given. These are supported by papers in these Proceedings, except as noted.

"Integrating Field Databases using Data Models in FieldLog," by Boyan Brodaric (Geological Survey of Canada and Pennsylvania State University). For more information, please see his papers cited above.

"Removing Science Workflow Barriers to Adoption of Digital Geological Mapping by Using the GeoMapper Universal Program and Visual User Interface," by George H. Brimhall and Abel Vanegas (University of California, Berkeley).

"Using Handheld Personal Computers as Field Data Collection Tools: Some Lessons Learned in the School of Hard Knocks in the Wingate Wash Project and Related Projects using FieldLog/Fieldworker Software Exported to ArcInfo," by Terry L. Pavlis (University of New Orleans) and Jason Little (California Division of Mines and Geology).

"Field Geologic Data Collection with ArcPad and ArcGIS," by Mike Price (ESRI). For more information, please see the section entitled "Vendor Presentations and Contact Information."

"Quebec Geomining Information System (SIGÉOM): Field Data Capture module," by Charles Roy (Systeme d'Information geominiere du Quebec [SIGEOM]). 
"Conclusions From Four Years Collecting Digital Map Data Using A PDA," by Van Williams (U.S. Geological Survey).

"Development and Use of a Laptop-Based Geological Mapping System: Experiences at the University of Kansas," by R.A. Black and J.D. Walker (University of Kansas).
Also, Steve Bedsole (Geographical and Environmental Data Services, Inc.) provided technical support to the field demonstration portion of the session. For more information, please see the section entitled "Vendor Presentations and Contact Information." 


\title{
Removing Science Workflow Barriers to Adoption of Digital Geological Mapping by Using the GeoMapper Universal Program and Visual User Interface
}

\author{
By George H. Brimhall and Abel Vanegas \\ University of California, Berkeley \\ Earth Resources Center Digital Mapping Lab \\ Department of Earth and Planetary Science \\ 307 McCone Hall \\ Berkeley, CA 94720-4767 \\ Telephone: (510) 642-5868 \\ Fax: (510) 643-8443 \\ e-mail: brimhall@socrates.berkeley.edu
}

\section{INTRODUCTION}

Currently, digital mapping technology is evolving rapidly through a challenging transitional period between lingering use of paper and conversion to promising digital media and electronic mapping methods. Until recently, digital mapping has referred to various facets of this transitional phase in terms of technology: cataloging existing maps in digital form for retrieval (Soller et al, 2000), devising a lexicon of geological names (Stamm et al, 2000), GIS information management (Brodaric, 2000), cartographic symbolization (Soller and Lindquist, 2000), production of final maps after scanning paper based maps (Stanford and MacKubbin, 2000), compilation and digitization (Furr, 2000), retrieving information using GIS (Fryer et al, 2000) and visualization (Morin, 2000). Progress has been faster in developing digital technology to support office map production than in actual mapping in the field. Our work is an effort to help close the gap between the promise and productivity of digital mapping.

The status of field data collection using digital mapping systems as opposed to digitization of paper maps, was summarized by Kramer (2000) including our progress developing GeoMapper within the Earth Resources Center of the University of California, Berkeley (ERC) (Brimhall, 1998, 1999, 2000; Brimhall and Vanegas, 2000, 2001;

Vanegas et al, 2000 ). GeoMapper in this earlier phase of development was a pen-based system for making geological maps in the field using Strata Software's PenMap as a digitizing tablet to create macro buttons expressing the basic geological symbols for structures, contacts, and colored area fills. By creating new maps directly in digital form in the field using GeoMapper to support digital tools, many of the aforementioned time consuming steps that are a byproduct of the transitional phase between traditional paper-based media and digital electronic form could be circumvented. At that point in time more than a year ago, customization of the GeoMapper mapping legend to accommodate a user's local geology (stratigraphy, mineralization, alteration and sample types) required a thorough knowledge of the entire PenMap macro file programming module suite (PenMap3, Formgen, PmwCustomizer and RastMap). Attainment of this level of programming proficiency requires both an investment of time of many months and a technical background in programming quite uncommon for many practicing field geologists. Hence, constructing a mapping legend for each new project area was a major undertaking impossible without programming skills and a considerable investment in time. Nevertheless, working in the ERC Digital mapping lab we completed GeoMapper mapping legends and mapping systems for the Western Mining Corporation (WMC) of Australia, Placer Dome Exploration for their Getchell Mine in Nevada, Codelco, Chile for their Chuquicamata mine, and for introductory and advanced field geology classes of the Department of Earth and Planetary Sciences, University of California Berkeley. We now are in our third year of digital mapping at UC Berkeley. The GeoMapper systems were tested, refined and improved through their use in both surface and underground geological mapping and function well over small to large scale maps in a wide spectrum of geological environments. GeoMapper has also been used in the ERC in support of abandoned mine characterization using hyperspectral visible light/infrared 
methods supported by real-time GPS and laser positioning (Montero-Sanchez and Brimhall, 1998, 2000; MonteroShanchez et al, 1999; Takagi and Brimhall, 2000).

\section{BARRIERS TO ACCEPTANCE OF DIGITAL TECHNOLOGY}

These ERC digital mapping research and development projects provided much knowledge about the nature of the modern mapping discipline in academia and industry. Especially revealing aspects have been desirable features and the breadth of technical demands on the systems covering a spectrum from new mappers in the field mapping classes to experienced professionals. Especially important is (1) the need to find ways to engage users whose backgrounds in computing is limited although they may be excellent experienced mappers. This work also revealed (2) a number of distinct barriers to acceptance of digital mapping that are surprisingly similar to those recognized for acceptance of mobile computing in the healthcare industry in daily practice (Stetson, 2001).

Acknowledgement and resolution of shortcomings is essential to advancement and acceptance of new technology.

\section{Learning From Medicine}

In healthcare, medical professionals (doctors and nurses) point out that slowness to accept pen computer-based systems is due to (1) cost, (2) cross vendor incompatibility, (3) office workflow disruption and (4) slowness and complexity of data entry. In a hospital, time is at an absolute premium. Any system that slows down a clinician is unacceptable. Stetson (2001) points out that medical software does seem designed to meet well-known office administrative requirements such as medical forms, but then ignores the bedside and laboratory clinical requirements of how doctors do their work with patients. Clinicians prefer digital systems that, in addition to administrative needs, meet their own workflow preferences as practitioners so that digital tools are both familiar enough and simple enough for personnel to quickly grasp and use confidently while performing their jobs.

\section{Learning From Mapping Experience}

Geological mapping has many similarities to medical practice both in terms of technical issues in map production in the office and performance in the field. Highlytrained scientists and engineers conduct their professional discipline by actively seeking information, making instantaneous interpretations and decisions. Contrary to common perceptions, the gravity of the interpretation by field mappers is often no less than in medicine. Our scientific conclusions often can affect the lives of numerous people and the efficacy of financial investment in the billions of dollars as in construction, water resource management, mining, environmental applications and emergency intervention and planning for natural hazards like earthquakes, floods and landslides. Consequently, a digital mapping system must meet the workflow needs of this user group if they are to work with confidence and facility and to supply vitally-important geo-spatial information and interpretations. Software systems designed largely for the office environment of map production cannot do this effectively. Finally, since mapping addresses three dimensional exposures, existing mapping systems that support only mapping in plan view leave a large gap in required mapping capabilities.

\section{THE PROMISE OF DIGITAL MAPPING}

If proven to be practical, economical and flexible in terms of mapping in plan or section, portable integrated field mapping systems supported by GPS, lasers and digital cameras could soon become commonplace not only for mapping on land, but underground, from the air, on the sea bed, and ultimately in space on other planetary surfaces. Resource sustainability on a global basis has become an imperative societal goal making geo-spatial phenomena the central scientific infrastructure. However, for digital mapping to realize its potential to serve these needs as a truly enabling generative technology worthy of becoming widely adopted and ultimately replacing the traditional paper methods while creating valuable new knowledge about the earth, a significant challenge remains to be overcome in software design and functionality as it does in medicine. The present limitations are surprisingly similar and stem from not fully acknowledging the scientific needs of practitioners, especially as being distinct from technological needs alone. We need to manage new technologies more effectively in doing science. Here we address only the issue of workflow and throughput, and view the remaining problems of cost and vendor incompatibility as being dependent upon the digital mapping systems first proving to be useful before they become commonplace.

\section{The Different Challenges of Science and Technology}

Science and technology are alternative perspectives of knowledge and especially of use of instrumentation.

Science seeks a deep understanding of natural phenomena while technology uses advanced technical means to serve human ends. A geological map is fundamentally an information-rich scientific document although it is produced technically. Digital mapping technology is rightly concerned with technical issues, yet another important dimension of the map is its scientific knowledge. This scientific knowledge is created by a highly-trained scientist with 
needs in the field quite distinct from those of office personnel who produce the map and deal with data base management. In some organizations, the mapper and map producer are one in the same individual. Recalling space exploration, man is the "most extraordinary computer of them all ...(whose) judgement, nerve and ... (ability to) learn from experience still make him unique" among instruments (John F. Kennedy in Sorensen, 1965). In advancing GeoMapper, we have viewed our challenge then to be in constructing a software architecture that above all else enables the scientific mission in the field and provides a compatibility with subsequent map production needs so the two activities become mutually supportive.

We perceive two main challenges in mapping software design. The first is creation of an effective visual user interface to manage mapping tools, graphics and files for local geology in such a way that the system being used actually feels to a geologist like normal mapping and produces professional quality maps at a rate sufficient to make the system cost effective by eliminating unnecessary paper media steps. Secondly, the software also needs to offer a practical means of incorporating the essential stratigraphic and lithological features of a wide range of geological terranes so that each geologists can begin new projects without delay using a newly-created and appropriate legend. With respect to both challenges, it is impractical to require users to know even macro language programming to create a usable visual interface for their work. The visual user interface constitutes the entirety of the link between their professional scientific skills and the new digital tools at their disposal. With this interface they confront the realities of nature to be mapped; therefore it must be familiar, comprehensive, easy to use and easy to personalize to local setting otherwise it is a formidable barrier.

\section{GEOMAPPER UNIVERSAL}

It is essential to realize that when we geologists map, we are in fact practicing our scientific discipline in the field through observation, exercising reasoning and using the scientific tools intrinsic to geology. A visual user interface must provide much more than graphic tools like points, lines and areas, colors and data bases in a generic visual user interface. The term "user friendly" does not convey much of the requirement as it does not inform one of what is really necessary to provide utility. Here we present our recent advances in designing the second generation of GeoMapper (GeoMapper Universal) with totally new visual user interfaces for a geologist to readily personalize the mapping legend for local geology on a project basis, learn the mapping system and readily conduct digital geological mapping using the scientific methods of field geology (Brimhall and Vanegas, 2001) including mapping in section view. Unless digital mapping capabilities meet both technological and scientific requirements of field geology as it is practiced today and are robust and easy to use, adoption will come only slowly after each barrier to use is removed. Present mapping capabilities with traditional methods are immensely powerful and the tools are simple and inexpensive. Traditionally, a geologist carries a map board with colored pencils, paper maps, a compass and scales. This tool box is quite similar to that of a doctor or a nurse. By practical necessity, the tools in both cases have evolved to the point of near perfection for what they present: an inexpensive, portable, light weight paperbased medium proven by the test of time to offer the essential information of science at the lowest cost.

\section{EVOLUTION OF MAPPING AS THE SCIENTIFIC BASIS OF GEOLOGY}

Mapping using paper media has been a core discipline of professional geology in the U.S. for a century in federal and state agencies, industry and academic training.

Interaction between these groups has proven mutually beneficial to advancing mapping techniques and science. The traditions have been proven globally in all types of field conditions, varied geology, and project scope from rapid reconnaissance to detailed mine mapping at a variety of scales. Mapping has evolved considerably from scientific support of mining by the U.S. Geological Survey (Lindgren and Turner, 1894, 1895) which set an international standard of excellence in surface mapping, color folio map production, cross sections and general scientific interpretive utility. Industrial geologists, initially in the Anaconda Company in Butte Montana, developed standardized mapping procedures for underground mines forming the basis of compilation of plan level maps, serial cross sections and three dimensional geological models used in exploration, development and resolution of vein apex mining law litigation (Brunton, 1901; Linforth, 1914; Sales, 1929, 1941; McLaughlin and Sales, 1933; McKinstry, 1948). To prepare students for this growing geological field, systematic field mapping classes for undergraduate students were instituted in the US and Canada; one of the first in 1892 at the University of California, Berkeley by Professor Andrew Lawson. Over the next half century, training in surface mapping evolved (Derry, 1947) and remains a requirement in the curricula of most earth science programs including intensive summer field training. Three kinds of information uniquely accessed in the field are addressed: direct observation and measurement, age relations and interpretation (Compton, 1985). Field camps still provide the systematic training of young geologists to address district scale investigations. Map compilations by the AAPG on a continental scale (Derry, 1980) especially correlation by lithotectonic units, age of the sea floor and orogenesis (Muelberger, 1996) provide the basis for crustal evolution models, ocean basin dynamics, metallogenic provinces, and energy resource 
appraisal. This evolution in mapping and ever-increasing use of maps in earth sciences, means that the challenges facing digital mapping are considerable and demand an exacting set of standards of digital systems, flexibility, and immediate adaptability. Digital mapping cannot compromise these professional standards and succeed.

\section{What We Do in the Field and How We Map}

To offer more than a generic graphical tool pad with device drivers for pen input and control of electronic instrumentation, it is essential to design a geological user interface around the practical needs of earth scientists and engineers to map field relationships and to produce finished maps and data bases as part of our workflow. Fundamentally, all mapping is a reasoned abstraction; a simplified scaled rendering and projection of complex reality made visible through observation on the small scale of exposures which are mapped on larger scales onto a chosen plane of projection as a representation. We reduce four dimensional space-time to a two dimensional plane with line, area and symbol attributes to convey time. Orientation and numerical data are related to symbols. How and what we map are determined by our purpose, map scale and time frame. In adapting digital tools for mapping, there are advantages in retaining traditions in so far as they remain useful and provide familiarity and continuity that aid learning a new digital system.

\section{Interactive Feedback in a Continuum of Geo-spatial Activity}

In the process of developing GeoMapper to implement mapping in a style even approaching the practicality and level of excellence developed over the twentieth century, one is forced to confront the profound complexity of what we geologists actually do in the field and call "geological mapping." Geological mapping is the practice of systematically delineating, classifying and recording a complex variety of natural geological features in an organized and disciplined fashion and applying the scientific method of hypothesis testing using graphical relationships. The body of necessary knowledge is immense. Cognition and spatial problem solving is an on-going part of mapping which is then, intrinsically, a real-time process. Through the process of mapping, new insights continuously emerge from the map patterns which provide guidance as to what features to map next, which direction to go next, and which multiple working hypotheses to entertain until one proves superior to the others. Hence, geological mapping is an interactive, real-time scientific discipline which accommodates identification of complicated geospatial and temporal features, flexibility in interpretation, error assessment in making interpretations, and managing unforeseen complexity in the earth as it unfolds on a developing map.

\section{The Mapping Continuum and the Visual User Interface}

Translated into a digital formalism, mapping proves to be a great deal more than what is often referred to in the digital media world as "field data capture, 3-D modeling, GIS analysis, data base management or visualization." Mapping is, in practice, all of these processes undertaken together simultaneously in real-time outdoors or underground immersed in nature. Mapping is not a sequence of discrete point measurements although to non-geologists it may appear so. Instead, mapping is a continuum of activities requiring one to keep oriented, located, and continually aware of their lithological and structural environment. In the transition from paper to digital records, digital mapping has been to some extent disintegrated into separate component parts so that each component can take advantage of a specific digital tool; some in the office and others in the field. In making a digital mapping field system however, all the parts need to function together in harmony and be readily accessed and implemented in the routine that mappers deem convenient and essential to workflow and throughput. The problem is that while technological adaptation and substitution can mimic and replace certain traditional mapping procedures, we need to reintegrate the component parts of the new digital technology around the actual activities of the scientist in the field using the visual user interface and pen stylus as the sole control. Our focus has been on finding the most direct means of mapping using digital technology with as few interruptions and departures from how we normally map.

\section{Digitizing Tools}

GeoMapper uses a variety of digital tools including Strata Software's PenMap as a digital graphical tool implementing powerful components of mapping in the style of an "electronic plane table." In computer usage these tools are points, lines, symbols and areal pattern and color attributes which are located graphically as geo-spatial features. Through the GeoMapper visual user interface we organize such raw graphic tools and file structures into a geological formalisms such as lithology, formations, structures etc. Device drivers for using digital GPS and laser equipment in surveying are also an integral part of the PenMap tool package.

\section{GEOMAPPER UNIVERSAL'S ARCHITECTURE}

GeoMapper uses several computer programs to execute the mapping process in a manner consistent with 
established procedures, preferred work sequences and efficiency sufficient as to be considered practical. Since the earth is complex and geology enormously varied, organization is the critical issue to rapid startup, workflow, compilation, data management and map production.

GeoMapper Universal provides users a range of organizational features which (1) simplify personalization for local geology around a project orientation, (2) implement geological mapping in either plan and arbitrary section views, (3) separate common mapping activities used most frequently from those that are used only occasionally, and (4) export and manage data files.

\section{Project Manager}

The GeoMapper visual user interface is logical and largely self explanatory from the standpoint of a geologist. The first activity in starting a new mapping project is to investigate and define the local geological stratigraphic column. Once a digital mapping legend is created, a user does not need to go back though this step whenever they start a new days' mapping. Hence, we have combined these two steps into a single Project Manager startup screen in GeoMapper Universal (figure 1). The screen shows the names of the Projects, here as "general geology." By clicking on Create a New Project Legend, a new project title can be added to the list and selected at will from all those created. Then click either on Start Mapping or Personalize Legend to proceed.

\section{Legend Maker}

The stratigraphic section in an area of interest is the geologist's link with time and process and defines the units to be mapped. In any region of the U.S., the local stratigraphic section can be easily downloaded digitally or

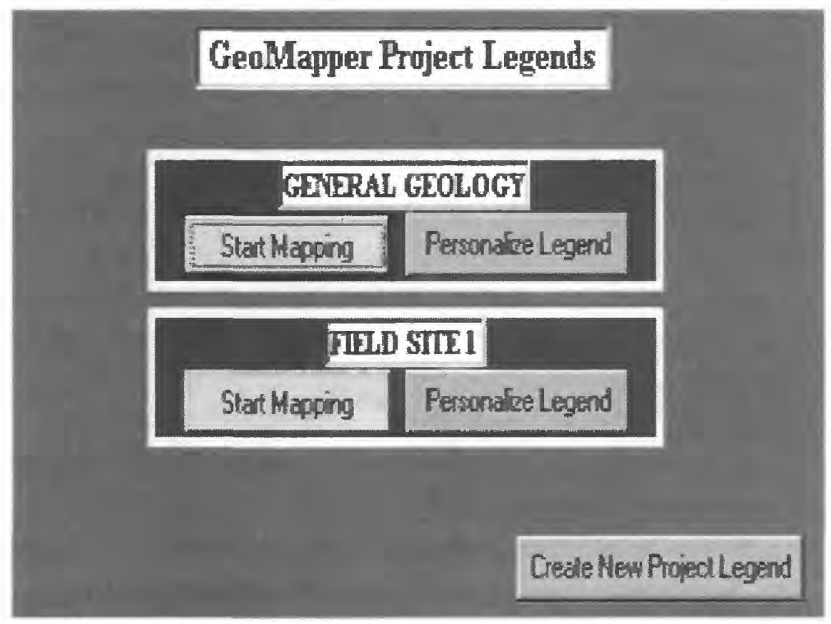

Figure 1. Project Manager is the first computer screen of GeoMapper Universal. With it, one elects to either make a new mapping legend or start mapping. retrieved conventionally from the Correlation of Stratigraphic Units of North America (COSUNA) (Childs and Salvador, 1985) from the AAPG Bookstore. To create such a legend in GeoMapper we use Legend Maker which is implemented when one clicks on Personalize Legend in the Project Manager (figure 2). To personalize the legend a user simply needs to use point and click skills to effect changes in the design of the formation and lithology buttons, select their area fill patterns and/or colors, and typein their descriptive names. Typically this process takes less than an hour. A hard copy of the legend can be printed. This Legend Maker feature of GeoMapper removes the most serious barrier to using digital mapping: that of readiness to map.

\section{Start Mapping}

Once the geological legend has been made, one clicks on Start Mapping on the Project Manager window (figure 1). From this point on, GeoMapper's visual user interface shows arrays of buttons arranged so as to provide a logical, self-explanatory set of features used in mapping.

\section{Button Tool Bars}

Tool bars are arrays of buttons which can be touched by the pen stylus to implement mapping steps. A combination of color coding, grouping, sequential ordering, and button design make it possible to begin mapping in a very short time, often less than a few hours. The organization of the visual interfaces is designed around the requirements of mapping practice. The structure of the files created within project areas is consistent with extraction of information to solve real geological problems. Immediate results are accomplished by provision of user protocols offering the basic geological formalisms organized into like features: lithology, structure, formations, mineralization, alteration and sampling sites that collectively constitute the essential and complex geo-spatial and temporal features contained in geological maps. Toolbars increase the speed of mapping considerably.

\section{Logic behind Color-Coded Button Mapping}

GeoMapper's architecture implements mapping tools with buttons, in contrast to pull-down menus which can interrupt the thought process of mapping and leave you stranded as to what to do next. GeoMapper includes only the commands necessary for preparing a map file in which mapping can be accomplished with the variety of mapping tools expected in geology. Furthermore, the buttons are shown in the general sequence of their use so that scientific logic guides the selection of mapping tools. Button color-coding facilitates eye and hand coordination when selecting frequently used buttons from a feature group or to point out important buttons in a sequence group. We 


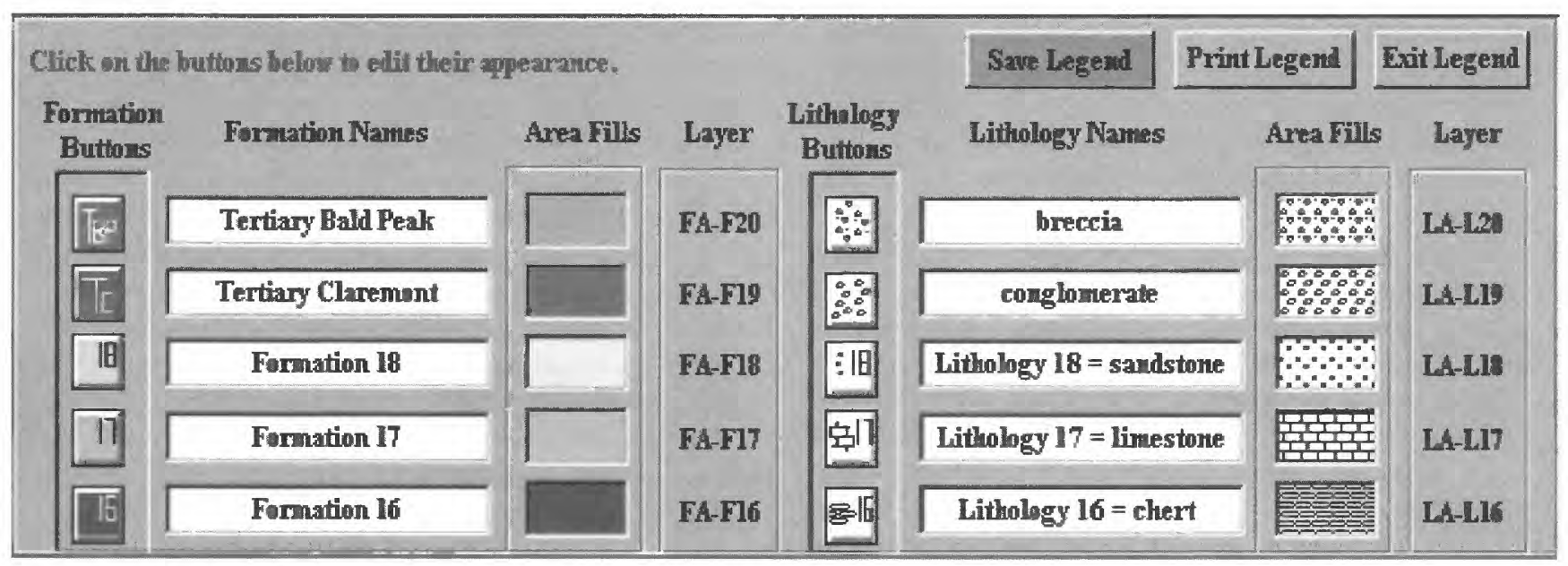

Figure 2. Legend Maker is shown here, partially completed by a user. This is where the local geology of a project is entered in terms of lithology, formations and age sequence, using only point and click methods. The Formation buttons use the standard geological time scale symbolism with Epoch or Period in caps and subscript initials for the formation name. The Lithology buttons show the pattern used for that rock type.

use a stop light method with green, yellow and red phases of activity. Green buttons refer to the most commonly used buttons in geological mapping. Yellow buttons refer to procedures that are used only rarely, for example if you need to erase or undo the last work. Red buttons refer to procedures that are essential to do before you stop mapping, for example saving your files or doing export of critical files. Other colors refer to special use functions.

Light blue buttons refer to a sequence of steps to map base maps. These buttons are used only once in a project. Purple buttons group instruments like GPS and lasers into setup buttons to select the instruments, and turn them on and finally turn them off. Magenta buttons manage section view mapping functions and all algebraic transformations done in GeoMapper.

\section{Button Mapping Starting With the Master Toolbar}

GeoMapper tool bars contain both the geological features needed to map the earth as well as a visual interface to use all the digital electronic equipment a user selects.

The first tool bar which appears, Master Toolbar, manages maps and instruments, and the taking of rock, soil, and water samples and infrared spectra (figure 3 ). In the GeoMapper button interface shown, referenced to numbered buttons in parentheses, a mapper begins using the buttons located in the upper left corner and proceeds across this row towards the right and eventually onto the second row. In support of the sequence logic, features that are essential to a mapping project including data entry are color-coded with green buttons. The save and exit features are colored red as they are crucial steps when working with digital map files and must be implemented before exiting. The most frequently used buttons from the editing and zooming feature groups are color-coded yellow. The base map preparation sequence group of buttons are color coded-cyan, and the instrument communications group (GPS and Laser) is colored magenta. The initial map file preparation runs through a sequence of buttons beginning with opening up a map file (1); loading the mapping legend (configuration) (2); compiling and selecting base maps and setting their display parameters such as using a digital topographic base map either with or with an ortho-photo show (3-7); loading survey points (8); setting the automatic saving timer (9); setting the mapping units (meters or feet), projection types, and datum for the GPS (10-11); turning off previous methods of input (12); plotting a survey point (13); turning off the survey point graphic (14); using the laser range finder (15-16) and the magnetic declination correction use laser back site correction (17) to set the declination on the laser, then mapping a ground line with the laser (18); plotting the survey tape (19) and the scale bar (20) for scale orientation; and, setting the display screen parameters (21).

From this point, the mapper can then proceed directly to the second row and use the Lithology (29), Structure (30), Formation (31), Mineralization (32), and Alteration (33) buttons to open their respective mapping tools as needed. When the Lithology (29), Structure (30), Formation (31), Mineralization (32), and Alteration (33) buttons are touched by the pen stylus, each expand to show their own tool bars. Use of sequential tool bars reduces the amount of computer screen display used up by the legend and maximizes the area of the map.

\section{Lithology Toolbar}

Lithologies can be mapped either as lines with different styles or as patterned infills. Clicking on the Lithology 


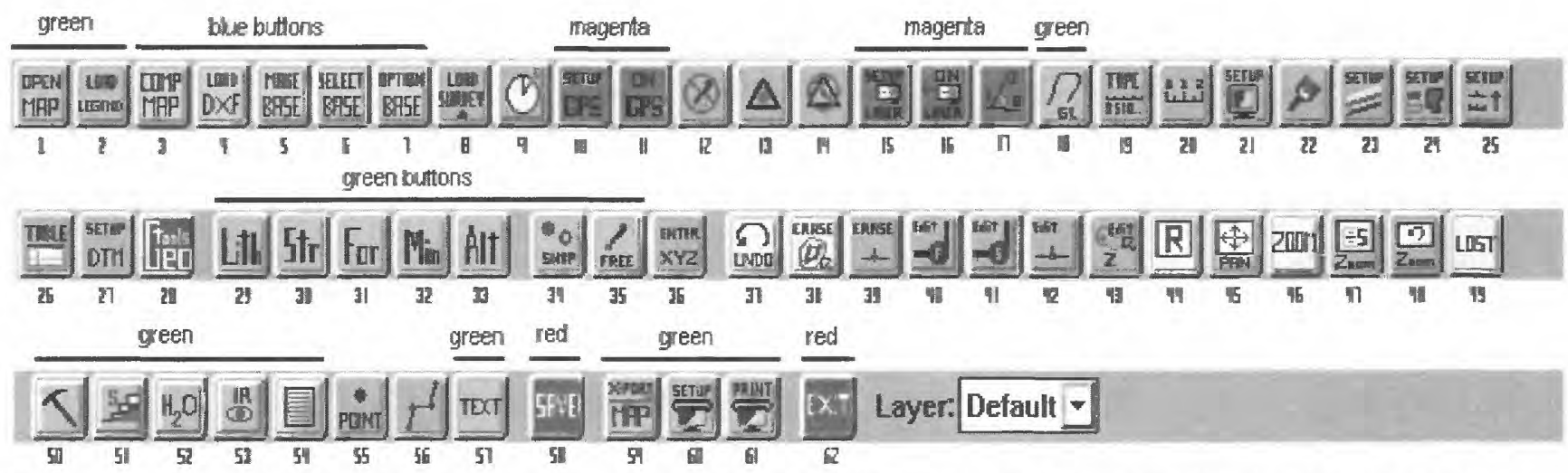

Figure 3. Master Toolbar: Numbered buttons are; 1- Open Map file, 2- Load a Legend Toolbar (configuration), 3Compile Maps , 4- Load DXF file (vector graphics), 5- Make Base Map (vector base map made out of loaded vector graphics), 6- Select Base Map, 7- Set Base Map Options, 8- Load Survey Points, 9- Set AutoSave timer, 10- Select GPS, 11- Start GPS, 12- Methods of Input Off, 13- Survey Point, 14- Survey Graphics Off, 15- Set LASER, 16- Start LASER, 17- ID Angle correction for LASER, 18- Map Ground Line w/ LASER, 19- Plot Survey Tape, 20- Plot Map Scale, 21- Set Map Display Options, 22- Paint Buttons Utility, 23- Layers Tool box, 24- Set GIS Table Options and Area Fills (transparency), 25- Set Symbols (default size and orientation), 26- GIS Table (Form Generator) Utility, 27- Set DTM Parameters, 28- GeoMapper Tools Toolbar, 29- Lithology Toolbar, 30- Structure Toolbar, 31- Formations Toolbar, 32 Mineralization Toolbar, 33- Alteration Toolbar, 34- Snap node for instrument method of input, 35- Free node for pen method of input, 36- Type-in coordinate data method of input, 37- Undo/Redo graphics input, 38- Erase graphics (drag a polygon to select graphic nodes), 39- Erase symbols, 40- Move individual polyline nodes, 41 - Move individual polyline nodes, snapping onto other nodes, 42- Move, rotate, or resize symbols, 43- Edit the elevations (drag a polygon to select graphic nodes), 44- Redraw the map graphics, 45- Pan the map, 46- Zoom Utility box, 47-Zoom in/out to the previous view, 48-Zoom out by five, 49-Zoom out to show all of the map, 50- Plot Rock Sample, 51- Plot Soil Sample, 52- Plot Water Sample, 53- Plot Infra-Red Sample, 54- Plot Notes reference, 55- Plot Point graphic , 56- Plot Polyline graphic, 57Plot Text graphic w/ settings, 58- Save Map file and Legend changes, 59- Export Map for Compilation, 60- Setup Printer and Paper size, 61- Print Map file, 62- Exit Map file.

button causes 20 Lithology $(1,2, \ldots .20)$ buttons to show on the right of the Area button as area fills and 10 of those Lithologies $(1,2, \ldots 10)$ that can be mapped as lines found to the right of the Line button (figure 4). The buttons are arranged in an age sequence that decreases as you move to the right on the toolbar. Button number 1 is marble, 2 is quartzite, 3 is serpentinite, 4 is peridotite, 5 is gabbro, 6 is granite, 7 is porphyry, 8 is diorite, 9 is tuff, and 10 is schist before any personalization. The lithological patterns programmed follow Compton (1985). The Lithology toolbar also contains the basic structural features of contacts and strike and dip so that a mapper needn't change tool bars while doing the most basic mapping activities. This saves time.

\section{Structure Toolbar}

Clicking on the Structure button brings up a full set of structural symbols given in both azimuthal and down-dip methods (shown with a D) (figure 5). When a symbol is selected, the mapper enters azimuthal and dip data. The program then plots the symbol in its correct orientation automatically. Contacts are shown in black, faults in blue, veins in red and fold axes in black. Dashed lines represent uncertain positions of these features. Different thickness of faults and veins are given as separate buttons.

Structural symbols include contacts, faults (normal, thrust), strike and dip, horizontal beds, vertical beds, cleavage, foliation, trend and plunge, plunging anticline, and plunging syncline.

\section{Formations Toolbar}

The Formation button causes 20 Formations $(1,2, \ldots$ 20) buttons to appear (figure 6). The buttons are arranged in sequence of age with the youngest on the right end of the toolbar buttons. Formation color infills are often completed in the office by snapping onto the nodes along contacts. This makes a sharp demarcation of color on both sides of the contact line with no gap. Coloration of the entire map by formation using this toolbar creates the most visible attributes of completed geological maps.

\section{Mineralization Toolbar}

The Mineralization button brings up a suite of oxide and sulfide facies mineral symbols that are used with the four mineralization style buttons representing dissemina- 


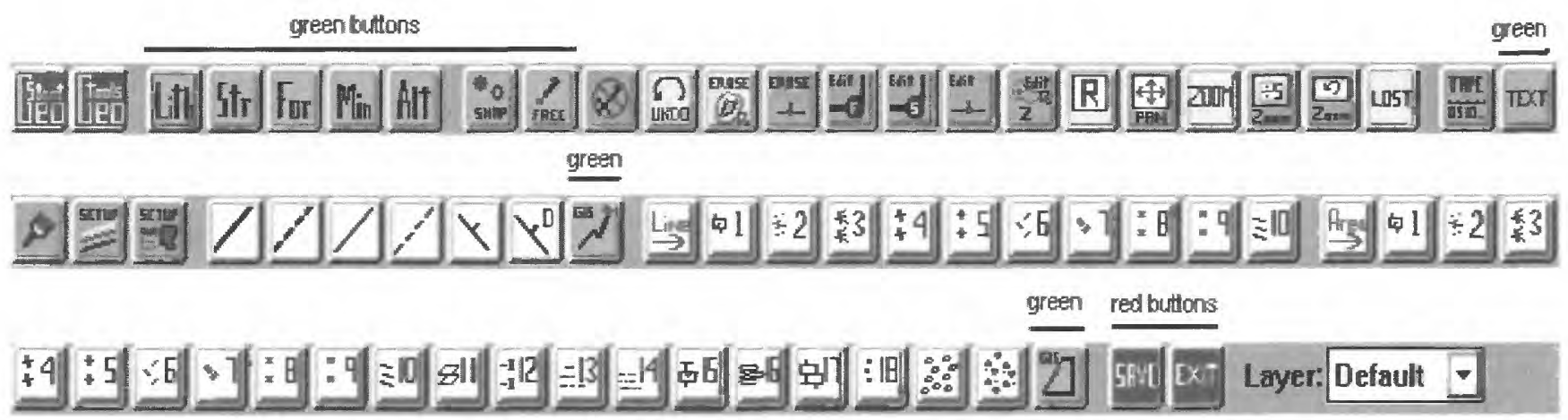

Figure 4. Lithology Toolbar shows the local rock types in an area, in age sequence. Lithologies can be mapped either using a line style or areas filled with patterns. Buttons are changed automatically by a user when they use Legend Maker.

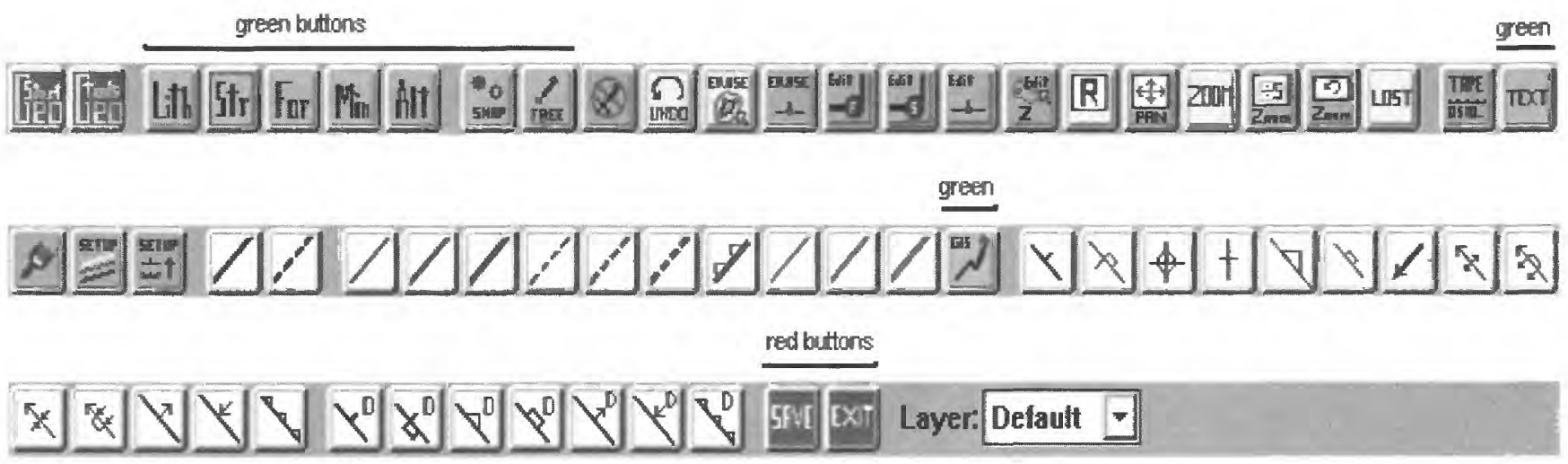

Figure 5. Structure Toolbar shows the common structural symbols used in mapping.

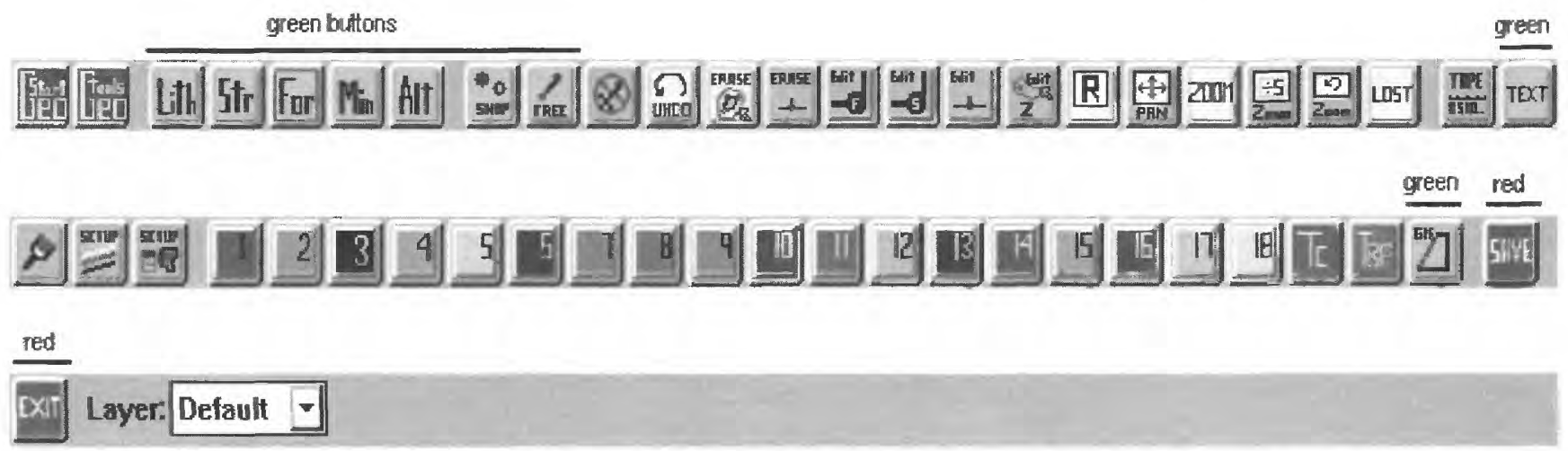

Figure 6. Formation Toolbar shows the local rock formations in an area in age sequence. Buttons are changed automatically by a user when they use Legend Maker.

tion, veinlets, stockworks and breccias (figure 7). Oxides facies minerals include calcite, quartz, limonite, hematite, goethite, cuprite, tenorite, pyrophyllite, and kaolinite. Sulfide facies minerals include galena, sphalerite, tenantite, pryrite, bornite, chalcocite, chalcopyrite, covellite, digenite, enargite, molybdenite, and anhydrite. These features are customizable.

\section{Alteration Toolbar}

The Alteration button brings up two sets of buttons for Propylitic, Argillic, Potassic, Sericitic, Advanced Argillic, Silicification, Garnetization, and Carbonation facies of hydrothermal alteration (figure 8). The first set, is used to map alteration as a color-coded line and the second set is 
green butons
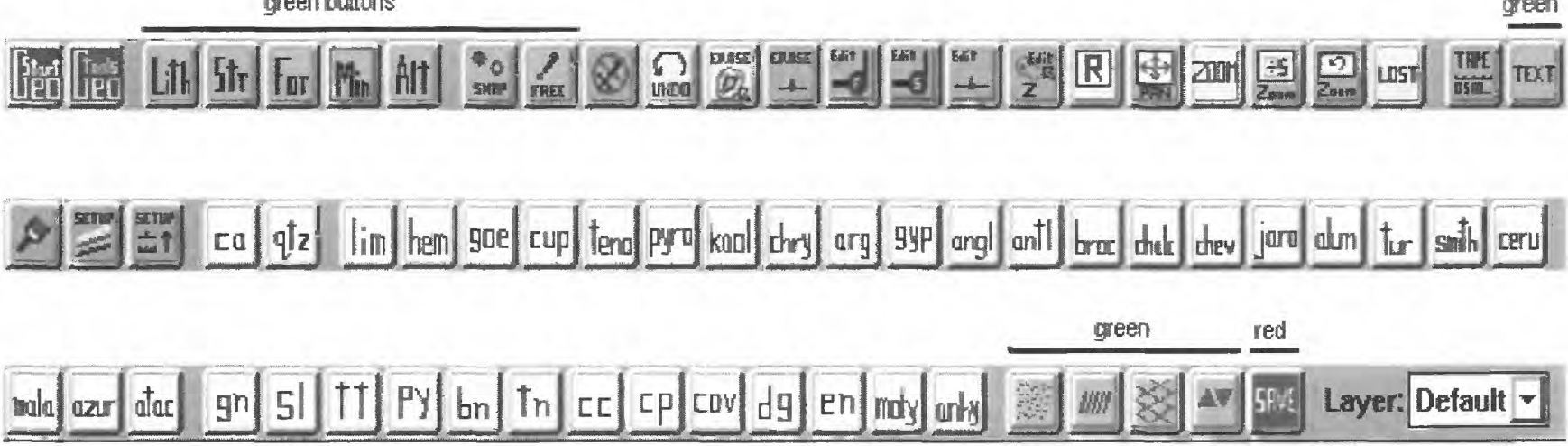

Figure 7. Mineralization Toolbar shows common ore minerals and mineralization styles.

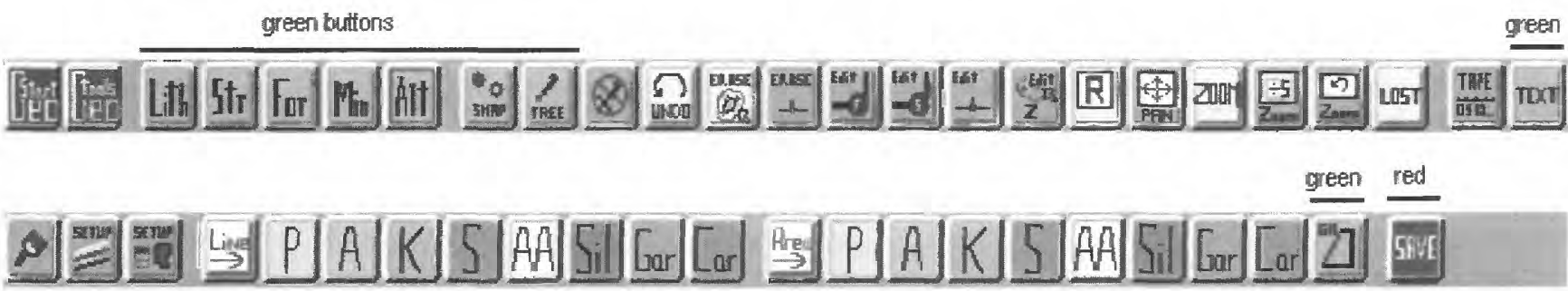

Figure 8. Alteration Toolbar shows the most common types of wall rock alteration.

used if you prefer to map alteration as a color-coded area. These features are customizable.

\section{GeoMapper Tools Toolbar}

This tool bar opens up the final set of buttons shown in figure 9 in magenta to map in geology in section view, for example when mapping the side walls in mines or exposed cliff faces, or road cuts in any orientation besides plan view. This type of mapping is usually done using a digital photograph as the base map so our mapping tools can be used to trace contacts and add infill patterns. With the laser set up and located using the GPS for positioning and its declination corrected for local magnetic declination, the Capture Photograph button (1) can be used to download an image from a camera to register the direction of the photo, the date of the snap shot, and a description.

The next button is the Field GeoRef Points button (2) which opens an instruction window for geo-referencing the photo in the field using the Laser. The Plan Map View button (3) will guide you in transforming (4) the field georeference points which are imported by the GeoReference Image button to create a section view georeference. The Raster BaseMap Utility button (5) will use the section view geo-reference points to create a base map of the image. Finally a section view frame (6) is defined around the image base map by following the instructions of the Section View Frame button.

\section{Section Mapping Algorithm}

Although we typically map in horizontal plan view in GeoMapper, we can map in any arbitrary section by user matrix algebraic transformations that we have coded in Visual Basic. This is done by taking a digital photograph of the inclined surface you wish to map and measuring the orientation of the inclined surface (figure 10). A laser is used to locate georeferencing points on the photo. Using rotation matrices, we rotate the plane of the photo into horizontality where we map as though it was inclined using the full geological legend. When the mapping is complete, we simply undo the rotation by another matrix transformation and restore the section to its proper position, bringing with it the geology and all three-dimensional data such as contacts, symbols, and color infills.

\section{Scientific Logic and Uncertainties}

As in mapping with traditional paper and pencil media, GeoMapper has been designed to implement the fundamental guidelines of the scientific method including rigorous separation of fact and interpretation by showing uncertainty. This is done by modulating line character from being solid where contacts are well-located and dashed where they are inferred. The outline of outcrops can also be mapped separately from a color infill which covers the entire area underlain by a given formation. This is a powerful and novel feature of GeoMapper as the 
green butions

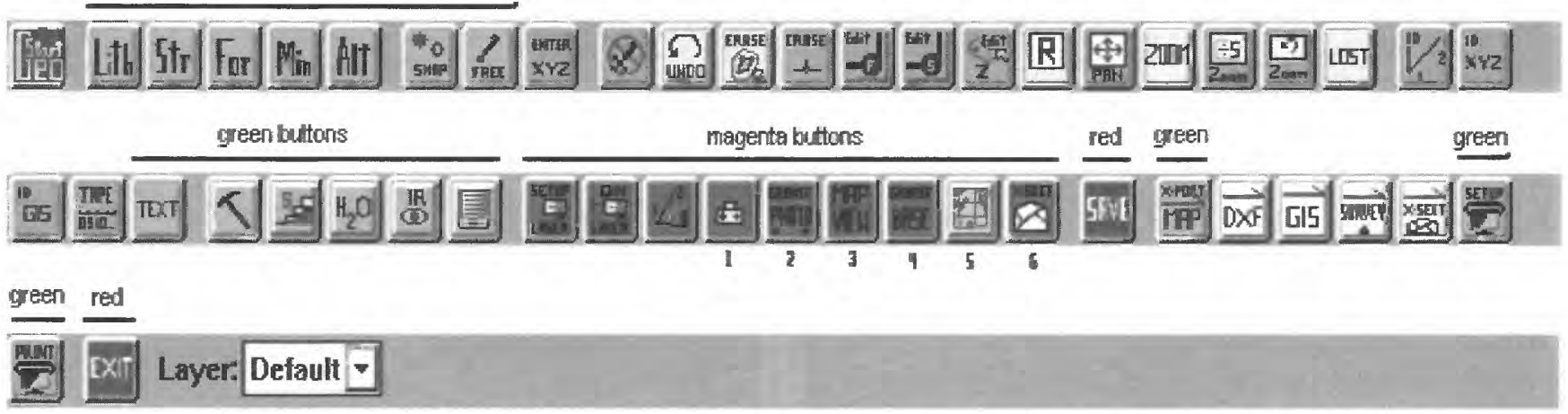

Figure 9. Tool Toolbar contains special features such as those necessary for mapping in section and exporting completed maps and numerical data bases.

outcrops record the primacy of the data on which interpretations are based.

\section{Map Scale and Spatial Resolution}

We have constructed scale bar symbols which can be placed anywhere on a map when needed. By mapping small-scale data-rich features like outcrops separately from the overall formations, a map may be drawn at any scale appropriate for a question at hand. When one zooms out, those features may be too small to see at a broader scale,

\section{GeoMapper Cros: Section Mapping Steps Overview:}

(1) Stend perpendicular to surface and laser in control points (1LL,2LR,3UL.AUR) in fleld of viow

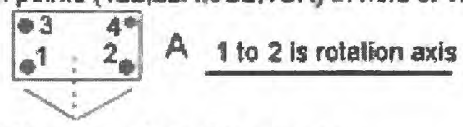

(2) Moasure hilklope angle of with compass

(3) Rolate control poinis lo hortzonial B

(4) Assign these new coordinales lo analogous points in image in Rastback and rectify

(5) Make a new backmep which is stretched C

(6) Map on stretched image using Ceomapper

(7) Un-rotate strelched image and export fles A

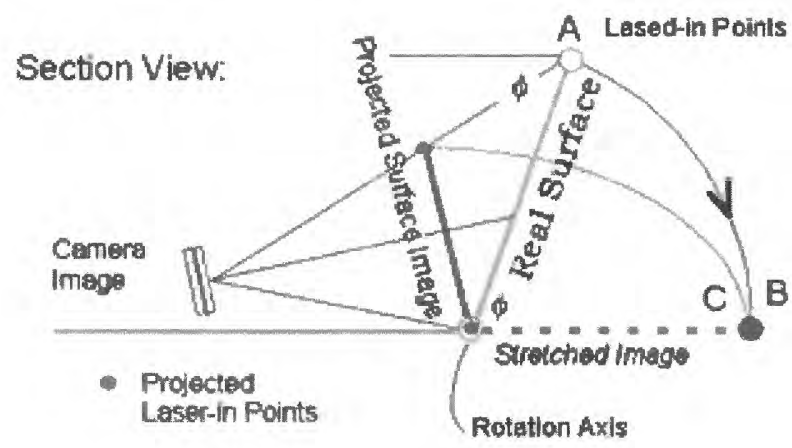

Figure 10. Geometry of the section mapping algorithm used in GeoMapper Universal, as accessed from the Tool Toolbar. but they are preserved and can be shown on a detailed scale by zooming back in.

\section{Map Compilation and Bi-directional Data Transfer}

Digital mapping creates new scientific knowledge. The original map with its contacts modulated for the level of certainty, outcrops and color formation infills, represents this knowledge in its purest, primary form.

Geographic Information Systems (GIS) can process primary data inputs created by mapping, and in so doing, are useful printing output, data storage, and interpretive tools. In that respect, GeoMapper Universal can be viewed as the front end of GIS systems. Compilation of maps as new map information is available can be done either within GeoMapper as a growing aggregate map file or exported as small sub-areal maps to GIS systems. GIS information can be ported into GeoMapper including base maps, ground lines, and survey point data.

\section{REFERENCES}

Brodaric, B., 2000, Digital geological Information: From the Field to the map to the Internet, in D.R. Soller, ed., Digital Mapping Techniques ' 00 - Workshop Proceedings: U.S. Geological Survey Open-file Report 00-325, p. 3-12, <http://pubs.usgs.gov/openfile/of00-325/brodaric.html>.

Brimhall, G.,1998, Direct digital field mapping using pen-based PC computers supported by differential global positioning systems and laser range finders: Geol. Soc. Amer. Abstracts with Programs, v. 30, no. 7, p. A-256.

Brimhall, G., 1999, Evaluation of digital mapping classes in introductory and advanced field classes at UC Berkeley: Geol. Soc. Amer. Abstracts with Programs, v. 32, no. 7, p. A-191.

Brimhall, G.H, 2000, The Earth Resources Center Digital Mapping Lab: University of California, Berkeley, $<$ http://socrates.berkeley.edu/ earthres/>. 
Brimhall G. and Vanegas, A., 2000, Digital mapping of geology and ore deposits with GeoMapper: Geol. Soc. Amer. Abstracts with Programs, v. 32, no. 7, p. A-514.

Brimhall, G. and Vanegas, 2001, Digital Mapping Using Pen PC Computers, Differential Mode GPS, Laser Range Finders and Digital Cameras: Geomapper User Manual, Earth Resources Center Digital Mapping Lab, University of California, Berkeley.

Brunton, D.W., 1901, Geological mine-maps and sections: Trans. Amer. Inst. Min. Engrs., v. 86, p. 508.

Childs, O.E. and Salvador, A., 1985, Correlation of Stratigraphic Units of North America (COSUNA): Amer. Assoc. of Petrol. Geologists, Bull., v. 69, p. 173-189, <http://www.aapg.org/datasystems/LibraryPricing.html>

Compton, R.R., 1985, Geology in the Field: John Wiley and Sons, New York, 398 pages.

Derry, D.R., 1947, Geological Mapping: Canadian Mining and Metallurgical Bulletin, v. 40, p. 682-688.

Derry, D.R., 1980, World Atlas of Geology and Mineral Deposits: Halsted press, London, 110 pages.

Fryer, S., Gregson, J., Connors, T., Poole, A., and Heise, B., 2000, The National Park Service Digital Geologic map Model: Transformation from paper to Digital, Featuring legends, Cross sections, Map Notes, and Keyword Searchability, in D.R. Soller, ed., Digital Mapping Techniques ' 00 - Workshop Proceedings: U.S. Geological Survey, Open-file Report 00-325, p. 69-82, $<$ http://pubs.usgs.gov/openfile/of00-325/fryer.html>.

Furr, T.W, 2000, Digital Geological Mapping for the State of Oklahoma, in D.R. Soller, ed., Digital Mapping Techniques '00 - Workshop Proceedings: U.S. Geological Survey, Open-file Report 00-325, p. 191-194, $<$ http://pubs.usgs.gov/openfile/of00-325/furr.html>.

Johnson, K. and Brimhall, G., 1999, Novel real-time digital mapping method for caves as a supplement to speleothem based paleo-climate reconstruction: Geol. Soc. Amer. Abstracts with Programs, Cordilleran Section meeting, v. 31, no. 6, p. A-67.

Kramer, J.H., 2000, Digital Mapping Systems, in D.R. Soller, ed., Digital Mapping Techniques ' 00 - Workshop Proceedings: U.S. Geological Survey, Open-file Report 00-325, p. 13-19, $<$ http://pubs.usgs.gov/openfile/of00-325/kramer.html>.

Lindgren, W. and Turner, H.W, 1894, Description of the gold belt; description of the Placerville sheet, California: U.S. Geological Survey, Geologic Atlas of the United States Folio GF-3.

Lindgren, W. and Turner, H.W., 1895, Description of the gold belt; description of the Smartsville sheet, California: U.S. Geological Survey, Geologic Atlas of the United States Folio GF- 18.

Linforth, F.A., 1914, Applied geology in the Butte mines: Trans. Amer. Inst. Min Engrs., v. 86, p. 508.

McLaughlin, D.H. and Sales, R.H., 1933, Utilization of geology by mining companies, in Ore deposits of the Western United States (Lindgren Volume), Amer. Inst. of Mining and Metallurgical Engineers, New York, p. 683-686.
Montero Sanchez, I., and Brimhall G., 1998, Novel application of digitally integrated mapping systems for the mineralogical characterization of abandoned mines: Geol. Soc. Amer. Abstracts with Programs, v. 30, no. 7, p. A-358.

Montero Sanchez, I., Brimhall, G., Alpers, C., 1999, Use of UV/VIS/IS spectroscopy to characterize mine waste dumps in the Penn Mine, Calaveras County, California: Geol. Soc. Amer. Abstracts with Programs, Cordilleran Section meeting, v. 31, no. 6, p. A-91.

Montero Sanchez, I., and Brimhall, G., 2000, Fast mineral identification algorithm for reflectance spectra of iron oxide, iron oxyhydroxide and iron sulfate minerals: Geol. Soc. Amer. Abstracts with Programs, v. 32, no. 7, p. A-180.

Morin, P.J., 2000, What Visualization Contributes to Digital Mapping, in D.R. Soller, ed., Digital Mapping Techniques ' 00 - Workshop Proceedings: U.S. Geological Survey, Open-file Report 00-325, p. 131-136, <http://pubs.usgs.gov/openfile/of00-325/morin.html>.

Sales, R.H., 1929, Ore discovery and development: Eng. and Min. Jour., v. 128, p. 277-279.

Sales, R.H., 1941, Mine maps and models, in Peels's Mining Engineer's handbook, Section 19: John Wiley and Sons, New York, p. 2-11.

Soller, D.R., 2000 , Introduction, in D.R. Soller, ed., Digital Mapping Techniques ' 00 - Workshop Proceedings: U.S. Geological Survey, Open-file Report 00-325, p. 1-2, <http://pubs.usgs.gov/openfile/of00-325/intro.html>.

Soller, D.R. and Berg, T.M., and Wahl, R., 2000, Developing the National Geologic Map Database, Phase 3- an Online, "Living" Database of Map Information, in D.R. Soller, ed., Digital Mapping Techniques ' 00 - Workshop Proceedings: U.S. Geological Survey, Open-file Report 00-325, p. 49-52, <http://pubs.usgs.gov/openfile/of00-325/soller4.html>.

Soller, D.R. and Lindquist, T., 2000, Development and Public review of the draft "Digital Cartographic Standard for geologic Map Symbolization”, in D.R. Soller, ed., Digital Mapping Techniques ' 00 - Workshop Proceedings: U.S. Geological Survey, Open-file Report 00-325, p. 43-48, $<$ http://pubs.usgs.gov/openfile/of00-325/soller3.html>.

Sorensen, T.C., 1965, Kennedy: Harper and Row, New York, p. 527.

Stamm, N.R., Wardlaw, B.R., Soller, D.R., 2000, GEOLEX- The national Geologic Map database's Geologic Names Lexicon, in D.R. Soller, ed., Digital Mapping Techniques ' 00 - Workshop Proceedings: U.S. Geological Survey, Open-file Report 00-325, p. 31-42, <http://pubs.usgs.gov/ openfile/of00-325/stamm.html>.

Stanford, L.R. and MacKubbin, V.T., 2000 , Application of a Digital Geologic Base Model in ArcView GIS, in D.R. Soller, ed., Digital Mapping Techniques ' 00 - Workshop Proceedings: U.S. Geological Survey, Open-file Report 00325, p. 55-56, <http://pubs.usgs.gov/openfile/of00-325/ stanford.html>.

Stetson, 2001, Healthcare: Barriers to Acceptance of Mobile Computing in healthcare: A look at why medical professionals are slow to accept pen computers in daily practice: Pen Computing, p. $18-20$, v. 8 number 38 . 
Takagi, T. and Brimhall, G., 2000, A simple and inexpensive diffuse reflectance standard target for accurate calibration in low-altitude airborne ultraviolet-visible near infrared (UV/VIS/NIR) spectroscopy: Geol. Soc. Amer. Abstracts with Programs, v. 32, no. 7, p. A-372.
Vanegas, A., Brimhall, G. and Lerch, D., 2000, Preparation of accurate $(+/-1 \mathrm{M})$ digital ortho-photos: ERC digital mapping lab data sets for field camps and industrial field projects: Geol. Soc. Amer. Abstracts with Programs, v. 32, no. 7, p. A-514. 


\title{
Using Handheld Personal Computers as Field Data Collection Tools: Some Lessons Learned in the School of Hard Knocks in the Wingate Wash Project and Related Projects Using FieldLog/Fieldworker Software Exported to Arcinfo
}

\author{
By Terry L. Pavlis ${ }^{1}$ and Jason Little ${ }^{2}$ \\ ${ }^{1}$ Dept. of Geology and Geophysics \\ University of New Orleans \\ New Orleans LA 70148 \\ Telephone: (504) 280-6325 \\ Fax: (504) 280-7396 \\ e-mail: tpavlis@uno.edu \\ ${ }^{2}$ California Division of Mines and Geology \\ $801 \mathrm{~K}$ St. MS 12-31 \\ Sacramento, CA 95814 \\ e-mail: jlittle@consrv.ca.gov
}

\section{INTRODUCTION}

In the last 2 years, development of handheld computers with sunlight readable screens and significant mass storage that does not depend on conventional hard disk technology has afforded the opportunity to revolutionize field geology. These devices are relatively inexpensive yet rugged, have sufficient battery life for several days of field work, and are small enough ( $1 \mathrm{~kg}$ or less) that they can be easily carried in the field in nearly any environment. Gone are the days of the "lonely field geologist with map, notebook, compass and hammer in hand crossing the wilderness". That geologist may still be lonely and walking across the wilderness, but will now carry a handheld device(s) that simultaneously acts to replace the conventional map, notes, and camera that were the routine field gear of the 20th century geologist. Technologies exist for a "black box" device that could serve as an all in one location tool (through gps), visualization tool (through computer and display), and compass/inclinometer (automatic "brunton") and there is no doubt these devices will be used routinely within a decade. Thus, the geoscience community must come to grips with this evolving technology and develop a better method for both data acquisition and data management.
Perhaps most important in this context is that new field studies will need to be thought out carefully from the outset, not only in terms of their scientific objective, but also the plan for data management and data release in forms that will be widely available. Presently, software lags far behind hardware in potential applications to geologic problems, and until that software void is filled the community will probably resist the inevitable conversion to these technologies. In essence, the geoscience community needs its own "killer ap" to convince the general geoscience community to switch over to these new technologies. Presently there is no software that approaches this "killer ap" potential, and the burden is on the geoscience community to move beyond the present status quo.

At the University of New Orleans we began experimenting with the software and hardware for handheld devices 4 years ago, and have variable degrees of success in implementation. We have largely avoided the use of conventional wintel PC based system because of both cost (our intent was to use the devices in field classes) and limitations of battery life+weight+durability of these devices. This paper outlines some of our successes and failures in this context. We use as our primary example a study in eastern California where we used this technology throughout the research project and have developed a database 
that includes all the basic field observations during the study. We have also used the systems in other settings, including in the very wet and cold environments of the southern Alaskan coastal ranges, and with groups of students in field classes working in the California desert.

\section{THE WINGATE WASH PROJECT}

In 1997 we began a detailed 1:24k mapping study of the Wingate Wash area in the eastern California desert. The work was initiated through a basic research grant from NSF, but was expanded after funding from the USGS National Cooperative Mapping Program's EDMAP component for two student theses in the area. Final preparation of the GIS database is being accomplished through the California Division of Mines and Geology.

The study area encompasses parts of Death Valley National Park as well as the China Lake Naval Air Weapons Station (NAWS), each of which presented distinct logistical challenges. For the park, our work was located in a newly declared California desert wilderness area. As a result of wilderness restrictions, all access to this area was restricted to what could be carried by pack horse or on our own backs. This restriction placed extreme limitations on field gear because we needed equipment that could use either lightweight disposable batteries or that could be charged with a small solar panel. In the case of the NAWS reservation, the logistics were completely different. Our initial work involved daily commutes of $\sim 40$ miles on slow, dirt roads and frequent hourly restrictions brought on by military exercises. In this case field efficiency was the primary consideration and any system that required extra time in the field was considered a liability. Some of our work from NAWS involved "car camp" setups at the boundary between NAWS and Death Valley National Park, and hiking to areas in the park from these camps. These camps had no serious weight restrictions for supplies, but weight restrictions on devices were a major consideration because these areas required some very long $(>10 \mathrm{~km})$ hikes across alluvial fans to get to the areas of interest.

These logistical considerations were a primary factor in our decision to use a data collection system based on handheld devices rather than conventional wintel PC based systems. At that time the smallest laptop computers were $>2 \mathrm{~kg}$, color screens were virtually invisible in the bright sunlight of the California desert, and battery life was generally $<2 \mathrm{hrs}$. As discussed below, some of these restrictions have now been resolved with wintel systems, but the weight/battery life issue is still a real consideration in choice of systems where long hikes are involved in daily field work.

These limitations led us to choose a field system based on the GSC FieldLog package (http://www.gis.nrcan.gc.ca/) for data compilation and a commercial package for the
Apple Newton handheld called Fieldworker. Use of FieldLog also required a laptop for data compilation, and a second commercial program, AutoCAD <www.autodesk.com>, to serve as the map drawing tool and database engine behind FieldLog. Total investment for the system was $\sim \$ 500$ 1000 /handheld device, $\$ 500$ for handheld software, $\$ 2000$ for a laptop (not a real expenditure in this case, however, as this was not a new purchase), $\$ 400-\$ 1000$ AutoCAD software (academic pricing; commercial prices are significantly higher), $\$ 600-900 /$ digital camera and $\sim 500$ for incidentals (batteries, solar panel, cables, gps, etc.). Our initial funding was insufficient to purchase all of this equipment and thus, the entire field crew was not outfitted with the devices until we were nearly two years into the project. The cost for this system remains similar today, although with the demise of the Apple Newton, the fieldworker software has been ported to WinCE devices and these are the devices we presently use.

\section{History-A Case of Ignorance Wastes Hours}

We began the work totally ignorant of use of the system and were still reading software manuals and experimenting with new hardware hours before we began the work. This approach is not recommended because each of us who used the system initially were ready to throw the device off a cliff after the first day of use. This frustration was not entirely due to ignorance of the system, however, because most of our initial frustrations stemmed from wasted time in the field fiddling with menus and learning the quirks of the software. Moreover, for veteran field geologists dragging out a keyboard, untangling cables, pushing buttons and monitoring equipment requires the learning of a new, largely alien, field routine and many will probably never adapt to the change. Most of our group, however, adapted to the system reasonably well within two days and were completely comfortable with the system in a week. This was particularly true of students who typically were comfortable with the system by the end of their second day.

Our biggest ignorance-related mistake was a failure to develop a logical data structure for the project prior to beginning the field work. As a result our first field season of notes required extensive editing and reformatting for eventual incorporation into the database. After attending a two day GSC shortcourse on the FieldLog software, however, this problem was largely eliminated, although new problems ultimately appeared. As the project progressed we became relatively comfortable with use of the handheld devices for routine recording of structural data and notes. Nonetheless, most of us never adapted to several data recording features that should typically be developed in a full geologic GIS. Specifically, the data structure recommended by the GSC includes a series of long pick lists for developing GIS tables on the fly for point data such as rock types (which includes tables on textural features, sed- 
imentary structures, etc), mineralogical variations (e.g. phenocryst types in volcanic units), and photographs. Although these data would have been extremely useful in later interpretation phases of the study, we quickly abandoned routine recording in these data tables in the field because it required too large of an investment in our most valuable field commodity: time to carefully look at the rocks. Our conclusion was that these data could easily be added at a later date from the field notes, and thus, the lab was the more efficient place for doing this data entry.

Digital photographs and logging these photos into a database poses a special problem. In the early generations of cameras and handhelds that we initially used there was no control on file names for the photos until the photos were downloaded to a laptop. Thus, file names of field photos could not be logged until the end of the day after downloading - a very tedious task at the end of the day. Later devices eliminated this problem through PCMCIA flash card readers. These devices allow photos to be transferred to a handheld, or at least change file names on the photos to something that could be logged into the database. Nonetheless, even this process caused loss of valuable field time, and as a result we typically did not link field photographs into the database until the later, data compilation phases in the lab.

By the second year of the project we had a relatively streamlined data collection system and daily additions to the database were routine. Nonetheless, our map compilation and map production lagged far behind our field notebased database. That is, all of our maps were paper field sheets until well into the second year of the project. The problem was, like earlier problems of database management, brought on primarily by ignorance. That is, the first author was an AutoCAD neophyte and because map management techniques had neither been taught at the GSC shortcourse nor had yet been incorporated into the FieldLog manual, this task was avoided until we learned how to deal with these issues. Ultimately through hours of time with AutoCAD manuals and numerous communications to GSC personnel, we managed to incorporate a georeferenced topographic base into our project and were able to plot all of our station data (including structural symbols) onto the base map. In addition to the basic learning time of adapting to the AutoCAD drawing tools, we probably wasted as much as 3-4 person days in troubleshooting various problems that arose during georeferencing and datum conversions. This wasted time was partially the result of our simultaneously learning of the AutoCAD and FieldLog interfaces, but also resulted from quirks in the FieldLog extensions that are not well documented and are difficult to diagnose for a FieldLog/AutoCAD neophyte.

After overcoming these hurdles, map compilation in AutoCAD/FieldLog went relatively smoothly. The effort was time consuming, but in the end we believe this map compilation step is important step in developing an accurate geologic map that would be lost in a full-fledged digi- tal acquisition system. Specifically, with several individuals contributing to the map there were the inevitable discrepancies at boundaries between the mapping by different individuals. Moreover, as we compiled the map line by line, we recognized errors that were unrelated to this classic "map boundary fault" problem; e.g. dangling contacts, contacts that clearly disobeyed $v$ 'ing rules for known dip, etc. Thus, compilation led to a series of field checking days to correct map discrepancy; an important step in insuring map accuracy.

Based on this experience, we believe that serious consideration should be given to how these kind of problems will be resolved as we ultimately move toward full on the fly digital mapping. Had we simply merged three independently compiled maps, it is clear that some of the discrepancies in our mapping would not have been recognized. That is, we probably would have been able to resolve the map boundary "faults" but it would have been difficult to diagnose our more subtle mapping errors.

Thus, a case can be made that a standard map compilation step, like the one required by FieldLog, may be a preferred method to insure map accuracy. We believe this is an important topic that needs discussion by the broader geoscience community.

Following completion of the map compilation phase, we used the data export capabilities in FieldLog to generate a series of files in ArcInfo export format ("e00" files) from the AutoCAD linework, and these files were transferred to the GIS lab at the California Division of Mines and Geology.

When written to Arc export format, each data set is reduced to an ASCII text file that lists all the attributes, tolerances, and X Y coordinates of each vital point on the map. This file is then read by ArcInfo and converted into a spatial database called a coverage. A peculiar problem resulted when these files were read to the Unix-based systems at the CDMG. The normal filename extension for these files is .e00, but the Wingate files had an extension of .E00. ArcInfo did not recognize the .E00 extension as a valid format because of case sensitivity in Unix; an easily resolved, but initially confusing problem in the export file.

The second hurdle was a bit more challenging. When attempting to import the line data from the Wingate Wash project, the process repeatedly failed, giving a "segment violation" error message. By reviewing the .e00 file in a text editor, it became apparent that FieldLog had stored and exported line records containing over 500 vertices or shaping points. Since Arc only stores lines in chunks of only 500 or less points, importing the FieldLog data was impossible without modification. These modifications meant opening the. $\mathrm{e} 00$ file in a text editor and manually splitting the records for long lines into two or more records, and then editing the rest of the .e00 file to match the new line records. An .e00 file is generally a long and monotonous list of $x, y$ coordinates, elimination of this step would save a great deal of time and eyestrain. After this 
edit step, the line coverage imported without difficulty. See figure 1 for an overview of this process.

The structural data, stored as a point coverage, was much easier to work with than the line coverage. The initial import process went smoothly and the data was displayed on the screen within minutes of receiving the file. The only modification made to this file was the positioning of the dip annotation for bedding symbols. The dip numbers were positioned directly over the center of the symbols, making the data hard to read. Each dip number has a different offset relative to its associated point, based on the strike or rotation of the symbol. In light of this, an AML (a script using arc macro language) was written to perform this task automatically, thus saving the writer hours of tedious labor.
Once the files were imported into ArcInfo the data was edited for line errors and laid over a vectorized topographic base map. The process of labeling the polygons, which adds areal information to the database, is being done manually by referring to a hand labeled map of the area. While it is common to import polygon information to and from ArcInfo using .e00 format, the given data did not include anything beyond points and lines. If this is truly a limitation of the FieldLog system, this, combined with the long line issue discussed above, make exporting FieldLog data to ArcInfo an unfortunately cumbersome process. It is possible that we may have been able to save some time in this step by using fills (hatch commands) in AutoCAD to develop polygon objects. Nonetheless, because the manual does not specify this as a option we

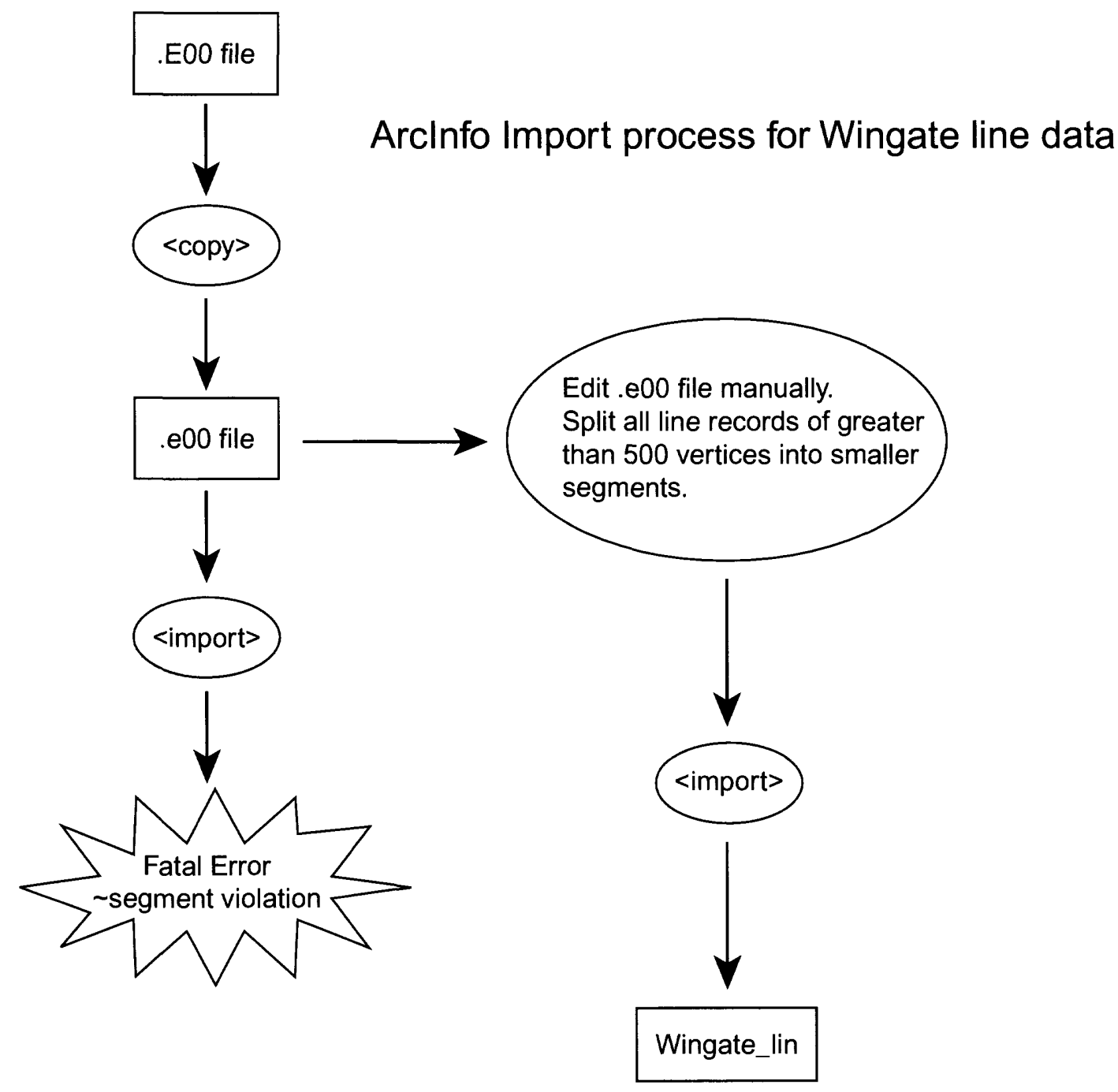

Figure 1. Flowchart outlining the process used to import the line data into ArcInfo. 
decided it was potentially a time consuming task that might not lead to the desired result. An ESRI extension of AutoCAD (ArcCAD) would have served this function as well, and we experimented with this program. However, given the uncertainties of this program, we opted to not use it in developing the output geologic map objects.

One feature that we tried to develop fully in the map themes of the GIS was a distinction between linework layers into the four basic types of geologic contacts and the standard 3-part division of geologic contacts based on accuracy. That is, the linework themes were organized into depositional contact, intrusive contact, fault, and unconformity themes, with different layers for bedrock contacts vs approximate (dashed) vs inferred (dotted) contacts. We believe this approach is a critical one that should be routinely used as more maps become true GIS systems because distinction of these fundamental attributes is a key factor that would allow GIS applications to produce a more easily understood geologic map.

Finally, we note that when the full GIS is completed, ALL of the basic field data as well as lab data (geochemical and geochronological data) collected during this study will be incorporated as point, line and polygon themes that can be readily manipulated. Perhaps most important in this context is that nearly all of our photographs will be incorporated into the database. Thus, in the final product, the user of the map will be able to query the database and get various field photographs from different points within the study area.

\section{OTHER APPLICATIONS OF THE FIELD SYSTEM}

In addition to the Wingate Wash study, we also used these systems in field studies in southern Alaska, and for one upper division geology field class. Each of these cases had unique experiences worth noting.

In the Alaskan field studies, the first author was the primary user of the field system. He worked with two different research groups during 3 field seasons using this equipment, but no coworkers opted to use the system. This initially was largely a problem of insufficient equipment, but later, when equipment was available, coworkers resisted using the equipment for two reasons. First, we had not allotted specific time for training on the equipment. From previous experience we knew that at least two days of working with the software was needed before most workers were efficient at using the system. Given the cost of our logistics-primarily helicopter-based field support -we all agreed that it was unwise to use these systems where the benefit was low relative to the cost of the field effort. Second, all coworkers on these projects were veteran field geologists who had well established field techniques. Thus, unlike students, there was a tendency to resist use of the systems in favor of well-established techniques.

In these Alaskan projects most of our work was not standard geologic mapping. Rather, much of our effort was in collecting outcrop based point-data; e.g. fault kinematic data, sampling, metamorphic fabric measurements, etc. Some conventional mapping was done, however, and FieldLog ultimately proved very useful for map construction. Where point data were used, the database capabilities, particularly the spatial query feature of FieldLog, proved very useful for structural analyses; e.g. outlining structural domains for plotting on stereographic projections.

In the case of the undergraduate field class it is not clear that our experience is a good representation of using these systems as a field tool because: 1) the first author was still learning the system at the time the class was actually taught; hence, he made many mistakes in teaching with the system; and 2) we had a serious equipment problem with new Fujitsu pencentra handhelds - a bad serial port prevented using GPS systems to log position into the database. Note, this problem has yet to be resolved as of this writing and poses serious questions on the use of Fujitsu devices (see below). The combination of these two problems produced extreme frustration among the students with use of the system because they largely failed to recognize the time-saving features of the applications.

Nonetheless, the students adapted very quickly to using the system in the field. Specifically, by the second day of field work they had no problems with routinely using the systems.

\section{APPRAISAL OF SYSTEM}

The field system used in these studies functioned well for its main intended purpose. That is, as a basic database engine for map compilation and field data entry through a handheld device. The final product that will arise from the Wingate Wash project will be a great deal more than a simple digital geologic map. Instead it will contain a rich database attached to the map in a standard GIS format. Thus, future researchers can draw on much more than a geologic map, which is inherently difficult to analyze by itself, and users will also have full access to all the basic field observations. Thus, clarification of field relationships left unresolved by this study will be much simpler for future workers, because all these data will be available. We hope that this study can serve as a basic model for how many future geologic mapping products are released. Nonetheless, this product will undoubtedly be considered primitive in the near future as the technology progresses.

Although the system achieved its basic goals, we believe that we are still far from a "killer ap" for geologic mapping and field GIS systems. The learning curve for adapting to the field system is sufficiently steep that most 
geologists would probably not take the time to develop the expertise to independently put together a project like the Wingate Wash database. In a large organization, where a dedicated staff member might become proficient in the more subtle features of the program, some of these problems would be less apparent. That is, routine data entry and data manipulation in the software is easily learned in a few days, particularly by younger workers like the geology field class who had no difficulty adapting to the system. However, what those students did not necessarily recognize was that many hours were spent "behind the scenes" in preparing the databases and maps that were needed for the field work. Thus, someone has to devote the time for these efforts, and that time investment is significant. Admittedly, once the basic setups are learned, these steps can be done more efficiently, but until a member of an organization obtains those skills, the system can be very frustrating to use. In academia this responsibility will invariably fall on the shoulders of a faculty member, and it is doubtful most faculty would devote as much effort as the first author did in this study.

In addition to the setup times for a project, the FieldLog system also ultimately requires export to a standard format such as ArcInfo or MapInfo for release in a form that would be more widely available to the public. These steps require yet another layer of expertise, at some level, to take the geologist's product and convert it into a form for widespread distribution. This was, in fact, the intent of the software as developed by the GSC; i.e. to insulate the geologist from the nuts and bolts of GIS systems and allow the geologist to focus on the geologic problems at hand. Although true in theory, in practice the system may not actually achieve that goal. This is particularly true in small organizations or an academic environment where there is no staff member, other than the geologist, to handle the data conversions and final GIS preparation. Indeed, the use of the AutoCAD/FieldLog system also requires significant training with a moderately steep learning curve which, although less steep than software like ArcInfo, is probably comparable to programs like ArcView. Admittedly, once the user becomes comfortable with the drawing tools of AutoCAD it is a much richer drawing environment than the rather limited drawing tools of ArcView. Nonetheless, it is debatable that this drawing environment is worth the effort required in personnel and data conversions that result from use of the AutoCAD environment.

We will probably continue to use this system for one to two years because we have already invested in the hardware, software, and training needed to use the system. Nonetheless, the software is developing rapidly and it may be necessary to move to a different system more quickly. Specifically, two new products may offer a software solution that will combine the best features of the GSC system-highly portable handheld devices with long battery life and a simple user interface for the field componentwith the full-features of a GIS system like ArcInfo. These are:

1) ESRI's porting of the ArcView system to windows CE devices ("Arcpad" see: <www.esri.com>). As advertised, this software package appears to allow field data entry similar to the features in Fieldworker $<$ http://www.fieldworker.com/ $>$ as well as limited drawing tools for entry of line and polygon data onto a map.

2) A new version of Fieldworker that retains the familiar data field entry of older versions of fieldworker, but also allows for map display and map data entry.

We have not yet used either of these products, however, and cannot yet give an appraisal of their ease of use.

\section{THE FUTURE?}

It seems clear that in the very near future handheld devices will revolutionize all field data collection, both in the earth sciences and in other field sciences. They afford the opportunity to log a rich range of information that is routinely collected by the field observer, and will ultimately afford new types of data collection. The simplest, and most obvious example of a technology that already exists, is the use of a recording compass/inclinometer device to replace the familiar brunton compass. Unlike the devices we have used to date, which in many cases are a time sink, this type of device would potentially lead to huge increases in the efficiency of field work because routine measurement and recording of structural features could be accomplished in a fraction of the time required with a conventional compass.

Although some of these data may be useful for the field observer, the primary value of collecting these data is for use by other researchers who may, in later years, be interested in a field area and would like access to as much information about the area as they can possibly obtain. As data collection systems become more sophisticated, it may ultimately be possible for a continuous video stream to be recorded during all field operations; a data set that could be extremely valuable, but also difficult to manipulate. Other tools now available include laser ranging devices, which allow detailed mapping of cliff faces without having to climb to the sites, and high-precision differential GPS systems that can log real time positions to $\mathrm{cm}$ levels of precision. Both of these devices may ultimately force geologists to modify many traditional field procedures in the interest of increased accuracy afforded by these devices. That is, in cases where logistics allow easy access, it might be preferable to walk all contacts while recording positions, or survey in contacts, rather than the 
traditional field method of making point observations and drawing map contacts because the high-tech methods allow a much higher level of accuracy to the field data.

\section{APPENDIX: HARDWARE EVALUATION AND CONSIDERATIONS FOR PURCHASE OF HARDWARE}

In this study we were fortunate to have a large equipment grant that ran concurrently with the field study. Thus, we were able to experiment with several different devices. Although our equipment inventory was far from exhaustive, we learned several critical things during the course of the study. The following is not a recommendation of what to buy, but what to look for when evaluating equipment for purchase.

First, in the choice of any field computer, be it a handheld device or a wintel PC, the choice of display is critical for success of field operations. Until recently color displays were essentially unreadable in the field and the only practical field displays were monochrome. This has changed in the last two years with develop of transflective displays. Nonetheless, these displays also have important problems. Specifically, in many of these systems the display is very good in bright sunlight-although admittedly colors are often odd, but is murky and hard to read in normal lighting. Thus, in some cases (e.g. the Fujitsu Pencentra 130) the device is excellent in the field, but has little value for other applications indoors. In other cases (e.g. the Fujitsu Stylistic LT) the advertised transflective screen is useless because the manufacture used a shiny screen coat that reflects sunlight and glare makes the transflective feature marginal for most conditions.

Second, digitizer options can greatly affect the functionality of pen interfaces. Since most handhelds, and most wintel systems worth using in the field, use a pen interface, the nature of this interface is very important in ways that are not obvious at the outset. There are two general classes of digitizer: EM digitizers and touch-screen systems. Of the two, the touch screen systems are most widely available and are universal on handhelds. However, they have serious limitations, particularly where they serve as a replacement for a mouse as a pointing device. Specifically, they suffer from two problems: 1 ) if the digitizer is excessively sensitive, an accidental contact of a hand on the screen can make the cursor "jump" across the screen-not desirable if you are trying to carefully draw a line; and 2) the cursor cannot track the pen on a touchscreen and thus, the "pen down" command in a drawing mode can produce unwanted problems, particularly if the digitizer is inaccurate. In our experience it is the second problem that is most frustrating. That is, when using a touchscreen for drawing, you do not generally know exactly where the line will start until the pen first contacts the screen, and if this position is wrong-either by an inaccurate digitizer or the user holding the device at an odd angle-the lines will be mislocated, requiring annoying editing at a later time. In sketch modes this can produce whole lines that are mislocated, or in point-click digitizing modes (straight line segments connecting digitizing points) this can lead to erratic digitizing errors. Some newer wintel system get around this problem by allowing a separate button to operate as a "mouse click" so that the cursor can be moved to the right position, then the "click" activates the point. However, this procedure undoubtedly takes some time to adjust to. EM digitizers do not suffer from this problem because the system tracks the cursor when it is in close proximity to the screen. Unfortunately, EM digitizers are expensive and have largely been replaced because of cost-consciousness of most users, particularly in the handheld market.

Third, the form-factor of a handheld or wintel PC is also an important decision. In PC's the choice of laptop vs pen tablet is a personal choice that should not be made lightly. Laptops/clamshell systems are best for typing, but are hard to use in a drawing mode; i.e. the keyboard gets in the way of hands and it is very easy to accidentally strike a key. On the other hand, pen tablets require an external keyboard or reliance on handwriting software (still less than perfect); an awkward arrangement that requires getting used to.

Finally, we have also experimented with several generations of digital cameras. These devices have evolved so quickly it is difficult to make useful appraisals, but any user should recognize the importance of rapid data transfer, and file naming problems inherent in these devices. Thus, for field systems the user should always purchase a PCMCIA flash card reader to allow routine data transfers and file naming needed to keep track of field photographs. This option is inexpensive for Smartmedia cards and Compact flash, but to our knowledge is still not available for Sony's proprietary "memory stick" devices. 
122 


\title{
Quebec Geomining Information System (SIGÉOM): Field Data Capture Module
}

\author{
By Charles Roy
}

\author{
Ministère des Ressources Naturelles \\ Secteur des mines \\ Service de la géoinformation \\ $5700,4 \mathrm{e}$ avenue Ouest (A-214) \\ Charlesbourg, Qc. G1H 6R1 \\ Telephone: (418) 627-6269 (5236) \\ Fax: (418) 643-2816 \\ e-mail: charles.roy@mrn.gouv.qc.ca
}

The Province of Quebec, one of the 10 provinces of Canada, covers 1.7 million square kilometers north of the New England states. The richness of its mining potential is well known, and is located mainly in the Abitibi area where famous examples of Kuroko copper deposits are described. The gross income related to the mining industry is about US\$ 2 billion. Mining exploration expenses per year are about US\$50 million. The Ministry of Natural Resources is the custodian of the mining activity, spending about US\$20 million per year to support it.

Géologie Quebec is the division of the Mining Sector responsible for field survey and the main geographic information system (SIGÉOM). SIGÉOM has been developed over the last 10 years, with data entry being performed at a rate of US\$ 1.2 million per year. It currently holds nearly all of the province's mining vector information. More than 131,000 outcrops, 23,000 faults, 139,000 contacts, 8,000 folds, and 14,000,000 chemical results are stored in SIGÉOM's database. Clients can choose from more than 15,000 products related to geoscientific information (<http://www.geologie-quebec.gouv.qc.ca $>$, products heading).

The system is designed with a corporate perspective. It reflects the mission of the organization, and it supports processes from data capture to data distribution. In this respect, the field data capture modules are no exception. The objectives are both to achieve corporate objectives and to give the maximum flexibility to the end user.

A paper model, called Geofiche, is used by geologists in the field. The information is then transferred to an Oracle database using input forms. Over 140 validations are applied to achieve a high degree of standardization.
This process is located at the end of the Autonomy vs Corporate objectives spectrum. The very structured process minimizes the differences that exist in different geological environments and between field geologists. Although the argument is relevant, the overall possibilities offered by the legend and symbol library give a great number of possible combinations, minimizing the threshold of standardization. The addition, modification and edition of classification parameters, although always subject to management approval, also contribute to the flexibility of the system.

In order to assure that the overall objective of data integration and delivery to clients is uncompromised, nothing is developed independent of the system.

Field data modules are part of the importation function family used to load the system with external data. The Geofiche module is the second version, organised around a highly compatible Oracle environment from a previous one built on a Clipper platform.

The capture of computerized information is done during the field season, at night, using a desktop or a laptop computer that runs Oracle and MicroStation software. Data transfer to SIGÉOM is done at the end of the summer by exporting the Oracle database and re-importing into the SIGEOM structures. The geometric features are then constructed using highly tailored functions specially designed to build the outcrop description and regional geological features. Using this streamlined procedure, and regardless of the scale or the details, a preliminary map is produced within three months of completion of field work. A final version is then developed, incorporating thin section and geochemical analysis details. 
124 


\title{
Conclusions From Four Years Collecting Digital Map Data Using A PDA
}

\author{
By Van S. Williams \\ U.S. Geological Survey \\ Box 25046, MS 913 \\ Denver Federal Center \\ Denver, CO 80225-0046 \\ Telephone: (303) 236-1289 \\ Fax: (303) 236-0214 \\ e-mail: vwilliam@usgs.gov
}

\section{INTRODUCTION}

Recording geological field observations on a personal digital assistant (PDA) is a practical and effective first step toward digital map compilation in the field. A small investment in equipment and time can increase productivity substantially. Advantages include elimination of digitizing of attitude symbols and of double entry of numeric data; notes and photos linked directly to the draft geologic map onscreen, quick search of notes for key phrases; reduced risk of data loss, more compact and portable note archives, and more legible and better organized notes that can be shared across a mapping team. Disadvantages are the cost of the PDA, time investment to become skillful at hand writing intelligible to the PDA, and hand writing recognition that is generally slightly slower than pen on paper. Advantages of a PDA are multiplied when used in conjunction with GPS, a laptop computer, and a digital camera. In addition to holding traditional field notes, PDAs support sketches, data entry forms with check boxes and pull down lists, drill hole databases, and even topographic base maps and orthophotos.

\section{DISCUSSION}

Field geologists engaged in geologic mapping are pressed by ever increasing expectations on the rate of production while at the same time they are given the additional task of delivering the data in digital form. One response has been to try to increase efficiency by developing and adopting practical techniques to collect points and lines in digital format during the course of field work, rather than collecting analog data by traditional methods and converting it to digital format in the office. The Canadian Geological Survey (Brodaric, 1997) pioneered digital field compilation using the original PDA, the Apple Newton. USGS field mappers have followed and now have several years of experience using later generation PDAs such as Palm Pilots or Pocket PCs (Walsh, 1999a, 1999b, Williams, 1999). In this brave new world the rapidograph, greenline, and field notebook are becoming superfluous.

To date, PDAs at the USGS have been used primarily to record point attributes, either on customized data entry forms or as freeform notes and sketches. The recent introduction by ESRI of ArcPad software running on some Pocket PCs has allowed some users to begin also collecting lines drawn over map or orthophoto images.

Previously, methods of line collection in the field described by Kramer (1998) required much heavier and more expensive specially constructed ruggedized laptop PCs.

Methods used for collecting field notes on Palm Pilot PDAs at the USGS fall into two main categories. One uses a system of forms with text boxes, check boxes, and pick lists to populate a database. These forms can be designed fairly easily using the Pilot Forms program from PenDragon, a Visual Basic addin from AppForge, or other programs. Forms for Windows CE PDAs can be designed using Microsoft Embedded Visual Basic, which is a free program that requires some programming skills. To a limited degree they can also be designed within ESRI's ArcPad application.

A form-based system may be the best choice to ensure complete data collection to populate a highly structured database, but it may not be the best approach to entice 
beginning users. Perhaps for that reason, some USGS geologists prefer to use freeform notes. From these geologist's perspective, forms are slower, a little more complicated to learn to use, and may be perceived as stifling individuality. Few field geologists collect their data on paper forms, and most will be more receptive to recording data digitally if not required to change their familiar format. Later, they may come to see some convenience in customizing forms to fit their own preferences.

Numeric attitude data recorded in freeform notes entered using the Palm "Memopad" or the Pocket PC "Notes" applications can still be extracted automatically to generate attributed point databases if the numeric portion is flagged (Williams, 1999). This requires more programming support than a forms-based approach, but appears simpler to the geologist in the field. Digital field photos and sketches drawn in PDA paint programs can be linked to the notes and database on a laptop PC or even on a pocket PC-type PDA.

In addition to generating digital field notes, PDAs offer the geologist quick reference to large graphical databases while in the field. For example, a geologist in the field drawing contacts between glacial geologic units may have to rely excessively on landform interpretation in areas of poor exposure. Referring to a database of water well drillers' logs stored on the PDA may provides a peek into the subsurface and improve the interpretation.

\section{REFERENCES}

Brodaric, Boyan, 1997, Field Data Capture and Manipulation Using GSC Field log v.3.0, in D.R. Soller, ed., Proceedings of a Workshop on Digital Mapping Techniques: Methods for Geologic Map Data Capture, Management, and Publication U.S. Geological Survey, Open-file Report 97-269, p. 77-81, <http://pubs.usgs.gov/openfile/of97-269/brodaric.htmlMl>.

Kramer, J.H., 1998, Advances in Digital Field Mapping: Geological Society of America Annual Meeting, Abstracts with Programs v.30(7), p. A-256, <http://www.geosociety.org>.

Williams, V.S., 1999, Simple Techniques Used at the USGS for Compiling Digital Geologic Maps in the Field: Geological Society of America Annual Meeting Abstracts with Program, v.31(7), p A-191, <http://www.geosociety.org/>.

Walsh, G.L, Reddy, J.E., Armstrong, T.R., Burton, W.C., 1999a, Geologic mapping with a GPS Receiver and a Personal Digital Assistant Computer Streamlines Production of Geologic Maps: Geological Society of America Annual Meeting Abstracts with Program, v.31(7), p. A-192, $<$ http://www.geosociety.org $>$.

Walsh, G.J., Reddy, J.E., and Armstrong, T.R., 1999b, Geologic Mapping and Collection of Geologic Structure Data with a GPS Receiver and a Personal Digital Assistant PDA Computer, in D.R. Soller, ed, Digital Mapping Techniques ' 99 -Workshop Proceedings: U.S. Geological Survey Open-file Report 99-386, p. 127-131, $<$ http://pubs.usgs.gov/openfile/of99-386/walsh.html>. 


\title{
Development and Use of a Laptop-Based Geological Mapping System: Experiences at the University of Kansas
}

\author{
By Ross Black and J. Douglas Walker \\ University of Kansas \\ Dept. of Geology \\ 120 Lindley Hall \\ Lawrence, KS 66044 \\ Telephone: 785-864-4974 \\ Fax: 785-864-5276 \\ e-mail: black@ku.edu,jdwalker@ku.edu
}

\section{INTRODUCTION}

Since 1998 the Geology Department at the University of Kansas has used field hardened laptop computers, commercial GIS software, and a locally written extension to the software in courses teaching geological field mapping, as well as in student and faculty field mapping projects. This is, of course, in addition to the ubiquitous use of computers in research laboratory and classroom settings.

The computers are used in conjunction with undergraduate Field Camp, advanced graduate mapping courses, thesis and dissertation mapping, and geophysical and hydrological data acquisition. This paper describes the use of field computers by undergraduate and graduate students in general field mapping projects in courses, Field Camp, and thesis work.

\section{REASONS FOR USING FIELD COMPUTERS}

The field systems allow geographic information systems (GIS) technology to be integrated into the field geology program. They allow multiple base materials to be swapped in and out of the map display easily, including topographic maps at different scales, aerial photographs, orthophotos, satellite images, and digital elevation models (Walker, et al., 1996). Once the base maps and other materials are scanned and properly registered to a spheroid, datum, projection, and coordinate system, these materials can be preloaded onto the laptops on campus, eliminating the need for large format hardcopies of the base materials. The software allows the mapper to roam and zoom quickly, accurately, and repeatably without the need to wrestle with folded, ripped, and stained base maps.
The systems also allow other technologies to be easily integrated into the mapping process. While it is still imperative to teach students how to locate themselves on the topographic map by traditional methods, such as triangulation, it is now very easy to integrate GPS technology into the mapping process. The GPS units can be hooked directly to the computer via a cable. However, our students have found the cable to be inconvenient and really unnecessary because the software tracks the cursor location. The student just reads the map coordinate off of the GPS screen and moves the cursor to that point on the screen before drawing the geological feature on the map.

The major step forward for the students, however, is that the entire mapping process is streamlined. Data acquisition, database development, and map production are now all one seamless process. In the past, these were separate processes requiring transferring the map information manually onto multiple media or typing and digitizing the field information manually if a computer was used for map compilation back at base camp. This tedious, time consuming work is now unnecessary, since the database is built on the fly and the map can simply be printed out every evening. It is also much more convenient for the students to back up the files to tape each night and not have to worry about the map being destroyed by accident.

\section{HARDWARE}

The hardware used in the mapping program has evolved during the past few years (Walker and Black, 2000). The first field hardened laptops purchased were AMREL Rocky II units (http://www.amrel.com). In 1998 we purchased five of these units, along with several Garmin GPS units (http://www.garmin.com) under a grant 
from the Technology Fund of the University of Kansas. These laptop units were incredibly durable, being able to withstand the full force of a graduate student falling onto a granite outcrop. Only one of the hinges and some of the corner pads had to be replaced the first year. The main problem with these units was the weight. They each weigh about nine pounds.

In 2000 we purchased five new, smaller units. These were Panasonic Toughbooks (http://www.panasonic.com), which only weigh about four pounds (Figure 1). They have a smaller screen, about eight inches across, and a smaller keyboard, which bothered some of the larger students. However, these units were so light and rugged that they were vastly more popular that the original Rocky units. More importantly, these units had sunlight-readable touch screens. Our software extension to the commercial GIS software is essentially a point and touch interface for the field geologist, such that no typing is necessary on the outcrop, unless the student chose to also use the computer as a digital field notebook. Most students found this to be most convenient, in spite of the small keyboard.

\section{SOFTWARE}

The software consists of a standard commercial GIS package, ArcView by ESRI (http://www.esri.com), combined with a commercial extension to this package, EditTools by Ianko Tchoukanski (http://www.ian-ko.com), and an ArcView extension written by students at the University of Kansas, GeoEditor (Walker and Black, 2000; http://geomaps.geo.ukans.edu). In the field, a background basemap is displayed in a standard ArcView View. The various geological features such as contacts, structures, and strikes and dips are then simply drawn onto the touch screen. Once the geometry of the feature has been drawn on the basemap, the user then clicks on the appropriate GeoEditor button on the button bar and a series of windows pops up allowing the geologist to add all the attributes for the feature to the attribute table by simply touching large buttons with a finger tip or stylus (Figure 2).

Students quickly become proficient with the simple tree structure of the drop down window style. Once the map is made, the students check and correct line topology and build unit polygons using the EditTools extension.

\section{USE OF COMPUTERS IN FIELD COURSES}

We first used the field computers in an advanced mapping course for graduate students. This was done during a two-week long course taught in California. Subsequently, we have used the computers during part of the second half of the KU undergraduate field camp (Figure 3), a course of three-week duration. These courses have been held over

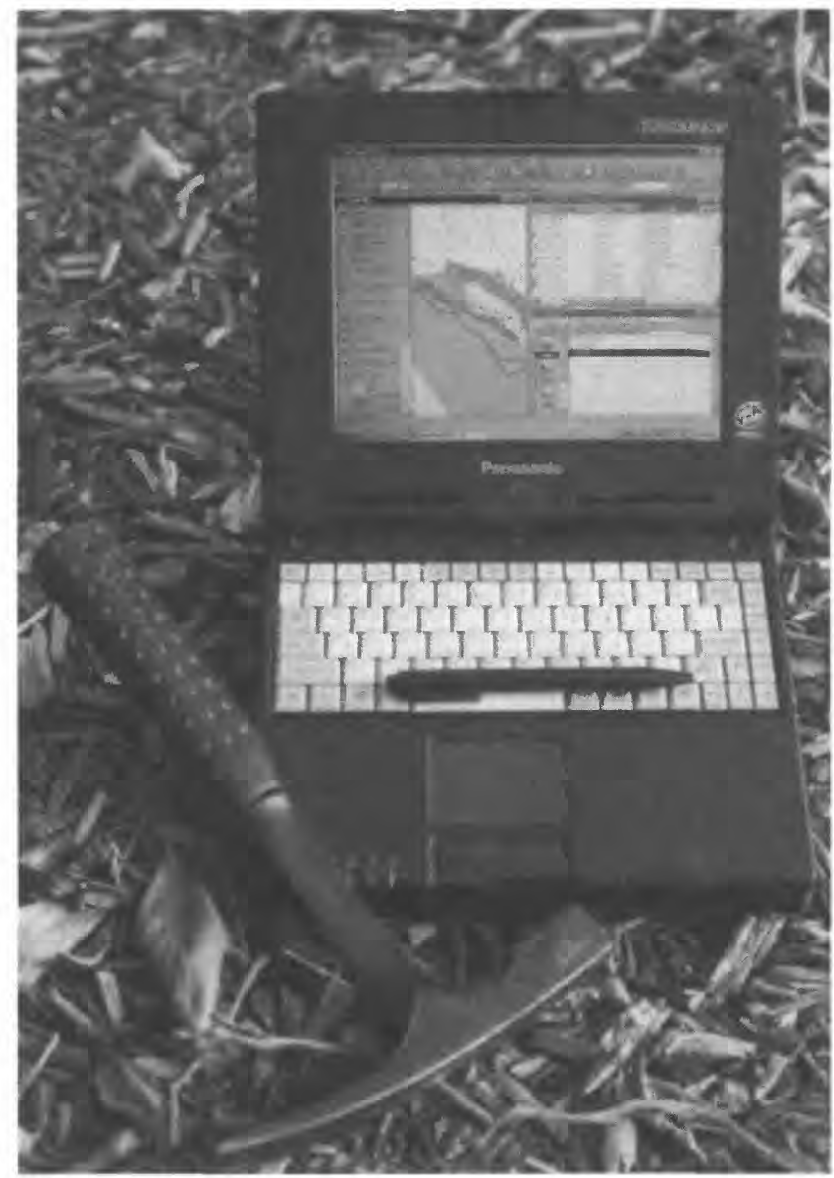

Figure 1. Panasonic Toughbook ruggedized laptop computer with rock hammer for scale. A field map and editable data tables are shown on the screen.

the last three years, and we have tried to modify the software as needed from each field experience. The graduate and undergraduate students, of course, had very different backgrounds. All of the graduate students had attended field camps, many of the graduate students had used ArcView before, and some had already done mapping for thesis work. The undergraduate students, on the other hand, had only completed the first half of field camp, and most had not been exposed to GIS in any form.

We give each group a similar introduction to using ArcView and GeoEditor. This consists of a $\sim$ three hour course on basic GIS functions and digitizing. Such tasks as attribute identification, spatial query, and snapping of one line to another are done during this introduction. Previously, this tutorial was done at field camp; presently we are doing this as a standard laboratory exercise in the undergraduate structural geology course (required of all students taking field camp).

The results of our teaching experience have been mostly positive. The only group that did not adapt immediately and well to using field computers was the graduate students. They had some difficulties adjusting to mapping on computers in the field and it took several days for them 


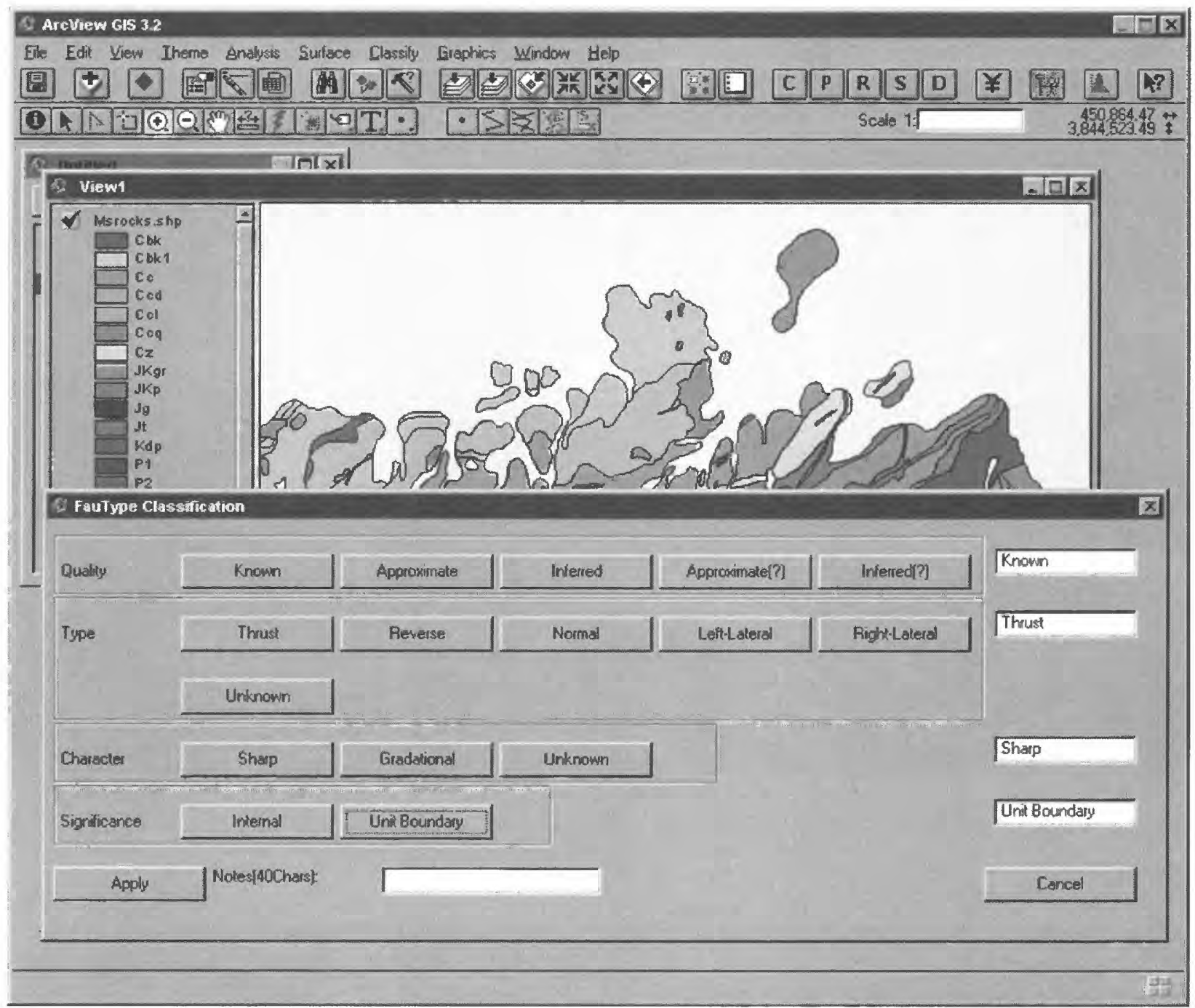

Figure 2. The GeoEditor software features drop-down windows for classifying contacts, rock units, and other geological features on the fly.

to become proficient and comfortable. One student in particular thought that the use of computers in the field was distracting and unnecessary (see further comments below). The undergraduates, on the other hand, wholly embraced the use of GIS and field computers for mapping. Most students were mapping well by the end of the first day, and all by the middle morning of the second. Most students also integrated their note taking into the computer.

Moreover, the undergraduate mapping experience seems to have been enhanced by the use of the field computers and GIS software. There are many reasons for this. First, field camp is the first experience that most students have with drafting illustrations using pencil/pen and paper/mylar. Most of the graduate students and current geologic professional have taken at least some technical illustration courses (the junior author of this paper, for example, had two and a half years of drafting courses in junior high and high school). For this reason, drawing and coloring maps neatly and proficiently is a much greater challenge than is realized (or admitted) by most field instructors. Several students have commented on how much easier it is to draft on a computer than keep track of colored pencils or try to keep rapidograph pens operating.

The second and possibly most important reason is that undergraduate students (and in a year or two, graduate students) have had computers incorporated into almost every aspect of their education. For this reason, using computers is not a new skill, but one that is well tested for them. In fact, one of the main reasons we have found for students having battery life problems in the field is that they spend their lunch time modifying the screen displays or playing games.

Third, the field computer and database structure make many non-mapping tasks easier for the students. Because structural data (e.g., strikes and dips) are stored in a database, they can be imported directly or with slight modifi- 


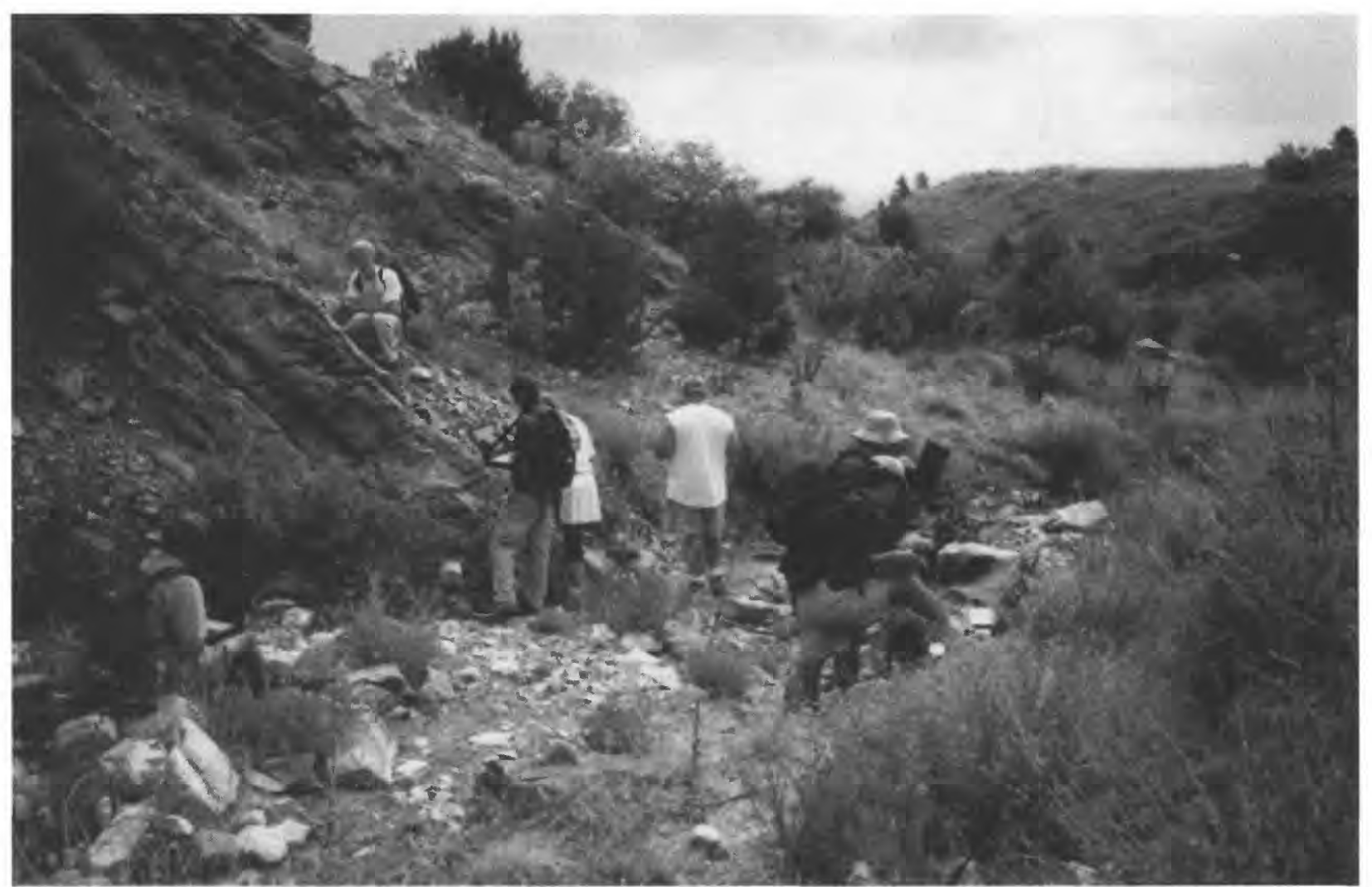

Figure 3. Undergraduate students using field-hardened laptop computers on the outcrop. The systems have been used as part of the field camp curriculum for the past three summers.

cation into stereonet programs. Stereograms and their interpretations can then be easily generated, skipping several non-geologic steps for the student. In addition, topographic profiles generated from digital elevation models (DEMs) can be extracted by the software and plotted directly on the geologic map. This allows for more accurate and much faster generation of geologic cross sections for the students. The cross sections can then be compared to the map viewed on topography using 3-D visualization packages. All this means that the students can spend more time on the geology and interpretation, and less on mundane and tedious tasks.

\section{ADVANTAGES AND DISADVANTAGES}

The main disadvantage of using laptops in a field environment is the weight and size of the hardware. The original laptops used at field camp weighed nine pounds and seemed rather clumsy to use until the students had used them for several days. Smaller, lighter units have been a great improvement, even with the tradeoff of a smaller screen and smaller keyboard.

A major factor in the choice of any computer to be used in a field environment is the readability of the screen in direct sunlight. Some older, inexpensive LCD technologies were not sunlight-readable. The newer active matrix screens are usually at least adequate for the job. Touch screens are a major advantage when performing mapping, as drawing directly on the basemap with a pencil-like stylus is much more natural than drawing with a cursor and touchpad or trackball. In addition, if the software is properly designed, much of the data entry can be reduced to tapping buttons on the screen for the most common rock types, structures and other features.

Without modification, off-the-shelf GIS programs are adequate for geological field mapping, but are rather hard to use. ArcView is no exception. However, the program can be customized through the writing of 'extensions'. In early versions of the program these extensions had to be written in a proprietary language, Avenues. (GeoEditor is an example of such an extension.) The recently released version can apparently be customized using Visual Basic.

There are also several pedagogical advantages. First, students can map on multiple basemaps using standard topographic maps, DEMs, satellite images, or aerial photographs. In this way the students gain experience and insight into remote sensing and other data. Second, it is easy to overlay maps from different students. This can lead to discussion and insights into why contacts may be 
placed in different locations from map to map. Lastly, the computer allows for easy map compilation and presentation.

One of the biggest advantages for using GIS software and a database approach to geologic maps is that it forces students to classify features as they enter data in the field. Because of this, students cannot return at the end of the day with maps where they do not understand the nature of some of the geologic contacts. This makes the students much more aware of how they map and that they must examine features in the field.

Perhaps the most telling episode to us about the value of the field-based computer approach is an experience we had with the teaching assistant (TA) for the 2001 undergraduate field camp. This TA was the same graduate stu- dent who took the graduate course three years earlier and disliked the system (see above). After being a TA and working with the field computers for three weeks, he declared that he wished he had the opportunity to use the system in his field mapping.

\section{REFERENCES}

Walker, J.D., Black, R.A., Linn, J.K., Thomas, A.J., Wiseman, R., and D'Attilio, MG., 1996, Development of Geographic Information Systems Oriented Databases for Integrated Geological and Geophysical Applications: GSA Today, v. 6, no. 3, pp. 1-7.

Walker, J.D., and Black, R.A., 2000, Mapping the Outcrop: Geotimes, v. 45, no. 11, pp. 28-31. 
132

132

132 


\title{
Rock Classification for Geologic Map Database Applications
}

\author{
By Stephen M. Richard \\ Arizona Geological Survey \\ $416 \mathrm{~W}$. Congress, \#100 \\ Tucson, AZ 85701 \\ Telephone: (520) 770-3500 \\ Fax: (520) 770-3505 \\ e-mail: srichard@iname.com or Richard_Steve@pop.state.az.us
}

\begin{abstract}
Lithologic class definitions are based on descriptions of observable features in an Earth material. The structure of lithologic descriptions is recursive in that an Earth material may consist of parts that are also described as Earth materials. A hierarchy of lithologic classification is based on degree of specificity of class definitions. Lithologic classes have an implicit spatial dimension that is the volume of the rock body that can be considered representative of the class. Rock volume units are defined to identify and characterize rock bodies in the Earth. These units are described as aggregations of lithologic constituents with particular relationships between the constituents.

Lithologic classification for a geoscience database system is designed to classify the lithologic constituents used to define rock volume units. Because of differences in scale and geologic focus, different classification schemes for lithologic constituents can be defined, with overlapping domains of classification. Lithologic classification is thus non-unique.
\end{abstract}

\section{INTRODUCTION}

One of the major goals of geoscience is to describe and understand the Earth. This is typically pursued using an analytic approach. A geologist starting to study a new area first collects observations in the field, to determine what sort of geologic phenomena are present. As mappable units are recognized, they are defined. A mappable unit is an identifiable part of the earth that can be distinguished at the chosen map scale from adjacent parts of the earth. A geologic map depicts the distribution of mappable units on the mapping surface. By delineating the distribution of the mappable units, the geologist determines the spatial and geologic relationships between the units. The logic of the geometrical disposition of geologic map units is one basis for determining geologic history (Ady, 1993).

The definition of mappable units is the fundamental problem that must be solved by a geologist in the field. The process is complicated for many reasons. The Earth is heterogeneous. There are continuous variations in many rock properties at many scales. Not much of the Earth is directly observable. The definition of mappable units will reflect the interests that motivate a geologist to study the geology of an area, as well as the experience and education of the geologist (Brodaric and Gahegan, 2000).

The Earth is typically subdivided into bodies of material that can be recognized based on some observable features. Two common approaches to defining rock bodies are 1) to define bodies bounded by surfaces that can be identified (e.g. a stratigraphic unit bounded by marker beds); and 2) to define bodies based on identifying characteristics of the material itself (e.g. a particular kind of granite). In the first case, the lithology of the rock body itself may be relatively consistent, but does not provide sufficient conditions to identify the unit; the boundary surface must be identified to determine if a particular segment of the Earth is within or outside the unit. In the second case, the properties of the rock body itself define sufficient conditions to identify the unit. Rock units of this second type are the focus of the following discussion and will be referred to in this paper without further elaboration as 'rock volume units'. Although any observable feature may be used to define a rock volume unit; this paper is concerned with rock volume units whose definition is based on lithology (physical characteristics of a rock).

Rock volume units are rock bodies that are identified by a set of defining lithologic characteristics. The definition of a rock volume unit has an implicit dimension over which the defining characteristics may be considered homogeneous (Table 1). This dimension defines the smallest volume of rock that is representative of the entire unit. This representative volume is analogous to a unit cell 
Table 1. Rock volume 'unit cells' have different dimensions.

\begin{tabular}{|l|l|c|}
\hline Volume Unit type & Definition & Dimension (m) \\
\hline Pluton & Defined by typical hand sample & 0.1 \\
Turbidite & Series of beds showing Bouma sequence & 1 \\
Glacial till & Outcrop of large-block polymict sedimentary breccia & $10 \mathrm{~m}$ \\
Tectonic mélange & Tectonically interleaved rocks from different settings & $100 \mathrm{~m}$ \\
\hline
\end{tabular}

in crystallography. Many rock volume units are heterogeneous at several scales. This heterogeneity is accommodated by either expanding the representative volume of rock in the definition, or by defining the unit as composite, with more than one lithologic component, each with its own 'defining representative volume'. A composite unit definition must also include a description of the characteristic relationships between the lithologic components. This paper is a discussion of some of the rules and assumptions underlying the definition of rock volume units necessary to form a classification system.

\section{CLASSIFICATION SYSTEMS}

A classification system is a scheme for assigning members of a set to membership in subsets of the set. A classification system must include several parts. A fundamental, and easily overlooked, part of the system is a definition of the domain of classification - that is the set of things that may be classified under the scheme. Secondly, there must be a definition of the kinds of criteria used to determine membership in a particular subset - referred to as a class. The third part of a classification system is the collection of class definitions that provide the criteria for assigning objects in the domain of classification to membership in a particular class. A practical classification system must provide unambiguous criteria to determine class membership. The criteria for class membership must be defined such that different observers can agree on the classification of particular objects.

Different kinds of classification systems are defined based on the multiplicity of the mapping between objects in the classification domain and the classes in the system (Hainaut et al., 1996):

Total - a thing in the classification domain belongs

to at least one class

Disjoint (exclusive) - a thing in the classification domain may belong to only one class Covering - a thing in the classification domain belongs to one and only one class (total and disjoint)
Free - a thing in the classification domain may belong to 0 to many classes (neither total nor disjoint)

\section{ROCK VOLUME UNIT CLASSIFICATION}

The purpose of classifying rock volume units is to provide a basis for identifying and describing particular bodies of material in the Earth. This may occur in a number of contexts. The field geologist develops a classification system for rock bodies in a map area in order to define mappable units. A map compiler uses classifications assigned to rock volume units to determine similarity between map units on different maps, or as criteria for forming composite map units. A non-expert geologic data consumer uses the classification system to identify rock units of interest without having to study the descriptions of the units in detail. Earth scientists use standard classification systems to characterize rocks as part of the process of describing them. These applications highlight two sorts of classification-one aimed at identifying particular bodies of rock in a particular region, and one aimed at grouping similar kinds of rock that may be present in many places. Both of these sorts of classification are based on similar criteria, but differ in their degree of specificity.

This varying degree of specificity leads to a hierarchy of classification that is an inherent part of the classification system. At the top of the hierarchy are classes with nonrestrictive definitions, and relatively large membership. Each level of the hierarchy narrows the definition for class membership, grouping classified objects into smaller and smaller subsets.

Classification of rocks thus varies along two major axes-the degree of classification specificity and the dimension of the representative volume classified. Handsample-dimension lithologic classification systems are designed to group kinds of rocks based on a $1-30 \mathrm{~cm}$ diameter representative volume. A particular hand-sample rock name, based on a naming scheme like that proposed by the British Geological Survey (e.g. Robertson,1999), is a very specific kind of rock volume classification meant to 
identify a particular rock body characterized at the dimension of a hand-sample. A geologic rock-volume map unit is a relatively specific classification meant to identify a particular rock body, but the dimension of the representative volume may vary from hand-sample size to $\mathrm{km}$-scale. A lithologic map unit is a less specific rock-volume classification meant to group similar kinds of geologic rock-volume units.

Because what we observe is determined by our biology, there is a level of rock classification that is 'natural' to most people. At this basic level, chunks of sensory input are processed as a whole, not an aggregation of parts, much in the manner that we recognize a face (Lakoff, 1987). Everyday rock names recognized by non-geologists represent this basic level of rock classification. Such terms include granite, schist, gneiss, sandstone, slate and marble. A basic-level classification system for a trained geologist would include a wider variety of classifications, but the exact list would depend on the experience and the interests of the geologist. Basic-level rock classes are identifiable without close inspection, limiting the classification criteria to features observable with the unaided human eye. This places an effective minimum dimension limit on the order of $1 \mathrm{~cm}$, and a maximum dimension limit on the order of $300 \mathrm{~m}$-about the largest mountainscale outcrop that can be taken in at one look.

This basic level rock classification should form the core (most commonly used part) of a rock-classification hierarchy in a geologic data system. Only simple fabric and mineralogical criteria are applicable to this sort of classification. More specific rock classes, which subdivide the 'basic level classes', are defined using more subtle criteria, e.g. detailed modal mineralogy, grain-size distribution, or fabric criteria. More general super-classes group basic-level classes, typically based on more theoretical, genetic criteria, e.g. igneous, sedimentary, metamorphic, intrusive, extrusive, or based on compositional grouping, e.g. terrigineous, carbonate, pelitic.

Because the basic-level rock classification used by geologists is based only on simple fabric and mineralogical criteria, it is insufficient for a classification system that unambiguously defines class membership. The system works well for common rocks that are similar for the prototypes for each class, but classification becomes ambiguous for rocks that do not clearly match a prototype. The boundaries between the classes are fuzzy, and lithology varies continuously over many descriptive variables. The basic level classification does not clearly define boundaries between many classes in the lithologic continuum, e.g. gneiss vs. schist, sandstone vs. mudstone, hornfels vs. slate, granite vs. diorite, cal-clastic sandstone vs. limestone. Consensus among geologists on the exact definitions of the boundaries can not be expected, and in many cases will seem arbitrary. Nevertheless, these boundaries must be unambiguously defined in a geologic information system useful to both geologists and non-geologists, such that the results of queries to the system are predictable, comprehensible, and reproducible.

The domain for a rock volume unit classification system is defined to be 'any volume of the solid Earth that may be described for the identification of a particular material body in the Earth'. The representative volume used to define a rock volume unit must be large enough to be characterized as an aggregate of constituent parts (Richard, 1999). In practical terms, this means the smallest representative volumes are on the order of 1-10 cubic centimeters.

A rock volume classification system for use in a geoscience information system must be total, so that any rock can be classified. However, there are many examples of rocks that can be recognized as belonging to more than one class, depending on the criteria used for classification. Examples include low-grade metasedimentary rocks that may be described as metamorphic rocks and as sedimentary rocks, saprolites that may be described as surficial geologic units and as their bedrock parent, and calc-lithic sandstone that may be classified as both a sandstone and a limestone. Any classification system that attempts to define disjoint classes over the entire domain of 'rocks' must define ad hoc rules for classifying such rocks into unique classes, or add numerous new classes that include such composite kinds of rocks. A better solution is to allow separate classification schemes, based on different classification criteria, that are designed to classify rocks within some sub-domain of rocks. The domains of classification for these schemes may overlap, but classes in any particular scheme are disjoint. Rock volume classification over the whole domain of rocks is thus overlapping, or not disjoint.

In order to produce a classification system for rock volume units that allows different observers to classify rocks in the same way, the system must be based on physical properties of the rock recognizable by all observers. Strict adherence to this rule would not allow use of genetic interpretations in the classification of a rock volume unless they could be couched in purely descriptive terms. The properties used for field classification include modal mineralogy, grain size, grain shape, rock fabric (the arrangement of grains in an aggregate to form the rock), and structures in the rock (bedding, layering, etc.). Rock volume units may be defined based on other physical properties, such as magnetic susceptibility or density, but these are not generally used as field criteria.

In order to gain acceptance in the geoscience community, any rock classification system needs to be consistent with common usage. This may require some relaxation of the strict adherence to observable physical properties as criteria for classification, because traditional rock classifi- 
cation has always involved some genetic interpretation (igneous, sedimentary, metamorphic are fundamentally genetic). The operational rules for consistency are that existing terms may be redefined to narrow their meaning, but may not be redefined to include rocks that are not included as part of that class in common usage.

\section{DEFINITION OF A ROCK VOLUME UNIT}

The definition of a rock volume unit is a description of the characteristic properties, homogeneous on the dimension of the representative unit volume, that provide sufficient grounds for assigning membership in the rock volume unit. The essence of the unit definition is thus the description of a rock volume. Using an analytical approach, a rock volume is described as a collections of parts and relationships between parts. The lithologic components of a rock volume unit definition used to define a geologic rock volume map unit are 'base level' lithologic classes chosen by the geologist as dictated by their experience, the nature of the geologic environment, and the goal of the geologic mapping program.

At the smallest scale of lithologic description, the parts of a rock volume are grains of individual mineral substances. This is the scale of standard 'hand-sample' rock classification, e.g. a granite is a rock that consists of an aggregate of quartz, $\mathrm{K}$-feldspar, and plagioclase in certain proportions with a certain fabric (relationship between grains). This description may serve to define a single lithologic component representative of a homogeneous granite rock body (a pluton). More complex rock bodies that are internally heterogeneous are built up of parts that are themselves rock volume units. For example a conglomerate consists of an aggregation of clasts, each of which may have its own rock description. A migmatite is a mixed rock with particular kinds of rock-volume component parts in a particular arrangement. Some kinds of rock volume units are defined without specifying the hand-sample-scale description, for example classes like till or breccia do not depend on the particular handsample scale kinds of rock in the rock body. By expanding the dimension and complexity of the parts used to define a representative volume for a rock volume unit, units of arbitrary complexity may be defined.

\section{DATABASE DESCRIPTION OF ROCK VOLUME UNIT}

A rock volume unit description may be modeled as an aggregation of constituents and relationships between constituents, in which each constituent may be some other rock volume unit or a previously defined lithologic constituent (Figure 1). This model is structurally recursivethe modeled thing (rock volume unit) is a component in the model of itself. A lithologic constituent, which corresponds to the basic level rock classes discussed above, represents the smallest rock component that may be a part of a rock volume definition. Based on the discussion above, this will typically be a hand-sample size rock, identified simply by a classification in a previously defined classification scheme, or by a complete description that defines a more specific, particular rock. The description of a lithologic constituent is recursive in exactly the same manner as a rock volume unit description, but in this case, the smallest component is a mineral species (Richard, 1999). In both the rock volume unit and lithologic constituent descriptions, each part in the aggregation may have a role in the whole (e.g. phenocrysts in a hand sample, irregular veins in a migmatite unit), and also may have relationships to other parts in the aggregation.

Clearly, some constraints are desirable to assure that the descriptions of rock units are not absurd. Formal statement of the constraints is difficult. Intuitive constraints include: 1) Constituents playing a particular role in an aggregation must be distinct from other constituents in the same role. For example, if there are two kinds of quartz included in a sandstone, both playing the role 'cement', then there must be criteria to distinguish the two kinds of quartz (e.g. transparent quartz, and inclusion-rich quartz); 2) The representative dimension that defines a constituent should be equal to or smaller than the representative dimension for the unit as a whole. For example, a tillite (representative dimension-10's of $\mathrm{m}$ ) could not be a lithologic constituent playing the role 'clast' (with dimension $<1 \mathrm{~m}$ ) in the description of a cobble conglomerate; 3) In most cases, a rock volume unit can not be a constituent of itself, but this rule has exceptions, for example in extrusive volcanic autobreccia units.

\section{CLASSIFICATION IN A GEOSCIENCE DATABASE}

Rock volume classification has two important functions in a geoscience database. First, in the case of a rock description, a lithologic constituent of a rock volume unit may be identified using a standard rock classification in cases for which a detailed description of the actual lithologic constituent is unavailable or unnecessary. Second, in cases for which lithologic constituents are described in detail, assignment of the constituent to a standard rock classification allows users to search for standard kinds of rock without having to design queries that analyze the complete description structure. A lithology field in a rock description database is a place for classification of the constituents used to define rock volume units.

Different earth scientists with different geologic foci may use different basic-level classification schemes. Individual rocks may be classified differently using different schemes. Different rock classification schemes have 


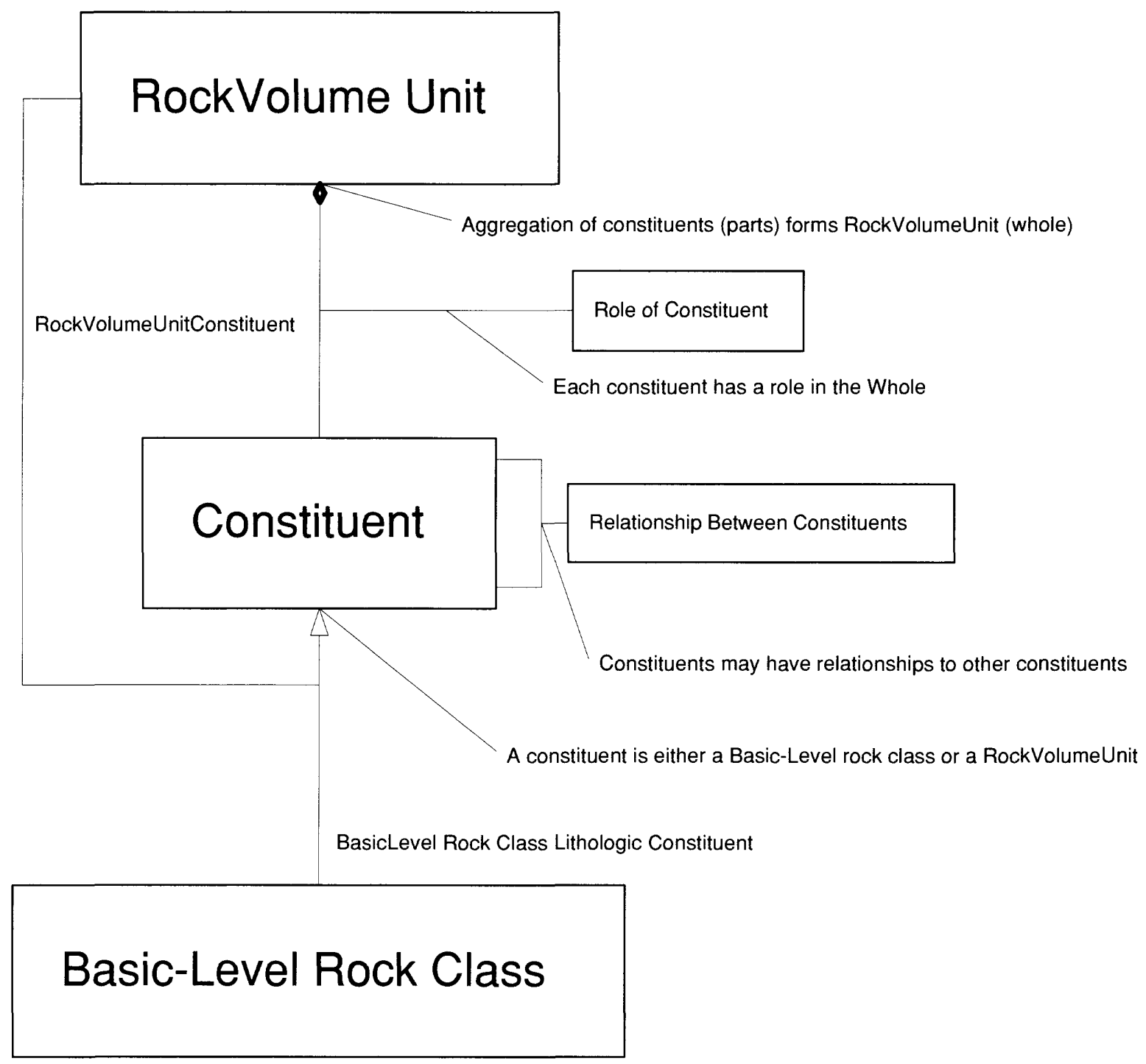

Figure 1. Simple schema for description of rock volume unit. Notation is based on UML.

different classification criteria, and may have different domains of classification. The domains of different schemes may overlap, but each scheme must be covering (total and disjoint) within its domain of classification.

The approach to a lithologic classification proposed here is fundamentally descriptive. Classification of a lithologic constituent is based on observable features of the material, and assignment of a material to a lithologic class implies that certain descriptive criteria are met. These criteria must be defined in the database in order to document the classification system. The descriptions that define the lithologic classes also serve to provide default values for rock properties that are assigned to a lithologic class, but not described in greater detail. The definition of a lithologic class must be associated with a classification scheme that defines the domain of classification and classification criteria. The definition must state the dimension of the representative volume for the class, the criteria that are sufficient to assign membership in the class, and to the extent possible, a default description of other aspects of rocks that are assigned to the class.

How many classification schemes for subdomains of the domain of earth materials are required? This question does not have a clear answer. Several different subdomains for classification of hand-sample-dimension lithology are commonly recognized by earth scientists. Surficial materials are classified according to properties related to the deposition of the material and weathering of the material at the rock-atmosphere (or hydrosphere) interface. Igneous rocks are classified according to properties related 
to the crystallization of the rock from a melt. Sedimentary rocks are classified according to properties related to the deposition of sediment and diagenesis of the sediment to form rock. Metamorphic rocks are classified according to properties related to the changes in the rock that make it a metamorphic rock. Other subdomains are identified based on more specific genetic origins. Volcanic rocks are classified according to composition and eruptive processes that affect lithology, and the domain of volcanic rocks overlaps with that of sedimentary and igneous rocks. The domain of biogenic sedimentary rocks overlaps with that of epiclastic sedimentary rocks. The Science Language Technical Team (http://geology.usgs.gov/dm/steering/ teams/language/charter.shtml) formed under the auspices of the North American Data Model Steering Committee (http://geology.usgs.gov/dm/steering/) is currently developing standardized language for a rock classification system for the basic lithologic constituents of rock volume units.

There is no standard method of classifying map-unitscale rock bodies according to lithologic criteria and many approaches are possible. Various classification systems are possible, each with some spatial scope and geologic intent. Until systematic approaches to such classification can be formalized, the usefulness of map-unit scale classification systems outside of their original spatial and thematic domain will be a function of how clearly the classes and boundaries between the classes are described.

\section{REFERENCES}

Ady, B. E., 1993, Towards a Theory of Spatio-Chronologic Relations for Geoscience: Sudbury, Ontario, Geological Survey Open-File Report 5854, 76 p.

Brodaric, B., and Gahegan, M., 2000, Geoscience Map Data Models, Open Systems GIS and Semantics: Proceedings, GeoCanada2000-The Millenium Geoscience Summit, Calgary, Alberta, p. 7.

Hainaut, Jean-Luc, Hick J.M., Englebert V., Henrard J., and Roland D., 1996, Representation of IS-A Relations: Dept. of Computer Science, Univ. of Namur, Belgium, Technical Report RP-96-016, available at $<$ http://www.info.fundp.ac.be/cgi-bin/pub-spec-paper?RP96-016>.

Lakoff, George, 1987, Women, Fire, and Dangerous Things: Chicago, IL, The University of Chicago Press, $614 \mathrm{p}$.

Richard, S. M., 1999, Geologic concept modeling, with examples for lithology and some other basic geoscience features, in Soller, D. R., ed., Digital Mapping Techniques 1999, Workshop Proceedings: U. S. Geological Survey Open-File Report 99-386, p. 59-75, <http://pubs.usgs.gov/openfile/ of99-386/richard.html>.

Robertson, S., 1999, Volume 2, Rock Classification, Metamorphic Rocks, in BGS Rock Classification Scheme: Nottingham, UK, British Geological Survey Research Report RR 99-02, 26 p. 


\title{
Interactive Geologic Maps Using ArcIMS, with Links to Related Data and Images
}

\author{
By David R. Collins ${ }^{1}$, Jorgina A. Ross ${ }^{1}$, and Detlev Doherr ${ }^{2}$ \\ ${ }^{1}$ Kansas Geological Survey \\ The University of Kansas \\ 1930 Constant Avenue \\ Lawrence, KS 66049 \\ Telephone: (785) 864-2139 \\ Fax: (785) 864-5317 \\ e-mail: david@kgs.ukans.edu \\ 2University of Applied Sciences \\ Badstrasse 24 \\ D- 77652 Offenburg \\ Germany
}

\section{INTRODUCTION}

The title expresses goals the Kansas Geological Survey (KGS) has been working toward for some time. This report extends concepts and objectives developed while working on an earlier effort for effective interactive digital maps on the Internet. That work was reported to the 1998 DMT Workshop in Champaign, Illinois (Ross, 1998). The current project goes beyond previous efforts that focused on methods for serving the contents of a geographic information system (GIS); the points, lines, and polygons representing features of the digital geologic map and the data in the attribute tables of the GIS describing those features.

In this project, real-time links are developed between an interactive geologic map of Montgomery County, Kansas, and related digital data and images stored in databases independent of the GIS. Most significant is the link established to the recently developed Kansas Geologic Names Database. Progress with the project was facilitated by the timely development of appropriate technologies, particularly improved software architectures.

The Kansas Geologic Names Database (LEXICON) has evolved, with extensive modification, from the text files used in publication of KGS Bulletin 231, Lexicon of Geologic Names of Kansas (through 1995), edited by Baars and Maples (1998). Development of the database was reported at the 1999 DMT Workshop in Madison, Wisconsin (Collins and Look, 1999). As indicated in that report, the database development process was a practical aid toward implementing the North American digital geologic map data model.

This report discusses the development of the Internet map service for Montgomery County and the associated interactive links to related data and images. The success of this effort supports other indications of the significant and increasing role that interactive Internet access to geologic maps and data will play in support of research, public policy analysis, and public information.

\section{OBJECTIVES}

The pilot project described in this report was designed to test the functionality of ESRI's ArcIMS software (Arc Internet Map Service) in the development of a standard Internet map service, using the digital geologic map of Montgomery County, Kansas. Capabilities for customizing the interactive map system are also tested. For each map object that corresponds to an individual or multiple geologic units displayed on the interactive map, the user should be able link to the Kansas Geologic Names Database, providing access to additional information about the specific geologic units represented. For other map objects representing structural or tectonic features, type or measured section locations, well sites or other features of interest (such as highways, survey boundaries, mineral leases, towns, etc.) the project should demonstrate the 
capability of linking to related digital information, images, photographs or databases.

Ease of use is a high priority. Equally important, however, the project seeks to establish a framework to facilitate future development of additional, well-designed, interactive, digital geologic maps.

\section{THE INTERACTIVE MAPPING ENVIRONMENT}

A generalized representation of an interactive map environment is presented in Figure 1. Use of commercially developed geographic information systems provides the most practical approach for implementing an interactive map service. Organizations may find, however, a wide range of options for peripheral systems supporting fieldwork, data capture, and information management that provide significant enhancements to the primary GIS. These options frequently include in-house systems tailored to meet unique requirements, circumstances, or capabilities of an organization.

Data capture and map production activities at the KGS are accomplished with GIMMAP, an in-house mapping system (Geodata Information Management, Mapping, and Analysis Package). For more general applications, the
KGS makes extensive use of GIS products from ESRI, including ArcInfo, ArcView, and ArcEditor. ESRI's Spatial Data Engine (ArcSDE) provides the gateway between the GIS packages and the Survey's database platform (ORACLE 8.1.7). The use of ESRI software is driven, in part, by the Survey's position as a research unit within the University of Kansas and the availability of ESRI site licensing through the University. At the heart of the interactive mapping environment is the Internet map server. As indicated previously, ESRI's ArcIMS was selected as the Internet map server for this project.

A diagram of the map service architecture is provided in Figure 2. ArcIMS (version 3) operates on the server side, providing map server management tools, geodata spatial servers, and the application server. Use of ArcIMS requires additional supporting components. A web server handles requests from clients and sends back a response. Requests are presented in HyperText Transfer Protocol (http). The KGS uses the Apache web server (version 1.3.14) running on a UNIX platform. Utilities in the Java Runtime Environment (JRE, version 1.2.1) provide the application program interface for running the Java2 components of ArcIMS.

The ArcIMS geodata spatial server provides two types of map services to the web server for response to the clients (users). With an image map service the client

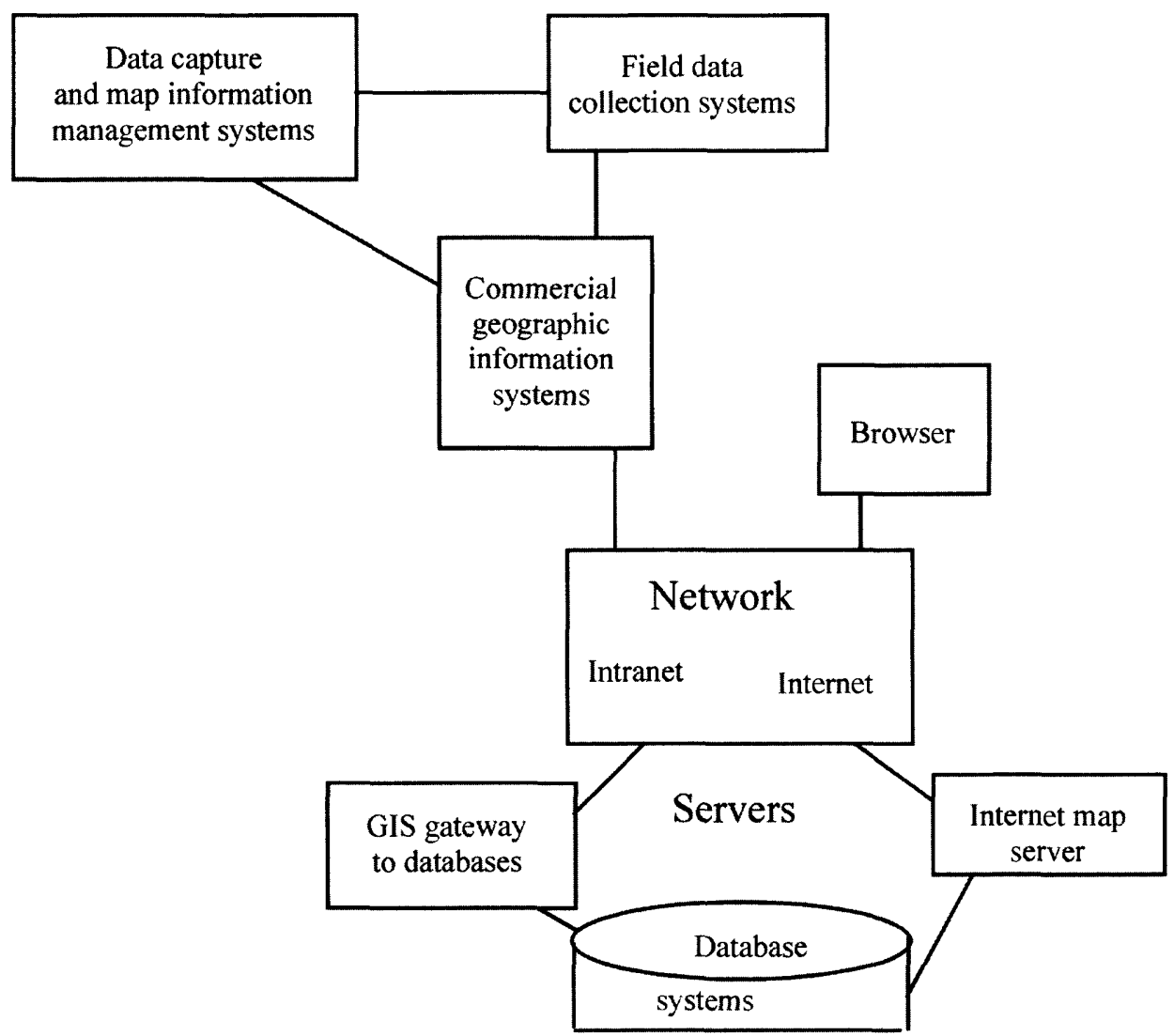

Figure 1. Generalized KGS interactive map environment. 
request is executed on the server and an image (GIF, JPEG, PNG) is generated and sent to the client machine. With a feature map service, vector features are streamed to the client machines. Many functions are then processed directly on the client machine. This project has utilized the image map service for its interactive mapping environment.

Additional map services query, geocode, and extract data from the databases for the geodata spatial server. These services do not affect the type of map service provided to the client (image or feature), but may or may not be required, depending on the type of client service. For more detailed information on this and other aspects of ArcIMS architecture and functionality, refer to ArcOnline, the ESRI resource center, at $<\mathrm{http}$ ///arconline.esri.com/arconline/>.

\section{DEVELOPING A WEB SITE WITH ArcIMS}

The ArcIMS Manager provides three software packages for map service development: Author, Designer, and Administrator. Through these packages, ArcIMS establishes protocols and uses parameters and options selected by the developer to generate the files and Java script needed for operation of the Internet map service.

\section{Author}

The Author package creates the basic map design and saves the attributes of shape files derived from the GIS in an ArcXML file (with extension '.AXL'). Figure 3 shows the use of Author to define layers from existing shape files. Figure 4 illustrates the use of Author for definition of layer properties. The process for defining layer properties is very similar to that used in ArcView. These steps result in an ArcXML output file used by the map service of the ArcIMS geodata spatial server.

\section{Designer}

The Designer package is a Wizard-based utility used to create the map service web pages and their layout for HTML or Java viewers. The ArcIMS host name is specified with Designer (Figure 5). For the KGS the host name is www.kgs.ukans.edu. After specifying the Web site directory and Web page title, a variety of standard options are available for design of your own web site (Figure 6).

\section{Administrator}

The Administrator package regulates functions of the map services on the geodata spatial server, such as stopping and starting. It is also used for creating new map services. This requires establishing a number of critical map service properties. The ArcIMS Administrator is used to name the map service, define the physical location of the .AXL file used by the geodata spatial server, specify the type of service (image or feature), and define the URL and related physical address for the web service. Figure 7 illustrates the use of the Administrator package.

\section{Standard ArcIMS map services}

The web site developed for this project is illustrated in Figure 8. This is basically the standard result derived from ArcIMS using Author, Designer and Administrator.

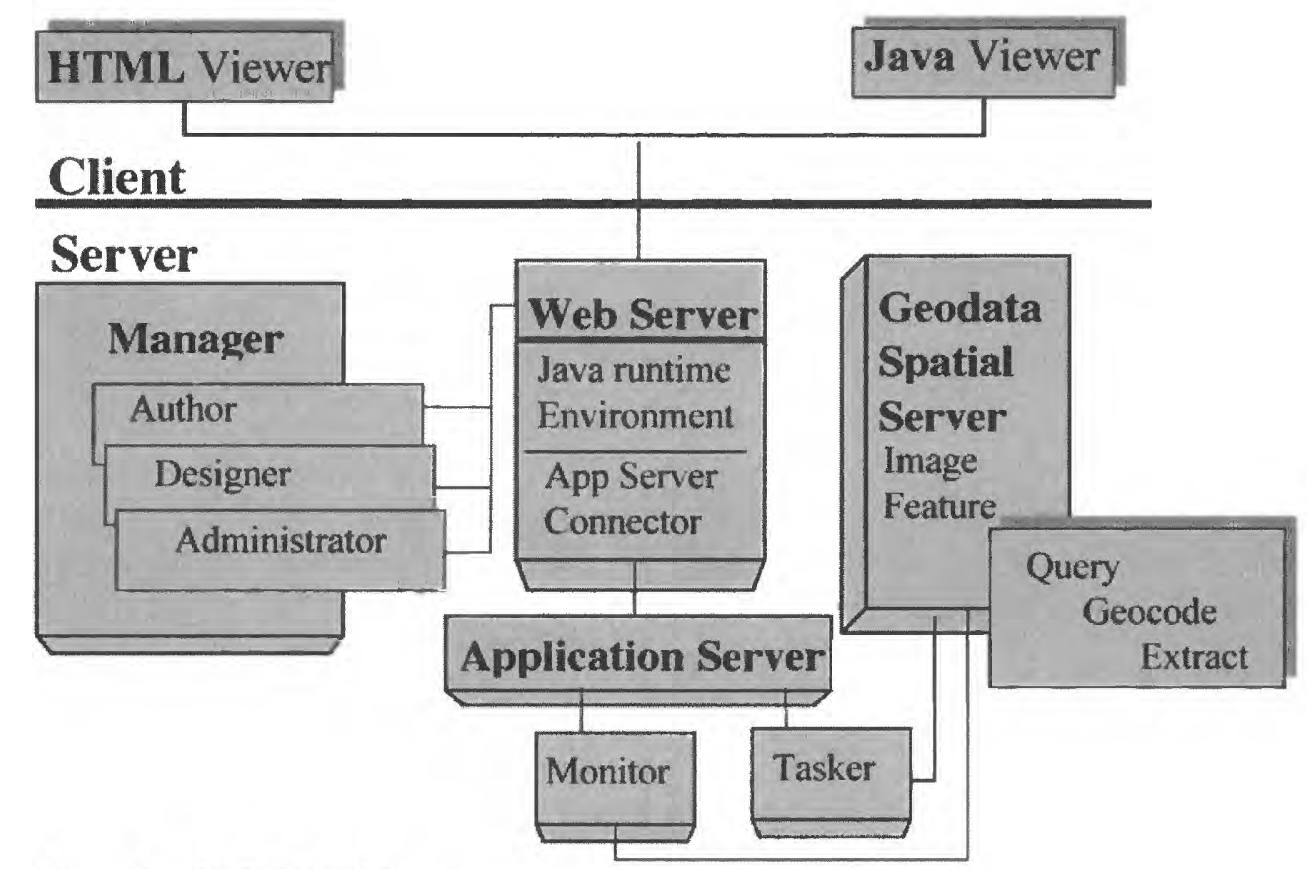

Figure 2. ArcIMS Architecture. 


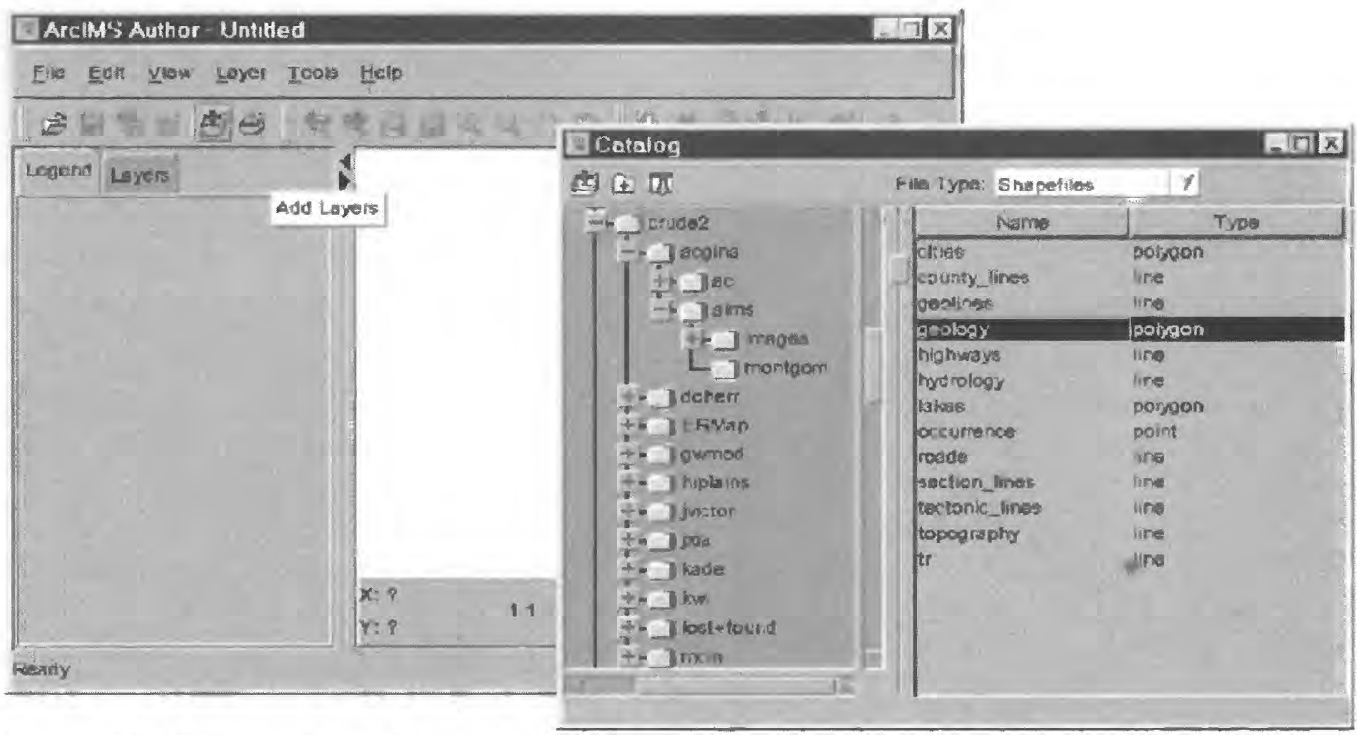

Figure 3. Defining layers from existing shape files, using the ArcIMS Author package.

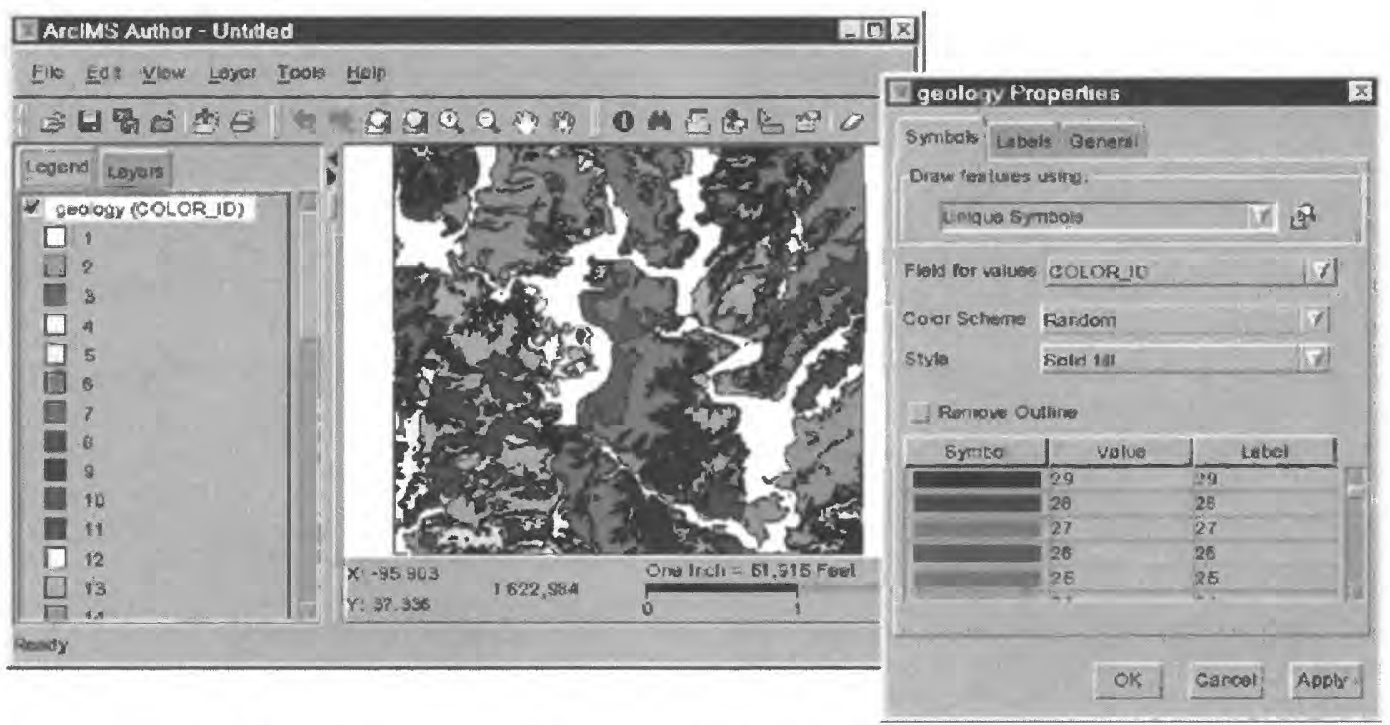

Figure 4. Definition of layer properties, using the ArcIMS Author package.

Customizing has been limited to the addition of hot-links to the Kansas Geologic Names Database and other digital information. The customizing is accomplished by directly editing the Java script and Java parameter files produced for the standard presentation by ArcIMS. For example, this additional work is required to establish hot-links and alias names of layers or attribute fields. A detailed explanation of the steps involved in customizing is provided in KGS Open-file Report 2001-33 (Doherr, Collins, and Ross, 2001).

\section{DEVELOPMENT OF AN ONLINE STRATIGRAPHIC LEXICON}

Internet access to the Kansas Geologic Names

Database was developed prior to establishing the Internet map service for Montgomery County. The online stratigraphic lexicon was developed using the PL/SQL programming package (Oracle Corp., 1996, 1998). It offers a procedural language that permits a variety of different possibilities for data access using SELECT commands, data manipulation, and data presentation in web pages. Many, but not all, of the procedures and functions developed in PL/SQL as part of this new program package (LEXICON) are also for linking the Kansas Geologic Names Database to an interactive geologic map.

As indicated in Figure 9, several select functions have been developed in the trial version. The second option, selecting data for a given sequence ID and map unit, uses the same starting parameters and the same procedures and functions as those needed in a query from an interactive geologic map. Prior development of the LEXICON pack- 


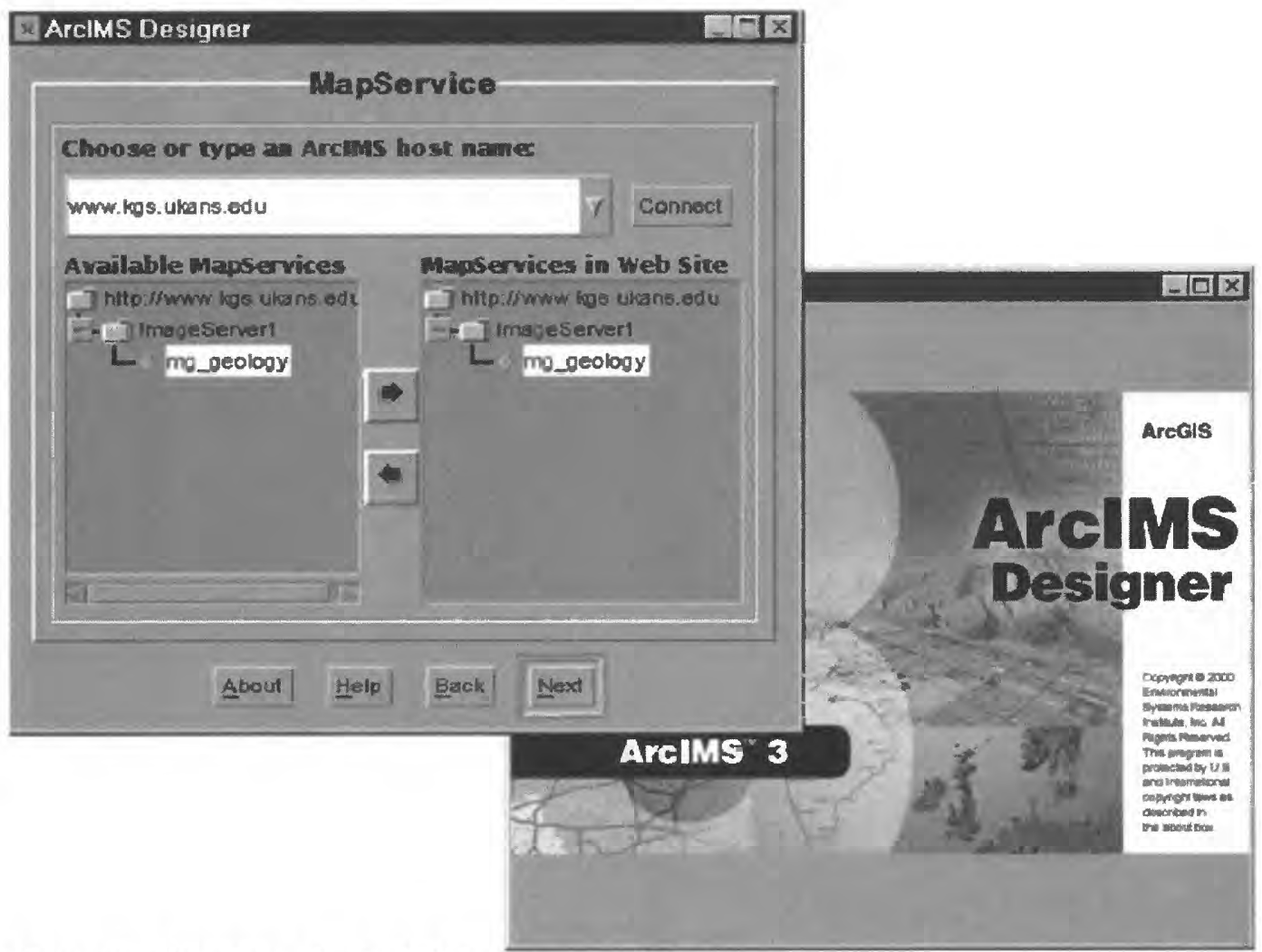

Figure 5. Specifying the ArcIMS host name with Designer.

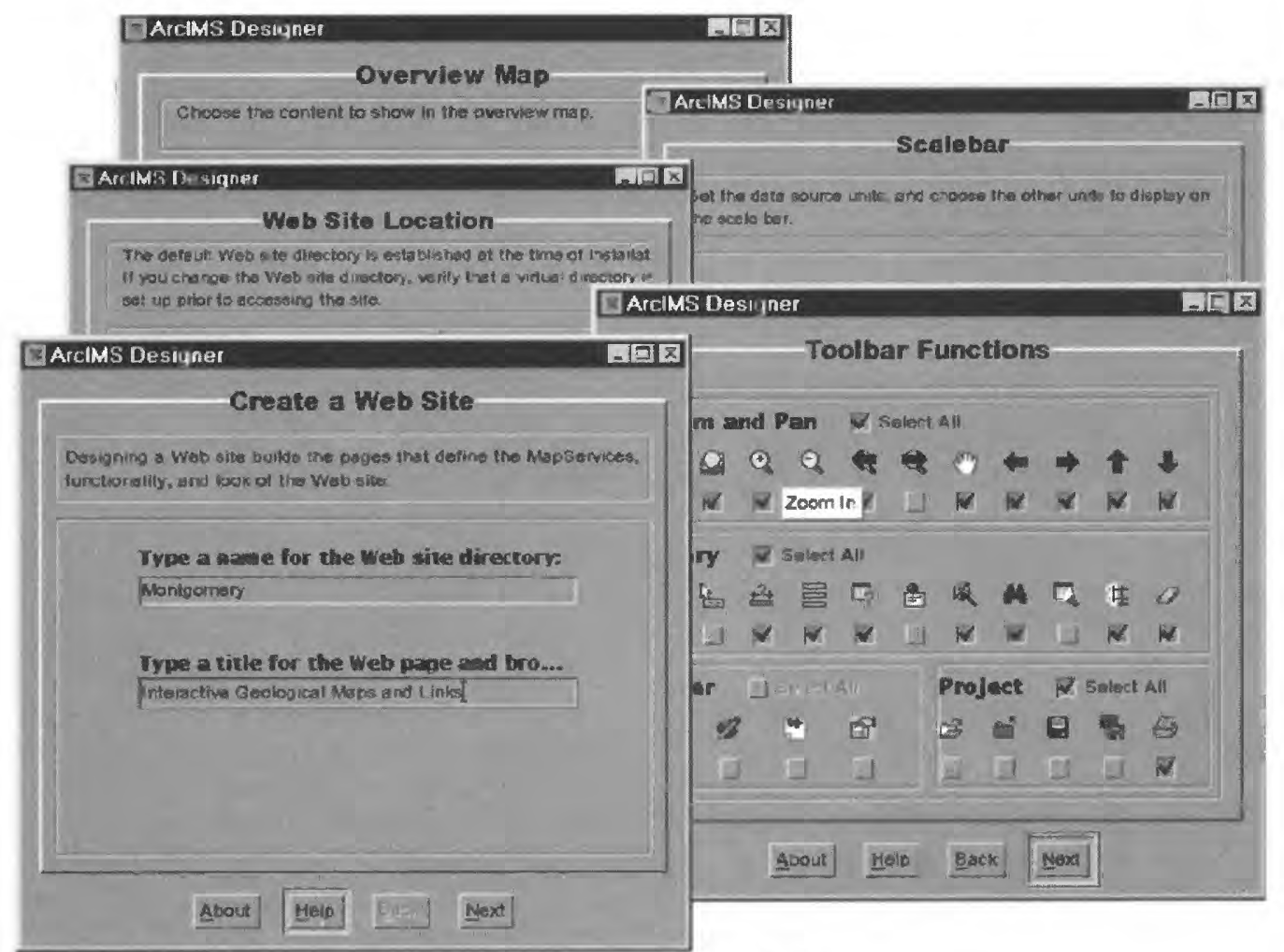

Figure 6. Utilities for creating and designing a map website. 


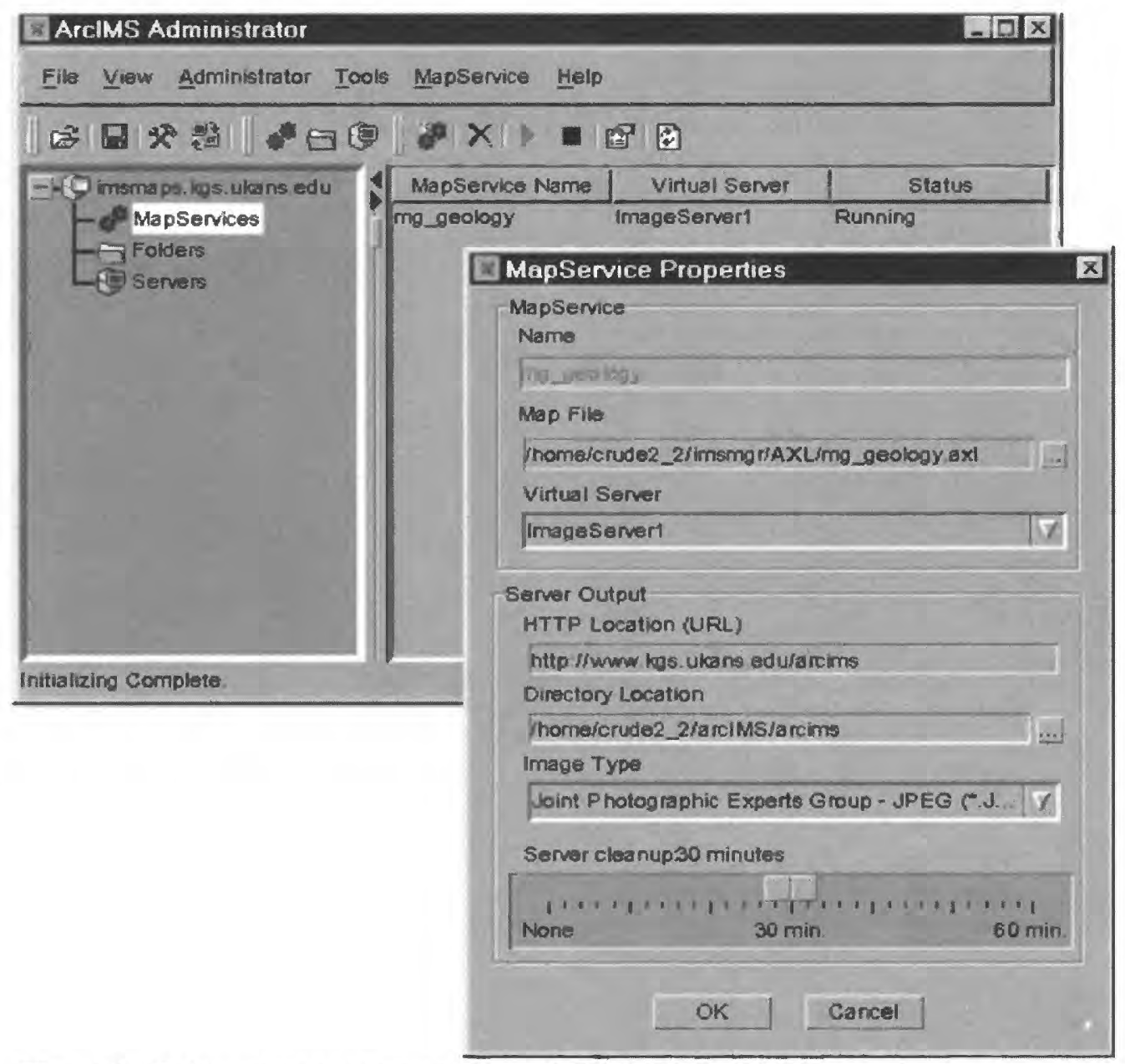

Figure 7. Setting map service properties with ArcIMS Administrator.

age permitted testing of these procedures and functions before they were used with the interactive map.

The heart of the Kansas Geologic Names Database is found in three primary tables, UNITS, SOURCES, and CITATIONS. Figure 10 presents the relationship between these tables and the general nature of their information content.

The structure of the data tables is important for all the select commands included in programs for online database presentation and for defining hyperlink access. For the initial development of Internet presentations, only some of the existing data tables and data fields in those tables have been used. The tables and fields most important for the current project are shown in Figure 11.

'KID' is the acronym for the ten-digit, 'Kansas IDentification' numbers used to uniquely identify records in ORACLE databases of the Kansas Geological Survey. The UNITS table is related to the CITATIONS table by the correspondence between the KID of the UNITS table and the UNIT_KID of the CITATIONS table. Similarly, the KID of the SOURCES table and the SOURCE_KID of the CITATIONS table relate the SOURCES table to the CITATIONS table.
The design of the original text files for KGS Bulletin 231 (Baars and Maples, 1998) imposed some undesired constraints on the initial development of the Kansas Geologic Names Database. One problem involves a lack of clear links between a particular abandoned nomenclature and associated citations when there have been changes in nomenclature for a rock unit.

In many cases the revised nomenclature for a unit is basically the same as the abandoned form except for a change in rank or in the name of the parent unit. In other cases the name may not change at all, but the interval of rocks represented by that name may be redefined. In these situations, the old form of nomenclature is listed under the new form in Bulletin 231. These types of name changes sometimes resulted in several abandoned names appearing as a list under the most recent form. For example 'Kansas City limestone' and 'Kansas City Formation' are listed with the current nomenclature of the 'Kansas City Group'. Citations related to all of the identified forms of nomenclature are then grouped together in Bulletin 231, following the list of variations in nomenclature. The links between each citation and the corresponding appropriate variant must be interpreted from text. The limited information 


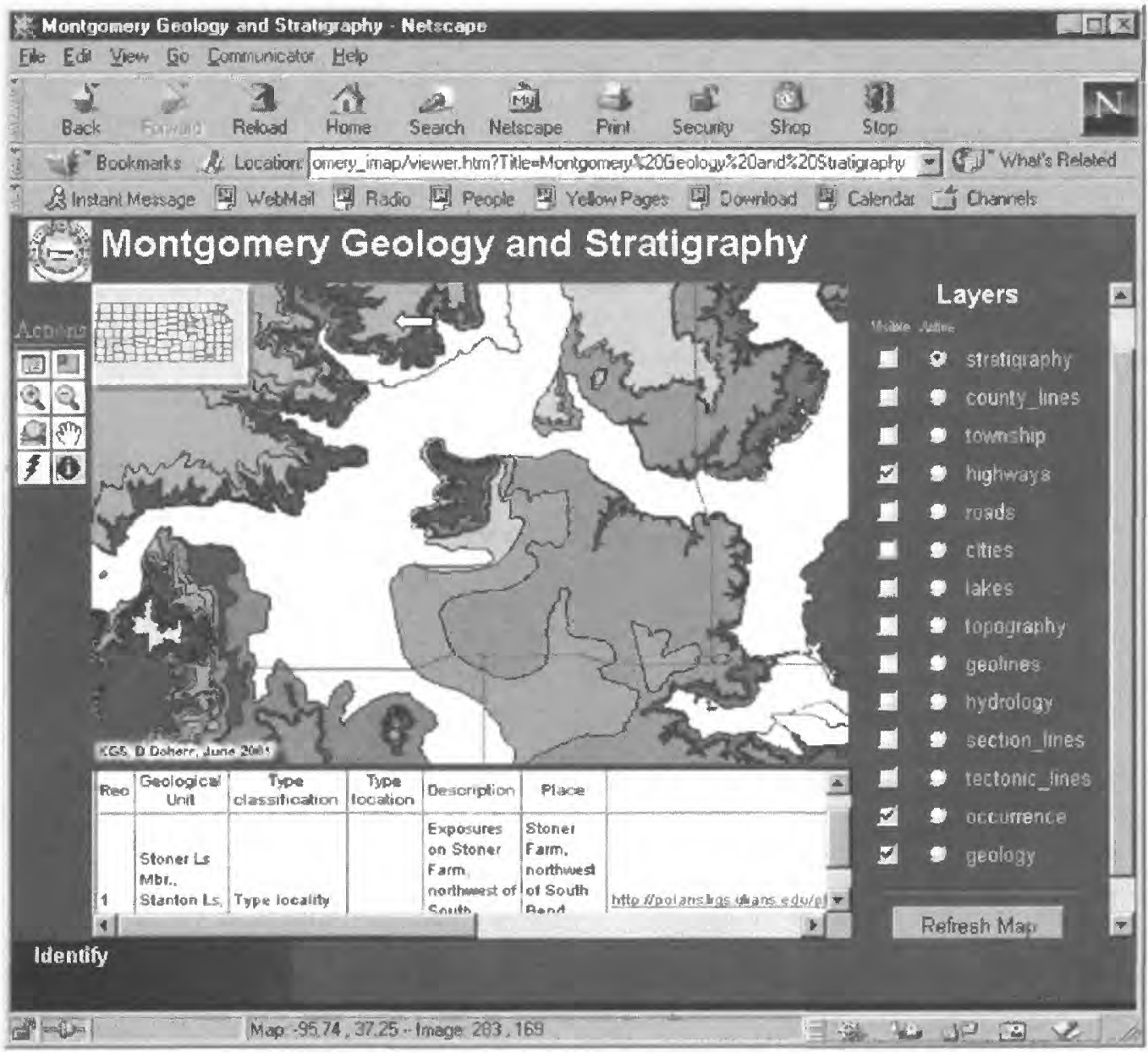

Figure 8. Web site for the interactive geologic map of Montgomery County.

provided in many of the abstracts in Bulletin 231 is sometimes insufficient to establish the correspondence without reference to the original source document.

As a matter of expedience, the database was initially developed so that all citations following such groupings of nomenclature changes in Bulletin 231 are associated with the unique UNIT_KID for the nomenclature heading the list. Thus, in the UNITS table, records associated with the Kansas City variants would have the entries as shown in Table 1.

All references to the Kansas City Formation or Kansas City limestone would be found by all records in the CITATIONS table (see Table 2) where the value in the
UNIT_KID field matches the KID of the UNITS table for the Kansas City Group.

As indicated previously, the SOURCE_KID in the CITATIONS table provides the link to the KID in the SOURCES table for information on each citation's publication source (Table 3).

Eventually each citation in the database will be linked to the specific form of unit nomenclature used in that reference source.

Geologic maps and numerous published reports present information on stratigraphic sequences representing the regional geologic interpretations at the time of publication. These sequences are identified in the SEQUENCES

Table 1. The UNITS table.

\begin{tabular}{|l|l|l|}
\hline KID & CURRENT_UNIT_KID & USAGE \\
\hline 1006546176 & & Kansas City Group \\
\hline 1006546177 & 1006546176 & Kansas City Formation \\
\hline 1006546179 & 1006546176 & Kansas City limestone \\
\hline
\end{tabular}


Table 2. CITATIONS table.

\begin{tabular}{|l|l|l|l|l|}
\hline KID & SOURCE_KID & UNIT_KID & PAGES_PLATES & ABSTRACT \\
\hline 1006546182 & 1006546874 & 1006546176 & p. 7 & $\begin{array}{l}\text { Basal formation of Missouri } \\
\text { group; extends from... }\end{array}$ \\
\hline 1006546198 & 1006547491 & 1006546176 & $\begin{array}{l}\text { p. 68, fig. 14, 74- } \\
111\end{array}$ & $\begin{array}{l}\text { At conference May 1947, } \\
\text { revised definition of Kansas } \\
\text { City Group was agreed to... }\end{array}$ \\
\hline
\end{tabular}

Table 3. SOURCES table.

\begin{tabular}{|l|l|r|l|l|}
\hline KID & AUTHOR & YEAR & TITLE & PUBLISHER \\
\hline 1006546874 & H. Hinds & 1912 & The coal deposits of Missouri & $\begin{array}{l}\text { Missouri Bureau of } \\
\text { Geology and Mines }\end{array}$ \\
\hline 1006547491 & $\begin{array}{l}\text { R. C. } \\
\text { Moore }\end{array}$ & 1949 & $\begin{array}{l}\text { Divisions of the Pennsylvanian } \\
\text { System in Kansas }\end{array}$ & $\begin{array}{l}\text { Kansas Geological } \\
\text { Survey }\end{array}$ \\
\hline
\end{tabular}

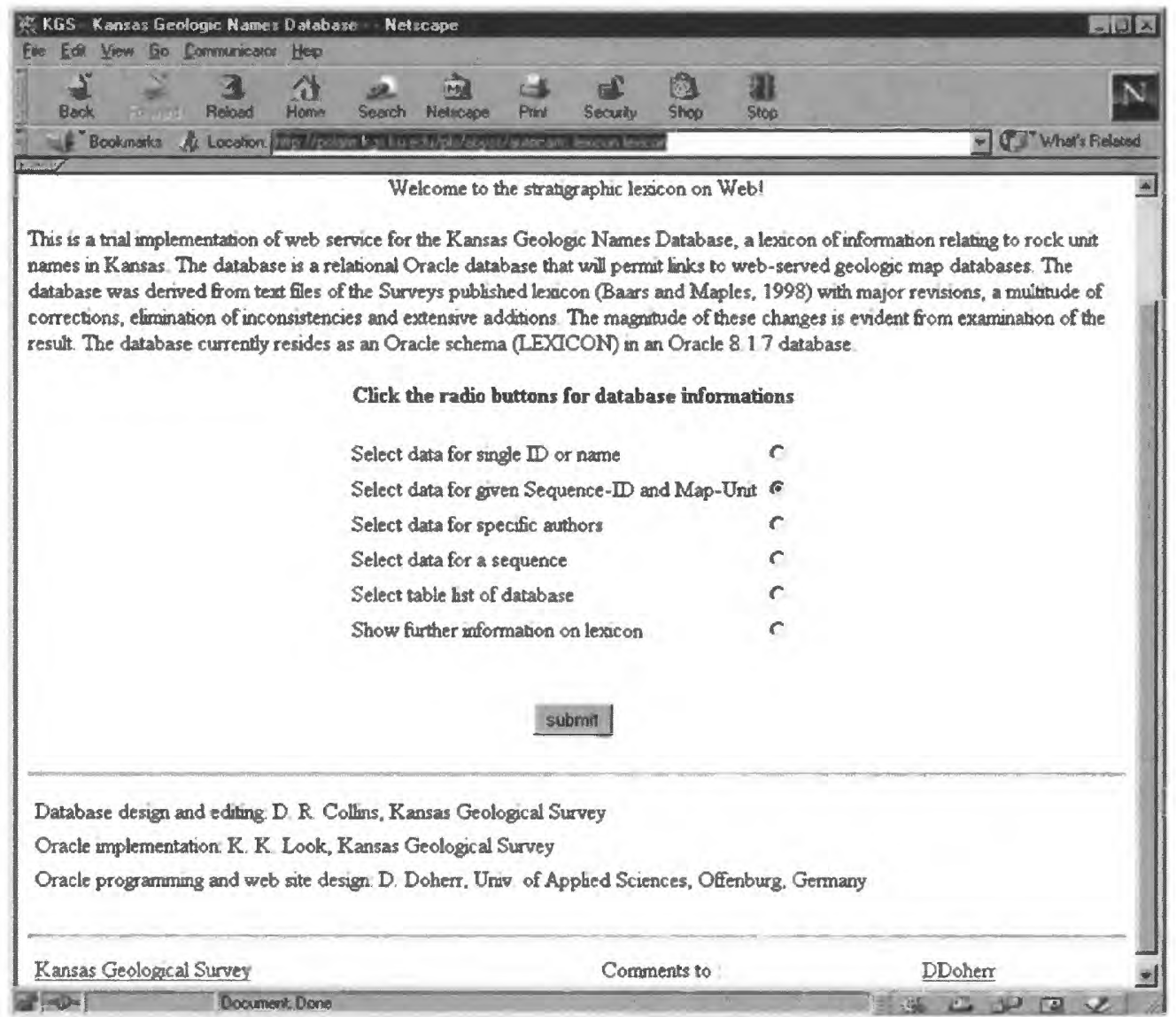

Figure 9. Home page for the online version of the Kansas Geologic Names Database.

table with a unique KID, NAME, and SOURCE_KID for the sequence. Figure 12 shows the selection of a specific stratigraphic unit (the Iola Limestone) from a scroll table of names from the stratigraphic sequence of units associated with the geologic map of Montgomery County, Kansas
(Bennison, 1996). Figure 13 shows the web presentation of the resulting report.

Type localities - stratotype locations - of rock units are extracted from the OCCURRENCES table, which is related to the UNITS table by UNIT_KID. The current 


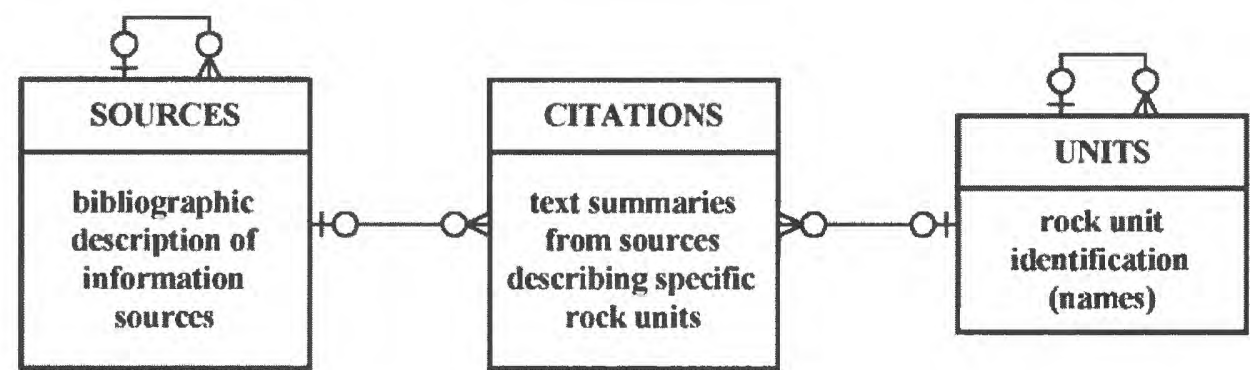

\section{Relationship Key}

$$
\begin{aligned}
& \text { one -- to -- many } \\
& \text { many - to - one }
\end{aligned}
$$

Figure 10. Primary tables in the Kansas Geologic Names Database, reflecting the interface of information source descriptions and defined rock units with specific citations.

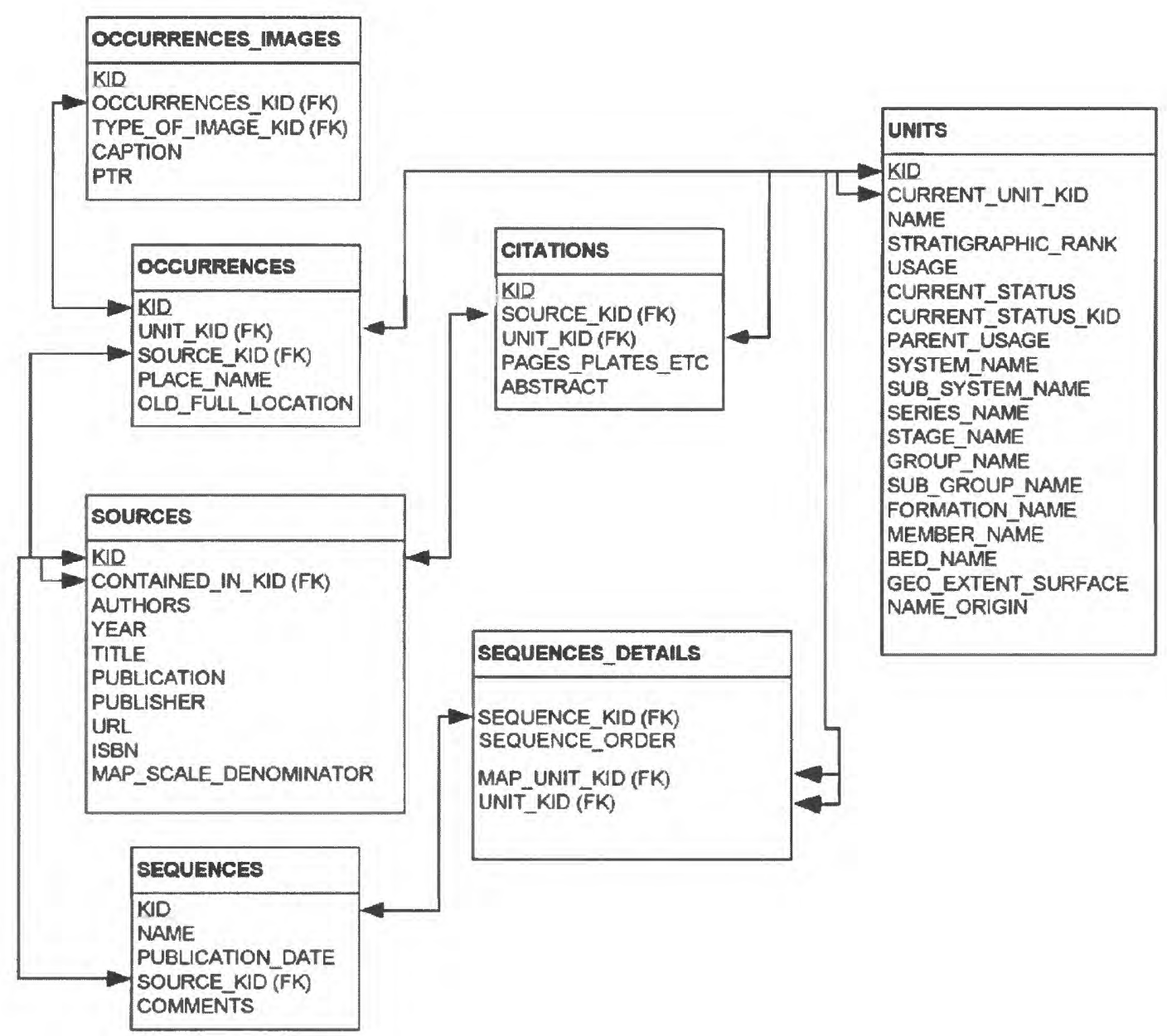

Figure 11. Tables, data fields and relations from the Kansas Geologic Names Database (LEXICON) that are significant for this project. Arrows show the relationship between different tables. "(FK)" = Foreign Key. 


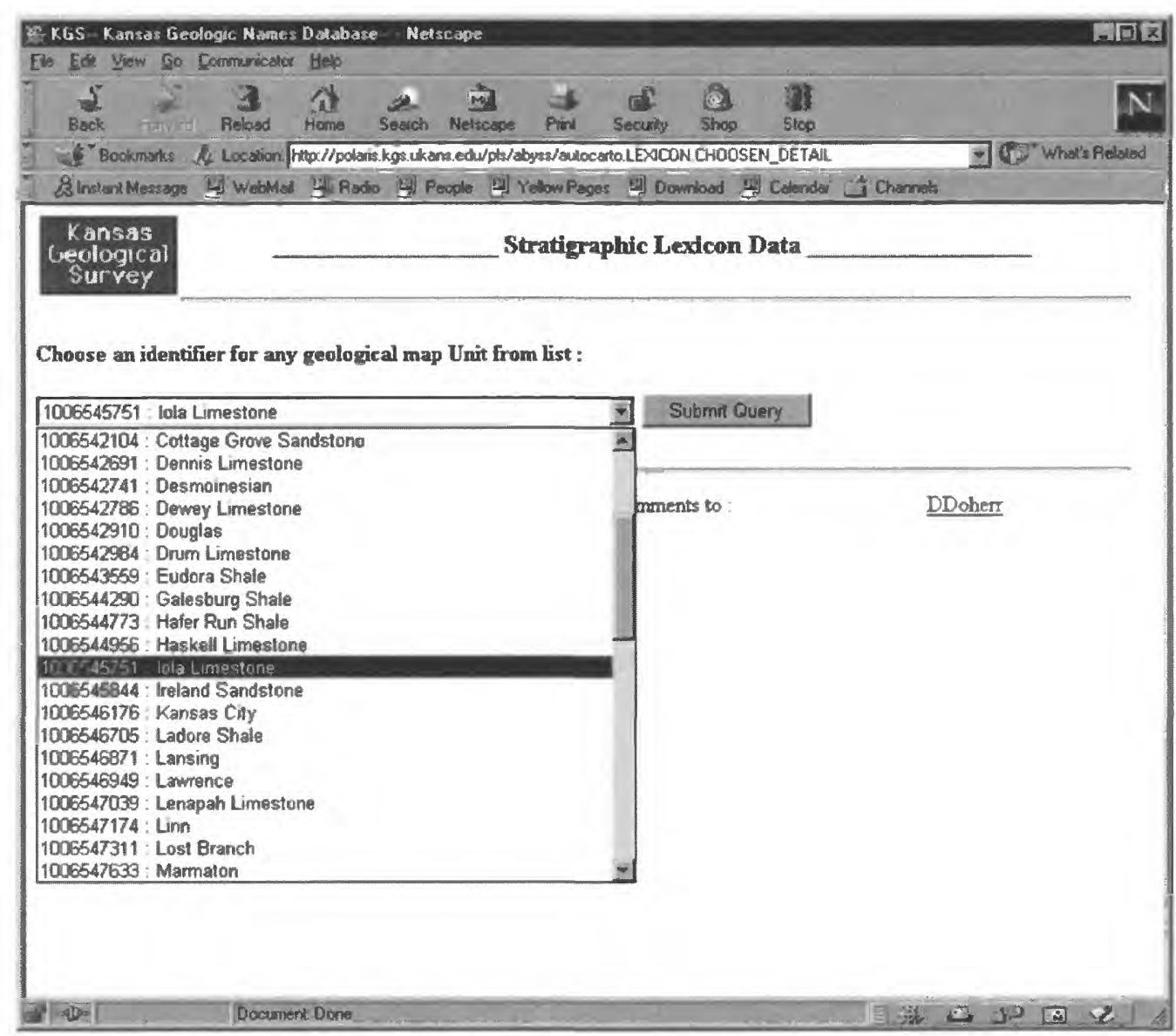

Figure 12. Selection of a specific stratigraphic unit from a scroll table presenting names from a sequence of units associated with a particular map or report.

implementation does not make full use of the information contained in the OCCURRENCES table, but instead uses the simplest available query. This will be modified along with other extensions in the future.

The web output for the selected data is presented as a table, produced by several Oracle procedures that generate the header and footer for the web page and construct the data display, with appropriate formatting. See KGS Openfile Report 2001-33 (Doherr. Collins, and Ross, 2001) for details.

\section{LINKING DIGITAL GEOLOGIC MAPS TO INFORMATION BEYOND THE GIS ATTRIBUTE DATA}

The shape files of geological units contain tables with a variety of structured attribute data about the areas on the map, limited by polygons, representing exposures of mapped geologic units. This structure is extended to add data fields to the table, including one or more identifiers for links to the Kansas Geologic Names Database. Using
ArcIMS as described previously, a web presentation and web page design can be developed as an interactive geological map with several layers, with attribute data for all geologic and cartographic features. A query function presents these attribute data in the browser, below the map image. To link to the Oracle database for Kansas Geologic Names, a module in PL/SQL has been designed that takes the identifier(s) from the attribute field(s), connects to the Oracle system, and selects the stratigraphic data. A new browser window is opened to display the stratigraphic descriptions, in the same manner they are displayed using the online stratigraphic lexicon.

Stratigraphic intervals shown as polygons on a geologic map may represent one or more named rock units. From one map to another the grouping of units within mapped intervals may change. For example, the Tonganoxie Sandstone and Iatan Limestone members of the Stranger Formation are mapped as one interval on the Montgomery County map, but may be mapped separately in counties where the Iatan Limestone Member is more conspicuous. In other areas, a geologist might map the entire Stranger Formation as a single unit. Providing a useful link of digital geologic maps to the Kansas 


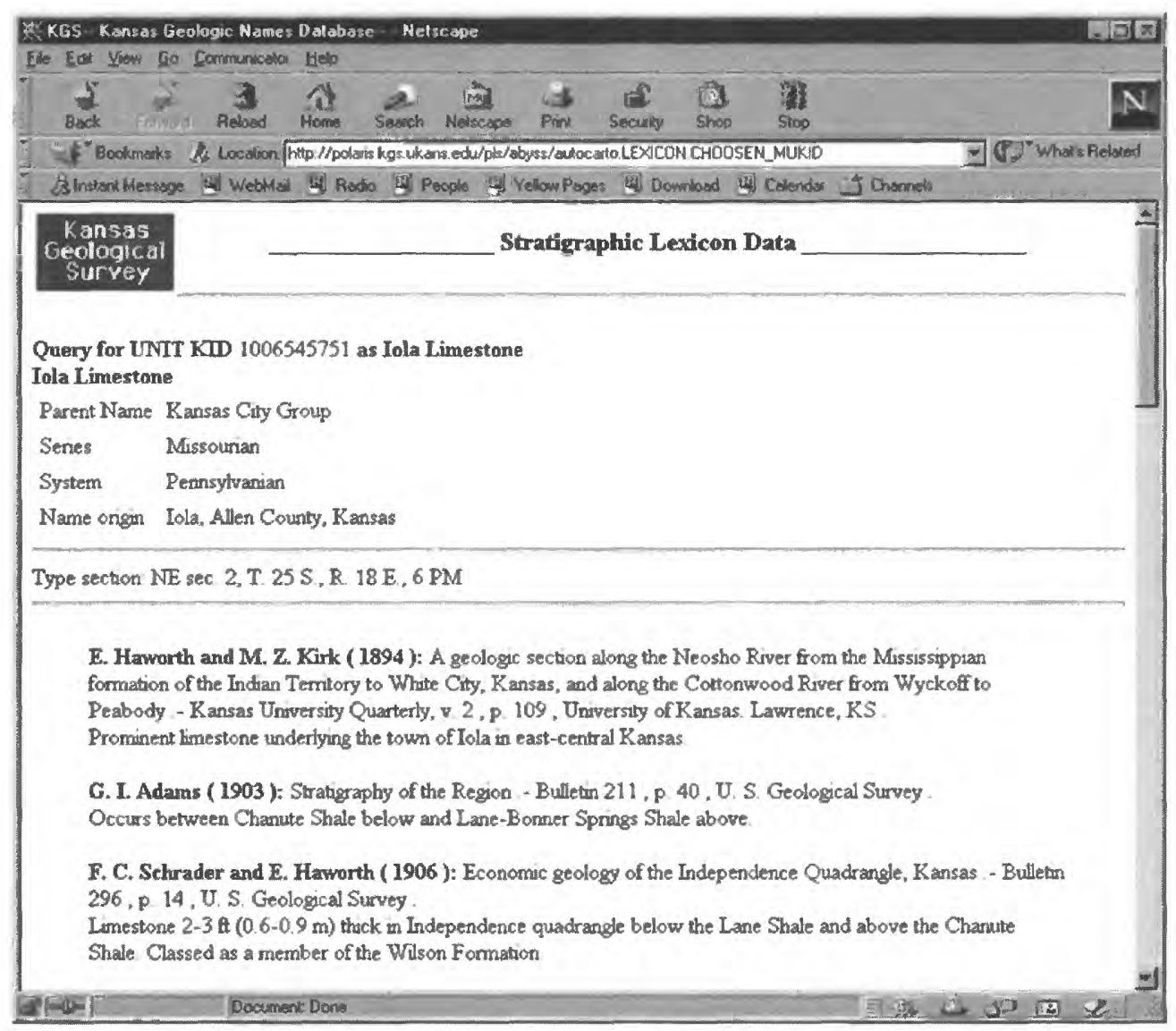

Figure 13. The resulting web page presentation of the report on the stratigraphic nomenclature history for the selected rock unit.

Geologic Names Database requires a database structure that permits correlation of mapped intervals on any map with the corresponding formally accepted nomenclature for the included rock units.

The SEQUENCES_DETAILS table (see Figure 11) is a correlation table defining many-to-many relationships between sequences, mapped units, and geologic unit names recognized for their past or present use in the professional geologic nomenclature. Within the SEQUENCES_DETAILS table, the SEQUENCE_KID for a map is associated with unique MAP_UNIT_KIDs for each of the geologic intervals represented on the map. Typically, the mapped interval is a recognized stratigraphic unit (member, formation, group, etc.). In that case there will be one record in the SEQUENCES_DETAILS table for that mapped interval on that map, with the map's SEQUENCE_KID and matching values for the MAP_UNIT_KID and UNIT_KID. Occasionally, the mapped interval is a grouping of geologic units recognized by the author as present in the area, but not shown in the detail of the map (e.g., the Tonganoxie Sandstone and Iatan Limestone members of the Stranger Formation). In this case there will be multiple records with the same SEQUENCE_KID and MAP_UNIT_KID, but with unique UNIT_KIDs for each of the units within the mapped interval. Where the grouping does not correspond to a recognized stratigraphic unit at a higher level, the MAP_UNIT_KID of the SEQUENCES_DETAILS table will appear as the KID for a record in the UNITS table. The unit will be identified as a 'mapped interval' in the CURRENT_STATUS field of the UNITS table with an informal descriptive term or phrase used as the unit name in the NAME field.

To find the citations for a specific mapped interval, the select command must find those records (one or more) in the CITATIONS table containing the UNIT_KID identifiers from the SEQUENCES_DETAILS table associated with the MAP_UNIT_KID and SEQUENCE_KID parameters. Where multiple UNIT_KIDs are found with a single query, there will be a different data set selected from the CITATIONS table for each UNIT_KID.

As an example, Figure 14 shows the selection of a polygon representing the Lane Shale and Wyandotte Limestone formations of the Kansas City Group. With the 'stratigraphy' layer active, and the 'Identify' action selected from the tool buttons to the left of the map, the report shown in Figure 15 can be generated by clicking on the 


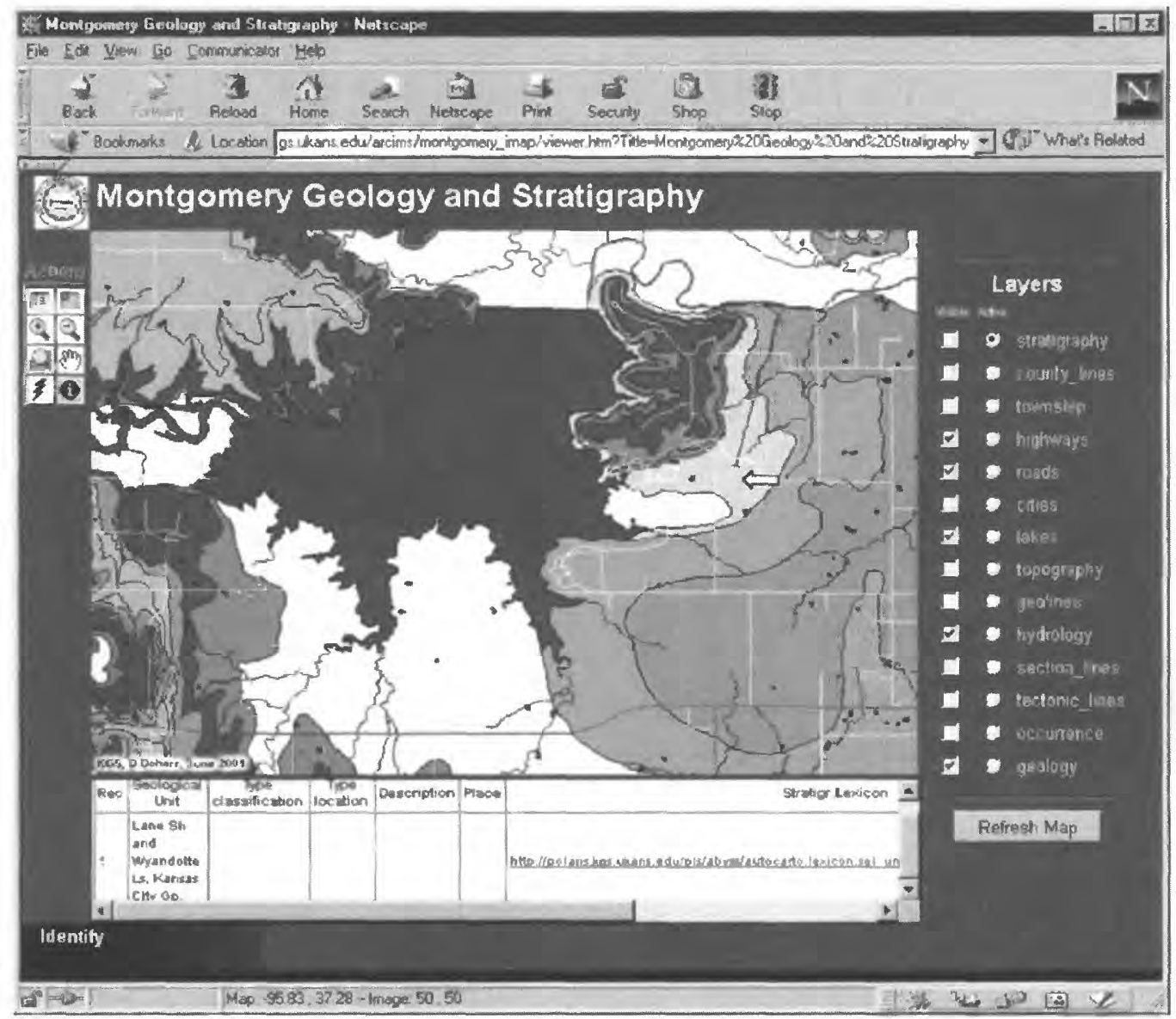

Figure 14. Selection of a polygon for a mapped interval with a non-standard aggregation of stratigraphic units.

URL found in the 'Stratigr.Lexicon' field of the attribute table displayed below the map (see Figure 14).

The first part of the report presents a single citation from the Montgomery County map (Bennison, 1996) explaining the non-standard grouping of units within the mapped interval. This is followed by separate reports (in the same scroll window) on the nomenclature history of the two units included in the interval. With the 'stratigraphy' layer active, the same nomenclature report could also be generated by selecting the 'Hyperlink' action button (represented with a lightning bolt) and clicking directly on the polygon of interest.

Graphic images related to the geologic map can also be retrieved from the ORACLE database using hyperlinks. Selecting 'geology' as the active layer and selecting the 'hyperlink' action tool button (Figure 16), an image of the portion of the stratigraphic column including an interval of interest can be displayed in a separate window by clicking on one of the polygons representing the desired interval. Figure 17 shows the result of clicking on a polygon representing the Lane Shale and Wyandotte Limestone (see Figure 16).

\section{CONCLUSIONS}

The pilot project described here tests the functionality of ESRI's ArcIMS software (Arc Internet Map Service) in the development of a standard Internet map service. The results indicate tremendous potential. Using ArcIMS, ArcSDE, and Oracle, the Kansas Geological Survey has successfully implemented a prototype interactive geologic map service. The architecture and stability of ArcIMS makes the development process and use of the resulting system practical.

Capabilities for customizing the interactive map system were also successfully tested. PL/SQL, combined with HTML, was found to be a satisfactory programming environment for report writing functions. Most of the procedures and functions developed in PL/SQL, Java, or HTML for the prototype system are directly transferable to future interactive map projects, greatly enhancing the efficiency of development. Map objects representing individual or multiple geologic units displayed on the interactive map were successfully linked to the Kansas Geologic Names Database, providing access to additional information about the specific geologic units represented. The 


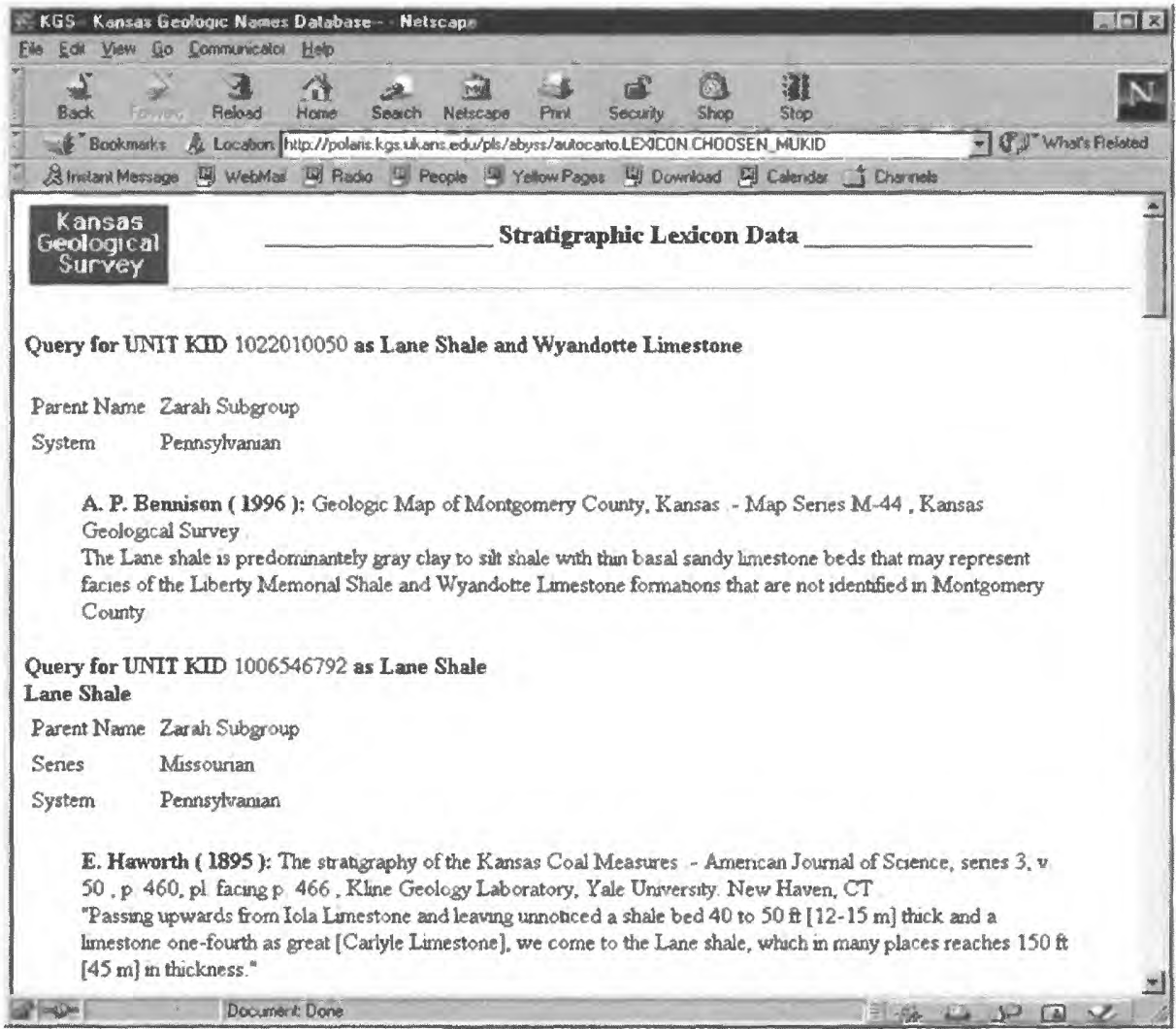

Figure 15. Report on nomenclature for the mapped interval consisting of the Lane Shale and remnants of the Wyandotte Limestone.

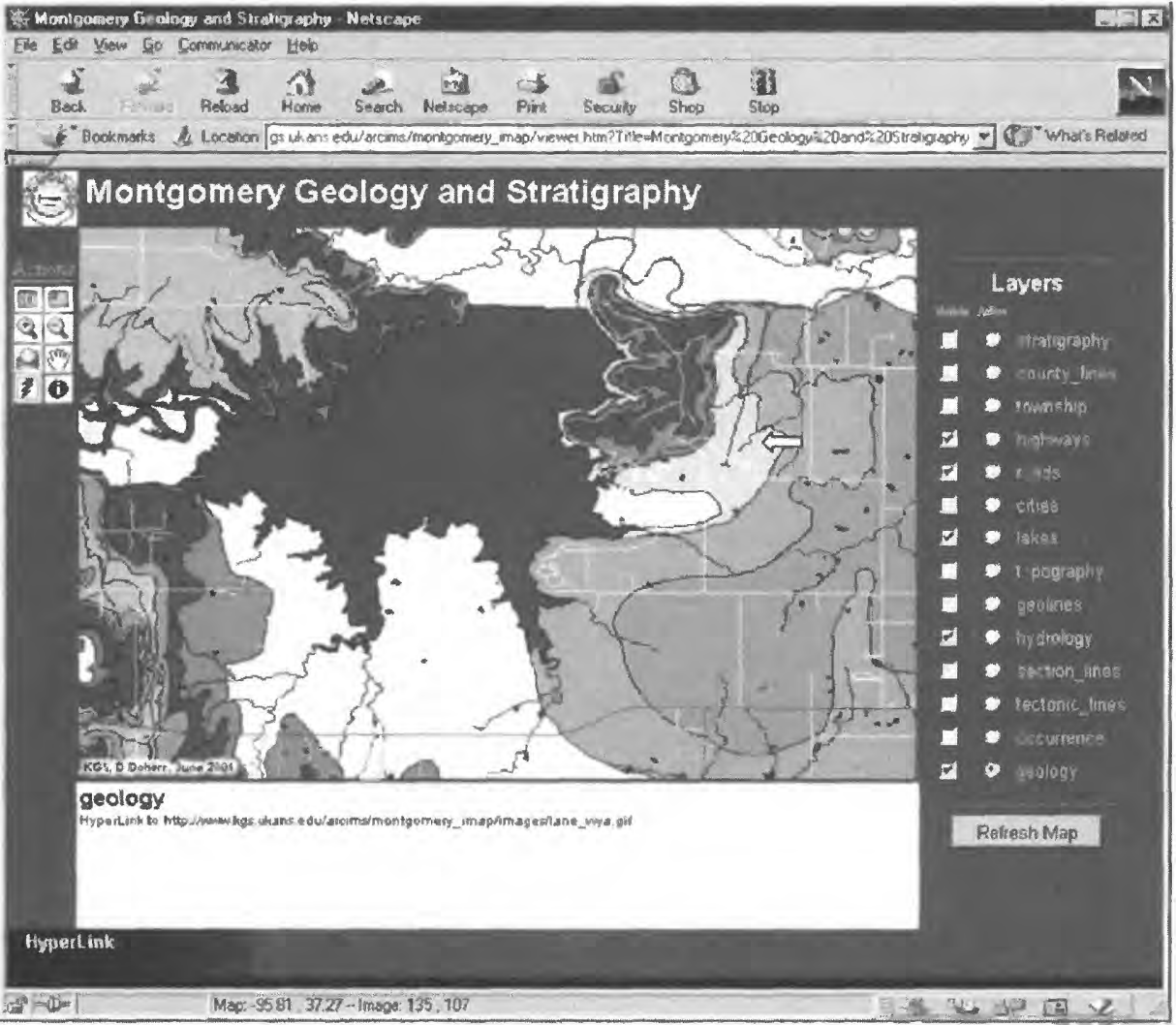

Figure 16. Use of the Hyperlink action tool with the 'geology' layer active. 


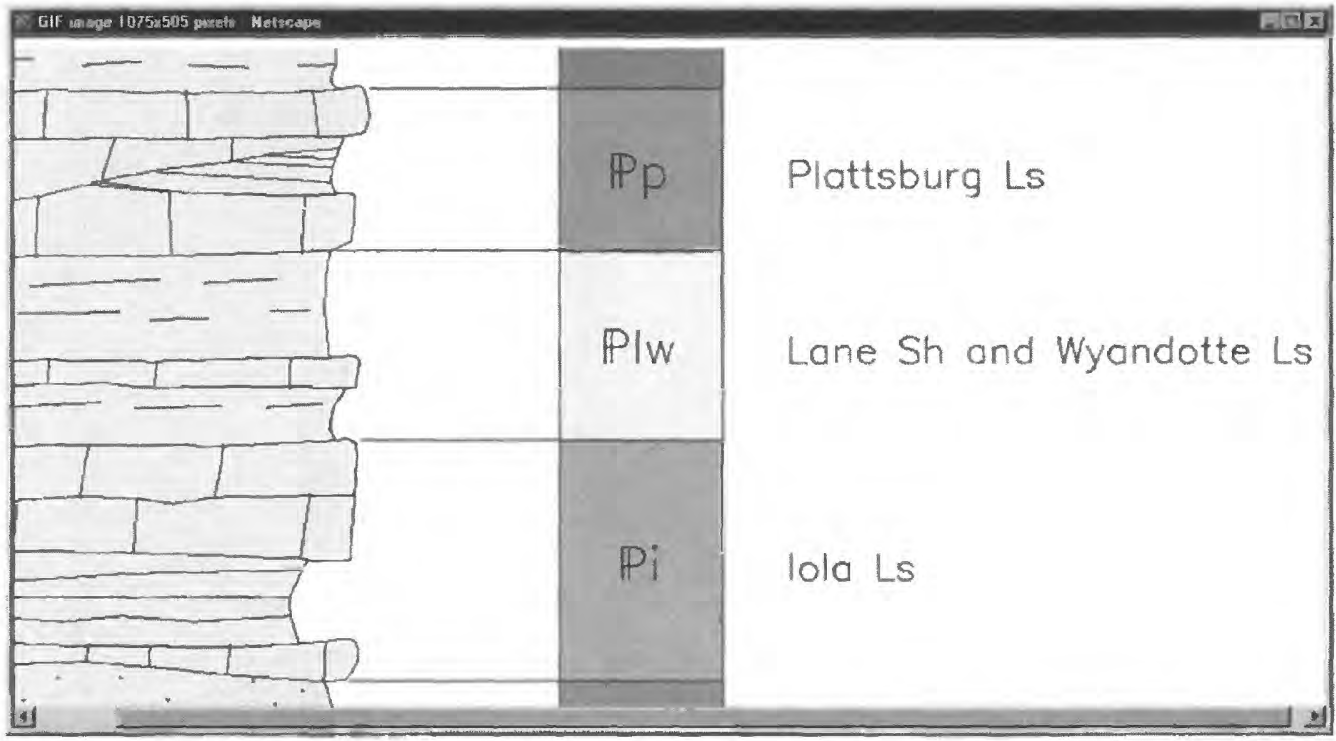

Figure 17. Digital graphic image of a portion of the stratigraphic column for Montgomery County, Kansas, linked to the selected polygon on the interactive geologic map (Figure 16).

project has also demonstrated the capability of linking map objects to external, digital information in the form of images, photographs or databases.

Changes to databases linked to the interactive geologic map are available to the user in real-time. It is hoped that a well designed digital geologic map data model, served on the Internet with live links to these geologic databases, will encourage contributions of information and corrections to the database managers and facilitate appropriate data collection in the field.

The trial Internet implementations of the interactive geologic map of Montgomery County, Kansas and of the Kansas Geologic Names Database may be accessed during their evaluation process at the following URLs:

- Interactive map: <http://www.kgs.ukans.edu/arcims/ montgomery_imap>

- Online LEXICON: $<$ http://polaris.kgs.ukans.edu/pls/abyss/ autocarto.lexicon.lexicon>

Once the products are formally released by the Kansas Geological Survey, their location on the Survey's web site may change, but they will be accessible through the Survey's home page at <http://www.kgs.ku.edu/ $>$.

\section{REFERENCES}

Baars, D.L. and Maples, C.G., (eds.) 1998, Lexicon of Geologic Names of Kansas (through 1995): Kansas Geological Survey, Bulletin 231, 271 p.

Bennison, A.P., 1996. Geologic Map of Montgomery County, Kansas: Kansas Geological Survey, Map M-44, published scale 1:50,000, data compilation at 1:24,000.

Collins, D.R., and Look, K., 1999, Development of the Kansas Geologic Names Database: A Link to Implementing the Geologic Map Data Model Standards, in Soller, D.R., (ed.) Digital Mapping Techniques ' 99 - Workshop Proceedings: U.S. Geological Survey Open-file Report 99-386, p.107111, <http://pubs.usgs.gov/openfile/of99-386/collins.html>.

Doherr, D., Collins, D.R., and Ross, J.A., 2001, Interactive Online Geologic Maps with Interactive Links to Multimedia Archival Data; a pilot project for Montgomery County, Kansas, February - July, 2001: Kansas Geological Survey, Open-file Report 2001-33.

Oracle Corporation, 1996, 1998, ORACLE Application Server PL/SQL Web Toolkit: Oracle Corp., Part A60119-02, 43 p.

Ross, J.A., 1998, Providing Spatial Data and GIS Applications Via the Internet, in Soller, D.R., (ed.) Digital Mapping Techniques ' 98 - Workshop Proceedings: U.S. Geological Survey Open-file Report 98-487, p. 85-90, <http://pubs.usgs.gov/openfile/of98-487/ross1.html> and $<$ http://www.kgs.ukans.edu/General/Geology/dmt/ spatial.html>. 


\title{
The Growing Issue of GIS Certification and Its Possible Ramifications to Geological Mapping Science
}

\author{
By David J. McCraw
}

\author{
New Mexico Bureau of Geology and Mineral Resources \\ 801 Leroy Place \\ Socorro, New Mexico 87801 \\ Telephone: (505) 835-5594 \\ Fax: (505) 835-6333 \\ e-mail:djmc@nmt.edu
}

\section{INTRODUCTION}

Since the mid 1990s, the issue of GIS certification has been growing. Controversy surrounds the issue, often fueled with reactionary sentiment, to the point that it is not always clear exactly what is being implied by the term "GIS certification." Indeed, while it is most commonly associated with the certification of GIS practitioners, or people, it is not uncommon to see the term being applied to GIS data. The certification issues applied to both people and data are discussed below and their possible ramifications to geologic mapping science are examined.

\section{BACKGROUND}

The call for certification of GIS professionals originates from 3 main sources: 1) the certified and licensed surveying profession via the National Council of Examiners for Engineering and Surveying (NCEES), 2) the International Organization for Standardization (ISO), and 3) a handful of (over-?) zealous GIS academicians. Why is there a need to certify? Apparently certification and licensure is carried out to protect consumers and the general public and to benefit the profession. Are GIS data used to determine official and legal location? The answer is no. Does the public need protection from management issues that are derived from the implications of a GIS dataset or database? Doubtful. Thus, the only logical justification for certification is to benefit the profession by assuring that GIS individuals meet basic levels of competency and follow a code of ethics. This in itself is not a bad thing. It will become clear from the discussion of these three certification-proposing bodies below that GIS certification is both real and imminent. Ultimately, it will be the GIS profession's choice how it defines and handles certification.

\section{The NCEES Model Law Controversy}

In 1995, NCEES modified its Model Law on surveying to include the practice of photogrammetry and included references to GIS and LIS use when applied to surveying activities. Photogrammetrists' concerns were addressed in 1997 when the American Society for Photogrammetry and Remote Sensing (ASPRS), the American Congress on Surveying and Mapping (ASCM), the Management Association for Private Photogrammetric Surveyors (MAPPS), and the American Society of Civil Engineers (ASCE), participated with the National Society of Professional Surveyors (NSPS) on a task force to modify the Model Law. This 1995 revision in the Model Law is what initiated the GIS certification controversy. The surveying communities in a few states (e.g., California, North Carolina) were able to convince their legislators to mandate that surveyors participate in specific aspects of GIS. Specifically, spatial data at the parcel level must have a surveyor involved in the compilation, maintenance, and quality certification of that data. Suddenly, it appeared to many people that any agency using GISderived base maps created by GIS personnel unsupervised by a licensed surveyor could be in violation of the law.

The GIS community became active in the review of the NCEES Model Law in 1999 when the task force was expanded to include representatives of the Urban and Regional Information Systems Association (URISA) and the National States Geographic Information Council (NSGIC). The main concerns of GIS practitioners with the Model Law include: the breadth of the preamble (definition section), the reference to specific GIS/LIS tools in 
the preamble, and the concern that many aspects of GIS should clearly not be under the jurisdiction of a surveyor (J. R. Plasker in Sommers, 2000). (This review of the Model Law by these GIS task force members can be downloaded in pdf format at Kemp (2000b)). The problem in the preamble occurs where it defines the practice of surveying using GIS/LIS tools: “...creating, preparing, or modifying electronic or computerized data, including land information systems, and geographic information systems, relative to the performance of the activities in the above described items (a) through (c)." Plasker (in Sommers, 2000 , p. 28) states: “...on closer reading, the subsections (a) through (c) define areas of surveying practice that are generally not controversial in their definition; nevertheless, the perception that the Model Law intends to place additional controls on GIS use can, and probably should be mitigated." However, he goes on to state that recent developments in GIS and related geospatial data technologies (e.g., improved accuracies in GPS and the elimination of selective availability) do now allow unregulated practitioners "to accomplish certain surveying activities [that could become] detrimental to general public safety or individuals' property rights" (in Sommers, 2000, p. 28). Because of this, J. S. Greenfield (in Sommers, 2000), a surveyor, sees the need for a surveyor (or perhaps a certified GIS technician) to supervise and certify GIS parcel data.

\section{The International Certification Movement of the ISO}

The ISO is a global federation of national standards bodies from 130 countries whose directive is to develop voluntary international standards covering all technical fields except electrical and electronic engineering. It is comprised of numerous technical committees staffed by qualified individuals from the private sector, research universities and institutes, national governments, and international organizations. The goal of Technical Committee 211, Geographic Information/Geomatics' is "to establish a structured set of standards for information concerning objects or phenomena that are directly or indirectly associated with a location relative to the Earth. These standards may specify, for GI [Geographic Information], methods, tools, and services for data management (including definition and description), acquiring, processing, analyzing, accessing, presenting, and transferring such data in digital/electronic form between different users, systems, and locations" (ISO/TC211 website, <http://www.statkart.no/isotc211>). As Kemp (2000a) points out, there is no reference to developing a set of standards for the people who work in GI.

In 1998 however, Canadian representatives of ISO/TC211 proposed a work item on "qualifications and certification of personnel" so as better to assess the qualifications of consultants seeking funding from foreign aid agencies for work in developing countries. Dr. Robert
Maher, of the Centre of Geographic Sciences in Nova Scotia, drafted TC211 document N573, which called for the committee to:

- Develop a report which describes a system for the qualification and certification of GIScience/Geomatics personnel by an independent body,

- Define the boundaries between GIScience/Geomatics and other related disciplines/professions,

- Specify GIScience/Geomatics technologies and tasks,

- Establish competency levels and skill sets for GI personnel,

- Research other similar certification processes of existing professional associations, and

- Develop a plan for the accreditation of candidate institutions and programs, for the certification of the individual in the GIS workplace, and for collaboration with other professional bodies.

This proposal was voted upon in March 1999 in Vienna, Austria. Of the 32 countries eligible to vote, 12 voted for, 9 against, and 11 abstained. The United States and the majority of the EU all voted against the proposal, largely based upon the position that it is inappropriate for a technical standards organization to determine and establish international professional credentials. Opposition was also raised by the International Cartographic Association (ICA), the International Federation of Surveyors (FIG), and the International Society for Photogrammetry and Remote Sensing (ISPRS). Nevertheless, as ISO protocol only requires a majority acceptance, the proposal was established as Project 19122, with Maher designated as project leader. The project is proceeding (see Kemp, 2001c) and a final report addressing the requirements called for in document N573 is due in September 2001.

\section{Advocacy by GIS Professors and Organizations}

Although certification of GIS professionals has only become a major issue in the last five years or so, the idea has been around for awhile and can be first found in the literature in Goodchild and Kemp (1992), Burley (1993), and Obermeyer (1993). Responding to the certification program established for photogrammetrists by the ASPRS in 1991, a dozen or so GIS academicians have been actively pursuing certification for GIS technicians. Perhaps the most active or vocal of these has been William Huxhold of the University of Wisconsin-Milwaukee, the current president of the University Consortium of Geographic Information Science (UCGIS). He states: "after 25 or more years in implementing and using GIS, the state of GIS professionalism in the U.S. remains as it was back in the 1960s and 1970s: no professional standards for GIS professionals, and no accreditation of educational pro- 
grams that confer GIS certificates" [his boldface]

(Huxhold, 2001a).

Citing Pugh's (1989) attributes of a profession, first evaluated in light of GIS by Obermeyer (1993), Huxhold (2001a) claims that while GIS has a specialized body of knowledge, a mission, a formal organization, a common language, specialized training, and a culture and lore, it lacks Pugh's final 2 profession-defining attributes: a code of ethics and certification. Although Craig (1993) first called upon GIS practitioners to establish a code of ethics, no standard has been established, according to Huxhold (2001a). He concludes that in spite of the fact that up to a half million people are working in GIS in the U.S. (his calculation), there is no "profession" of GIS. Furthermore, Huxhold noted an article published in U.S. News Online in November of 1999 that reported that the "data mapper" was one of the 21 hot new careers for the 21 st Century (Huxhold in Sommers, 2000; Huxhold, 2001b). To summarize his viewpoint, if GIS does not establish accreditation of academic programs and certification of its personnel, we'll all just be data mappers.

In addition to several active GIS professors individually seeking certification of GIS personnel, two major GIS organizations, URISA and UCGIS, are now actively pursuing certification. URISA established a certification committee in July of 1998 which now seats 26 members from government, private industry, and academia. It is currently working on a program to develop and distinguish between GIS "core skills," to be required of all certified GIS practitioners, and additional discipline-dependent skills specific to some 23 different fields (<http://www.urisa.org/ certification/certific.htm $>$ ). A special edition of the URISA Journal devoted entirely to certification and related issues is planned for summer or fall of 2001.

In November 1998, UCGIS organized a "Summit on Geographic Information Science" at the national GIS/LIS Conference. Representatives from 11 "GIS-interested" professional organizations discussed certification activities amongst GIS educational issues (see education link at $<$ http://www.ucgis.org >). In conclusion, there can be little doubt that given the efforts of both GIS professionals and professional organizations, to an extent in response to the NCEES Model Law and to the international efforts of ISO Technical Committee 211, GIS certification in some form is imminent in the U.S.

\section{CERTIFICATION OF GIS PROFESSION- ALS: PROS AND CONS}

The benefits of certification are listed at the top of the URISA Certification website (<http://www.urisa.org/ certification/certific.htm>): career recognition through evaluation and approval of individuals, improvement of performance leading to greater career productivity and increased customer/client satisfaction, and ability to remain current in the field through renewal requirements of the certification program. Huxhold (2001a) lists additional benefits of certification: 1) it helps define the profession; 2) it assures quality in work performed; 3 ) it sets a standard of competency; 4) it helps prospective employers identify qualified individuals; 5) it ensures continued expertise; and 6) it improves the marketability of the professional. He suggests that certified practitioners will have higher salaries than non-certified workers.

At an Internet discussion site on certification hosted by the URISA Certification committee, approximately half of the commentors are quite opposed to certification. Major oppositional themes cited there include: 1) it is an unnecessary bureaucracy; 2) the cost of certification hurts the individuals who must pay to be certified and only benefits the certifying organization; 3 ) it threatens free-market principles by hindering advancement of the field; 4) it can place limits on skills and skill development and 5) it can incite workplace resentment and other feelings of ill will. In addition, it is unclear whether there will be any type of grandfather clause exempting those with large amounts of experience in the field.

The overall control of the certification process is an important issue. Who will administer certification of GIS professionals? Cordova (1999) sums up the potential problems that could arise as this issue is answered: "An undignified scramble to corner the market is inevitable...a cottage industry of competing certification organizations, and, eventually, an entire class of associated bureaucrats will arise... when a national standard finally emerges, those who hold substandard certificates will have to start the process over again. The next step will be designating accrediting organizations to certify the certifiers, and so forth. Workers will have no choice but to participate in the scam, at their expense, because their livelihoods will depend on getting that certificate." Keith Clarke (in Sommers, 2000) points out that to place control of certification in a single, possibly self-appointed body, with broad authority to set standards, content, curriculums, and testing is like "trying to shut the barn door after the horse has long ago bolted." He argues that, like the Internet, GIS is owned by everyone and no one should attempt to control "the geography in g-commerce." He concludes that while some form of GIS certification is inevitable, "at best, it will die its own harmless death from redundancy and datedness. At worst, it could cost our nation the lead in the most exciting enterprise of the new world era" (Clarke in Sommers, 2000).

\section{CERTIFICATION OF GIS DATA}

As alluded to above, the issue of GIS certification is often confusing because it is unclear whether the discussion centers around certifying people or their data. The idea that GIS data must be certified, however, is both 
redundant (assuming the dataset is backed up or "certified" by its metadata) and unnecessary. GIS data are referential in nature. Base maps in a GIS are not the record of original survey measurements but are instead representations of these original documents. Bruce Joffe (in Sommers, 2000) summarizes what steps should be taken to protect the public from an inappropriate use of non-certified GIS map data: 1) GIS mapped features should explicitly refer to their source documents and be supported with easy-tounderstand metadata; 2) GIS maps and data should always contain an explicit statement of intended use and a disclaimer for other uses, i.e., "this is not the product of a survey;" 3) Public officials should avoid implying that their GIS maps determine official location; and 4) GIS data that have been manipulated to create coherent displays when combined with other data should retain the original mapped coordinates as feature attributes, as well as metadata describing the data transformations.

Any certification of data must be flexible due to the variability of GIS use across several technical and nontechnical fields. The very nature of GIS use, i.e., as a tool, is procedural based. There are variability in data requirements for different applications. Because of this, data accuracy at a certain level may not always be required and thus certification of that data is unnecessary.

Instead of GIS data certification, GIS professionals should establish a data verification process on any new dataset. This should involve checking both the data and the metadata for compliance to local, state, and federal standards. It is the responsibility of the GIS supervisor to understand the level of accuracy required and to be able to evaluate the metadata in order to guarantee that level has been met. The metadata thus become instrumental in this verification process. If the data and metadata specifications do not match, then the data should be considered suspect.

\section{RAMIFICATIONS OF CERTIFICATION TO GEOLOGICAL MAPPING SCIENCE}

It appears that agencies that carry out digital geological mapping would benefit from the establishment of formal GIS certification. Large organizations with sizeable human resource bureaucracies (e.g., the USGS, and a few of the larger state surveys) will save time in the evaluation process of applicants by relying on their certificates.

Small organizations with limited resources and knowledge (e.g., most state surveys) can hopefully avoid hiring mistakes by requiring certificates. However, geological GIS specialists must have extensive knowledge and experience in other disciplines beyond the GIS fundamentals. Besides a background in geology, the geological GIS specialist should have an understanding of both soil science and geography, ESPECIALLY the sub-discipline of geography that is cartography! Any GIS technician can compile datasets and produce a "GIS map," but it takes a highly trained individual to take numerous, highly complex types of geologic and/or pedologic datasets, and combine them into both a functional and beautiful geologic map. That, after all, has always been the goal of geological mapping science, both in the days of traditional, photomechanical cartography and today.

As mentioned above, URISA's Certification Committee is developing certification guidelines for both the core GIS fundamentals as well as "add-on" skills pertinent to some 23 defined disciplines. One wonders who will establish the necessary standards in these distinct discipline areas. One would hope and expect that these would not be developed by the URISA committee. Have any geologists or cartographers been contacted to develop a necessary list of skills needed for certification in these disciplines? One also wonders to what extent it will become necessary for GIS practitioners to be certified in both fundamentals and in the application of GIS in their respected disciplines. The case should be made that the geological GIS specialist, for example, would need add-on skills in not one, but three distinct proposed discipline areas: 1) Geoscience, Geology, \& Soils Engineering, 2) Geography \& Cartography, and 3) Environmental Science \& Natural Resources. After GIS certification is established and is a criteria for employment, will the geological GIS specialist need these 3 special certificates in addition to the basic GIS certificate?

It can be argued that a majority of the geological GIS specialists learned of their geological / pedological / cartographic / environmental / and natural resource skills primarily from on-the-job training. One could also argue that many of these specialists actually developed their GIS fundamental skills on-the-job as well. Is it really necessary that these individuals take these competency exams? Perhaps many of the larger surveys and agencies would pay for the training and examination, but can they afford the time involved away from geological mapping? And what would happen to those who failed the tests and yet are nonetheless highly competent?

Finally, can the state surveys afford to pay the higher salaries that certified GIS practitioners would demand? Probably not. So must these agencies hire fewer specialists to handle greater workloads or will they be resigned to hire "substandard," non-certified personnel? Will morale be affected when a new, inexperienced but certified individual is hired at a comparable salary to that of the uncertified geological GIS mapping specialist who has collected extensive experience in the many facets of his or her profession?

\section{CONCLUSIONS}

While the call for certification of GIS personnel can be traced to the early 1990s, the issue has gained promi- 
nence in the early 2000s. This has come about in response to the NCEES Model Law controversy brought about by U.S. surveyors, to the efforts of the Canadian delegation of ISO's Technical Committee 211 on the international front, and to the strong advocacy for certification by a number of GIS academicians and the GIS organizations in which they actively participate. There are many pros and cons to the issue and it appears that the GIS profession as a whole is quite divided. Discussions surrounding the issue are often complicated by the implication that GIS data need be certified as well as the GIS personnel who create, manipulate, present and maintain it. This is unnecessary if FGDCcompliant ("certified") metadata and legal disclaimers accompany the data.

While GIS certification could be of obvious benefit to the human resources departments that hire geological GIS mapping specialists, its overall benefit to the geological mapping agencies is questionable. Although it would provide a minimum level of competency, geological GIS specialists "wear too many hats" to be pigeonholed into a simple certification specialty area. This could prove to be costly to both the individual and to his or her agency. Higher salaries demanded by certified GIS technicians will likely put additional strains on the geologic agency and its GIS workplace. In summary, it appears that GIS certification will have an overall negative impact on geological mapping science to the point where geological mapping agencies should and likely will ignore it.

\section{REFERENCES}

Burley, J. B., 1993, GIS certification: Precedents and choices: Journal of the Urban and Regional Information Systems Association, Vol. 5, no.2, p. 17-19.

Craig, W. J.,1993, A GIS code of ethics: What can we learn from other organizations?: Journal of the Urban and Regional Information Systems Association, Vol. 5, no. 2, p. 13-16.
Cordova, H., 1999, GIS certification sparks second thoughts: GeoWorld, v. 12, p. 8-9, <http://www.geoplace.com/gw/ 1999/0599/599form.asp>.

Goodchild, M. F., and Kemp, K. K., 1992, GIS accreditation: What are the options?: American Congress of Surveying and Mapping Bulletin, November-December, p. 44-47.

Huxhold, W. E., 2001a, Certifying GIS professionals: Urban and Regional Information Systems Association, $<$ http://www.urisa.org/ GIS_CERT_PRES/index>.

Huxhold, W. E., 2001b, GIS certification and accreditation: It's time to get serious (lest we all become "data mappers"): draft submitted to GeoInfo Systems, available at Kemp (2000b).

Kemp, K. K., 2000a, Background on international GIS professional certification efforts: [unpublished manuscript], $<\mathrm{http}$ //cem.uor.edu/users/kemp/certification/geoinfo.html>.

Kemp, K. K., 2000b, Professional certification in GIS, current activities around the world: [unpublished manuscript], $<\mathrm{http}$ ://cem.uor.edu/users/kemp/certification>.

Kemp, K. K., 2000c, Update on ISO TC211 meeting, Reston, VA, Sept. 4-5, 2000: [unpublished manuscript], $<$ http://cem.uor.edu/users/kemp/certification/ isotc211_9_00.html>.

Obermeyer, N. J., 1993, Certifying GIS professionals: Challenges and alternatives: Journal of the Urban and Regional Information Systems Association, Vol. 5, no. 1, p. 67-76.

Obermeyer, N. J., and Onsrud, H. J., 1997, Educational policy and GIS: Accreditation and certification: University Consortium of Geographic Information Science White Paper on accreditation and certification, $<$ http://www.ncgia.ucsb.edu/other/ucgis/ed_priorities/ a\&c.html>.

Pugh, D. L., 1989, Professionalism in public administration: Public Administration Review, Vol. 49, p. 1-8.

Sommers, R., 2000, Defining the GIS profession and debating certification and regulation: Geospatial Solutions, v. 7, p. 22, $<$ http://www.geoinfosystems.com/0600/0600somers.html $>$. 


\title{
Map Authorship and Citation Guidelines: Summary of a Discussion Session
}

\author{
By C. R. Berquist, Jr. ${ }^{1}$ and David R. Soller ${ }^{2}$ \\ IVirginia Division of Mineral Resources \\ c/o Department of Geology \\ College of William and Mary \\ PO Box 8795 \\ Williamsburg, VA 23187 \\ Telephone: (757) 221-2448 \\ Fax: (757) 221-2093 \\ e-mail: crberq@facstaff.wm.edu \\ ${ }^{2}$ U.S. Geological Survey \\ 908 National Center \\ Reston, VA 20192 \\ Telephone: (703) 648-6907 \\ Fax: (703) 648-6937 \\ e-mail: drsoller@usgs.gov
}

\section{INTRODUCTION}

Among the geological surveys there exist many approaches to determining authorship credit and citation format for geologic maps, digital geologic maps, and associated digital data bases. Progress has been made toward understanding this complex issue, through discussions at many venues, including previous Digital Mapping Techniques (DMT) workshops. Berquist (1999) and Richards (2000) suggested authorship and citation policies and formats which provoked discussion and debate among the community of geologists, cartographers, earth-science editors, and librarians. Continuing the effort to clarify (if not resolve) this topic, an open discussion at DMT'01 was devoted to Map Authorship and Citation Guidelines. The content and results of this session are provided here.

Clearly, there are different philosophies on how to assign credit for geologic map products. For two of the major authorship/credit issues faced by agencies, here are some rather conflicting views expressed in the discussion session at last year's DMT workshop:

- "if you make a contribution, including GIS work, then you're an author" vs.

"only the mappers and regional stratigraphers/compilers should be authors"
- "the database is part of the map (image)" vs.

"the database is a product separate from the map (image)"

Resolution of those issues, as outlined below, is the purview of each agency and its mapping projects. This year's DMT discussion session was designed to explore common ground and common solutions to the issues, in the hope that good ideas developed by any of the geological surveys could be used by the entire community. We intentionally avoided discussion of criteria that may define the inclusion and ranking of individuals as authors, because those details are the responsibility of the publishing agencies. Furthermore, the session did not address the manner in which various types of authorship, GIS, and cartographic credit are noted on the map itself. Instead, the session focused on citation format and content by defining several principal issues, then holding an open discussion of each issue and asking for a show of hands by participants to establish the generalized degree of acceptance of each issue.

The session began with a review of previous work. In our session introduction, we synthesized our thoughts and those of other geological survey personnel who have shared information with us during the past year. Included in that introduction was a brief overview of copyright and 
contracting issues that may have some bearing on the rationale for assigning authorship to map products. Although copyright and authorship do not have precisely the same meaning, it may be instructive to view the problems of authorship of digital products from the perspective of copyright (ownership). Facts (e.g., the information in a telephone book) cannot be copyrighted. However, the expression of facts (layout, color, graphics, symbology, etc.) can be copyrighted (Harris, 1998). Indeed, some localities have more than one telephone book, each copyrighted by different organizations. In contrast, in geological science a greater sense of ownership is ascribed to the information - we certainly do not take someone else's map information, merely change the "expression" or display of that map, and then assign new authors to the new map. Geologist-authors of the original maps should retain authorship of subsequent map images, no matter how the maps are reproduced (scan or GIS image at any scale, projection, or color/symbology). The geologist created the map representation of rock descriptions and area/volume relationships of rock bodies and is responsible for the "science" behind the map (of course, eventually, revisions in scientific substance may warrant changes in authorship).

This viewpoint on authorship would seem to contradict the legal notion that when the "expression" of facts are changed, new ownership or copyright (and therefore new authorship) is possible. The information on geologic maps is, however, largely interpretive, not strictly factual, hence the science's rationale for retaining the source lineage of information in subsequent map representations and products. Despite this rationale, in the legal arena, published geologic maps may be regarded as legitimate factual information. It may therefore be prudent to regard our geologic maps as subject to legal definitions of fact.

The advent of GIS and digital map production techniques has introduced a significant complication to the copyright issues noted above. When digitizing a geologic map to create a published map product, the spatial data files in one sense may be considered comparable to an intermediate product of older map production technology (the scribe coats and acetate stickups). However, these files are now a desired end-product in themselves because they form the basis for map databases available for use in a GIS. If the map digitizing work is performed under contract, a contract generally should address copyright issues for products created under that agreement. This is prudent because in some circumstances these map files can be claimed for copyright (owned) by the contractor.

The legal differentiation of map image from map database files connotes the need to identify the responsible authors of each product. In many cases, authorship would be the same for both products. However, given the legal implications, this should not be assumed without due consideration of how the files were created, and whether their content differs from the information shown on the published map.
During both the pre-digital and the modern digital process of map production, errors that occur on preliminary, author-submitted maps were corrected and/or supplemented by errors introduced during cartographic preparation of the final, published map. Individuals who created the printing negatives (in the pre-digital age) or the digital data set are capable of omitting information, inserting incorrect information, and making errors in scribing or digitizing lines and other features. Before maps were digitally produced, these errors were an accepted part of the process, and the cartographer was not assigned any formal responsibility for their role in the final product.

How then can it be argued that the preparers of the digital map files, the GIS-compatible map databases, may in some cases warrant designation of formal responsibility for the product and, hence, shared authorship? We believe the answer is simply this: if the map database is published or released by the agency to the public, both the author's and the agency's authority and reputation are implicitly conveyed with the product. In contrast, pre-digital cartographic materials and digital files used solely to print a map are merely part of the map production process; hence they are not referenceable products. Also, information in databases may not be the same in structure, content, or use to that shown on source maps; for example, the difference between a map unit description on a printed map (or field sheet) and the equivalent information in a database (which may be derived from dissection of the map unit description and parsing that information into database fields, a process that may involve insight and interpretations not formally shown on the published map or field sheet). Further, on typical geologic maps, the location of geologic information (contacts, structure measurements, etc.) are located relative to topographic and cultural features on the base map. Once the geologic information is captured digitally, the location of each geologic feature becomes absolute (in some numeric coordinate system) and always will carry some new error, introduced by the capture process (e.g., georeferencing the source map). The digitized geologic information in a database now "floats in space" and is no longer explicitly tied or attached to the original topographic base upon which the field information was compiled. As a result, the geologic database (GIS) information becomes in some measure different from the source geologic map information. In our world of increasing litigation, agencies of course are now carefully considering if and how the content of each map and associated database product may differ, and assigning authorship credit and responsibility accordingly.

\section{PURPOSE}

This paper is intended only to provide a summary of ideas presented at the discussion session and a brief and admittedly subjective record of the participant's reactions. 
This paper is not a formally proposed guideline derived by broad debate and consensus - it merely contains some citation formats that we propose may be useful. The issue of map authorship credit and responsibility, as noted above, was not the focus of the discussion session. These suggested formats were discussed but not reviewed and approved by the discussion participants. Although many of the ideas evolved from examples and discussions shared by our colleagues in other geological surveys, the responsibility for the proposal's shortcomings lie with the authors of this paper. It is hoped that these ideas, which represent in part a synthesis of previous work, may prove useful to geological surveys and to the geoscience community, as we all strive to protect and realistically portray the origin of each published map product.

\section{CENTRAL ISSUES}

As a group, the DMT'01 participants recognized that the authorship and citation issue is complex, and that discussion has not sufficiently matured to encourage all organizations to agree to a single standard (and such may never be the case). However, the session explored the possibility that interagency consensus could be reached on certain basic issues. These are explored below as they were presented in the discussion session.

\section{Who Should Author a Geologic Map Product?}

Each agency must control the content of its products, and this discussion session was not intended to prescribe a uniform approach to how map authors are determined. Geologic mapping is a rigorous intellectual and physical activity, and the people involved deserve appropriate credit for their contributions to the science and to society. In part because of technological advances that promote conversion of published maps to digital format, a product may have an extensive lineage of contributors and source materials, and there exist among the geological surveys many approaches to determining who should receive credit.

Discussion participants generally agreed with this position.

\section{Should a Suggested Citation be Provided on Each Map?}

The discussion session addressed the content and format of the map citation. It did not address the manner in which various types of authorship, GIS, and cartographic credit are noted on the map. Specifically because the authorship, other credit, title, and citation standards may be confusing to our users, we strongly suggested that the suggested citation be explicitly given, directly below and clearly related to the map collar information regarding title, date, authorship, and other credits (as per Berquist,
1999). The following might be placed on the map, to draw attention to the citation:

"When referring to this map, the following citation should be used:"

(insert citation, in agency's adopted format, here)

In response to this suggestion, the discussion participants voted a clear "yes".

\section{New Mapping vs. Existing Maps}

As a first step toward defining citation formats, let us assume that map publications may fundamentally be classified as:

1) products based on new mapping - In this case, field work and/or compilation has produced a body of scientific information that can be considered significantly different from pre-existing mapping. Of significance, it is likely that all persons who made a contribution to the final product (geologist and GIS/cartography staff) will be available for planning, discussion, and completion of the work, and are capable of reaching a mutually agreeable decision on the title and authorship.

2) products based on published mapping - In this case, previously published map(s) are recompiled into a new product. The original geologist author may not be available for consultation and inclusion in the process of digital conversion and/or a geologic revision. In this situation, the authorship criteria is subject to a hierarchy and variety of agency rules involving the amount and/or significance of revisions.

The discussion participants clearly agreed that these are two fundamentally different types of publications.

\section{Is a Map Database a Product, Separate from a Map?}

We then proposed that there exist two fundamental products in a digital map publication, and that these products are closely related:

1) the geologic database, which contains all spatial and attribute information for the geology of the map area. Included in this database should be the information needed to represent the author's preferred cartographic depiction of the geology.

2) the image (in paper or electronic format) generated by

the author's preferred cartographic depiction of the geology.

Should we recognize the existence of both of these two different, but related products? The decision affects how these map products are defined and managed by the agency, and how they are cited by the public. It is certainly debatable whether the map database is a product fundamentally different from its many possible physical repre- 
sentations (e.g., a paper map showing the geologist's preferred depiction of the geology). Some geologists and agencies consider the database and the paper map to be the same product. Is that a valid contention? In some cases this may be essentially correct, but in other cases the database structure and content may contain more complexity than can be shown on the paper map. Furthermore, although the map and database may, upon initial release, be two components of the same product, in time there may be revisions to the database necessitated by error-checking and minor additions that will cause the content of the printed map (inherently a static product) and the map database (potentially a dynamic product) to diverge. Prior to designation of the map database as a fundamentally new product (e.g., upon recompilation of the area's geology), successive versions of the database may become significantly different from the printed map. Unless the agency identifies two distinct but related products, it will be a challenged to manage a single product that may, over time, be comprised of two diverging manifestations.

This discussion session did not address the scientific content of the map and database, but merely sought to identify agency philosophy toward how its products are managed. As noted, it is our contention that a map image and its map database are two separate, but clearly related, products.

After lengthy discussion, the audience was almost evenly divided on this issue.

\section{PROPOSED CITATION FORMATS}

To illustrate and to provoke discussion on the various questions and issues noted above, we presented to the discussion participants some example citations (below). However, discussion on the above issues consumed most of the allotted session time, and so participant response to the content shown below could not be reasonably assessed. We hope that further discussion regarding these example citations may ensue, and evolve toward a set of common ideas or informal guidelines that might assist each geological survey and agency.

For purposes of map authorship and citation, the two classes of map product identified in the discussion session (i.e., existing maps and new mapping) can be treated quite differently. Simple examples of these two classes are given below. More complex cases, such as the anthologies discussed in Richard (2000), were not discussed here, but clearly are of significance to any robust agency policy.

\section{Products Based on New Mapping}

For products based on new mapping, the situation is relatively simple - the mapping team should identify the contributions of the various team members (geologists, GIS specialists, cartographers, and, in some cases, data- base managers) and provide that information in the appropriate citation format. In some geological surveys, it is the policy for scientists alone to receive authorship credit on a new map. It was not our intent to debate this philosophy in the discussion session.

Here is the proposed suggested citation for a new map product (note that use of "Digital" in title is now generally agreed to be unnecessary since digital map production methods are now the norm). This citation is in common use today:

Doe, J.K., and Smith, A.B., 1999, Geologic map of the XYZ Quadrangle: The Geological Survey, Map X123 , scale $1: 24,000$.

If an agency recognizes two separate, related products - paper map and geologic database - then the proposed suggested citations would be:

Doe, J.K., and Smith, A.B., 1999, Geologic map of the XYZ Quadrangle: The Geological Survey, Map M123 (Part A), scale 1:24,000.

Doe, J.K., Digits, C.D., and Smith, A.B., 1999, Geologic database of the XYZ Quadrangle, v.1.0: The Geological Survey, Map M-123 (Part B), ArcInfo Export file and dBase file, scale 1:24,000, available on CDROM or $<\mathrm{URL}$, if any $>$.

Note that the examples show the two products as part $A$ and $B$ of a single numbered map. An agency might just as readily choose to designate the products in separate series (e.g., printed and digital product series).

Is it necessary to cite the distribution media (e.g., "CDROM")? For the scientist, when citing a published work, it may be irrelevant. However, for purposes of cataloging and describing a published product for a library or publications sales office, we assume it will be necessary. Please note that the product title includes the database version number - it may be more appropriate to place this information and/or the time stamp toward the end of the citation.

Inclusion of additional author(s) in the database product indicates that skills in database design and GIS were deemed essential to the content and end-use of this product. That may not always be the case, and authorship decisions are, explicitly, the domain of the mapping project and agency. From the above citations, we would expect that J.K. Doe played a responsible, significant, and active role in the creation of both the map and the database, since Doe is senior author on both publications.

In the example above, the map and the database contain fundamentally the same scientific information. Which should be cited? As noted by Steve Richard (Arizona Geological Survey, personal communication), the answer depends on how the information was used. For example: 
- if in your scientific report you relied upon the geologic interpretations (the "science"), then cite the paper map.

- if you used the map information in a GIS-based analysis (for example, a spatial and attribute analysis of geology, water quality, and infrastructure), then you would cite the database, because the analyses rely in part on the geometry of the features in the geologic database.

\section{Products Based on Published Mapping}

This situation is more complex. Obviously, an existing product may have been: converted to digital format; adapted to fit a modern digital base map, new mapping paradigms, or newer adjacent geologic mapping; and/or recompiled. Because the original author(s) may not have participated in this process, authorship credit may be uncertain. For discussion purposes, we subdivided this category of products as follows:

\section{A) Raster Image of Published Map:}

When a paper map is scanned to create a raster image, the information content can be identical. Nevertheless, an agency may choose to catalog the image as a separate product, for reasons including:

- scans and post-processing (e.g., to create a .pdf file) are not necessarily of sufficient quality and resolution to

faithfully reproduce the source maps, and - paper maps and digital files may be managed and curated in significantly different ways.

If the agency chooses to manage the image as a distinct product, then the following formats are suggested. Note that because this product is simply a scanned rendition of the previously published map, the original authorship should be retained intact. The map series identifier may, however, be different.

Doe, J.K., and Smith, A.B., 2001, Geologic map of the XYZ Quadrangle [scan]: The Geological Survey, Map D-15, one Adobe Acrobat (PDF) file, scale $1: 24,000,<\mathrm{URL}$, if any $>$.

\section{OR}

Doe, J.K., and Smith, A.B., 2001, Geologic map of the XYZ Quadrangle: The Geological Survey, Map D15, [scan of Map M-123, published 1999], one Adobe Acrobat (PDF) file, scale 1:24,000, <URL, if any>.

The discussion participants seemed to agree with this approach, but were divided as to whether the file type should be noted. The second citation may be preferred, as it provides more information on the original map product.
Some participants noted that, in their agency, the scanned rendition of the map is not given a unique map series designation nor managed separately from the paper map.

\section{B) Geologic Map Based on Published Map:}

In some cases, the newly-released geologic map may be essentially unchanged from the original map; the map may have been converted to digital format, but without addition or revision of scientific content. In other cases, the original map may have been modified to fit a modern digital base map, or to adapt to new mapping paradigms, or to incorporate newer adjacent geologic mapping. Also, the original map may have been recompiled. These cases each should be treated differently. The proposed solution is a bit awkward perhaps, but retains full reference to the source map:

1) the original map was unmodified - this case is analogous to II-A, above ("Raster image of published map"), because the product is a digital file from which a faithful rendition of the source map can be displayed or plotted. In this case, however, the file is derived from a vector-based digital map created with a CAD or GIS software package. The proposed suggested citation retains intact the original author list, modifies (i.e., "digitized from ...") the title to reflect the fact that this is a new product, and appends the original, full citation:

Doe, J.K., and Smith, A.B., 2001, Geologic map of the XYZ Quadrangle, digitized from Doe and Smith 1999 map: The Geological Survey, Map D-30, one Adobe Acrobat (PDF) file, scale 1:24,000, available on CDROM or $<\mathrm{URL}$, if any $>$ [digitized from Doe, J.K., and Smith, A.B., 1999, Geologic map of the XYZ Quadrangle: The Geological Survey, Map M123, scale 1:24,000].

2) the original map was modified - here, the digital file contains information that provides a display or plot derived from, but not identical to, the information content on the source map. In this case, the proposed suggested citation includes a new author list but in the title it retains intact the original author list (unless multiple authors, then "Doe and others"), modifies (i.e., "adapted from ...") the title to reflect the fact that this is a new product, and appends the original, full citation:

Smith, A.B., and Digits, C.D., 2001, Geologic map of the XYZ Quadrangle, adapted from Doe and Smith 1999 map: The Geological Survey, Map D-31, one Adobe Acrobat (PDF) file, scale 1:24,000, available on CDROM or $<\mathrm{URL}$, if any $>$ [adapted from Doe, J.K., and Smith, A.B., 1999, Geologic map of the XYZ Quadrangle: The Geological Survey, Map M-123, scale $1: 24,000]$. 


\section{C) Geologic Database Derived from Published Map:}

If a map database is created (as perhaps in II-B, above) from a published geologic map, the agency might choose to release it as a separate product, as discussed in this paper's introductory section. If so, this new product may or may not have the same author list as the source map. The proposed suggested citation includes ideas from section I and II-B-2, above:

Digits, C.D., 2001, Geologic database of the XYZ Quadrangle (v.1.0), adapted from Doe and Smith 1999 map: The Geological Survey, Map D-45, ArcInfo Export file and dBase file, scale 1:24,000, available on CDROM or $\angle \mathrm{URL}$, if any $>$ [adapted from Doe, J.K., and Smith, A.B., 1999, Geologic map of the XYZ Quadrangle: The Geological Survey, Map M-123, scale 1:24,000].

\section{FINAL NOTE}

Discussions on this subject tend to be lively. We anticipate that, in various formal and informal venues, the issues will be further debated. Certainly, we do not expect the ideas presented herein to survive intact during each agency's development of authorship and citation policies. However, we do hope that the DMT discussions will both support development of agency policies and perhaps draw the agencies toward a more common style and philosophy for authorship and citation format. Because policies that deal with products of computer technology are not well defined, it seems prudent or necessary that we, the community of informed and interested map producers and users, set the standards and conventions that would preserve the relationship of the geologist-authors to their product, the map image; we also should identify and preserve the appropriate authorship and/or credit for those professionals who are responsible for creating the database files.

\section{REFERENCES}

Berquist Jr., C.R., 1999, Digital map production and publication by geological survey organizations; A proposal for authorship and citation guidelines, in Soller, D.R., ed., Digital Mapping Techniques '99-Workshop Proceedings: U.S. Geological Survey Open-File Report 99-386, p. 39-42, <http://pubs.usgs.gov/openfile/of99-386/berquist.html>.

Harris, L.E., 1998, Copyright Law Issues in Modern Cartography, in D.R. Fraser, ed., Policy Issues in Modern Cartography, Elsevier Science Ltd 1998, LCCN 98-25805.

Richard, S.M., 2000, Proposal for Authorship and Citation Guidelines for Geologic Data Sets and Map Images in the Era of Digital Publication, in Soller, D.R., ed., Digital Mapping Techniques '00-Workshop Proceedings: U.S. Geological Survey Open-File Report 00-325, p. 159-168, $<$ http://pubs.usgs.gov/openfile/of00-325/richard.html>. 


\section{Vendor Presentations and Contact Information}

This Digital Mapping Techniques workshop was attended by technical experts from selected software and hardware companies. These individuals provided technical trouble-shooting and general information needed by the geological survey workshop attendees, and the workshop organizers offer sincere thanks for their significant contributions to the meeting. The DMT workshop series is designed as a collegial event, where information is freely shared, in recognition of a common set of goals. Our colleagues in the vendor community certainly contributed to the workshop's success. Their contact information is given below.

Mike Price (Environmental Systems Research Institute, Inc., [ESRI]) provided technical guidance and support for ESRI products, and an oral presentation entitled "Field geologic data collection with ArcPad and ArcGIS." Mike also provided assistance to the field demonstration portion of the Special Session on Field Data Capture of Geologic Map Information. For information about the products and software discussed, see: (for ArcGIS) <http://www.esri.com/library/whitepapers/pdfs/ ArcGIS8.1.pdf>; (for ArcPad) <http://www.esri.com/ library/whitepapers/pdfs/arcpad.pdf $>$; and (for Metadata) $<$ <ttp://www.esri.com/library/whitepapers/pdfs/metadata.pdf>. ESRI also hosted a technical luncheon featuring an overview of ESRI products. We sincerely thank ESRI and Mike for their generosity and for their interest in this meeting.

Mike Price, Mining Industry Manager Environmental Systems Research Institute, Inc. 380 New York St., Redlands, CA 92373-8100

Telephone: (909) 793-2853, extension 11677 e-mail:mprice@esri.com

Corporate Web site: <http://www.esri.com>

Darren Gabriel and Chris Ogier (ERDAS) hosted a technical luncheon featuring an overview of EDRAS software and applications. We sincerely appreciate ERDAS's generosity and the time provided by Darren and Chris.

Darren Gabriel and Chris Ogier

ERDAS Worldwide Headquarters

2801 Buford Highway, N.E.

Atlanta, GA 30329-2137 USA

Telephone: (877) 463-7327 or (404) 248-9000

e-mail: dgabriel@erdas.com,cogier@erdas.com

Corporate Web site: <http://www.erdas.com>
Skip Pack (Dynamic Graphics, Inc.) provided an oral presentation on 3-D software and visualization techniques, entitled "The Three-dimensional Geologic Model as an Access Portal." The presentation was supported by a paper in these Proceedings.

Skip Pack

Dynamic Graphics, Inc.

1015 Atlantic Avenue

Alameda, CA 94501

Telephone: $510522-0700$

Fax: 510 522-5670

e-mail: skip@dgi.com

Corporate Web site: <http://www.dgi.com/>

GE-Smallworld and Techni Graphic Systems provided technical support and coauthorship for a presentation on building a prototype map database (Soller and others, this volume).

Robert Laudati

GE-Smallworld Systems, Inc.

5600 Greenwood Plaza Blvd., Suite 300

Englewood, CO 80111

Telephone: (303) 779-6980

e-mail: robert.laudati@smallworld-us.com

Corporate Web site: <http://www.swldy.com>

Roger A. Fredericks, Business Development Manager Techni Graphic Systems, Inc.

2301 Research Blvd., Suite 101

Fort Collins, CO 80526

Telephone: (970) 224-4996

Fax: (970) 224-3001

e-mail: rogerf@tgstech.com>rogerf@tgstech.com

Corporate Web site: <http://www.tgstech.com>

Steve Bedsole (Geographical and Environmental Data Services, Inc.) provided technical support and an explanation of company services to the field demonstration portion of the Special Session on Field Data Capture of Geologic Map Information. We sincerely thank Steve for his expertise and his interest in this meeting.

Steve Bedsole

Geographical and Environmental Data Services, Inc. 4590 S. Shades Crest Rd.

Bessemer, AL 35022

Telephone: (205) 426-4989

Fax: (205) 426-4990

e-mail: sbedsole@geoenvirodata.com 
Mark E. Odegard (GETECH, Inc.) provided an industry perspective on the use of GIS and digital mapping for resource exploration, in an oral presentation entitled "Mega-Regional to sub-basinal data capture, mapping, and interpretation using ArcView."
Mark E. Odegard

GETECH, Inc.

12503 Exchange Dr., \#510

Stafford, TX 77477

Telephone: (281) 240-0004

e-mail: meo@getech.com 


\title{
Data Structure for the Arizona Geological Survey Geologic Information System: Basic Geologic Map Data
}

\author{
By Stephen M. Richard and Tim R. Orr \\ Arizona Geological Survey \\ 416 W. Congress, \#100 \\ Tucson, AZ 85701 \\ Telephone: (520) 770-3500 \\ Fax: (520) 770-3505 \\ e-mail: Richard_Steve@pop.state.az.us
}

\section{INTRODUCTION AND PURPOSE}

Geoscience data are used for land-management decision-making, for engineering design, in the search for mineral resources, and for scientific research.

Traditionally, geologic information has been stored and disseminated using geologic maps and written reports (Bernknopf et al., 1993). Because of the complexity of the earth, much of the information included in a geologic map is buried in several layers of abstraction. Specific applied use of geologic data typically requires preparation of a derivative map designed to show a particular aspect of the geologic data. Such maps might be designed to show rock lithology, the orientation of bedding or foliation in layered rocks, the acid buffering capacity of the rocks, or to show rocks of a particular age. Production of such derivative maps designed for a specific purpose commonly requires a geologically sophisticated analysis of the original map, as well as cartographic design and drafting of the derivative map.

Computer-based geographic information systems allow the manipulation and analysis of much larger and more sophisticated geographic data sets than was possible using paper maps and physical overlays. These systems provide tools to manipulate and integrate geologic data with other geographic data to a greater extent than ever before possible. A well designed, data-rich information system could automate much of the process of producing derivative maps designed for specific applications. This would free the data user to explore the data in more ways, and to experiment with different representations of the data. Providers of geoscience data, like the Arizona Geological Survey, must redesign information delivery systems to facilitate the integration of their geologic data resources into automated systems, and to maximize the usefulness of geologic information.
To this end, the Arizona Geological Survey is developing a computer-based geologic information system designed to meet the needs of mineral exploration geologists, researchers in search of detailed technical information, land managers or planners requiring information pertinent to regulatory, planning, and development functions, and curiosity-driven users from the general public. Many of these users may not be expert geologists, but still need to be able to query the system to obtain information. The underlying data model must be flexible enough to encompass a wide range of earth science information, storing it in such a fashion that it does not become obsolete with advances in geologic science.

Based on several years of development and discussion with other database developers (see papers in Soller, 1997; 1998; 1999; 2000; and this volume), this system has evolved into a structure with a variety of inter-related components, summarized in Table 1. This document defines a relational database implementation of the metadata, cartography, geologic map, and geoscience infrastructure parts of the Arizona geologic information system necessary to represent the basic geologic information and cartography recorded on a typical geologic map. This information includes the assignment of map units to regions on the map, the classification of boundaries between the map units as faults or contacts (here referring to depositional or intrusive contacts), the recording of basic point-referenced structural data, and the cartographic representation of these features. Subsequent documents will describe the detailed geoscience description tables (map units, lithology, age dates, stratigraphic relationships, etc.). The implementation is based on Microsoft Access (currently using the Access 2000 version; datasets are distributed with Access 97 tables for wider accessibility) as the relational database, and ESRI ArcInfo (v.8.0.1) and ArcView (v.3.2) as the geographic data system. 
Table 1. Components of Arizona Geological Survey Information System.

\begin{tabular}{|c|c|c|}
\hline Component Name & Function & Status $(11 / 3 / 2001)$ \\
\hline MetaData & $\begin{array}{l}\text { Stores basic information about people, projects, } \\
\text { organizations, the DataSet catalog, system development } \\
\text { metadata }\end{array}$ & implemented \\
\hline $\begin{array}{l}\text { Arizona Rock Unit } \\
\text { Lexicon }\end{array}$ & $\begin{array}{l}\text { Stores definition and default descriptions of rock units } \\
\text { used for geologic mapping in Arizona. Based on USGS } \\
\text { geologic name lexicon and AZGS AzStrat [R.A.Trapp, } \\
\text { unpublished] }\end{array}$ & $\begin{array}{l}\text { Designed, implemented, } \\
\text { not populated }\end{array}$ \\
\hline $\begin{array}{l}\text { Arizona Geologic } \\
\text { Bibliography }\end{array}$ & $\begin{array}{l}\text { Stores bibliography of published literature concerning } \\
\text { Arizona geology [Trapp et al., 1996] }\end{array}$ & $\begin{array}{l}\text { Implemented, populated, in } \\
\text { maintenance }\end{array}$ \\
\hline Geologic Map & $\begin{array}{l}\text { Stores map legend definitions, and map view definitions. } \\
\text { This component may have multiple instances specific to } \\
\text { particular geologic data sets or projects. }\end{array}$ & $\begin{array}{l}\text { Default map visualization } \\
\text { implemented and in use. }\end{array}$ \\
\hline $\begin{array}{l}\text { Cartography } \\
\text { Infrastructure }\end{array}$ & $\begin{array}{l}\text { Stores definitions and descriptions of graphical elements } \\
\text { used to construct geologic maps, along with default legend } \\
\text { for symbolizing standard map units and features. }\end{array}$ & $\begin{array}{l}\text { Implemented, partially } \\
\text { populated }\end{array}$ \\
\hline Rock Samples & $\begin{array}{l}\text { Stores information locating and describing rock samples } \\
\text { collected in the field for geochronology, geochemistry, } \\
\text { representative lithology, etc. }\end{array}$ & $\begin{array}{l}\text { Implemented, partially } \\
\text { populated }\end{array}$ \\
\hline Geochronology & $\begin{array}{l}\text { Stores detailed analytical information for isotopic age } \\
\text { dates. }\end{array}$ & $\begin{array}{l}\text { Implemented, populated } \\
\text { based on Reynolds et al. } \\
\text { [1986], data structure not } \\
\text { finalized }\end{array}$ \\
\hline Geochemistry & $\begin{array}{l}\text { Stores analytical data for whole rock, trace element, and } \\
\text { isotopic analyses of rocks. }\end{array}$ & Planned \\
\hline $\begin{array}{l}\text { Geoscience } \\
\text { Infrastructure }\end{array}$ & $\begin{array}{l}\text { Stores basic geoscience terminology Classification } \\
\text { Concepts, definitions and descriptions of standard mineral } \\
\text { and lithology terms, and the standard geologic time scale } \\
\text { used by AZGS (GSA, DNAG, Palmer, 1983). Data in this } \\
\text { component database is not specific to a location, and } \\
\text { applies to all geologic data sets. }\end{array}$ & $\begin{array}{l}\text { Designed and implemented, } \\
\text { some tables partially } \\
\text { populated }\end{array}$ \\
\hline $\begin{array}{l}\text { Geoscience } \\
\text { Descriptions }\end{array}$ & $\begin{array}{l}\text { Set of table templates for description of geologic features } \\
\text { specific to individual geologic datasets. }\end{array}$ & $\begin{array}{l}\text { Designed, implemented, } \\
\text { not populated }\end{array}$ \\
\hline
\end{tabular}

\section{GEOLOGIC MAP DATA}

A geologic data set is a collection of map unit definitions, interpretations of the nature of the boundaries between the map units, locations of faults and boundaries between the map units defined, and descriptions (quantitative and qualitative) of the nature of the map units, structures, faults, and map unit boundaries. Data set as used here is independent of the format of the data-it may be digital or analog (Richard, 2000). A geologic map image is a visual representation of a geologic data set for an area, designed to communicate information to a user. The map image is defined by the map area extent, the geologic data (both spatial location and classification) used, the choice of symbols for geologic features, the map projection and scale, a specification of the surface represented by the map, and the cultural and physiographic base map. The path from a geologic data set to a geologic map image requires selecting symbols to represent the distribution of the map units, the location and type of map unit boundaries and faults, and the location and relevant data for point observations (orientation measurements). These symbols are placed on a base map that represents the map area by means of a projection and some elevation model to represent topography on the mapped surface. The base map provides a visual reference frame to depict the spatial relationships between geologic features, and a means of physically locating the features depicted. Design of the base map is an important aspect of cartography. This definition of a map image makes no distinction between a standard geologic map (map surface $=$ earth surface), a mine-level map (map surface $=$ horizontal plane), or a geologic cross section (map surface $=$ vertical plane along section line).

A digital geologic data set represents a geologic data set in a georeferenced form using a set of computer files. A digital geologic data set is defined by:

1. The conceptual model that is the basis for the geologic data set.

2. A logical data schema that is a mapping of the conceptual model underlying the geologic data set to 
data structures that can be represented by an automated system (e.g. relational tables, described in this report).

3. A physical implementation schema that defines the organization of data into files, the detailed structure of the files, and the representation of data in the files. The file format dictates the software and hardware sys-tems that are compatible with the data.

4. A projection and map horizon specification that describes how the three-dimensional location of features on the Earth is specified.

5. The data instances contained in the files (locations of contacts and faults, map unit definitions, classification of areas to map units....).

6. A set of definitions that specify the meaning of attributes applied to included data instances.

\section{DATA MODEL IMPLEMENTATION COMPONENTS}

This report describes the logical and physical implementation of a database system for the representation of geologic features represented on geologic maps. It is assumed that the reader is familiar with the basics of the ESRI coverage data model and the use of ESRI ArcView GIS 3.x and Microsoft Access 97-2000 software.

This database implementation is a second-generation effort, and supercedes the data structure outlined in Richard and Thieme (1997). The design is an outgrowth from a proposed North American standard data model ('NADM') for geologic maps (Johnson et al., 1998), overseen by the North American Data Model Steering Committee (http://geology.usgs.gov.dm). In the course of implementing this database, the Johnson et al. (1998) model was found inadequate to allow inclusion of information in existing AZGS databases and for a complete representation of geologic information. Focus then shifted to the NADM "Cordlink" variant model (Brodaric et al., 1999 ) as a starting point. Various aspects of this model were also found insufficient or unsatisfying. The logical model presented here was evolved to reduce the number of tables and allow greater flexibility and logical consistency. The final implementation resembles the Johnson et al. (1998) NADM 4.3 model only in very general terms. The model builds on the design philosophy laid out in Richard (1998), the conceptual model described in Richard (1999), and the recent parallel development of an object-oriented data model by Brodaric and others (Brodaric, 2000; Brodaric and Hastings, 2001; Brodaric and Gahegan, 2000).

The core components of the model are:

1. Classification Concept table(s). At the core of the model is a table or group of tables with similar structure that define terminology. The essential elements of these ClassificationConcept tables are a unique identifier, a name, and a definition/description. The unique identifier follows the global unique identifier scheme described below. The name is a string that allows human identification of the concept (e.g. 'basalt'), and the definition/description is a free text field that defines the term or describes its meaning precisely.

2. Relationship tables. These are tables that link data instances. The meaning of the link is defined by a relation-ship type attribute. The data instances that fill roles in a relationship may be any individual classification concept, description, or relationship; the kinds of valid role fillers are determined by the relationship type attribute. Three sorts of relationship tables are included with different structure and application. Hierarchy Relationship tables define parent-child relationships in hierarchies; these may be taxonomic (IsA) or meronymic (Part-Whole). Simple Relationship tables link data instances, which may have a sequence; typically these link description parts (e.g. image to rock description, age date to rock description, chemical analysis to location). The most complex relationships are Attributed Relationships, which allow an attribute value to be associated with the link, along with a sequencing index, and classification confidence and classification basis attributes.

3. Description tables. These are tables tailored to particular kinds of descriptions. Spatial objects (points, lines, polygons...) are represented in a description table. In addition, the core model includes tables for structural measurements, rock samples, text, geochronologic ages, chemical substances, lithologic description, stratigraphic time, spatial objects, images, and measured quantity. Only the spatial object, structural measurement and rock sample tables are described here. Some description tables are linked to ClassificationConcepts directly through the sharing of a unique identifier, and provide a structured description to characterize the classification concept. Others provide descriptions of 'real world' instances (a particular rock sample, a particular contact, a particular fault....).

4. Map Visualization tables. These are a set of tables used to define map visualizations. This group includes three tables:

(a) Map View Definition table - specifies a title, author, design scale, map extent, symbolization scheme and classification scheme for the map; (b) Map Legend - relates each symbol used in the map visualization to a classification concept; (c) Cartographic Object table - defines the symbols used on the map in implementation-independent terms. 
Three modes of defining assignment of symbols to spatial objects represented on the map are used. First, in this database, all spatial objects have a default classification attribute and a default cartographic object attribute. This default symbolization corresponds to that assigned by the original author of the map visualization (default visualization). Second, symbols may be associated with spatial objects through the map legend, (symbol - classification link) and a spatial classification attributed relationship (spatial object - classification link). This approach corresponds to the NADM 4.3 and Cordlink Variant approach. Finally, a general visualization links spatial objects to symbols through an attributed relationship link (symbolization scheme) whose type is the identifier for the map view definition. This final approach corresponds most closely to how map visualizations are actually generated from spatial data. The relationship attribute is the rotation to apply to structure measurement symbols, or, in the case of purely cartographic annotation symbols, the text string to display.

\section{Identification Scheme}

Unique identification of data instances in an internationally distributed data warehouse is achieved by partitioning responsibility for maintenance of unique identifiers. The Arizona Geological Survey uses a 3-component composite key, consisting of 3 long ( 4 byte) integers. At the top level, each organization providing data to the system must be assigned a NameSpace by the overall system manager. Note that a NameSpace is a

ClassificationConcept. The name string and an integer identifier for the NameSpace must be globally unique. Within each NameSpace, every data file must have a unique integer identifier, and should have a unique name string. The system manager for the NameSpace must assign a unique identifier number to each data table, geographic data set (coverage, shapefile, etc.), image, text file, etc. that will be used by the system. Information about each data file (called a DataSet here) is stored in a central DataSet table maintained within each NameSpace. This table is analogous to a 'catalog' in the Open GIS consortium model. The DataSet table must include a physical address (url) for each DataSet so that it can be located automatically when accessed. Within each DataSet, every data instance has a unique integer identifier number. The field containing this identifier is generally named with a string in the form 'DataSetName' \& 'ID'. In summary, the unique, global identifier for any data instance is a tuple consisting of 3 integers: \{NameSpaceID, DataSetID, ObjectID . Because this system has not been adopted outside the Arizona Geological Survey at present, the NameSpaceID is not explicitly included in tables here.
Because some database software cannot join on multiple fields, implementation considerations require generating a single UniqueID from the DataSetID and ObjectID under some conditions. This is done using the formula ID = (DataSetID * 10000000) + ObjectID .

\section{Metadata}

Feature level metadata is implemented by linking every data instance with an origin TrackingRecord, either as an attribute of the instance, or by inheriting origin tracking from the DataSet that contains the instance. The TrackingRecord defines a person, organization, and project (an 'activity') that generated the data instance, along with a link to a data processing description for how the information was obtained and introduced to the database. Each TrackingRecord may be linked (through a SimpleRelationship) to one or more bibliographic citations.

\section{Table and Field Naming Conventions}

Tables and fields are named using strings with no spaces. The first letter of separate words in the name is capitalized, and no underscore separates words in the name. Typing an underscore is error-prone, and under many display conditions, underscores may be difficult to see. Because of limitations in ArcInfo (v8.0.1) and ArcView (v.3.2) software, field names in spatial data native tables are limited to 10 characters.

\section{DATA OVERVIEW AND ORGANIZATION}

Three schema at the end of this document are presented to assist in understanding the data structure. Figure 1 is a simplified schema showing the tables necessary to represent the basic geologic data and cartography contained in a typical geologic map visualization. This schema includes the three kinds of relationship tables used to implement the general relationship structure. Metadata, implementationspecific description of cartographic objects, and description representation is not expanded in this schema. Figure 2 is a simplified schema showing the description of spatial objects. Fields in the spatial object table (AAT and PAT in ESRI terminology) represent a default visualization and classification scheme, which uses the geologic symbolization and classification of the original map author. This schema also includes some representation of descriptionsample locations and structural measurements are included. It does not include the correlation tables necessary for building general relationships between objects, or any metadata tables. Figure 3 is a simplified schema showing 
links to graphic object and color definition tables

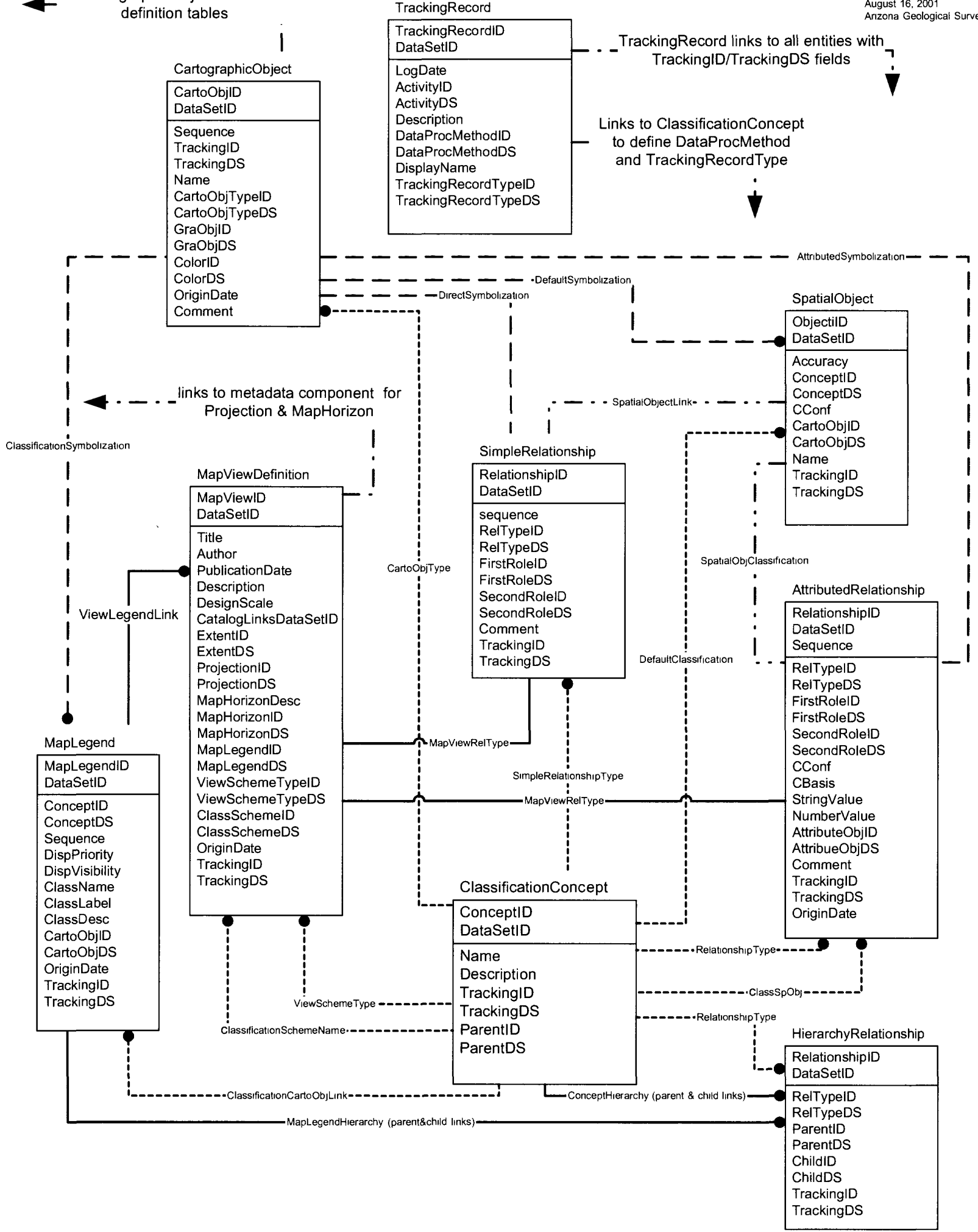

Figure 1. Simplified schema for geoscience database implementation. Map visualization represented by general relationship links between cartographic, classification, and spatial objects. Metadata, implementation-specific description of cartographic objects, and description representations are not expanded in this schema. Different line patterns used to facilitate tracing links. 


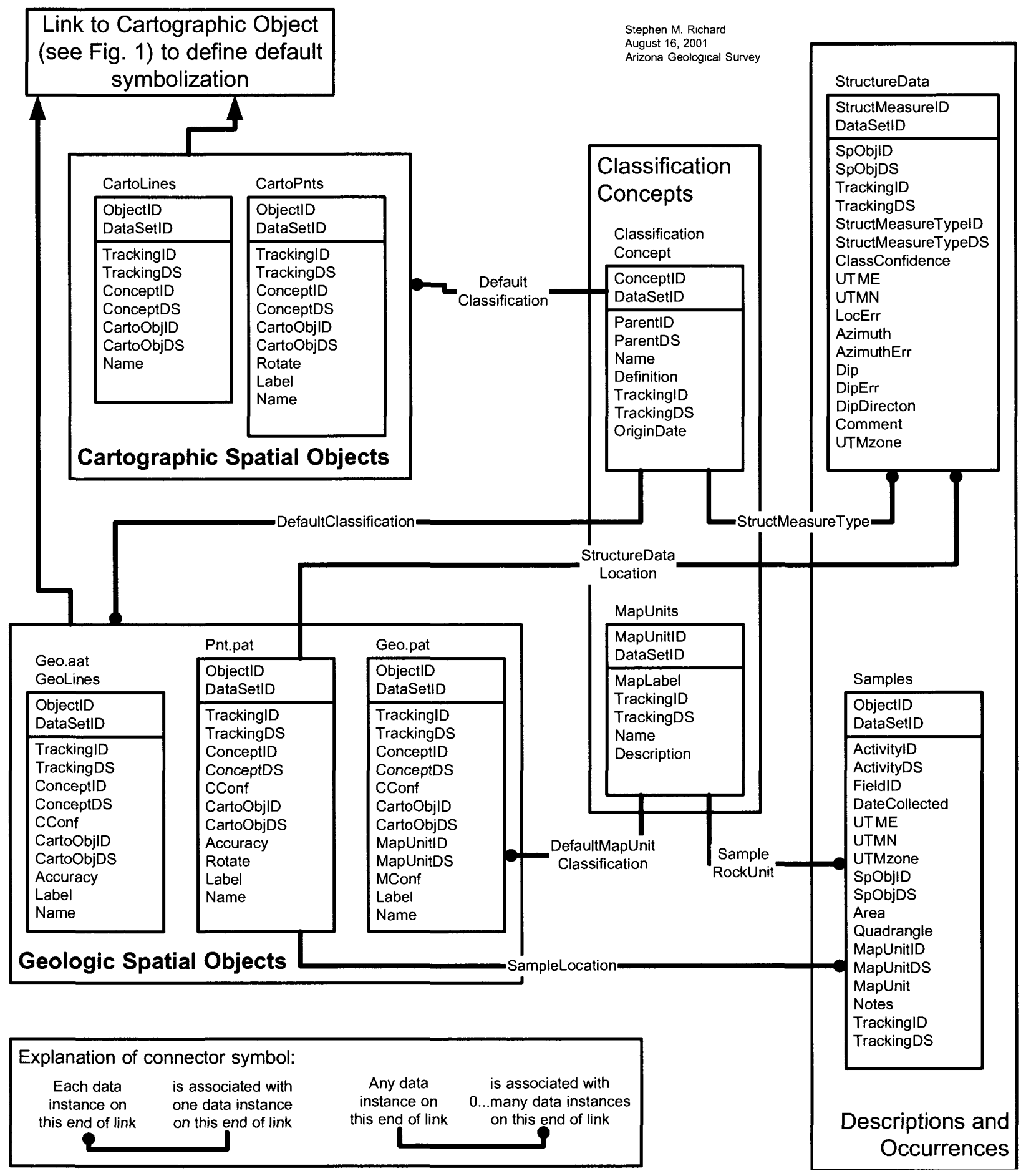

Figure 2. Schema for basic geologic map description relational implementation. Metadata links not shown.

a more in-depth (but not complete) view of the featurelevel metadata implementation. All the tables shown on these schemata are described in this text, and the figures should be referenced throughout the following discussion.

The geologic and cartographic information in the database is organized into several ArcInfo coverages and ESRI shapefiles. The basic geology defined in the Geo coverage requires the point-line-polygon topology implemented by an ArcInfo coverage. Other spatial data may be in coverages or ESRI shapefiles. The Geo polygon and arc coverage contains the lines that represent geologic contacts and faults, and the associated polygons based on those lines that define the outcrop area of map units. The Pnt point data set contains the field observation stations that record things such as structural measurements and collected rock samples. The GeoLines line data set contains the geologic 


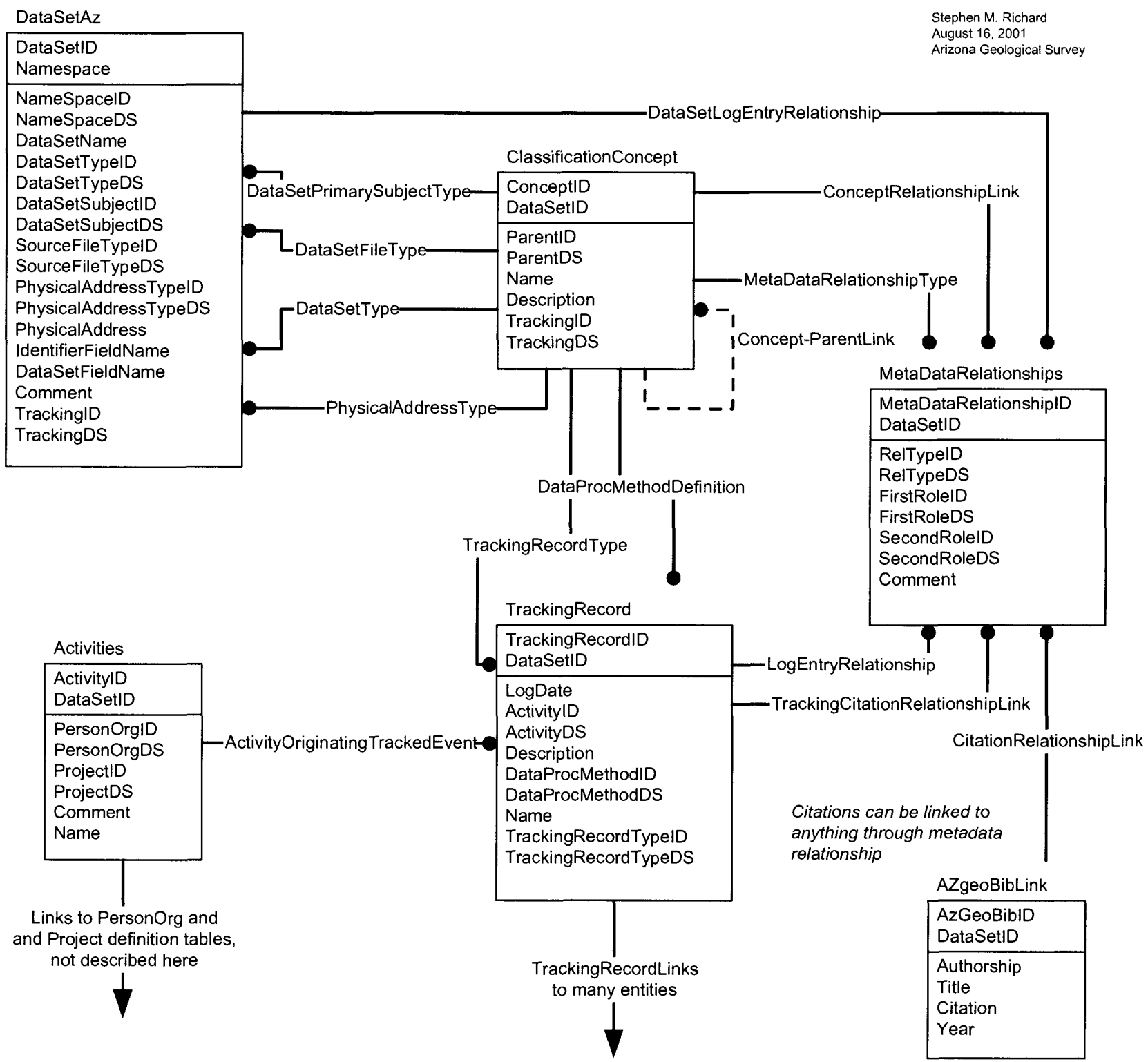

Figure 3. Schema for basic metadata relational implementation.

lines that do not define boundaries between rock units, such as concealed faults and fold hinge surface traces. The CartoLines line dataset contains cartographic lines, such as text lead-in lines. Last, the CartoPnts point dataset locates the cartographic point features used in the default map layout, such as text labels.

Every spatial object (point, line, or polygon) is uniquely identified by a compound primary key consisting of a source-file identifier, named DatasetID, and a unique identifier within that file, named 'DataSetName' \& ID (referred to as ObjectID here). The ArcInfo-assigned User-ID field, a seemingly good candidate for unique identifiers, is not immutable under build and clean operations on the data set. Therefore, ObjectID was added as a userdefined attribute, and the uniqueness constraint must be enforced by the user. The ObjectID values in the tables in this database should not be edited unless the user fully understands the data structure and the ramifications of editing the primary key in a relational database table. All points, lines, and polygons have a TrackingID attribute that joins with the TrackingRecord table to show the source origination and tracking information for each object. Geologic points and lines also have an Accuracy attribute that defines the location uncertainty in meters for the point or line. The compound object key, ObjectID and DatasetID, and the compound source tracking key, TrackingID and TrackingDS, plus the Accuracy attribute for geologic points and lines, are the minimal set of attributes fundamental to each spatial object.

A number of other attributes are also included in the coverage and shapefile tables to facilitate visualization of the geologic data in a default layout, and to allow querying 
against a default classification scheme equivalent to the original source map. These default values also make simple analyses of the map possible in non-relational database environments required by some users of AZGS data. The compound classification concept attribute, ConceptID and ConceptDS, defines the default classification of every object (Fault; Bedding; Surficial Map Unit...); the classification confidence attribute, CConf, provides a subjective measure of the confidence level for the classification of the object (Low; Standard...); and the compound cartographic object attribute, CartoObjID and CartoObjDS, defines the cartographic object used to symbolize each feature in the default visualization (" 0.35 pt. solid black line (24K)"; "Inclined bedding symbol - color black (24K)"; "PMS-1205"...). There is also a Label attribute used to store any specific labels or names associated with an object, such as unit names for geologic polygons, and a Name attribute that contains a brief description of each object for intelligibility. Polygon features have a map unit confidence attribute, MConf, that provides a subjective measure of the identification confidence of a polygon to a particular map unit (Low; Standard...). Point features also have a Rotate attribute, measured anticlockwise, starting from a compass azimuth of $90^{\circ}$, that defines the degree of rotation of graphical elements used for feature symbolization in the ArcView project. The rotation magnitude is specific to the graphical environment of ArcView 3.2 using the AZGSgeo.ttf true type font. Use of these geographic data sets with a different GIS platform and/or font may require that the rotation values in the Rotate attribute be recalculated.

In the summaries that follow, each table includes a compound unique identifier and a tracking record link. These universal fields are described here rather than in the tables below. Italicized words are names of other tables in the database.

- ObjectID: Integer, width 16. First part of the compound primary key. Uniquely identifies each record in a particular table. Domain: Integers $>0$ and $<10^{16}$, no duplicates. (Name varies from table to table)

- DataSetID: Integer, width 16. Second part of the compound primary key. Uniquely identifies the record in the DataSet $A Z$ table that defines the data set that contains the definitive instance of this object. Domain: Integers $>0$ and $<10^{16}$, must be defined in the DataSetAZ table.

- TrackingID: Integer, width 16. First part of the compound primary key for link to the origin tracking record for each object. It is a foreign key that joins to the TrackingID field of the TrackingRecord table. Domain: Integers $>0$ and $<10^{16}$, must have match in table identified by TrackingDS value.

- TrackingDS: Integer, width 16. The DataSetID for the table that contains the data object identified by
TrackingID. Domain: Integers $>0$ and $<10^{16}$, must be defined in the DataSetAZ table.

\section{GEOLOGIC SPATIAL DATA}

\section{Geology Coverage}

The geospatial data for a particular geologic data set are represented in a set of Arc/Info coverages or ESRI shapefiles. These files contain spatial objects that represent geologic features at corresponding locations in the physical world. A minimum of two files are required to represent a geologic map - one that represents geologic faults and contacts, and one that represents the distribution of map units. AZGS geologic map databases include these in one Arc/Info coverage with polygon and line topology, named Geo. A third file may be included to represent point-located data (structure measurements, rock descriptions, sample locations). AZGS geologic map databases include these in an Arc/Info point coverage or an ESRI point shapefile, named GeoPnts. A fourth file may be necessary to represent those geologic lines that do not define polygon topology (concealed faults, fold hinges, dikes, marker beds...). AZGS geologic map databases include these in one Arc/Info line coverage or ESRI line shapefile, named Geolines. Fields in the data table associated with this extra line-file are equivalent to the arc attributes in the Geo coverage, and are not described separately here.

The Geo coverage is a polygon and arc coverage that contains geologic lines that bound polygons (contacts, faults, mapping boundaries...), or represent surfaces that are discontinuous within polygons (faults that become buried or die out). The polygon topology defined by the lines in this coverage identifies the distribution of geologic map units.

\section{Polygon Attributes}

- ObjectID/DataSetID: Compound key, unique identifier for each spatial object

- TrackingID/TrackingDS: Compound foreign key, link to origin tracking record.

- ConceptID/ConceptDS: Link to classification concept that classifies the kind of map unit a particular polygon represents. It is a foreign key that joins to the ConceptID field of the ClassificationConcept table. See Table 2 for example values.

- CConf: Character, width 16. Assigns a qualitative confidence level to the classification of the kind of unit represented by the polygon. Domain: 'low', 'standard', or 'high'.

- CartoObjID/CartoObjDS: Compound foreign key, link to cartographic object used to symbolized this 
spatial object on the default map visualization. It is a foreign key that joins to the CartoObjID field of the Cartographic-Object table. See Table 3 for example values.

- MapUnitID/MapUnitDS: Compound foreign key, link that identifies the geologic map unit associated with each polygon of type "Rock Volume Map Unit" (ConceptID = 2406) or "Surficial Map Unit" (ConceptID = 2405). It is a foreign key that joins to the ObjectID/DataSetID of the MapUnits table. See Table 4 for example values.

- MConf: Character, width 16. For polygons of type "Rock Volume Map Unit" (ConceptID = 2406) or "Surficial Map Unit" (ConceptID = 2405), indicates the subjective confidence of the person making the map unit classification in the assignment of the material within the polygon to a particular rock

Table 2. Example classification concept ID codes used in the Geo.pat table.

\begin{tabular}{|c|l|}
\hline ConceptID & \multicolumn{1}{|c|}{ Name } \\
\hline 2405 & Surficial Map Unit \\
\hline 2406 & Rock Volume Map Unit \\
\hline 2424 & Not Defined \\
\hline
\end{tabular}

Table 3. Example cartographic object codes used in the Geo.pat table.

\begin{tabular}{|c|c|l|}
\hline CarteobiD & Seq & \\
\hline 999 & 1 & Transparent \\
\hline 1008 & 1 & PMS-100 \\
\hline 2200 & 1 & Blue (R135,G207,B254) \\
\hline 2231 & 1 & Transparent background \\
\hline 2231 & 2 & Blue (R39,G146,B182) lst pattern layer \\
\hline 2254 & 1 & PMS-454 background \\
\hline 2254 & 2 & PMS-1205 1st pattern layer \\
\hline
\end{tabular}

volume or surficial geologic map unit. Otherwise the field does not contain a value. Domain: 'low', 'standard', or 'high'.

- Label: Character, width 50. Equivalent to the geologic map unit labels on the default map visualization. This attribute represents the default classification of each polygon to a particular rock unit and is included to make symbolizing and viewing the default map visualization relatively simple. The label is queried if the classification confidence is low.

- Name: Character, width 255. Equivalent to the geologic map unit names in the map explanation on the default map visualization. This is a redundant field added to simplify the use of the data set in non-relational database environments.

\section{Arc Attributes}

- ObjectID/DataSetID: Compound key, unique identifier for each spatial object

- TrackingID/TrackingDS: Compound foreign key, link to origin tracking record.

- Accuracy: Float (real), single precision. Represents the spatial uncertainty in the location of a feature, in meters. For example, a value of 10 for a line feature indicates that the geologic entity represented by the line on the default map visualization is within 10 meters of the mapped feature's actual location on the ground. At present this uncertainty combines the geologic uncertainty in the accuracy of location (e.g. for a gradational or poorly exposed contact), and the numerical uncertainty in the computer representation of the line location resulting from accumulated calculation and digitizing errors. The uncertainty must be greater than the numerical precision of the $\mathrm{X}, \mathrm{Y}$ coordinates that locate a point (i.e. the accuracy cannot exceed the precision). This value determines the line style

Table 4. Example rock unit identification codes used in the Geo.pat table.

\begin{tabular}{|c|l|}
\hline MapUnitID Name \\
\hline 0 & Area not digitized \\
\hline 1 & Abrigo Formation (Middle Cambrian) \\
\hline 2 & Abrigo Formation (Middle Cambrian) - lower sandstone and mudstone unit \\
\hline 4 & Abrigo Formation (Middle Cambrian) - upper sandstone, marl, and limestone unit \\
\hline 5 & Bolsa Quartzite (Cambrian) \\
\hline 6 & Bolsa and Abrigo Formations, undivided \\
\hline 7 & Bolsa, Abrigo and Martin Formations, undivided, photogeologic identification \\
\hline 8 & Martin Formation (Devonian) \\
\hline 25 & Mafic sill (Cretaceous); sedimentary and volcanic sequence east of the Recortado Well Fault \\
\hline 26 & Sandstone photogeologic unit 1 (Cretaceous or Jurassic) \\
\hline
\end{tabular}


that represents the line by using standard solid, dashed, and dotted lines. For most existing maps, this length will be based on standard map accuracy, i.e. the geologic entity is located within the width of the line shown on a map for a solid line. In this data set, location uncertainties are qualitatively estimated. A value of 0 indicates that accuracy is not defined, as in the case of cartographic lines. Domain: rational numbers $>$ numerical precision of data and $<10^{8}$.

- ConceptID/ConceptDS: Same as for geology polygon coverage. See Table 5 for example values.

- CConf: Same as for geology polygon coverage.

- CartoObjID/CartoObjDS: Same as for geology polygon coverage. See Table 6 for example values.

- Label: Character, width 50. When used, contains strings that identify line features that have a label associated with them, as in the case of named faults. Domain: Free text.

- Name: Character, width 255. Identifies the default classification of each type of line. This is a redundant field added to simplify the use of the data set in non-relational database environments.

Table 5. Example classification concept values used in the Geo.aat table.

\begin{tabular}{|c|l|}
\hline ConceptDo & \multicolumn{1}{|c|}{ Name } \\
\hline 7 & Contact, not classified, timing not specified \\
\hline 58 & Fault, High-angle, normal separation \\
\hline 596 & Fault, Generic high-angle, separation unknown \\
\hline 642 & Mapping boundary surface \\
\hline 2423 & Contact, intraformational, timing not specified \\
\hline
\end{tabular}

\section{Point Coverage}

The GeoPnt coverage is a point coverage that represents geologic spatial features located at a distinct point (structural measurement stations, rock samples collection stations...).

\section{Point Attributes}

- ObjectID/DataSetID: Compound key, unique identifier for each spatial object

- TrackingID/TrackingDS: Compound foreign key, link to origin tracking record.

- Accuracy: Same as for geology arc coverage, see above.

- ConceptID/ConceptDS: Same as for geology polygon coverage. Typical value: ConceptID $=3340$ Field Observation Station.

- CConf: Same as for geology polygon coverage.

- CartoObjID/CartoObjDS: Same as for geology polygon coverage. See Table 7 for example values.

- Label: Character, width 50. When used, contains strings that are equivalent to any labels associated with point features on the default map visualization, e.g. sample identification numbers.

- Rotation: Integer, width 4. Specifies the font symbol rotation that correctly represents the azimuth of the geologic feature displayed on the default map visualization at this point. This value is specific to the graphical environment of ArcView 3.2 using the AZGSgeo.ttf font.

- Name: Same as for geology arc coverage, see above.

\section{CARTOGRAPHIC SPATIAL OBJECTS}

Cartographic elements for the default map visualization of a particular geologic data set are included in a line and a point shapefile. Because the locations of points and lines in these shapefiles are chosen to provide cartographic clarity, the Accuracy and CConf fields are irrelevant and therefore not included. Otherwise the fields are the same as those in the geologic line and point coverages (geo.aat and pnt.pat), described above. The CartoLines shapefile contains the cartographic lines (text lead-in lines...) used in the default map visualization. The CartoPnts shapefile contains the cartographic points (text labels, fault symbols, fold geometry symbols...) used in the default map visualization. Table 8 lists some kinds of points included in this shape file, and Table 9 lists some associated cartographic object examples.

Table 6. Example cartographic object codes used in Geo.aat table.

\begin{tabular}{|c|l|}
\hline Carto ObjD & \multicolumn{1}{|c|}{ Name } \\
\hline 53 & Null line symbol \\
\hline 54 & $0.5 \mathrm{pt}$ dashed black line (24K) (Approximate contact) \\
\hline 55 & $0.5 \mathrm{pt} \mathrm{solid} \mathrm{black} \mathrm{line} \mathrm{(24K)} \mathrm{(Accurate} \mathrm{contact)}$ \\
\hline 59 & $1.5 \mathrm{pt}$ dashed black line (24K) (Approximate fault) \\
\hline 60 & $1.5 \mathrm{pt} \mathrm{solid} \mathrm{black} \mathrm{line} \mathrm{with} \mathrm{queries} \mathrm{(24K)} \mathrm{(Queried} \mathrm{accurate} \mathrm{fault)}$ \\
\hline 61 & $1.5 \mathrm{pt}$ solid black line (24K) (Accurate fault) \\
\hline 65 & $2.5 \mathrm{pt}$ solid black line (24K) (Map neat line) \\
\hline
\end{tabular}


Table 7. Example cartographic object codes used in the GeoPnt.pat table.

\begin{tabular}{|c|l|}
\hline CartoobjD & Name \\
\hline 52 & Null point symbol \\
\hline 2055 & Inclined bedding symbol - color black (24K) \\
\hline 2056 & Approximate inclined bedding symbol - color black (24K) \\
\hline 2057 & Inclined crenulated or warped bedding symbol - color black (24K) \\
\hline 2058 & Inclined bedding w/tops known symbol - color black (24K) \\
\hline 2059 & Overturned bedding symbol - color black (24K) \\
\hline 2060 & Overturned bedding w/tops known symbol - color black (24K) \\
\hline 2062 & Vertical bedding symbol - color black (24K) \\
\hline 2064 & Vertical bedding w/tops known symbol - color black (24K) \\
\hline 2076 & Generic inclined foliation symbol - color black, open triangle (24K) \\
\hline 2093 & Inclined eutaxitic foliation symbol - color black (24K) \\
\hline 2143 & Minor anticline symbol - color red (24K) \\
\hline 2165 & Fault attitude symbol - color black (24K) \\
\hline 2172 & Circle with filled central circle (USGS 26.2 .5$)$ - color black (24K) \\
\hline
\end{tabular}

Table 8. Example classification concept codes used in the CartoPnts. table.

\begin{tabular}{|c|l|}
\hline ConceptiD & \multicolumn{1}{|c|}{ Name } \\
\hline 3057 & Discrete feature point symbols \\
\hline 3317 & Annotation, unit label \\
\hline 3318 & Annotation, structural measurement label \\
\hline 3321 & Annotation, generic text \\
\hline
\end{tabular}

\section{THEMATIC GEOLOGY DATABASE TABLES}

The majority of geologic information is stored in thematic databases specific to particular kinds of geoscience information, and linked to the Spatial Object tables by explicit links, or through relationship links. Information in these thematic tables includes structural measurements, rock sample descriptions, text descriptions, geochronologic age data, chemical and isotopic analytical data, lithologic descriptions, stratigraphic time scales, and images. This thematic geoscience part of the database is the least developed aspect of the system at present. Only basic map unit description, structural measurement and rock sample tables are described here. The thematic tables are specific to the particular geologic data set. These tables are included in a Microsoft Access database associated with each geologic data set.

\section{Map Unit Table}

The MapUnits table defines the map units used to classify polygons in the Geo coverage. In a more complete implementation, the MapUnitID would be a link to a more complete description in a series of tables for lithology, rock volume, and geologic surface description (geoscience description component of database, see Table 1).

\section{Database Table Fields}

- MapUnitID/DataSetID: Compound key, unique identifier for map unit.

- TrackingID/TrackingDS: Compound foreign key, link to origin tracking record.

- OriginDate: Date/Time. Records when the record was created. This information provides more detailed information on the time that records were

Table 9. Example cartographic object codes used in the CartoPnts table.

\begin{tabular}{|c|l|}
\hline CartoObjID & \multicolumn{1}{|c|}{ Name } \\
\hline 2134 & anticline symbol - color black $(24 \mathrm{~K})$ \\
\hline 2169 & normal fault symbol - color black $(1000 \mathrm{~K})$ \\
\hline 2177 & plunge arrowhead - color black $(12 \mathrm{~K})$ \\
\hline 2270 & Small structural measurement label - color black (24K) \\
\hline 2270 & Small unit label - color black (24K) \\
\hline 2271 & Large dike label - color black (250K) \\
\hline 2271 & Medium generic text label - color black (24K) \\
\hline 2271 & Medium structural measurement label - color red (24K) \\
\hline
\end{tabular}


originally entered, supplementing the information in the associated TrackingRecord table.

- MapLabel: Text, width 25. Text string for standard map label for this unit.

- Name: Text, width 255. Identifies the map unit name or rock type.

- Description: Memo. Full description of the rock unit.

\section{Samples Table}

The Samples table contains location and description information for rock samples collected within the extent of the geologic data set. The inclusion of both the UTM coordinates for the sample location and a link to a spatial object representing the sample location is redundant, but both forms of location are included for reliability. If the link with the spatial object data set is corrupted, the Samples table still contains sufficient information to locate the sample. Likewise, the sample table can be exported for data exchange without including a data set with location spatial objects.

\section{Database Table Fields}

- ObjectID/DataSetID: Compound key, unique identifier for sample.

- TrackingID/TrackingDS: Compound foreign key, link to origin tracking record.

- ActivityID/ActivityDS: Compound foreign key, link to Activity for collection of the sample. Activities for sample collection should indicate the person who collected the sample. Domain: Integers $>0$ and $<10^{16}$.

- FieldID: Text, width 30. Records the sample identifier assigned to the rock collected in the field by the original collector.

- DateCollected: Date/Time. Records when a sample was collected.

- UTME: Number, real, single precision. UTM easting coordinate for sample location. Domain: $122000<$ UTME $<700000$.

- UTMN: Number, real, single precision. UTM northing coordinate for sample location. Domain: $3420000<$ UTMN $<4110000$.

- UTMzone: Number, long integer. Zone number for UTM coordinates. Domain: 11 or 12 for the State of Arizona.

- Accuracy: Same as for geology point coverage.

- SpObjID/SpObjDS: Compound foreign key, link to spatial object that represents sample location.

- Area: Text, width 64. Geographic area name from Arizona Geological Survey Place Names list. Domain: Place names included in Trapp and Reynolds (1998).
- Quadrangle: Text, width 64. Name of USGS 7.5 minute quadrangle that contains the sample location. Domain: USGS 7.5 minute Quadrangle names.

- MapUnitID/MapUnitDS: Compound foreign key, link that identifies the geologic map unit in the MapUnits data set from which the sample was collected.

- Notes: Memo. Free text notes on sample.

\section{Structural Measurement Data Table}

The StructureData table contains values that define the orientation of structural features. The inclusion of both the UTM coordinates for the station location and a link to a spatial object representing the station location is redundant, but both forms of location are included for reliability. If the link with the spatial object data set is corrupted, the StructureData table still contains sufficient information to locate the station. Likewise, the StructureData table can be exported for data exchange without including a data set with location spatial objects. A separate correlation table to link stations with locations is unnecessary because each station has a unique location.

\section{Database Table Fields}

- StructMeasureID/DataSetID: Compound key, unique identifier for measurement.

- TrackingID/TrackingDS: Compound foreign key, link to origin tracking record.

- SpObjID/SpObjDS: Compound foreign key, link to spatial object in geology points coverage that represents the measurement location.

- Name: Text, width 255. Provides a descriptive name for each type of structural measurement.

- StructMeasureTypeID/StructMeasureTypeDS: Compound foreign key, link to classification concept that identifies the kind of structure measured. It is a foreign key that joins to the ConceptID field of the ClassificationConcept table. See Table 10 for example values.

- CConf: Same as for geology polygon coverage.

- UTME: Same as for Samples Table.

- UTMN: Same as for Samples Table.

- UTMzone: Same as for Samples Table.

- Accuracy: Same as for geology point coverage.

- Azimuth: Number, single-precision real. Records the trend or strike of a structural feature in degrees. For planar surfaces, the measurement is recorded using the right-hand rule (i.e. the measurement is made such that the down-dip direction is to the right when facing in the azimuth direction). The magnitude of the angle is measured clockwise starting from a compass azimuth of $0^{\circ}$. Domain: Real numbers, from 0 to 360 . 
Table 10. Example structural measurement type codes used in the StructureData table.

\begin{tabular}{|c|c|}
\hline 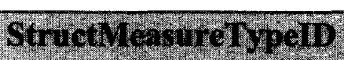 & Wrine \\
\hline 42 & Close disjunct cleavage \\
\hline 543 & Flow foliation \\
\hline 544 & Eutaxitic foliation \\
\hline 567 & Minor fault surface \\
\hline 572 & Lineation, generic tectonic \\
\hline 581 & Fold hinge, anticline \\
\hline 588 & Orientation, fault surface \\
\hline 762 & Bedding, crude or indistinct \\
\hline 768 & Bedding, planar parallel \\
\hline 3324 & Bedding, planar parallel, w/tops \\
\hline 3326 & Bedding, contorted or variable \\
\hline
\end{tabular}

- AzimuthErr: Number, single-precision real. Records the uncertainty, in degrees, associated with an azimuth measurement. For example, an AzimuthErr of 5 for an Azimuth of 127 would indicate that the azimuth actually falls within the range from 122 to 132 degrees. Domain: Real numbers, $>0$ and $<10^{8}$.

- Dip: Number, single-precision real. Records the angle between a planar or linear feature and horizontal (degrees). The angle is measured in the vertical plane perpendicular to strike for planar features and parallel to trend for linear features. The dip angle here measures total rotation rather than the conventional inclination measurement. For overturned beds this results in dips $>90^{\circ}$. This allows conceptually consistent representation of the dip for upright, overturned, or doubly overturned structures. Upright beds have dip $<90$, overturned beds have $90<\operatorname{dip}<=180$. Doubly overturned beds have dip $>180$. Domain: Real numbers, $>=0$ and $<10^{8}$.

- DipErr: Number, single-precision real. Records the uncertainty, in degrees, associated with a dip measurement. For example, a DipErr of 3 for a Dip of 29 would indicate that the dip actually falls within the range from 26 to 32 degrees. Domain: Real numbers, $>0$ and $<10^{8}$.

\section{ARIZONA GEOLOGIC DATA SYSTEM TABLES}

The lookup tables defined below contain supporting data maintained by the Arizona Geological Survey to support all databases within the organization. These tables are included as a Microsoft Access database. By default, each data set below references a table that is included in the Arizona Geological Survey namespace.

\section{Classification Tables}

\section{Classification Concept Table}

The ClassificationConcept table is a collection of terminology definitions - a term with a definition. These terms are used to classify other objects in all parts of the database. A unique identifier (ConceptID - DatasetID pair) identifies each concept. Thus the name of the concept may be changed without updating other links. The Arizona Geological Survey geologic information system has separate classification concept tables that are specific to different components of the system (e.g. Rock Unit Lexicon, Standard lithologic terms, etc.). Each of these classification concept tables has its own data set identifier defined in the DataSetAz table.

\section{Database Table Fields}

- ConceptID/DatasetID: Compound key, unique identifier for concept.

- TrackingID/TrackingDS: Compound foreign key, link to origin tracking record.

- Name: Text, width 255. Provides a descriptive name for each classification concept.

- ParentID/ParentDS: Compound foreign key, link to ClassificationConcept that represents the concept type. Semantically this is equivalent to the parent of the concept and the links between classification concepts and parent concepts define the classification concept hierarchy. This hierarchy is represented by the HierarchyRelationship table for use in general database queries. Inclusion of this attribute with each classification concept facilitates management of a single, simple tree hierarchy for classification concepts, but future development may allow a more complex concept hierarchy with multiple parent links. The ParentID is a foreign key that joins to the ConceptID field in this same table. Domain: Integers $>0$ and $<10^{16}$.

- Definition: Memo. Defines each classification concept.

- OriginDate: Date/Time. Records when the record was created.

\section{Relationship Tables}

Three sorts of relationship tables are used for representing semantic links between objects in the database (see Relationship Table Discussion, above). In the Arizona Geological Survey geologic information system, each component of the system (cartography, rock unit lexicon, standard lithology, geochronology...) has relationship tables specific to that sub-domain. A particular geologic data set may include several different relationship tables of 
each of the types described below, each with its own DataSetID defined in the DataSetAz table.

\section{Attributed Relationship Table}

The AttributedRelationship table is used for representing relationships between objects in the database, i.e. for linking instances of two entities in which each relationship instance is assigned one or more attributes. This table is constructed to allow up to 5 attributes: CConf (Concept Confidence), CBasis (Concept Basis), StringValue (any string), Number Value (any number), or Attribute (a link to another object in the database). The RelTypeID link defines the semantics of the relationship links. Relationship constraints on RelType specify which attributes may have values, and specify the domains of those values. Examples of attributed relationships include geologic classification of spatial objects, and various kinds of fractional analyses (e.g. chemical analysis, modal mineral analysis, grain size distribution).

\section{Database Table Fields}

- RelationshipID/DataSetID: Compound primary key that uniquely identifies each record in the AttributedRelationship table. Although the compound key \{RelTypeID, RelTypeDS, FirstRoleID, FirstRoleDS, SecondRoleID, SecondRoleDS \} provides a unique key, the table has a standard \{ObjectID, DatasetID\} key to allow a relationship to play a role in another relationship using the standard relationship tables. Domain: Integers $>0$ and $<10^{16}$, no duplicates.

- TrackingID/TrackingDS: Compound foreign key, link to origin tracking record.

- Sequence: Number, long integer. Third part of compound primary key. Orders multiple instances of a single relationship link; use for ordered aggregation.

- RelTypeID/RelTypeDS: Compound foreign key, link to classification concept that identifies the kind of relationship. This allows the AttributedRelationship table to represent any relationship that is defined by a ClassificationConcept.

- FirstRoleID/FirstRoleDS: Compound foreign key that identifies the object that fills the first role in the AttributedRelationship.

- SecondRoleID/SecondRoleDS: Compound foreign key that identifies the object that fills the second role in the AttributedRelationship.

- CConf: Same as for geology polygon coverage.

- CBasis: Text, length 255. Indicates the basis for assigning the relationship. Ideally this and CConf should be ClassificationConcept terms, but a text field is implemented here as an interim measure to get a better feeling for what sort of terms are required to assign values for confidence and basis.
- StringValue: Text, length 255. Allows assignment of a text attribute value for the relationship. An example is a text string that is displayed at a point location as cartographic annotation, in which case the relationship links the point with a TextFormat cartographic object. Domain: Free text.

- NumberValue: Number, single-precision real. Allows assignment of a numeric attribute value for the relationship. Examples include assignment of a fractional abundance for a component in a fractional analysis, or a symbol rotation value for a point location-structure symbol link. Domain: Real numbers, $>0$ and $<10^{8}$.

- AttributeObjID/AttributeObjDS: Compound foreign key that identifies an attribute object associated with this AttributedRelationship instance.

- OriginDate: Date/Time. Records when the record was created.

- Comment: Memo. Additional information about a relationship instance.

\section{Hierarchy Relationship Table}

The HierarchyRelationship table represents parentchild relationships. Multiple tree hierarchies may be represented, each identified by a HierarchyType - a classification concept that defines the nature of the hierarchy. For implementation simplicity, a hierarchy is represented in this table as a set of links between each parent and all the child objects beneath it in the hierarchy tree (its transitive closure). The depth of any child object in the tree is determined by the number of parent objects linked to it. This representation makes response to queries that require all kinds (sub types) of a thing (e.g. 'all spatial objects', 'all map units') simple to execute. Currently, each child has only one parent.

\section{Database Table Fields}

- RelationshipID/DataSetID: Compound key that uniquely identifies relationship; see discussion for AttributedRelationship, above.

- TrackingID/TrackingDS: Compound foreign key, link to origin tracking record.

- HierarchyTypeID/HierarchyTypeDS: Compound foreign key, link to ClassificationConcept that identifies the kind of hierarchy. This allows the HierarchyRelationship table to represent multiple concept hierarchies as well as other unrelated hierarchies or part-whole trees.

- ParentID/ParentDS: Compound foreign key, link to the parent object in the relationship.

- ChildID/ChildDS: Compound foreign key, link to the child object in the relationship. 


\section{Simple Relationship Table}

This table is used to represent relationships that link instances of any two objects in which no uncertainty is involved and the relationship has no attributes. Examples include aggregations of parts, and linking SpatialObjects to Cartographic-Objects for symbolization.

\section{Database Table Fields}

- RelationshipID/DataSetID: First part of compound key that uniquely identifies relationship; see discussion for AttributedRelationship, above.

- TrackingID/TrackingDS: Compound foreign key, link to origin tracking record.

- Sequence: Number, long integer. Third part of compound primary key. Orders multiple instances of a single relationship link. Use for ordered aggregation relationship. Domain: Integers $>0$ and $<10^{16}$.

- RelTypeID/RelTypeDS: Compound foreign key, link to classification concept that identifies the kind of relationship. This allows the SimpleRelationship table to represent any relationship that is defined by a ClassificationConcept.

- FirstRoleID/FirstRoleDS: Compound foreign key, link to object that fills the first role in the SimpleRelationship.

- SecondRoleID/SecondRoleDS: Compound foreign key, link to object that fills the second role in the SimpleRelationship.

- Comment: Memo. Contains any additional information about a relationship instance.

\section{Metadata Tables}

\section{Activities Table}

The Activities table is a link to an activity responsible for update of, or addition to, the database. An activity is a particular person, working for a particular organization, under the auspices of a particular project.

\section{Database Table Fields}

- ActivityID/DatasetID: Compound key that uniquely identifies the activity.

- Name: Text, width 255. Provides a unique name identifier for each activity.

- PersonOrgID/PersonOrgDS: Compound foreign key that uniquely identifies the \{person, organization\} tuple associated with the activity. See Table 11 for example values.

- ProjectID/ProjectDS: Compound foreign key that uniquely identifies the project associated with the activity. See Table 12 for example values.
- Comment: Memo. Contains descriptive text about each activity.

\section{Bibliographic Citations Table (AZgeoBibLinkTable)}

The AZgeoBibLinkTable table is derived from the Arizona Geological Survey bibliographic data base (AzGeoBib, Trapp et al. (1996), DataSetID $=4$ in the DataSetAZ table), and provides a mechanism for citing published literature. In this database citations are related to tracking records through the MetadataRelationship table. This derivative table is included to replace links to the full AzGeoBib database.

\section{Database Table Fields}

- AzGeoBibID/DataSetID: Compound key that uniquely identifies the citation in AzGeoBib.

- Authorship: Text, length 255. Author of cited publication. Format: 'Last Name, First Initial.Middle Initial.'; Author names separated by comma, with ', and ' before last author.

- Title: Text, length 255. Title of cited publication.

- Citation: Text, length 255. A text citation for the location of publication.

- Year: Date/Time. Year of publication for citation.

\section{DataSetAZ Table}

The DataSetAZ table is a catalog of the data sets within the Arizona Geological Survey namespace. A data set is any collection of data that is held in an individual file or table. Examples include individual ArcInfo coverages, ESRI shapefiles, tables in Microsoft Access databases, dBase tables in individual .dbf files, and files containing images (e.g. tiff, jpeg). The contents of the DataSetAZ table define the 'Arizona Geological Survey' namespace. This table is analogous to an Open GIS Consortium 'Catalog'. In the more complete metadata implementation, a geographic dataset is associated with map extent, projection, and map horizon objects that define the original geometry of the spatial data.

\section{Database Table Fields}

- DataSetID: Number, long integer. First part of the compound primary key, uniquely identifies data set in the DataSetAZ table.

- NameSpace: Text, width 50. Second part of the compound primary key. Identifies the agency or organization that owns or maintains the data set. Example: 'Arizona Geological Survey'.

- NameSpaceID/NameSpaceDS: Compound foreign key that joins to the ConceptID field of the ClassificationConcept table. There is a 1:1 correspondence between NameSpaceID and values in the NameSpace field; either can serve as the sec- 
Table 11. Example PersonOrg codes used in the Activities Table.

\begin{tabular}{|c|c|c|c|}
\hline Peronbug & Darstin & Personkane & O. \\
\hline 1 & 15 & Dr. Stephen M. Richard & Arizona Geological Survey \\
\hline 2 & 15 & Mr. Tim R. Orr & Arizona Geological Survey \\
\hline 13 & 15 & Mr. Ray C. Harris & Arizona Geological Survey \\
\hline 14 & 15 & Mr. Ray C. Harris & U. S. Bureau of Mines \\
\hline
\end{tabular}

Table 12. Example ProjectID codes used in the Activities Table.

\begin{tabular}{|c|c|l|l|}
\hline Frof & Filet & \\
\hline 1 & 17 & $\begin{array}{l}\text { Arizona NADM implementation } \\
\text { development }\end{array}$ & $\begin{array}{l}\text { Develop NADM 5.2 implementation and use for new geologic } \\
\text { map of Arizona database }\end{array}$ \\
\hline 2 & 17 & $\begin{array}{l}\text { DI-8 Version 3 database } \\
\text { development }\end{array}$ & Construct database with geologic data compiled for Map 35. \\
\hline 4 & 17 & Null & No project assigned \\
\hline 13 & 17 & Statemap 1999 Surficial & Surficial Geologic maps of Avra Valley and Green Valley areas \\
\hline 16 & 17 & $\begin{array}{l}\text { AZ Geologic Map Index database } \\
\text { conversion }\end{array}$ & conversion of DI-9 (AZ Map Index) to new AZ datastructure \\
\hline 20 & 17 & $\begin{array}{l}\text { Statemap 1999, } \\
\text { Roskruge/Waterman Digital Data }\end{array}$ & $\begin{array}{l}\text { Digital geologic information for the Roskruge and Waterman } \\
\text { Mountains }\end{array}$ \\
\hline
\end{tabular}

ond part of the compound key that identifies a DataSet. Both a string value and an numeric value are included to facilitate implementation using the convention adopted for this database system that a data object within a particular namespace is identified by a compound primary key consisting of 2 long integers.

- TrackingID/TrackingDS: Compound foreign key, link to tracking record that records origin of dataset. This tracking record is inherited by records in the data set if they do not have individual tracking records.

- DataSetName: Text, width 255. Uniquely identifies the data set within the NameSpace.

- DataSetTypeID/DataSetTypeDS: Compound foreign key, link to ClassificationConcept that identifies the physical data structure of the data set (e.g. ArcInfo coverage, Microsoft Access table....). See Table 13 for example values.

- DataSetSubjectID/DataSetSubjectDS: Compound foreign key, link to a ClassificationConcept that classifies the data set according to a subject classification term. The subject classification term identifies the domain of interest for the data in the data set. In future implementations, the data set subject will be used for error and consistency checking. A more complete key word index for data sets would need to be implemented through a correlation table (Simple Relationship) allowing a many-to-many join between data sets and subjects. See Table 14 for example values.

- SourceFileTypeID/SourceFileTypeDS: Number, long integer. Classifies each data set by its physical file type or format. It is a foreign key that joins to the ConceptID field of the ClassificationConcept table. Domain: See Table 15.

- PhysicalAddressTypeID/PhysicalAddressTypeDS: Compound foreign key, link to ClassificationConcept that identifies the type of physical address that records where the data set is stored. Example values: $2726=$ DOS-style path name; $2727=$ Microsoft Network file path name.

- PhysicalAddress: Text, width 255. Identifies the actual physical location of the data set.

- IdentifierFieldName: Text, width 50. The name of the field in the DataSet that contains the identifier component of the compound unique identifier for

Table 13. Example data set type codes used in the DataSetAZ table.

\begin{tabular}{|l|l|}
\hline Difold & \\
\hline 2744 & Classification/Description/Definition Dataset \\
\hline 2761 & Generic Attributed Relationship Dataset \\
\hline 2762 & Description Container Dataset \\
\hline 2794 & Geographic Dataset \\
\hline
\end{tabular}


Table 14. Example data set subject codes used in the DataSetAZ table.

\begin{tabular}{|c|l|}
\hline DatasetSubjectiD & \\
\hline 2759 & NADM Implementation Infrastructure \\
\hline 2767 & AZ Cordlink base table \\
\hline 3306 & Graphic Definition Tables \\
\hline 3336 & Roskruge and Waterman Mountains and western Avra Valley \\
\hline
\end{tabular}

Table 15. Example source file type codes used in the DataSetAZ table.

\begin{tabular}{|c|l|}
\hline Soured NeT Neld & Name \\
\hline 2542 & Microsoft Access Database Table \\
\hline 2543 & dBase Table \\
\hline 2544 & ESRI coverage, point \\
\hline 2545 & ESRI coverage, arc \\
\hline 2547 & ESRI coverage, polygon \\
\hline 2548 & AV shapefile, point \\
\hline 2549 & AV shapefile, line \\
\hline
\end{tabular}

each record. The field name is typically the table name or an object type name with 'ID' appended. Identifier field names always end with the string 'ID'.

- DataSetFieldName: Text, width 50. Records the name of the field in the DataSet that contains the data set component of the compound unique identifier for each record. By convention, this field is named 'DataSetID', but some variations occur.

- Comment: Memo. Provides additional descriptive information about each data set.

\section{Metadata Relationship Table}

The MetadataRelationship table is a

SimpleRelationship table that provides a general mechanism for semantic links between metadata instances. A RelType (relationship type) identifier links to a ClassificationConcept that defines the semantics of the relationship. Constraints on kinds of objects that may play the first and second role, and the number of fillers allowed for each role, will eventually be specified by a ValidRelationshipConstraint data structure, but this part of the database is currently being revised and is not described here. This table may be used to implement a many-tomany join between tracking records and citations, project hierarchy (large project with subprojects), organization successor (when an organization changes name), organization aggregation (to represent individual departments as part of a larger organization), StartDate and EndDate links between Person-Organization affiliations and a metadata dates entity, PersonOrg-ContactInformation links to allow multiple contact addresses and types (phone, internet, surface mail...), and Object-LogEntries to allow multiple tracking records to be related to any object, to track revi- sions, comments, etc. See description of SimpleRelationship table for fields in this table.

\section{Tracking Record Table}

The TrackingRecord table keeps a record of the intellectual and physical sources for objects and data by defining links to tables that describe the processes and activities through which data was created. Data objects that have a TrackingID/TrackingDS link are directly linked to a TrackingRecord of TrackingRecordType

'OriginTracking' that provides information on the original source of the object. The TrackingRecord data structure includes a link to an Activity (tuple of person, organization, project) responsible for the tracked event, and a link to a ProcessingMethod that describes the procedure used to represent the feature in digital form. Links to citations for publications relevant to the origin of the information are constructed through a MetaDataRelationship link (see MetadataRelationship table).

Tracking records may also be LogEntries that document updates or comments related to any data object. LogEntry tracking records are linked to data objects using a MetaDataRelationship link, allowing a many-to-many relationship between log entries and data objects.

\section{Database Table Fields}

- TrackingID/DataSetID: Compound primary key, uniquely identifies each record.

- TrackingRecordTypeID/TrackingRecordTypeDS: Compound foreign key, link to ClassificationConcept that identifies the type of tracking record. See Table 16 for example values.

- Name: Text, width 255. Uniquely identifies each origin tracking record and is included for intelligibility.

- LogDate: Date/Time. Records when an entry was created.

- ActivityID/ActivityDS: Compound foreign key, link to Activity in the Activities table that is responsible for the tracked event. See Table 17 for example values.

\section{- DataProcMethodID/DataProcMethodDS:}

Compound foreign key, link to a data processing name and definition in the ClassificationConcept table. A complete data processing object define the steps in developing a particular data item (digitized 
Table 16. Tracking Record Type codes used in the TrackingRecord table.

\begin{tabular}{|c|c|c|}
\hline Concepton & hame & Defrimilon \\
\hline 2534 & Origin Tracking Record & Tracking record that records the origin of a data object or data set \\
\hline 2742 & Log Entry Tracking Record & Tracking record type for tracking records that add information about a data entity \\
\hline 2765 & $\begin{array}{l}\text { Termination Tracking } \\
\text { Record }\end{array}$ & Tracking record that indicates a data object has been supe \\
\hline 3210 & $\begin{array}{l}\text { Feature-level Origin } \\
\text { Tracking Record }\end{array}$ & $\begin{array}{l}\text { Use as supertype to group tracking records that document origin of individual } \\
\text { feature records in data sets. }\end{array}$ \\
\hline 3211 & $\begin{array}{l}\text { Feature-Level Tracking for } \\
\text { D18 V3 }\end{array}$ & $\begin{array}{l}\text { Supertype to group feature tracking records for Geologic map of Arizona Database, } \\
\text { v3 }\end{array}$ \\
\hline 3228 & $\begin{array}{l}\text { Feature-Level Tracking for } \\
\text { Infrastructure Objects }\end{array}$ & Tracking record type for records that track data objects in the infrastructure tables \\
\hline 3231 & Dataset Origin Tracking & $\begin{array}{l}\text { Tracking records that record facts about the origin of a Dataset, and are inherited } \\
\text { by contents of data set unless feature-level tracking is included for data set }\end{array}$ \\
\hline
\end{tabular}

Table 17. Example Activity ID codes used in the TrackingRecord table.

\begin{tabular}{|c|l|l|}
\hline Activin & \multicolumn{1}{|c|}{ Conment } \\
\hline 1 & SMRDataModelDevelopment & $\begin{array}{l}\text { Stephen M. Richard, Arizona Geological Survey, Arizona data model } \\
\text { implementation development }\end{array}$ \\
\hline 2 & SMR-DI8V3DevelopmentActivity & $\begin{array}{l}\text { Stephen M. Richard, Arizona Geological Survey, D1-8 Version 3 database } \\
\text { development }\end{array}$ \\
\hline 4 & Null & No Activity assigned; Null N Null, None, Null \\
\hline 5 & BLMMOSSdigitizeMap26 & $\begin{array}{l}\text { BLM activity to produce MOSS version of Reynolds, 1988, AZGS Map26; } \\
\text { Jason . Brander, Bureau of Land Management, Digitize Geologic Map of } \\
\text { Arizona, using MOSS }\end{array}$ \\
\hline 45 & RCHRoskrugeWatermanDI & $\begin{array}{l}\text { Digitizing, editing, and attribution of geologic information by Ray Harris } \\
\text { from data collected for Statemap 1999 contract; Ray C. Harris, Arizona } \\
\text { Geological Survey, Statemap 1999, Roskruge/Waterman Digital Data }\end{array}$ \\
\hline 82 & PAPRoskrugeWatermanD1 & DI-9 database contributions by Phil Pearthree \\
\hline
\end{tabular}

spatial feature, record in a data table) as an ordered aggregation of 'DataProcessingSteps' (a

MetadataRelationship).

- Description: Memo. Free text description of tracked event, or additional information.

\section{Cartographic Tables}

\section{Cartographic Object Table}

The CartographicObject table is an implementationindependent representation of symbols used to display points, lines, polygons, and text on a map visualization. This is done by defining links to tables that provide implementation-dependent descriptions of graphical objects used for symbolization. Graphical object tables in this database are designed to describe symbology for ArcView 3.2 running in a Microsoft Windows environment.

Individual cartographic objects may consist of several graphical objects stacked according to the sequence attribute in the table, with the lowest sequence symbol overlain by subsequent symbols in the sequence. A CartographicObject defines links to tables that define implementation-specific graphical objects and colors; these tables are not explained here. The DataSetID for the linked tables serves to indicate what sort of graphical element is being specified.

Geologic structure symbols present a special problem, because a standard strike-and-dip symbol is considered to be the same CartographicObject, irrespective of its orientation, and while the same symbol is used for each measurement location (SpatialObject), the symbol is rotated depending on a value (the azimuth) specific to a StructureMeasurement associated with that SpatialObject. SpatialObject must be joined with CartographicObject through an attributed relationship(s) that includes the rotation value as its attribute. The CartoObjType may be used to determine if the symbolization depends on an AttributedRelationship.

\section{Database Table Fields}

- CartoObjID/DatasetID: Compound unique identifier for each Cartographic Object

- TrackingID/TrackingDS: Compound foreign key, link to origin tracking record.

- Sequence: Number, integer. Third part of the compound primary key. Corresponds to the layer order in which graphical elements are created. For example, an ornamented line, such as a line with 
queries, would be created using two layers. The first layer, the line itself, would have a sequence value of 1 , while the second layer, the query symbol, would have a sequence value of 2 . Domain: Integers $>0$ and $<10^{8}$.

- Name: Text, width 255. Uniquely identifies and describes each cartographic object and is included for intelligibility.

- CartoObjTypeID/CartoObjTypeDS: Compound foreign key, link to ClassificationConcept that classifies the graphical element type. It is a foreign key that joins to the ConceptID field of the ClassificationConcept table. See Table 18 for example values.

- GraObjID/GraObjDS: Compound foreign key, link to a specific graphical element. It is a foreign key that joins to the GraObjID field of either the GraphicLine table (GraObjDS $=26$ ), the GraphicLineOrnamented table $(\mathrm{GraObjDS}=412)$, the GraphicPattern table (GraObjDS $=411)$, or the GraphicTextFormat table (GraObjDS $=420$ ) (these tables are not described in this document). See Table 19 for example values.

Table 18. Example cartographic object type codes used in the CartographicObject table.

\begin{tabular}{|c|l|}
\hline Cartowpypd & Name \\
\hline 1957 & Cartographic Object -- point \\
\hline 1958 & Cartographic Object -- line \\
\hline 2392 & Point symbol from font \\
\hline 2393 & Annotation at point \\
\hline 2408 & Fill, solid \\
\hline 2409 & Fill, pattern \\
\hline 3019 & Line, solid \\
\hline 3020 & Line symbol, dash-dot pattern \\
\hline 3021 & Line symbol, ornamented \\
\hline
\end{tabular}

- ColorID/ColorDS: Compound foreign key, link to a specific color defined in a Color table (not described in this document).

- OriginDate: Date/Time. Records when the record was created.

- Comment: Memo. Provides additional descriptive information about a record.

\section{Map Legend Table}

The MapLegend table contains relationship links between a ClassificationConcept and an implementationindependent CartographicObject used to symbolize objects belonging to the class. A particular map legend may contain only one instance of each symbol included, but different symbols may correspond to the same classification concept (e.g. symbols for horizontal, inclined, vertical, and overturned planar bedding). The MapLegend table assigns a Name, Label, and Description for objects of that class which are used to generate the explanation to display on the map. The Sequence field orders items in the legend. Legend items may be present that have no corresponding classification concept; these typically act as headings. The compound key for the MapLegend table is the tuple \{MapLegendID, DataSetID, Sequence\}.

Hierarchy in the legend is represented by a

HierarchyRelationship with RelTypeID = MapLegendID.

\section{Database Table Fields}

- MapLegendID/DataSetID: First parts of compound key for each MapLegend object.

- TrackingID/TrackingDS: Compound foreign key, link to origin tracking record.

- Sequence: Third part of compound primary key. Orders records with the same MapLegendID/DataSetID values within a legend display.

Table 19. Example graphic object codes used in the CartographicObject table.

\begin{tabular}{|c|c|l|}
\hline Gra ObjII & GrabjoS & \\
\hline 11 & 26 & thick line $(1.5 \mathrm{pt})$, solid \\
\hline 7 & 26 & medium line $(0.5 \mathrm{pt})$, dash-dot \\
\hline 10 & 26 & thick line $(1.5 \mathrm{pt})$, standard medium dash \\
\hline 20 & 26 & medium line $(0.75 \mathrm{pt})$, dotted \\
\hline 14 & 411 & cross hatch, lines at $30^{\circ} 90^{\circ}$ and $150^{\circ}$, separation $=4 \mathrm{pt}$. \\
\hline 33 & 411 & vertical hatch, separation $=1$ pt. \\
\hline 0 & 411 & Null Pattern \\
\hline 2 & 412 & Query \\
\hline 3 & 412 & Perpendicular hash \\
\hline 4 & 412 & X pattern \\
\hline 6 & 420 & Arial, Normal, Spacing: 1, JUST_LEFT, 11 point \\
\hline 12 & 420 & AzGSArial, Normal, Spacing: 1, JUST_LEFT, 7 point \\
\hline 19 & 420 & Arial, Bold, Spacing: 1, JUST_LEFT, 7 point \\
\hline
\end{tabular}


- ConceptID/ConceptDS: Compound foreign key, link to classification concept that is symbolized by the associated cartographic object in this table.

- CartoObjID/CartoObjDS: Compound foreign key, link to CartographicObject that specifies the symbolization for spatial objects classified to the associated ConceptID for this legend item.

- DispPriority: Long Integer. A priority number that allows the user to specify the order in which objects are drawn when the map is displayed. Objects with larger numbers are drawn on top of, and may hide, objects with smaller numbers.

- DispVisibility: Text, width 1. Determines whether or not a symbol is displayed in the legend. Domain ' $\mathrm{Y}$ ' (the symbol is displayed in the legend); ' $\mathrm{N}$ ' (the symbol remains hidden from view when the legend is displayed).

- ClassName: Text, width 255. The name for the geologic feature represented by the cartographic object (CartoObjID) in this MapView. This is the name associated with the symbol in the map legend graphic.

- ClassLabel: Text, width 16. The label to use in the map display to identify the geologic feature represented by the cartographic object (CartoObjID) in this MapView.

- ClassDesc: Memo. A text block for use in the map legend display that describes the geologic feature represented by the cartographic object (CartoObjID) in this MapView. Generally this description will correspond to the ConceptID that the symbol represents, modified by location and identification accuracy values from the classification scheme.

- OriginDate: Date/Time. Automatically filled with the date and time this record was added to the database.

\section{Map View Definition Table}

The MapViewDefinition table defines a Title, Description, Extent, Projection, DesignScale, MapHorizon, ClassificationScheme and MapLegend to use for a particular MapView. A MapView is a collection of SpatialObjects within a bounded area (the Extent), classified using a particular ClassificationScheme, and symbolized using a particular MapLegend. The MapView does not necessarily use all the items in the MapLegend, or all the SpatialObjects classified under the

ClassificationScheme. Every ClassificationConcept in the ClassificationScheme that is related to a Spatial-Object included in the MapView must have a CartographicObject assigned by the MapLegend associated with the MapView.

SimpleMapView - All SpatialObjects symbolized in the MapView are entirely within the MapExtent, and the set of CartographicObjects in the MapLegend is the same as the set of Cartographic-Objects used to symbolize spatial objects in the view.

GeneralMapView - SpatialObjects may come from different DataSets that may have extents different from the MapView extent, and the MapLegend may include Cartographic-Objects not used in the MapView. SpatialObjects symbolized in the MapView must be clipped to the MapExtent, and the MapLegend must be filtered to select only the items that appear in the MapView.

The ViewSchemeType in the MapViewDefinition table determines how the MapView is constructed. In addition to specifying if the view is a GeneralMapView or SimpleMapView, the ViewSchemeType also varies along a second dimension based on how the link between Cartographic-Objects and SpatialObjects is defined, as follows:

DefaultMapView - Represents a default visualization of a geologic data set. Default ClassificationConcepts, CartographicObjects, necessary CartographicObject attributes (e.g. rotation for strike-and-dip symbols) and featurelinked annotation (polygon labels, dip values) are assigned using fields embedded in the SpatialObject tables.

SimpleRelationship aggregates the DataSets containing the SpatialObjects through a simple relationship of type MapViewID; sequence attribute establishes display order for DataSets. All DataSets contain data within the same MapExtent. The MapLegend can be produced through a query that returns the union of unique

ClassificationObject/CartographicObject pairs included in the records for all Spatial-Objects represented in the view. MapLegendID and ClassSchemeID are not required, but a predefined MapLegend is necessary to structure the MapLegend display, display order, and explanatory name, label and text (ClassName, ClassLabel, ClassDesc) for features; otherwise the default legend layout for the particular GIS implementation will be used.

DirectMapView - MapViewID is a RelationshipType for a SymbolizationScheme Relationship linking SpatialObject with CartographicObject, and MapLegendID identifies the appropriate Map-Legend objects. All CartographicObjects used must be included in the MapLegend. The ClassificationSchemeID link in the MapViewDefinition identifies the classification scheme used as the basis for assigning symbols to spatial objects. The direct scheme is necessary for individually varying symbolization (e.g. structure symbols), and also allows for map generalization in which an object classified in the same way may be symbolized differently.

NADM43MapView - SpatialObjects are linked with ClassificationConcepts through a ClassificationScheme specified by the MapViewDefinition, and ClassificationConcepts are linked with CartographicObjects through the MapLegend. Assignment of CartographicObjects to Spatial-Objects requires two joins, and the ClassificationConcepts used are conceptually equivalent to Cartographic-Objects because, in order to 
symbolize an object differently, it must be classified differently. Thus, in order to rotate structure symbols to the correct display azimuth, ClassificationConcepts for each azimuth must be generated, or the azimuth attribute of the data to symbolize must be propagated from the structural measurement table, through the SpatialObject, ClassificationScheme link (Spatial-Object-Classification), and MapLegend link (Classification-CartographicObject).

\section{Database Table Fields}

- MapViewID/DataSetID: First parts of compound key for each MapView object.

- TrackingID/TrackingDS: Compound foreign key, link to origin tracking record.

- Title: Text, length 255. Records the title displayed on the map view.

- Author: Text, length 255. Records the authorship displayed on the map view. For views that attempt to duplicate a published map, this would be the original authorship of the published map.

- PublicationDate: Date/Time. Records the date of creation of the map view. For views that attempt to duplicate a published map, this would be the original date of map publication.

- Description: Memo. Text description of the map. Could be used to store text blocks for display on the map layout. Should describe purpose of map.

- DesignScale: Number, Long Integer. Records display scale for which map view has been designed. The number is the denominator of the scale fraction. For example, if the map is designed for display at $1: 24000$, this field would contain the value '24000'.

- CatalogLinksDatsetID: Number, Long Integer. Identifier for a simple relationship data set (in DataSetAZ catalog table) that contains set of links of type 'MapView components', linking the MapViewID with the DataSetID's for all data sets required to construct the MapView. This aggregation must identify at least the data sets containing spatial data used by the map view, and the relationship tables that contain classification and symbolization links.

- ExtentID/ExtentDS: Compound foreign key, link to an Extent object (in an Extents metadata table) that defines the boundary of the geology displayed in this map view.

- ProjectionID/ProjectionDS: Compound foreign key, link to a projection in a Projection metadata table (not described in this document). The projection describes the mapping between a non-planar map horizon and the planar map view surface.

- MapHorizonDesc: Memo. Description of the map horizon, which is the physical surface that contains the geologic features displayed on this map view. Domain: Free text.
- MapHorizonID/MapHorizonDS: Compound foreign key, link to MapHorizon record in a MapHorizon metadata table (not described in this document). This link defines the base map and representation of the 3-D geometry of the physical surface represented by the map view.

- MapLegendID/MapLegendDS: Compound foreign key, link to the MapLegend aggregation in the MapLegend table. The MapLegendID serves as the filter for selecting ClassificationConceptCartographicObject links, and identifies the symbols used in the map view.

- ViewSchemeTypeID/ViewSchemeTypeDS: Compound foreign key, link to the classification concept that defines how symbols are assigned to spatial objects for this map view. Domain: $2785=$ NADM4.3 type (spatial object-classification, classification-symbol); $2786=$ MapLegend and Direct (spatial object-symbol through relationship table); and $3364=$ Default (spatial object-symbol through attribute in native spatial object table).

- ClassSchemeID/ClassSchemeDS: Compound foreign key, link to the ClassificationConcept that represents a collection of AttributedRelationship links between spatial objects and classification concepts that assign geologic significance to spatial objects. This value is used as the RelationshipType to select the relevant classification links.

- OriginDate: Date/Time. Extra information field automatically filled with the date and time this record was added to the database.

\section{Acknowledgements}

This database design has been developed over several years with the help of J.P. Thieme and S.M. Kneale. Discussions with Boyan Brodaric, Jon Matti, Gary Raines, and Bruce Johnson have sharpened my thinking and helped develop ideas for this design.

\section{REFERENCES}

Bernknopf, R. L., Brookshire, D. S., Soller, D. R., McKee, M. J., Sutter, J. F., Matti, J. C., and Campbell, R. H., 1993, Societal Value of Geologic Maps: Washington, D.C., U. S. Geological Survey Circular 1111, 53 pages.

Brodaric, B., 2000, Digital Geological Knowledge: From the Field to the Map to the Internet, in Soller, David R., Ed., Digital Mapping Techniques ' 00 - Workshop Proceedings, U. S. Geological Survey Open-File Report 00-325, p. 3-12, <http://pubs.usgs.gov/openfile/of00-325/brodaric.html>.

Brodaric, B., and Gahegan, M., 2000, Geoscience Map Data Models, Open Systems GIS and Semantics, Proceedings, GeoCanada2000-The Millennium Geoscience Summit, Calgary, Alberta, p. 7. available at <http://www.gisworld.org/gac-gis/2000/1147.pdf>, Accessed June 14, 2001. 
Brodaric, B. and Hastings, J., 2001, Evolution of an ObjectOriented, NADM-Based Data Model Prototype for the USGS National Geologic Map Database Project [web page, abstract]: Annual Conference of the International Association for Mathematical Geology, IAMG2001, Cancun, Mexico, Available at <http://www.kgs.ku.edu/ Conferences/IAMG/Sessions/I/brodaric.html>, Accessed June 14, 2001.

Brodaric, B., Journeay, M., Talwar, S., and others, June 18, 1999 , CordLink Digital Library Geologic Map Data Model Version 5.2 (Web Page), Available at <http://cordlink.gsc.nrcan.gc.ca/cordlink1/info_pages/ English/dm52.pdf>, Accessed June 13, 2001.

Johnson, B. R., Brodaric, B., and Raines, G. L., 1998, Digital Geologic Maps Data Model, V. 4.3 (Web Page): Available at <http://ncgmp.usgs.gov/ngmdbproject $>$, U. S. Geological Survey.

Palmer, A.R., compiler, 1983, The Decade of North American Geology 1983 Geologic Time Scale: Geology, v. 11, no. 9, p. 503-504.

Reynolds, S. J., Florence, F. P., Welty, J. W., and others, 1986, Compilation of Radiometric Age Determinations in Arizona: Tucson, Arizona Bureau of Geology and Mineral Technology Bulletin 197, 258 pages.

Richard, S. M., 2000, Proposal for Authorship and Citation Guidelines for Geologic Data Sets and Map Images in the Era of Digital Publication, in D.R. Soller, ed., Digital Mapping Techniques 2000-Workshop Proceedings: U.S. Geological Survey Open-File Report 00-325, p. 159-168, <http://pubs.usgs.gov/openfile/of00-325/richard.html>.

Richard, S. M. 1999, Geologic concept modeling, with examples for lithology and some other basic geoscience features, in D.R. Soller, ed., Digital Mapping Techniques 1999Workshop Proceedings: U. S. Geological Survey Open-File
Report 99-386, p. 59-75, <http://pubs.usgs.gov/openfile/ of $99-386 /$ richard.html $>$.

Richard, S. M., 1998, Digital Geologic Database Model (Web Page): Available at <http://www.azgs.state.az.us/ GeoData_model.pdf>, Accessed June 13, 2001.

Richard, S. M., and Thieme, J. P., 1997, Data structure for Arizona Geological Survey digital geologic maps: Tucson, Arizona Geological Survey Open-File Report 97-5, 15 p.

Soller, D. R., 1997, Proceedings of a Workshop on Digital Mapping Techniques: Methods for Geologic Map Data Capture, Management, and Publication, Lawrence, KS: U.S. Geological Survey Open-File Report 97-269, 120 p., $<$ http://pubs.usgs.gov/openfile/of97-269/>.

Soller, D. R., 1998, Digital Mapping Techniques '98 Workshop Proceeding, Champaign, IL: U.S. Geological Survey Open-File Report 98-487, 134 p., $<$ http://pubs.usgs.gov/openfile/of98-487/>.

Soller, D. R., 1999, Digital Mapping Techniques '99 Workshop Proceedings, Madison, WI: U.S. Geological Survey Open-File Report 99-386, 190 p., $<$ http://pubs.usgs.gov/openfile/of99-386/>.

Soller, D. R., 2000, Digital Mapping Techniques '00 Workshop Proceedings, Lexington, KY: U.S. Geological Survey Open-File Report 00-325, 210 p., $<$ http://pubs.usgs.gov/openfile/of00-325/>.

Trapp, R. A., and Reynolds, S. J., 1998, Physiographic areas in Arizona used by the Arizona Geological Survey: Tucson, Arizona Geol. Survey, Digital Information Series DI-10, 4 pages, 1 floppy disc.

Trapp, R. A., Schmidt, N., and Reynolds, S. J., 1996, AZGEOBIB, Version 2.1: A List of References on the Geology of Arizona: Arizona Geological Survey Open-File Report OFR-96-01, p. 308. 


\title{
Geology of the Cretaceous West Gulf Coastal Plain in Southwestern Arkansas
}

\author{
By William D. Hanson and Daniel K. Smith \\ Arkansas Geological Commission \\ 3815 West Roosevelt Road \\ Little Rock, AR 72204 \\ Telephone: (501) 296-1877 \\ Fax: (501) 663-7360 \\ e-mail: doug.hanson@mail.state.ar.us
}

Cretaceous units in southwestern Arkansas are currently being mapped under the National Cooperative Geologic Mapping Program-STATEMAP Project number 1434-94-A-1223. Twenty-two 7.5-minute quadrangles have been mapped to date. By July 1, 2001 seven more maps will be completed. Next fiscal year (2001-2002), the Onia and Fifty-Six quadrangles in north-central Arkansas will be mapped. ArcView 3.2 and Canvas 6.0 are used to create the digital maps. Paper copies of these maps are available from the Arkansas Geological Commission as Open-File Reports. Geologic worksheets, geologic maps reduced to $1: 48,000$, are being produced from digitized geologic maps. Each will have a brief lithologic description of the units on the back of each sheet.

Cretaceous rocks of the West Gulf Coastal Plain in southwestern Arkansas consist of the Lower Cretaceous
Trinity Group, which includes the Dierks Limestone Lentil and DeQueen Limestone Member, and the Upper Cretaceous Woodbine Formation, Tokio Formation, Brownstown Marl, Ozan Formation, Annona Chalk, Marlbrook Marl, Saratoga Chalk, Nacatoch Sand, and Arkadelphia Marl. The Trinity Group consists of sand, clay, limestone, gravel, and gypsum, while the Upper Cretaceous units consist of sand, clay, marl, chalk, and water-laid volcanic tuff. These units are primarily sedimentary in origin and were deposited in a near-shore marine environment. Most of these formations are bounded by unconformities. Lower Cretaceous units strike eastwest and dip to the south approximately 80-100 feet per mile. Upper Cretaceous units strike northeast-southwest and dip to the south approximately 80 feet per mile. 
190 


\title{
GIS May Make Maps Fast: But Cartography is Still an Art!
}

\author{
By William S. Schenck ${ }^{1}$ and Nicole M. Minni ${ }^{2}$ \\ ${ }^{1}$ Delaware Geological Survey \\ University of Delaware \\ Delaware Geological Survey Building \\ Newark, DE 19716-7501 \\ Telephone: (302) 831-8262 \\ Fax: (302) 831-3579 \\ e-mail: rockman@udel.edu \\ ${ }^{2}$ Water Resources Agency \\ University of Delaware \\ Paradee Center \\ 69 Transportation Circle \\ Dover, DE 19903 \\ Telephone: (302) 735-8204 \\ Fax: (302) 735-8203 \\ e-mail: nminni@udel.edu
}

\begin{abstract}
Cartography and cartographers alike are evolving and trying to adapt to the new GIS technology. I would suggest to you that cartography has been evolving since its beginnings 2000 years ago and possibly even earlier if evidence could be found. "Mapping" began when the first humans tried to document their surroundings. The middle centuries were the true beginnings of what we all think of as maps. The realization that the world wasn't flat and the development of the Cartesian coordinate system led to an increasingly more correct representation of the geography of the Earth. During this time maps were truly considered "Artwork" and in fact most "cartographers" of the day were artists of great fame. We now refer to these maps as "Old World maps," filled with art and artwork and not very accurate by today's standards.

In the middle 1800 s we began to use "aerial photography" to help produce maps. These "birdseye" views began as artists produced lithographs after ascending in hot air balloons. In the early 1900 s the aircraft provided the platform needed to get accurate "birdseye" views using what we recognize now as aerial photographs. But even with these more accurate views, cartography still required the human (artistic) touch.
\end{abstract}

We are getting more and more remote views of our planet and we have different electronic sensors that satellites use as well as photos taken by astronauts to help us get an even better understanding of the spatial layout of our planet. Satellite technology has propelled map making forward at a shocking pace, leaving many true cartographers behind. Now we have to know GIS to create maps, but there is still a portion of this craft that is art based.

Today all kinds of data can be mapped using GIS technology. We can perform massively complicated computations on spatial data and produce a graphic, geospatial result that most of us still would call a map. These maps have a different "look" to them and many of us are willing to make concessions and accept this new type of digital map; however, I would tell you that at the present time, the art of Cartography is still very much alive, especially in the area of thematic maps and especially those that get published.

In January 2001, the Delaware Geological Survey published the new Bedrock Geologic Map of the Piedmont of Delaware and Adjacent Pennsylvania (Plank and others, 2000; Schenck and others, 2000). This is the first geologic map that the Survey has produced totally in a digital environment. Most of the problems encountered producing this map began when we started using GIS (ArcInfo) to do 
"cartography". Moving the map into Adobe Illustrator and completing the map in that environment solved many of these problems.

Cartography is evolving once more and eventually researchers and people alike will accept the "look" of a plotter printed graphic map allowing cartography to move into the 21 st century and beyond. When future researchers look at this map, they will likely say, "this map was produced when cartography was still an art!

\section{REFERENCES}

Plank, M. O., Schenck, W. S., Srogi, L., 2000, Bedrock Geology of the Piedmont of Delaware and Adjacent Pennsylvania: Delaware Geological Survey Report of Investigation No. 59, 52p., 1 Plate.

Schenck, W. S., Plank, M. O., and Srogi, L., 2000, Bedrock Geologic Map of the Piedmont of Delaware and Adjacent Pennsylvania: Delaware Geological Survey Geologic Map Series No. 10, Scale 1:36,000. 


\title{
Illinois 1998/1999 Digital Orthophoto Quadrangles: Recent Additions to the Illinois Natural Resources Geospatial Data Clearinghouse
}

\author{
By Sheena K. Beaverson and Christopher S. McGarry \\ Illinois State Geological Survey \\ 615 E. Peabody Dr. \\ Champaign, IL 61820 \\ Telephone: (217) 244-9306 \\ Fax: (217) 333-2830 \\ e-mail: beavrsn@isgs.uiuc.edu
}

\begin{abstract}
State and federal agencies entered into a joint funding agreement with the U. S. Geological Survey (USGS) to purchase the full set of Digital Orthophoto Quadrangles (DOQs) for Illinois. The State of Illinois, through the Illinois State Geological Survey (ISGS), is receiving only one set of these data as the contracted deliverable. These DOQs are based on 1998/1999 aerial photography that has been registered to map coordinates (Beaverson and Krumm, 2000). The DOQ data set includes over 4,100 45megabyte files, about 210 gigabytes of data, on $\mathrm{CD}$ ROMs. The ISGS obtained external funding to support image enhancement and metadata extraction using the EASI/PACE Image Processing software and file compression using MrSID software, and to distribute data files online, free of charge, at the Illinois Natural Resources Geospatial Data Clearinghouse <http://www.isgs.uiuc.edu/ nsdihome $>$. Compressed image files are roughly 3 megabytes in size and can be viewed with standard GIS software, image manipulation software, or with a webenabled viewer. Approximately $70 \%$ of the Illinois DOQ map images have been received, processed, archived and made available for download; DOQ shipments will be complete by the end of 2001 .

Compressed files are accessible on-line through a simple, text-based, tabular download interface and a map-driven interface using ArcIMS software. The ArcIMS map service, a third place winner of the 2001 Geography Network Challenge <http://www.geographynetwork.com>, provides real-time image display, project status, and file download
\end{abstract}

capabilities (Figure 1). The goal of the DOQ processing and delivery system is to make this dataset available to as many people as possible. A casual user, such as a property owner, can simply use a web browser to view the area of interest and print a copy of the image displayed on-screen. Government employees or commercial users can view and download the DOQ file for use in engineering or mapping applications. Also, because the online image display interface is served using ArcIMS software, GIS professionals using ArcGIS will be able to directly connect to the database and display the imagery without downloading the files. The Illinois 1998/1999 DOQ data set constitutes the most comprehensive up-to-date, large-scale geographic base data set available for the state. Historically, DOQ data access has been difficult due to large file sizes and limited choices of projection. By implementing a robust delivery system, the taxpayers of the state of Illinois are provided with unprecedented access to these valuable DOQ data.

\section{REFERENCES}

Beaverson, S.K. and Krumm, R.J., 2000, Illinois State Geological Survey Web-Based Resources: The Illinois Natural Resources Geospatial Data Clearinghouse and the ISGS internal GIS Resources Web, in D.R. Soller, ed., Digital Mapping Techniques ' 00 - Workshop Proceedings: U.S. Geological Survey Open-File Report 00-326, p.141-145, <http://pubs.usgs.gov/openfile/of00-325/beaverson.html>. 


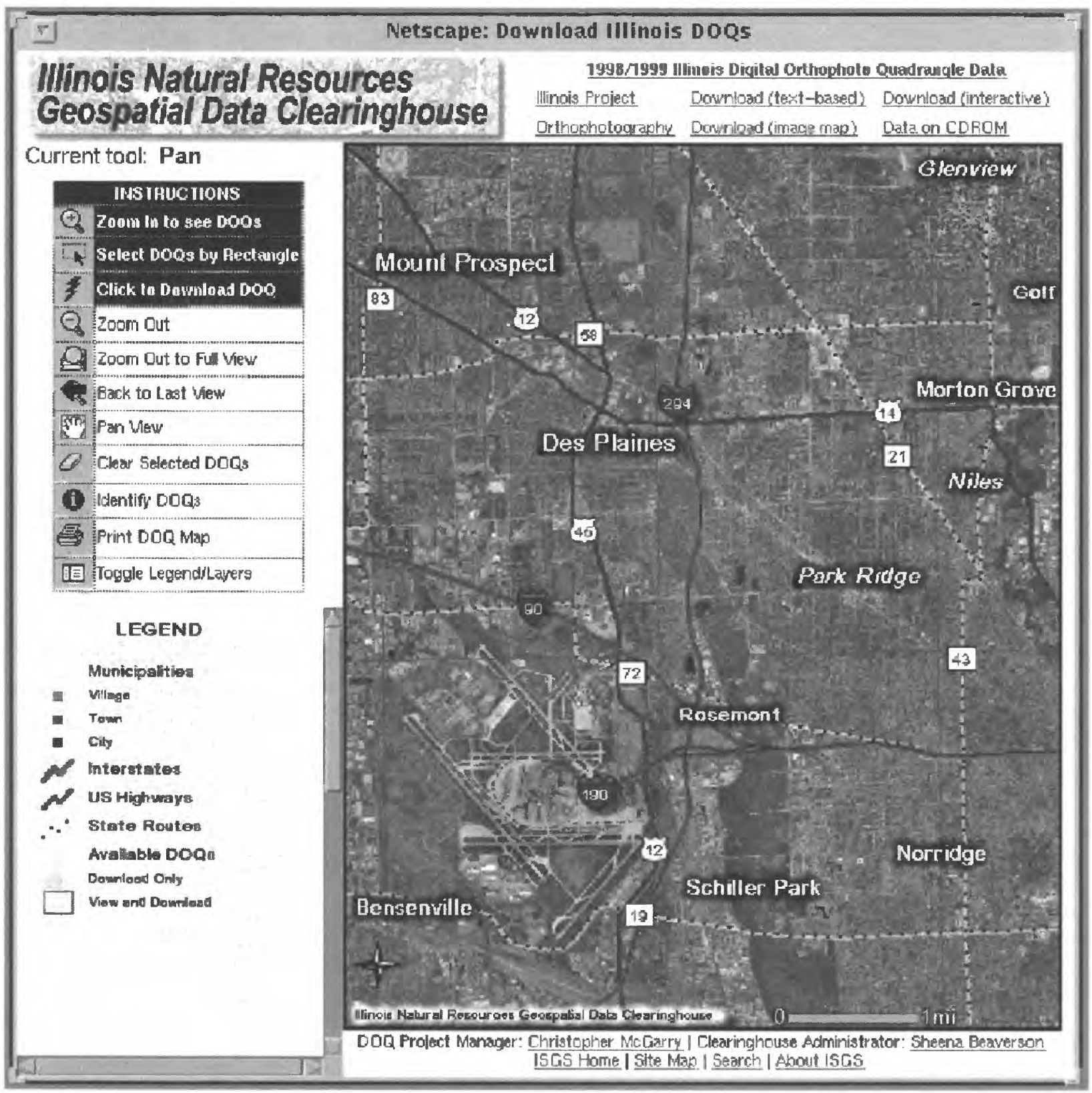

Figure 1. Interactive map interface for viewing and downloading DOQ files for Illinois at $<$ http://www.isgs.uiuc.edu/nsdihome/webdocs/doqs/launchims.html $>$. 


\title{
Making Improved Geotechnical Maps with Spatial Analysis
}

\author{
By Steven L. Martin \\ Kentucky Geological Survey \\ University of Kentucky \\ 228 Mining and Mineral Resources Building \\ Lexington, KY 40506 \\ Telephone: (859) 257-5500 \\ Fax: (859) 257-1147 \\ e-mail: smartin@kgs.mm.uky.edu
}

Geologic maps of McCracken County in the Jackson Purchase Region of western Kentucky show a wide variety of unconsolidated to moderately consolidated materials. These materials consist of unconsolidated silt, clay, sand, and gravel of alluvial, lacustrine, and loessal origin; poorly consolidated sandy, clayey continental gravel; and poorly to moderately consolidated sand, lean to plastic clay, and mixtures of interlayered silt, sand, and clay deposited in lacustrine and near-shore deltaic environments. This region is known to be susceptible to a number of geotechnical problems in response to natural phenomena such as springs, erosional agents (flooding and landslides), and earthquakes. Previous studies have shown relationships between geologic map units and geotechnical behavior. These studies include field and laboratory investigations that predict behavior of lithologic units when disturbed by engineering and construction practices, as well as the behavior of lithologic units in response to natural phenomena. Traditional geotechnical maps have been reclassifications of geologic map units based on similar rock types and engineering properties. Improved geotechnical maps will be produced using one or more of the following geospatial techniques:

1) comparing geologic map units to surface slope

2) comparing geologic map units to subsurface horizons using geophysical and borehole analysis

3) using remote sensing to detect properties of geologic map units

4) analyzing geotechnical test results in the context of geologic map units.
To enhance the usability of our maps, a database of geotechnical information will be included. This database will contain information about geotechnical materials, their properties, how these materials might behave, and how they might affect man-made structures under certain conditions. It is our goal to build a database that relates geologic factors to engineering problems. For example, the most common unconsolidated to poorly consolidated material in the area is silt and clay. An important property of this material is moisture content. If the moisture content is high, its slope stability is poor, and this will affect structures such as roads and buildings (Finch, 1968; Nichols, 1968). Also exposed in the area is a moderately consolidated, plastic clay formation. This clay's mineral composition, specifically, calcium montmorillonite, is an important property. When exposed, the clay desiccates, producing a volume change, thus affecting slope stability (Finch, 1968; Nichols, 1968). In the future, we hope to develop a system in which the user can select a formation, and have a choice of information to choose from (lithologic, geotechnical, geohazard, economic, etc.) (Fig. 1). This information would not replace site investigations, but could assist in engineering or construction planning.

\section{REFERENCES}

Finch, W.I., 1968, Engineering geology of the Paducah West and Metropolis quadrangles in Kentucky: U.S. Geological Survey Bulletin 1258-B, 19 p.

Nichols, T.C., Jr., 1968, Engineering geology of the Paducah East quadrangle in Kentucky: U.S. Geological Survey Bulletin 1258-A, $13 \mathrm{p}$. 


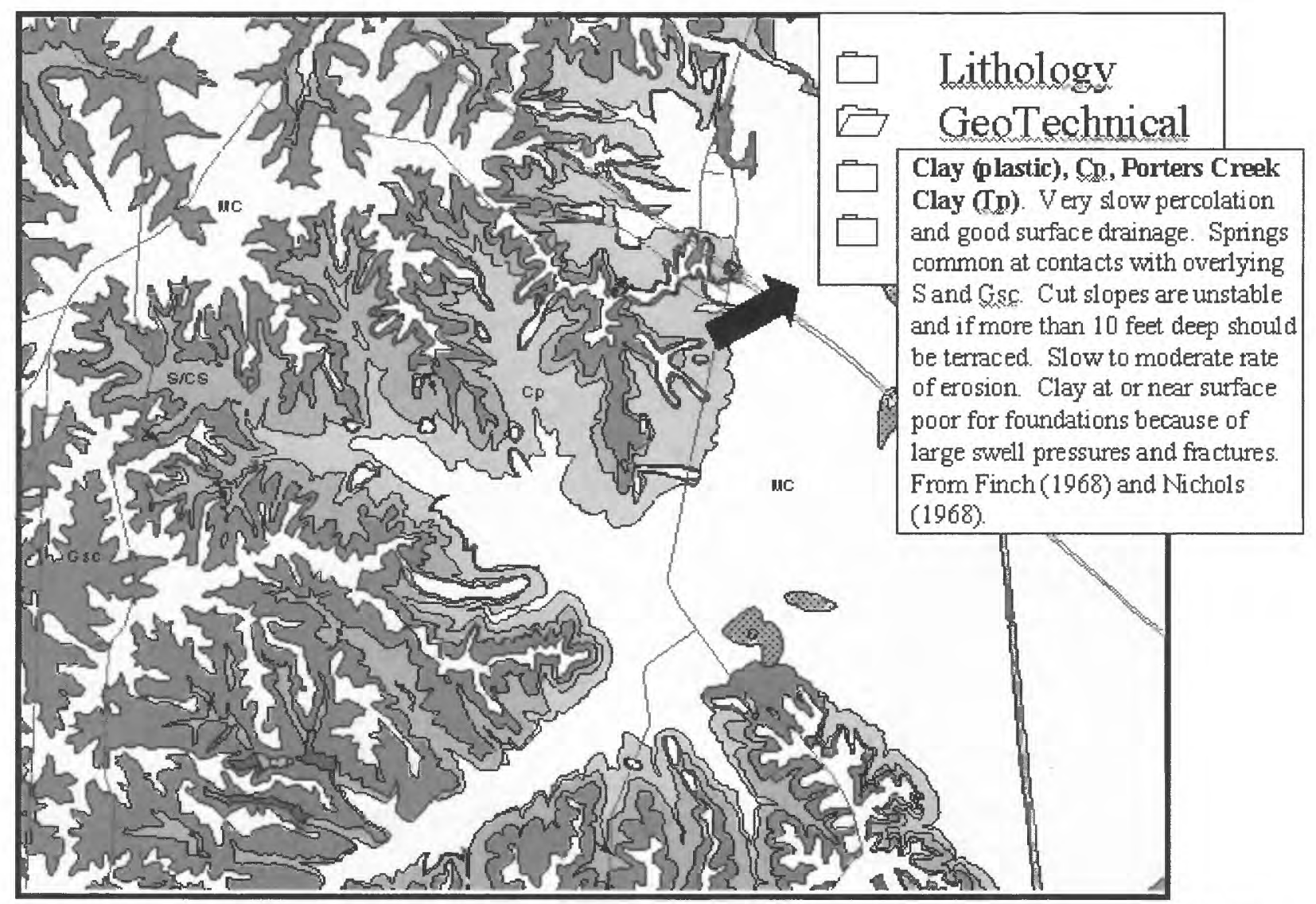

Figure 1. Geotechnical map of part of McCracken County showing information related to a geotechnical unit. $\mathrm{MC}=$ silt and clay (light gray). $\mathrm{Cp}=$ plastic clay (gray). $\mathrm{S} / \mathrm{CS}=$ sand/clayey sand (medium gray). Gsc=gravel,sand, and clay (dark gray). G=gravel (gray stipple). Location of local roads and fractures also shown. 


\title{
GIS Data Compilation Techniques for Mapping the Geology of the Fort Polk Region of Louisiana
}

\author{
By R. Hampton Peele and Richard P. McCulloh \\ Louisiana Geological Survey \\ Louisiana State University \\ Baton Rouge, LA 70803 \\ Telephone: (225) 578-5320 \\ Fax: (225) 578-3662 \\ e-mail: hampton@1su.edu,mccullo@1su.edu
}

For the map area of the Fort Polk region in western Louisiana (figure 1), the nonalluvial contacts of the surface geology were mapped from field work, at 1:24,000-scale, in the context of previous work; whereas, alluvium, underlying a continuous network of low-relief bottomland landforms, was interpreted principally from topographic maps. Economic geology was mapped from field work; and geologic hazards, comprising only flood zones, were recompiled from Federal Emergency Management Agency data. The surface geology is represented with polygons, except for faults, which are lines in a separate GIS layer. The economic geology is a mixed representation of polygons and points, in separate layers. The geologic hazards are represented with polygons. The study area encompasses the Fort Polk Military Reservation and Peason Ridge Military Installation in west-central Louisiana.

\section{OVERVIEW OF GIS METHODS}

\section{Software}

The digitizing effort was performed with the Direction Trace Line String function of INTERGRAPH'S GEOVEC software. GEOVEC runs on top of Bentley's MicroStation and INTERGRAPH'S Base Imager; and it employs the MicroStation Feature Collection System. Topology was built, using ESRI's ArcInfo. The final GIS was assembled, within the ESRI ArcView environment.

\section{Process}

\section{Intergraph}

The initial digitizing effort consisted of three phases:

1. Initially, all lines were digitized from scans of the

Vellum and Mylar sheets, then smoothed and filtered.
2. Circles were placed, as flags, to indicate where digitizing errors had been made.

3. Corrections were made where the flags had been placed; and the flags were removed.

Once the digitized lines had been corrected, the line cleaning process began. These tasks were all performed within the INTERGRAPH MGE environment. First, Duplicate Line Processor was run on each file of digitized linework. Duplicate Line Processor eliminates all duplicate lines and breaks all line intersections.

Each quadrangle of digitized linework was georeferenced using the Control Point Setup function of INTERGRAPH's MGE software. All eight control points, at 2.5-minute intervals, were used for each quad as we georeferenced them in the Louisiana ("State Plane")

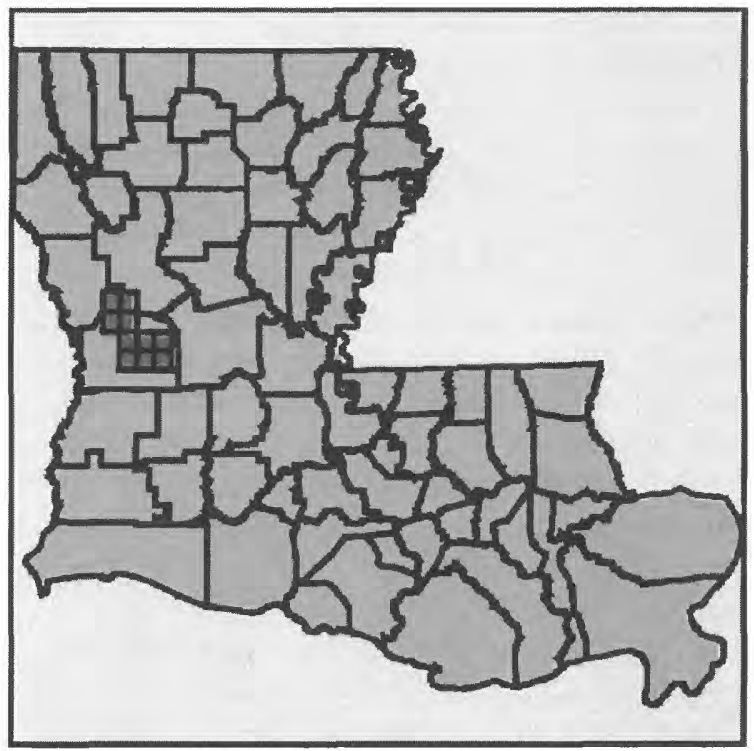

Figure 1. Study area, western Louisiana. 
Coordinate System, North Zone, as referenced to the North American Datum (NAD), 1927.

Each digital quad file was converted into the Universal Transverse Mercator coordinate system, as referenced to the World Geodetic System (WGS), 1984, to satisfy the specifications of the U.S. Army Corps of Engineers. For quality assessment of the georeferencing process, we generated a graticule in the UTM coordinate system and overlayed it with the converted files. The graticule was created by using the Grid Generation function of INTERGRAPH's MGE software.

After the alluvium and nonalluvium quads were overlayed, the composite linework was edited to show the alluvium occluding the other surface-geologic units, as it does in reality. Full-scale color plots were made for the geologists to review. The results of the reviews by the geologists were Mylar sheets of both the lines to be added and the lines to be deleted. The lines to be added were digitized, cleaned, georeferenced and overlayed with the alluvium and nonalluvium. Then flags were placed around the digital lines that were to be deleted. After these edits had been made the edgematching process began.

In order to achieve a seamless mosaic we planned to use the graticule, instead of the digitized quad boundaries, for the final GIS geologic quadrangle boundaries. The edgematching process began by creating a new blank design file of the same projection, overlaying it with all of the design files for each of the ten quadrangles, turning on all layers in all files, and performing a fence copy of all the linework into the new blank design file. The linework and the graticule were merged into a mosaic; and edgematching was performed, all using MGE. MGE's End Point Processor was used to flag all dangling ends for the alluvium and nonalluvium layers. All other layers were turned off, including the quad boundaries. And, with the interactive guidance of the geologists, the contacts were manually edgematched.

From this master mosaic design file, only the alluvial and nonalluvial contacts, the faults, and the graticule, for the individual quad areas were fence-copied into ten new UTM, WGS84 design files. After running the Duplicate Line Processor on each of these ten new design files, there were no duplicate lines, and intersections had been broken where the contacts and faults crossed the graticule. Finally, the short segments outside the graticule were deleted from each of these new digital quads, completing the line-development process. The next task was to create topology.

\section{ArcInfo}

We used ArcInfo's IGDStoARC translator to translate the final ten INTERGRAPH design files into ArcInfo coverages. We then used the "Build" command in ArcInfo to construct polygon topology from the contact lines. Sometimes the process failed, indicating that some duplicate lines still remained in the digital quad. In such classes, MGE's Duplicate Line Processor was run again on the final design file, before attempting to translate again and build topology.

\section{ArcView}

Once polygon topology was constructed for the ArcInfo coverages, they were then translated into ArcView shapefiles, by simply "Adding" them to an ArcView View window and "Converting" them into ArcView shapefiles. The database for each shapefile was populated with attributes within ESRI's ArcView software. After populating the database with geologic-unit abbreviations, we sorted the "Area" field into ascending order, smallest to largest, to facilitate finding any slivers that might exist. These slivers were "Unioned" with adjacent unit polygons, one by one, in ArcView. Finally, customized hues were created in ArcView for each geologic unit type. ArcView could then automatically render all the unit polygons, for each of the ten shapefiles, by reading the unit abbreviations within each shapefile database. After completing the population of the databases with feature attribute records and performing final quality assurance tasks, the data development was complete.

\section{MAP COMPILATION PROCESS}

\section{Alluvial Linework}

We drew the alluvial linework on Vellum, overlaying USGS 1:24,000 quadrangle maps (figure 2). This technique was a continuation of our methodology from previous non-GIS projects. We completed this component long before completion of the field mapping of the other units.

\section{Nonalluvial Linework}

In the field, we put notes directly on standard topographic quadrangles, corresponding to the localities where we found exposures (figure 3 ). In the lab, these notes were later inked to increase contrast for photocopying. Then full-size photocopies were made. We color-coded the exposure locations, with highlighting of different colors, to indicate the different geologic units. The nonalluvial polygon boundaries were created by using these highlighted locations to indicate the unit type, while fitting the boundaries to the topography. We then traced these lines, as well as the faults, in different colors, on Mylar (figure 4). 


\section{Georeferencing of Data}

The alluvium and nonalluvium overlays were formatted with corner ticks, 2.5-minute reference crosses and corners, and quadrangle boundaries, all transferred from the quad sheets. These reference points were later used to georeference the digitized quadrangles.

\section{Merged Nonalluvial \& Alluvial Linework}

After these formatted hardcopy overlays were manually edgematched and labeled, scans of them were used as source data in the digitizing process. The alluvial and nonalluvial unit boundaries (contacts) were scanned, digitized, and georeferenced separately, then merged in the GIS to create a composite of surface geology polygons (figure 5). Small but numerous subsequent problems deriving from this procedure indicated that manually combining the two layers prior to scanning would have been preferable.

\section{Topology and Final Plots}

After constructing topology for the polygons, populating the database with geologic-unit attributes and performing final quality assurance tasks, the data development was complete. Finally, we created ArcView layouts for mapson-demand (figure 6) and FGDC compliant metadata files. A seamless mosaic of all completed maps is shown in figure 7.

\section{REFERENCE}

Peele, R. H., and McCulloh, R. P., 2000, GIS data development of the geology of the Fort Polk region of west-central Louisiana, in D.R. Soller, ed., Digital Mapping Techniques '00-Workshop Proceedings: U.S. Geological Survey Open-File Report 00-325, p. 119-124, $<$ http://pubs.usgs.gov/openfile/ofo0-325/peele.html>. 


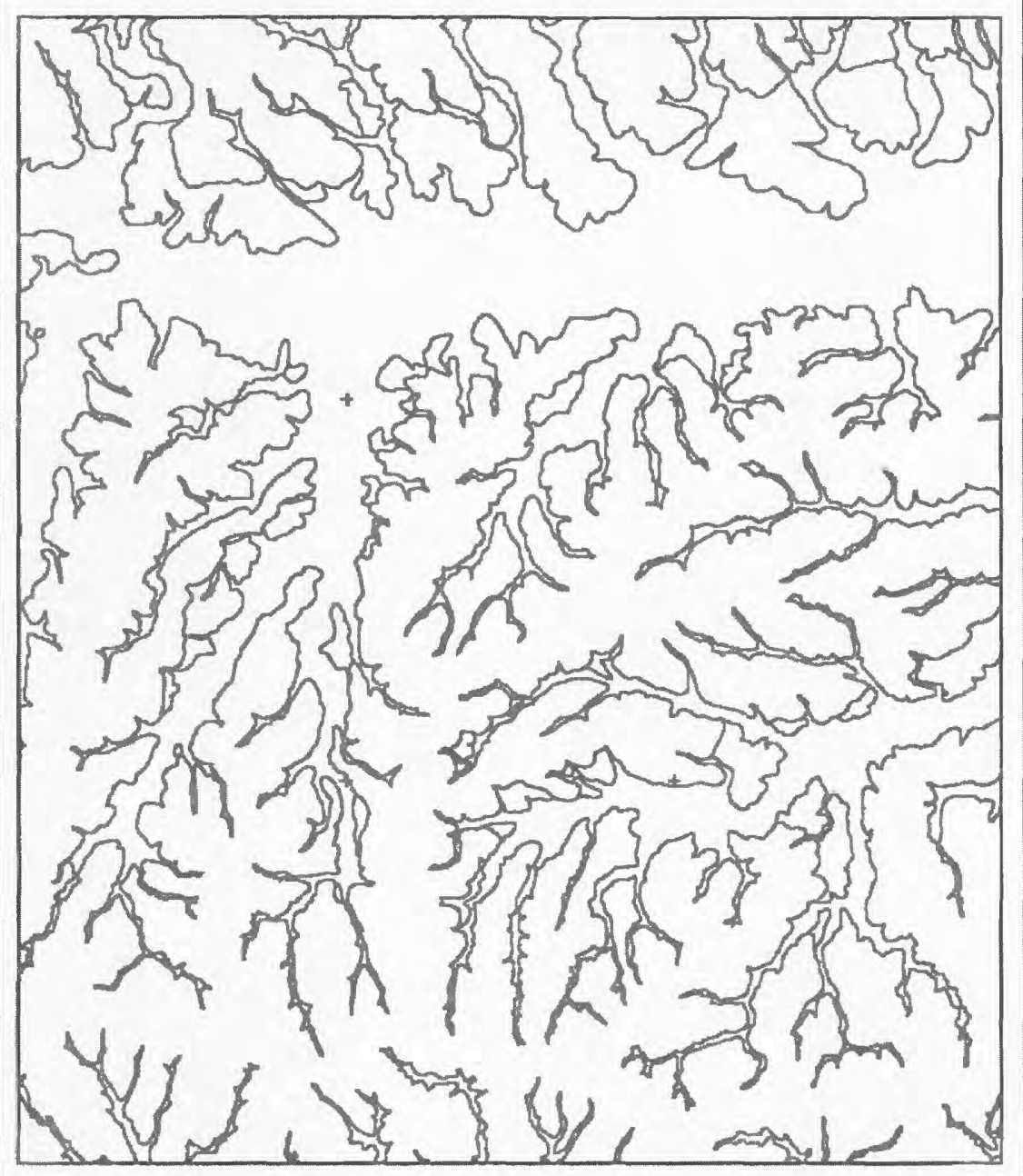

Figure 2. Alluvial linework for a quadrangle. 


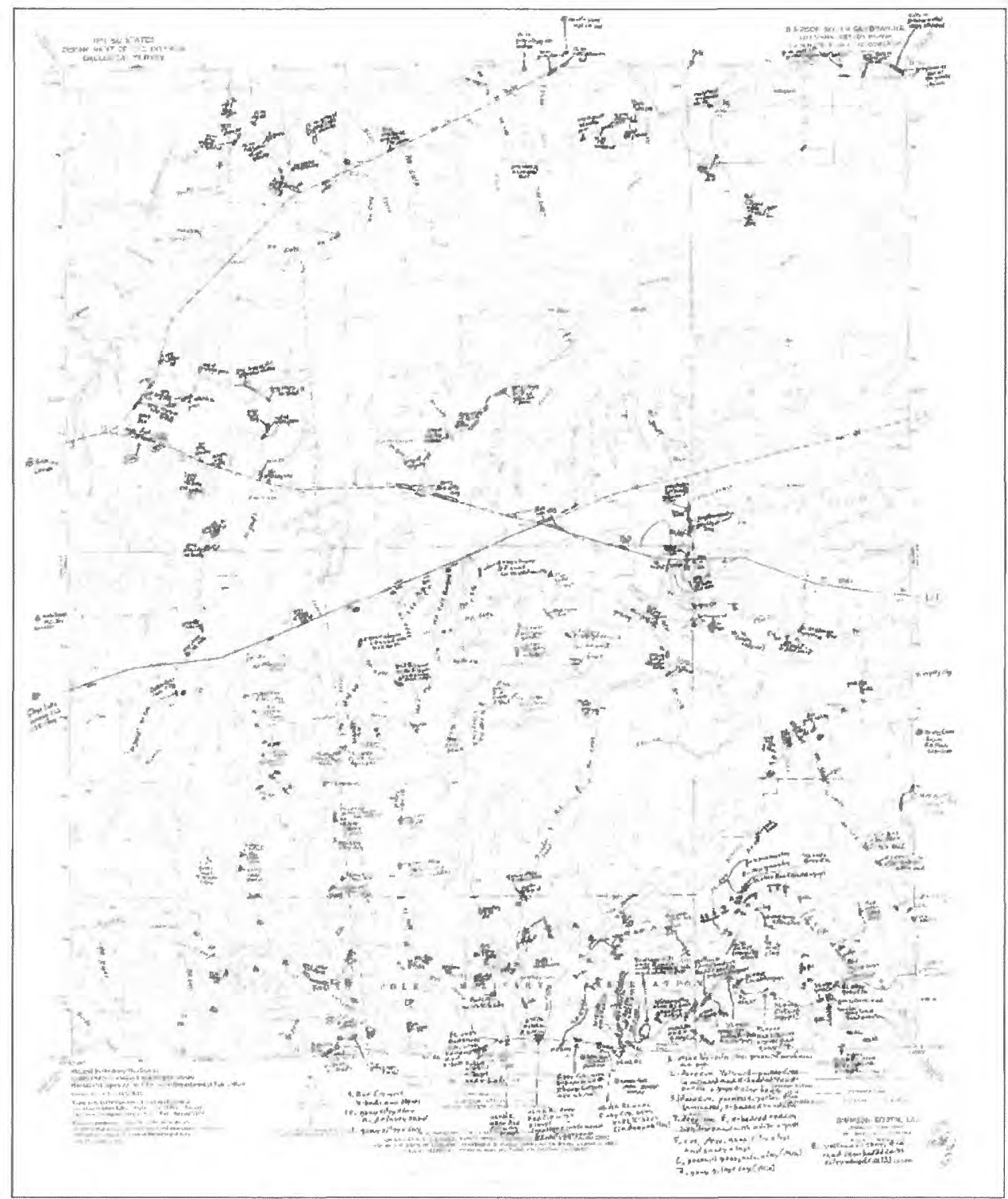

Figure 3. Example of field notes. 


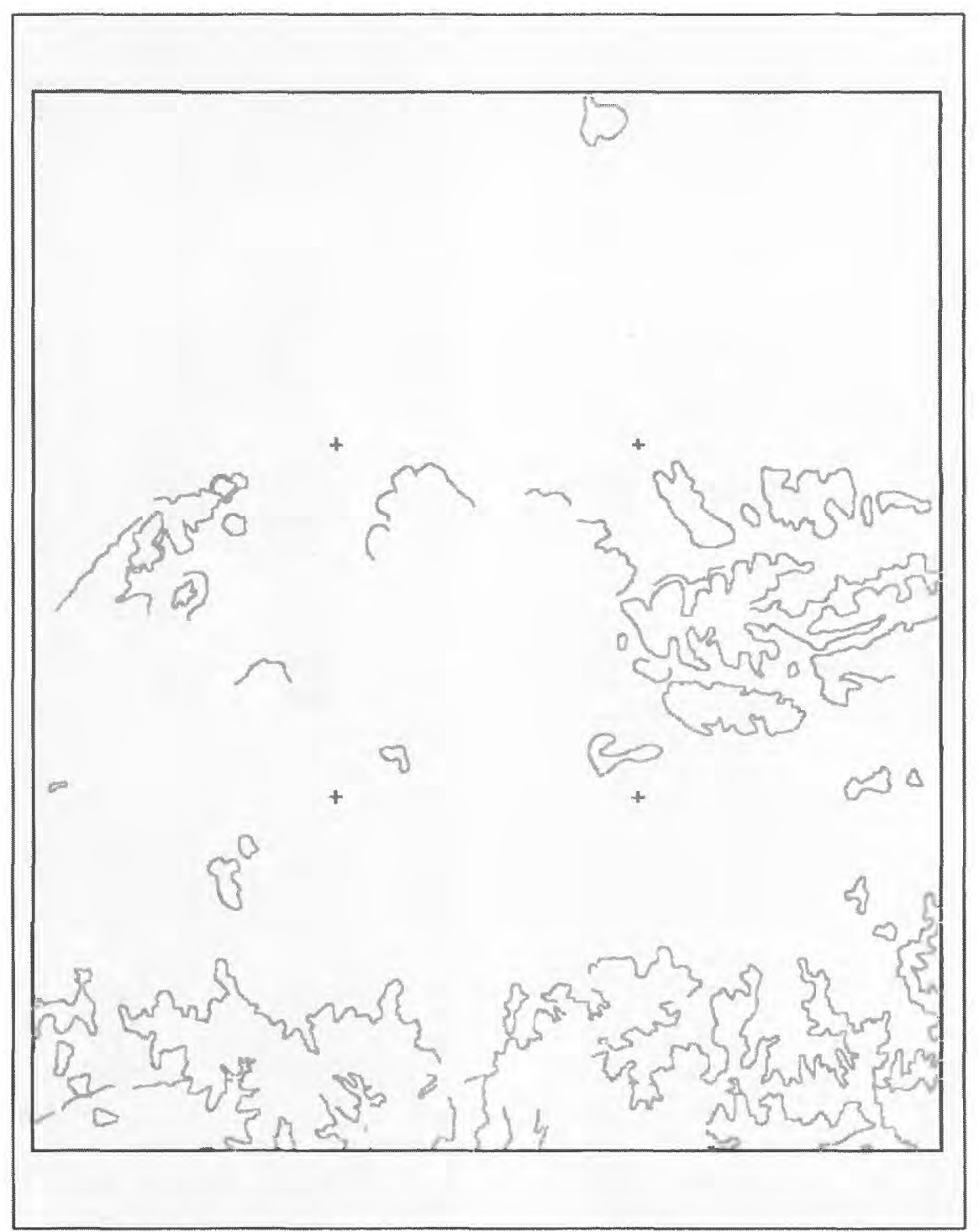

Figure 4. Non-alluvial linework. 


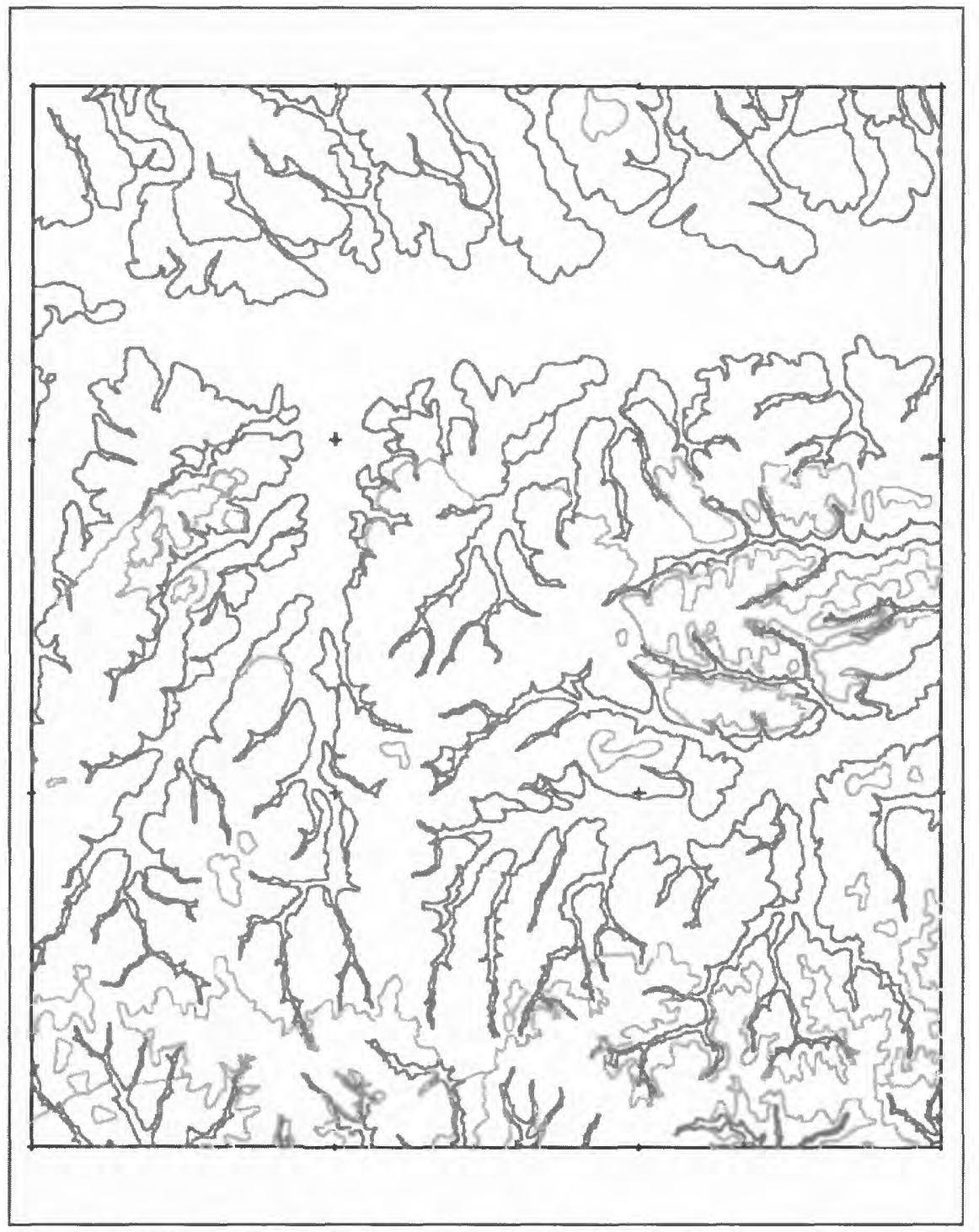

Figure 5. Composite of alluvial and non-alluvial contacts. 


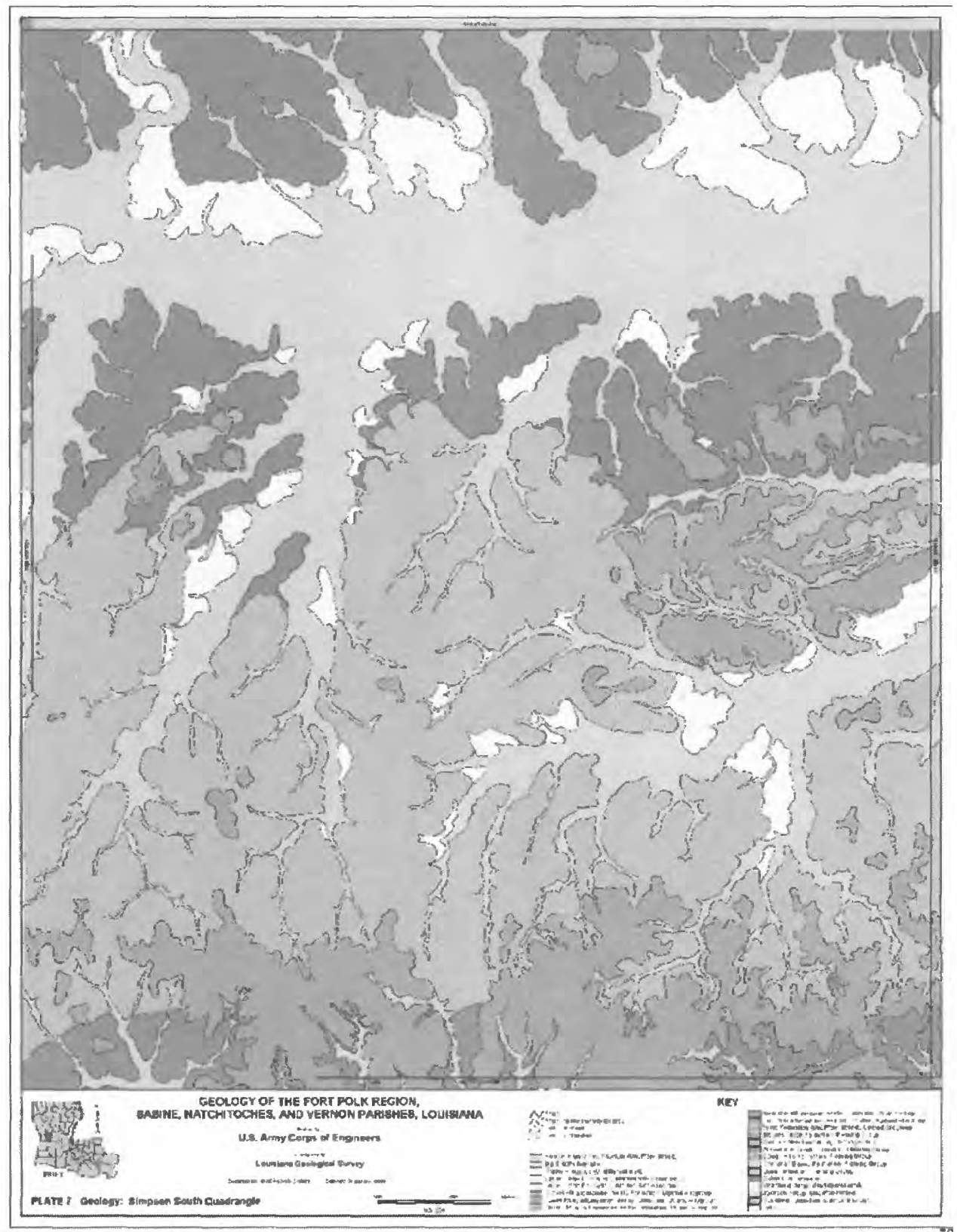

Figure 6. ArcView layout of geology of part of the Fort Polk region. 


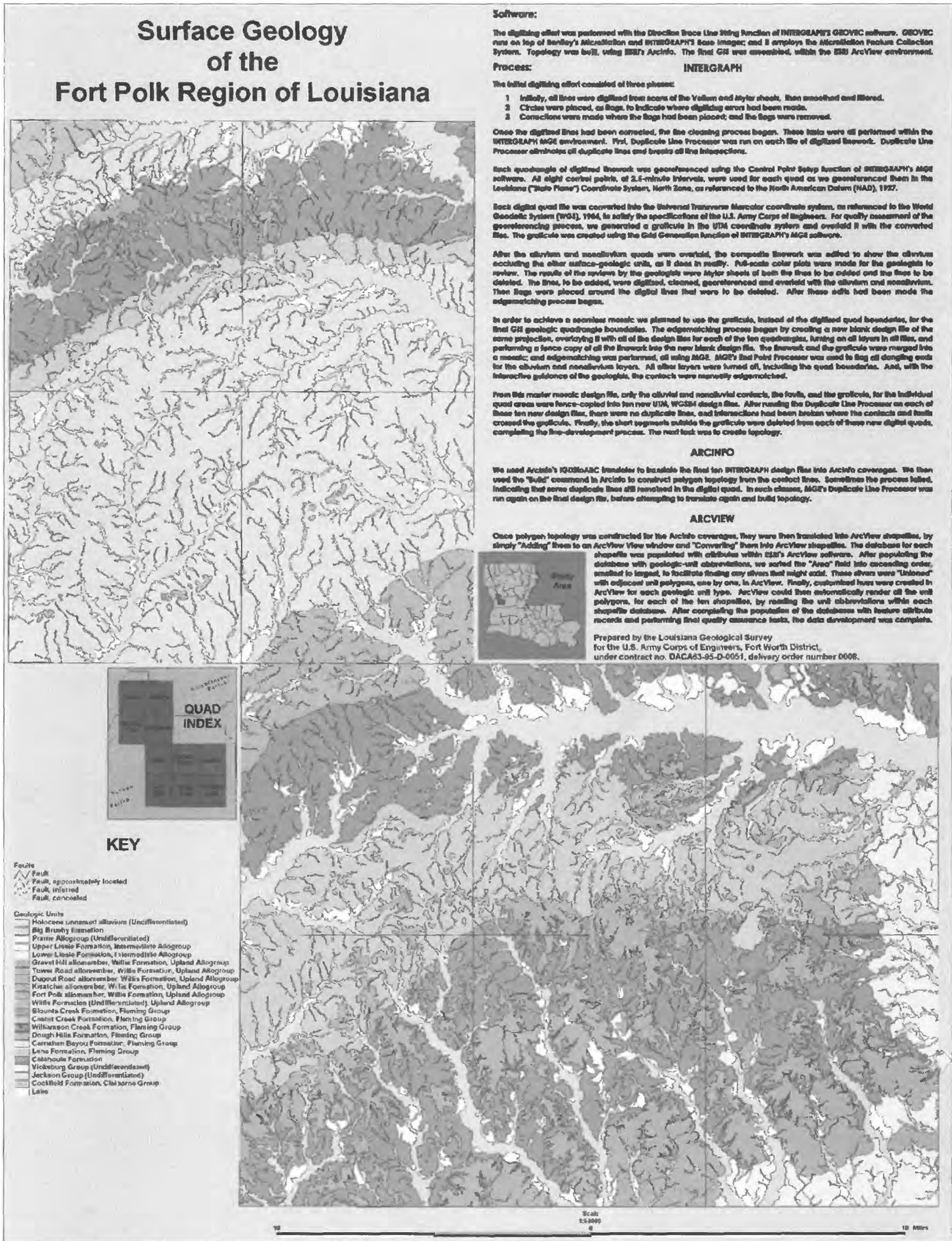

Figure 7. Seamless mosaic of 10 1:24,000-scale quadrangles in the Fort Polk region. 
206 


\title{
Geographic Information Systems (GIS) Applications to Karst Studies - Frederick Valley, Maryland
}

\author{
By David K. Brezinski and Liana E. Dunne \\ Maryland Geological Survey \\ 2300 St. Paul Street \\ Baltimore, MD 21218 \\ Telephone: (410) 554-5500 \\ Fax: (410) 554-5502 \\ e-mail: dbrezinski@mgs.md.gov; ldunne@mgs.md.gov
}

\section{INTRODUCTION}

The Frederick Valley, a lowland underlain by limestone rocks in eastern Frederick County, Maryland, is one of the most rapidly developing areas in the State. The Maryland Geological Survey (MGS) in cooperation with the Maryland State Highway Administration (SHA) is currently studying the geology of the Frederick Valley in an effort to evaluate the frequency and character of karst features and to assess their relationship to geologic formations (lithology), man-made features (roads, quarries), or other attributes that may be responsible for their distribution. A major goal of this study is to produce detailed geologic and karst features maps that are fully GIS functional and can be integrated into many GIS systems. Highway designers and engineers can benefit from having such detailed analysis of karst hazards to help them develop cost effective and safe highway systems for the State of Maryland.

\section{INTEGRATING GEOLOGY AND GIS}

Although the original agreement between the MGS and the SHA did not involve the production of digital maps, early in the project it was recognized that the use of a GIS to compile the maps would facilitate on-going spatial data analysis by MGS geologists. The six 7.5-minute quadrangles included in the study are Buckeystown, Point of Rocks, Woodsboro, Catoctin Furnace, Frederick, and Walkersville. The Maryland Geological Survey's goal is to produce a total of thirteen digital maps to satisfy this agreement.

The initial digital geologic map to be produced was the Buckeystown 7.5-minute quadrangle. The base layers, including topology, hydrology, transportation, and political boundaries, were developed from digital line graph (DLG) data from the United States Geological Survey (USGS), and converted into coverages in ArcInfo 8.0.1. The digital geologic layers and the supporting database were developed from information provided by the principal investigator. Data for some layers, including bedrock geology, Quaternary alluvium, and bedding and planar features, were collected using standard field techniques and compiled on a series of mylar sheets. Mylars were scanned to raster images which were then transformed to vector files using a combination of heads-up digitizing and raster to vector conversion. The karst features layer data were collected in the field using a global positioning system (GPS). The karst features layer was developed as an Arclnfo point coverage file from the GPS spot locations of sinkholes, depressions and springs. Additional GPS data for streambeds and drainage areas were collected and used in a spatial analysis of local sinkhole development, discussed below. The perimeters of selected large sinkholes are measured periodically using a GPS to monitor growth rate.

Creation of the two digital maps, geology and karst, per quadrangle involves assembling appropriate GIS layers and associated data tables with map layout elements. This is all being completed in ArcInfo 8.0.1 software. The final release of all digital elements will be available as coverages, shapefiles, and .PDF formats. With the advent of the new ArcGIS, duplicate layout production in both ArcView and ArcInfo will not be necessary.

\section{EVALUATING GEOLOGIC PROBLEMS WITH GIS}

Potential patterns of karst development can be identified by analyzing the digital karst data using a GIS. One of the issues under investigation is the role of stratigraphy in the development of karst features. An inventory was 
made of the number and type of karst features present in the limestone formations. The Frederick Valley has several karst prone stratigraphic intervals. While the Frederick Valley proper is underlain by the Cambrian and

Ordovician strata of the Frederick and Grove Formations, an ancillary area to the west is underlain by the limestone and dolomite conglomerates of the Triassic Leesburg Formation. Although some earlier, unpublished, studies suggest that the karst features are largely restricted to the Ordovician Grove Formation, recent geologic mapping, utilizing digital techniques, indicates both the Grove and the Frederick Formation are susceptible to karst sinkhole activity. Based on the number and types of karst features present in each formation, both formations seem to be equally karst prone.

An important issue in karst development concerns the restructuring of drainage from highway development and quarry operations. In a particular region along Interstate 70 in Frederick City, the proximity of this sinkhole-prone area to both the nearly century old Frederick Quarry and Interstate 70 has raised questions as to which factor is responsible for the karst proclivity. Precise GPS location of the recently active and historically active karst features initially fails to yield any definitive answers for this active karst area. However, when GPS transects, made along the historic drainages, are added, a closer correlation is apparent. When the drainage lowland is added to the stream channel transects, many, if not most, of the sinkholes fall within these lowland areas. Consequently, this close correlation of the stream channels with the karst features points to the theory that karst features are predominately drainage related. This relationship is important when considering future highway development or city expansion. 


\title{
Three Dimensional Representations of Aeromagnetic and Isostatic Residual Gravity Surfaces with Geology in Montana
}

\author{
By Patrick J. Kennelly \\ Montana Bureau of Mines and Geology \\ Montana Tech of the University of Montana \\ Butte, MT 59701-8997 \\ Telephone: (406) 496-2986 \\ Fax: (406) 496-4451 \\ e-mail: pkennelly@mtech.edu
}

\section{INTRODUCTION}

The U.S. Geological Survey has recently released 500 meter grids of aeromagnetic and isostatic residual gravity data covering the state of Montana (McCafferty et. al., 1998). These potential field data sets can be useful for interpreting lateral changes in density or the abundance of magnetic minerals in surficial or subsurface geology.

Correlation of aeromagnetic and isostatic residual gravity patterns to maps of surficial geology is often the first step in making interpretations such as those noted above. This requires the overlay of potential field data with the mapped geology. Although Geographic Information System (GIS) technology makes this overlay simple, the resulting displays are often difficult to visualize, especially for users unfamiliar with potential field data.

This paper outlines a method for using GIS to create three-dimensional (3D) displays of potential field and geologic data. First, a 3D surface is built from the aeromagnetic or gravity data. Then, a layer representing geology can be draped over these surfaces, with geologic formations represented with colors.

\section{AEROMAGNETIC DATA}

The U.S. Geological Survey Open-file report 98-333 (McCafferty et. al., 1998) merged existing aeromagnetic data covering the state of Montana into one grid consisting of $500 \times 500$ meter grid cells. This grid was constructed using information from 65 separate aeromagnetic surveys conducted over a 40 year interval (see <http://greenwood.cr.usgs.gov/pub/open-file-reports/ ofr-98-0333/mt_indmap.html >). The 65 surveys varied in many of their specifications, including terrain clearance, sampling rates, line spacing, and reduction procedures. For example, spacing of flight lines varies from 0.167 miles to 6 miles. Specifications for all 65 original surveys are summarized in a table at <http://greenwood.cr.usgs.gov/ pub/open-file-reports/ofr-98-0333/mt_indtab.html>. The aeromagnetic data was processed by the U.S. Geological Survey as outlined at <http://greenwood.cr.usgs.gov/pub/ open-file-reports/ofr-98-0333/mt_proc.html>.

The resulting grid for Montana has a spatial resolution of 500 meters, with each grid cell assigned a measure of the local magnetic field in nano-teslas. These values define a continuous potential field surface, much as the elevation Digital Elevation Model (DEM) grid cells define a topographic surface. Variations in the aeromagnetic potential field are due to lateral variations in content of magnetic minerals in surfical or subsurface geology, especially variations in the mineral magnetite (Telford et. al., 1976).

\section{ISOSTATIC RESIDUAL GRAVITY DATA}

McCafferty et. al. (1998) also created gravity grids from more than 40,000 stations within or adjacent to Montana. This data was extracted from a gravity database maintained by the National Geophysical Data Center (from Department of Defense unclassified data) and augmented with data from the USGS and several university theses and dissertations. A Bouguer gravity grid was created using observed gravity relative to the IGSN-71 datum, reduced to the Bouguer anomaly using the 1967 gravity formula and a reduction density of $2.67 \mathrm{~g} / \mathrm{cc}$. Terrain corrections were calculated radially outward from each station to a distance of $167 \mathrm{~km}$ using a method developed by Plouff (1977). The data were converted to a grid using minimum curvature techniques. 
The isostatic residual gravity grid applies further corrections to the Bouguer gravity anomaly grid to account for lateral variations at the crust/mantle interface resulting from topography (Simpson et.al., 1986). The computation assumes an Airy model of isostacy, thus topographic highs have associated low density crustal roots to provide bouyancy, allowing them to "float" on the mantle in a manner similar to an iceberg on water. The isostatic correction used the Bouguer gravity anomaly grid, a topographic grid, and three assumptions. It assumed a crustal thickness of $30 \mathrm{~km}$., a density for the crust of $2.67 \mathrm{~g} / \mathrm{cc}$, and a density contrast between crust and mantle of 0.35 $\mathrm{g} / \mathrm{cc}$.

Given these assumptions, the resulting isostatic residual gravity grid should give the best image of lateral density variations associated with surficial or near-surface geology. The isostatic residual gravity grid cells are 500 meters, with each grid cell assigned a value of the local isostatic residual gravity field in miligals (mgal). The grid cells define a continuous surface for the isostatic residual gravity field.

\section{COMMON METHODS OF DISPLAYING POTENTIAL FIELDS WITH GEOLOGY}

Two methods are generally used to display potential field data and geology simultaneously. The first method assigns colors to the geology based on geologic formations, and overlays equipotential contours of the gravity or magnetic field. The second method assigns colors to equipotential intervals, and overlays geologic formation contacts as a layer of lines.

Figure 1 is a black and white example of a color geologic map with equipotential contours of magnetic data. This display is not easy to interpret, even in color. Equipotential lines define aeromagnetic highs and lows, but the two are often difficult to differentiate. To interpret this display, individual contours would have to be labeled, or all highs and lows would have to be annotated.

Additionally, isolated spikes in the areomagnetic surface create closely spaced contours that conceal the underlying geology. Finally, even users experienced with interpreting topographic contours could have trouble interpreting aeromagnetic field highs and lows, as usual topographic rules of thumb (e.g. broad lows draining downstream) do not apply.

Figure 2 is a black and white example of a color isostatic residual gravity map with a geologic formation contact overlay. This display clearly indicates gravity highs and lows, but geologic formations are difficult to visualize. Only larger geologic polygons can be labeled at this scale. Also, it is difficult to see the continuity of formations that are comprised of a number of polygons.

\section{THREE DIMENSIONAL POTENTIAL FIELD SURFACES DRAPED WITH GEOLOGY}

An alternative method for displaying geology and potential fields simultaneously is documented in an example from the Mari Lake region of east-central Saskatchewan, Canada (Harris et.al., 1999). In this example, a three dimensional surface is created from the aeromagnetic potential field. The z-value for this surface is the strength of the areromagnetic field in nanoteslas. The geology is displayed in color and draped over the 3D surface. The Mari Lake example uses high resolution magnetic data and detailed geologic mapping to create a large scale 3D map image.

This same method, however, can be applied to statewide geologic, gravity, and magnetic data. In our poster, we show 3D surfaces from isostatic residual gravity and aeromagnetic data overlain by geology from the 1:500,000 Geologic Map of Montana (Ross et. al., 1955). The geologic data was digitized as a vector coverage, then converted to a grid. Grid values relate to the geologic formation information and are used to assign colors to the geology. Grid cells for this new grid match in size and location those of the isostatic residual gravity and aeromagnetic grids distributed by the USGS.

Once the geology has been converted to a grid, the geology can be displayed on a 3D potential field surface with ArcView and the 3D Analyst extension. To create such displays, open a 3D scene, add the geology grid theme, and use the legend editor to assign colors based on geologic formation information. Then, select "3D properties" under the "Theme" dropdown menu. In the "Assign base height by:" portion of the menu, select the radio button for "Surface", then select a potential field grid. To enhance the 3D effect, select "Properties" under the "3D Scene" dropdown menu. Then, adjust the "Vertical exaggeration factor:" until the appropriate 3D effect is achieved. These numbers are not true vertical exaggerations as horizontal units are in distance (meters) and vertical units are in nanoteslas for aeromagnetic data and miligals for gravity data. In our examples below, the vertical exaggeration factors are $30 x$ 's for the aeromagnetic data and $750 \mathrm{x}$ 's for the isostatic residual gravity data.

Figure 3 shows a color geology map displayed in black and white on an aeromagnetic surface. The most obvious correlation is between isolated, volcanic intrusives and sharp spikes in the magnetic field. Examples can be seen in the southwest of the map, as well as in a single spike in the northwest. Other less magnetic intrusive volcanics, such as the Idaho batholith on the west-central Idaho border, have no such associated highs. 


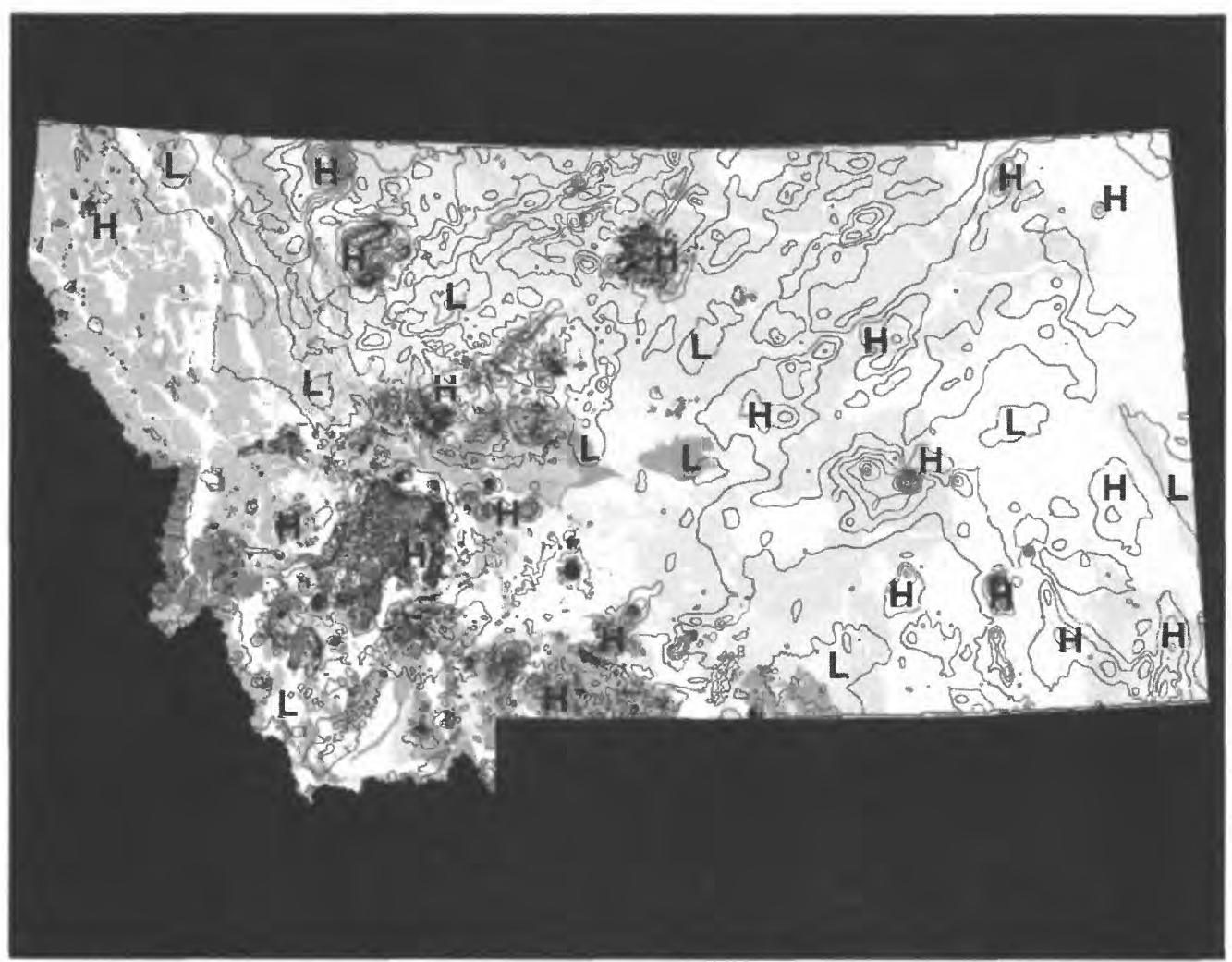

Figure 1. A geologic map of Montana overlain with aeromagnetic equipotential contours. The contour interval for the aeromagnetic data is 200 nanoteslas.

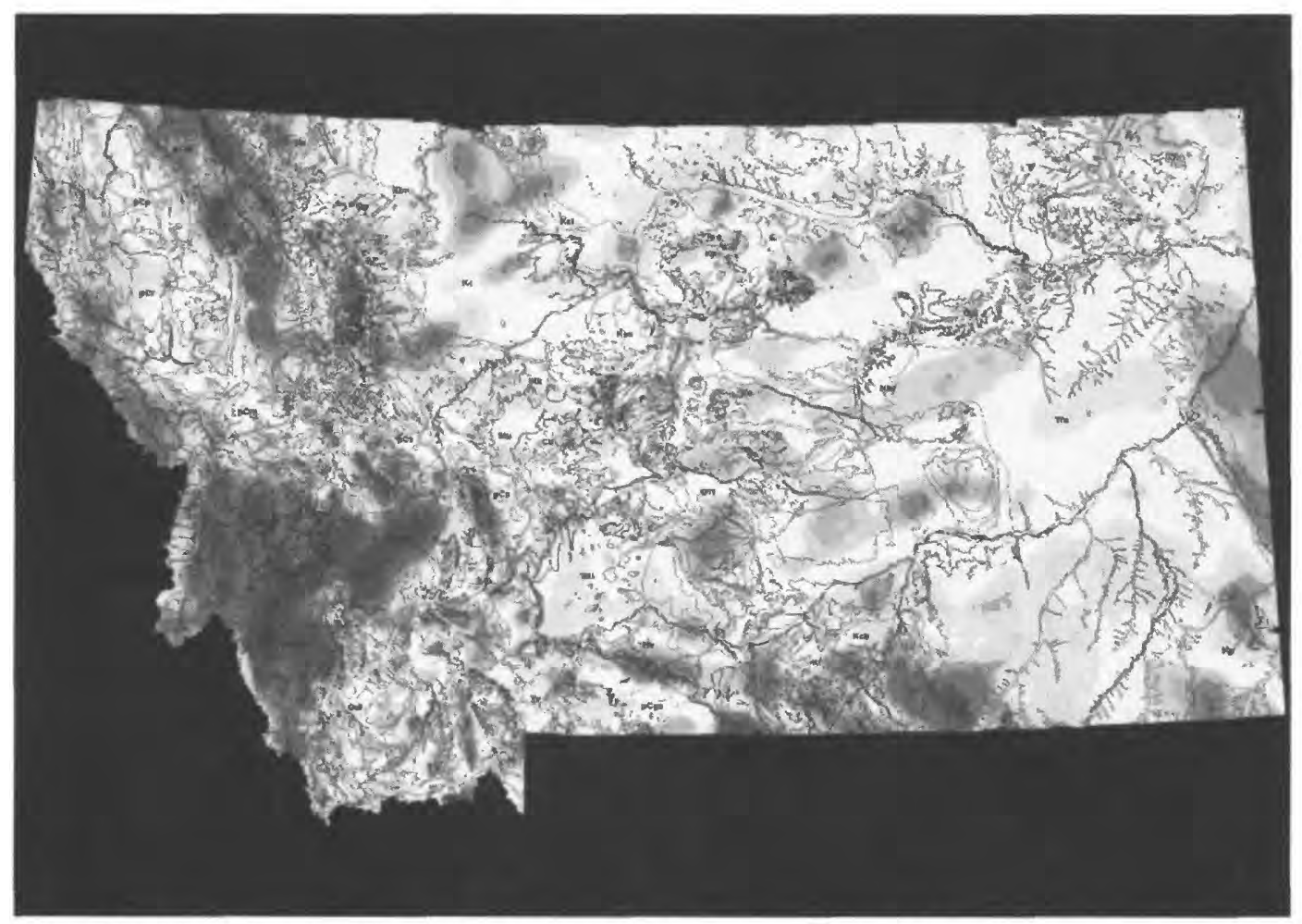

Figure 2. The isostatic residual gravity map of Montana overlain with geologic contacts. 


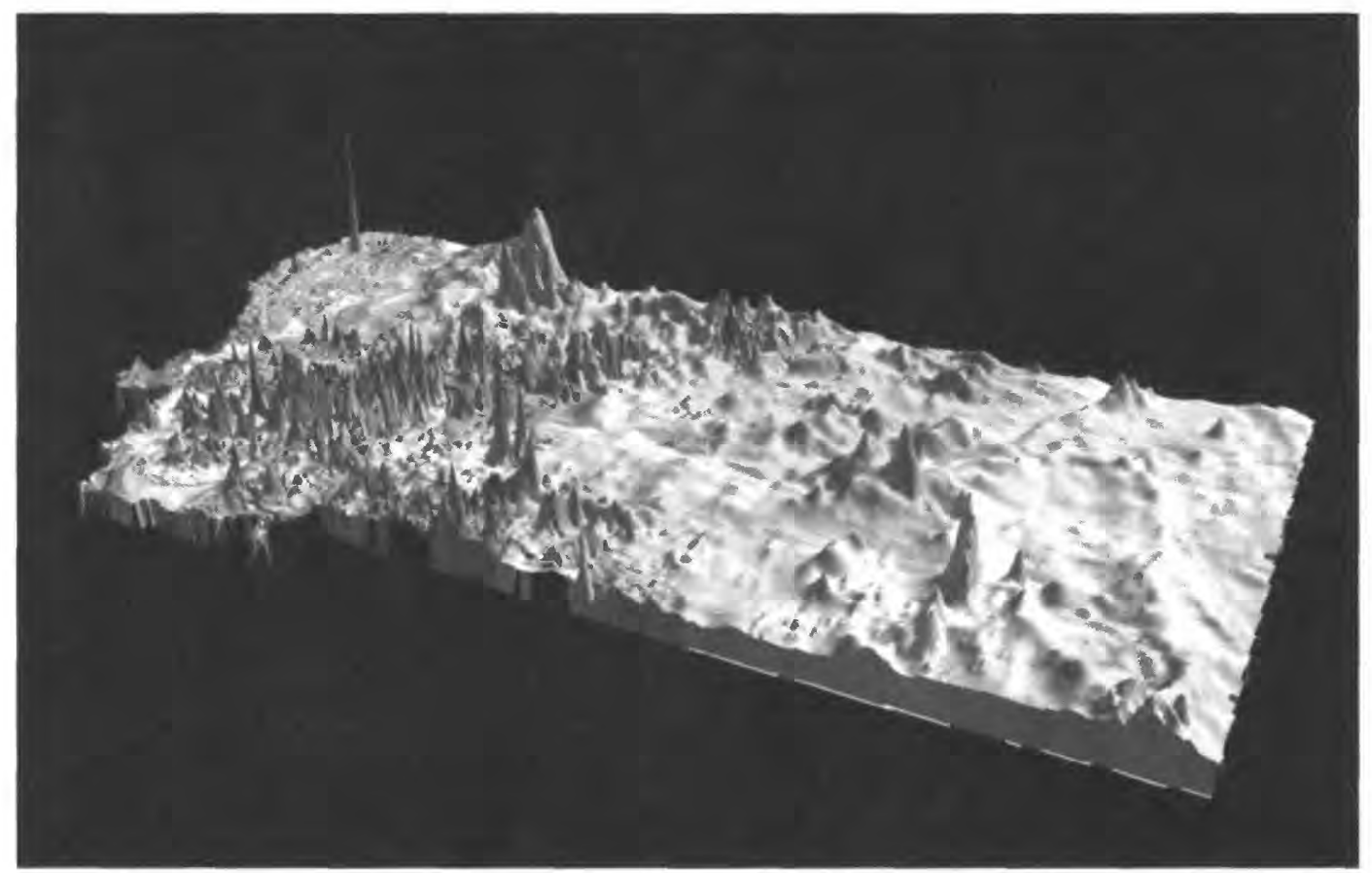

Figure 3. A geologic map of Montana draped over a 3D aeromagnetic surface. The horizontal scale is in meters and the vertical scale is in nanoteslas. The "vertical exaggeration" is 30x.

Figure 4 shows a color geology map displayed in black and white on an isostatic residual gravity surface. This map illustrates lateral changes in density of rock formations. The narrow NNW trending Cedar Creek anticline is defined by a gravity high and adjacent lows on the western edge of Montana. A broader feature, the Sweet Grass arch, is defined by an isostatic residual gravity high in northwestern Montana. The Powder River basin in southeastern Montana is defined by a gravity low correlating to Tertiary sediments surrounded by Cretaceous rocks. As with its magnetic intensity, the Idaho batholith on the western edge of Montana has no large density variations with surrounding formations.

\section{CONCLUSIONS}

The resulting images clearly display both geologic and potential field data. This facilitates the visual correlation of aeromagnetic and isostatic residual gravity anomalies with geologic features. In this manner, such displays can be used for effective communication or exploration of geophysical potential field data.

Aeromagnetic and isostatic residual gravity data for other states is also available from the U.S. Geological
Survey. These data can be accessed from $<$ http://crustal.usgs.gov/crustal/geophysics/index.html>. To view a version of this paper with color figures, please refer to <http://mbmgsun.mtech.edu/pdf/gis-dmtposter.pdf $>$.

\section{REFERENCES}

Cordell, L., Phillips, J. D., and Godson, R. H., 1992, U.S. Geological Survey potential-field geophysical software, version 2.0: U.S. Geological Survey Open-file Report 92-18A$\mathrm{G}, 16 \mathrm{p}$.

Harris, J.R., Viljoen, D.W., and Rencz, A.N., 1999, Integration and visualization of geoscience data. In Remote Sensing for the earth sciences(A. N. Rencz, ed.), Vol. 3: Manual of remote sensing, (R. A. Ryerson, ed.), 3rd ed, John Wiley \& Sons, Inc., New York, p. 341.

McCafferty, A.E., Bankey, V., and Brenner, K.C., 1998, Merged aeromagnetic and gravity data for Montana: A web site for distribution of gridded data and plot files: U.S. Geological Survey Open-file Report 98-333, 20 p,

<http://greenwood.cr.usgs.gov/pub/open-file-reports/ofr-98$0333 />$.

Plouff, D., 1977, Preliminary documentation for a FORTRAN program to compute gravity terrain corrections based on topography digitized on a geographic grid: U.S. Geological Survey Open-File Report 77-535, 43 p. 


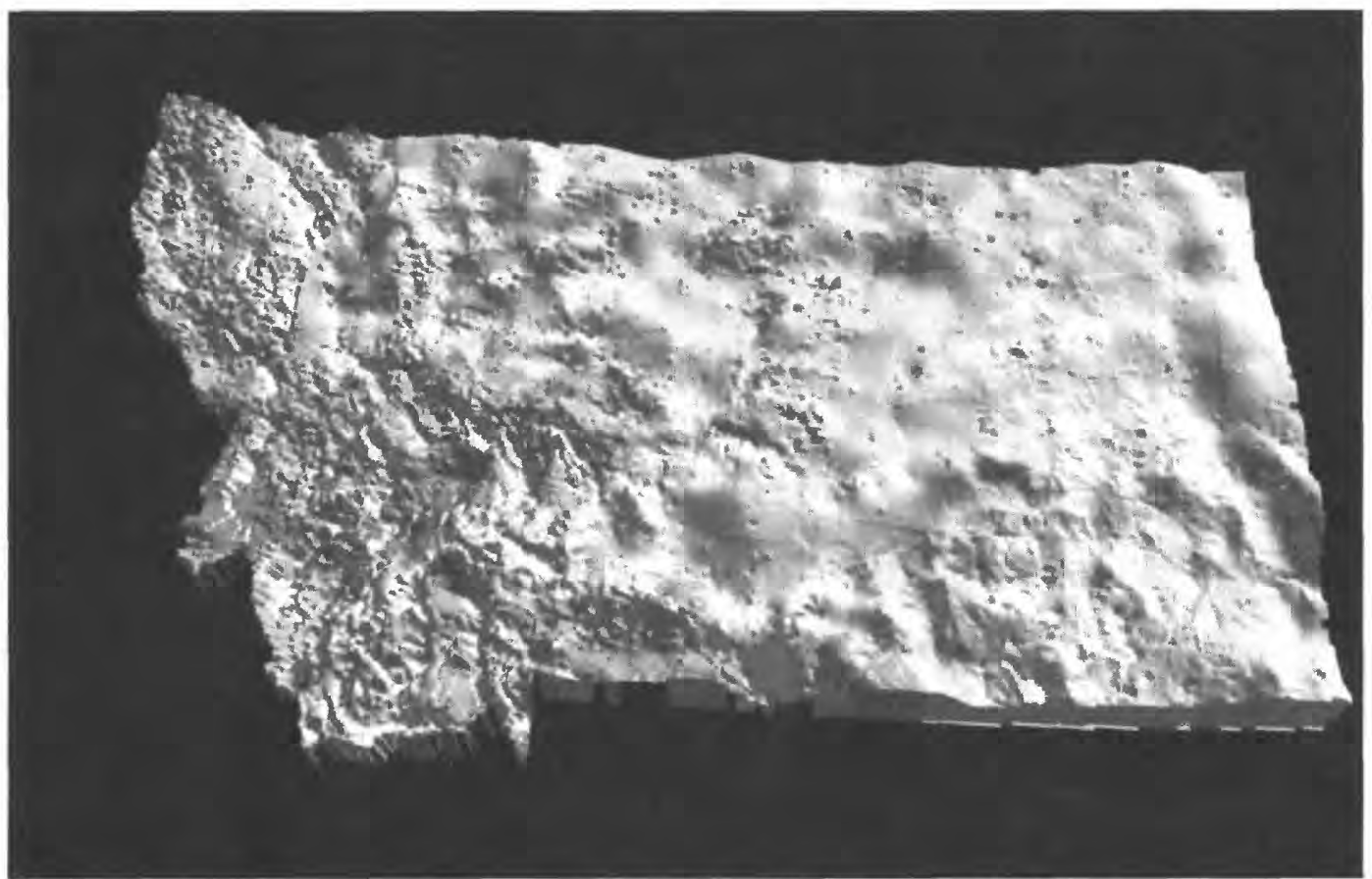

Figure 4. A geologic map of Montana draped over a 3D isostatic residual gravity surface. The horizontal scale is in meters and the vertical scale is in milligals. The "vertical exaggeration" is $750 \mathrm{x}$.

Ross, C. P., D. A. Andrews, and I. J. Witkind, 1955, Geologic map of Montana: Montana Bureau of Mines and Geology Geologic Map Series Geol-1, 2 sheets. Scale 1:500,000. (Out of print).

Simpson, R.W., R. C. Jachens, R.J. Blakely and R. W. Saltus, 1986 , A new isostatic residual gravity map of the contermi- nous United States with a discussion on the significance of isostatic residual anomalies. J. Geophys. Res., 91. pp. 83488372.

Telford, W. M., Geldart, L. P., Sheriff, R.E., and Keys, D.A., 1976. Applied Geophysics, Cambridge University Press, New York and Melbourne, First Edition, 118p. 



\title{
Development of a Digital Geologic Map for Mesa Verde National Park
}

\author{
By Anne R. Poole1, Steve Fryer ${ }^{2}$, Tim Connors ${ }^{3}$, Bruce Heise ${ }^{4}$, \\ Joe Gregson ${ }^{2}$, and Allan Loy ${ }^{5}$
}

\author{
1National Park Service \\ Intermountain GIS Center \\ University of New Mexico \\ Bandelier Hall West \\ Albuquerque, NM \\ Telephone: (505) 346-2885 x260 \\ Fax: (505) 346-2889 \\ e-mail: Anne_Poole@nps.gov \\ 2National Park Service \\ Natural Resources Information Division \\ 1201 Oak Ridge Drive, Suite 350 \\ Fort Collins, CO 80525 \\ Telephone: (970) 225-3584 \\ Fax: (970) 225-3585 \\ e-mail: Joe_Gregson@nps.gov, \\ Steve_Fryer@nps.gov \\ ${ }^{3}$ National Park Service \\ Geologic Resources Division \\ 12795 West Alameda Parkway \\ P.O. Box 25287. \\ Denver, CO 80225 \\ Telephone: (303) 969-2093 \\ Fax: (303) 987-6792 \\ e-mail: Tim_Connors@nps.gov
}

\section{ABSTRACT}

The maps shown on this poster were generated from digital geologic data for Mesa Verde National Park in Colorado. The data consist of several different coverages, each representing a different type of geologic feature (rock units, faults, etc.). The making of these coverages served as a pilot project for testing the National Park Service Digital Geologic Map model, which will eventually be used to create standardized Geologic Resource Inventories for 265 units of the National Park System.
${ }^{4}$ National Park Service

Geologic Resources Division

12795 West Alameda Parkway

P.O. Box 25287.

Denver, CO 80225

Telephone: (303) 969-2017

Fax: (303) 987-6792

e-mail: Bruce_Heise@nps.gov

${ }^{5}$ GIS Operations

Mesa Verde National Park

P.O. Box 8

Mesa Verde, CO 81330

Telephone: (970) 529-4614

Fax: (970) 529-5028

e-mail: Allan_Loy@nps.gov

\section{THE NATIONAL PARK SERVICE DIGITAL GEOLOGIC MAP MODEL}

Beginning in 1998, the National Park Service (NPS) initiated a geologic resources inventory to document and evaluate the geologic resources of 265 National Park System units (national parks, monuments, recreational areas, historic sites, seashores, etc.). A major part of this inventory is the compilation of digital geologic map products and their accompanying supporting information. To ensure uniform data quantity and quality, geologic-GIS 
data standards are being developed by the NPS Inventory and Monitoring (I\&M) Program and Geological Resources Division (GRD). The challenge of this standardization is twofold:

1. The standards must be adaptable to diverse geological conditions; and be capable of capturing all of the information present on a typical paper geologic map.

2. The finished data must be "user-friendly"; that is, immediately useful to park resource managers and other staff, even those with little GIS or no geologic expertise.

The current version of the digital map model (Fryer et al., 2000) outlines a series of ArcInfo coverages. Each GIS layer represents a different type of geologic information digitized from the source map. While most of these layers consist of only one type of feature (point, line, or polygon), some, such as CODEGLG, include both line and polygon data. Accessory INFO tables hold additional data on rock unit type and age, and reference information on the source maps used to create the coverages. This model was originally developed from the Washington State ArcInfo GIS data model (Harris 1998) and has been extended to include components of the North American Geologic Map Data Model (Johnson et al., 1998).

It is the goal of the NPS Inventory and Monitoring Program to produce digital products that are immediately useful to anyone familiar with their analog counterparts in this case, a paper geologic map. Therefore, each digital geologic map product will come with ArcView legend files that automatically display the proper shades and symbols for each data type. Map unit descriptions will also be automated by including them in a Windows Help File that can be linked with CODEGLG and other coverages in a customized ArcView project.

Some examples of geologic themes in the data model and the accessory data files to which they are linked are listed in Figure 1. In an actual geologic map for a park, the "CODE" portion of the coverage name is replaced by an official four-letter code used to identify each NPS unit (i.e. "MEVE" for Mesa Verde National Park). Figure 2 illustrates how certain coverages may contain both area (i.e. rock type) and line (contact type) features.

\section{THE DIGITAL GEOLOGIC MAP OF MESA VERDE}

Although it is not the intention of the National Park Service to initiate new mapping projects, this has become necessary in instances where adequate published maps do not exist. Such was the case for Mesa Verde National Park in southwestern Colorado. All previously published maps of the park lacked the desired level of detail, so the services of Mary O. Griffitts, a retired professional geologist and an expert on the local geology, were employed to create a new map at 1:24,000 scale. The resulting map sheets, drafted on mylar, were tablet digitized in ArcInfo to create coverages for the park's geologic inventory. For Mesa Verde these coverages included map units and their associated contacts, fault lines, joints, igneous dikes, nonigneous linear geologic features (in this case, travertine deposits along joints which were too thin to be mapped as polygons), and structural point data (i.e. strike and dip and other measurements/observations). Many other coverage types are outlined in the NPS map model, but were not deemed necessary for this park. A park with significant volcanic features, on the other hand, might make use of the ash unit (CODEASH) or volcanic point feature (CODEVNT) coverage types. Considering the wide variety of geologic resources that can be found in our national parklands, the model is being designed to be flexible enough to store any type of data that might be found on a geologic map.

Customized Arc View legend files (showing standardized symbology and/or colors pertaining to the age of the rock unit) were created and distributed along with the digital data to the park's GIS staff. When possible, these legends were given the same name as their associated coverage, so that they will load automatically when placed in the same directory as that coverage. These files are not only great timesavers but are also aids to anyone unfamiliar with either geologic data representation or the manipulation of the appearance of data in a GIS.

Rock type descriptions provided by Dr. Griffitts, as well as legend text from older maps of the area, were included in an accompanying Windows Help File,

MEVEUNIT.HLP. In this file each map unit is listed on its own topic page, which is given an ID code identical to the unit's geologic symbol (which is also listed in the GLG_SYM field in certain coverages and hence serves as the link between coverage and help file). A contents page shows the names of all units in their proper stratigraphic order, and a references page lists sources from which the descriptions were derived. Keyword searches can be performed on this file using terms pertaining to lithology, formal unit names, time period, and other aspects. This help file, in addition to being useful on its own, is designed to be incorporated into the NPS Theme Manager, an ArcView extension developed to allow park staff with little GIS knowledge to access geographic data.

The new geologic resources inventory has been incorporated into Mesa Verde's GIS and has already been employed for post-wildfire geologic hazards studies. We anticipate that it will continue to prove its usefulness as new resource management issues arise.

\section{REFERENCES}

Fryer, Steve, Gregson, Joe, Connors, Tim, Poole, Anne, and Heise, Bruce, 2000, The National Park Service Digital Geologic Map Model: Transformation from paper to digital, featuring legends, cross sections, map notes, and keyword searchability, in D.R. Soller, ed., Digital Mapping 
COVERAGES

\begin{tabular}{|c|}
\hline $\begin{array}{c}\text { CODEGLG } \\
\text { potyline } \\
\text { Map wit polygons, and linear data } \\
\text { describing the interface between wits }\end{array}$ \\
\hline $\begin{array}{l}\text { CODEGLN } \\
\text { line } \\
\text { Map units represented as lines die } \\
\text { to scale limitations }\end{array}$ \\
\hline $\begin{array}{l}\text { CODEDKE } \\
\text { line } \\
\text { individual lithologic dikes }\end{array}$ \\
\hline $\begin{array}{l}\text { CODEFLT } \\
\text { line } \\
\text { Fouils }\end{array}$ \\
\hline $\begin{array}{l}\text { CODEFLD } \\
\text { line } \\
\text { Linear fold axes hingelines }\end{array}$ \\
\hline $\begin{array}{c}\text { CODEATD } \\
\text { point } \\
\text { Attifude observation points } \\
\text { (ie. strike and dip or other structural measurememss) }\end{array}$ \\
\hline
\end{tabular}

Figure 1. Some examples of geologic themes in the data model and the accessory data files to which they are linked.
ACCESSORY DATA FILES

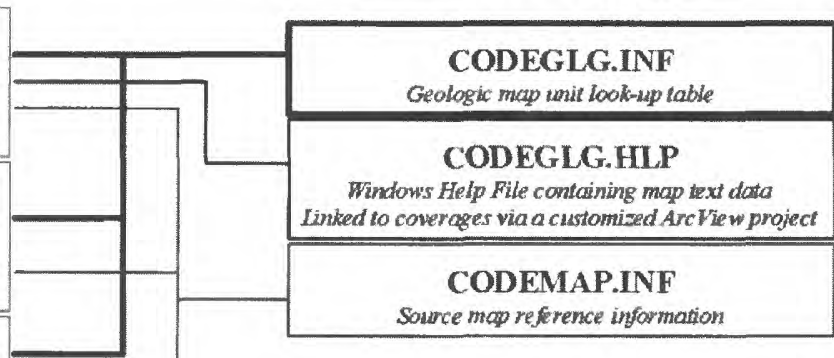

Source mog reference information

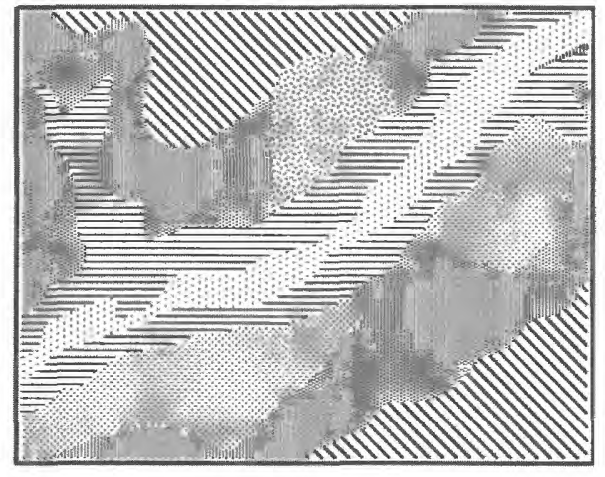

MEVEGLG - polygon

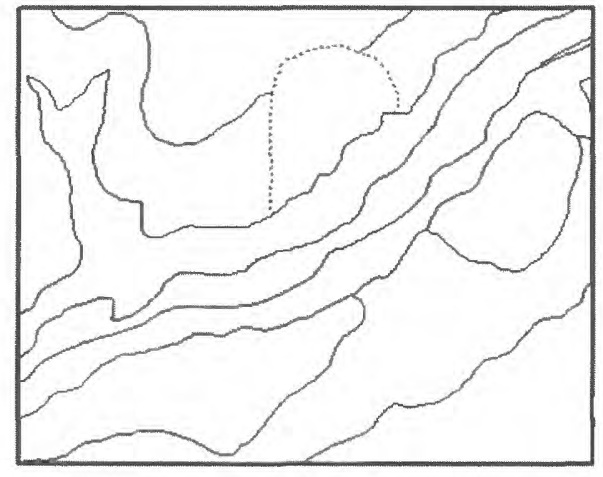

MEVEGLG - arc

Figure 2. Some coverages contain both polygon and arc features. For example, MEVEGLG stores information on both rock type and contact line type.

Techniques '00-Workshop Proceedings: U.S. Geological Survey Open-File Report 00-325, p.69-81, $<$ http://pubs.usgs.gov/openfile/of00-325/fryer.html>.

Harris, C.F.T., 1998, Washington State's 1:100,000-Scale Geologic Map Database: An ArcInfo Data Model Example, in D.R. Soller, ed., Digital Mapping Techniques '98Workshop Proceedings: U.S. Geological Survey Open-File
Report 98-487, p. 27-35, <http://pubs.usgs.gov/openfile/ of $98-487$ /harris.html>.

Johnson, B.R., Brodaric, Boyan and Raines, G.L., 1998, Draft Digital Geologic Map Data Model, Version 4.2: American Assoc. of State Geologists/U.S. Geological Survey Geologic Map Data Model Working Group. May 19, 1998, <http://geology.usgs.gov/dm/model/Model42.pdf>. 



\section{Brief Summaries from the New Jersey Geological Survey}

\section{DwellField}

\author{
By Gregory C. Herman
}

\author{
NJ Department of Environmental Protection \\ NJ Geological Survey \\ PO Box 42729 Arctic Parkway \\ Trenton, New Jersey 08625 \\ Telephone: (609) 984-6587 \\ Fax: (609) 633-1004 \\ e-mail: gregh@njgs.dep.state.nj.us
}

3DWellField.avx. is an ArcView 3.x Extension used for generating and visualizing 3D shapefiles of well-field well-construction parts, inclined planes, packer-test results, and geophysical logs based on borehole and rock-core records. Data required for shapefile generation can be compiled outside of ArcView, then joined with a twodimensional (2D) coverage of well locations inside ArcView in order to generate and visualize the well-field components. The extension generates 3D multipart shapefiles of well parts for cased, open, screened, and packertested intervals, 3D plane shapefiles of inclined stratigraphic contacts, water-bearing zones, and borehole fractures, and 3D polyline shapefiles of geophysical borehole logs. The extension also provides a tool for calculating the depth(s) of intersection for an inclined plane of known location and orientation for each well in the well field.

\section{Surficial Geology of the Highstown Quadrangle, Middlesex and Mercer Counties, New Jersey}

\author{
By Scott D. Stanford \\ NJ Department of Environmental Protection \\ NJ Geological Survey \\ PO Box 42729 Arctic Parkway \\ Trenton, New Jersey 08625 \\ Telephone: (609) 292-2576 \\ Fax: (609) 633-1004 \\ e-mail: scotts@njgs.dep.state.nj.us
}

Pliocene fluvial sand of the Pensauken Formation is the dominant surficial deposit in this quadrangle. This sand covers the underlying bedrock formations, which consist of Cretaceous sand and clay onlapping Triassic sandstone. The Cretaceous sands are important aquifers. Recharge to these aquifers moves through the Pensauken Formation. The configuration of paleochannels at the base of the Pensauken is an important control on how water enters the Cretaceous sands. These paleochannels are mapped using records of several hundred wells and test borings, which are shown on the map. Elevation of the base of the Pensauken, which traces the channel forms, is shown by red contours. Overprint patterns show small topographic depressions formed by permafrost processes during the last glacial maximum about 20,000 years ago. These depressions are seasonally wet and support distinctive plant communities. 


\section{Ground-Water Recharge and Aquifer Recharge Potential for Monmouth County, New Jersey}

\author{
By Mark A. French \\ NJ Department of Environmental Protection \\ NJ Geological Survey \\ PO Box 42729 Arctic Parkway \\ Trenton, New Jersey 08625 \\ Telephone: (609) 984-6587 \\ Fax: (609) 633-1004 \\ e-mail: markf@njgs.dep.state.nj.us
}

The purpose of this map is to show ground-water recharge and aquifer-recharge potential. Ground-water recharge is calculated and ranked using the methodology found in New Jersey Geological Survey (NJGS) Report GSR-32 "A Method for Evaluating Ground-Water Recharge Areas in New Jersey" by Emmanual G. Charles and others, 1993. The method estimates ground-water recharge rather than aquifer recharge. Ground-water recharge includes but does not distiguish between recharge to aquifer and non-aquifers.

The methodology used a soil moisture budget to simulate recharge for all combinations of soils, land use and land cover (LULC) and climate. These estimates showed that long term recharge could be made using factors developed for climate, soil and LULC. Using tables of recharge constants, climate and recharge factors, ground-water recharge can be estimated using a simple formula:

$$
\begin{gathered}
\text { Recharge }=(\text { recharge factor } \mathrm{x} \text { climate factor })- \\
\text { recharge constant }
\end{gathered}
$$

The result is a range of recharge in inches/year for areas on the map. These values are then ranked into 5 catagories using the volumetric ranking as describe in Charles and others (1993) based upon the natural breaks in the volumetric data. The resulting map was shaded based upon these rankings.

Aquifer-recharge potential was appraised by examining non-domestic well-yield data. Using a statewide aquifer listing and map developed by Greg Herman and others (NJGS Open File Map OFM-25 "Aquifers of New Jersey," 1998); a 5-tier rankings system was developed for each aquifer, for which there were data, using median yield. For aquifers without data, rankings were developed based upon the professional judgement of NJGS geologic and hydrogeologic staff. Well yield data were used because it was the most comprehensive set of data available about aquifers.

Once the aquifer rankings were established, these were combined with the ground-water-recharge rankings to produce the aquifer-recharge potential map. The combination produced a $5 \times 5$ matrix of ground-water recharge versus aquifer recharge rankings. The map shows how ground-water recharge rates relate to the quality (as measured by well yield) of the underlying aquifer.

\section{Fossil Dinosaur Tracks - Newly Found Fossil Dinosaur Track and Geologic Setting in Newark Basin}

\author{
By Zehdreh Allen-Lafayette
}

\author{
NJ Department of Environmental Protection \\ NJ Geological Survey \\ PO Box 42729 Arctic Parkway \\ Trenton, New Jersey 08625 \\ Telephone: (609) 292-2576 \\ Fax: (609) 633-1004 \\ e-mail: zehdreh@njgs.dep.state.nj.us
}

The AFossil Dinosaur Tracks@ poster was created for a science fair for 4th graders at Washington Crossing State Park. It was a short term project ( $11 / 2$ days) that needed revision and tweaking. I had the chance to revamp it for Earth Science week. NJGS had a display at the New Jersey State Museum that included this poster and a fossil trackway found in northern New Jersey, which was on loan from Rutgers University. This poster focuses on the Hadrosaurus which is the New Jersey state dinosaur and a herbivore. This poster is nicknamed the veggiesaurus poster.

The ANewly Found Fossil Dinosaur Track@ poster was created for the Earth Day 2000 festivities at DEP, using the previous poster as a template. The State Museum loaned the fossil track and museum employees wrote text to suit. Since the track is thought to have been made by a Dilophosaurus-like dinosaur the poster focuses on the Dilophosaurus, a carnivore. This poster was nicknamed the Hello-I-love-you-you're-meat-osaurus poster. 


\section{Drought Indicators for New}

\section{Jersey}

\author{
By Jeffrey L. Hoffman
}

\author{
NJ Department of Environmental Protection \\ NJ Geological Survey \\ PO Box 42729 Arctic Parkway \\ Trenton, New Jersey 08625 \\ Telephone: (609) 292-2576 \\ Fax: (609) 633-1004 \\ e-mail: jeffh@njgs.dep.state.nj.us
}

New Jersey is divided into 6 drought regions. The drought condition in each region is based on specific water-supply indicators in each region. These include precipitation and streamflow deficits, reservoir levels, and ground-water levels. Based on these indicators, best professional judgement, and consultation with appropriate parties, DEP staff determine the drought condition in each region.

This plot summarizes the indicators. Reservoir levels are given both for New Jersey reservoirs as well as the
Delaware River Basin reservoirs in New York. DRBC reservoirs are critical to the water supply of the Delaware River Basin and the Delaware \& Raritan Canal and thus to New Jersey. Indicators are shown only for those water resources significant to each drought region.

A number of blocks show other data relevant to droughts in New Jersey. The 'U.S. Drought Monitor' is a summary of current national conditions. The 'Declared' Drought Status in Neighboring Areas' block summarizes declared drought status in nearby areas. The '90-Day Precipitation Deficits' is a county-based summary of recent precipitation deficits. The "Average Source of Potable Withdrawals' block shows the sources of potable water withdrawn in each county on average over the period 1990-1996. The 'Resource Importance as a NJ Water Source' block is an evaluation of the importance of each resource to a region compared to other sources of water to that region. The 'Work Underway' block describes the current efforts by NJDEP to expand the data networks currently monitoring NJ's water supply and drought condition. The 'Water Transfers' block shows the volume of water transferred between drought regions during normal and emergency operations. These are approximate numbers.

This approach does not address the issues of ecological droughts or water supplies from confined aquifers. 



\title{
Integrated Digital Geospatial Data for the Cape Girardeau, Missouri Area in the New Madrid Seismic Zone: A Central United States Atlas Concept
}

\author{
By Rick H. Bradford \\ USGS, Mid-Continent Mapping Center \\ 1400 Independence Road \\ Rolla, Missouri 65401 \\ Telephone: (573) 308-3765 \\ Fax: (573) 308-3652 \\ e-mail: rbradford@usgs.gov
}

\begin{abstract}
Through a cooperative partnership between the Geologic Discipline (GD)-Eastern Region, Earth Surfaces Process Team and National Mapping Discipline (NMD)Mid-Continent Mapping Center, a project is underway to integrate digital geospatial data for the Cape Girardeau, Missouri area in the New Madrid Seismic Zone. The primary goal is the fusion of earth science information of cartographic, geographic, hydrologic and geologic data using geographic information system (GIS) tools and providing access to these data.
\end{abstract}

The concept to develop a prototype central United States atlas for electronic presentation of geospatial data initiated from the need to increase public knowledge of USGS products, data, and services including NMD Geospatial Data and Science Programs and GD National Cooperative Geologic Mapping Program and National Earthquake Hazards Reduction Program, and to increase public awareness of earthquake risks in the central United States. With the availability of internet access, GIS technologies and geospatial data, users will have the capability to evaluate options and make informed management decisions that effectively reduce economic risks and improve public safety.

The prototype atlas will be comprised of multi-scale products ranging from $1: 24,000$ to $1: 2,000,000$ including existing and new map data. For the larger-scale prototype, a 15-minute area was selected for the 1:24,000 quadrangles including the Cape Girardeau, Thebes, Scott City and McClure quads (figure 1). The geographic and cartographic data sets include Digital Raster Graphics (DRG),
Digital Orthophoto Quads (DOQ), Digital Elevation Models (DEM), Digital Line Graphs (DLG), Geographic Names (GNIS), Environmental Protection Agency (EPA) chemical sites and Corps of Engineers (COE) data. The geologic data sets include four main layers: bedrock, surficial, fault and point. These layers have attributed and symbolized using ArcInfo and ArcView. Other historical geologic maps will be included as well as new data from the Missouri Geological Survey and Central United States Earthquake Consortium (CUSEC)- State Geologists. A limited number of geospatial data layers have been merged only for product prototypes at this time. In addition, these layers have been merged and edge aligned for the 7.5minute data sets listed above to produce a 15 -minute prototype product.

For the medium-scale prototype at 1:100,000, the new 1:24,000 data will be incorporated with the existing $30 \mathrm{x}$ 60-minute Cape Girardeau quadrangle data. For the smaller-scale prototype at 1:250,000, the CUSEC Paducah quadrangle and other existing data will be used for products. All prototypes will require peer technical reviews and geologic evaluations before providing access to these data. For internal review purposes only, a limited number of 7.5-minute data sets have been demonstrated using ArcIMS.

These digital geospatial data will provide users with information that can be easily integrated into other Web applications and promote the value of regional geologic data integrated with other geographic and cartographic data. 


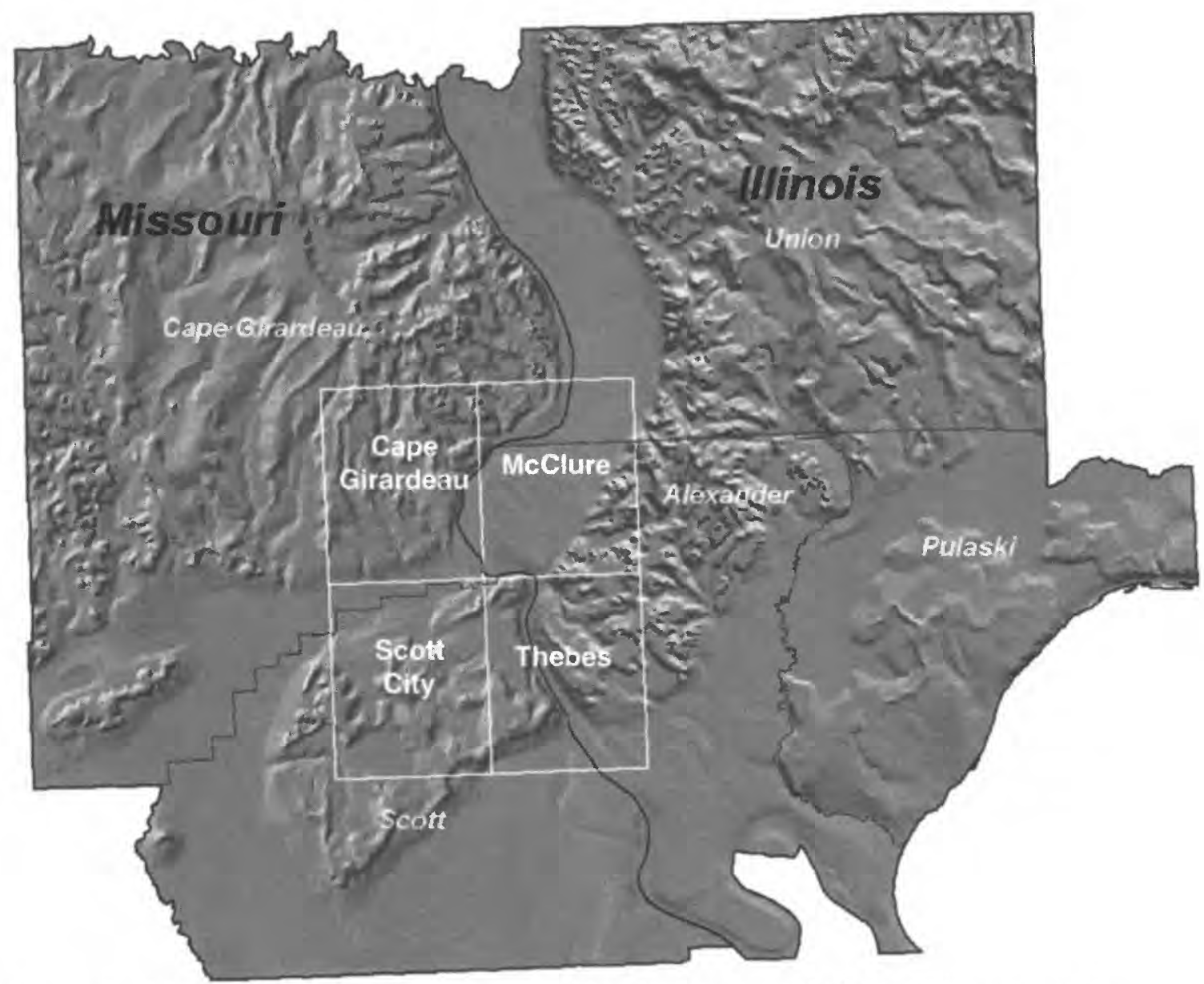

Figure 1. Map showing area of the prototype, within the four named $7.5^{\prime}(1: 24,000$-scale $)$ quadrangles. 


\title{
Will a Standard Data Model Work for Washington, DC Area Geologic Geospatial Data?
}

\author{
By Adam M. Davis \\ U.S. Geological Survey \\ e-mail: amdavis@usgs.gov \\ Department of Geology \\ Indiana University \\ 1001 E. 10th St \\ Bloomington, IN 47405
}

\begin{abstract}
The U.S. Geological Survey Eastern Region Earth Surface Processes Team (EESP) assembled a database to accompany Geographic Information System (GIS) geologic layers of the western portion of the Washington DC Metropolitan Area. The process of assembling this database involved combining spreadsheets, map unit description text files, and Arc/Info attribute tables into one database. The database design attempts to provide data storage efficiency, ease of data retrieval, compliance with the standard data model effort, and consistency with the language and style of the data as it was collected and originally entered into digital format. At the end of its compilation process the database was converted to a format compliant with the North American Data Model standard for geologic map data (NADM). Application of the NADM to Washington DC Area geologic map data had several problems. One problem was that the NADM was complex and had abstract terminology that was different from the terminology used by EESP. In addition, there were several data elements that didn't seem to fit into the NADM format, including: Minerals for an entire rock unit rather than for just a rock composition, Clast and Matrix chemistry information for certain types of rocks such as conglomerates, and information about planar features of the map units such as bedding and foliation. The data model does provide ways to preserve the individuality and integrity of the geologist's interpretation and data, but it is complicated, causing confusion about where certain data elements fit into the data model.
\end{abstract}

\section{INTRODUCTION}

The U. S. Geological Survey Eastern Region Earth Surfaces Processes Team (EESP) has created a geologic map database based on bedrock and surficial geology maps of the Washington DC Area. The team attempted to convert its database into a format that conformed to the North American Data Model for geologic map databases, Version 4.3 (NADM). The NADM is part of an effort to standardize methods and language for representing and storing geologic geospatial data. More information about the NADM can be found at the North American Data Model Steering Committee's web site, <http://geology.usgs.gov/dm>.

The EESP wanted to use a data model that would preserve the integrity of its data. The team wanted to ensure that the observations and interpretations of the field geologists would not be distorted by the method of digital data representation and storage. The EESP felt that several issues or concerns must be addressed when creating the database. These include:

- Keeping the integrity of the geologists' observations and interpretations,

- Accounting for needs of prospective users,

- Ensuring that the data are easily extracted from the storage format, and

- Ease of implementation.

In addition, geologists have expressed concern that a standard data model can endanger the individuality of geologist interpretations. This individuality may be lost with the use of standard language and/or the standard format, and efforts must be made to preserve this individuali- 
ty while pursuing the communication benefits of a data model standard.

This paper discusses how well the NADM addresses these concerns, after discussing some specifics about an attempt to place the EESP geologic map data into the NADM. Conveying some of the issues and problems that were encountered during the EESP's application of the NADM will hopefully provide some useful feedback that can be incorporated into future iterations of the model.

\section{METHODS}

The EESP has constructed a geologic map database for the Washington, DC Area. It currently contains geologic data from three $30 \times 60$ minute quadrangles:

Frederick, Washington West, and Fredericksburg. The team has taken attributes from the three quadrangle geologic maps and incorporated them into a single database using a process involving collaboration between field geologists and Geographic Information System (GIS) design personnel.

Initially, the geologic map attribute data recorded by EESP geologists for this area were entered into a spreadsheet format that contained 46 columns for each map unit. The fields were: $\langle$ MAPUNIT $\rangle,<$ SURF_BED $>$, $<$ SURFTYPE $>$, <LITHPRI $>$, <LITHSEC $>$, <LITHTER $>$, $<$ FORM $>$, $<$ MEMBER $>$, $<$ GROUP $>,<$ SUPERGROUP $>$, $<$ ROCKCLASS $>,<$ AGE $>,<$ GEOCHR $>$, $<$ GEOCHRTECH $>$, <GEOCHRREF $>$, <FOSSIL $>$, $<$ FOSSILTYPE $>,<$ FOSSILREF $>$, <CORRELEXTR $>$, $<$ ORIGIN $>$, <RES $>,<$ RESREF $>$, <COLOR $>$, <MINPRI $>$, $<$ MINSEC $>,<$ MINOTH $>$, <CLASTPRI $>,<$ CLASTSEC $>$, $<$ CEMENT $>,<$ THICKAPPRX $>,<$ THICKRANGE $>$, $<$ BEDTHIN $>,<$ BEDMEDIUM $>,<$ BEDTHICK $>$, $<$ CONTUP $>$, <CONTLOW $>$, <FOLPRI $>$, $<$ FOLSEC $>$, $<$ FOLTER $>$, <CMPM $>$, <RMPM $>$, <RMRM $>$, $<$ DEFORMAGE $>,<$ DEFORMTECH $>,<$ DEFORMREF $>$, and $<$ COMMENTS $>$. Table 1 is an example of the first 7 fields of this spreadsheet.
These data were then normalized (i.e., number of fields required to store the data reduced) where possible and put into a format that is easier to convert to the NADM. Please see Davis et al. (2001) to examine the resulting MS Access database (dcdb_eesp.mdb) in detail. Highlights of the format transformation include placing lithological, mineralogical, planar feature, and clast information into their own tables. Some data elements were not readily normalized or split off as reference ("look-up") tables. These fields of data compose the table [CHARACTER], shown in Table 2.

After the initial database design was complete, queries were written to convert to the NADM format and new reference tables were created. The converted database was stored as the file dcdb_dm.mdb (Davis et al., 2001).

Version 1.0 of the two databases (the Eastern Earth Surface Processes Team and the NADM versions dcdb_eesp.mdb and dcdb_dm.mdb, respectively) were evaluated by geologists of the Eastern Earth Surface Processes Team through reviews for Davis et al. (2001) and various informal discussions. These databases were compared and the NADM was evaluated in terms of its success in accommodating the data of the EESP.

\section{RESULTS}

In several ways, the NADM was difficult to implement. It is a complex model and does not seem to accommodate all of the data elements that are specific to the EESP geologic maps. As a result, only approximately 50 per cent of the EESP data was placed into the NADM. The following data elements were not placed into the NADM:

- Primary, Secondary, and Other minerals of map units

- Clast and Matrix chemistry of rocks like conglomerates or breccias

- The map units' dominant and secondary planar features

- Existence and reference for fossil information

Table 1. First 7 fields of the single table that initially held all of the data for the DC area geologic map database.

\begin{tabular}{|c|c|c|c|c|c|c|}
\hline MAPUNIT & SURF_BED & SURFTYPE & LITHPRI & LITHSEC & LITHTER & FORM \\
\hline & Surficial & Alluvium & silt & sand & gravel & \\
\hline $\mathrm{Qt}$ & Surficial & terrace, lower & sand & gravel & boulders & \\
\hline Qcf & Surficial & colluvium, fine & quartz (milky) & quartzite & & \\
\hline $\mathrm{Qc}$ & Surficial & colluvium, coarse & quartzite & greenstone & & \\
\hline $\mathrm{Qr}$ & Surficial & Residuum & quartz (milky) & clay & & \\
\hline $\mathrm{Ql}$ & Surficial & lag gravel & quartz (milky) & & & \\
\hline QTt & Surficial & terrace, high & gravel & boulders & sand & \\
\hline $\mathrm{Kp}$ & Surficial & Coastal Plain & gravel & sand & silt and clay & Potomac \\
\hline $\mathrm{Jd}$ & Bedrock & & diabase & & & Diabase \\
\hline $\mathrm{Jdl}$ & Bedrock & & diabase & & & low-titanium quartz normative diabase \\
\hline Jdo & Bedrock & & diabase & & & olivine-normative diabase \\
\hline Jdg & Bedrock & & diabase & & & late diabase cumulates \\
\hline $\mathrm{Jdh}$ & Bedrock & & diabase & & & hi-titanium quartz normative diabase \\
\hline Jdc & Bedrock & & diabase & & & early diabase cumulates \\
\hline
\end{tabular}


- Map Unit radiometric ages

- Appalachian physiographic province

- Origin (i.e., how the rock formed)

- The natural resource type of a map unit

- Character of the bedding within sedimentary units

- Appalachian deformational event

- Metamorphic minerals

- Metamorphic ages

These data were not placed in the standard format for a variety of reasons. Either the place for them within the model was difficult to determine, they were not accounted for by the model, or some combination of these factors. In some cases, entire tables would need to be added to the NADM in order to accommodate the EESP data, because appropriate tables do not currently exist. This is certainly an anticipated part of the NADM evolution. In other cases, new fields would need to be added to existing NADM tables. Among the data that did go into the NADM, some of it didn't fit quite right and some of the NADM field specifications were modified. Some notes and further description concerning the lack of fit of some of these data elements are:

- Clast Information for map units, including clast and matrix chemistry of rocks like conglomerates, did not seem to have a place in the NADM. The table CLASTS was created during the design process of dcdb_eesp.mdb and is shown in Table 3 .

- Mineralogical information for the entire rock unit was recorded by the EESP, rather than mineralogical description given for individual rock compositions within the unit. The NADM recognizes the mineralogical information associated with individual lithologies in the table "Rock Composition" in the field "mineralogy_desc". An example of this table is shown as Table 4. By contrast, the dcdb_eesp.mdb has its own mineralogical table, called "MINERALS" to store mineralogical data associated with the whole map unit. A sample from this table is displayed as Table 5. This minerals table allows individual minerals to be stored as well as their rank (i.e., primary, secondary, other) and type.

- A METAMORPH table was created in dcdb_eesp.mdb, because there isn't one in the NADM.

- The CHARACTER table (Table 2) contains these fields that the NADM does not readily accommodate or promote:

- Province - contains a value designating a Physiographic Province

- Rock_grp - a rock classification custom tailored to a recent field trip. These data were placed into the lith_class field of the NADM despite an imperfect fit

- Map_Unit - to connect to tables that were added

- ORIGIN - contains information about the manner in which the unit formed. The data contained in this field was placed into the field lith_form of the RockComposition table despite an imperfect fit

- BEDDING - thin, thick, medium or a combination of these

- DEF_EVENT - Regional deformational or orogenic event

- RESOURCE - the societal uses of a map unit

- RES_REF - reference for the societal uses

- FOSSIL - fossils present in the unit

- FOS_REF - reference(s) for the fossil information.

As the EESP finds more uses for the dcdb_eesp.mdb and its accompanying ArcView shape files containing the

Table 2. First 8 fields of the CHARACTER table of dcdb_eesp.mdb.

$\begin{array}{lllllll}\text { MAP_UNIT } & \text { ROCK_CLASS } & \text { PROVINCE } & \text { ROCK_GRP } & \text { PERIOD } & \text { FOSSIL } \\ \text { Ctbh } & \text { SEDCARB } & 5 & \text { LS } & \text { Lower Cambrian } & \text { Trilobites } \\ \text { Ct } & \text { SEDCARB } & 5 & \text { LS } & \text { Lower Cambrian } & \text { Trilobites } \\ \text { Ccp } & \text { METSEDSILIC } & 4 & \text { Metasedimentary } & \text { Lower Cambrian } & \text { NR } \\ \text { Ca } & \text { METSEDSILIC } & 4 & \text { Metasedimentary } & \text { Lower Cambrian } & \text { Skolithus, trilobite Walcott (1896) } \\ \text { Ch } & \text { METSEDSILIC } & 4 & \text { Metasedimentary } & \text { Lower Cambrian } & \text { Skolithus } \\ \text { Chs } & \text { METSEDSILIC } & 4 & \text { Metasedimentary } & \text { Lower Cambrian } & \text { Skolithus } \\ \text { Cwo } & \text { METSEDSILIC } & 4 & \text { Metasedimentary } & \text { Lower Cambrian } & \text { NR } & \\ \text { Cwm } & \text { METSEDSILIC } & 4 & \text { Metasedimentary } & \text { Lower Cambrian } & \text { NR } & \\ \text { Cwmq } & \text { METSEDSILIC } & 4 & \text { Metasedimentary } & \text { Lower Cambrian } & \text { NR } & \text { age uncertain } \\ & & & & & & \text { age uncertain } \\ \end{array}$

Table 3. The CLASTS table of dcdb_eesp.mdb.

\begin{tabular}{llll} 
MAP_UNIT & CLAST_LITH & CLAST_RANK & CEMENT \\
Cf & Limestone & Primary & calcium carbonate \\
Cfr & Limestone & Primary & calcium carbonate \\
$\mathrm{Cl}$ & meta-arenite & Primary & quartzofeldspathic matrix \\
$\mathrm{Cl}$ & muscovite-biotite schist & Secondary & quartzofeldspathic matrix \\
$\mathrm{Clc}$ & red jasper & Secondary & quartz \\
$\mathrm{Clc}$ & vein quartz & Primary & quartz \\
$\mathrm{Clo}$ & meta-arenite & Primary & quartzofeldspathic \\
$\mathrm{Clo}$ & muscovite-biotite schist & Secondary & quartzofeldspathic \\
$\mathrm{Cs}$ & metasedimentary rocks & Primary & quartzofeldspathic matrix \\
\hline
\end{tabular}


Table 4. Some of the possible fields of the Rock_Composition table of the North American Data Model standard for geologic map data, version 4.3

\begin{tabular}{|c|c|c|c|c|c|c|}
\hline $\begin{array}{l}\text { Coa_id } \\
62\end{array}$ & $\begin{array}{l}\text { Comp_seq } \\
1\end{array}$ & $\begin{array}{l}\text { Rock_name } \\
\text { schist }\end{array}$ & $\begin{array}{l}\text { Lith_class } \\
\text { metamorphic }\end{array}$ & Lith_form & $\begin{array}{l}\text { Mineralogy_desc } \\
\text { Dominantly quartz and } \\
\text { biotite with garnet } \\
\text { porphyroblasts }\end{array}$ & $\begin{array}{l}\text { Color_desc } \\
\text { Black and gray }\end{array}$ \\
\hline 62 & 2 & gneiss & metamorphic & & $\begin{array}{l}\text { Dominantly quartz, } \\
\text { biotite, and hornblende }\end{array}$ & Black and gray \\
\hline
\end{tabular}

Table 5. The MINERALS table of dcdb_eesp.mdb

\begin{tabular}{llll} 
MAP_UNIT & MINERAL & MIN_RANK & MIN_TYPE \\
$\mathrm{Ca}$ & clay & Secondary & \\
$\mathrm{Ca}$ & quartz & Primary & \\
$\mathrm{Car}$ & clay & Secondary & \\
$\mathrm{Car}$ & quartz & Primary & \\
$\mathrm{Ccbs}$ & calcite & Secondary \\
$\mathrm{Ccbs}$ & dolomite & Primary & \\
$\mathrm{Ccbs}$ & quartz & Other & \\
$\mathrm{Ccp}$ & clay & Secondary \\
$\mathrm{Ccp}$ & graphite & Primary \\
\hline
\end{tabular}

spatial data, new methods of classifying the data will be required, resulting in the need to add fields to the database. For example, two applications have required that map units be grouped according to Appalachian Physiographic Province, so this data element was added into the database as the field "Province".

\section{DISCUSSION AND CONCLUSIONS}

During this process of attempting to fit EESP data into the NADM, the NADM was evaluated with regard to usability characteristics, including:

- Keeping the integrity of the geologists' observations and interpretations,

- Accounting for needs of prospective users,

- Ensuring that the data are easily extracted from the storage format, and

- Ease of implementation.

The NADM provides options for preserving the integrity of geologist observations by allowing the addition of tables and fields where appropriate, but requires placement of data into fields and tables whose names and position in the data model are not intuitive to geologists. One example of an unnecessary complexity that makes the model less intuitive is the fact that lithologic data is separated into "Rock Unit" data and "Rock Composition" data, which are housed in different portions of the data model. Of course, software tools eventually can be built to "insulate" the geologist from the NADM, but these tools are expensive to develop and not yet available.

The NADM does not account for many of the specific needs of the EESP and its clients. Fields and tables had to be added to the NADM in order to ensure that these needs can be met. For example, clast chemistry in the Leesburg conglomerate is important for landfill siting considerations and clast chemistry doesn't have a place in the NADM. For another example, a field needed to be added that described the resource potential of map units, and the NADM table to which it should belong is uncertain.

Extracting data from the database into user-friendly formats is an issue for both of the databases (dcdb_eesp.mdb and dcdb_dm.mdb). In fact, it is a common issue that database designers face. Typically, "queries" (or "views" depending on the database management software) are written to put the data into a format that geologists and others can work with. The amount of query writing required is directly proportional to the complexity of the data storage model, and is large for the dcdb_dm.mdb (the NADM compliant version), but not much larger than for the dcdb_eesp.mdb database. One example of this type of query is one that was written for the dcdb_eesp.mdb database ("output5", see Table 6) to combine province information with lithology and mineralogy information. This query helped facilitate the communication of various geological processes and features through a series of thematic maps. Queries such as these provide custom snapshots of the data that are very important to the usability of the database. Without these custom views of the data, the EESP geologists have had trouble understanding their own data and finding what they want to know about map units.

Table 6. Some of the fields of [output5] - a query used for data retrieval.

\begin{tabular}{|c|c|c|c|c|c|}
\hline $\begin{array}{l}\text { MAP } \\
\text { UNIT }\end{array}$ & NAME & NAME_RANK & PROVINCE & ROCK_GRP & PRIM_LITH \\
\hline Cam & amphibolite & Formation & 2 & Mafic & amphibolite \\
\hline Car & Araby & Formation & 5 & Metasedimentary & sandy metasiltstone \\
\hline Cef & felsic metavolcanic rocks & Member & 2 & Metavolcanic & \\
\hline $\mathrm{Ccg}$ & breccias greenstones & Member & 2 & Metavolcanic & \\
\hline $\mathrm{Cch}$ & Chopawamsic & Formation & 2 & Metavolcanic & metavolcanics \\
\hline Ccp & carbonaceous phyllite & Formation & 4 & Metasedimentary & carbonaceous phyllite \\
\hline
\end{tabular}


The NADM is not easy to implement. Careful scrutiny coupled with trial and error are required to figure out how data should be placed into this model. Removing the legend and symbolization portions and dissolving the compound object-singular object divide would help simplify this standard, but might limit its potential.

The NADM is a very important standard that will help geologists to communicate with other professionals in a uniform way, but should be made easier to implement and be further tested by potential users before it is adopted. Despite its problems, the NADM is a tangible example of a standard geologic map data model that can be improved upon, and Version 4.3 of the NADM has been very useful as a stimulus to discuss and explore data storage and representation issues in the Geologic Mapping community.

\section{REFERENCE}

Davis, A.M., Southworth, C.S., Reddy, J., Schindler, J.S., Mixon, R.B., Lyttle, P., 2001, Geologic Map Database of the Washington DC Area featuring data from three $30 \times 60$ minute quadrangles: Frederick, Washington West, and Fredericksburg. U.S. Geological Survey Open File Report, OFR-01-227 (CDROM), <http://pubs.usgs.gov/openfile/of01-227>. 
230 


\title{
Selling Science to the American Public
}

\author{
By the Central Publications Group
}

\author{
U.S. Geological Survey \\ Box 25046, MS 902 \\ Denver Federal Center \\ Denver, CO 80225-0046 \\ Telephone: (303) 236-5476 \\ Fax: (303) 236-6287 \\ e-mail: delane@usgs.gov
}

\section{HOW THESE MAPS “SELL” SCIENCE}

The Central Publications Group (part of the Geologic Division, U.S. Geological Survey) has recently produced several maps designed to appeal to a popular audience. Two of these are geologic maps, one of the Grand Canyon (Billingsley, 2000) and the other of the Colorado National Monument (Scott and others, 2001), and a third is a map showing locations of historical earthquakes in the populous northeastern United States (Wheeler and others, 2001a).

Because the publications group and some of the authors anticipate that these maps will have an audience beyond the technical sphere, they designed the map sheets to include many photographs and artistic drawings that supplement the scientific data. For example, the map sheet for the Grand Canyon includes several drawings from 19th-century USGS reports, giving an historical perspective to our science. The map sheet for the Colorado National Monument includes visually prominent sections on history and ecology, in addition to geology, that are illustrated with drawings and photographs of wildlife and petroglyphs, as well as of landforms. Both map sheets also include all the conventional components of a geologic map report: the map itself, a correlation diagram, cross sections, and a complete technical description of the map units.

The core information on the two geologic maps is technical, the same information that would be supplied to a scientific audience. The publications differ from conventional geologic maps in that additional graphics were included to increase their popular appeal. These maps will be eye-catching additions to the publications sold by the visitor centers at the Grand Canyon and the Colorado National Monument. However, the map showing earthquake data from a period of more than 300 years for the northeastern United States was specifically designed to appeal to a nontechnical audience. The supplemental illustrations are photographs of earthquake damage from the late 20th century and, most dramatically, images of newspaper headlines from the mid-20th century and woodcuts from the mid-18th century that recorded the earthquakes of those eras. A quotation from a 1755 broadside, set as a graphic in large type, appeals to the imagination in a way that the basic data of scientific discourse may not: "See! how poor Wretches from their Beds Affrightedly arise, And to their clatt'ring Windows run, With Horror in their Eyes!"

The earthquake map is supplemented by a fact sheet (Wheeler and others, 2001b), and a press conference was held upon the release of both of these publications (see the press release at $<$ http://www.usgs.gov/public/press/ public_affairs/press_releases/pr $1445 \mathrm{~m} . \mathrm{html}>$. Analysis of server activity for the week following the press conference showed 2,497 downloads of the PDF (Adobe Acrobat Portable Document Format) file for the fact sheet and 35,463 downloads of the PDF file for the map sheet (Eugene Ellis, written commun., 2001).

\section{HOW THE MAPS WERE PRODUCED}

The two geologic maps were first compiled on scalestable mylar film, digitized in ArcInfo (or digitized in another program and converted to ArcInfo), and then exported as ArcView shapefiles. The shapefiles were imported into Adobe Illustrator 8.0 via the plug-in filter MAPublisher, and the layout of the map sheets was completed in Adobe Illustrator (for a full description of this production process, see Lane and others, 1999; for an updated description of the process, see the Microsoft PowerPoint presentation of the session at USGS Publications 2000 conference entitled "Publishing maps from GIS software-MAPublisher and ArcInfo" on 
Wednesday, May 10, 2000, available online at $<$ http://capp.water.usgs.gov/pub2000/>). The point symbols on the maps were exported from ArcInfo as EPS (Encapsulated PostScript) files. The topographic bases for both maps were derived from DLG (Digital Line Graph) files. Following the generation of the basic geologic map components, a graphic artist added scanned photographs and original art, and other design elements, working with the images in Adobe Photoshop and Illustrator. The graphic artist completed the final designs and layouts in Illustrator.

For the earthquake map, the authors plotted the locations of earthquakes and imported them into ArcInfo. They created the shaded-relief base map in ArcInfo from USGS DEM's (Digital Elevation Models) and exported it as an EPS file. All our attempts to open this EPS file in Illustrator were fruitless, the process taking 8 hours or more without success. (In our experience, importing large graphics files from ArcInfo and ArcView is often not feasible, possibly because of the way graphics are drawn in those programs.) Therefore we rasterized the shaded-relief base at high resolution ( $325 \mathrm{dpi}$ ) in Photoshop and then imported it into the Illustrator 8.0 layout, an approach that we had previously found to be successful. A graphic artist imported word-processing files into the Illustrator layout and formatted the text there. The artist then added scanned photographs, woodcuts, newspaper headlines, and other design elements, also working with the images in Photoshop and Illustrator, and completed the final design and layout in Illustrator.

\section{REFERENCES CITED}

Billingsley, G.H., 2000, Geologic map of the Grand Canyon 30' x $60^{\prime}$ quadrangle, Coconino and Mohave Counties, northwestern Arizona: U.S. Geological Survey Geologic Investigations Series I-2688, scale 1:100,000; includes pamphlet, 15 p., <http:/geology.cr.usgs.gov/pub/i-maps/ i-2688/>.

Lane, D.E., Donatich, Alex, Brunstein, F.C., and Shock, N.A., 1999, Digital geologic map production and database development in the Central Publications Group of the Geologic Division, U.S. Geological Survey, in Soller, D.R., ed., Digital mapping techniques '99-Workshop proceedings: U.S. Geological Survey Open-File Report 99-386, p. 11-15, $<$ http://pubs.usgs.gov/openfile/of99-386/lane.html>.

Scott, R.B., Harding, A.E., Hood, W.C., Cole, R.D., Livaccari, R.F., Johnson, J.B., Shroba, R.R., and Dickerson, R.P., 2001, Geologic map of Colorado National Monument and adjacent areas, Mesa County, Colorado: U.S. Geological Survey, Geologic Investigations Series I-2740, scale 1:24,000; includes pamphlet, $40 \mathrm{p}$., <http://geology.cr.usgs.gov/pub/i-maps/i-2740/>.

Wheeler, R.L., Trevor, N.K., Tarr, A.C., and Crone, A.J., 2001a, Earthquakes in and near the northeastern United States, 1638-1998: U.S. Geological Survey Geologic Investigations Series I-2737, scale 1:1, 500,000, $<$ http://geology.cr.usgs.gov/pub/i-maps/i-2737/>.

Wheeler, R.L., Trevor, N.K., Tarr, A.C., and Crone, A.J., 2001b, Earthquakes in and near the northeastern United States, 1638-1998: U.S. Geological Survey Fact Sheet 0006-01, $<$ http://geology.cr.usgs.gov/pub/fact-sheets/fs-0006-01/>. 


\title{
Cartographic Choices for the Surficial Geologic Map of Central and Southern New Jersey
}

\author{
By Will R. Stettner and Elizabeth D. Koozmin
}

\author{
U.S. Geological Survey \\ National Center, MS 903 \\ 12201 Sunrise Valley Drive \\ Reston, VA 20192 \\ Telephone: (703) 648-4343 \\ Fax: (703) 648-6138 \\ e-mail: ekoozmin@usgs.gov
}

\section{INTRODUCTION}

The Surficial Geologic Map of Central and Southern New Jersey (Newell and others, 2000) consists of portions of eight 1:100,000-scale quadrangles. This map was a product of a cooperative agreement between the U.S. Geological Survey (USGS) and the New Jersey Geological Survey; the USGS did final compilation, editing, and production. The authors began field work in 1984; their first compilation was completed (using traditional ink-ongreenline methods) and reviewed by 1996 . The resulting product is a model not only of a geomorphic system that has responded to extreme climate changes, but also of modern surficial processes, including the influence of humans on the landscape.

After peer review, the editing and production of the maps began in 1996. A decision was made to forego digitizing the map in ArcInfo and bridge the traditional-to-digital cartography gap by employing digital graphic production methods (such as Adobe Illustrator). Much of that decision was due to the state of the base-map materials and the fact that current technology had far supplanted their usefulness. Map editing was done using the hand-colored paper copies. Corrections were then made to the greenlines.

There are 65 map units, two of which are shown only in the cross sections. Linework consists solely of contacts, scarps, and arrows showing sediment flow directions or channels. Compared with a bedrock geologic map (which may have contacts, folds, faults, structural data, and many other features), one might think that the surficial counterpart would be much simpler to produce. A closer look at the maps, and some details about its production, reveal a deeper complexity.

\section{GEOLOGIC LINEWORK AND POLYGONS}

The production tool of choice in the USGS Eastern Publications Group is Adobe Illustrator (AI). Creating AI files from the greenlines presented a challenge to the cartographers. First, a traditional cartographer scribed the geologic contacts in order to get clean, smooth linework with which to work. Film positives were made from the scribecoats. The film positives were given to a contractor, Geologic Data Systems (GDS) of Denver, Colo., to be scanned. Raster images of the linework were then autovectorized and edited to produce geologic unit polygons.

The southern sheet was digitized and the polygons were tagged with the geologic unit identifications by GDS using AutoCAD. The data were exported as DXF files. Using the MAPublisher filter, the files were opened in AI, whereby each unit was automatically placed in its own layer; however, the DXF format had a limit of the number of nodes that could be used to create a polygon, and exceeding that number prevented the AI file from opening. GDS modified the DXF files by decreasing the number of nodes, but this step took several iterations to complete.

The central sheet also was digitized using AutoCAD and tagged by GDS, but this time the data were exported as ArcInfo SHAPE files. Again, using MAPublisher, the files were opened in AI, this time more easily than the DXF files, but all the units were in one layer. The units 
then were manually separated into their own layers. The total number of polygons for both sheets is about 7,000.

\section{BASE MAP}

For the authors' compilation, before digital mapping technology had evolved, a photomosaic of the eight 1:100,000-scale quadrangles was produced. This mosaic was simply one combination of drainage, topography, and cultural features (roads, town and geographic feature labels, and so on). This method of producing compilation materials limited the options for a digital base map later in the process.

Once production was underway, a separate mosaic of the map's drainage linework (from the eight quadrangles) was produced. This mosaic was then scanned and digitized by GDS using AutoCAD. This step was necessary in order to ensure an accurate match to the geologic contacts because, for many of the units, either open-water shorelines (rivers, ponds, oceans, and marshes) or single-line drainages (creeks, some rivers) also acted as unit boundaries. After the geologic units were imported as described above, black geologic contact lines had to be "hidden" by the blue drainage lines. This task was accomplished in AI. Separate mosaics of culture and topographic contours also were produced and scanned.

\section{COLOR}

\section{Geologic Unit Colors}

Another cartographic challenge was choosing colors. The traditional colors for Quaternary and Tertiary units on U.S. Geological Survey maps are limited to yellows and oranges. With 65 units and a wide variety of environments to be represented, the colors shown here are a drastic departure from tradition (see table 1).

The Quaternary sediments found throughout the map needed to contrast with the Tertiary and Cretaceous units, so they retained the traditional oranges and yellows. Dark browns, grays, and a dark green (for cranberry bogs) were used to show manmade units. The dune field deposits (unit Qe) needed to stand out on their own, so they are the only blue polygons on the map.

In the Piedmont, the authors wanted the very small colluvial, alluvial, and terrace deposits to be visible against the widespread residuum (unit Qsw). In addition, the diabase- and basalt-block colluvium, which were weathering products of the Triassic basin rocks, needed to be emphasized so that the underlying bedrock trend could be expressed. The entire Piedmont had to stand out clearly from the Coastal Plain, and it had to be matched to the unfinished northern sheet by Stone and others (in press); as it turned out, the color choices made on the central sheet eventually influenced many of the colors on the adjoining northern sheet.

In the Coastal Plain, there were several issues. The Pleistocene beach-barrier to lagoon units of the Cape May Formation needed to contrast with the modern beach deposits, so they were assigned a suite of bright greenyellow tones. A distinction needed to be made between freshwater-swamp and salt-marsh deposits, but both had to be green. The Pleistocene colluvial units needed to contrast well with the Tertiary and Cretaceous units from which they were derived. Lastly, the sinuous traces of ancient river-channel bar forms developed on the Bridgeton Formation needed a subtle representation; use of a pattern resolved that problem.

\section{Base-Map Colors}

The drainage is shown in 100 percent cyan ink as is typical of most USGS geologic maps. Because of the density of information, the underlying culture and topographic layers needed to be readable only in the background of the map. These two layers also had to be distinguished from each other. The contouqrs are shown in 100 percent contour brown (an ink used by the USGS on topographic sheets). Usually, the base map on USGS geologic maps is shown using a 50 percent biangle screened black, which breaks up the image somewhat. For this set of maps, a 100 percent gray ink was used instead because the culture was a raster image and screening it would have made it illegible.

\section{REVISIONS}

Of course, no map is perfect the first time it is proofed. Authors and editor reviewed many color plots before and after the base-map information was added. Three sets of problems needed resolution.

Because the digitizer at GDS was tagging polygons using the authors' hand-colored draft copy as a guide, some polygons were, in the end, unidentifiable and were tagged as such. Working with the authors, the cartographer was able to resolve these errors.

As mentioned above, joining the geologic contacts with the drainage required patient examination of many of the units for accurate placement. For instance, the alluvial units needed to be centered on the drainage. They also had to "V" upstream according to the topography.

In addition, when the senior author finally saw his map in a cleaner form, he observed that certain areas needed to be "fine tuned" for a variety of reasons. These types of adjustments were made in several areas on both sheets. In addition, the central sheet needed to join accurately with the northern sheet of Stone and others (in press). 

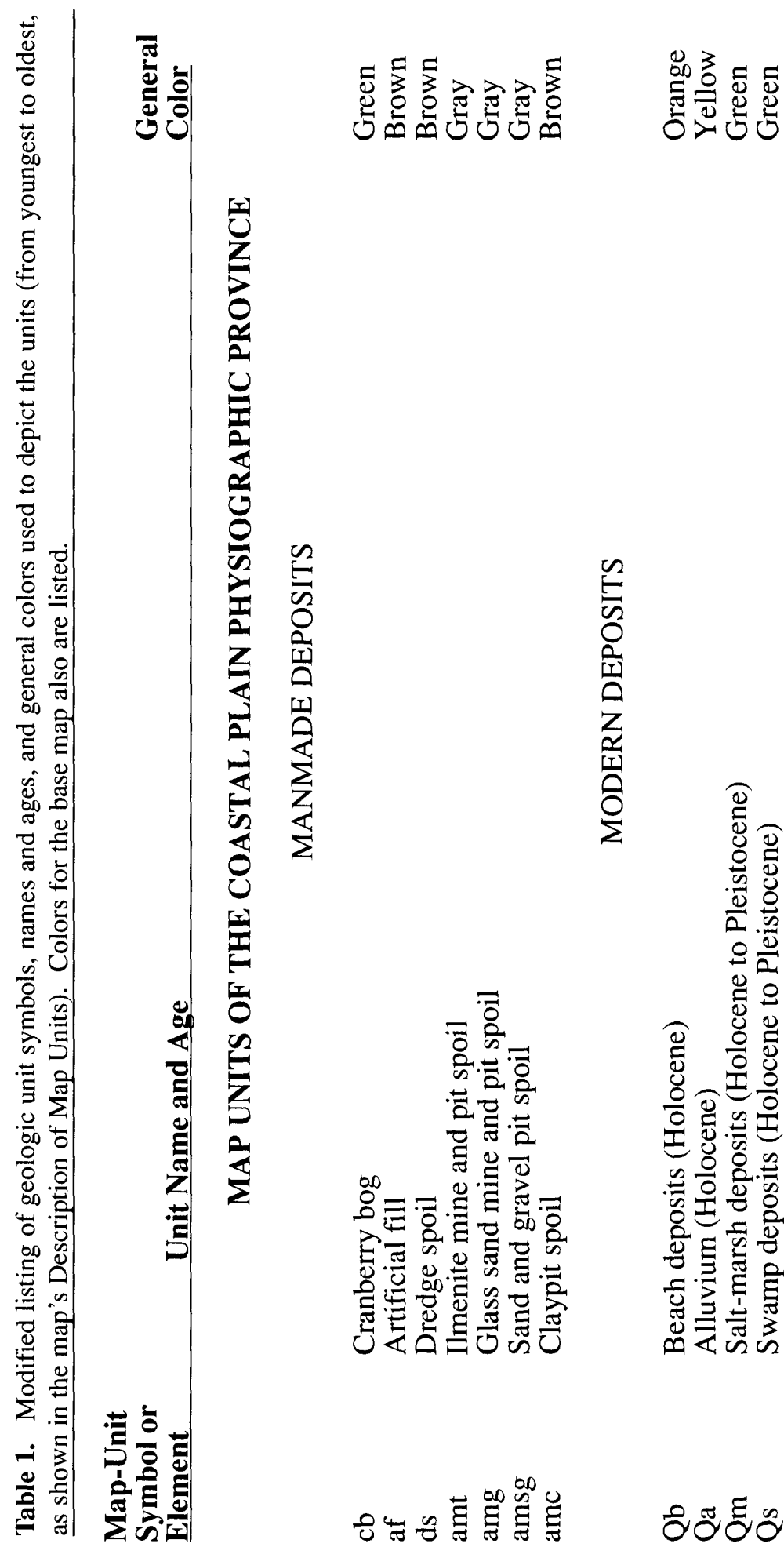

ฮี

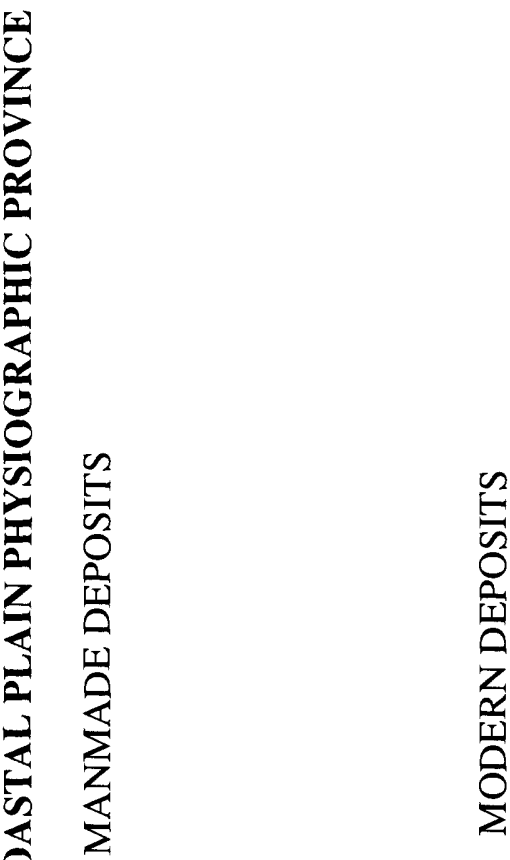

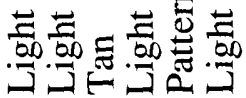

$=\overline{0}$

क.

흐를

훙

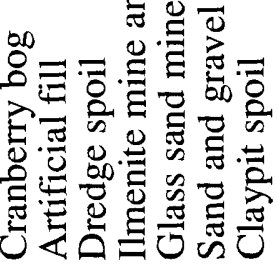

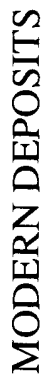

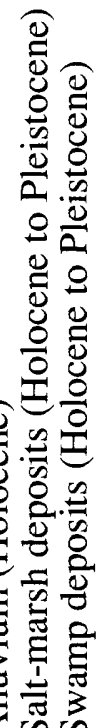

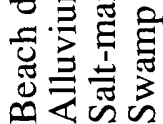

$\stackrel{\varrho}{\varrho}$

疍

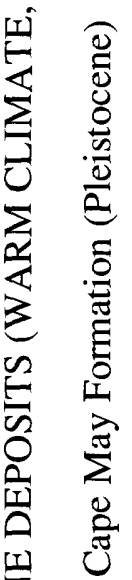

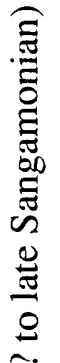

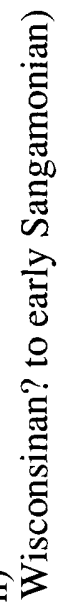

2
5
0
0
01
0
$z$
$z$
0
0

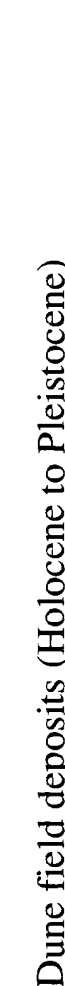

离

?

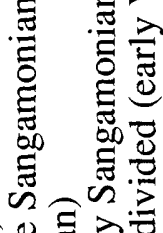

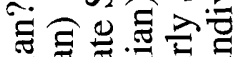

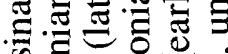

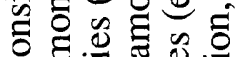

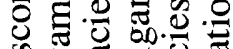

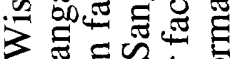

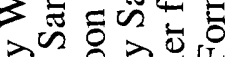

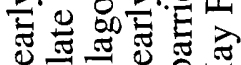

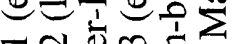

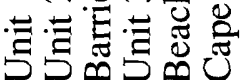

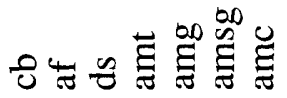

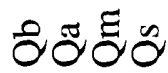

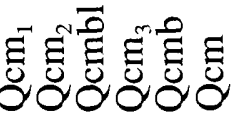




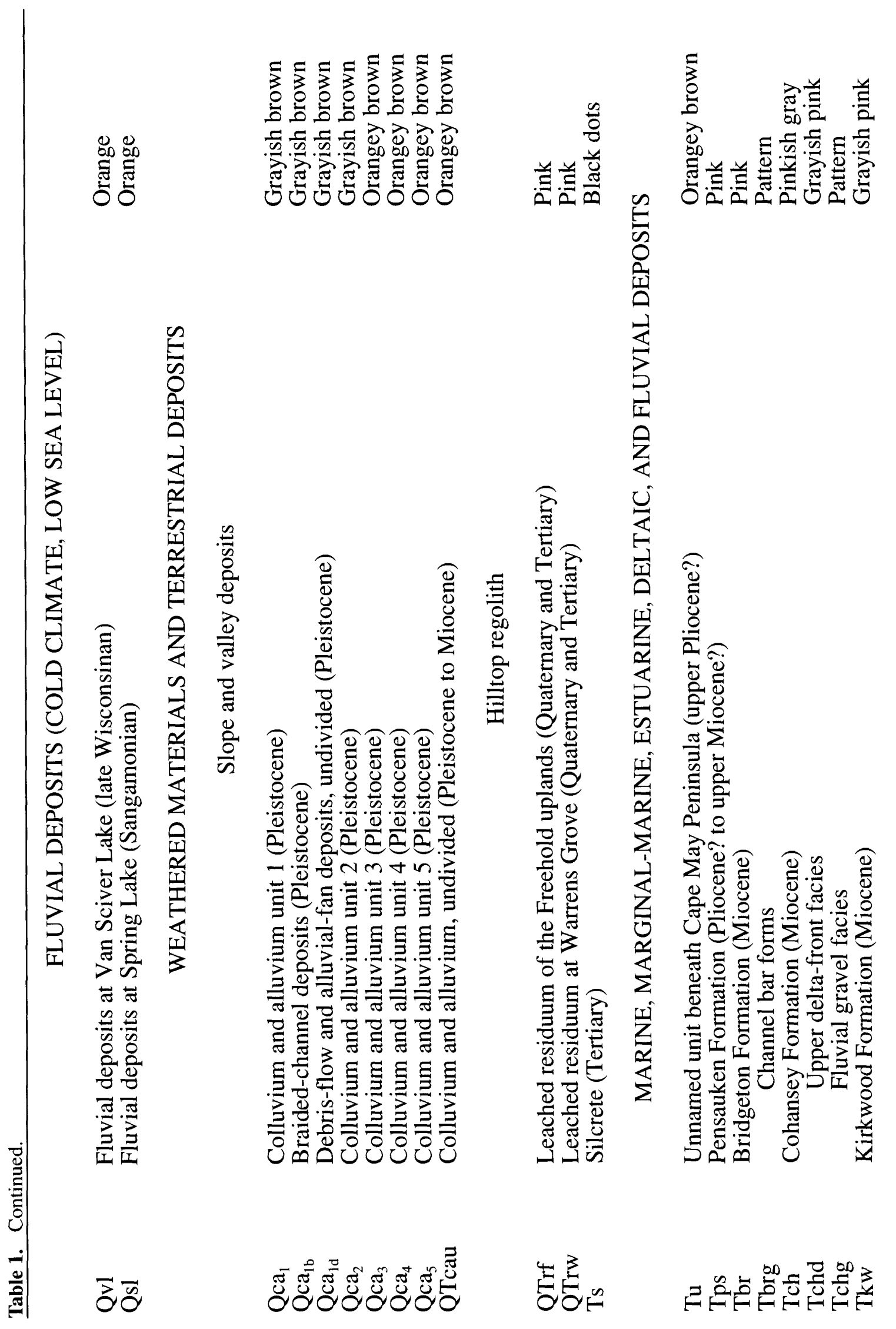




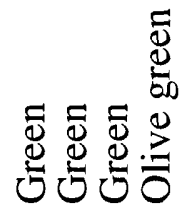

ติ
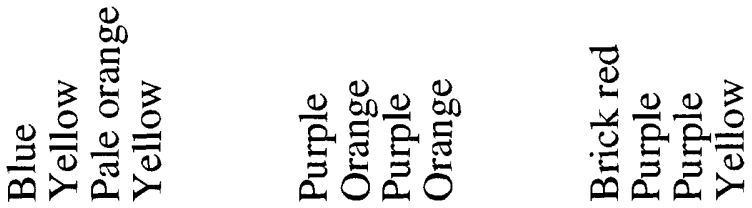

ఖ্ت
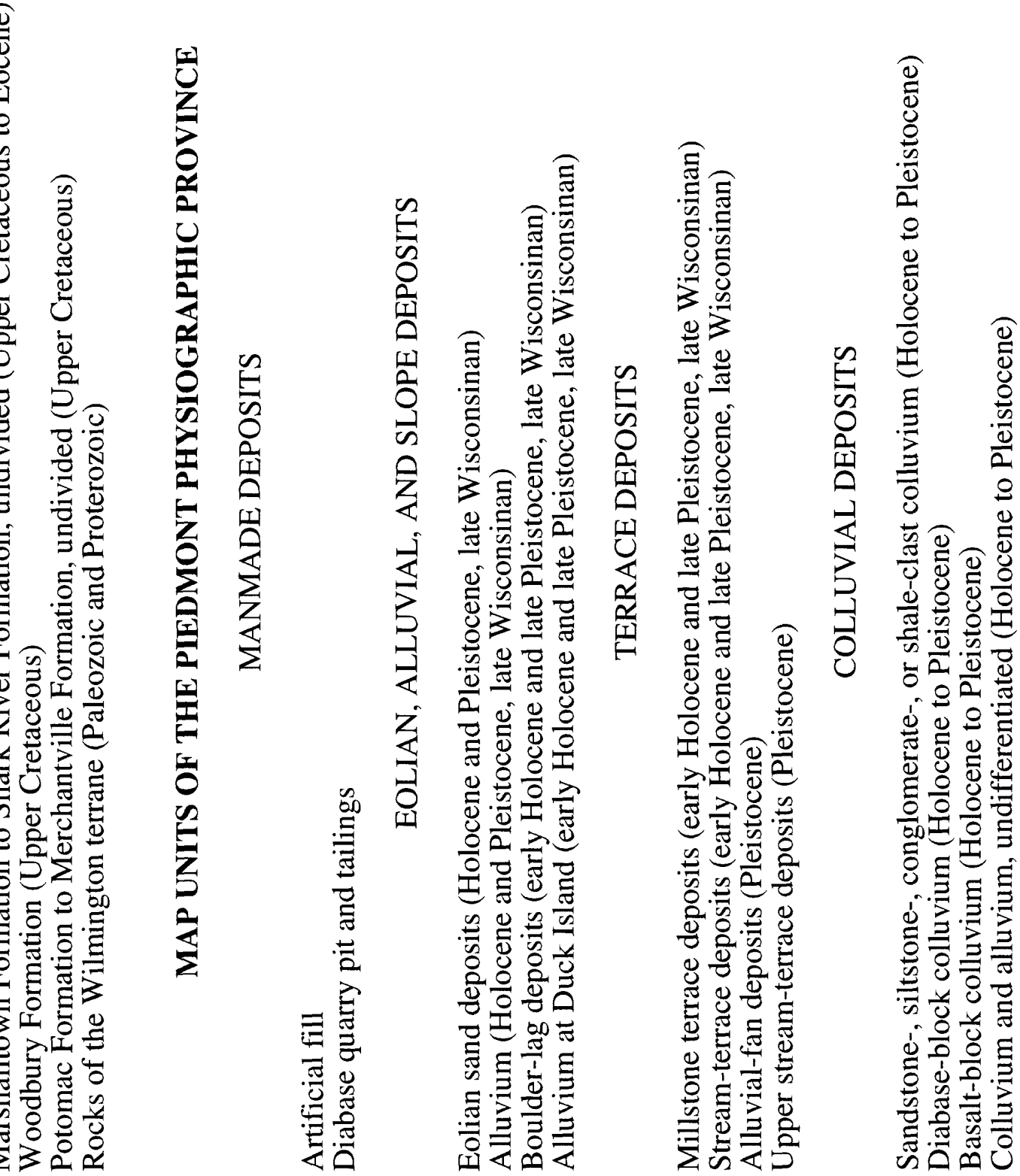

章 $\quad \overrightarrow{0}$

๘

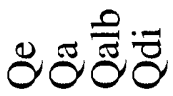

$\overline{\bar{c}} \bar{a} \tilde{z} \bar{z}$

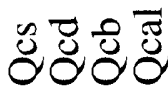



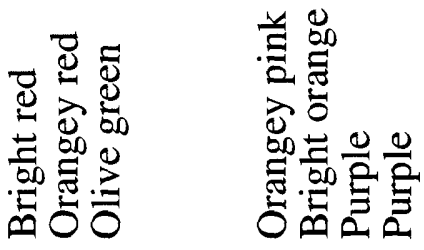

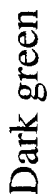
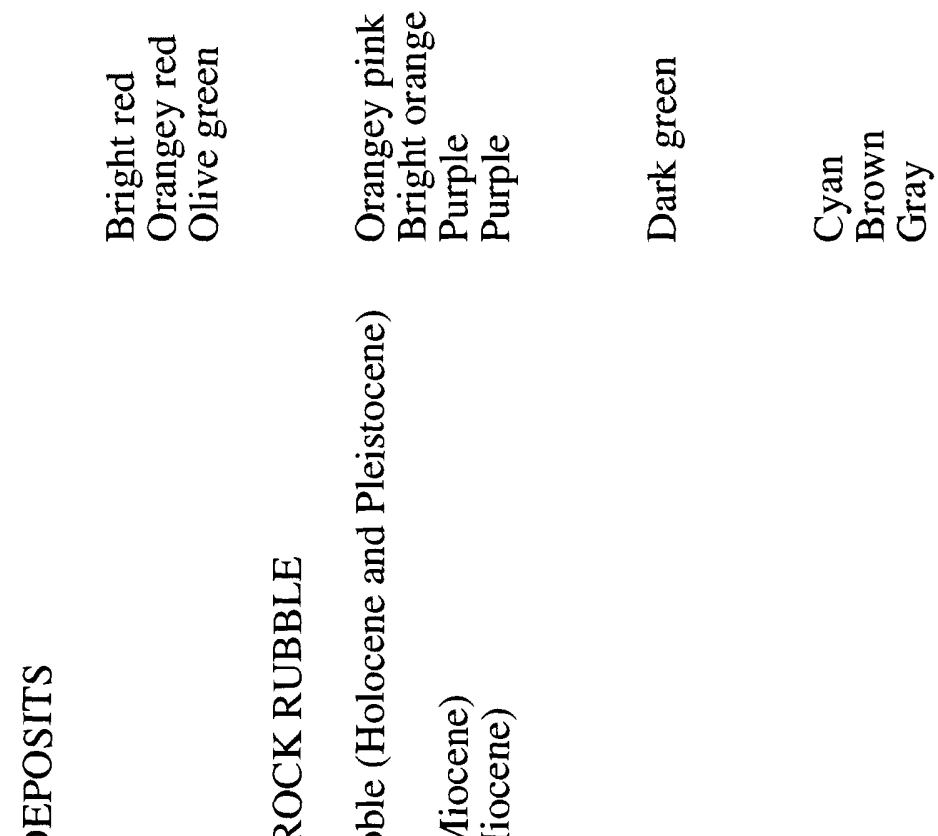

过

띠 을

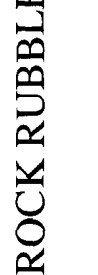

$\stackrel{7}{8}$

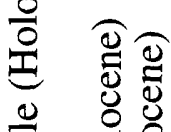

穴

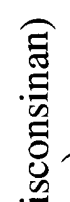

율

乙

\&

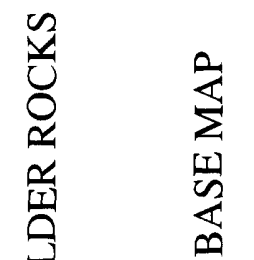

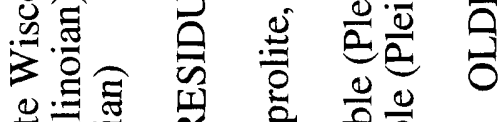

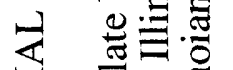

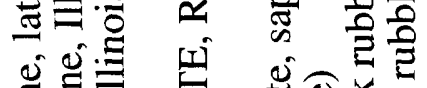

ষ

过

$\frac{\infty}{0} \cdot \frac{1}{2}$

Q

$\cong$ 卷

क

웜

䠉.

造零

氙 总

象守

ส

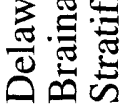

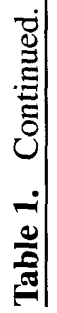

总导苍苍

응. 옹 물

$8 \overline{0}$

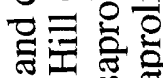

추유

공 卷

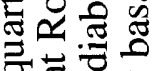

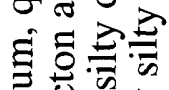

클

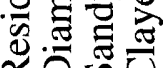

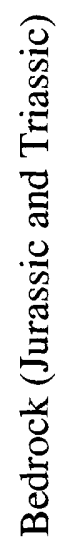


However, the AI files were now far removed from the original DXF and SHAPE files. It is possible that, in the future, the AI files will be exported through MAPublisher to ArcInfo where they would become a useful part of a larger database (for instance, the National Geologic Map Database).

\section{SUMMARY}

If these maps had been produced using the traditional scribecoats for linework and peelcoats for color separation, modification to both linework and color after the first proof would have been very difficult, time consuming, and expensive. Adobe Illustrator gave the production team and the authors a chance to easily adjust contacts and to modi- fy the colors until the right combination was reached. The resulting product visually presents the cumulative effects of geomorphic processes that have affected the landscape since the early Miocene (about 24 million years ago).

\section{REFERENCES}

Newell, W.L., Powars, D.S., Owens, J.P., Stanford, S.D., and Stone, B.D., 2000, Surficial geologic map of central and southern New Jersey: U.S. Geological Survey Miscellaneous Investigations Series Map I-2540-D, scale 1:100,000 ( 3 sheets and pamphlet).

Stone, B.D., Stanford, S.D., and Witte, R.W., in press, Surficial geologic map of northern New Jersey: U.S. Geological Survey Miscellaneous Investigations Series Map I-2540-C, scale $1: 100,000$. 
240 


\title{
APPENDIX A \\ List of Workshop Attendees
}

\author{
[Grouped by affiliation]
}

Alaska Division of Geologic and Geophysical Surveys Lawrence Freeman

Arizona Geological Survey

Stephen Richard

Arkansas Geological Commission

Angela Braden

Jerry Clark

William Hanson

Daniel Smith

California Division of Mines and Geology

Dave Wagner

Colorado State University (National Park Service)

Steve Fryer

Delaware Geological Survey

William Schenck

Dynamic Graphics, Inc.

Skip Pack

University of California, Berkeley

George Brimhall

ERDAS

Darren Gabriel

Chris Ogier

ESRI

Mike Price

Artie Robinson

Geographical \& Environmental Data Services, Inc.

Steve Bedsole

Geological Survey of Alabama

Sharon Alexander

Ruth Collier
Geological Survey of Alabama (continued)

Phillip Henderson

G. Daniel Irvin

April Lafferty

Robert Mink

Henry Moore

Jeff Natharius

Ed Osborne

Karen Richter

Nick Tew

Geological Survey of Canada

Eric Boisvert

Peter Davenport

Murray Journeay

Serge Paradis

Georgia Geological Survey

Mark Cocker

GE-Smallworld

Robert Laudati

GETECH, Inc.

Mark Odegard

Government of Quebec, Canada

Charles Roy

Idaho Geological Survey

Jane Freed

Loudon Stanford

Illinois State Geological Survey

Dan Nelson

Curt Abert

Sheena Beaverson

Marie-France DuFour

Patrick Johnstone

Robert Krumm

Scott Medlin 
Indiana Geological Survey

Rick Hill

Paul Irwin

INRS-Georessources

Marco Boutin

Kansas Geological Survey

David Collins

Jorgina Ross

Kentucky Geological Survey

Matthew Crawford

Douglas Curl

Steven Martin

Jerry Weisenfluh

Louisiana Geological Survey

Richard McCulloh

Robert Paulsell

John Snead

Maryland Geological Survey

Liana Dunne

Missouri DNR/DGLS

Edith Starbuck

Montana Bureau of Mines and Geology

Susan Smith

National Park Service

Tim Connors

Anne Poole

Natural Resources Canada

Vic Dohar

Dave Everett

Terry Houlahan

New Hampshire Geological Survey

Rick Chormann

New Jersey Geological Survey

Michael Girard

Ronald S. Pristas

New Mexico Bureau of Mines \& Mineral Resources

Mark Mansell

David J. McCraw

Ohio Geological Survey

Thomas Berg

James McDonald
Oklahoma Geological Survey

T. Wayne Furr

Oregon Department of Geology and Mineral Industries Clark Niewendorp

Paul Staub

Penn State University / Geological Survey of Canada Boyan Brodaric

Pennsylvania Geological Survey

Gary Fleeger

William Kochanov

Thomas Whitfield

South Carolina Geological Survey

Scott Howard

Techni Graphic Systems

Roger Fredericks

Scott Simmons

Tennessee Division of Geology

Elaine Foust

University of California, Santa Barbara / NCGIA

Jordan Hastings

University of Alabama

Doug Behm

Marty Gates

University of Kansas

Ross Black

University of New Orleans

Terry Pavlis

U.S. Geological Survey

Rick Bradford

Adam Davis

Martha Garcia

Bob Jachens

Elizabeth Koozmin

Diane Lane

Michele McRae

Randall Schumann

Peter Schweitzer

Dave Soller

Nancy Stamm

Ronald Wahl

Bruce Wardlaw

Van Williams 
Utah Geological Survey

Kent Brown

Virginia Division of Mineral Resources

Rick Berquist

Washington Department of Natural Resources

Charles Caruthers
West Virginia Geological Survey

Scott McColloch

Wisconsin Geological and Natural History Survey

Mindy James

Kathy Roushar

Kurt Zeiler 
244

\section{(}




\section{APPENDIX B}

\section{Workshop Web Site}

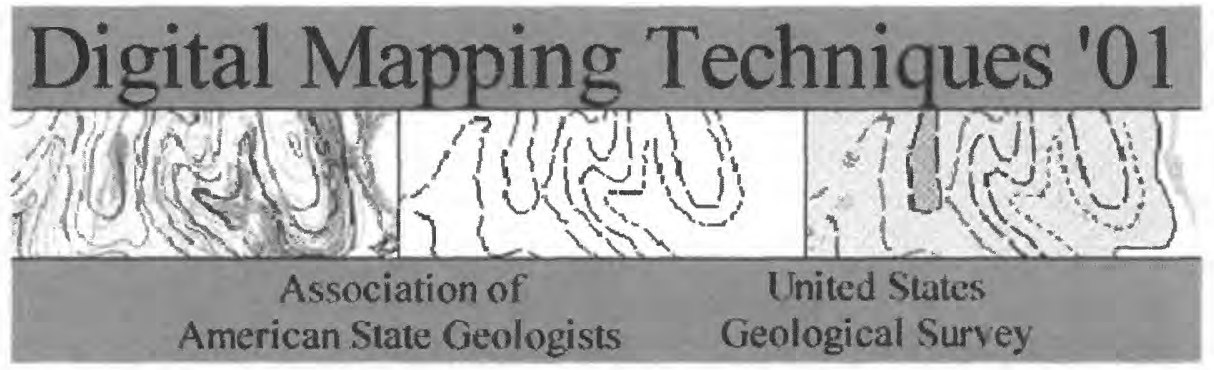

Convened by the Association of American State Geologists and the US Geological Survey

May 20-23, 2001

Tuscaloosa, Alabama

Hosted by the

Geological Suner of Alabama

\section{Workshop

\section{Poster Specs (Registration}

Agenda

The Workshop on Digital Mapping Techniques 2001 (DMT "01) is an invitation-only event designed to bring together scientists, cartographers, and GIS specialists, mostly at State and Federal agencles, who are using digital techniques to create and manage geologic maps.

Topics will focus on methods of data capture (especially field techniques), 3-D data visualization, creating and managing geologic maps in a standard data model, digital map production, and progress toward building the National Geologic Map Database.

This web site will be updated frequently as the meeting approaches.

\footnotetext{
Page updated Friday, January 05, 2001

This page is maintained by the Geological Survey of Alabama, GIS Section comments or suggestions? gisegsa state. al.us
} 
246 


\section{APPENDIX C}

Lists of Addresses, Telephone Numbers, and URLs for Software and Hardware Suppliers.

[Information contained herein was provided mostly by the authors of the various articles and has not been checked by the editor for accuracy]

Adobe Illustrator, Photoshop, and Acrobat - Adobe Systems, Inc., 345 Park Ave., San Jose, CA 95110-2704 USA, (800) 833-6687, <http://www.adobe.com>.

Allaire Cold Fusion — < <ttp://www.allaire.com>.

AMREL Rocky II field computers - 11801 Goldring Road, Arcadia, CA 91006, (800) 882-6735, $<$ http://www.amrel.com>.

Apache web server - The Apache Software Foundation, <http://www.apache.org/>.

AppForge Inc. - 3040 Peachtree Road NW, Atlanta, GA 30305, <http://ns.goodmews.org/>.

ArcInfo, ArcView, ArcPad, ArcIMS, ArcSDE - Environmental Systems Research Institute, Inc., 380 New York St., Redlands, CA 92373-8100 USA, (909)793-2853, <http://www.esri.com>.

AutoCAD, DXF (Drawing Interchange File) - Autodesk, Inc., 111 McInnis Parkway, San Rafael, CA 94903 USA, (800) 538-327-8627, <http://www3.autodesk.com>.

Bentley MicroStation — 685 Stockton Drive, Exton, PA 19341, (800) 236-8539, (610) 458-5000 (international), $<$ http://www2.bentley.com/default.cfm>.

Descartes, Geoterrain — Microstation-Bentley Systems Inc. 685 Stockton Drive, Exton, PA 19341-0678, (800) 236-8539, <http://www.bentley.com>.

Digital Video Plotter (DVP) — DVP GEOMATIC SYSTEMS INC. 49-203 DU Bel-Air, Lévis, (QC), Canada, G6V 6K9, CAN/USA, (800) 363-9513, <http://www.dvp.ca>.

EASI/PACE Image Processing Kit - PCI Geomatics software

$<$ http://www.pcigeomatics.com/product_ind/easipace.html>.

ERDAS - 2801 Buford Highway, N.E., Atlanta, GA 30329-2137, (877) 463-7327, <http://www.erdas,com/hom.asp>.

FieldLog - Geological Survey of Canada, <http://www.gis.nrcan.gc.ca/>.

Fieldworker — <http://www.fieldworker.com/>.

Fujitsu $-<h t t p: / / w w w . f u j i t s u p c . c o m>$.

Garmin GPS units - 913-397-8200 or 1-800-800-1020, <http://www.garmin.com>.

Geologic Data Systems, Inc. - 1600 Emerson Street, Denver, CO 80218, gds@data.com, <http://www.gdata.com>. 
GIMMAP - Kansas Geological Survey, 1930 Constant Avenue, Lawrence, KS 66047, 785-864-2139, Open-file report 88-45(a-d), $587 \mathrm{p}$.

Intergraph Geovec, MGE - (800) 791-3357, (256) 730-7191 (international), <http://www.intergraph.com/gis/>.

Java Runtime Environment and related Java software - Sun Microsystems, Inc., (800) 786-7638, $<$ http://java.sun.com/>.

Mapograph - KARGL reflector projector, RKI-Riebe-Kelsey Instruments, Inc., San Antonio, Texas, 78217 USA, (210) $822-2150$.

MAPublisher - Avenza Systems, Inc., 6505B Mississauga Road, Mississauga, ON, Canada L5N 1A6, (800) 884-2555, $<$ http://www.avenza.com>.

Microsoft PowerPoint, Visio - Microsoft Corporation. One Microsoft Way, Redmond, WA 98052-6399 USA, (425) 882-8080, <http://www.microsoft.com/office/visio/>.

MrSID compression software — LizardTech <http://www.lizardtech.com>.

Oracle 8i and Oracle Spatial - Oracle Corporation, 500 Oracle Parkway, Redwood City, CA 94065, 1-800-ORACLE-1, $<$ http://www.oracle.com/ $>$.

Panasonic Toughbooks - <http://www.panasonic.com $>$.

Pendragon Forms - Pendragon Software Corporation, 1580 S. Milwaukee Ave, Suite 515, Libertyville, IL 60048, $<$ http://www.pendragon-software.com>.

PenMap - Strata, The Business and Innovation Centre, Angel Way, Bradford, United Kingdom BD7 1Bx , <http://www.penmap.com/>, and Condor Earth Technologies, Inc., 21663 Brian Lane, Sonora, CA 95370-3905, (209) 532-0361, <http://www.condorearth.com/>.

Sharp JX-610 - Sharp Electronics of Canada, <http://www.sharp.ca>.

Sun Ultrasparc and SOLARIS 2.8 - Sun Microsystems Inc., 901 San Antonio Rd., Palo Alto, CA 94303, (650) 960-1300, <http://www.sun.com/>. 